\title{
2003-28
}

Final Report

\section{Refinement And Validation Of The Hydraulic Fracture Test}

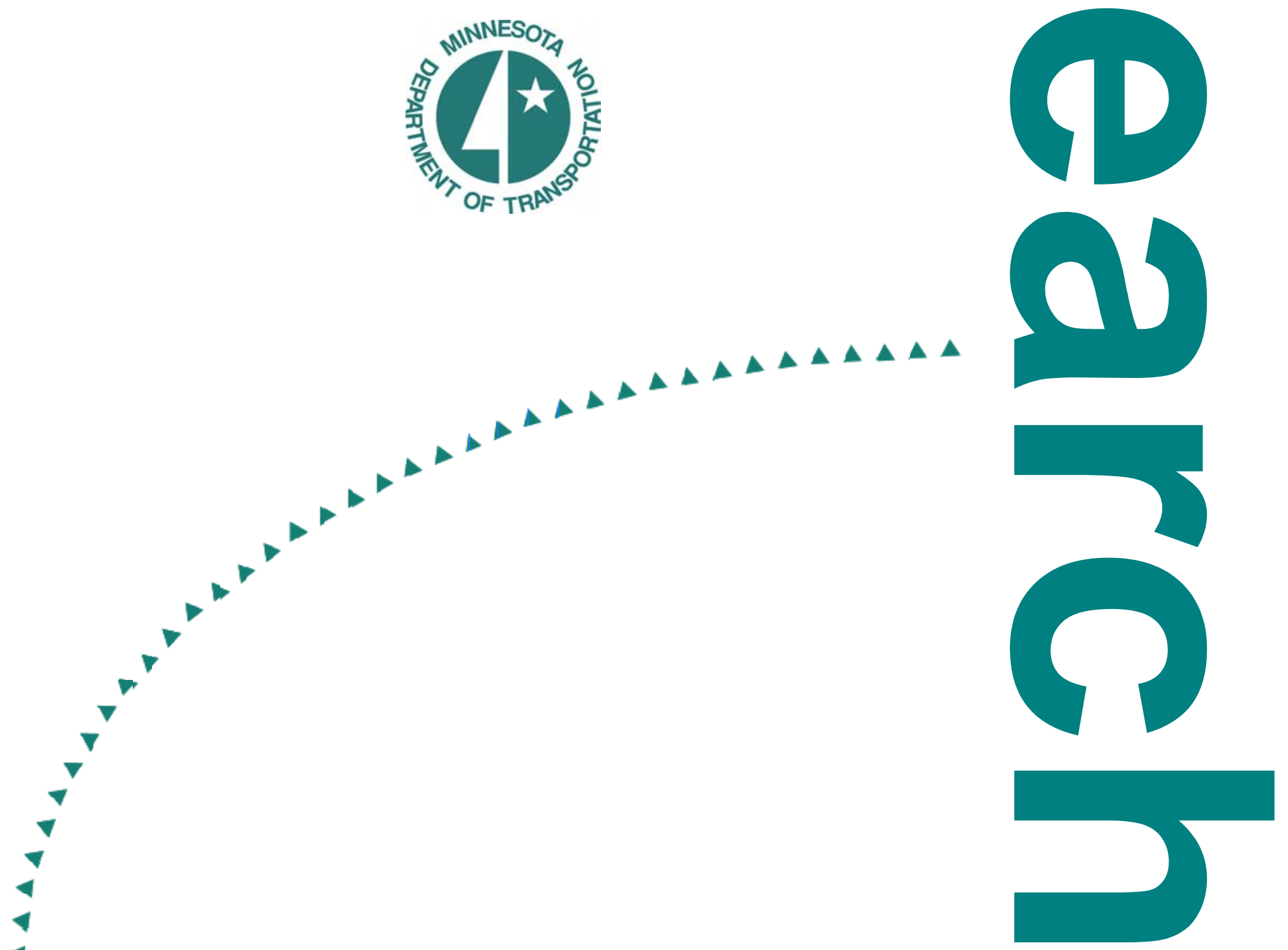




\section{Technical Report Documentation Page}

\begin{tabular}{|c|c|c|c|}
\hline $\begin{array}{l}\text { 1. Report No. } \\
\text { MN-RC 2003-28 }\end{array}$ & 2. & \multicolumn{2}{|c|}{ 3. Recipients Accession No. } \\
\hline \multicolumn{2}{|c|}{ 4. Title and Subtitle } & 5. Report Date & \\
\hline \multicolumn{2}{|c|}{ Refinement and Validation of the Hydraulic Fracture Test } & \multicolumn{2}{|c|}{6.} \\
\hline Rebecca A. Embacher and Mark B. Snyder & 7. Author(s) & \multicolumn{2}{|c|}{ 8. Performing Organization Report No. } \\
\hline \multicolumn{2}{|c|}{ 9. Performing Organization Name and Address } & \multicolumn{2}{|c|}{ 10. Project/Task/Work Unit No. } \\
\hline \multirow{2}{*}{\multicolumn{2}{|c|}{$\begin{array}{l}\text { University of Minnesota Department of Civil Engineering } \\
500 \text { Pillsbury Drive SE }\end{array}$}} & \\
\hline & & \multicolumn{2}{|c|}{$\begin{array}{l}\text { 11. Contract (C) or Grant (G) No. } \\
\text { (c) } 74708 \text { (wo) } 91\end{array}$} \\
\hline \multirow{3}{*}{\multicolumn{2}{|c|}{$\begin{array}{l}\text { 12. Sponsoring Organization Name and Address } \\
\text { Minnesota Department of Transportation } \\
\text { 395 John Ireland Boulevard Mail Stop } 330 \\
\text { St. Paul, Minnesota } 55155\end{array}$}} & \multirow{2}{*}{\multicolumn{2}{|c|}{$\begin{array}{l}\text { 13. Type of Report and Period Covered } \\
\text { Final Report }\end{array}$}} \\
\hline & & & \\
\hline & & \multicolumn{2}{|c|}{ 14. Sponsoring Agency Code } \\
\hline \multicolumn{4}{|c|}{$\begin{array}{l}\text { 15. Supplementary Notes } \\
\text { http://www.lrrb.gen.mn.us/PDF/200328.pdf }\end{array}$} \\
\hline \multicolumn{4}{|c|}{$\begin{array}{l}\text { The Washington Hydraulic Fracture test was developed under the Strategic Highway Research Program to } \\
\text { address the need for a rapid, inexpensive test for concrete aggregate freeze-thaw durability. The original test and } \\
\text { analysis procedures were not sufficiently reliable and accurate to merit widespread adoption and implementation. } \\
\text { Several follow-up research efforts have been performed and each has resulted in improvements to the test. This } \\
\text { report describes the results of recent research efforts to improve the test. }\end{array}$} \\
\hline \multirow{2}{*}{\multicolumn{4}{|c|}{$\begin{array}{l}\text { The "hydraulic fracture index" has been replaced by a model that predicts freeze-thaw test dilation as a } \\
\text { function of the distribution of particle mass retained on various sieves after testing. This model was developed } \\
\text { using data obtained from freeze-thaw and hydraulic fracture testing of } 18 \text { quarried carbonate and gravel aggregate } \\
\text { sources, and the resulting correlation is exceptional ( } \mathrm{r} \text {-squared }=0.98 \text { ). In addition, a large test chamber was } \\
\text { developed to allow testing of aggregate samples five times larger than the original small chamber, thereby allowing } \\
\text { aggregate durability characterization with a single test run. } \\
\text { It is believed that the hydraulic fracture test is now ready for more broad-based validation testing and } \\
\text { eventual widespread acceptance and implementation as an accurate screening tool for concrete aggregate freeze- } \\
\text { thaw durability. }\end{array}$}} \\
\hline & & & \\
\hline \multicolumn{2}{|c|}{ 17. Document Analysis/Descriptors } & \multirow{4}{*}{\multicolumn{2}{|c|}{$\begin{array}{l}\text { 18. Availability Statement } \\
\text { No restrictions. Document available from: } \\
\text { National Technical Information Services, } \\
\text { Springfield, Virginia } 22161\end{array}$}} \\
\hline Freeze-thaw & Aggregate & & \\
\hline Durability & Hydraulic fracture & & \\
\hline Concrete & & & \\
\hline 19. Security Class (this report) & 20. Security Class (this page) & 21. No. of Pages & 22. Price \\
\hline Classified & Classified & & \\
\hline
\end{tabular}




\title{
REFINEMENT AND VALIDATION OF THE HYDRAULIC FRACTURE TEST
}

\author{
Final Report
}

\author{
Prepared by \\ Rebecca A. Embacher \\ Mark B. Snyder \\ Department of Civil Engineering \\ University of Minnesota
}

\section{December 2003}

\author{
Published by \\ Minnesota Department of Transportation \\ Research Services Section, MS 330 \\ 395 John Ireland Boulevard \\ St. Paul, MN 55155
}

This report represents the results of research conducted by the authors and does not necessarily represent the views or policy of the Minnesota Department of Transportation and/or the Center for Transportation Studies. This report does not contain a standard or specified technique.

The authors and the Minnesota Department of Transportation and/or Center for Transportation Studies do not endorse products or manufacturers. Trade or manufacturers' names appear herein solely because they are considered essential to this report. 


\section{ACKNOWLEDGMENTS}

The authors would like to express their appreciation to the Minnesota Department of Transportation (Mn/DOT) for their financial and technical support of the research described herein, including their efforts in performing the supplementary magnesium sulfate tests. Special thanks are offered to Karl Peterson, David Rettner, Nancy Whiting and Douglas Schwartz for their technical support and guidance.

The authors would also like to express their appreciation to Dr. Donald Janssen of the University of Washington Department of Civil Engineering, the originator of the Hydraulic Fracture Test concept, for his technical support and guidance on this project. Dr. Janssen also loaned the University of Washington's hydraulic fracture test equipment to the project team, which greatly expedited completion of the project test program.

Special thanks are also offered to the following people, all of whom were University of Minnesota student research assistants, for their efforts during the laboratory phases of this project: Joel Coudron, Anna Boenig, Tim Havlicek, Trevor Odden, Shane Ortlepp, Brandon Pierce, Sarah Schmidt, Michelle Boltjes, Nate Erpestad, Lindsey Handel, Nick Popehn, Jim Stremel and Dan Troolin. The successful completion of this project would not have been possible without their efforts. 


\section{TABLE OF CONTENTS}

CHAPTER 1

CHAPTER 2

CHAPTER 3

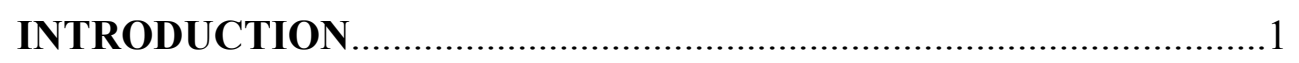

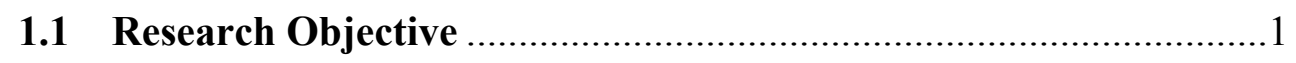

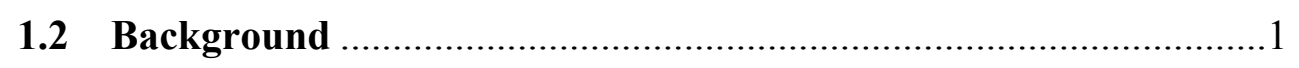

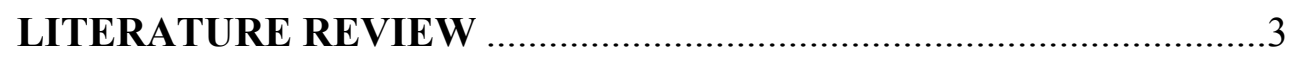

2.1 Test Description - Original Hydraulic Fracture Test .................... 3

2.2 Michigan Department of Transportation Study ..........................5

2.2.1 Study Objectives and Test Program.........................................5

2.2.2 Results and Conclusions Related to Test Procedures and

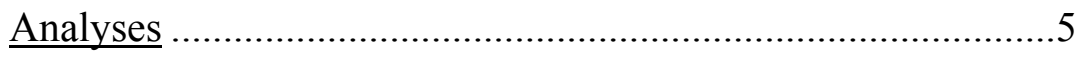

2.3 University of Minnesota Graduate School Study ..........................7

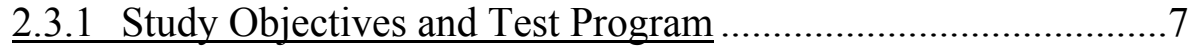

2.3.2 Test Results, Analyses and Conclusions ................................8

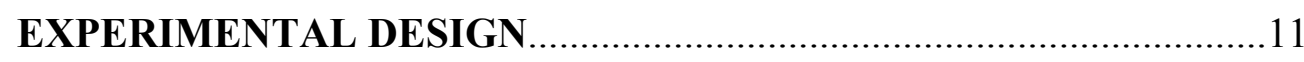

3.1 General Description of Test Program ...................................... 11

3.2 Coarse Aggregate Samples..................................................... 12

3.2.1 Size-Fraction Test Sampling ............................................... 12

3.2.2 As-Produced Material ........................................................... 14

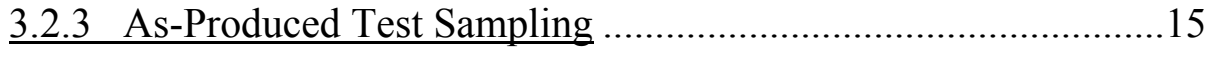

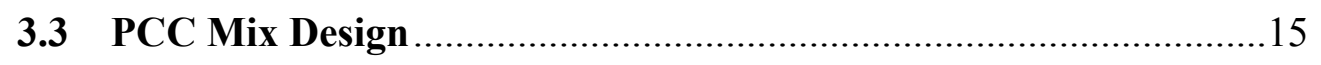

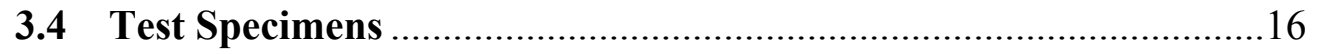

3.5 Hydraulic Fracture Testing - Small Chamber .............................16

3.5.1 Small Chamber Test Samples ................................................ 16

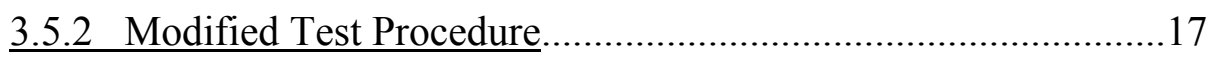

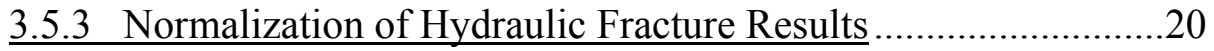

3.6 Hydraulic Fracture Testing - Large Chamber .............................22

3.6.1 Large Chamber Test Samples ............................................22

3.6.2 Test Procedure …..........................................................22

3.6.3 Normalization of Hydraulic Fracture Test Results ..................22 


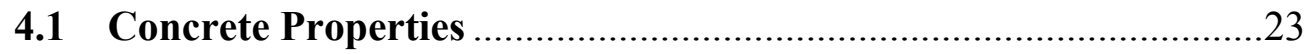

4.2 Specific Gravity and Absorption Capacity …………………….......26

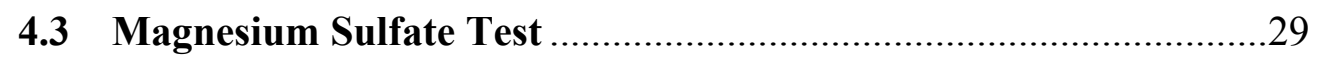

4.3.1 Correlation with Rapid Freezing and Thawing Test Results......31

4.3.2 Correlation with Absorption Capacity Test Results ....................33

4.4 Percentage of Deleterious Material ..................................................33

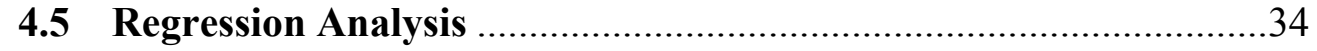

4.6 Hydraulic Fracture - Large Chamber.............................................

4.6.1 Original Large Chamber Development .......................................38

4.6.2 Large Chamber Modifications....................................................40

4.6.3 Consistency with Small Chamber Results....................................42

CHAPTER 5 CONCLUSIONS AND RECOMMENDATIONS ....................................45

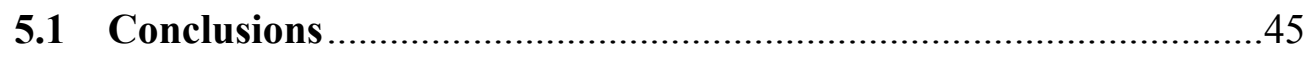

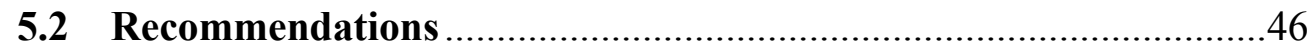

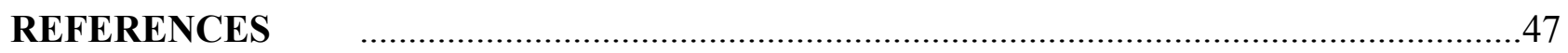

APPENDIX A Modified Hydraulic Fracture Test Procedures..............................................A-1

APPENDIX B $\quad$ PCC and Coarse Aggregate Property Data..................................................B-1

APPENDIX C Hydraulic Fracture Test Results - Small Chamber ....................................C-1

APPENDIX D $\quad$ Hydraulic Fracture Test Results - Large Chamber ................................... D-1

APPENDIX E Development of Regression Models................................................................. E-1 


\section{LIST OF FIGURES}

Figure 2.1 Predicted versus actual dilations using Hietpas' HFT count-based model (3) .........10

Figure 2.2 Predicted versus actual dilations using Hietpas' HFT mass-based model (3) ..........10

Figure 4.1 Durability factor versus coarse aggregate absorption (carbonate sources only)......29

Figure 4.2 Durability factor versus mass loss from magnesium sulfate test..........................32

Figure 4.3 Absorption capacity versus magnesium sulfate test mass loss (carbonate sources only)

Figure 4.4 Actual versus predicted dilation per 100 cycles using small chamber test results (mass-based model, 19.0 to $37.5-\mathrm{mm}$ original particle sizes)...............................39

Figure 4.5 Calibration test data for original Minnesota large chamber (3) ...........................41

Figure 4.6. Calibration test data for modified large chamber .42

Figure 4.7. Actual versus predicted percent dilation per 100 cycles for large and small chamber test results (mass-based model, 19.0 to $37.5-\mathrm{mm}$ original particle sizes).

Figure A.1 Photo of typical tumbler drum and drive unit A-3

Figure A.2 Photo of small chamber interior with neoprene lining..... A-4

Figure A.3 Photo of silane-treated aggregate sample in double boiler. A-7

Figure A.4 Photo of large test chamber (filled with aggregate) and strike-off bar. A-8

Figure A.5 Photo of small chamber closed in horizontal position.

Figure A.6 Photo of small test chamber (with muffler) ready for pressure release. A-11

Figure A.7 Photo of small test chamber during pressure release (without muffler) A-11

Figure E.1 Scatter plot matrix for responses and explanatory variables (percentage of mass passing, 4.75 to $12.5 \mathrm{~mm}$ [\#4 to $0.5 \mathrm{in}])$

Figure E.2 Scatter plot matrix for responses and transformed explanatory variables (percentage of mass passing, 4.75 to $12.5 \mathrm{~mm}$ [\#4 to $0.5 \mathrm{in}])$. .E-6

Figure E.3 Actual versus predicted rapid freezing and thawing test results for models N1 and $\mathrm{N} 2$ (untransformed data, percentage of mass passing, 4.75 to $12.5 \mathrm{~mm}$ [\#4 to $0.5 \mathrm{in}])$

Figure E.4 Actual versus predicted rapid freezing and thawing test results for models N3 and N4 (transformed data, percentage of mass passing, 4.75 to $12.5 \mathrm{~mm}$ [\#4 to 0.5 in]) 
Figure E.5 Actual versus predicted rapid freezing and thawing test results for models N5 and N6 (transformed data, percentage of mass passing, 4.75 to $12.5 \mathrm{~mm}$ [\#4 to 0.5 in])

Figure E.6 Actual versus predicted rapid freezing and thawing test results for models N7 and $\mathrm{N} 8$ (transformed data, percentage of mass passing, 4.75 to $12.5 \mathrm{~mm}$ [\#4 to $0.5 \mathrm{in}])$

Figure E.7 Actual versus predicted rapid freezing and thawing test results for models L1 and L2 (percentage of mass passing, 4.75 to $12.5 \mathrm{~mm}$ [\#4 to $0.5 \mathrm{in}]$ ). E-15

Figure E.8 Actual versus predicted rapid freezing and thawing test results for models L1b and L2a (percentage of mass passing, 4.75 to $12.5 \mathrm{~mm}$ [\#4 to $0.5 \mathrm{in}]$ ). E-18

Figure E.9 Scatter plot matrix for responses and explanatory variables (percentage of mass passing, 12.5 to $19.0 \mathrm{~mm}$ [0.5 to $0.75 \mathrm{in}])$ E-21

Figure E.10 Scatter plot matrix for responses and transformed explanatory variables (percentage of mass passing, 12.5 to $19.0 \mathrm{~mm}$ [0.5 to $0.75 \mathrm{in}])$

Figure E.11 Actual versus predicted rapid freezing and thawing test results for models N1a and L2a (percentage of mass passing, 12.5 to $19.0 \mathrm{~mm}$ [0.5 to $0.75 \mathrm{in}]$ ).

Figure E.12 Scatter plot matrix for responses and explanatory variables (percentage of particles passing, 12.5 to $19.0 \mathrm{~mm}$ [0.5 to $0.75 \mathrm{in}])$ E-31

Figure E.13 Scatter plot matrix for responses and transformed explanatory variables (percentage of particles passing, 12.5 to $19.0 \mathrm{~mm}$ [0.5 to $0.75 \mathrm{in}])$..... E-32

Figure E.14 Actual versus predicted rapid freezing and thawing test results for models N1a and L2f (percentage of particles passing, 12.5 to $19.0 \mathrm{~mm}$ [0.5 to $0.75 \mathrm{in}]$ ). E-36

Figure E.15 Scatter plot matrix for responses and explanatory variables (percentage of mass passing, 19.0 to $25.0 \mathrm{~mm}$ [0.75 to 1 in]) E-40

Figure E.16 Scatter plot matrix for responses and transformed explanatory variables (percentage of mass passing, 19.0 to $25.0 \mathrm{~mm}$ [0.75 to $1 \mathrm{in}])$. E-42

Figure E.17 Actual versus predicted rapid freezing and thawing test results for models N1a* and L2b (percentage of mass passing, 19.0 to $37.5 \mathrm{~mm}$ [0.75 to $1.5 \mathrm{in}]$ ). E-47

Figure E.18 Scatter plot matrix for responses and explanatory variables (percentage of particles passing, 19.0 to $37.5 \mathrm{~mm}$ [0.75 to $1.5 \mathrm{in}]$ ) E-50 
Figure E.19 Scatter plot matrix for responses and transformed explanatory variables (percentage of particles passing, 19.0 to $37.5 \mathrm{~mm}$ [0.75 to $1.5 \mathrm{in}])$.........................................

Figure E.20 Actual versus predicted rapid freezing and thawing test results for models N1c and L2b (percentage of particles passing, 19.0 to $37.5 \mathrm{~mm}$ [0.75 to $1.5 \mathrm{in}]$ ) ............... E-57

Figure E.21 Graphs $(\mathrm{a}-\mathrm{j}$ ) illustrating outlier (case 13, Sheily Grey Cloud [Larson]) in model N1a (percentage of mass passing, 19.0 to $37.5 \mathrm{~mm}$ [0.75 to 1.5 in]) ...................E-60

Figure E.22 Graphs $(a-j)$ illustrating model N1a* with deleted outlier (case 13, Shiely Grey Cloud [Larson]) (percentage of mass passing, 19.0 to $37.5 \mathrm{~mm}$ [0.75 to $1.5 \mathrm{in}]$ ) E-62 


\section{LIST OF TABLES}

Table 3.1 Summary of aggregate sources, locations and expected durabilities.........................13

Table 3.2 Small chamber hydraulic fracture test matrix ......................................................18

Table 3.3 Screens used in preparing HFT test samples for various initial size fractions ..........19

Table 3.4 Screens used in testing HFT samples for various initial size fractions.......................20

Table $4.1 \quad$ Summary of air void system measurements …………………...............................24

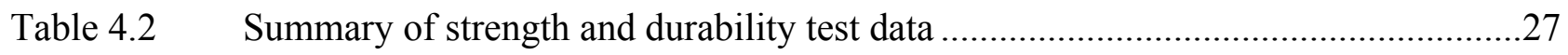

Table 4.3 Summary of specific gravity and absorption capacity test results ............................28

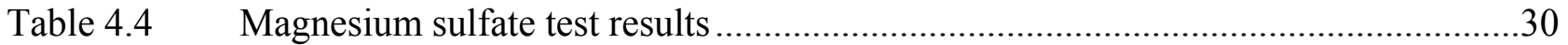

Table 4.5 Percentage of potentially deleterious aggregate particles in each gravel source

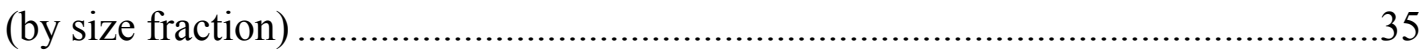

Table 4.6 Total potentially deleterious noncarbonate aggregate particle content in each gravel source (by size fraction) .............................................................................

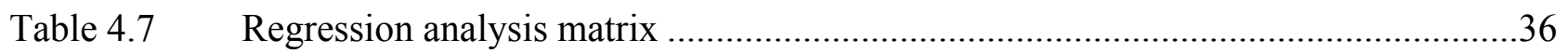

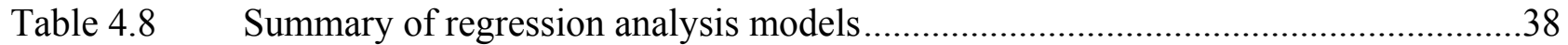

Table B.1 PCC mix proportions, air and slump data for freeze-thaw test specimens .................. 1

Table B.2 Strength and durability data for each mixture......................................................

Table B.3 Unit weight and void content data for aggregate sources ..........................................

Table B.4 As-produced sieve analysis for project aggregate sources .......................................... B-6

Table C.1 HFT results (mass retained) for small chamber samples

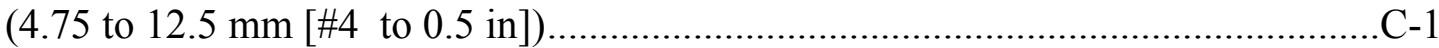

Table C.2 HFT results (normalized, mass retained) for small chamber samples

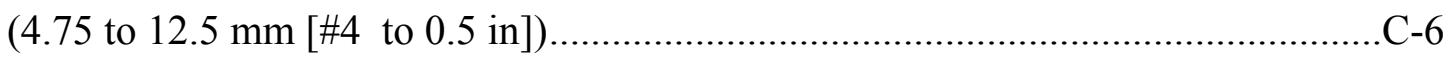

Table C.3 HFT results (mass retained) for small chamber samples

(12.5 to $19.0 \mathrm{~mm}[0.5$ to $0.75 \mathrm{in}]$ ).

Table C.4 HFT results (particle counts) for small chamber samples

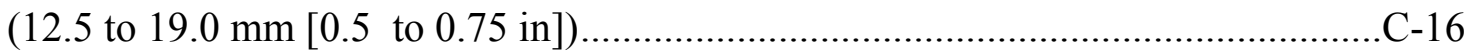

Table C.5 HFT results (normalized, mass retained) for small chamber samples

(12.5 to $19 \mathrm{~mm}[0.5$ to $0.75 \mathrm{in}])$.

Table C.6 HFT results (normalized, particle counts) for small chamber samples

(12.5 to $19 \mathrm{~mm}[0.5$ to $0.75 \mathrm{in}])$ 
Table C.7 HFT results (mass retained) for small chamber samples

(19.0 to $37.5 \mathrm{~mm}$ [0.75 to $1.5 \mathrm{in}]$ )

Table C.8 HFT results (particle counts) for small chamber samples

(19.0 to $37.5 \mathrm{~mm}$ [0.75 to $1.5 \mathrm{in}]$ ).

Table C.9 HFT results (normalized, mass retained) for small chamber samples

(19.0 to $37.5 \mathrm{~mm}$ [0.75 to $1.5 \mathrm{in}])$

Table C.10 HFT results (normalized, particle counts) for small chamber samples

(19.0 to $37.5 \mathrm{~mm}$ [0.75 to $1.5 \mathrm{in}]$ )

Table D.1 HFT results (mass retained) for large chamber samples

(19.0 to $37.5 \mathrm{~mm}$ [0.75 to $1.5 \mathrm{in}])$.

Table D.2 HFT results (particle counts) for large chamber samples

(19.0 to $37.5 \mathrm{~mm}$ [0.75 to $1.5 \mathrm{in}]$ )

Table D.3 HFT results (mass retained, normalized) for large chamber samples

(19.0 to $37.5 \mathrm{~mm}[0.75$ to $1.5 \mathrm{in}]$ ).

Table D.4 HFT results (particle counts, normalized) for large chamber samples (19.0 to $37.5 \mathrm{~mm}[0.75$ to $1.5 \mathrm{in}]$ ). D-4

Table E.1 Regression analysis matrix .E-1

Table E.2 Nonlinear regression models using untransformed data (percentage of mass passing, 4.75 to $12.5 \mathrm{~mm}$ [\#4 to $0.5 \mathrm{in}]$ )

Table E.3 Nonlinear regression models using transformed data (percentage of mass passing, 4.75 to $12.5 \mathrm{~mm}$ [ $\# 4$ to $0.5 \mathrm{in}]$ )

Table E.4 Multiple linear regression models for response variable "percent dilation per 100 cycles" (percentage of mass passing, 4.75 to $12.5 \mathrm{~mm}$ [\#4 to $0.5 \mathrm{in}]$ ).....

Table E.5 Multiple linear regression models for response variable "durability factor" (percentage of mass passing, 4.75 to $12.5 \mathrm{~mm}$ [\#4 to $0.5 \mathrm{in}]$ ).

Table E.6 Reduced multiple linear regression models for response variable "percent dilation per 100 cycles" (percentage of mass passing, 4.75 to $12.5 \mathrm{~mm}$ [\#4 to $0.5 \mathrm{in}]$ ) ..........E-16

Table E.7 Reduced multiple linear regression models for response variable "durability factor" (percentage of mass passing, 4.75 to $12.5 \mathrm{~mm}$ [\#4 to $0.5 \mathrm{in}]$ ).

Table E.8 Nonlinear regression models for response variable "percent dilation per 100 cycles" (percentage of mass passing, 12.5 to $19.0 \mathrm{~mm}$ [0.5 to $0.75 \mathrm{in}]$ ) E-24 
Table E.9 Multiple linear regression models for response variable "durability factor" (percentage of mass passing, 12.5 to $19.0 \mathrm{~mm}$ [0.5 to $0.75 \mathrm{in}]$ )

Table E.10 Nonlinear regression models for response variable "percent dilation per 100 cycles" (percentage of particles passing, 12.5 to $19.0 \mathrm{~mm}$ [0.5 to $0.75 \mathrm{in}]$ )

Table E.11 Multiple linear regression models for "durability factor" (percentage of particles passing, 12.5 to $19.0 \mathrm{~mm}$ [0.5 to $0.75 \mathrm{in}]$ )

Table E.12 Nonlinear regression models for response variable "percent dilation per 100 cycles" (percentage of mass, 19.0 to $37.5 \mathrm{~mm}$ [0.75 to $1.5 \mathrm{in}]$ )

Table E.13 Multiple linear regression models for response variable "durability factor" (percentage of mass, 19.0 to $37.5 \mathrm{~mm}$ [0.75 to $1.5 \mathrm{in}]$ )

Table E.14 Nonlinear regression models for response variable "percent dilation per 100 cycles" (percentage of particles passing, 19.0 to $37.5 \mathrm{~mm}$ [0.75 to $1.5 \mathrm{in}]$ )

Table E.15 Multiple linear regression models for response variable "durability factor" (percentage of particles passing, 19.0 to $37.5 \mathrm{~mm}$ [0.75 to $1.5 \mathrm{in}]$ ) .E-56

Table E.16 Summary of regression analysis models .E-58 


\section{EXECUTIVE SUMMARY}

"D"-cracking and other forms of aggregate-related freeze-thaw damage have often been associated with concrete pavements in Minnesota. The most widely accepted methods of evaluating aggregate freeze-thaw durability involve the preparation and freeze-thaw testing of concrete beams that contain the aggregate in question. These tests are generally timeconsuming, sometimes requiring months to complete, and often require the use of expensive equipment and/or highly skilled operators. A more rapid test of aggregate freeze-thaw durability, called the Washington Hydraulic Fracture Test (WHFT), was developed by Dr. Donald J. Janssen (University of Washington) and Dr. Mark B. Snyder (formerly of Michigan State University). The WHFT equipment is relatively inexpensive and allows a single laboratory technician to assess the freeze-thaw durability of several samples of aggregate in as few as seven working days (1).

The WHFT simulates the effects of freeze-thaw cycles on saturated aggregate particles by forcing water into and out of the pore structure of dried aggregate particles in a water-filled pressure vessel. The water is forced into the aggregate pores using a pressurized nitrogen source, and rapid release of the pressure allows compressed air trapped within the aggregate pores to expand, expelling water from the aggregate and creating internal stresses similar to those produced during freezing and thawing. Aggregate fracture occurs when the aggregate pore structure does not allow rapid dissipation of the pore pressures and the aggregate particles are relatively weak. The amount of fracturing that results from this test has been shown to be an indicator of aggregate freeze-thaw susceptibility.

The WHFT was further developed under research efforts funded by the Michigan Department of Transportation (MDOT) in 1996 and the University of Minnesota Graduate College in 1997 (2, 3). These projects resulted in several refinements and improvements to the WHFT test apparatus and procedures and successfully demonstrated the potential value of the WHFT as a rapid freezethaw durability screening test for many concrete coarse aggregates. However, this research also resulted in the development of recommendations for test procedure changes and equipment 
modifications that it was hoped would further reduce required testing efforts and might improve the reliability and interpretation of the WHFT results.

The primary objective of the current research effort was to improve the Minnesota Department of Transportation's (Mn/DOT's) ability to rapidly evaluate the potential freeze-thaw durability of coarse aggregate sources intended for use in portland cement concrete (PCC) pavement applications. This was to be accomplished by further refining the WHFT test apparatus and procedures and to validate them using aggregate samples obtained from Minnesota sources.

The most significant equipment and procedure modifications involve the development of a larger test chamber that allows the testing of a sufficiently large sample in a single test, and the development of models that accurately predict freeze-thaw test dilation as a function of the distribution of sample mass over various mechanical sieves following 50 WHFT pressurization cycles. The new equipment and procedures appear to offer better correlation with the results of rapid freezing and thawing tests than either the magnesium sulfate test (ASTM C88) or the current Mn/DOT absorption capacity criterion for carbonate aggregate sources.

Additional hydraulic fracture testing should be performed with the modified large hydraulic fracture test chamber using mass measurements and particle counts in the 19 to $38 \mathrm{~mm}(0.75$ to $1.5 \mathrm{in})$ range to further validate the use of the large test chamber. Additional testing and research should also be performed to verify and determine the nature of the outlier hydraulic fracture test results, as described in the project report.

1. D. J. Janssen and M. B. Snyder, SHRP C-391: Resistance of Concrete to Freezing and Thawing (Washington, DC: Transportation Research Board, 1994).

2. M. B. Snyder, D. J. Janssen and W. Hansen, Adoption of a Rapid Test for Determining Aggregate Durability in Portland Cement Concrete (Ann Arbor, MI: University of Michigan Department of Civil Engineering, 1996).

3. J. J. Hietpas, Refinement and Validation of the Washington Hydraulic Fracture Test (Minneapolis, MN: University of Minnesota Department of Civil Engineering, 1998). 


\section{CHAPTER 1 INTRODUCTION}

\subsection{Research Objectives}

The objective of the research described herein was to improve the Minnesota Department of Transportation's (Mn/DOT's) ability to rapidly evaluate the potential freeze-thaw durability of coarse aggregate sources intended for use in portland cement concrete (PCC) pavement applications. This was to be accomplished by refining the Washington Hydraulic Fracture Test (WHFT) and validating the apparatus and procedures using Minnesota aggregates.

\subsection{Background}

"D"-cracking and other forms of aggregate-related freeze-thaw damage have often been associated with concrete pavements in Minnesota. The best approach for preventing these types of distress is to avoid using aggregate sources that are known to be susceptible to freeze-thaw damage in concrete applications. The most widely accepted methods of evaluating aggregate freeze-thaw durability involve the preparation and freeze-thaw testing of concrete beams that contain the aggregate in question. These tests are generally time-consuming, sometimes requiring months to complete, and often require the use of expensive equipment and/or highly skilled operators. Furthermore, the variable nature of many aggregate sources necessitates frequent testing to ensure the adequate freeze-thaw resistance of material being produced at any given point in time.

A more rapid test of aggregate freeze-thaw durability was developed under the Strategic Highway Research Program (SHRP). This test, called the Washington Hydraulic Fracture Test (WHFT), was developed by Dr. Donald J. Janssen (University of Washington) and Dr. Mark B. Snyder (formerly of Michigan State University) (1). The WHFT equipment is relatively inexpensive and allows a single laboratory technician to assess the freeze-thaw durability of several samples of aggregate in as few as seven working days.

The WHFT simulates the effects of freeze-thaw cycles on saturated aggregate particles by forcing water into and out of the pore structure of dried aggregate particles in a water-filled 
pressure vessel. The water is forced into the aggregate pores using a pressurized nitrogen source, and rapid release of the pressure allows compressed air trapped within the aggregate pores to expand, expelling water from the aggregate and creating internal stresses similar to those produced by the formation of ice or salt crystals, or the movement of absorbed water ahead of a freezing front. Aggregate fracture occurs when the aggregate pore structure does not allow rapid dissipation of the pore pressures and the aggregate particles are relatively weak. The amount of fracturing that results from this test has been shown to be an indicator of aggregate freeze-thaw susceptibility.

The WHFT was further developed under a research effort funded by the Michigan Department of Transportation (MDOT) and completed by Drs. Janssen and Snyder, along with Dr. Wil Hansen of the University of Michigan, in 1996 (2). The primary goal of the Michigan project was to correlate the results of the WHFT with those of the freeze-thaw test being used by MDOT at that time. This project successfully demonstrated the value of the WHFT as a rapid freeze-thaw durability screening test for many concrete coarse aggregates. However, this research also resulted in the development of recommendations for test procedure changes and equipment modifications that it was hoped would further reduce required testing efforts and might improve the reliability and interpretation of the WHFT results.

Many of the equipment and procedural modifications proposed as a result of the MDOTsponsored study were implemented and evaluated under the study described in this report in an effort to provide Mn/DOT and other highway agencies with the best possible tool for evaluating aggregate freeze-thaw durability. 


\section{CHAPTER 2}

\section{LITERATURE REVIEW}

\subsection{Test Description - Original Hydraulic Fracture Test}

The test begins by obtaining a sample of washed and oven-dried coarse aggregate with particle sizes ranging from 19 to $32 \mathrm{~mm}$ ( 0.75 to $1.25 \mathrm{in})$. The sample quantity must be sufficient to fill the 51-mm (2-in) deep by 254-mm (10-in) diameter test chamber (typically $2.6-3.0 \mathrm{~kg}$ [5.7$6.6 \mathrm{lb}$ ] of aggregate). The sample is submerged in a water-based silane solution for one minute to inhibit the hydrophilic tendencies of some aggregates; without this treatment, some freezethaw susceptible particles may become saturated during testing, which prevents the development of internal particle stresses and fracture during testing. The sample is then drained and ovendried again. The sample is tumbled in a rock tumbler for one minute to provide uniform handling and to fracture any weakened or partially broken pieces. The sample is then screened over a 9.5-mm (0.375-in) sieve and all particles passing the sieve are discarded. Particles retained on the $9.5-\mathrm{mm}(0.375$-in) sieve become the test sample, and the number of particles and mass of the sample are recorded as the initial particle count and mass.

The sample is placed in the test chamber, and the chamber is then closed and bolted shut. The test chamber is then rotated onto its edge so that the pressure isolation/release valve is oriented vertically, and the chamber is filled with water. The water supply and release valves are secured and chamber is pressurized to $7930 \mathrm{kPa}(1150 \mathrm{psi})$ using a nitrogen source, forcing water into the pore structure of the aggregate and compressing the air in those pores. The pressure is maintained for 5 minutes, after which the nitrogen supply valve is closed. The pressure release valve is then opened rapidly, resulting in a nearly explosive decompression of the chamber, which allows the compressed air in the aggregate pores to expand and push the water back out through the pore structure. This movement of water through the pore structure during depressurization produces internal particle stresses similar to those that develop when ice forms and water moves through the aggregate pores during freezing, and may cause some particles to fracture. The chamber is refilled with water and the process is repeated in a similar manner (with 2-minute pressurizations on subsequent pressurization cycles) for a total of 10 pressurization and release cycles, after which time the chamber is drained and the aggregate particles are removed, 
oven-dried, tumbled, and sieved over 9.5-mm (0.375-in) and 4.75-mm (\#4) screens. The number of particles and mass of the aggregate retained over each screen are determined, and the material retained on the $9.5-\mathrm{mm}(0.375$-in) screen is retained and subjected to an additional 10 cycles of pressurization. The process is repeated for a total of 50 cycles of pressurization.

The percentage of particles that fractured during each 10 cycles of pressurization was originally estimated as:

$$
\mathrm{FP}_{\mathrm{i}}=100\left(\mathrm{n} 4_{\mathrm{i}}+\mathrm{n}_{\mathrm{i}}-\mathrm{n}_{0}\right) / \mathrm{n}_{0}
$$

where:

$\mathrm{FP}_{\mathrm{i}}=$ estimated percent fractures after " $\mathrm{i}$ ” pressurization cycles,

$\mathrm{n} 4_{\mathrm{i}}=$ number of particles passing the $9.5-\mathrm{mm}(0.375-\mathrm{in})$ sieve but retained on the $4.75-\mathrm{mm}$ [\#4] sieve after "i”" pressurization cycles,

$\mathrm{n}_{\mathrm{i}}=$ number of particles retained on the $9.5-\mathrm{mm}(0.375-\mathrm{in})$ sieve, and

$\mathrm{n}_{0}=$ number of particlers initially tested.

The percentage of particles that fractured was then used to calculate the Hydraulic Fracture Index (HFI), which was originally defined as the number of cycles necessary to produce 10 percent fracturing. If 10 percent fracturing was achieved in 50 or fewer cycles, the HFI was originally calculated by linear interpolation as:

$$
\mathrm{HFI}=\mathrm{A}+10\left[\left(10-\mathrm{FP}_{\mathrm{A}}\right) /\left(\mathrm{FP}_{\mathrm{B}}-\mathrm{FP}_{\mathrm{A}}\right)\right]
$$

where:
A = number of cycles just prior to achieving 10 percent fracturing,
$\mathrm{FP}_{\mathrm{A}}=$ percentage of fracturing just prior to achieving 10 percent fracturing, and
$\mathrm{FP}_{\mathrm{B}}=$ percentage of fracturing just after achieving 10 percent fracturing. 
If 10 percent fracturing had not occurred by the end of 50 pressurization cycles, the HFI was originally computed as a linear extrapolation of the percent of fractures between zero and 50 cycles:

$$
\mathrm{HFI}=50\left(10 / \mathrm{FP}_{50}\right)
$$

where:

$\mathrm{FP}_{50}=$ percent fracturing after 50 pressurization cycles.

Complete descriptions of the equipment, procedures and calculations associated with the Hydraulic Fracture Test, as well as information concerning the development and validation of the test, are provided in references 1 and 2.

\subsection{Michigan Department of Transportation Study}

\subsubsection{Study Objectives and Test Program}

The primary objective of this study was to determine whether the HFT could be adopted by the Michigan Department of Transportation (MDOT) as a part of their acceptance testing for concrete aggregates. Testing was performed on aggregates that span the range of materials likely to be considered for use in concrete applications, including natural and manufactured aggregates and a range of aggregate durability. Freeze-thaw tests were performed on all of the selected aggregates using MDOT test procedures, which are essentially a variation on ASTM C 666 Procedure B with careful control of the aggregate gradation and vacuum-saturation of the coarse aggregates prior to casting freeze-thaw beams. The results of these tests and additional information concerning the aggregate sources is provided in reference 2 .

\subsubsection{Results and Conclusions Related to Test Procedures and Analyses}

Many tests were performed using different chamber pressures, chamber sizes (standard 50-mm [2-in] depth vs. 254-mm [10-in] depth), pressure release systems (manual vs. pneumatically actuated), actuator pressures and chamber linings (neoprene or none). The results of these tests led to several findings and test modifications: 
- Neoprene chamber lining. It was found that the expansion of the pressure chamber during pressurization cycles was sufficient to allow aggregate particles to settle and reorient themselves, resulting in some crushing of the particles when the chamber contracted upon release of the pressure. This crushing of particles artificially inflated estimates of particle fractures due to the hydraulic fracture mechanism and contributed to poor correlations between HFT and freeze-thaw test results for certain aggregate types. A thin (0.8-mm [0.03in]) neoprene pad was glued to the chamber lids to cushion the aggregate during the chamber contraction and reduce the incidence of fracture by this mechanism. Fracture rates decreased substantially (generally by more than 50 percent) with this modification.

- Changes in HFI, particle fracture equations. The reduction in fracture rates due to the use of the neoprene pads necessitated a change in the hydraulic fracture index. The index definition was revised to represent the number of pressurization cycles required to achieve 5 percent fracturing. Equations 2.2 and 2.3 were modified as follows:

$$
\begin{gathered}
\mathrm{HFI}=\mathrm{A}+10\left[\left(5-\mathrm{FP}_{\mathrm{A}}\right) /\left(\mathrm{FP}_{\mathrm{B}}-\mathrm{FP}_{\mathrm{A}}\right)\right] \\
\mathrm{HFI}=50\left(5 / \mathrm{FP}_{50}\right)
\end{gathered}
$$

In addition, equation 2.1 (for estimating the number of fractured particles) was also modified (as shown in equation 2.1a below) to take into account an apparent overestimation provided in the original equation:

$$
\mathrm{FP}_{\mathrm{i}}=100\left(\mathrm{n}_{\mathrm{i}} / 2+\mathrm{n}_{\mathrm{i}}-\mathrm{n}_{0}\right) / \mathrm{n}_{0}
$$

- Correlations between HFI and dilation. It was difficult to correlate the HFI with dilation measurements and durability factors obtained through freeze-thaw testing because the range of dilation measurements typically associated with good durability ( 0 to 0.04 percent per 100 cycles) is very compact and tied to a broad range of HFI (anything greater than 100) while the range of dilation measurements associated with marginal or poor durability (anything greater than 0.04 percent per 100 cycles) is broad and tied to a narrow range of HFI ( 0 to 50 for poor durability, 50 to 100 for marginal durability). In addition, the open-ended nature of 
the HFI (equation 2.3a gives undefined or very large values when the percentage of fractures is zero or a very small number) makes a linear correlation difficult. For these reasons, the project researchers elected to pursue correlations between dilation and direct outputs of the HFT: particle fractures and mass loss.

- Computation of particle fractures. It was observed that for certain types of aggregate (e.g., sandstone, siltstone, clay ironstone and shale) an individual particle would fracture into many pieces, leading to inflated estimates of particle fractures. This problem was believed to contribute to difficulties in establishing correlations between HFT outputs and freeze-thaw test results.

- Sample size effects. Correlations between estimated fracture rates, computed mass loss and freeze-thaw dilations were improved when the size of the sample considered was increased (i.e., when the results of three small chamber runs were combined to produce a single test result).

Detailed descriptions of the Michigan study tests, results, analyses and conclusions are included in reference 2.

\subsection{University of Minnesota Graduate School Study}

\subsubsection{Study Objectives and Test Program}

The purpose of this project was to further refine and validate the HFT by developing new test procedures and acceptance criteria. Specific objectives included:

- Development of a correlation between mass loss and/or particle fracturing to dilation data obtained from previous freeze-thaw tests.

- Determination of appropriate acceptance/rejection criteria using the models developed above.

- Determination of the sample size required for reliable testing.

The Michigan study showed that the amount of aggregate fracturing was strongly influenced by the shape of the pressure release rate curve, which was, in turn, affected by the size, plumbing and valve operation of the test chamber. Even when seemingly identical chambers were used under identical operating conditions (chamber pressure and actuator pressure), variations in 
fracture rate were observed between different apparatus. Further investigation showed that the different chambers had different apparent release rates, in spite of the use of identical operational parameters. A calibration procedure was developed to determine the combinations of chamber pressure and actuator pressure that would ensure similar pressure release rate curves; similar fracture rates were then observed for the different pieces of equipment (3).

Upon completion of the calibration process, several aggregate sources (with particle sizes in the 19 to $32 \mathrm{~mm}$ [0.75 to $1.25 \mathrm{in}$ ] range) were tested using the smaller chamber. Test and analysis procedures were similar to those developed under the SHRP program and modified under the Michigan study, except that several sieves were added to the screening operation (resulting in separate particle counts and mass measurements for materials retained on each of these sieves) and that the only particles used for subsequent pressurization cycles were those that were still in the original particle size range. This latter step helped to eliminate the overestimation of particle fracturing that occurred when a single particle would fracture repeatedly.

The sieve sizes used in this study were the 16-, 13-, 9.5- and 4.75-mm $(0.625-, 0.5-, 0.375$-inch and \#4) sieves. The 19-mm and 25-mm (0.75-in and 1-in) sieves, which had been used in the SHRP and Michigan studies to prevent clogging of the smaller sieves, were eliminated in favor of the smaller $16-\mathrm{mm}$ and $13-\mathrm{mm}$ ( 0.625 -in and 0.5 -in) sieves to provide better tracking of particle size distributions after fracture and to ensure that any particle passing the top sieve did so because a fracture had taken place and not because the particle had been oriented differently during different screening operations.

\subsubsection{Test Results, Analyses and Conclusions}

Models were developed to correlate the data obtained from the HFT to dilation data obtained using AASHTO TP17 (T161 Procedure C). These models made use of either the cumulative particle counts or the masses retained on the different sieves, as shown below: 


\section{Hietpas Particle Count-based Dilation Model}

$\%$ Dilation $/ 100$ cycles $=3.143-3.135 \mathrm{E}-2 * \mathrm{C}_{+16 \mathrm{~mm}}[+0.625 \mathrm{in}]+2.301 \mathrm{E}-2 * \mathrm{C}_{13}-16 \mathrm{~mm}[0.5-0.625 \mathrm{in}]$

$$
\begin{aligned}
& +2.001 \mathrm{E}-2 * \mathrm{C}_{10}-13 \mathrm{~mm}[0.375-0.5 \mathrm{in}]-6.424 \mathrm{E}-3 * \mathrm{C}_{5}-10 \mathrm{~mm}[\# 4-0.375 \mathrm{in}] \\
& \mathrm{r}^{2}=0.77, \mathrm{n}=7
\end{aligned}
$$

where:

$$
\left.\mathrm{C}_{13}-16 \mathrm{~mm} \text { [0.5 - } 0.625 \mathrm{in}\right], \mathrm{C}_{10-13 \mathrm{~mm}[0.375-0.5 \mathrm{in}]} \text { and } \mathrm{C}_{5-10 \mathrm{~mm} \text { [\#4 - } 0.375 \mathrm{in}]}=\text { cumulative }
$$
particle counts within the indicated sieve ranges after 50 cycles of pressurization, expressed as a percentage of the initial sample particle count; and

$\mathrm{C}_{+16 \mathrm{~mm}[+0.625 \mathrm{in}]}=$ particle count on the $16-\mathrm{mm}[0.625$-in] sieve after 50 cycles of pressurization, expressed as a percentage of the initial sample particle count.

\section{Hietpas Particle Mass-based Dilation Model}

$\%$ Dilation $/ 100$ cycles $=1.396-1.399 \mathrm{E}-2 * \mathrm{M}_{+16 \mathrm{~mm}[+0.625 \mathrm{in}]}-2.861 \mathrm{E}-2 * \mathrm{M}_{13}-16 \mathrm{~mm}[0.5-0.625 \mathrm{in}]$

$$
\begin{gathered}
+0.238 * \mathrm{M}_{9.5-13 \mathrm{~mm}[0.375-0.5 \mathrm{in}]}-0.207 * \mathrm{M}_{4.75-9.5 \mathrm{~mm}[\# 4-0.375 \mathrm{in}]} \\
\mathrm{r}^{2}=0.95, \mathrm{n}=7
\end{gathered}
$$

where:

$$
\mathrm{M}_{13-16 \mathrm{~mm}[0.5-0.625 \mathrm{in}]}, \mathrm{M}_{10-13 \mathrm{~mm}[0.375-0.5 \mathrm{in}]} \text { and } \mathrm{M}_{5-10 \mathrm{~mm} \text { [\#4 - } 0.375 \mathrm{in}]}=\text { cumulative }
$$
particle masses within the indicated sieve ranges after 50 cycles of pressurization, expressed as a percentage of the initial sample particle mass; and

$\mathrm{M}_{+16 \mathrm{~mm}[+0.625 \mathrm{in}]}=$ particle mass on the $16-\mathrm{mm}$ [0.625-in] sieve after 50 cycles of pressurization, expressed as a percentage of the initial sample particle mass.

Figures 2.1 and 2.2 present data plots showing predicted and measured dilations using these models for the seven aggregate sources used in their development.

It was concluded that these models of freeze-thaw test dilation (for which many states already have acceptance/rejection criteria) as a function of hydraulic fracture test results (i.e., particle counts and mass measurements) offered potentially significant advantages over the use of an index value. Further refinement and validation of these models were necessary because of the small number of aggregate sources used in their development. 


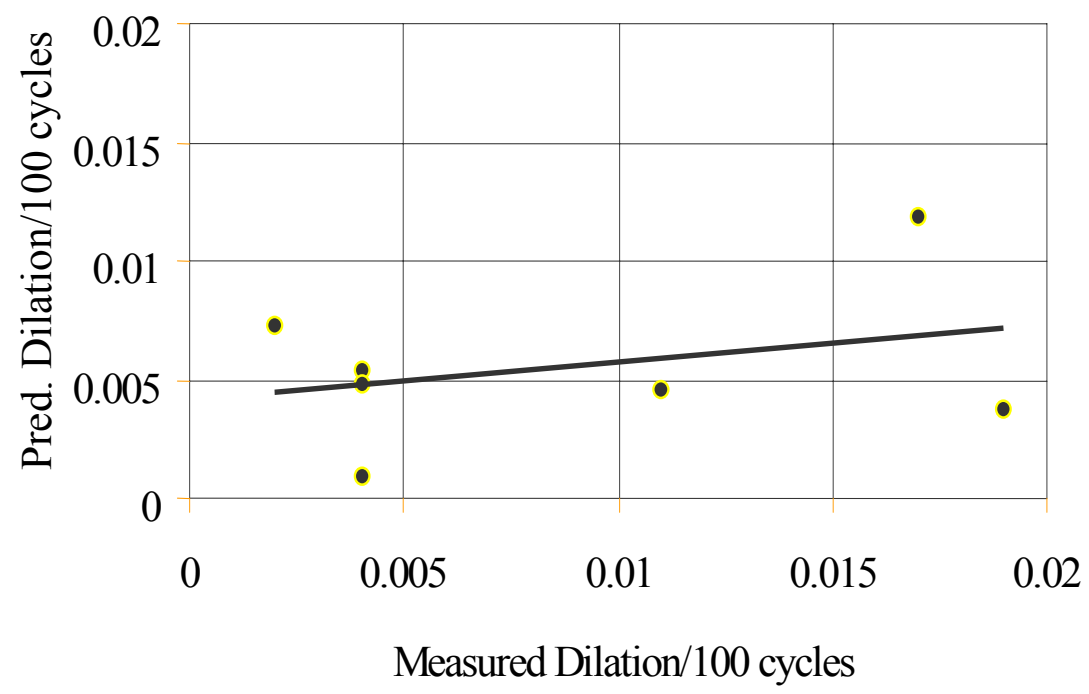

Figure 2.1. Predicted versus actual dilations using Hietpas' HFT count-based model (3).

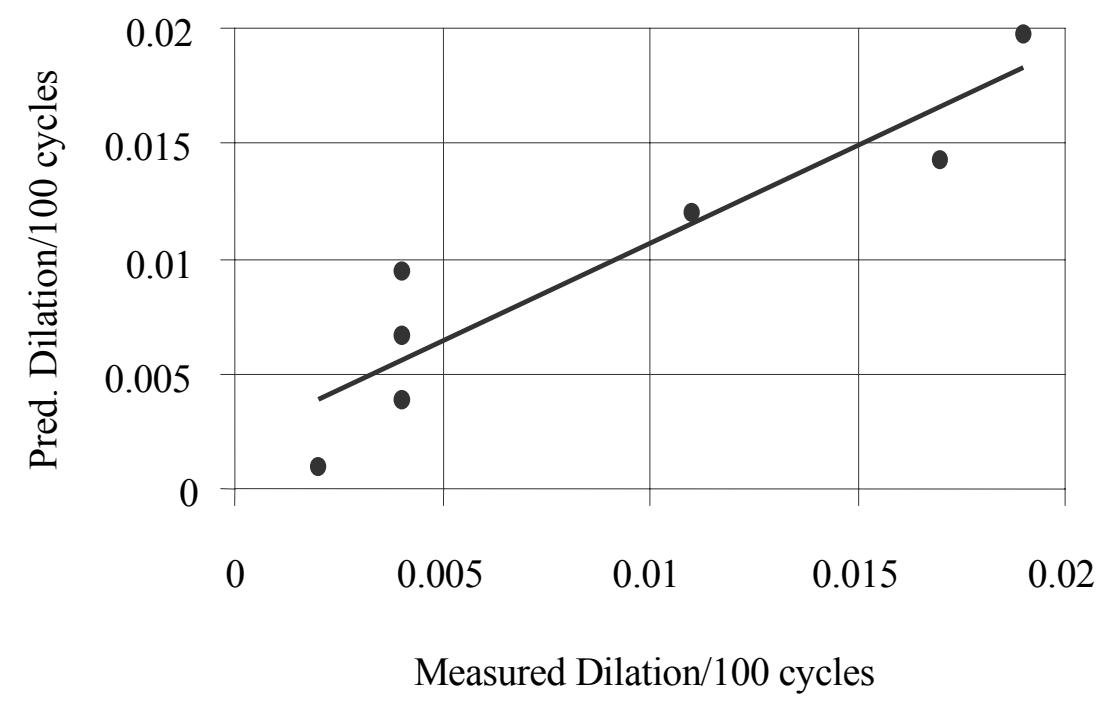

Figure 2.2. Predicted versus actual dilations using Hietpas' HFT mass-based model (3). 


\section{CHAPTER 3}

\section{EXPERIMENTAL DESIGN}

\subsection{General Description of Test Program}

The first phase and principal phase of the current research program involved the validation of the WHFT procedural modifications proposed in the recent Michigan-funded research. The principal changes center around the use of additional sieves to better characterize the nature of the fracturing that takes place during the test. Data obtained from the sieve analyses were then used to develop models for predicting freeze-thaw test dilation as a function of aggregate particle counts and masses retained on the various sieves. Additional WHFT tests were run with aggregate samples representing size fractions different from that typically tested to determine the effects of rapid freezing and thawing on aggregate particle sizes less than $19.0 \mathrm{~mm}$ (0.75 in). The following aggregate size fractions were used in the test program:

- 19.0 to $37.5 \mathrm{~mm}(0.75$ to $1.5 \mathrm{in})$

- 12.5 to $19.0 \mathrm{~mm}(0.5$ to $0.75 \mathrm{in})$

- 4.75 to $12.5 \mathrm{~mm}$ (\#4 to $0.5 \mathrm{in})$

Twenty aggregate sources were selected to represent a range of aggregate freeze-thaw durability. Samples from each aggregate source were tested to determine fundamental properties such as absorption capacity, specific gravity and unit weight. The aggregates were then used to prepare air-entrained concrete mixtures for use in casting freeze-thaw and strength specimens and to prepare the hydraulic fracture test samples.

Freeze-thaw testing was performed on the cast beams, and the durability factor and percent dilation associated with each aggregate source was determined. These values were used in the development of models correlating rapid freezing and thawing test results to the cumulative counts and mass of particles passing designated sieve screens.

The second phase of the proposed research program involved the modification of the WHFT aggregate test chamber to accommodate larger samples of aggregate. The SHRP and Michigan 
studies both indicated that a representative sample of at least 600 aggregate particles is required to reduce the variability between replicate test results to acceptable levels. The original test apparatus can hold only approximately 200 particles (sized 19 to $37.5 \mathrm{~mm}$ [0.75 to $1.5 \mathrm{in}]$ ), which means that at least three tests must be performed and combined to obtain a single test result. The use of a larger chamber would permit an entire 600-particle sample to be processed in a single test, thereby further reducing test time requirements.

\subsection{Coarse Aggregate Samples}

\subsubsection{Size-Fraction Test Sampling}

Twenty Minnesota and Iowa aggregate sources were selected to represent a broad range of aggregate freeze-thaw durability (see table 3.1); sixty-five percent of the selected aggregate sources were obtained from quarries, while the remaining thirty-five percent were from gravel pits. Aggregate samples were obtained from each source (using the ASTM D 75 procedures) in quantities sufficient for all the proposed characterization tests, WHFT and freeze-thaw durability testing. The samples were screened into the previously described particle size fractions (i.e., 4.75 to $12.5 \mathrm{~mm}, 12.5$ to $19.0 \mathrm{~mm}, 19.0$ to $37.5 \mathrm{~mm}$ [\#4 to $0.5 \mathrm{in}, 0.5$ to $0.75 \mathrm{in}$, and 0.75 to 1.5 in]) until sufficient quantities of each size fraction had been obtained.

Each aggregate source size fraction was thoroughly remixed to ensure uniformity of the material, since the original samples were sometimes obtained from more than one stockpile, each containing the same source aggregate but with varying top sizes. Samples were obtained from each aggregate source size fraction for performing the following tests:

- specific gravity and absorption capacity testing (ASTM C 127 "Specific Gravity and Absorption of Coarse Aggregate"),

- magnesium sulfate testing (ASTM C 88 "Standard Test Method for Soundness of Aggregate by Use of Sodium Sulfate or Magnesium Sulfate"),

- hydraulic fracture testing, and

- for determining the percentage of carbonates present. 
Table 3.1. Summary of aggregate sources, locations and expected durabilities.

\begin{tabular}{|c|c|c|c|c|c|c|}
\hline \multirow[b]{2}{*}{ Aggregate Source } & \multirow[b]{2}{*}{$\begin{array}{l}\text { Mn/DOT Pit } \\
\text { Designation }\end{array}$} & \multirow[b]{2}{*}{$\begin{array}{c}\text { Expected } \\
\text { Durability }\end{array}$} & \multicolumn{4}{|c|}{ Location } \\
\hline & & & County/State & SEC & TWN & RNG \\
\hline \multicolumn{7}{|c|}{ QUARRIED } \\
\hline Aaland, Zumbrota & 25083 & Fair & Goodhue, MN & 34 & 110 & 15 \\
\hline Big Springs, Harmony & 23096 & Good & Fillmore, $\mathrm{MN}$ & 09 & 101 & 10 \\
\hline Bryan Rock, Shakopee & 70006 & Poor & Scott, MN & 29 & 115 & 23 \\
\hline Coralville Concrete Ledge, Waterloo & $\mathrm{N} / \mathrm{A}$ & Poor & Waterloo, IA & & & \\
\hline Early Chapel & 155011 & Poor & Early Chapel, IA & & & \\
\hline Edward Kramer \& Sons, Burnsville & 19106 & Good & Dakota, $\mathrm{MN}$ & 33 & 027 & 24 \\
\hline Goldberg, Rochester & 55037 & Good & Olmsted, MN & 36 & 108 & 14 \\
\hline Michigan Limestone, Cedarville Plant & 197001 & Good & Mackinac, MI & & & \\
\hline Osmundson, Grand Meadow & 50011 & Fair & Mower, MN & 09 & 103 & 14 \\
\hline Shiely Grey Cloud (Larson) & 182002 & Good & Washington, $\mathrm{MN}$ & 26 & 27 & 22 \\
\hline Southern MN Corp. (SMC) Mankato & 74071 & Poor & Steele, MN & 33 & 108 & 20 \\
\hline Swedberg & 66084 & Poor & Rice County, MN & 04 & 109 & 20 \\
\hline Ulland Northwood, Iowa & 193018 & Good & Worth, IA & 10 & 99 & 22 \\
\hline \multicolumn{7}{|c|}{ GRAVEL } \\
\hline Ashwill, Kingston & 47076 & Uncertain & Meeker, MN & 34 & 120 & 29 \\
\hline Johnson, Henderson & 72001 & Good & Sibley, MN & 26 & 113 & 26 \\
\hline Johnson Le Sueur & 140002 & Poor & Le Sueur, MN & 15 & 111 & 26 \\
\hline Loeffler, Halma & 35002 & Good & Kittson, MN & 17 & 160 & 46 \\
\hline Mark, Underwood & 56003 & Good & Otter Tail, MN & 10 & 132 & 41 \\
\hline Northern Con, Luverne & 67001 & $\begin{array}{l}\text { Good - } \\
\text { Poor }\end{array}$ & Rock, MN & 06 & 102 & 44 \\
\hline North Star Kasota & 140001 & Poor & Le Sueur, MN & 04 & 109 & 26 \\
\hline
\end{tabular}




\subsubsection{As-Produced Material}

In addition to the sampling/testing of each size fraction, an "as-produced" materials blend was prepared for use in producing air-entrained concrete mixtures from which freeze-thaw and strength specimens were cast. These "as-produced" blends comprised 50 percent material retained on the $19 \mathrm{~mm}$ ( $0.75 \mathrm{in}$ ) sieve, and 50 percent passing the same sieve, a blend commonly used in Minnesota PCC paving mixtures. This blend was accomplished as follows:

- 50 percent 19.0 to $37.5 \mathrm{~mm}$ ( 0.75 to 1.5 in) material

- 25 percent 12.5 to $19.0 \mathrm{~mm}$ ( 0.5 to 0.75 in) material

- 25 percent 4.75 to $12.5 \mathrm{~mm}$ (\#4 to 0.5 in) material

Further sieve analyses were not performed on the blended materials. The specified blend was not achieved for two of the aggregate sources (Ashwill, Kingston and Waterloo, Iowa), as described below.

\section{Ashwill, Kingston}

The CA60 gradation band was used in the development of the as-produced aggregate proportions for this source, which was deficient in aggregate particles larger than $19.0 \mathrm{~mm}$ (0.75 in). The following proportions were used for Ashwill, Kingston:

- 37.5 percent 12.5 to $19.0 \mathrm{~mm}$ ( 0.5 to 0.75 in) material

- 62.5 percent 4.75 to $12.5 \mathrm{~mm}$ (\#4 to 0.5 in) material

Waterloo, Iowa

Aggregate from this source was available from a previous durability study performed in 1998 . For the 1998 study, the aggregate was sieved into component size fractions and re-blended to meet the middle of the AASHTO M43 specification Grade 467 (37.5-mm [1.5-in] top size). Therefore, the proportions of the as-produced material from this source were as follows:

- 50 percent 19.0 to $37.5 \mathrm{~mm}$ (0.75 to 1.5 in) material

- 20 percent 12.5 to $19.0 \mathrm{~mm}$ ( 0.5 to $0.75 \mathrm{in})$ material

- 27.5 percent 4.75 to $12.5 \mathrm{~mm}$ (\#4 to 0.5 in) material

- 2.5 percent minus \#4 material 
It should be noted that the tests performed on cast PCC specimens using this aggregate source under the 1998 study were identical to some of the tests that would have been performed under the current study; where possible, the 1998 test results were used and the tests were not repeated in the current study. These tests are described in more detail in section 3.4 of this report.

\subsubsection{As-Produced Test Sampling}

Samples were split from the newly developed "as-produced material" and prepared for use in airentrained PCC mixtures and for use in determining the following fundamental aggregate properties:

- ASTM C 127 "Specific Gravity and Absorption of Coarse Aggregate”

- ASTM C 29 "Unit Weight and Voids in Aggregate"

- ASTM C 136 "Sieve Analysis of Fine and Coarse Aggregates"

\subsection{PCC Mix Design}

A standard air-entrained PCC paving mixture was prepared for each of the 20 selected aggregates sources; Mn/DOT Mix 3A41 (meeting the requirements of specification 2461) was used as the base mix design. The mixtures consisted of natural river sand, Type I cement, water and an air-entraining admixture. The air-entraining admixture was used to ensure that any freeze-thaw durability problems observed were due to the coarse aggregate and not the cement mortar matrix. The coarse aggregate was conditioned to be in a saturated, surface-dry (SSD) condition at the time of batching to guarantee critical saturation when subjected to rapid freezing and thawing; the fine aggregate was oven-dry at the time of batching. A water-cement ratio of 0.40, the maximum currently allowed in Minnesota PCC paving mixtures, was used for most of the PCC mixtures prepared under this study. Table B-1 (see appendix B) summarizes the batch weights used to prepare each PCC mixture.

The plastic air content was measured with the Press-R-Meter in accordance with ASTM C 231 "Air Content of Freshly Mixed Concrete by the Pressure Method," and the slump was measured using a standard slump cone in accordance with ASTM C 143 "Slump of Hydraulic Cement 
Concrete." Table B-1 (see appendix B) summarizes the plastic air content and slump measurements for each mixture.

\subsection{Test Specimens}

Six beam test specimens measuring $75 \mathrm{~mm} \times 100 \mathrm{~mm} \times 400 \mathrm{~mm}(3 \mathrm{in} \times 4$ in $\times 16$ in $)$ and three cylindrical specimens measuring $152 \mathrm{~mm}$ diameter $\times 305 \mathrm{~mm}(6 \mathrm{in} \times 12$ in) were cast from each mixture for freeze-thaw and strength testing (14-day compression and 14-day static modulus of elasticity), respectively. The compressive strength tests and static modulus of elasticity testing were performed in accordance with ASTM C 39 "Compressive Strength of Cylindrical Specimens" and ASTM C 469 "Static Modulus of Elasticity and Poisson's Ratio of Concrete in Compression," respectively. A slice was taken from one freeze-thaw beam of each mixture and prepared for linear traverse analysis (ASTM C 457 "Microscopical Determination of Parameters of the Air-Void System in Hardened Concrete") to verify that an adequate air void system was present, thereby ensuring that any freeze-thaw durability problems observed could be attributed solely to the use of a non-durable aggregate rather than unsound mortar.

The freeze-thaw beams were cured in a lime-saturated water bath for 14 days, after which time they were subjected to rapid freezing and thawing in accordance with AASHTO TP17 (T161 Procedure C). The freeze-thaw durability of these mixtures was evaluated using the relative dynamic modulus (calculated according to ASTM C 215 "Fundamental Transverse, Longitudinal, and Torsional Resonant Frequencies of Concrete Specimens”) and dilation criteria.

\subsection{Hydraulic Fracture Testing - Small Chamber}

\subsubsection{Small Chamber Test Samples}

Five samples of oven-dry coarse aggregate sufficient to fill the test chamber (approximately 2.6 to $3.0 \mathrm{~kg}$ [5.6 to $6.6 \mathrm{lb}$ ] of aggregate) were made from each source for each of the three previously defined size fractions. Thus, a total of approximately 300 hydraulic fracture test samples were prepared for the small chamber (five samples representing each of three size fractions for each of 20 sources). Some sources did not contain enough material larger than 19 $\mathrm{mm}(0.75 \mathrm{in})$ to prepare five replicate specimens (as indicated in table 3.2 ), so the actual total number of test samples prepared was somewhat less than 300 . 
Testing of the samples was performed randomly within blocks of replicates (i.e., one replicate specimen of each source within a particular size fraction was tested in random order before the next block of replicates was tested, also in random order). This was done to minimize the potential effects of both random and systematic bias due to the effects of any extraneous factors that may have been present (e.g., operator procedural differences, uncontrolled and unforeseen changes in the test equipment, etc.).

A few specimens were either untested (due to time and funding constraints) or were spoiled (as a result of occasional handling or testing errors). Table 3.2 presents a summary of which tests were completed with respect to initial size fraction, aggregate source and replicate number. Table cells labeled N/A (not available) indicate that the original source material was deficient in $19.0 \mathrm{~mm}(0.75 \mathrm{in})$ plus material, thereby preventing the preparation of the replicate sample. A total of 272 specimens did yield usable results after testing, including no fewer than three replicates for each source-size fraction for which material was available.

\subsubsection{Modified Test Procedure}

The original hydraulic fracture test procedure (as briefly described previously in section 2.1) was modified slightly to account for the additional size fractions included in the experimental design. The following is a brief description of the test procedure followed during this study; the complete modified procedure is presented in appendix A.

The test begins by obtaining an appropriately sized sample of oven-dry coarse aggregate that is sufficient to fill the 51-mm (2-in) deep by 254-mm (10-in) diameter test chamber. This typically requires 2.6 to $3.0 \mathrm{~kg}$ (5.7 to $6.6 \mathrm{lb}$ ) of aggregate. The sample is submerged in a water-based silane solution (Hydrozo Enviroseal 40 was used for this study) for one minute to inhibit the hydrophilic tendencies of some aggregates, which may reduce the effectiveness of the test. The sample is then drained and oven-dried again. The sample is tumbled in a rock tumbler for one minute to provide uniform handling and to fracture any weakened or partially broken pieces. 
Table 3.2. Small chamber hydraulic fracture test matrix.

\begin{tabular}{|c|c|c|c|c|c|c|c|c|c|c|c|c|c|c|c|}
\hline \multirow{5}{*}{ Aggregate Source } & \multicolumn{15}{|c|}{ Completed Hydraulic Fracture Testing (as denoted by a "X") } \\
\hline & \multicolumn{15}{|c|}{ Initial Size Fraction } \\
\hline & \multicolumn{5}{|c|}{4.75 to $12.5 \mathrm{~mm}$ (\#4 to $0.5 \mathrm{in})$} & \multicolumn{5}{|c|}{12.5 to $19.0 \mathrm{~mm}(0.5$ to $0.75 \mathrm{in})$} & \multicolumn{5}{|c|}{19.0 to $37.5 \mathrm{~mm}(0.75$ to $1.5 \mathrm{in})$} \\
\hline & \multicolumn{15}{|c|}{ Replicate Number } \\
\hline & 1 & 2 & 3 & 4 & 5 & 1 & 2 & 3 & 4 & 5 & 1 & 2 & 3 & 4 & 5 \\
\hline Ashwill & $\bar{X}$ & $\bar{X}$ & & $\bar{X}$ & $\bar{X}$ & $\bar{X}$ & $\bar{X}$ & $\bar{X}$ & $\mathrm{X}$ & $\mathrm{X}$ & N/A & N/A & N/A & $\mathrm{N} / \mathrm{A}$ & N/A \\
\hline Big Springs, Harmony & $\mathrm{X}$ & $\mathrm{X}$ & $\mathrm{X}$ & & & $\mathrm{X}$ & $\mathrm{X}$ & $\mathrm{X}$ & $X$ & $\mathrm{X}$ & $\mathrm{X}$ & $\mathrm{X}$ & $\mathrm{X}$ & $\mathrm{X}$ & $\mathrm{X}$ \\
\hline Bryan Rock, Shakopee & $\mathrm{X}$ & $\mathrm{X}$ & $\mathrm{X}$ & $\mathrm{X}$ & & $\mathrm{X}$ & $\mathrm{X}$ & $\mathrm{X}$ & $X$ & $\mathrm{X}$ & $\mathrm{X}$ & $\mathrm{X}$ & $\mathrm{X}$ & $\mathrm{X}$ & $\mathrm{X}$ \\
\hline Cedarville Plant, Michigan & $\mathrm{X}$ & $\mathrm{X}$ & & $\mathrm{X}$ & & $\mathrm{X}$ & $\mathrm{X}$ & $\mathrm{X}$ & $\mathrm{X}$ & $\mathrm{X}$ & $\mathrm{X}$ & $\mathrm{X}$ & $\mathrm{X}$ & $\mathrm{X}$ & \\
\hline Early Chapel & $\mathrm{X}$ & $\mathrm{X}$ & $\mathrm{X}$ & $\mathrm{X}$ & $\mathrm{X}$ & $\mathrm{X}$ & $\mathrm{X}$ & $\mathrm{X}$ & $\mathrm{X}$ & $\mathrm{X}$ & $\mathrm{X}$ & $\mathrm{X}$ & $\mathrm{X}$ & $\mathrm{X}$ & $\mathrm{X}$ \\
\hline Edward Kramer \& Sons, Burnsville & $\mathrm{X}$ & $\mathrm{X}$ & & $\mathrm{X}$ & $\mathrm{X}$ & $\mathrm{X}$ & $\mathrm{X}$ & $\mathrm{X}$ & $\mathrm{X}$ & & $\mathrm{X}$ & $\mathrm{X}$ & $\mathrm{X}$ & $\mathrm{X}$ & $\mathrm{X}$ \\
\hline Goldberg, Rochester & $\mathrm{X}$ & $\mathrm{X}$ & $\mathrm{X}$ & $\mathrm{X}$ & & $\mathrm{X}$ & & $\mathrm{X}$ & $\mathrm{X}$ & $X$ & $\mathrm{X}$ & $\mathrm{X}$ & $\mathrm{X}$ & $\mathrm{X}$ & $\mathrm{X}$ \\
\hline Grandmeadow, Osmundson & $\mathrm{X}$ & $\mathrm{X}$ & $\bar{X}$ & $\bar{X}$ & & $\mathrm{X}$ & $\mathrm{X}$ & $\mathrm{X}$ & $\mathrm{X}$ & $\mathrm{X}$ & $\mathrm{X}$ & $\mathrm{X}$ & $\mathrm{X}$ & $\mathrm{X}$ & $\mathrm{X}$ \\
\hline Halma, Loeffler Sand \& Gravel & $\mathrm{X}$ & $\mathrm{X}$ & $\mathrm{X}$ & $\mathrm{X}$ & $\mathrm{X}$ & $\mathrm{X}$ & $\mathrm{X}$ & $\mathrm{X}$ & $\mathrm{X}$ & $\mathrm{X}$ & $\mathrm{X}$ & $\mathrm{X}$ & $\mathrm{X}$ & $\mathrm{X}$ & $\mathrm{X}$ \\
\hline Johnson Henderson & $\mathrm{X}$ & $\mathrm{X}$ & & $\bar{X}$ & $\mathrm{X}$ & $X$ & $\mathrm{X}$ & $\mathrm{X}$ & $X$ & $\mathrm{X}$ & $\mathrm{X}$ & $X$ & $X$ & $X$ & $\mathrm{X}$ \\
\hline Johnson, Le Sueur & $\mathrm{X}$ & $\mathrm{X}$ & & $\mathrm{X}$ & $\mathrm{X}$ & $\mathrm{X}$ & $\mathrm{X}$ & $\mathrm{X}$ & $\mathrm{X}$ & $\mathrm{X}$ & $\mathrm{X}$ & $\mathrm{X}$ & $\mathrm{X}$ & $\mathrm{X}$ & $\mathrm{X}$ \\
\hline Mark, Underwood & $\mathrm{X}$ & $\mathrm{X}$ & $\mathrm{X}$ & $\bar{X}$ & & $\mathrm{X}$ & $\mathrm{X}$ & $\mathrm{X}$ & $\mathrm{X}$ & $\mathrm{X}$ & $\mathrm{X}$ & $\mathrm{X}$ & $X$ & $X$ & $X$ \\
\hline North Star Kasota & $\mathrm{X}$ & $\mathrm{X}$ & & $\mathrm{X}$ & $\mathrm{X}$ & $\mathrm{X}$ & $\mathrm{X}$ & $\mathrm{X}$ & $\mathrm{X}$ & $\mathrm{X}$ & $\mathrm{X}$ & $\mathrm{X}$ & $\mathrm{X}$ & $\mathrm{X}$ & $\mathrm{X}$ \\
\hline Northern Con, Luverne & $\mathrm{X}$ & $\mathrm{X}$ & & $\bar{X}$ & & $\mathrm{X}$ & $\mathrm{X}$ & $\mathrm{X}$ & $X$ & $\mathrm{X}$ & $\mathrm{X}$ & $\mathrm{X}$ & $\mathrm{X}$ & $X$ & $\mathrm{X}$ \\
\hline Shiely Grey Cloud (Larson) & $\mathrm{X}$ & $\mathrm{X}$ & $\mathrm{X}$ & $\mathrm{X}$ & & $\mathrm{X}$ & $\mathrm{X}$ & $\mathrm{X}$ & $\mathrm{X}$ & $X$ & $\mathrm{X}$ & $\mathrm{X}$ & $X$ & $\mathrm{X}$ & $X$ \\
\hline SMC Mankato & $\mathrm{X}$ & $\mathrm{X}$ & & $\bar{X}$ & $\mathrm{X}$ & $\mathrm{X}$ & $\mathrm{X}$ & $\mathrm{X}$ & & $\mathrm{X}$ & $\mathrm{X}$ & $X$ & $\mathrm{X}$ & $\mathrm{X}$ & $\mathrm{X}$ \\
\hline Swedberg & $\mathrm{X}$ & $\mathrm{X}$ & $\mathrm{X}$ & $\mathrm{X}$ & $\mathrm{X}$ & $\mathrm{X}$ & $\mathrm{X}$ & $\mathrm{X}$ & $\mathrm{X}$ & $\mathrm{X}$ & $\mathrm{X}$ & $\mathrm{X}$ & $\mathrm{X}$ & $\mathrm{X}$ & $\mathrm{X}$ \\
\hline Ulland Northwood, Iowa & $\mathrm{X}$ & $\mathrm{X}$ & $\mathrm{X}$ & $\mathrm{X}$ & $\mathrm{X}$ & $\mathrm{X}$ & $\mathrm{X}$ & $\mathrm{X}$ & $X$ & $\mathrm{X}$ & $\mathrm{X}$ & $\mathrm{X}$ & $\mathrm{X}$ & $\mathrm{X}$ & $\mathrm{X}$ \\
\hline Waterloo, Coralville Concrete Ledge & $\mathrm{X}$ & $\mathrm{X}$ & $\mathrm{X}$ & $\mathrm{X}$ & $\mathrm{X}$ & $\mathrm{X}$ & $\mathrm{X}$ & $\mathrm{X}$ & $\mathrm{X}$ & $\mathrm{X}$ & $\mathrm{X}$ & $\mathrm{N} / \mathrm{A}$ & $\mathrm{X}$ & $\mathrm{X}$ & N/A \\
\hline Zumbrota, Aaland & $\mathrm{X}$ & $\mathrm{X}$ & $\mathrm{X}$ & $\mathrm{X}$ & $\mathrm{X}$ & $\mathrm{X}$ & $\mathrm{X}$ & $\mathrm{X}$ & $X$ & $\mathrm{X}$ & $X$ & $\mathrm{X}$ & $\mathrm{X}$ & $\mathrm{X}$ & $\mathrm{X}$ \\
\hline
\end{tabular}

N/A: Source deficient in $19 \mathrm{~mm}$ plus material.

$\square$ : Sample prepared, however, testing not completed due to time constraints or errors. 
Table 3.3. Screens used in preparing HFT test samples for various initial size fractions.

\begin{tabular}{|c|c|c|c|}
\hline \multirow[b]{2}{*}{ Sieve Size } & \multicolumn{3}{|c|}{ Initial Size Fraction } \\
\hline & $\begin{array}{c}4.75 \mathrm{~mm} \text { to } 12.5 \mathrm{~mm} \\
\text { (\#4 to } 0.5 \mathrm{in})\end{array}$ & $\begin{array}{c}12.5 \mathrm{~mm} \text { to } 19.0 \mathrm{~mm} \\
(0.5 \mathrm{in} \text { to } 0.75 \mathrm{in})\end{array}$ & $\begin{array}{l}19.0 \mathrm{~mm} \text { to } 37.5 \mathrm{~mm} \\
(0.75 \mathrm{in} \text { to } 1.5 \mathrm{in}) \\
\end{array}$ \\
\hline No. of Sub-Samples & 5 & 4 & 3 \\
\hline $37.5 \mathrm{~mm}(1.5 \mathrm{in})$ & & & X-Material Excluded \\
\hline $25.0 \mathrm{~mm}(1 \mathrm{in})$ & & & $\mathrm{X}$ \\
\hline $19.0 \mathrm{~mm}(0.75 \mathrm{in})$ & & X-Material Excluded & $\mathrm{X}$ \\
\hline $16.0 \mathrm{~mm}(0.625 \mathrm{in})$ & & $\mathrm{X}$ & $\mathrm{X}$ \\
\hline $12.5 \mathrm{~mm}(0.5 \mathrm{in})$ & X-Material Excluded & $\mathrm{X}$ & \\
\hline $9.50 \mathrm{~mm}(0.375 \mathrm{in})$ & $\mathrm{X}$ & $\mathrm{X}$ & \\
\hline $8.00 \mathrm{~mm}(0.3125 \mathrm{in})$ & $\mathrm{X}$ & & \\
\hline $6.35 \mathrm{~mm}(0.25 \mathrm{in})$ & $X$ & & \\
\hline $4.75 \mathrm{~mm}(\# 4)$ & $\mathrm{X}$ & & \\
\hline Pan & X-Material Excluded & X-Material Excluded & X-Material Excluded \\
\hline
\end{tabular}

The sample is then split into small sub-samples which are screened over the appropriate sieve sizes, as indicated (by " $\mathrm{X}$ ") in table 3.3. The smaller sub-samples are required to prevent overloading of the sieves by the aggregate. The material retained on the largest screen size used and on the pan is excluded from the sample for all three cases, as shown in table 3.3. For example, if the size fraction 19.0 to $37.5 \mathrm{~mm}(0.75$ to $1.5 \mathrm{in})$ was the target particle range, the material would need to be screened over the 37.5-mm (1.5-in), 25.0-mm (1-in), 19.0-mm (0.75in) and 16.0-mm (0.625-in) sieves and over the pan. The particles retained on the 37.5-mm (1.5in) sieve and on the pan would be excluded from the sample, since these particle sizes do not fall within the target particle range. The material retained on the next sieve size smaller than the target particle range (in this example, the $16.0-\mathrm{mm}$ [0.625-in] sieve) is included in the sample. This material is included in the target particle range to account for the particles which may or may not be retained on the $19.0 \mathrm{~mm}$ screen in future screenings due to reorientation of the particles.

The mass and number of particles retained on the remaining screens are determined (except for the 4.75 to $12.5 \mathrm{~mm}$ (\#4 to $0.5 \mathrm{in}$ ) size range, for which only the particle masses are determined due to the extremely large number of particles that make up this sample). The sample is then placed into the test chamber, which is closed and bolted shut.

The test chamber is then rotated onto its edge so that the pressure isolation/release valve is oriented vertically, and the chamber is filled with water. The water supply and release valves are 
secured and chamber is pressurized to $7930 \mathrm{kPa}(1150 \mathrm{psi})$ using a nitrogen source, forcing water into the pore structure of the aggregate and compressing the air in those pores. The pressure is maintained for 5 minutes, after which the nitrogen supply valve is closed. The pressure release valve is then opened rapidly, resulting in a nearly explosive decompression of the chamber, which allows the compressed air in the aggregate pores to expand and push the water back out through the pore structure. This movement of water through the pore structure during depressurization produces internal particle stresses similar to those that develop when ice forms and water moves through the aggregate pores during freezing, and may cause some particles to fracture. The chamber is refilled with water and the process is repeated in a similar manner (with 2-minute pressurizations on subsequent pressurization cycles) for a total of 10 pressurization and release cycles, after which time the chamber is drained and the aggregate particles are removed, oven-dried, tumbled, and sieved over 9.5-mm (0.375-in) and 4.75-mm (\#4) screens. The number of particles and mass of the aggregate retained over the screens are listed in table 3.4. The mass and number of particles retained over each screen is determined, and the material that is retained on the $4.75-\mathrm{mm}$ and larger sieves is retained and subjected to an additional 10 cycles of pressurization. The process is repeated for a total of 50 cycles of pressurization.

Table 3.4. Screens used in testing HFT samples for various initial size fractions.

\begin{tabular}{|c|c|c|c|}
\hline \multirow[b]{2}{*}{ Sieve Size } & \multicolumn{3}{|c|}{ Initial Size Fraction } \\
\hline & $\begin{array}{l}4.75 \text { to } 12.5 \mathrm{~mm} \\
(\# 4 \text { to } 0.5 \mathrm{in})\end{array}$ & $\begin{array}{c}12.5 \text { to } 19.0 \mathrm{~mm} \\
(0.5 \text { to } 0.75 \mathrm{in})\end{array}$ & $\begin{array}{c}19.0 \text { to } 37.5 \mathrm{~mm} \\
(0.75 \text { to } 1.5 \mathrm{in})\end{array}$ \\
\hline \multicolumn{4}{|l|}{$37.5 \mathrm{~mm}(1.5 \mathrm{in})$} \\
\hline $25.0 \mathrm{~mm}(1 \mathrm{in})$ & & & $\mathrm{X}$ \\
\hline $19.0 \mathrm{~mm}(0.75 \mathrm{in})$ & & & $\mathrm{X}$ \\
\hline $16.0 \mathrm{~mm}(0.625 \mathrm{in})$ & & $\mathrm{X}$ & $\mathrm{X}$ \\
\hline $12.5 \mathrm{~mm}(0.5 \mathrm{in})$ & & $\mathrm{X}$ & $\mathrm{X}$ \\
\hline $9.50 \mathrm{~mm}(0.375 \mathrm{in})$ & $\mathrm{X}$ & $\mathrm{X}$ & $\mathrm{X}$ \\
\hline $8.00 \mathrm{~mm}(0.3125 \mathrm{in})$ & $\mathrm{X}$ & $\mathrm{X}$ & $\mathrm{X}$ \\
\hline $6.35 \mathrm{~mm}(0.25 \mathrm{in})$ & $\mathrm{X}$ & $\mathrm{X}$ & $\mathrm{X}$ \\
\hline $4.75 \mathrm{~mm}(\# 4)$ & $\mathrm{X}$ & $\mathrm{X}$ & $\mathrm{X}$ \\
\hline Pan & $\mathrm{X}$ & $\mathrm{X}$ & $\mathrm{X}$ \\
\hline
\end{tabular}

\subsubsection{Normalization of Hydraulic Fracture Results}

The hydraulic fracture data was normalized to account for variations in particle counts and mass retained between individual samples due to the differences in particle size and shape. Each 
sample was normalized by comparing the number or mass of particles retained on each sieve after 50 cycles to the total number or mass of particles contained in the initial size fraction at 0 pressurization cycles. The percent of particles and mass retained for each sample was calculated as defined below:

Percentage of Original Particles Retained (POPR) $=$

$100 \times$ Number of particles on sieve $I$ (after 50 cycles)

Total number of particles in sample at 0 cycles

Percentage of Original Mass Retained $(\mathrm{POMR})=$

$100 \times \underline{\text { Mass retained on sieve } I \text { (after } 50 \text { cycles) }}$

Total mass of sample at 0 cycles

(Eqn. 3.2)

where: $\quad I=$ pan, 4.75-mm (\#4), 8.00-mm (0.3125-in), 9.50-mm (0.375-in), 12.5-mm (0.5-in), 16.0-mm (0.625-in), 19.0-mm (0.75-in), 25.0-mm (1-in), or 37.5-mm (1.5-in) sieve

The average percentage of particles and mass retained for each source was also calculated by combining all the replicates of each source together into one sample as defined below:

Average Percentage of Original Particles Retained (APOPR) $=$

$$
100 \times \frac{\sum_{k=1}^{n} \text { Number of particles on sieve } I \text { (after } 50 \text { cycles) }}{\sum_{k=1}^{n} \text { Total number of particles in sample at } 0 \text { cycles }}
$$

Average Percentage of Original Mass Retained $($ APOMR $)=$

$$
100 \times \frac{\sum_{k=1}^{n} \text { Mass retained on sieve } I \text { (after } 50 \text { cycles) }}{\sum_{k=1}^{n} \quad \text { Total mass of sample at } 0 \text { cycles }}
$$


where: $\quad I=$ pan, 4.75-mm (\#4), 8.00-mm (0.3125-in), 9.50-mm (0.375-in), 12.5-mm (0.5-in), 16.0-mm (0.625-in), 19.0-mm (0.75-in), 25.0-mm (1-in), or 37.5-mm (1.5-in) sieve $\mathrm{k}=$ replicate number $\mathrm{n}=$ total number of replicates

\subsection{Hydraulic Fracture Testing - Large Chamber}

\subsubsection{Large Chamber Test Samples}

Three samples of oven-dry coarse aggregate sufficient to fill the large test chamber (approximately $15 \mathrm{~kg}$ [33 lb] of aggregate) were prepared with the 19.0 to $37.5 \mathrm{~mm}(0.75$ to 1.5 in) size fraction of the following four sources, which represent a range of freeze-thaw resistance: Johnson Henderson (Gravel), North Star Kasota (Gravel), Edward Kramer and Sons (Quarried Carbonate) and Early Chapel (Quarried Carbonate). As described previously for the small chamber, the order of testing the individual replicates was determined randomly to minimize the effects of random and systematic bias due to the effects of possible extraneous factors.

\subsubsection{Test Procedure}

The general test procedure followed when using the large hydraulic fracture chamber is the same as that discussed for small chamber use (see section 3.5.2) and described in Appendix A. The only difference is that replicate tests are not required because the large chamber holds enough aggregate particles to accurately characterize the D-cracking potential of a coarse aggregate source with a single test sample.

\subsubsection{Normalization of Hydraulic Fracture Test Results}

The large chamber hydraulic fracture data were interpreted in the same manner as described for the small chamber data (see section 3.5.3). 


\section{CHAPTER 4 \\ TEST RESULTS AND ANALYSES}

\subsection{Concrete Properties}

Microscopical analyses of the concrete air void systems were performed on one polished concrete slice taken from a selected strength specimen for each mixture to verify that any durability failures were due to the coarse aggregate and not to the cement mortar matrix. Table 4.1 presents a summary of the air void characteristics measured for each concrete mixture. Most authorities $(4,5,6)$ recommend a spacing factor of $0.2 \mathrm{~mm}(0.008 \mathrm{in})$ or less and a specific surface equal to or exceeding $27 \mathrm{~mm} / \mathrm{mm}^{3}\left(600 \mathrm{in}^{2} / \mathrm{in}^{3}\right)$ for concrete intended to be resistant against repeated cycles of freezing and thawing. All mixtures but one met the specific surface criterion, and the spacing factor criterion was met for 15 of the 20 mixtures. The five mixtures that exceeded the spacing factor criterion did so by 10 percent or less (as indicated in italics in table 4.1). No mixture failed both the specific surface and spacing factor criteria.

Table 4.2 presents the average durability factors and dilation measures for each PCC mixture. Neville reported that durability factors greater than 60 indicate satisfactory freeze-thaw durability, durability factors between 40 and 60 indicate doubtful freeze-thaw performance, and durability factors less than 40 indicate unsatisfactory durability (7). Mn/DOT considers durability factors greater than 80 as satisfactory, durability factors between 40 and 80 as fair, and durability factors less than 40 as unsatisfactory. The Mn/DOT criteria reflect an expected concrete pavement design life of 35 years. Dilations exceeding 0.04 percent per 100 cycles are also generally considered to indicate nondurable concrete.

Using the durability factors categories adopted by Mn/DOT, the aggregate sources would be categorized as follows (in order of descending durability factor, with the measured durability factor given in brackets for each aggregate source):

\footnotetext{
“Satisfactory" Freeze-Thaw Resistance (DF > 80)

$>$ Michigan Limestone, Cedarville Plant (Quarried) [99.3]

$>$ Shiely Grey Cloud (Larson [Quarried]) [98.8]
} 
Table 4.1. Summary of air void system measurements.

\begin{tabular}{|c|c|c|c|c|c|}
\hline Source & $\begin{array}{c}\text { Batch } \\
\text { No. }\end{array}$ & $\begin{array}{c}\text { Plastic Air } \\
\text { Content } \\
(\%) \\
\end{array}$ & $\begin{array}{c}\text { Hardened Air } \\
\text { Content } \\
(\%) \\
\end{array}$ & $\begin{array}{c}\text { Spacing } \\
\text { Factor } \\
(\mathrm{mm})\end{array}$ & $\begin{array}{c}\text { Specific } \\
\text { Surface } \\
\left(\mathrm{mm}^{2} / \mathrm{mm}^{3}\right) \\
\end{array}$ \\
\hline \multicolumn{6}{|c|}{ QUARRIED } \\
\hline Aaland, Zumbrota* & 1 & 6.4 & 5.26 & 0.1499 & 34.8 \\
\hline Big Springs, Harmony & 1 & 3.5 & 3.37 & 0.1448 & 40.7 \\
\hline Bryan Rock, Shakopee* & 1 & 3.5 & 3.32 & 0.2210 & 27.4 \\
\hline \multirow{3}{*}{ Coralville Concrete Ledge, Waterloo* } & 1 & 7.4 & 7.1 & 0.1220 & 37.2 \\
\hline & 5 & 4.7 & 5.1 & 0.2000 & 24.1 \\
\hline & 7 & 5.2 & 4.8 & 0.1630 & 31.5 \\
\hline Early Chapel* & 1 & 3.6 & 3.77 & 0.2057 & 27.5 \\
\hline Edward Kramer \& Sons, Burnsville & 1 & 4.9 & 3.34 & 0.1753 & 34.3 \\
\hline Goldberg, Rochester & 1 & 4.4 & 2.7 & 0.1880 & 34.8 \\
\hline Osmundson, Grand Meadow* & 2 & 5.0 & 4.52 & 0.1880 & 28.6 \\
\hline Michigan Limestone, Cedarville Plant & 1 & 5.9 & 4.2 & 0.1270 & 43.1 \\
\hline Shiely Grey Cloud (Larson) & 1 & 5.3 & 3.25 & 0.2108 & 29.3 \\
\hline SMC Mankato & 1 & 4.8 & 3.66 & 0.1905 & 30.5 \\
\hline Swedberg & 1 & 3.5 & 2.74 & 0.1753 & 36.9 \\
\hline Ulland Northwood, Iowa & 1 & 3.5 & 1.6 & 0.2134 & 39.0 \\
\hline \multicolumn{6}{|c|}{ GRAVEL } \\
\hline Ashwill, Kingston & 1 & 4.9 & 4.16 & 0.1372 & 40.0 \\
\hline Johnson, Henderson & 1 & 4.4 & 3.3 & 0.2210 & 27.2 \\
\hline Johnson Le Sueur & 1 & 5.7 & 4.9 & 0.1651 & 31.4 \\
\hline Loeffler, Halma & 1 & 5.9 & 4.9 & 0.1092 & 47.4 \\
\hline Mark, Underwood & 1 & 6.4 & 5.6 & 0.1524 & 32.1 \\
\hline Northern Con, Luverne & 1 & 7 & 3.2 & 0.1397 & 45.9 \\
\hline North Star Kasota & 1 & 4.5 & 2.5 & 0.1981 & 34.4 \\
\hline
\end{tabular}

* Linear traverse analysis performed by different operator than subsequent tests. 
Ashwill, Kingston (Gravel) [97.1]

> Ulland Northwood, Iowa (Quarried) [97.0]

$>$ Mark, Underwood (Gravel) [95.5]

$>$ Goldberg, Rochester (Quarried) [95.2]

$>$ Loeffler, Halma (Gravel) [93.9]

$>$ Johnson, Henderson (Gravel) [90.2]

$>$ Johnson, Le Sueur (Gravel) [88.3]

$>$ Northern Con, Luverne (Gravel) [83.8]

$>$ Aaland, Zumbrota (Quarried) [80.5]

"Fair" Freeze-Thaw Resistance (DF $=40$ to 80)

$>$ North Star Kasota (Gravel) [79.4]

$>$ Edward Kramer and Sons, Burnsville (Quarried) [78.6]

$>$ Osmundson, Grand Meadow (Quarried) [78.4]

"Unsatisfactory” Freeze-Thaw Resistance (DF < 40)

$>$ Early Chapel, Iowa (Quarried) [36.1]

> Coralville Concrete Ledge, Waterloo (Quarried) [31.2]

$>$ Swedberg (Quarried) [26.2]

$>$ Big Springs, Harmony (Quarried) [18.0]

$>$ Bryan Rock, Shakopee (Quarried) [16.0]

$>$ SMC Mankato (Quarried) [13.4]

\begin{abstract}
All of the mixtures exhibiting unsatisfactory durability factors also had excessive average dilations.

Specimens exhibiting unsatisfactory freeze-thaw resistance and containing marginal air void systems were visually inspected using a stereomicroscope to verify that the majority of deterioration was contained within the aggregate particles. Therefore, microscopic examinations were performed on slices taken from freeze-thaw damaged concrete specimens comprising "Bryan Rock, Shakopee" and "Early Chapel, Iowa" aggregates; physical inspection was not
\end{abstract}


performed on concrete specimens comprising "Ulland, Northwood", "Shiely Grey Cloud (Larson)", or "Johnson, Henderson" due to the high durability factors and low dilation measurements obtained for these specimens. Severe microcracking could be seen in the aggregate particles and not in the cement matrices of the freeze-thaw damaged concrete specimens with marginal spacing factors. Therefore, it can be concluded that all of the PCC mixtures exhibiting low durability factors did so because they contained deleterious aggregate materials and not because the cement matrix was nondurable.

The average strength measured for each PCC mixture is also presented in table 4.2 (see table B-2 for measured strength results of each PCC specimen). All strength test results are well within the range generally considered necessary for durable concrete (i.e., $\mathrm{f}_{\mathrm{c}}>27.6 \mathrm{MPa}[4000 \mathrm{psi}]$ ).

\subsection{Specific Gravity and Absorption Capacity}

The specific gravity and absorption capacity were determined for the "as-produced" materials and each size fraction of each source (i.e., 4.75 to $12.5 \mathrm{~mm}, 12.5$ to $19.0 \mathrm{~mm}, 19.0$ to $37.5 \mathrm{~mm}$ [\#4 to 0.5 in, 0.5 to 0.75 in, 0.75 to 1.5 in]) in accordance with ASTM C 127 "Specific Gravity and Absorption of Coarse Aggregate." Table 4.3 summarizes the results of these tests.

Mn/DOT considers quarried carbonates with measured absorption capacity values greater than 1.7 percent to have potential for durability problems and, therefore, does not allow the use of such sources in concrete paving applications. According to Mn/DOT specifications, the following aggregate sources would be considered unsatisfactory for use in paving applications based on the absorption capacity values measured for the as-produced material (as shown in brackets for each aggregate source):

> SMC Mankato [4.437\%]

$>$ Osmundson, Grand Meadow [3.781\%]

$>$ Aaland, Zumbrota [3.242\%]

$>$ Edward Kramer \& Sons, Burnsville [3.150 \%]

$>$ Shiely Grey Cloud (Larson) [2.972 \%]

$>$ Bryan Rock, Shakopee [2.928 \%] 
Table 4.2. Summary of strength and durability test data.

\begin{tabular}{|c|c|c|c|c|c|}
\hline Source & $\begin{array}{c}\text { Avg. } \\
\text { Compressive } \\
\text { Strength }^{1} \\
(\mathrm{MPa})\end{array}$ & $\begin{array}{l}\text { Avg. } \\
\text { Static E } \\
(\mathrm{GPa})\end{array}$ & $\begin{array}{c}\text { Avg. } \\
\text { DF }\end{array}$ & $\begin{array}{l}\text { Avg. } \\
\text { Dilation }^{2} \\
(\%)\end{array}$ & $\begin{array}{c}\text { Avg. } \\
\text { Dilation / } \\
100 \\
\text { Cycles } \\
(\%)\end{array}$ \\
\hline \multicolumn{6}{|c|}{ QUARRIED } \\
\hline Aaland, Zumbrota & 31.2 & & 80.5 & 0.029 & 0.011 \\
\hline Big Springs, Harmony & 40.7 & 31.4 & 18.0 & 0.044 & 0.050 \\
\hline Bryan Rock, Shakopee & 47.3 & & 16.0 & 0.089 & 0.118 \\
\hline Coralville Concrete Ledge, Waterloo $^{2}$ & 41.6 & 30.0 & 31.2 & 0.099 & 0.073 \\
\hline Early Chapel & 45.2 & & 36.1 & 0.089 & 0.050 \\
\hline Edward Kramer \& Sons, Burnsville & 30.1 & 21.6 & 78.6 & 0.053 & 0.018 \\
\hline Goldberg, Rochester & 42.8 & 27.6 & 95.2 & 0.012 & 0.004 \\
\hline Michigan Limestone, Cedarville Plant & 34.3 & 30.9 & 99.3 & 0.002 & 0.001 \\
\hline Osmundson, Grand Meadow & 48.4 & & 78.4 & 0.055 & 0.018 \\
\hline Shiely Grey Cloud (Larson) & 44.0 & 27.0 & 98.8 & 0.011 & 0.004 \\
\hline SMC Mankato & 36.5 & 24.2 & 13.4 & 0.068 & 0.111 \\
\hline Swedberg & 32.8 & 28.2 & 26.2 & 0.101 & 0.078 \\
\hline Ulland Northwood, Iowa & 40.9 & 34.6 & 97.0 & -0.008 & -0.003 \\
\hline \multicolumn{6}{|c|}{ GRAVEL } \\
\hline Ashwill, Kingston & 38.4 & 30.7 & 97.1 & 0.010 & 0.003 \\
\hline Johnson, Henderson & 35.5 & 29.0 & 90.2 & 0.016 & 0.005 \\
\hline Johnson Le Sueur & 30.3 & 28.8 & 88.3 & 0.023 & 0.008 \\
\hline Loeffler, Halma & 34.5 & 30.4 & 93.9 & 0.018 & 0.006 \\
\hline Mark, Underwood & 30.2 & 29.8 & 95.5 & 0.012 & 0.004 \\
\hline Northern Con, Luverne & 30.9 & 23.8 & 83.8 & 0.024 & 0.008 \\
\hline North Star Kasota & 34.7 & 30.1 & 79.4 & 0.032 & 0.011 \\
\hline
\end{tabular}

Modulus of elasticity and compression tests were performed after 28 days of curing.

2 Percent dilation is at failure (when the relative dynamic modulus reaches 60 percent) or 300 cycles, whichever came first. 
Table 4.3. Summary of specific gravity and absorption capacity test results.

\begin{tabular}{|c|c|c|c|c|c|c|c|c|}
\hline \multirow{3}{*}{ Source } & \multicolumn{4}{|c|}{ Specific Gravity (at $23^{\circ} \mathrm{C}$ ) } & \multicolumn{4}{|c|}{ Absorption Capacity (\%) } \\
\hline & \multirow[b]{2}{*}{$\begin{array}{c}\text { As- } \\
\text { Produced }\end{array}$} & \multicolumn{3}{|c|}{ Size Fraction $(\mathrm{mm})$} & \multirow[b]{2}{*}{$\begin{array}{c}\text { As- } \\
\text { Produced }\end{array}$} & \multicolumn{3}{|c|}{ Size Fraction $(\mathrm{mm})$} \\
\hline & & $\begin{array}{l}4.75- \\
12.5\end{array}$ & $\begin{array}{c}12.5- \\
19.0\end{array}$ & $\begin{array}{l}19.0- \\
37.5\end{array}$ & & $\begin{array}{l}4.75- \\
12.5\end{array}$ & $\begin{array}{c}12.5- \\
19.0\end{array}$ & $\begin{array}{c}19.0- \\
37.5\end{array}$ \\
\hline \multicolumn{9}{|c|}{ QUARRIED } \\
\hline Aaland, Zumbrota & 2.503 & 2.450 & 2.511 & 2.530 & 3.242 & 4.310 & 3.193 & 2.817 \\
\hline Big Springs, Harmony & 2.551 & 2.406 & $\mathrm{~N} / \mathrm{A}$ & 2.626 & 1.845 & 3.776 & $\mathrm{~N} / \mathrm{A}$ & 1.043 \\
\hline Bryan Rock, Shakopee & 2.497 & 2.508 & 2.489 & 2.560 & 2.928 & 3.233 & 2.733 & 2.610 \\
\hline Coralville PCC Ledge, Waterloo & 2.564 & 2.542 & 2.55 & N/A & 2.620 & 2.431 & 2.125 & $\mathrm{~N} / \mathrm{A}$ \\
\hline Early Chapel & 2.481 & 2.423 & 2.477 & 2.489 & 2.724 & 2.928 & 2.673 & 2.530 \\
\hline Edward Kramer \& Sons, Burnsville & 2.547 & 2.461 & 2.542 & N/A & 3.150 & 4.791 & 3.196 & N/A \\
\hline Goldberg, Rochester & 2.586 & 2.528 & 2.558 & 2.643 & 2.572 & 2.870 & 2.089 & 1.464 \\
\hline Michigan LS, Cedarville Plant & 2.764 & 2.773 & 2.765 & 2.774 & 0.454 & 0.633 & 0.483 & 0.355 \\
\hline Osmundson, Grand Meadow & 2.413 & 2.447 & N/A & 2.382 & 3.781 & 4.130 & N/A & 3.291 \\
\hline Shiely Grey Cloud (Larson) & 2.427 & 2.456 & 2.478 & 2.475 & 2.972 & 3.606 & 2.792 & 2.501 \\
\hline SMC Mankato & 2.445 & 2.430 & 2.435 & N/A & 4.437 & 5.031 & 4.201 & N/A \\
\hline Swedberg & 2.527 & 2.464 & 2.565 & 2.610 & 2.843 & 3.833 & 2.136 & 1.653 \\
\hline Ulland Northwood, Iowa & 2.736 & 2.606 & 2.721 & 2.669 & 0.950 & 1.520 & 0.884 & 0.707 \\
\hline \multicolumn{9}{|c|}{ GRAVEL } \\
\hline Ashwill, Kingston & 2.635 & 2.642 & 2.629 & $\mathrm{~N} / \mathrm{A}$ & 1.697 & 1.622 & 0.959 & $\mathrm{~N} / \mathrm{A}$ \\
\hline Johnson, Henderson & 2.653 & 2.605 & N/A & 2.657 & 1.131 & 1.460 & N/A & 0.987 \\
\hline Johnson Le Sueur & 2.639 & 2.631 & 2.652 & 2.636 & 1.443 & 1.586 & 1.246 & 1.263 \\
\hline Loeffler, Halma & 2.649 & 2.611 & 2.616 & 2.627 & 1.038 & 1.426 & 1.057 & 0.844 \\
\hline Mark, Underwood & 2.719 & 2.641 & 2.653 & 2.65 & 0.785 & 1.123 & 0.827 & 0.704 \\
\hline Northern Con, Luverne & 2.611 & $\mathrm{~N} / \mathrm{A}$ & $\mathrm{N} / \mathrm{A}$ & $\mathrm{N} / \mathrm{A}$ & 1.386 & $\mathrm{~N} / \mathrm{A}$ & $\mathrm{N} / \mathrm{A}$ & $\mathrm{N} / \mathrm{A}$ \\
\hline North Star Kasota & 2.655 & N/A & N/A & 2.654 & 1.129 & N/A & N/A & 0.951 \\
\hline
\end{tabular}

$>$ Swedberg $[2.843 \%]$

$>$ Early Chapel $[2.724 \%]$

$>$ Coralville PCC Ledge, Waterloo [2.620 \%]

$>$ Goldberg, Rochester [2.572\%]

$>$ Big Springs, Harmony [1.845\%]

Figure 4.1 presents a plot of durability factor results versus the measured absorption capacities for the as-produced quarried carbonate materials used in the PCC mixtures. Mn/DOT's accepted boundaries for satisfactory, fair and unsatisfactory freeze-thaw durability are shown, along with the 1.7 percent absorption capacity line. 


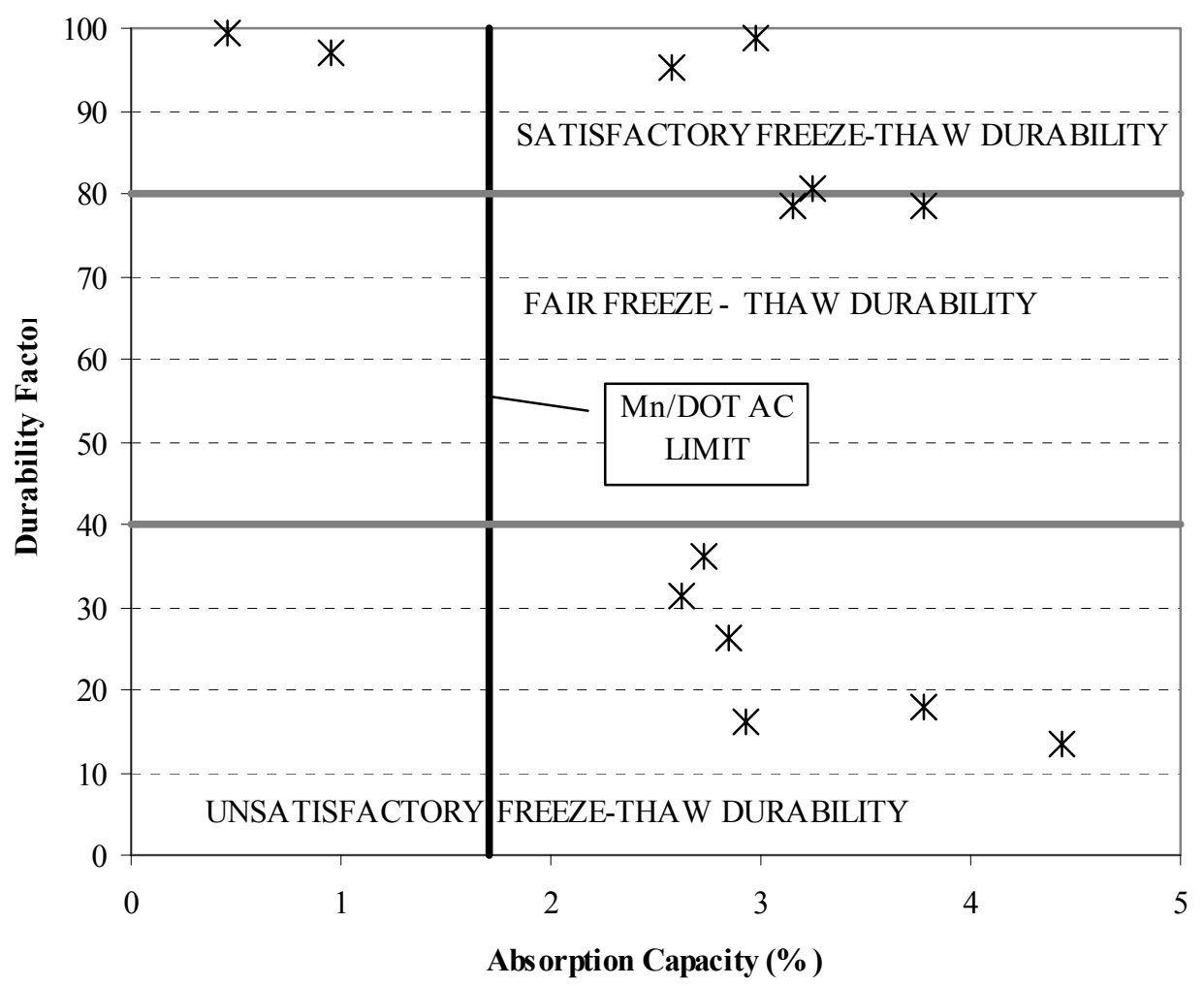

Figure 4.1. Durability factor versus coarse aggregate absorption (carbonate sources only).

In general, it appears that the $\mathrm{Mn} / \mathrm{DOT}$ acceptance limit for absorption capacity successfully eliminates all aggregate sources with unsatisfactory or fair freeze-thaw resistance (durability factor $<80$ ). However, the absorption capacity criterion also eliminates three sources (Goldberg - Rochester, Shiely Grey Cloud [Larson] and Aaland, Zumbrota) with satisfactory freeze-thaw resistance (durability factor greater than 80) and two other sources (Kramer and Sons, and Osmundson, Grand Meadow) that would probably provide satisfactory freeze-thaw resistance as well (durability factors very close to 80 ).

\subsection{Magnesium Sulfate Test}

Aggregate samples of each coarse aggregate source were brought to the Mn/DOT Research Laboratory for magnesium sulfate testing in accordance with ASTM C 88 "Standard Test Method for Soundness of Aggregate by Use of Sodium Sulfate or Magnesium Sulfate." The material was split into the following size fractions: 4.75 to $9.50 \mathrm{~mm}$ (\#4 to $0.375 \mathrm{in}$ ), 9.50 to $12.5 \mathrm{~mm}$ ( 0.375 to $0.5 \mathrm{in}$ ), 12.5 to $19.0 \mathrm{~mm}$ ( 0.5 to $0.75 \mathrm{in}$ ), 19.0 to $25.0 \mathrm{~mm}$ ( 0.75 to $1.0 \mathrm{in}$ ), and 
25.0 to $37.5 \mathrm{~mm}$ ( 1.0 to $1.5 \mathrm{in}$ ). Table 4.4 presents the percent mass loss due to magnesium sulfate testing for each aggregate sample (by source and size fraction).

According to ASTM C 33 "Standard Specification for Concrete Aggregates," the maximum allowable percent loss from the magnesium sulfate soundness test (at 5 cycles) is 18 percent in severe freeze-thaw locations. Mn/DOT specifies that coarse aggregate (by weight) used in concrete mixtures shall not exceed 15 percent loss at 5 cycles for any fraction (8). Shaded cells in table 4.4 indicate source/size fraction combinations that would not be allowed for use as coarse aggregate in PCC mix applications.

Table 4.4. Magnesium sulfate test results.

\begin{tabular}{|l|c|c|c|c|c||}
\hline \multirow{2}{*}{ Coarse Aggregate Source } & \multicolumn{5}{|c|}{ Sercent Mass Loss } \\
\cline { 2 - 6 } & \multicolumn{5}{|c|}{ Size Fraction (mm) } \\
\cline { 2 - 6 } & $\begin{array}{c}4.75 \text { to } \\
9.50\end{array}$ & $\begin{array}{c}9.50 \text { to } \\
12.5\end{array}$ & $\begin{array}{c}12.5 \text { to } \\
19.0\end{array}$ & $\begin{array}{c}19.0 \text { to } \\
25.0\end{array}$ & $\begin{array}{c}25.0 \\
37.5\end{array}$ \\
\hline & QUARRIED \\
\hline Aaland, Zumbrota & 36.18 & 32.39 & 17.34 & 18.51 & 5.95 \\
\hline Big Springs, Harmony & N/A & N/A & 13.05 & 7.03 & 5.14 \\
\hline Bryan Rock, Shakopee & 4.33 & 3.11 & 3.03 & 1.6 & 1.22 \\
\hline Coralville Concrete Ledge, Waterloo & 8.65 & 11.31 & 6.91 & N/A & N/A \\
\hline Early Chapel & 15.83 & 14.64 & 12.42 & 3.17 & N/A \\
\hline Edward Kramer \& Sons, Burnsville & 28.75 & 22.65 & 18.76 & 15.59 & N/A \\
\hline Goldberg, Rochester & 18.8 & 11.28 & 10.66 & 4.56 & 8.43 \\
\hline Michigan Limestone, Cedarville Plant & 1.23 & 1.42 & 0.3 & 1.41 & 0.54 \\
\hline Osmundson, Grand Meadow & 11.97 & 11.05 & 5.61 & 2.06 & 3.65 \\
\hline Shiely Grey Cloud (Larson) & 13.73 & 12.73 & 4.3 & 5.23 & 1.7 \\
\hline SMC Mankato & 55.51 & 66.18 & 39.71 & 36.34 & 38.21 \\
\hline Swedberg & 28.4 & 28.39 & 18.36 & 15.3 & 4.77 \\
\hline Ulland Northwood, Iowa & 5.86 & 4.73 & 1.64 & 2.35 & 1.94 \\
\hline & GRAVEL & & & & \\
\hline Ashwill, Kingston & 3.79 & 4.76 & 2.21 & N/A & N/A \\
\hline Johnson, Henderson & 6.56 & 11.15 & 3.57 & 6.23 & 7.57 \\
\hline Johnson Le Sueur & 8.46 & 9.36 & 5.38 & 7.25 & 4.97 \\
\hline Loeffler, Halma & 2.93 & 4.44 & 1.52 & 1.04 & N/A \\
\hline Mark, Underwood & 2.53 & 4.24 & 3.87 & 6.56 & 0.4 \\
\hline Northern Con, Luverne & 14.4 & 16.58 & 10.7 & 14.51 & 1.84 \\
\hline North Star Kasota & 6.99 & 5.75 & 2.12 & 5.22 & 0.91 \\
\hline
\end{tabular}

Note: Shaded areas indicate test results that fail Mn/DOT acceptance criterion for concrete aggregate. 
These results are based on tests of aggregate samples collected in 1998 and the size fractions available for soundness testing. Some aggregate sources were deficient in material with particle sizes larger than $19.0 \mathrm{~mm}$ (0.75 in), so these larger particle sizes were not always tested, as shown in table 4.4.

In general, it appears that the percent mass loss increases with decreasing particle size for most of the aggregate sources tested. While the reason for this trend is not known with certainty, the following hypotheses are offered:

(1) the weaker aggregate particles are typically broken down into smaller particles during production processing, resulting in numbers of weaker particles (possibly more susceptible to magnesium sulfate testing) in the smaller size fractions;

(2) it takes less internal expansive stress (due to salt crystallization) in smaller particles to produce fracturing than in larger size particles;

(3) smaller particles have a greater surface area per unit volume of material than do larger particles, thereby allowing a greater amount of solution to penetrate and form a greater volume of salt crystals; and/or

(4) a given amount of degradation per unit surface area will result in higher percentages of mass loss for a given sample mass as the average particle size decreases (and surface area increases).

\subsubsection{Correlation with Rapid Freezing and Thawing Test Results}

Figure 4.2 presents a plot of the freeze-thaw test results (durability factor) versus the results of magnesium sulfate testing (mass loss) for each aggregate source and size fraction. This figure also includes Mn/DOT's accepted boundaries for defining satisfactory, fair and unsatisfactory freeze-thaw durability, as well as the acceptance-rejection boundary for magnesium sulfate testing mass loss (i.e., 15 percent). In considering this graph, it is important to remember that freeze-thaw test beams comprised coarse aggregate representing all of the relevant particle size fractions ( 50 percent 19 to $38 \mathrm{~mm}$ [0.75 to $1.5 \mathrm{in}$ ], 25 percent 12.5 to $19 \mathrm{~mm}$ [0.5 to $0.75 \mathrm{in}$ ] and 25 percent 4.75 to $12.5 \mathrm{~mm}$ [ $\# 4$ to $0.5 \mathrm{in}$ ] material), as described previously. 


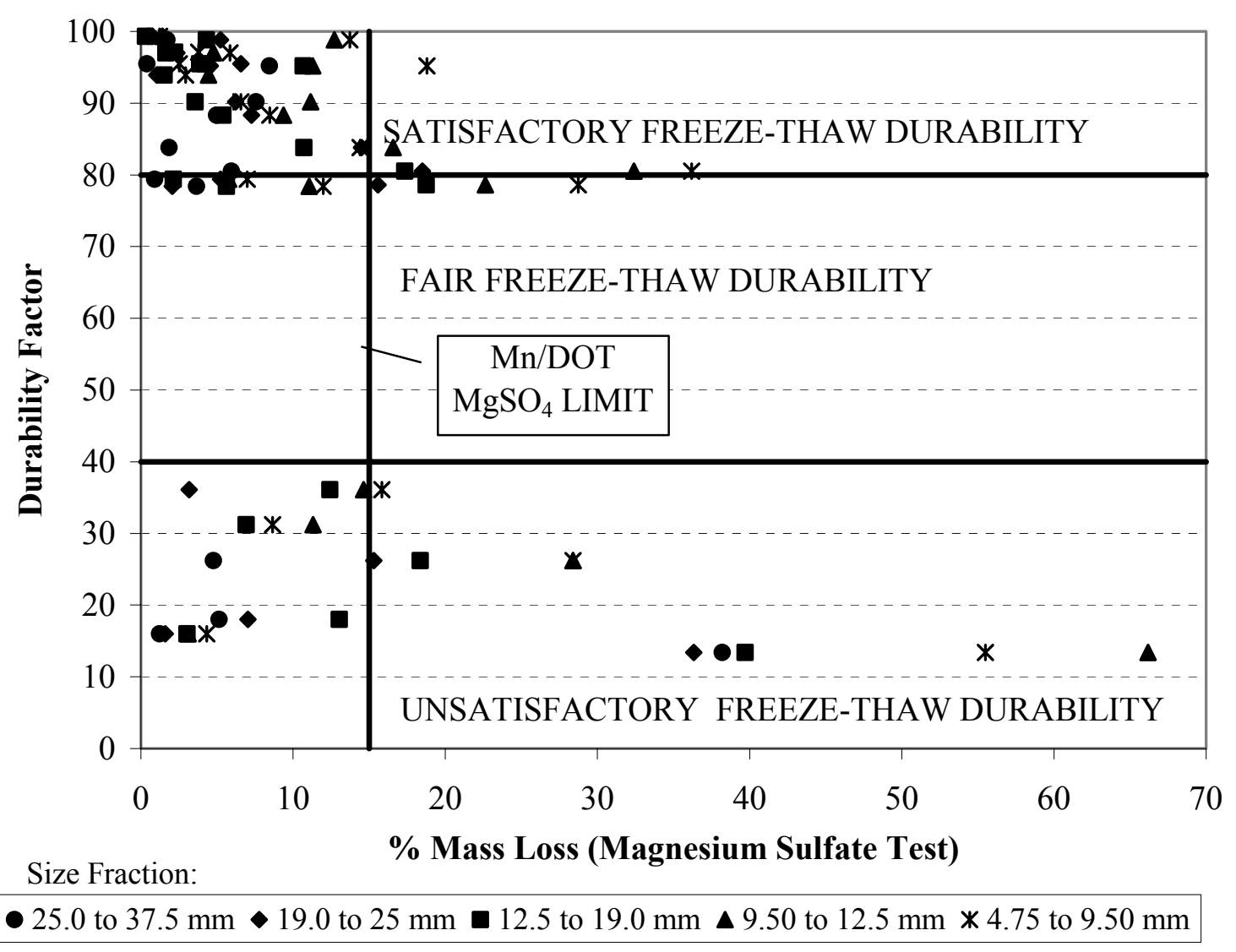

Figure 4.2. Durability factor versus mass loss from magnesium sulfate test.

Figure 4.2 indicates that the magnesium sulfate soundness test results (mass loss) did not correlate well with the results of the rapid freezing and thawing test (durability factor from AASHTO TP17 [T161 Procedure C]). The percent loss for all size fractions tested for Big Springs-Harmony, Bryan Rock- Shakopee, and Coralville Concrete Ledge-Waterloo was less than 15 percent by weight, which suggests that these sources should exhibit good freeze-thaw durability. However, the durability factors measured for concrete comprising these aggregate sources were 18, 16 and 31, respectively, indicating poor freeze-thaw resistance. Conversely, the magnesium sulfate test suggested that some aggregate sources were nondurable while the freezethaw testing indicated that they were durable. For example, concrete comprising AalandZumbrota and Edward Kramer and Sons had measured durability factors of 81 and 79, respectively (indicating durability), while the percentage of mass losses measured from the magnesium sulfate test ranged from 17 to 36 percent and 16 to 29 percent, respectively, for particle sizes less than $25.0 \mathrm{~mm}$ (indicating nondurability). 


\subsubsection{Correlation with Absorption Capacity Test Results}

Absorption capacity measurements were performed on the 4.75 to $12.5 \mathrm{~mm}, 12.5$ to $19.0 \mathrm{~mm}$ and 19.0 to $37.5 \mathrm{~mm}$ size fractions, while magnesium sulfate tests were performed on the 4.75 to $9.50 \mathrm{~mm}, 9.50$ to $12.5 \mathrm{~mm}, 12.5$ to $19.0 \mathrm{~mm}, 19.0$ to $25.0 \mathrm{~mm}$ and 25.0 to $37.5 \mathrm{~mm}$ size fractions. It was outside the scope of the project to perform further absorption capacity measurements on the small subset of sizes used in the magnesium sulfate testing. Therefore, the absorption capacity results for the three size fractions were used to reflect the individual subsets used for the magnesium sulfate tests. For example, the 19.0 to $37.5 \mathrm{~mm}$ absorption capacity values were used to reflect the 19.0 to $25.0 \mathrm{~mm}$ and 25.0 to $37.5 \mathrm{~mm}$ magnesium sulfate size fractions.

Figure 4.3 presents a plot of the absorption capacities measured for the quarried carbonate coarse aggregate sources versus the percentage of mass loss measured from the magnesium sulfate test for these same sources. In general, the magnesium sulfate test results correlate well with the results of absorption capacity testing, with mass loss measurements increasing approximately linearly with increases in absorption capacity. However, the acceptance/rejection criteria for the two tests (i.e., 15 percent mass loss for the magnesium sulfate test and 1.7 percent maximum allowable absorption) produced conflicting acceptance/rejection recommendations for 24 of the 54 aggregate source/size combinations tested.

\subsection{Percentage of Deleterious Material}

Aggregate particle types such as carbonates, iron oxides, shales, cherts and sandstones/siltstones are often deleterious in nature, with respect to concrete durability. The percentages of these particle types was determined for the gravel coarse aggregate size fractions subjected to hydraulic fracture testing, as shown in tables 4.5 and 4.6.

$\mathrm{Mn} / \mathrm{DOT}$ specifications for Class A concrete aggregate limit the carbonate content in gravel sources to 30 percent. According to these criteria, only the Ashwill Kingston and Mark, Underwood sources would be accepted for use, although all 7 gravel sources tested exhibited 


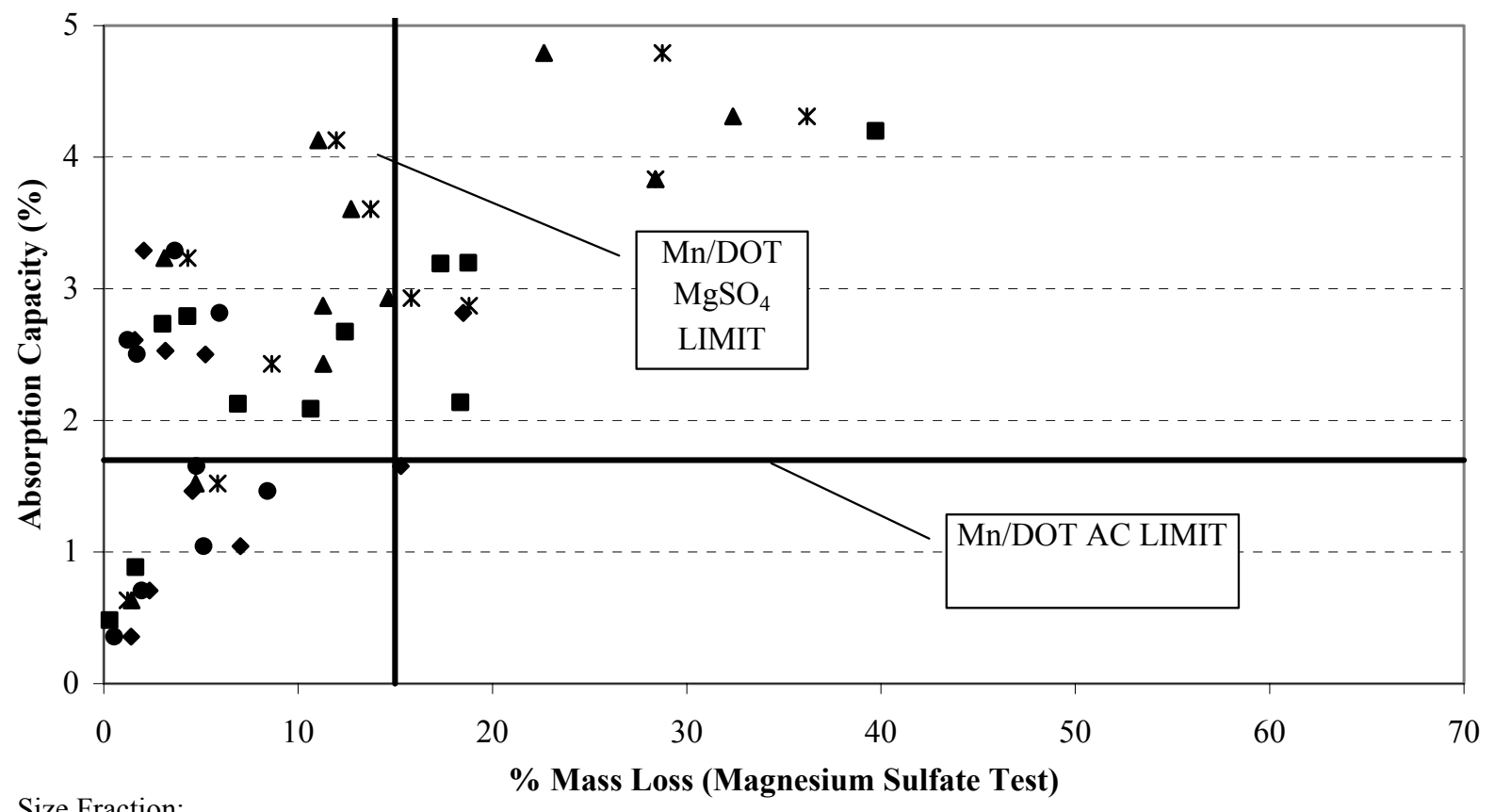

Size Fraction:

25.0 to $37.5 \mathrm{~mm} \bullet 19.0$ to $25 \mathrm{~mm} \mathbf{\square} 12.5$ to $19.0 \mathrm{~mm} \boldsymbol{\Delta} 9.50$ to $12.5 \mathrm{~mm} * 4.75$ to $9.50 \mathrm{~mm}$

Figure 4.3. Absorption capacity versus magnesium sulfate test mass loss (carbonate sources only).

acceptable freeze-thaw durability (durability factor approximately 80 or higher following ASTM C 666 or AASHTO T161).

\subsection{Regression Analysis}

The small chamber hydraulic fracture test results were modeled using the statistical analysis software package $A R C$, which was developed by Cook and Weisberg of the University of Minnesota Department of Applied Statistics (9).

Separate models were developed for each particle size fraction to predict percent dilation per 100 cycles of freezing and thawing and durability factor using as predictors the cumulative percentages of mass and/or particle counts passing each sieve screen (as described in section 4.1). Table 4.7 presents a list of the models developed and the response variables used in this study. 
Table 4.5. Percentage of potentially deleterious aggregate particles in each gravel source (by size fraction).

\begin{tabular}{|c|c|c|c|c|c|c|c|c|c|c|c|c|c|c|c|}
\hline \multirow{5}{*}{ Aggregate Source } & \multicolumn{15}{|c|}{ Particle Type } \\
\hline & \multicolumn{3}{|c|}{ Carbonate } & \multicolumn{3}{|c|}{ Shale } & \multicolumn{3}{|c|}{ Iron-Oxide } & \multicolumn{3}{|c|}{ Chert } & \multicolumn{3}{|c|}{ Sandstone/Siltstone } \\
\hline & \multicolumn{15}{|c|}{ Size Fraction (mm) } \\
\hline & $\begin{array}{l}19.0- \\
37.5\end{array}$ & $\begin{array}{c}12.0- \\
19.0\end{array}$ & $\begin{array}{c}4.75- \\
12.0\end{array}$ & $\begin{array}{l}19.0- \\
37.5\end{array}$ & $\begin{array}{c}12.0- \\
19.0\end{array}$ & $\begin{array}{l}4.75- \\
12.0\end{array}$ & $\begin{array}{c}19.0- \\
37.5\end{array}$ & $\begin{array}{c}12.0- \\
19.0\end{array}$ & $\begin{array}{c}4.75- \\
12.0\end{array}$ & $\begin{array}{c}19.0- \\
37.5\end{array}$ & $\begin{array}{c}12.0- \\
19.0\end{array}$ & $\begin{array}{c}4.75- \\
12.0\end{array}$ & $\begin{array}{l}19.0- \\
37.5\end{array}$ & $\begin{array}{c}12.0- \\
19.0\end{array}$ & $\begin{array}{c}4.75- \\
12.0\end{array}$ \\
\hline & \multicolumn{15}{|c|}{ Percentages } \\
\hline Johnson, Henderson & 50.9 & 28.7 & 34.6 & 0.0 & 0.0 & 0.0 & 0.0 & 0.0 & 0.4 & 19.3 & 0.0 & 0.5 & 0.0 & 2.5 & 2.6 \\
\hline Johnson, Le Sueur & 61.7 & 42.4 & 45.0 & 1.9 & 0.0 & 0.1 & 0.0 & 0.5 & 0.6 & 0.0 & 0.0 & 0.0 & 3.1 & 2.5 & 0.4 \\
\hline Ashwill, Kingston & $\mathrm{N} / \mathrm{A}$ & 23.0 & 29.2 & $\mathrm{~N} / \mathrm{A}$ & 0.4 & 0.4 & $\mathrm{~N} / \mathrm{A}$ & 0.0 & 0.9 & $\mathrm{~N} / \mathrm{A}$ & 0.0 & 0.0 & $\mathrm{~N} / \mathrm{A}$ & 0.0 & 1.0 \\
\hline Loeffler, Halma & 37.3 & 36.8 & 53.7 & 0.0 & 0.0 & 0.0 & 0.0 & 0.0 & 0.0 & 0.0 & 0.0 & 0.0 & 0.0 & 0.0 & 0.0 \\
\hline Mark, Underwood & 25.8 & 20.1 & 31.4 & 0.0 & 0.3 & 0.0 & 0.0 & 0.0 & 0.2 & 1.4 & 0.0 & 0.0 & 0.0 & 0.0 & 0.0 \\
\hline North Star Kasota & 29.3 & 44.7 & 47.6 & 0.0 & 0.0 & 0.0 & 0.0 & 0.0 & 0.6 & 0.0 & 0.0 & 0.0 & 0.0 & 0.0 & 0.6 \\
\hline $\begin{array}{l}\text { Northern Con, } \\
\text { Luverne }\end{array}$ & 53.8 & 60.5 & 60.1 & 0.0 & 0.0 & 0.1 & 0.0 & 0.4 & 0.5 & 2.5 & 1.4 & 0.8 & 0.0 & 0.0 & 0.0 \\
\hline
\end{tabular}


Table 4.6. Total potentially deleterious noncarbonate aggregate particle content in each gravel source (by size fraction).

\begin{tabular}{||l|c|c|c||}
\hline \multirow{3}{*}{ Aggregate Source } & \multicolumn{3}{|c|}{ Particle Type } \\
\cline { 2 - 4 } & \multicolumn{3}{|c|}{$\begin{array}{c}\text { All Noncarbonate } \\
\text { (Totals) }\end{array}$} \\
\cline { 2 - 4 } & $\begin{array}{c}\text { Size Fraction (mm) } \\
37.5\end{array}$ & $\begin{array}{c}12.0- \\
19.0\end{array}$ & $\begin{array}{c}4.75- \\
12.0\end{array}$ \\
\cline { 2 - 4 } & \multicolumn{3}{|c|}{ Percentages } \\
\hline Johnson, Henderson & 19.3 & 2.5 & 3.5 \\
\hline Johnson, Le Sueur & 5.0 & 3.0 & 1.1 \\
\hline Ashwill, Kingston & N/A & 0.4 & 2.3 \\
\hline Loeffler, Halma & 0.0 & 0.0 & 0.0 \\
\hline Mark, Underwood & 1.4 & 0.3 & 0.2 \\
\hline North Star Kasota & 0.0 & 0.0 & 1.2 \\
\hline $\begin{array}{l}\text { Northern Con, } \\
\text { Luverne }\end{array}$ & 2.5 & 1.8 & 1.4 \\
\hline
\end{tabular}

Table 4.7. Regression analysis matrix.

\begin{tabular}{|c|c|c|}
\hline $\begin{array}{c}\text { Explanatory Variables } \\
\text { (Cumulative } \\
\text { Percentage Passing) }\end{array}$ & Response Variable & $\begin{array}{c}\text { Initial Size } \\
\text { Fraction }\end{array}$ \\
\hline \multirow{2}{*}{ Mass } & Percent Dilation per 100 Cycles & \multirow{2}{*}{4.75 to $12.5 \mathrm{~mm}$} \\
\hline & Durability Factor & \\
\hline \multirow{2}{*}{ Particle Counts } & Percent Dilation per 100 Cycles & \multirow{4}{*}{12.5 to $19.0 \mathrm{~mm}$} \\
\hline & Durability Factor & \\
\hline \multirow{2}{*}{ Mass } & Percent Dilation per 100 Cycles & \\
\hline & Durability Factor & \\
\hline \multirow{2}{*}{ Particle Counts } & Percent Dilation per 100 Cycles & \multirow{4}{*}{19.0 to $37.5 \mathrm{~mm}$} \\
\hline & Durability Factor & \\
\hline \multirow{2}{*}{ Mass } & Percent Dilation per 100 Cycles & \\
\hline & Durability Factor & \\
\hline
\end{tabular}


Appendix E presents a detailed description of the development of each of these models. This section presents the models that were identified as being the best developed for each size fraction and response variable, and documents the selection of the single model that is believed to be best suited for general use with the hydraulic fracture test in accurately predicting the results of freeze-thaw durability testing using AASHTO TP17 (T161 Procedure C).

Table 4.8 lists the regression models developed for each initial size fraction (as described in Appendix E). In general, the correlation between the hydraulic fracture results (i.e., cumulative percentage of mass or particles passing) and rapid freezing and thawing test results increases with increasing particle sizes incorporated in the initial size fraction. These results support past research, where it was found that the greatest amount of freeze-thaw damage occurred with larger size particles due to the greater hydraulic pressures generated from the greater escape distances (4).

The model recommended for further development and use in hydraulic fracture testing is the model of freeze-thaw dilation as a function of the mass measurements obtained during hydraulic fracture testing for the 19 to $37.5 \mathrm{~mm}$ ( 0.75 to $1.5 \mathrm{in})$ initial size fraction. This model (presented below in equation 4.1) provided excellent correlation with freeze-thaw test results $\left(r^{2}=0.978\right)$ and offers the advantage of mass measurements, rather than the more time-consuming particle counts. Furthermore, it is based on the largest initial size fraction, which is consistent with traditional thinking that larger aggregate particle sizes generally tend to control freeze-thaw durability in concrete mixtures.

$$
\begin{aligned}
\% \mathrm{Dil} / 100 & =\mathrm{C}^{3 *}\left(6.714711 \mathrm{E}-9+1.493469 \mathrm{E}-9 * \mathrm{M}_{19} \mathrm{~mm}+[0.75 \mathrm{in}+]\right. \\
& -2.824751 \mathrm{E}-7 * \mathrm{M}_{16-19 \mathrm{~mm}[0.625-0.75 \mathrm{in}]}+3.648412 \mathrm{E}-7 * \mathrm{M}_{13-16 \mathrm{~mm}[0.5-0.625 \mathrm{in}]} \\
- & 5.631620 \mathrm{E}-7 * \mathrm{M}_{9.5-13 \mathrm{~mm}[0.375-0.5 \mathrm{in}]}+2.102003 \mathrm{E}-6 * \mathrm{M}_{8}-9.5 \mathrm{~mm}[0.313-0.375 \mathrm{in}] \\
- & \left.1.675012 \mathrm{E}-6 * \mathrm{M}_{4.75-8 \mathrm{~mm}[\# 4-0.313 \mathrm{in}]}+1.183342 \mathrm{E}-7 * \mathrm{M}_{4.75 \mathrm{~mm} \text { minus }\{\# 4 \text { minus }]}\right)
\end{aligned}
$$

where:

$$
\begin{aligned}
& \mathrm{C}=\text { Carbonate content }(100 \text { percent }=1.00) \\
& \mathrm{M}_{\mathrm{mm}[\mathrm{in}]}=\text { mass of particles sized in indicated range as a fraction of } \\
& \quad \text { original sample mass }(100 \text { percent }=1.00) \\
& \mathrm{r}^{2}=0.978\left(\mathrm{r}^{2}{ }_{\text {adj }}=0.957\right), \hat{\sigma}=0.009934, \mathrm{n}=18
\end{aligned}
$$


Table 4.8. Summary of regression analysis models.

\begin{tabular}{|c|c|c|c|c|c|}
\hline $\begin{array}{c}\text { Initial Size } \\
\text { Fraction }(\mathrm{mm})\end{array}$ & $\begin{array}{l}\text { Explanatory } \\
\text { Variable } \\
\text { (cumulative } \\
\text { percentage } \\
\text { passing) }\end{array}$ & $\mathrm{R}^{2}$ & $\begin{array}{l}\text { Adj. } \\
\mathrm{R}^{2}\end{array}$ & General Equation & $\begin{array}{l}\text { Table } \\
\text { No.* }\end{array}$ \\
\hline \multicolumn{6}{|c|}{ Percentage of Dilation per 100 Cycles of Rapid Freezing and Thawing } \\
\hline 4.75 to 12.5 & Mass & 0.333 & 0.256 & $\mathrm{Y}=\alpha+\mathrm{C}^{2.33} *\left(\beta_{1} * 38 \mathrm{M}^{2}+\beta_{2} * 14 \mathrm{M}^{0.31}\right)$ & E.6 \\
\hline \multirow{2}{*}{12.5 to 19.0} & Mass & 0.768 & 0.661 & $\begin{array}{l}\mathrm{Y}=\mathrm{C}{ }^{2} *\left(\alpha+\beta_{1} * 58 \mathrm{M}+\beta_{2} * 12 \mathrm{M}+\beta_{3} * 38 \mathrm{M}+\beta_{4} * 516 \mathrm{M}\right. \\
\left.+\beta_{5} * 14 \mathrm{M}\right)\end{array}$ & E. 8 \\
\hline & Particles & 0.806 & 0.717 & $\begin{array}{l}\mathrm{Y}=\mathrm{C}^{1.9} *\left(\alpha+\beta_{1} * 58 \mathrm{P}^{0.2}+\beta_{2} * 12 \mathrm{P}^{0.67}+\beta_{3} * 38 \mathrm{P}^{0.61}+\beta_{4} *\right. \\
\left.516 \mathrm{P}^{0.58}+\beta_{5} * 14 \mathrm{P}^{0.5}\right)\end{array}$ & E. 10 \\
\hline \multirow{2}{*}{19.0 to 37.5} & Mass & 0.978 & 0.957 & $\begin{array}{l}\mathrm{Y}=\mathrm{C}^{3 *}\left(\alpha+\beta_{1} * 34 \mathrm{M}+\beta_{2} * 58 \mathrm{M}+\beta_{3} * 12 \mathrm{M}+\beta_{4} * 38 \mathrm{M}+\right. \\
\left.\beta_{5} * 516 \mathrm{M}+\beta_{6} * 14 \mathrm{M}+\beta_{7} * 4 \mathrm{M}\right)\end{array}$ & E.12 \\
\hline & Particles & 0.913 & 0.869 & $\begin{array}{l}\mathrm{Y}=\mathrm{C}^{3} *\left(\alpha+\beta_{1} * 1 \mathrm{P}+\beta_{2} * 58 \mathrm{P}+\beta_{3} * 38 \mathrm{P}+\beta_{4} * 516 \mathrm{P}+\beta_{5} *\right. \\
14 \mathrm{P})\end{array}$ & E.14 \\
\hline \multicolumn{6}{|c|}{ Durability Factor } \\
\hline 4.75 to 12.5 & Mass & 0.395 & 0.284 & $\mathrm{Y}=\alpha+\mathrm{C}^{2.33} *\left(\beta_{1} * 38 \mathrm{M}^{2}+\beta_{2} * 516 \mathrm{M}+\beta_{3} * 14 \mathrm{M}^{0.31}\right)$ & E.7 \\
\hline \multirow{2}{*}{12.5 to 19.0} & Mass & 0.666 & 0.547 & $\begin{array}{l}\mathrm{Y}=\alpha+\mathrm{C} *\left(\beta_{1} * 58 \mathrm{M}+\beta_{2} * 12 \mathrm{M}+\beta_{3} * 38 \mathrm{M}+\beta_{4} * 516 \mathrm{M}+\right. \\
\left.\beta_{5} * 14 \mathrm{M}\right)\end{array}$ & E.9 \\
\hline & Particles & 0.734 & 0.611 & $\begin{array}{l}\mathrm{Y}=\alpha+\mathrm{C}^{*}\left(\beta_{1} * 38 \mathrm{P}^{0.61}+\beta_{2} * 516 \mathrm{P}^{0.58}\right)+\beta_{3} * 14 \mathrm{P}^{0.5}+\beta_{4} * \\
38 \mathrm{P}^{0.61}+\beta_{5} * 12 \mathrm{P}^{0.67}+\beta_{6} * 58 \mathrm{P}^{0.2}\end{array}$ & E.11 \\
\hline \multirow[b]{2}{*}{19.0 to 37.5} & Mass & 0.784 & 0.676 & $\begin{array}{l}\mathrm{Y}=\alpha+\mathrm{C}^{3} *\left(\beta_{1} * 1 \mathrm{M}^{1.06}+\beta_{2} * 34 \mathrm{M}^{-0.62}+\beta_{3} * 58 \mathrm{M}^{0.27}+\right. \\
\left.\beta_{4} * 38 \mathrm{M}^{0.65}+\beta_{5} * 516 \mathrm{M}^{0.73}+\beta_{6} * 14 \mathrm{M}^{0.84}\right)\end{array}$ & E.13 \\
\hline & Particles & 0.949 & 0.907 & $\begin{array}{l}\mathrm{Y}=\alpha+\mathrm{C}^{3} *\left(\beta_{1} * 34 \mathrm{P}^{0.53}+\beta_{2} * 58 \mathrm{P}^{0.62}+\beta_{3} * 12 \mathrm{P}^{0.61}+\beta_{4} *\right. \\
\left.38 \mathrm{P}^{0.58}+\beta_{5} * 516 \mathrm{P}^{0.58}+\beta_{6} * 14 \mathrm{P}^{0.55}\right) \\
+\beta_{7} * 4 \mathrm{P}^{0.5}+\beta_{8} * 14 \mathrm{P}^{0.55}\end{array}$ & E.15 \\
\hline
\end{tabular}

*Coefficient estimates are listed in designated table.

Figure 4.4 presents a plot of predicted dilations using the recommended model versus actual measured dilations for the 18 aggregate sources used to develop the model. The graph shows that the selected model is highly accurate.

\subsection{Hydraulic Fracture - Large Chamber}

\subsubsection{Original Large Chamber Development}

The SHRP study recommended that at least 600 to 800 aggregate particles in the 19 to $37 \mathrm{~mm}$ [0.75 to $1.50 \mathrm{in}$ ] size range be tested in the hydraulic fracture test apparatus to obtain a reliable estimate of aggregate freeze-thaw susceptibility (1). This typically required the testing of three or four replicate samples in the smaller chamber to achieve this particle count. The development 


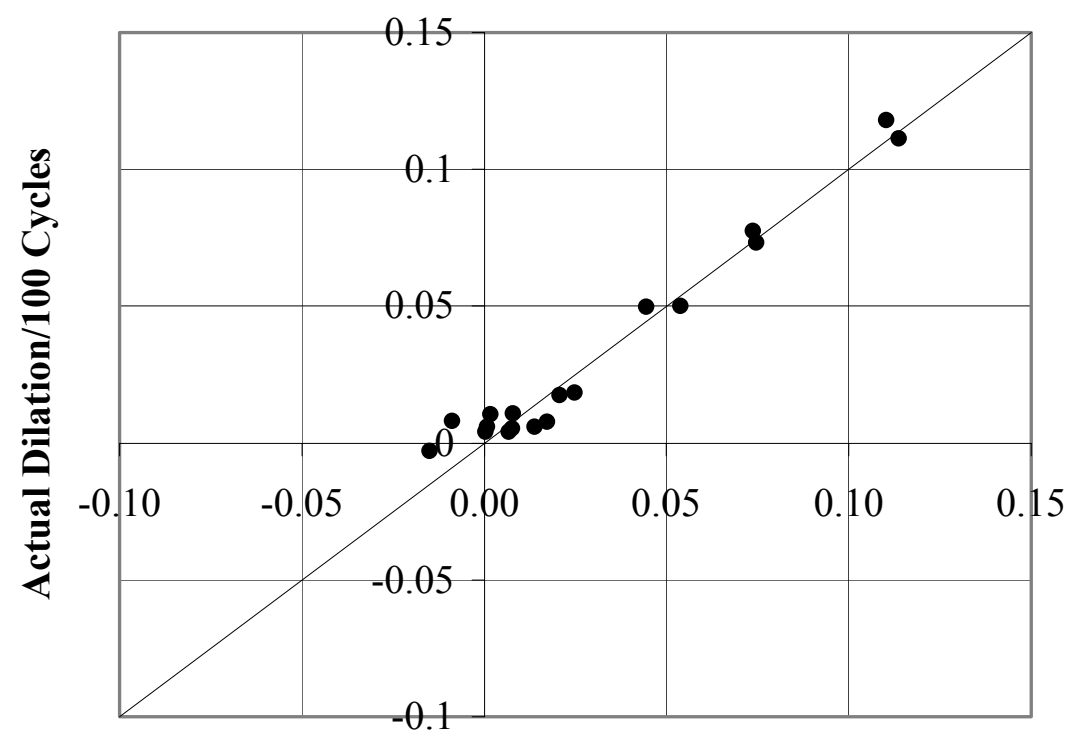

Predicted Dilation/100 Cycles

Figure 4.4. Actual versus predicted dilation per 100 cycles using small chamber test results (mass-based model, 19.0 to 37.5 -mm original particle sizes).

of a larger chamber was seen as a way to provide more uniform testing of the recommended large number of particles while reducing the need for replicate tests (and while reducing the time required to complete aggregate source testing).

The large chamber was initially developed under the University of Minnesota Graduate School study as described in detail in reference ( $\underline{3})$. The bullet list describes the modifications which were made to the small chamber design when constructing the large chamber ( $\underline{3})$ :

- the addition of larger valves to allow more rapid discharge of gas and water,

- $\quad$ an increase in the size of the pneumatically actuated ball valve (from 12.5-mm [0.5-in] to 19.0-mm [0.75-in] in diameter),

- the addition of larger pipes to connect the $9.50-\mathrm{mm}(0.375-\mathrm{in})$ exhaust port hole to the larger pneumatically actuated ball valve, 
- addition of a stand pipe in the test system to provide a water reservoir and reduce the possibility of gas entering the test chamber, and

- elimination of the 90-degree bend in the pressure release valve system to reduce head loss.

Calibration testing was performed to see if the newly developed large test chamber could achieve a release rate matching the calibration curve. Several attempts were made at matching the small chamber pressure release rate calibration curve, but they met with only limited success as the pressure was generally dissipated over a longer time interval than desired. Figure 4.5 presents a graph illustrating the results of the initial large chamber calibration attempts and shows that the large chamber pressure release rates were significantly lower than the calibration curve.

Hieptas ( $\underline{3}$ ) suggested correcting the problem in future studies by using even larger valves and pipes, and increasing the size of the pressure release port. The suggested modifications were made in the current study, as described below.

\subsubsection{Large Chamber Modifications}

Based on the suggestions described above, the following modifications were made to the large chamber under the current study:

- pressurization piping and valves were increased in size from $12.7 \mathrm{~mm}(0.50$ in) to $19.0 \mathrm{~mm}$ (0.75 in) diameter,

- maximum allowable pressure for the actuator was increased from $1.04 \mathrm{MPa}$ (150 psi) to 1.73 $\mathrm{MPa}(250 \mathrm{psi})$ and

- exhaust port hole diameter was increased from $12.7 \mathrm{~mm}(0.50 \mathrm{in})$ to $22.2 \mathrm{~mm}(0.875 \mathrm{in})$.

Calibration tests were performed to see if these modifications to the large chamber allowed the chamber to achieve the desired pressure release rate and match the small chamber calibration curve. Figure 4.6 shows that the calibration was successful with an actuator pressure of $205 \mathrm{psi}$, resulting in a close match of the calibration curve at durations of 0 to 0.015 and 0.04 to 0.06 seconds. Previous studies have indicated that it is most critical to match the calibration curve at a duration of 0.1 seconds, so the calibration achieved under this study was deemed acceptable. 


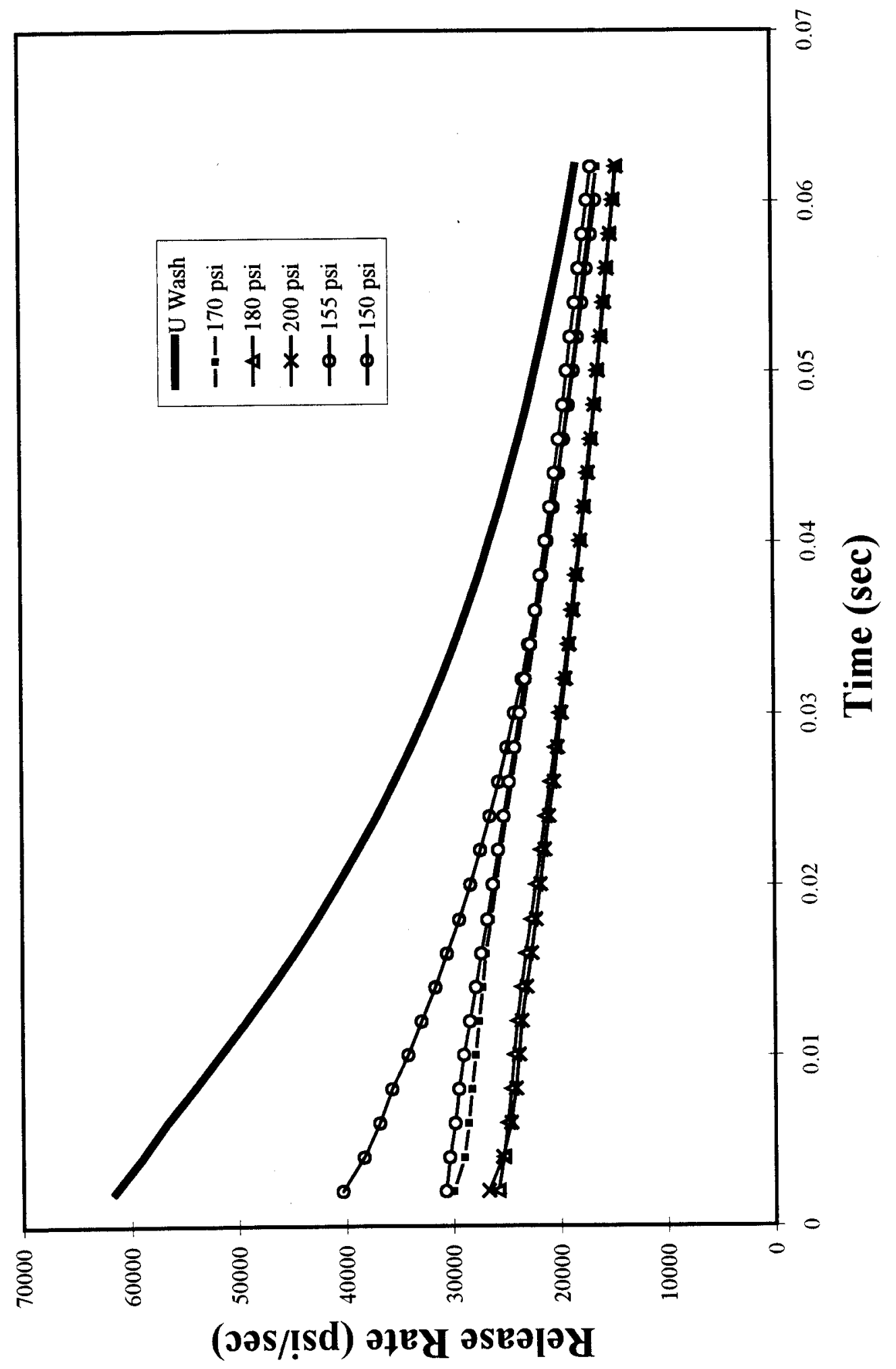

Figure 4.5. Calibration test data for original Minnesota large chamber (3). 


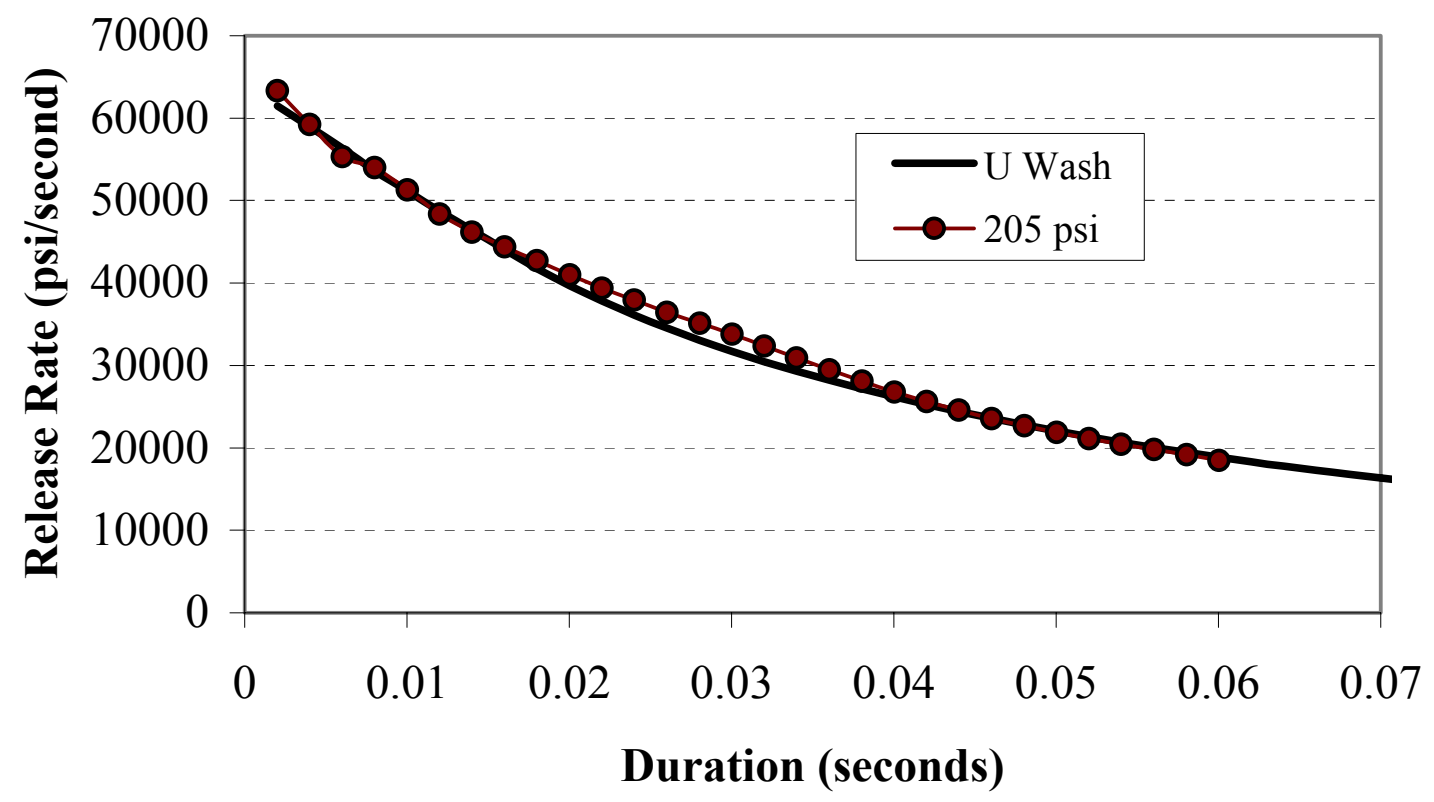

Figure 4.6. Calibration test data for modified large chamber.

\subsubsection{Consistency with Small Chamber Results}

The hydraulic fracture testing using the large chamber was performed on the initial size fraction (19.0 to $37.5 \mathrm{~mm}$ [0.75 to $1.5 \mathrm{in}]$ ) of the four aggregate sources previously described in section 3.6 of this report. These sources were selected to provide a range of durability values and were tested in accordance with the procedure described in appendix A.

The percent of original mass retained and percent of original particles retained (POMR and POPR, respectively) on the specified screens for each sample (replicate), along with the average percentages of original mass and particles retained (APOMR and APOPR, respectively) for each source, were calculated using the equations expressed in section 3.5.3. Appendix tables D.1 and D.2 present summaries of the mass measurements and particle counts retained on specified sieves at 0 and 50 cycles for the replicate tests of each source. The normalized mass data (i.e., POMR and APOMR) and particle count data (i.e., POPR and APOPR) are presented in tables D.3 and D.4, respectively, of appendix D. 
The cumulative percentages of mass passing each screen were determined according to equations E.3 to E.5, E.7, E.16, E. 17 and E.33 to E.35 (see Appendix E). These data were then input into the final model selected for the small chamber (equation 4.1) to see whether the large chamber test results were consistent with those of the small chamber. Figure 4.7 presents the graph of actual versus predicted percentage of dilation per 100 cycles for the small and large chamber data, along with the mean function developed using the small chamber data.

As illustrated in this figure, a fairly close fit is achieved with three of the four sources tested: North Star Kasota (fair freeze-thaw resistance), Johnson Henderson (satisfactory freeze-thaw resistance) and Early Chapel (poor freeze-thaw resistance). However, the mean function does not adequately predict the response for Edward Kramer and Sons, the second source classified as fair freeze-thaw resistance.

In general, the large chamber test results are fairly consistent with those achieved when using the smaller test chamber, thereby indicating the potential use of the large chamber for determining the durability of aggregate sources with varying freezing and thawing resistance. However, due to the limited testing, additional testing would be required to substantiate this conclusion and, therefore, allow the use of the larger chamber over the smaller. As stated previously, the development of the large chamber would provide more uniform testing of a sample (due to the large sample size) and would eliminate the need for replicate tests, thereby reducing the time required to complete testing of a particular aggregate source. 


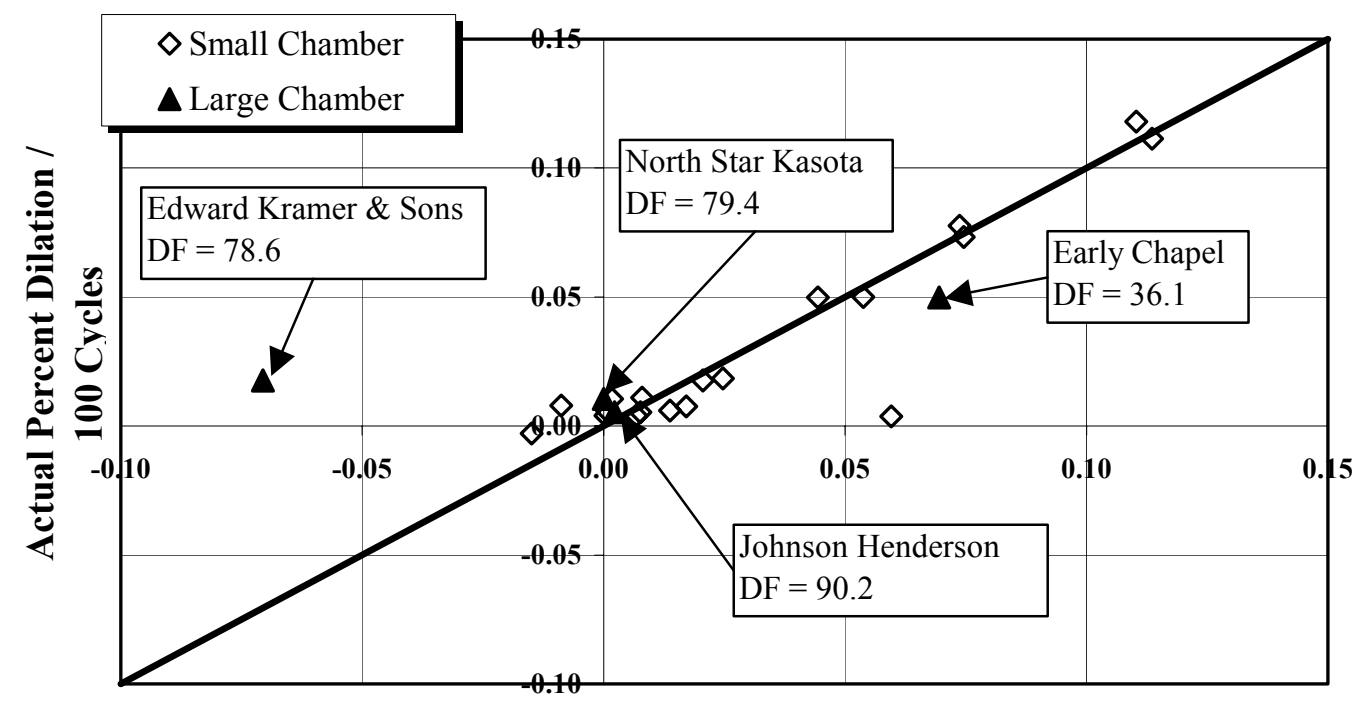

Predicted Percent Dilation / 100 Cycles

Figure 4.7. Actual versus predicted percent dilation per 100 cycles for large and small chamber test results (mass-based model, 19.0 to $37.5-\mathrm{mm}$ original particle sizes). 


\section{CHAPTER 5 \\ CONCLUSIONS AND RECOMMENDATIONS}

\subsection{Conclusions}

The following conclusions can be drawn from the results of this study:

- The hydraulic fracture test and data analysis procedure described in this report appear to offer a reliable, relatively rapid alternative to determining the potential freeze-thaw durability of concrete coarse aggregate sources.

- The results of regression analyses performed on hydraulic fracture test data show strong correlations between hydraulic fracture test outputs (i.e., cumulative percentage of mass and particle counts passing selected sieve screens) and concrete test specimen dilation data obtained from rapid freezing and thawing tests. The strength of these correlations increases as the top size of the particles in the hydraulic fracture test sample increases, which is consistent with the results of previous studies that link coarse aggregate top size to freezethaw durability for potentially nondurable aggregate sources. In this study, the strongest correlations were observed when considering particle mass measurements for samples with initial particle sizes in the 19 to $37.5 \mathrm{~mm}$ (0.75 to $1.5 \mathrm{in})$ range.

- The results of tests performed using the modified large hydraulic fracture test chamber indicate good potential of using the larger chamber in lieu of replicate tests using the smaller chamber, although additional validation work is required.

- For the aggregate sources considered in this study, it appears that the Mn/DOT absorption capacity limit of 1.7 percent on carbonate coarse aggregate successfully eliminated potentially nondurable aggregate sources (as identified through AASHTO TP17 [T161 Procedure C]), although it also appears to eliminate many potentially durable aggregate sources as well. In general, it can be concluded that absorption capacity is not wellcorrelated with concrete coarse aggregate freeze-thaw durability.

- Mass losses obtained from the magnesium sulfate soundness test (ASTM C 88) generally increased significantly with decreases in test sample initial particle size.

- The magnesium sulfate soundness test results did not generally correlate well with the results of the rapid freezing and thawing tests (AASHTO TP17 [T161 Procedure C], durability factor). 
- The magnesium sulfate soundness test results were generally well correlated with the absorption capacity of carbonate aggregate sources (see figure 4.3), but the acceptance/rejection criteria currently used for these two tests often fail to provide consistent acceptance/rejection recommendations for carbonate aggregates intended for use in concrete paving mixtures.

- The hydraulic fracture test and data analysis procedure described in this report appear to offer better correlation with the results of rapid freezing and thawing tests (AASHTO TP17 [T161 Procedure C]) than either the magnesium sulfate test (ASTM C88) or the current Mn/DOT absorption capacity criterion for carbonate aggregate sources.

\subsection{Recommendations}

- Additional freeze-thaw and hydraulic fracture tests should be performed using the small test chamber on additional aggregate sources to further validate and refine the final model identified in this study for predicting the freeze-thaw durability of concrete coarse aggregate. The hydraulic fracture tests should focus primarily of the use of 19 to $38 \mathrm{~mm}$ (0.75 to $1.5 \mathrm{in})$ test sample particle sizes, since this larger particle size appears to provide the best indications of potential freeze-thaw resistance. Furthermore, the hydraulic fracture tests should involve mainly mass measurements rather than particle counts because the mass measurement model produced the best correlations with freeze-thaw data, and because mass measurements are accomplished much more quickly than particle counts.

- Additional hydraulic fracture testing should be performed using the modified large hydraulic fracture test chamber using mass measurements and particles in the 19 to $38 \mathrm{~mm}(0.75$ to 1.5 in) range to further validate the large test chamber.

- Additional tests and research should be performed to verify and determine the nature of the outlier hydraulic fracture test results obtained for the Shiely Grey Cloud (Larson) source that was tested using the small chamber in this study.

- Similarly, additional tests and research should be performed to verify and determine the nature of the outlier hydraulic fracture test results obtained for the Edward Kramer and Sons source, which was an outlier in the large chamber testing performed during the project and did not produce the same sort of test results obtained using the small chamber in this study. 


\section{REFERENCES}

1. D. J. Janssen and M. B. Snyder, SHRP C-391: Resistance of Concrete to Freezing and Thawing (Washington, DC: Transportation Research Board, 1994).

2. M. B. Snyder, D. J. Janssen and W. Hansen, Adoption of a Rapid Test for Determining Aggregate Durability in Portland Cement Concrete (Ann Arbor, MI: University of Michigan Department of Civil Engineering, 1996).

3. J. J. Hietpas, Refinement and Validation of the Washington Hydraulic Fracture Test (Minneapolis, MN: University of Minnesota Department of Civil Engineering, 1998).

4. T. C. Powers, Research Department Bulletin RX033: The Air Void Requirements of FrostResistant Concrete (Skokie, IL: Portland Cement Association, 1949).

5. P. Klieger, Research Department Bulletin RX040: Studies of the Effect of Entrained Air on the Strength and Durability of Concretes Made with Various Maximum Sizes of Aggregates (Skokie, IL: Portland Cement Association, 1952).

6. R. C. Mielenze, V. E. Wokodoff, J. E. Backstrom, and H. L. Flack, "Origin, Evolution, and Effects of the Air-Void System in Concrete, Part 1 - Entrained Air in Unhardened Concrete, Part 2 - Influence of Type and Amount of Air-Entraining Agent, Part 3 - Influence of WaterCement Ratio and Compaction, Part 4 - The Air-Void System in Job Concrete," Journal of American Concrete Institute, Jul. 1958, Aug. 1958, Sep. 1958, Oct. 1958.

7. A. M. Neville, Properties of Concrete (London, UK: Pitman Publishing, Ltd, 1981).

8. Standard Specifications for Construction: 3137 Coarse Aggregate for Portland Cement Concrete (St. Paul, MN: Minnesota Department of Transportation, 1988).

9. D. R. Cook and S. Weisberg, Applied Regression Including Computing and Graphics (New York, NY: John Wiley and Sons, Inc., 1999).

10. A. Agresti, An Introduction to Categorical Data Analysis (New York, NY: John Wiley and Sons, Inc., 1996).

11. J. Devore and R. Peck, Statistics: The Exploration and Analysis of Data, Second Edition (Belmont, CA: Wadsworth, Inc., 1993).

12. D. R. Schwartz, Synthesis of Practice 134: D-cracking of Concrete Pavements, (Washington, DC: National Cooperative Highway Research Board, 1987). 
APPENDIX A

Modified Hydraulic Fracture Test Procedures 


\section{APPENDIX A}

\section{Modified Hydraulic Fracture Test Procedures}

\section{A.1. SCOPE}

A.1.1 This test method covers the resistance of aggregates to fracture under the effect of internal pressure expelling water from aggregate pores. The procedure is intended to assist in the identification of aggregates that cause deterioration in concrete when exposed to repeated cycles of freezing and thawing (D-cracking).

A.1.2 This procedure may involve hazardous materials, operations, and equipment. This procedure does not purport to address all the safety problems associated with its use. It is the responsibility of whoever uses this procedure to consult and establish appropriate safety and health practices and determine the applicability of regulatory limitations prior to use.

\section{A.2. REFERENCED DOCUMENTS}

\section{$\underline{\text { A.2.1 AASHTO Standards }}$}

T $2 \quad$ Sampling Aggregates

M 92 Wire Cloth Sieves for Testing Purposes

M $231 \quad$ Weights and Balances Used in the Testing of Highway Materials

\section{$\underline{\text { A.2.2 ASTM Standards }}$}

C 702 Method for Reducing Field Samples of Aggregate to Testing Size

D 3665 Practice for Random Sampling of Construction Materials

\section{A.3. SIGNIFICANCE AND USE}

A.3.1 As noted in the scope, the procedure described in this method is intended to aid in the identification of coarse aggregate samples that may be susceptible to D-cracking. Aggregate particles that exhibit a high rate of fracturing under repeated pressurization cycles are considered 
to be more susceptible to D-cracking when critically saturated and subject to cycles of freezing and thawing in field applications.

A.3.2 The relatively short time required for completion of this procedure (approximately eight working days) makes it suitable for use as a screening test to identify aggregate sources that should be subjected to more traditional (and more time consuming) testing prior to approval.

A.3.3 The results of this test, like D-cracking susceptibility, appear to be sensitive to the size of the aggregate particles tested. Therefore, this test may be appropriate for identifying aggregate particle size reductions that are necessary to avoid D-cracking in field applications.

A.3.4 The results of this test are also sensitive to the number of soft or nondurable particles (e.g., sandstone, clay ironstone, etc.) in the test sample. Therefore, this test may be appropriate for determining the amount of durable aggregate that must be blended with nondurable aggregate to produce a blend with sufficiently low D-cracking potential to provide acceptable performance.

\section{A.4. APPARATUS}

\section{A.4.1 Tumbling Apparatus}

A.4.1.1 The tumbling apparatus (hereafter referred to as the tumbler) shall consist of a rubber drum (for holding the sample) and a motorized drive unit, similar to the one shown in figure A.1.

Note 1 - Suitable tumblers of various sizes are available commercially for polishing rocks.

A.4.1.2 The rubber drum shall have inside dimensions of approximately $171 \mathrm{~mm}(6.75 \mathrm{in})$ in diameter by $203 \mathrm{~mm}$ ( $8 \mathrm{in}$ ) deep. The inside shall be faceted to facilitate tumbling of the aggregate particles. The drum shall have a removable cover (so that the sample can be placed in the drum), and the cover should not interfere with the rotation of the drum when it is mounted in or on the motorized drive unit.

A.4.1.3 The motorized drive unit shall be capable of rotating the drum about its cylindrical axis at a rate of $30 \pm 5$ revolutions per minute. 


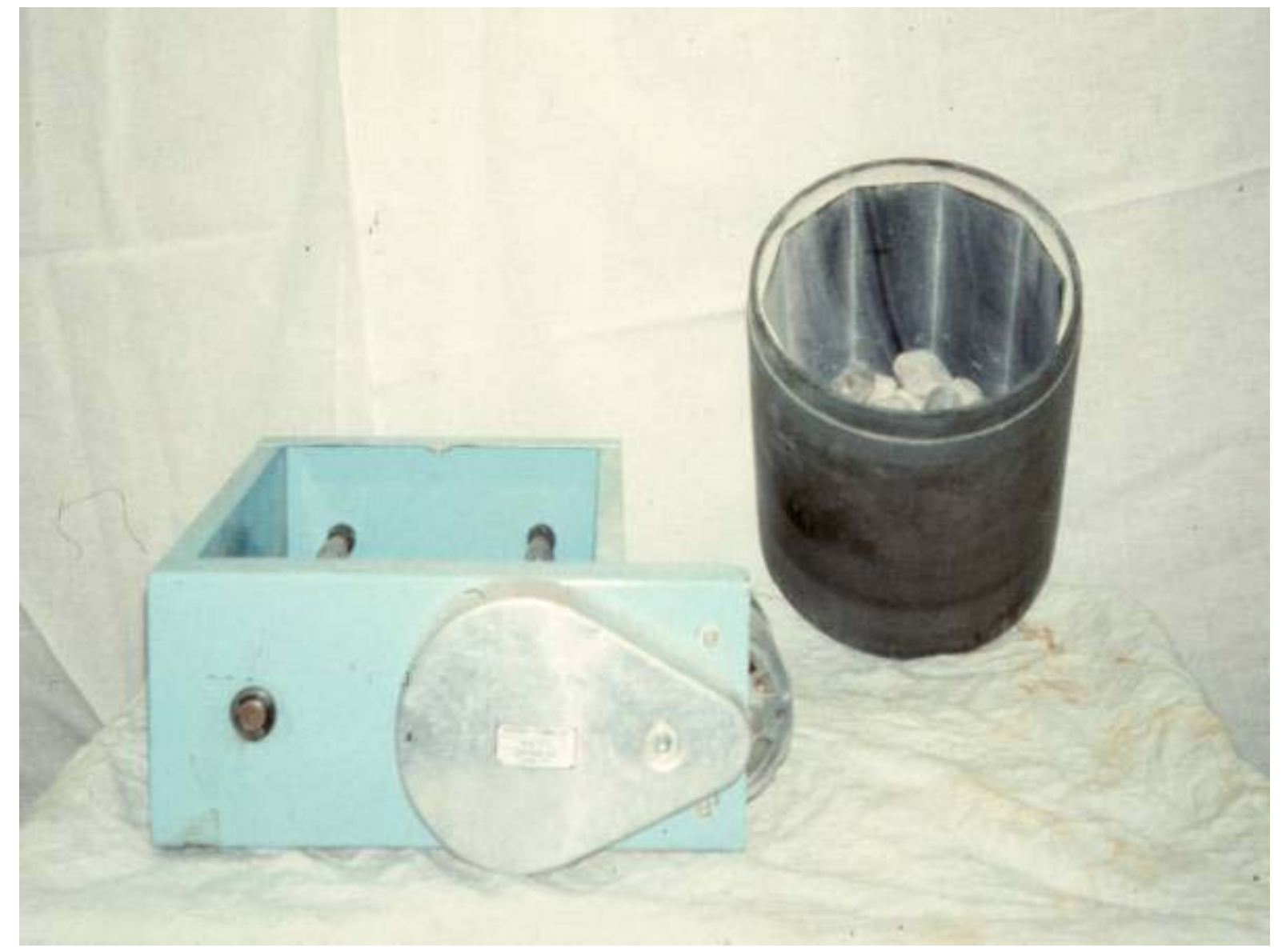

Figure A.1. Photo of typical tumbler drum and drive unit.

\section{A.4.2 Pressurization Apparatus}

A.4.2.1 The pressurization apparatus shall consist of: a pressure chamber able to safely withstand operating pressures of 10,000-kPa (1500-psi); a compressed nitrogen source; an adjustable pressure regulator with gauge having an output capacity of up to $10,000-\mathrm{kPa}(1500-$ psi); appropriate valves and fittings to permit filling with water and draining, and pressurization/rapid pressure release; and a stand to permit a 135 degree rotation of the pressurization apparatus.

A.4.2.2 The inside surfaces of the pressure chamber shall be suitably treated to prevent the physical fracture of aggregates by the expansion and contraction of the chamber during pressurization/de-pressurization cycles. 
Note 2 - For a cylindrical steel chamber with 25 -mm (1-in) thick walls and having inside dimensions of $254 \mathrm{~mm}$ (10 in) diameter by $51 \mathrm{~mm}$ ( $2 \mathrm{in}$.) high, a neoprene rubber sheet with a thickness of $0.8 \mathrm{~mm}(0.0313 \mathrm{in}$.) glued to the insides of the chamber lid and base has proven sufficient. No treatment was necessary for the inside wall of the cylinder, as shown in figure A.2.

Note 3 - Shop-built pressure chambers are not recommended for use in this test due to the difficulty in obtaining pressure-tight seals at the high pressures involved, as well as the hazards associated with high pressures. If a shopbuilt pressure chamber is used, it should be pressure-certified to provide a safety factor of at least 5 to 1 .

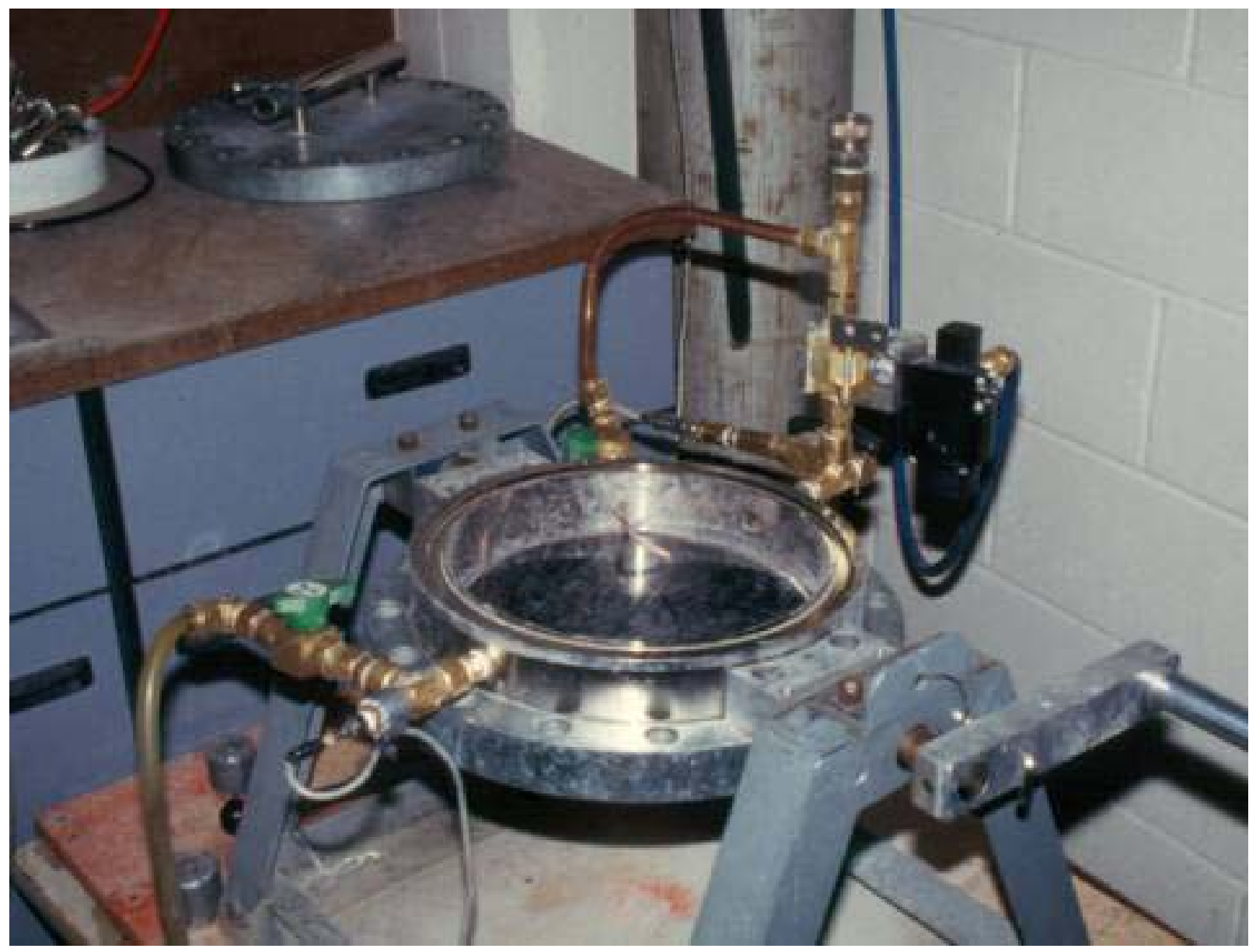

Figure A.2. Photo of small chamber interior with neoprene lining.

A.4.2.3 The pressure chamber shall be fitted with necessary valves and fittings to permit the application of pressure from the nitrogen source (pressurization valve), release of pressure (pressure release valve), filling with water (fill valve), and draining (drain valve). Additional valves and fittings may be provided where appropriate by the equipment manufacturer in order to achieve the necessary pressure release rate (see section A.4.2.5). 
A.4.2.4 A pressure regulator and gauge that attaches directly to a compressed nitrogen cylinder shall be provided. The regulator shall have a capacity of $10,000 \mathrm{kPa}(1500 \mathrm{psi})$. The gauge shall have a precision of 0.25 percent of full scale.

A.4.2.5 The apparatus should be capable of producing a drop in pressure of at least $2,100 \mathrm{kPa}$ (300 psi.) during a time interval of 0.01 second when the pressure release valve is open. This drop in pressure is termed the pressure release rate for a time duration of 0.01 second. The procedure for measuring the pressure release rate is described in Appendix A of the SHRP C 391 report.

\section{A.4.3 Drying Oven}

The drying oven should allow free circulation of air through the oven and should be capable of maintaining a temperature of $110^{\circ} \mathrm{C} \pm 5^{\circ} \mathrm{C}\left(230^{\circ} \mathrm{F} \pm 9^{\circ} \mathrm{F}\right)$.

\section{A.4.4 Balance}

The balance should conform to the requirements of AASHTO M 231 for the class of general purpose balance required for determining the principal mass of the sample being tested.

\section{A.5. SPECIAL SOLUTIONS REQUIRED}

A.5.1 A solution of alkylakoxysilane in water (referred to as silane solution) is used in Step A.7.3 as part of the sample preparation.

A.5.2 Appropriate precautions should be observed in handling the silane solution.

Note 4 - An appropriate silane solution is available commercially as Enviroseal 40 from Hydrozo, Inc. Other sources may provide suitable results as well.

Note 5 - Some aggregates absorb water at a very rapid rate, which prevents them from fracturing in the following test procedure. The silane treatment described in Step 7.3 reduces the absorption rate by effectively making the aggregates more hydrophobic. This treatment has been demonstrated to have no effect on the hydraulic fracture performance of aggregates with slower absorption rates. 


\section{A.6. SAMPLES}

A.6.1 Representative samples of aggregate sources should be obtained by appropriate means and in accordance with accepted procedures such as AASHTO T 2 and ASTM C 702 and D 3665.

A.6.2 Each aggregate sample to be tested should be screened to produce one or more test samples consisting of the desired particle sizes (step A.7.1 below). The size fraction recommended for indicating D-cracking potential contains only particles retained on the 19-mm (0.75-in.) sieve.

A.6.3 Replicate specimens may be run to determine test variability, and sufficient material should be collected in the initial sample to provide the necessary number of particles in each desired size range. Preliminary work has indicated that 600 to 800 particles must be tested to provide a reasonably accurate estimate of coarse aggregate D-cracking potential.

\section{A.7. PREPARATION OF TEST SAMPLE}

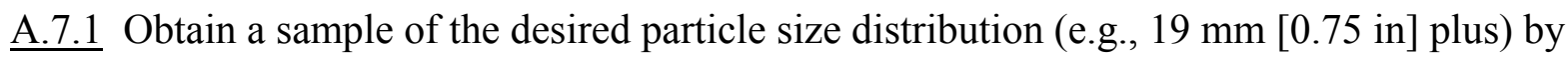
sieving to refusal using appropriate wire screens (AASHTO M 92). Individual test samples should contain sufficient quantities of aggregate to fill the pressure chamber.

A.7.2 The aggregate sample should be washed thoroughly and dried to a constant mass at a temperature of $110^{\circ} \mathrm{C} \pm 5^{\circ} \mathrm{C}\left(230^{\circ} \mathrm{F} \pm 9^{\circ} \mathrm{F}\right)$, and allowed to cool to room temperature.

Note 6 - Adequate ventilation should be supplied for the following three steps. The use of a fume hood may be appropriate.

A.7.3 Place the aggregate sample in the silane solution, making sure that all aggregate particles are submerged. Allow the specimen to remain in the silane solution for $30 \pm 5$ seconds.

A.7.4 Remove the specimen from the silane solution and allow excess solution to drain for five minutes.

Note 7 - Strainers suitable for immersing the aggregate in the silane solution and draining are readily obtainable from restaurant supply sources. An example is shown in figure A.3. 
Note 8 - The silane solution may be re-used if it is placed in a sealed container between uses. The solution should be discarded if it begins to thicken.

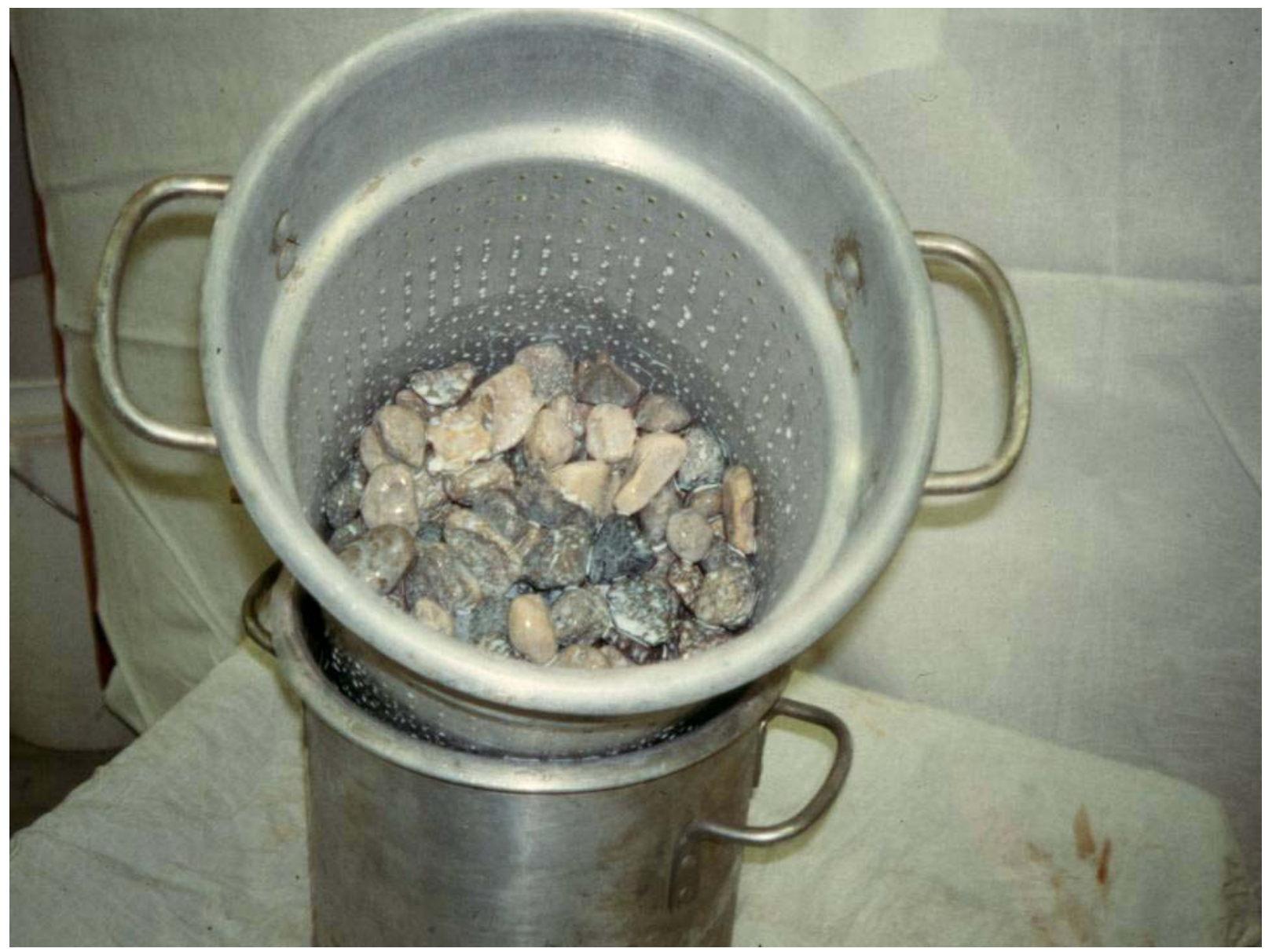

Figure A.3. Photo of silane-treated aggregate sample in double boiler.

A.7.5 Dry the specimens to a constant mass at a temperature of $110^{\circ} \mathrm{C} \pm 5^{\circ} \mathrm{C}\left(230^{\circ} \mathrm{F} \pm 9^{\circ} \mathrm{F}\right)$, and allow to cool to room temperature for one hour.

\section{A.8. TEST PROCEDURE}

A.8.1 Place enough aggregate in the tumbler to fill it approximately half way. Tumble the aggregate for 1 minute ( \pm 5 seconds). Remove the aggregate from the tumbler and discard any 
pieces passing the $4.75-\mathrm{mm}$ (\#4) sieve. Repeat until the entire aggregate test sample has been tumbled.

A.8.2 For noncarbonate aggregate sources, a qualified petrographer should examine the sample to estimate the carbonate content (by percent mass) of the aggregate sample.

A.8.3 Fill the test chamber with aggregate particles (as shown in figure A.4), being careful not to overfill the chamber (which may result in particle fracture due to closure of the chamber rather than due to the hydraulic fracture mechanism). Remove the aggregate from the test chamber and determine the mass of the test sample. Record this number as the initial sample mass.

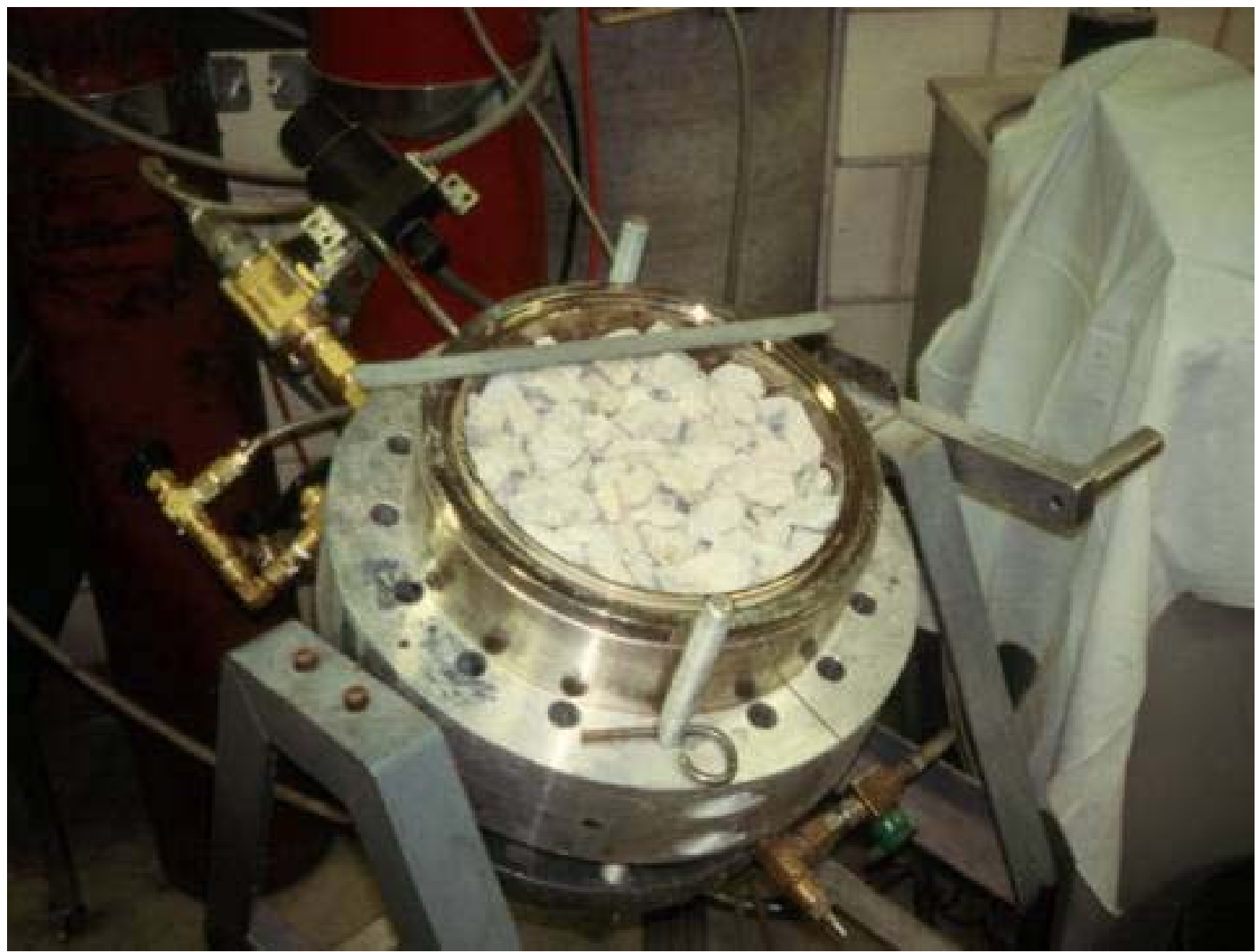

Figure A.4. Photo of large test chamber (filled with aggregate) and strike-off bar. 
A.8.4 Place the specimen in the pressure chamber and close the chamber as directed in the manufacturer's instructions (see figure A.5). Rotate the apparatus from the filling position (typically horizontal) to the testing (typically vertical) position.

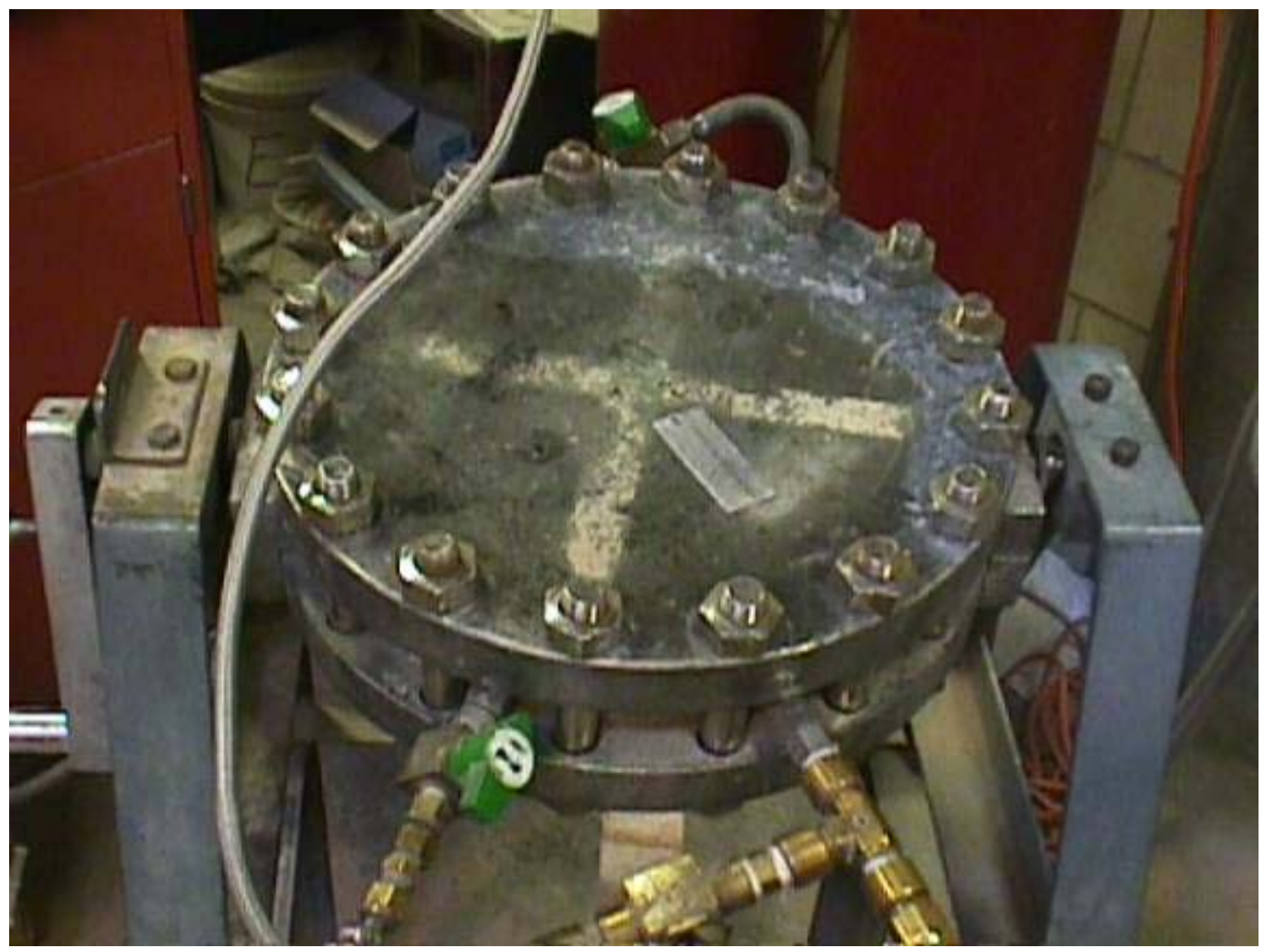

Figure A.5. Photo of small chamber closed in horizontal position.

A.8.5 Close the pressure valve and open the main valve on the nitrogen tank. The pressure regulator should be set to the pressure indicated on the calibration sheet provided with the equipment.

Note 9 - A minimum pressure of 7,930 $\mathrm{kPa}$ (1150 psi.) is currently recommended. Further work may justify a different chamber pressure. 
A.8.6 Connect the drain line to the pressure release valve. Open the fill and pressure release valves and fill the pressure chamber with water using the procedures described in the manufacturer's instructions. After the chamber is full and as water is flowing through the chamber and drain line, remove air bubbles from the chamber walls by pivoting the chamber to approximately 45 degrees on either side of the testing position and tapping the exterior of the chamber smartly with a rubber mallet. After the chamber has been filled and the air bubbles removed, close the pressure release valve, close the fill valve, and turn off the water supply. Remove the drain line from the end of the pressure release valve. This process should be completed in 2 minutes ( \pm 5 seconds).

A.8.7 After ensuring that all chamber valves are initially closed, pressurize the chamber for 5 minutes ( \pm 5 seconds) by opening the pressure valve. Adjust the pressure regulator as necessary to maintain the required pressure. At about 4.75 minutes, close the pressure valve.

A.8.8 After 5 minutes ( \pm 5 seconds) of pressurization, release the pressure to produce the prescribed pressure release rate by opening the pressure valve as described in the equipment manufacturer's instructions. Figures A.6 and A.7 show a small test chamber ready for pressure release and during pressure release, respectively.

A.8.9 Re-attach the drain line to the pressure release valve (now open), open the fill valve, and turn on the water supply to refill the chamber with water as before. Allow water to fill for approximately 30 seconds, rotating the chamber to 45 degrees either side of the test position and using the rubber mallet to remove any gas bubbles from the sides of the chamber. Close the pressure release valve, then the fill valve and turn off the water supply. Remove the drain line.

A.8.10 Re-pressurize the chamber after a total elapsed time of 1 minute $( \pm 5$ seconds) without pressure. Adjust the regulator as necessary to maintain the desired pressure. This pressurization time is 2 minutes ( \pm 5 seconds). After about 1.75 minutes, close the pressure valve.

$\underline{\text { A.8.11 }}$ Release the pressure after 2 minutes $( \pm 5$ seconds) by rapidly opening the pressure valve (as described in step 8.6 above). 
A.8.12 Repeat steps A.8.7 through A.8.9 eight additional times for a total of ten pressurization cycles. Rotate the pressure chamber back to the aggregate fill position to drain the chamber and remove the aggregate test sample.

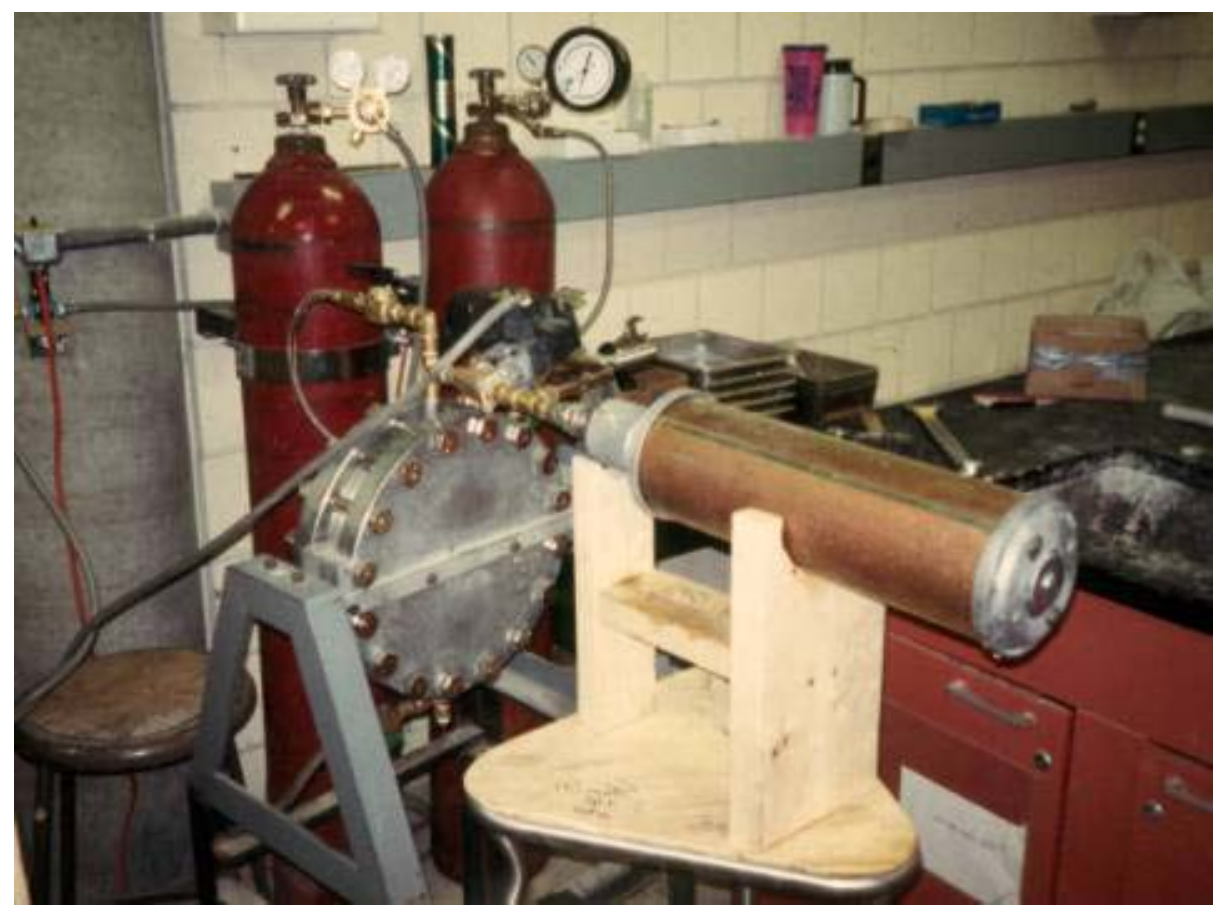

Figure A.6. Photo of small test chamber (with muffler) ready for pressure release.

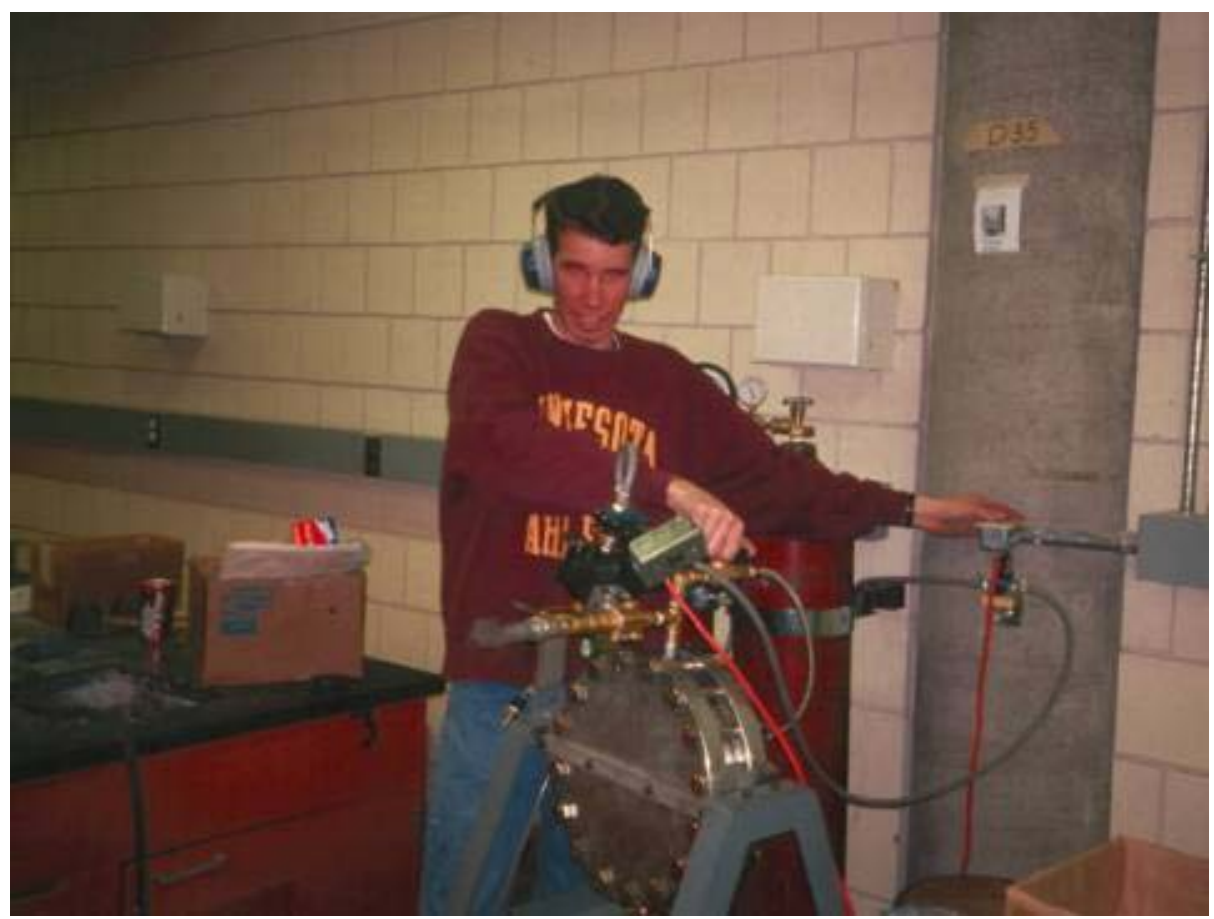

Figure A.7. Photo of small test chamber during pressure release (without muffler). 
A.8.13 Turn off the valve on the nitrogen bottle and open the drain valve. Drain the water from the pressure chamber by slowly opening the pressure valve and allowing the compressed gas in the line to force water out of the chamber.

A.8.14 Open the chamber and remove the test sample. Dry the specimen to a constant mass at a temperature of $110^{\circ} \mathrm{C} \pm 5^{\circ} \mathrm{C}\left(230^{\circ} \mathrm{F} \pm 9^{\circ} \mathrm{F}\right)$, and allow it to cool at room temperature for one hour.

A.8.15 Place enough aggregate in the tumbler to fill it approximately half way. Tumble the aggregate for 1 minute $( \pm 5$ seconds). Remove the aggregate from the tumbler, retaining all particles. Repeat until the entire aggregate test sample has been tumbled. Sieve the sample and determine (to the nearest $0.1 \mathrm{~g}$ ) the masses retained on the 16.0 - $\mathrm{mm}(0.625$-in), $12.5-\mathrm{mm}(0.5$-in), 9.5-mm (0.375-in.), 8-mm (0.3125-in) and 4.75-mm (\#4) sieves. Record these values, noting the number, i, of pressurization cycles completed. Remove the particles passing the 4.75-mm (\#4) sieve from the testing procedure, determine their mass to the nearest tenth of a gram, and save in a labeled container.

A.8.16 Repeat Steps A.8.4 through A.8.15 for a total of 50 pressurization cycles per test sample.

A.8.17 If necessary, test replicate samples of the same aggregate source until a sufficient quantity of material has been tested to provide a reasonably accurate estimate of coarse aggregate D-cracking potential (currently considered to be 600-800 aggregate particles).

\section{A.9. ANALYSIS OF DATA}

A.9.1 Determine the combined mass of particles retained on the $16.0-\mathrm{mm}(0.625$-in $), 12.5-\mathrm{mm}$ (0.5-in), 9.5-mm (0.375-in.), 8-mm (0.3125-in.) and 4.75-mm (\#4) sieves along with the mass of all particles passing the $4.75-\mathrm{mm}$ (\#4) sieve after 50 cycles of pressurization for all replicate test samples representing a given aggregate source. 
A.9.2 Determine the relative proportion of the masses of the various particle sizes to the original test sample mass (e.g., the original mass $=1.00$ and all final masses range from 0.00 to 1.00 and sum to 1.00$)$.

A.9.3 Estimate the freeze-thaw dilation that would occur in a concrete prism containing this aggregate source and tested using AASHTO TP17 using the following equation:

$$
\begin{aligned}
\% \text { Dil } / 100=\mathrm{C}^{3 *} & \left(6.714711 \mathrm{E}-9+1.493469 \mathrm{E}-9 * \mathrm{M}_{19} \mathrm{~mm}[0.75 \mathrm{in}]\right. \text { plus } \\
& -2.824751 \mathrm{E}-7 * \mathrm{M}_{16-19 \mathrm{~mm}[0.625-0.75 \mathrm{in}]}+3.648412 \mathrm{E}-7 * \mathrm{M}_{13}-16 \mathrm{~mm}[0.5-0.625 \mathrm{in}] \\
& \left.-5.631620 \mathrm{E}-7 * \mathrm{M}_{9.5-13 \mathrm{~mm}[0.375-0.5 \mathrm{in}]}+2.102003 \mathrm{E}-6 * \mathrm{M}_{8-9.5 \mathrm{~mm}[0.313-0.375 \mathrm{in}]}\right] \\
& \left.-1.675012 \mathrm{E}-6 * \mathrm{M}_{4.75-8 \mathrm{~mm}[\not 4-0.313 \mathrm{in}]}+1.183342 \mathrm{E}-7 * \mathrm{M}_{4.75 \mathrm{~mm}[\# 4] \text { minus }}\right)
\end{aligned}
$$

where:

$\mathrm{C}=$ Carbonate content $(100$ percent $=1.00)$

$\mathrm{M}_{\mathrm{mm}[\mathrm{in}]}=$ relative proportion of the masses of the various particle sizes to the original test sample mass $\mathrm{r}^{2}=0.978\left(\mathrm{r}_{\text {adj }}^{2}=0.957\right), \hat{\sigma}=0.009934, \mathrm{n}=18$

A.9.4 Apply appropriate acceptance or rejection criteria to the results of the analysis to determine the suitability of the given aggregate source or to suggest the need for additional or supplemental testing using this or other tests of concrete coarse aggregate freeze-thaw damage potential (e.g., ASTM C 666/AASHTO T161 or TP17, etc.). 


\section{APPENDIX B}

PCC and Coarse Aggregate Property Data 
Table B.1. PCC mix proportions, air and slump data for freeze-thaw test specimens.

\begin{tabular}{|c|c|c|c|c|c|c|c|c|c|c|}
\hline Aggregate Source & $\begin{array}{l}\text { Batch } \\
\text { Number }\end{array}$ & $\begin{array}{c}\text { Coarse } \\
\text { Aggregate } \\
\left(\mathrm{kg} / \mathrm{m}^{3}\right)\end{array}$ & $\begin{array}{c}\text { Fine } \\
\text { Aggregate } \\
\left(\mathrm{kg} / \mathrm{m}^{3}\right)\end{array}$ & $\begin{array}{l}\text { Cement } \\
\left(\mathrm{kg} / \mathrm{m}^{3}\right)\end{array}$ & $\begin{array}{c}\text { Water } \\
\left(\mathrm{kg} / \mathrm{m}^{3}\right)\end{array}$ & $\begin{array}{c}\mathrm{A} / \mathrm{E} \\
(\mathrm{mL} / 100 \mathrm{kgc})\end{array}$ & $\begin{array}{l}\text { w/c } \\
\text { Ratio }\end{array}$ & $\begin{array}{l}\text { Cement } \\
\text { Type }\end{array}$ & $\begin{array}{l}\text { Slump } \\
(\mathrm{mm})\end{array}$ & $\begin{array}{c}\text { Plastic } \\
\text { Air Content } \\
(\%)\end{array}$ \\
\hline \multicolumn{11}{|c|}{ QUARRIED } \\
\hline \multirow{2}{*}{ Aaland, Zumbrota } & 1 & \multirow{2}{*}{1095} & \multirow{2}{*}{712} & \multirow{2}{*}{350} & \multirow{2}{*}{156} & $0.037 * *$ & \multirow{2}{*}{0.45} & \multirow{2}{*}{ I } & 83 & 6.4 \\
\hline & 2 & & & & & $0.037 * *$ & & & 95 & 8.6 \\
\hline Big Springs, Harmony & 1 & 1058 & 712 & 350 & 140 & 0.083 & 0.40 & $\mathrm{I}$ & 45 & 3.5 \\
\hline \multirow{2}{*}{ Bryan Rock, Shakopee } & 1 & \multirow{2}{*}{1114} & \multirow{2}{*}{712} & \multirow{2}{*}{350} & 142 & $0.027 * *$ & 0.41 & \multirow{2}{*}{ I } & 51 & 3.5 \\
\hline & 2 & & & & 147 & $0.033 * *$ & 0.42 & & 64 & 4.6 \\
\hline Coralville Concrete Ledge, Waterloo & $1-11$ & 1092 & 704 & 319 & 144 & $0.012 * *$ & 0.45 & I & $76-84$ & 4.4-7.4 \\
\hline \multirow{2}{*}{ Early Chapel } & 1 & \multirow{2}{*}{1093} & \multirow{2}{*}{712} & \multirow{2}{*}{350} & 141 & 0.027 & 0.40 & \multirow{2}{*}{ I } & 45 & 3.6 \\
\hline & 2 & & & & 142 & 0.033 & 0.41 & & 32 & 3.7 \\
\hline Edward Kramer \& Sons, Burnsville & 1 & 1040 & 712 & 350 & 140 & 0.077 & 0.40 & $\mathrm{I}$ & 60 & 4.9 \\
\hline Goldberg, Rochester & 1 & 1072 & 712 & 350 & 140 & 0.073 & 0.40 & I & 64 & 4.4 \\
\hline Michigan Limestone, Cedarville Plant & 1 & 1146 & 712 & 350 & 140 & 0.073 & 0.40 & $\mathrm{I}$ & 64 & 5.9 \\
\hline \multirow{2}{*}{ Osmundson, Grand Meadow } & 1 & \multirow{2}{*}{1078} & \multirow{2}{*}{712} & \multirow{2}{*}{350} & \multirow{2}{*}{141} & $0.021 * *$ & \multirow{2}{*}{0.40} & \multirow{2}{*}{$\mathrm{I}$} & 32 & 4.6 \\
\hline & 2 & & & & & $0.024 * *$ & & & 38 & $6.0 * / 5.0$ \\
\hline Shiely Grey Cloud (Larson) & 1 & 1006 & 712 & 350 & 140 & 0.073 & 0.40 & $\mathrm{I}$ & 57 & 5.3 \\
\hline SMC Mankato & 1 & 1014 & 712 & 350 & 140 & 0.068 & 0.40 & $\mathrm{I}$ & 57 & 4.8 \\
\hline Swedberg & 1 & 1048 & 712 & 350 & 140 & 0.077 & 0.40 & $\mathrm{I}$ & 38 & 3.5 \\
\hline Ulland Northwood, Iowa & 1 & 1134 & 712 & 350 & 140 & 0.073 & 0.40 & $\mathrm{I}$ & 51 & 3.5 \\
\hline \multicolumn{11}{|c|}{ GRAVEL } \\
\hline Ashwill, Kingston & 1 & 1093 & 712 & 350 & 140 & 0.077 & 0.40 & $\mathrm{I}$ & 51 & 4.9 \\
\hline Johnson, Henderson & 1 & 1100 & 712 & 350 & 140 & 0.053 & 0.40 & $\mathrm{I}$ & 60 & 4.4 \\
\hline Johnson Le Sueur & 1 & 1094 & 712 & 350 & 140 & 0.073 & 0.40 & $\mathrm{I}$ & 57 & 5.7 \\
\hline Loeffler, Halma & 1 & 1098 & 712 & 350 & 140 & 0.073 & 0.40 & $\mathrm{I}$ & 70 & 5.9 \\
\hline Mark, Underwood & 1 & 1128 & 712 & 350 & 140 & 0.073 & 0.40 & $\mathrm{I}$ & 83 & 6.4 \\
\hline Northern Con, Luverne & 1 & 1083 & 712 & 350 & 140 & 0.073 & 0.40 & $\mathrm{I}$ & 108 & 7.0 \\
\hline North Star Kasota & 1 & 1101 & 712 & 350 & 140 & 0.045 & 0.40 & $\mathrm{I}$ & 83 & 4.5 \\
\hline
\end{tabular}

* Possible leak in air meter (reading was initially at 6.1\%); ran another plastic air test 15 minutes later due to difficulties with air test apparatus.

** ConChem air-entrainment admixture was used for these batches; for all other batches Daravair 1000 was used as the air-entraining admixture. 
Table B.2. Strength and durability data for each mixture.

\begin{tabular}{|c|c|c|c|c|c|c|}
\hline Source & $\begin{array}{l}\text { Batch } \\
\text { Number }\end{array}$ & $\begin{array}{l}\text { Compressive } \\
\text { Strength, } \\
\text { 14-day } \\
\text { (MPa) }\end{array}$ & $\begin{array}{c}\text { Static } \\
\text { Modulus } \\
\text { of } \\
\text { Elasticity, } \\
\text { 14-day } \\
(\mathrm{GPa})\end{array}$ & $\begin{array}{l}\text { Durability } \\
\text { Factor }\end{array}$ & $\begin{array}{c}\text { Dilation }^{1} \\
(\%)\end{array}$ & $\begin{array}{c}\text { Dilation / } \\
100 \text { Cycles } \\
(\%)\end{array}$ \\
\hline \multicolumn{7}{|c|}{ QUARRIED } \\
\hline \multirow{5}{*}{ Aaland, Zumbrota } & \multirow{3}{*}{1} & 30.0 & & 47.6 & 0.072 & 0.030 \\
\hline & & 32.4 & & 82.0 & 0.046 & 0.015 \\
\hline & & & & 81.9 & -0.008 & -0.003 \\
\hline & \multirow{2}{*}{2} & 24.6 & & 96.1 & 0.021 & 0.007 \\
\hline & & & & 94.8 & 0.015 & 0.005 \\
\hline \multirow{5}{*}{ Big Springs, Harmony } & \multirow{5}{*}{1} & 40.6 & 30.9 & 23.5 & 0.015 & 0.013 \\
\hline & & 39.7 & 32.0 & 11.0 & 0.010 & 0.018 \\
\hline & & 41.8 & 31.3 & 14.8 & 0.110 & 0.149 \\
\hline & & & & 15.3 & 0.005 & 0.006 \\
\hline & & & & 25.5 & 0.082 & 0.064 \\
\hline \multirow{5}{*}{ Bryan Rock, Shakopee } & \multirow{2}{*}{1} & 46.4 & & 17.2 & 0.107 & 0.124 \\
\hline & & 47.1 & & 13.8 & 0.068 & 0.099 \\
\hline & \multirow{3}{*}{2} & 44.3 & & 20.9 & 0.103 & 0.098 \\
\hline & & & & 21.8 & 0.117 & 0.107 \\
\hline & & & & 6.2 & 0.050 & 0.161 \\
\hline \multirow{13}{*}{$\begin{array}{l}\text { Coralville Concrete } \\
\text { Ledge, Waterloo }^{2}\end{array}$} & 1 & 39.5 & 31.9 & 56.8 & 0.101 & 0.036 \\
\hline & 2 & 35.4 & 27.4 & 47.0 & 0.100 & 0.043 \\
\hline & 3 & 38.4 & 27.9 & 41.4 & 0.082 & 0.040 \\
\hline & 4 & 37.2 & 27.9 & 39.0 & 0.094 & 0.048 \\
\hline & \multirow{2}{*}{5} & 44.2 & 31.2 & 44.0 & 0.119 & 0.054 \\
\hline & & & & 35.4 & 0.103 & 0.058 \\
\hline & 6 & 44.3 & 25.4 & 18.0 & 0.115 & 0.128 \\
\hline & 7 & 43.5 & 31.2 & 14.6 & 0.087 & 0.119 \\
\hline & 8 & 43.5 & 31.2 & 34.0 & 0.099 & 0.058 \\
\hline & 9 & 44.3 & 31.4 & 11.0 & 0.106 & 0.041 \\
\hline & 10 & 44.2 & 30.7 & 28.2 & 0.092 & 0.065 \\
\hline & 11 & 42.5 & 31.9 & 36.2 & 0.112 & 0.062 \\
\hline & 12 & 42.4 & 31.6 & 11.0 & 0.110 & 0.200 \\
\hline \multirow{5}{*}{ Early Chapel } & \multirow{3}{*}{1} & 41.5 & & 33.8 & 0.091 & 0.054 \\
\hline & & 44.4 & & 43.9 & 0.099 & 0.045 \\
\hline & & & & 38.0 & 0.086 & 0.045 \\
\hline & \multirow{2}{*}{2} & 44.6 & & 32.0 & 0.076 & 0.048 \\
\hline & & & & 32.6 & 0.093 & 0.057 \\
\hline \multirow{5}{*}{$\begin{array}{c}\text { Edward Kramer \& Sons, } \\
\text { Burnsville }\end{array}$} & \multirow{5}{*}{1} & 20.6 & 19.2 & 88.9 & 0.025 & 0.008 \\
\hline & & 38.3 & 22.0 & 83.8 & 0.039 & 0.013 \\
\hline & & 31.5 & 23.4 & 87.1 & 0.046 & 0.015 \\
\hline & & & & 61.6 & 0.078 & 0.026 \\
\hline & & & & 71.7 & 0.077 & 0.026 \\
\hline
\end{tabular}


Table B.2. Strength and durability data for each mixture (continued).

\begin{tabular}{|c|c|c|c|c|c|c|}
\hline Source & $\begin{array}{l}\text { Batch } \\
\text { Number }\end{array}$ & $\begin{array}{c}\text { Compressive } \\
\text { Strength, } \\
\text { 14-day } \\
(\mathrm{MPa})\end{array}$ & $\begin{array}{c}\text { Static } \\
\text { Modulus } \\
\text { of } \\
\text { Elasticity, } \\
\text { 14-day } \\
\text { (GPa) }\end{array}$ & $\begin{array}{l}\text { Durability } \\
\text { Factor }\end{array}$ & $\begin{array}{l}\text { Dilation }^{1} \\
\quad(\%)\end{array}$ & $\begin{array}{c}\text { Dilation / } \\
100 \text { Cycles } \\
(\%)\end{array}$ \\
\hline \multicolumn{7}{|c|}{ QUARRIED } \\
\hline \multirow{5}{*}{ Goldberg, Rochester } & \multirow{5}{*}{1} & 41.7 & 26.9 & 95.8 & 0.009 & 0.003 \\
\hline & & 43.5 & 27.9 & 95.6 & 0.014 & 0.005 \\
\hline & & 43.1 & 28.1 & 96.1 & 0.008 & 0.003 \\
\hline & & & & 94.8 & 0.011 & 0.004 \\
\hline & & & & 93.9 & 0.018 & 0.006 \\
\hline \multirow{5}{*}{$\begin{array}{c}\text { Michigan Limestone, } \\
\text { Cedarville Plant }\end{array}$} & \multirow{5}{*}{1} & 35.6 & 31.8 & 100.1 & 0.006 & 0.002 \\
\hline & & 33.1 & 31.5 & 99.4 & 0.005 & 0.002 \\
\hline & & 34.1 & 29.6 & 99.6 & 0.002 & 0.001 \\
\hline & & & & 99.2 & -0.009 & -0.003 \\
\hline & & & & 98.4 & 0.005 & 0.002 \\
\hline \multirow{5}{*}{$\begin{array}{l}\text { Osmundson, Grand } \\
\text { Meadow }\end{array}$} & \multirow{2}{*}{1} & 46.2 & & 66.9 & 0.077 & 0.026 \\
\hline & & 45.7 & & 72.1 & 0.065 & 0.022 \\
\hline & \multirow{3}{*}{2} & 49.5 & & 86.8 & 0.040 & 0.013 \\
\hline & & & & 89.4 & 0.038 & 0.013 \\
\hline & & & & 76.9 & 0.057 & 0.019 \\
\hline \multirow{5}{*}{$\begin{array}{c}\text { Shiely Grey Cloud } \\
\text { (Larson) }\end{array}$} & \multirow{5}{*}{1} & 44.3 & 26.6 & 99.4 & 0.012 & 0.004 \\
\hline & & 44.3 & 27.9 & 99.6 & 0.009 & 0.003 \\
\hline & & 43.4 & 26.5 & 100.2 & 0.006 & 0.002 \\
\hline & & & & 97.3 & 0.014 & 0.005 \\
\hline & & & & 97.3 & 0.014 & 0.005 \\
\hline \multirow{5}{*}{ SMC Mankato } & \multirow{5}{*}{1} & 35.9 & 25.6 & 8.4 & 0.054 & 0.129 \\
\hline & & 36.4 & 23.5 & 20.2 & 0.095 & 0.094 \\
\hline & & 37.2 & 23.6 & 5.2 & 0.036 & 0.138 \\
\hline & & & & 20.7 & 0.080 & 0.077 \\
\hline & & & & 12.5 & 0.075 & 0.119 \\
\hline \multirow{5}{*}{ Swedberg } & \multirow{5}{*}{1} & 30.4 & 28.7 & 27.5 & 0.089 & 0.064 \\
\hline & & 33.2 & 28.2 & 27.3 & 0.097 & 0.071 \\
\hline & & 35.0 & 27.7 & 23.1 & 0.112 & 0.097 \\
\hline & & & & 27.3 & 0.127 & 0.093 \\
\hline & & & & 25.7 & 0.079 & 0.062 \\
\hline \multirow{7}{*}{ Ulland Northwood, Iowa } & \multirow{7}{*}{1} & 39.9 & 34.1 & 97.7 & -0014 & -0.005 \\
\hline & & 42.0 & 35.0 & 95.5 & -0.007 & -0.002 \\
\hline & & & & 97.3 & -0.014 & -0.005 \\
\hline & & & & 98.0 & 0.006 & 0.002 \\
\hline & & & & 96.6 & -0.013 & -0.004 \\
\hline & & & & 96.4 & 0.012 & 0.004 \\
\hline & & & & 98.5 & 0.006 & 0.002 \\
\hline
\end{tabular}


Table B.2. Strength and durability data for each mixture (continued).

\begin{tabular}{|c|c|c|c|c|c|c|}
\hline Source & $\begin{array}{c}\text { Batch } \\
\text { Number }\end{array}$ & $\begin{array}{l}\text { Compressive } \\
\text { Strength, } \\
\text { 14-day } \\
(\mathrm{MPa})\end{array}$ & $\begin{array}{c}\text { Static } \\
\text { Modulus } \\
\text { of } \\
\text { Elasticity, } \\
\text { 14-day } \\
\text { (GPa) }\end{array}$ & $\begin{array}{c}\text { Durability } \\
\text { Factor }\end{array}$ & $\begin{array}{c}\text { Dilation }^{1} \\
(\%)\end{array}$ & $\begin{array}{c}\text { Dilation / } \\
100 \text { Cycles } \\
(\%)\end{array}$ \\
\hline \multicolumn{7}{|c|}{ GRAVEL } \\
\hline \multirow{5}{*}{ Ashwill, Kingston } & \multirow{5}{*}{1} & 38.1 & 31.1 & 95.2 & 0.003 & 0.001 \\
\hline & & 38.2 & 30.7 & 982 & 0.020 & 0.007 \\
\hline & & 38.9 & 30.2 & 97.4 & 0.008 & 0.003 \\
\hline & & & & 96.4 & 0.012 & 0.004 \\
\hline & & & & 98.5 & 0.006 & 0.002 \\
\hline \multirow{5}{*}{ Johnson, Henderson } & \multirow{5}{*}{1} & 34.2 & 28.6 & 78.3 & 0.029 & 0.010 \\
\hline & & 35.6 & 29.3 & 88.1 & 0.017 & 0.006 \\
\hline & & 36.6 & 29.0 & 89.7 & 0.015 & 0.005 \\
\hline & & & & 96.7 & 0.010 & 0.003 \\
\hline & & & & 98.2 & 0.010 & 0.003 \\
\hline \multirow{5}{*}{ Johnson Le Sueur } & \multirow{5}{*}{1} & 33.0 & 29.9 & 95.6 & 0.011 & 0.004 \\
\hline & & 29.2 & 29.4 & 93.4 & 0.023 & 0.008 \\
\hline & & 28.6 & 27.2 & 96.9 & 0.011 & 0.004 \\
\hline & & & & 80.2 & 0.036 & 0.012 \\
\hline & & & & 75.5 & 0.034 & 0.011 \\
\hline \multirow{5}{*}{ Loeffler, Halma } & \multirow{5}{*}{1} & 33.7 & 30.3 & 98.9 & 0.008 & 0.003 \\
\hline & & 35.2 & 31.4 & 93.7 & 0.019 & 0.006 \\
\hline & & 34.5 & 29.6 & 95.3 & 0.015 & 0.005 \\
\hline & & & & 96.6 & 0.015 & 0.005 \\
\hline & & & & 85.2 & 0.031 & 0.010 \\
\hline \multirow{5}{*}{ Mark, Underwood } & \multirow{5}{*}{1} & 30.9 & 31.1 & 97.9 & 0.007 & 0.002 \\
\hline & & 28.3 & 30.7 & 93.5 & 0.026 & 0.009 \\
\hline & & 31.4 & 27.6 & 93.1 & 0.015 & 0.005 \\
\hline & & & & 98.5 & 0.014 & 0.005 \\
\hline & & & & 94.7 & -0.002 & -0.001 \\
\hline \multirow{5}{*}{ Northern Con, Luverne } & \multirow{5}{*}{1} & 30.6 & 23.0 & 777.0 & 0.032 & 0.011 \\
\hline & & 31.0 & 24.2 & 75.3 & 0.020 & 0.007 \\
\hline & & 31.0 & 24.2 & 88.1 & 0.025 & 0.008 \\
\hline & & & & 88.0 & 0.024 & 0.008 \\
\hline & & & & 90.7 & 0.019 & 0.006 \\
\hline \multirow{5}{*}{ North Star Kasota } & \multirow{5}{*}{1} & 35.1 & 30.9 & 77.6 & 0.025 & 0.008 \\
\hline & & 35.4 & 29.2 & 73.8 & 0.025 & 0.008 \\
\hline & & 33.5 & 30.3 & 89.4 & 0.021 & 0.007 \\
\hline & & & & 68.6 & 0.045 & 0.015 \\
\hline & & & & 87.7 & 0.042 & 0.014 \\
\hline
\end{tabular}

1 Percent dilation is at failure (when the relative dynamic modulus reaches 60 percent) or 300 cycles which ever came first.

2 Static modulus of elasticity and compression tests were performed at 28 days. 
Table B.3. Unit weight and void content data for aggregate sources.

\begin{tabular}{|c|c|c|c|c|c|c|c|}
\hline \multirow[t]{2}{*}{ Aggregate Source } & \multirow{2}{*}{$\begin{array}{l}\text { Trial } \\
\text { No. }\end{array}$} & \multicolumn{2}{|c|}{$\begin{array}{l}\text { Unit Weight } \\
\left(\mathrm{lb} / \mathrm{ft}^{3}\right)\end{array}$} & \multicolumn{2}{|c|}{$\begin{array}{l}\text { Unit Weight } \\
\left(\mathrm{kg} / \mathrm{m}^{3}\right)\end{array}$} & \multicolumn{2}{|c|}{ Void Content (\%) } \\
\hline & & Result & Avg. & Result & Avg. & Result & Avg. \\
\hline \multirow{2}{*}{ Aaland, Zumbrota } & 1 & 93.6 & \multirow{2}{*}{94.3} & 1518.2 & \multirow{2}{*}{1529.4} & 40.0 & \multirow{2}{*}{39.5} \\
\hline & 2 & 95.0 & & 1540.6 & & 39.1 & \\
\hline \multirow{2}{*}{ Ashwill, Kingston } & 1 & 98.4 & \multirow{2}{*}{97.5} & 1595.1 & \multirow{2}{*}{1580.7} & 40.1 & \multirow{2}{*}{40.6} \\
\hline & 2 & 96.6 & & 1566.3 & & 41.2 & \\
\hline \multirow{2}{*}{ Big Springs, Harmony } & 1 & 96.2 & \multirow{2}{*}{96.6} & 1559.9 & \multirow{2}{*}{1566.3} & 39.5 & \multirow{2}{*}{39.2} \\
\hline & 2 & 97.0 & & 1572.7 & & 39.0 & \\
\hline \multirow{2}{*}{ Bryan Rock, Shakopee } & 1 & 93.6 & \multirow{2}{*}{93.7} & 1518.2 & \multirow{2}{*}{1519.8} & 39.8 & \multirow{2}{*}{39.7} \\
\hline & 2 & 93.8 & & 1521.4 & & 39.7 & \\
\hline \multirow{2}{*}{$\begin{array}{l}\text { Cedarville Plant, Michigan } \\
\text { Limestone }\end{array}$} & 1 & 102.5 & \multirow{2}{*}{102.3} & 1662.3 & \multirow{2}{*}{1659.1} & 40.5 & \multirow{2}{*}{40.6} \\
\hline & 2 & 102.1 & & 1655.9 & & 40.7 & \\
\hline $\begin{array}{l}\text { Coralville Concrete Ledge, } \\
\text { Waterloo }\end{array}$ & & & & & & & \\
\hline Early Chanel Jowa & 1 & 91.1 & 91.7 & 1476.6 & 1486.2 & 41.1 & 40.7 \\
\hline & 2 & 92.3 & 91.1 & 1495.8 & 1400.2 & 40.3 & 40.1 \\
\hline Edward Kramer \& Sons, & 1 & 98.4 & 985 & 1595.1 & 15967 & 37.1 & 370 \\
\hline Burnsville & 2 & 98.6 & & 1598.3 & & 36.9 & \\
\hline Goldberg Rochester & 1 & 100.7 & 1004 & 1633.5 & 1627.1 & 37.5 & 377 \\
\hline & 2 & 100.0 & & 1620.7 & & 38.0 & \\
\hline Johnson $\mathrm{H}$ & 1 & 106.1 & 1059 & 1720.0 & 17168 & 35.8 & 359 \\
\hline 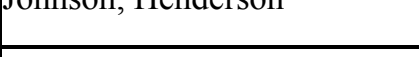 & 2 & 105.7 & 100.3 & 1713.6 & 1710.0 & 36.1 & 30.3 \\
\hline Le Sueur & 1 & 106.9 & 1072 & 1732.8 & 173 & 35.0 & 348 \\
\hline & 2 & 107.5 & & \begin{tabular}{|l|}
1742.4 \\
\end{tabular} & & 34.6 & \\
\hline Loeffl & 1 & 103.5 & 103.8 & 1678.4 & 1683.2 & 37.3 & 37.1 \\
\hline Loeffler, Halma & 2 & 104.1 & 105.0 & 1688.0 & 1005.2 & 36.9 & 31.1 \\
\hline Mark. L & 1 & 109.2 & 108.8 & 1771.2 & 1764.8 & 35.5 & 35.7 \\
\hline Inark, Underwood & 2 & 108.4 & 108.8 & \begin{tabular}{|l|}
1758.4 \\
\end{tabular} & & 36.0 & \\
\hline Northern Con, Luverne & 1 & 106.5 & 106.5 & 1726.4 & 1726.4 & 34.5 & 34.5 \\
\hline Ivorment Con, Luveme & 2 & 106.5 & 100.5 & 1726.4 & $17 / 20.4$ & 34.5 & 34.5 \\
\hline North Star Kasota & 1 & 108.4 & 108.6 & 1758.4 & 1761.6 & 34.4 & 34.3 \\
\hline & 2 & 108.8 & & 1764.8 & & 34.2 & \\
\hline Osmundson Grand Meadow & 1 & 91.9 & 923 & 1489.4 & 14958 & 38.9 & 386 \\
\hline & 2 & 92.6 & & 1502.2 & & 38.4 & \\
\hline Shielv Grev Cloud (Larson) & 1 & 93.2 & 93.4 & 1511.8 & 1515.0 & 38.3 & 38.2 \\
\hline & 2 & 93.6 & & 1518.2 & & 38.1 & \\
\hline SMC,$M$ & 1 & 94.2 & 93.4 & 1527.8 & & 38.1 & 387 \\
\hline 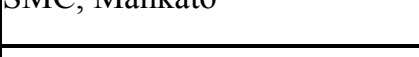 & 2 & 92.6 & & 1502.2 & & 39.2 & \\
\hline & 1 & 93.8 & 93.5 & 1521.4 & 1516.6 & 40.4 & 40.6 \\
\hline & 2 & 93.2 & & 1511.8 & & 40.8 & \\
\hline & 1 & 98.6 & 992 & 1598.3 & & 42.2 & \\
\hline & 2 & 99.8 & 99.2 & 1617.5 & 1007.9 & 41.5 & 41.0 \\
\hline
\end{tabular}


Table B.4. As-produced sieve analysis for project aggregate sources.

\begin{tabular}{|c|c|c|c|c|c|c|c|c|c|c|}
\hline \multirow[b]{2}{*}{$\begin{array}{c}\text { Sieve } \\
\text { Size } \\
(\mathrm{mm})\end{array}$} & \multicolumn{10}{|c|}{ Percentage of Mass Retained } \\
\hline & $\begin{array}{l}\text { Aaland, } \\
\text { Zumbrota }\end{array}$ & $\begin{array}{l}\text { Ashwill, } \\
\text { Kingston }\end{array}$ & $\begin{array}{c}\text { Big Springs, } \\
\text { Harmony }\end{array}$ & $\begin{array}{c}\text { Bryan } \\
\text { Rock, } \\
\text { Shakopee }\end{array}$ & $\begin{array}{c}\text { Cedarville } \\
\text { Plant, } \\
\text { Michigan } \\
\text { Limestone }\end{array}$ & $\begin{array}{c}\text { Coralville } \\
\text { Concrete } \\
\text { Ledge, } \\
\text { Waterloo }\end{array}$ & $\begin{array}{c}\text { Early Chapel, } \\
\text { Iowa }\end{array}$ & $\begin{array}{c}\text { Edward } \\
\text { Kramer \& } \\
\text { Sons, } \\
\text { Burnsville }\end{array}$ & $\begin{array}{l}\text { Goldberg, } \\
\text { Rochester }\end{array}$ & $\begin{array}{c}\text { Loeffler, } \\
\text { Halma }\end{array}$ \\
\hline 25.0 & 16.39 & 0.00 & 26.14 & 16.21 & 10.23 & 0.00 & 2.02 & 14.99 & 17.74 & 0.00 \\
\hline 19.0 & 15.22 & 0.00 & 12.00 & 15.76 & 21.78 & 17.35 & 26.42 & 22.75 & 20.82 & 30.91 \\
\hline 16.0 & 17.03 & 13.10 & 16.40 & 15.69 & 14.50 & 18.09 & 20.60 & 16.44 & 15.08 & 18.32 \\
\hline 12.5 & 15.59 & 35.93 & 19.88 & 19.45 & 22.10 & 20.70 & 16.25 & 14.42 & 14.93 & 15.77 \\
\hline 9.5 & 21.30 & 33.31 & 10.74 & 26.02 & 25.62 & 17.62 & 20.52 & 12.28 & 11.62 & 17.07 \\
\hline 8.0 & 7.81 & 7.94 & 4.41 & 5.56 & 4.10 & 8.33 & 8.69 & 6.29 & 6.22 & 8.34 \\
\hline 6.35 & 4.87 & 5.53 & 5.54 & 1.25 & 1.31 & 9.26 & 4.25 & 7.10 & 7.17 & 7.50 \\
\hline 4.75 & 1.77 & 4.18 & 4.88 & 0.06 & 0.35 & 8.65 & 1.25 & 5.74 & 6.43 & 2.08 \\
\hline pan & 0.00 & 0.00 & 0.00 & 0.00 & 0.00 & 0.00 & 0.00 & 0.00 & 0.00 & 0.00 \\
\hline Total: & 100 & 100 & 100 & 100 & 100 & 100 & 100 & 100 & 100 & 100 \\
\hline
\end{tabular}

\begin{tabular}{|c|c|c|c|c|c|c|c|c|c|c|}
\hline \multirow{2}{*}{$\begin{array}{c}\text { Sieve } \\
\text { Size } \\
(\mathbf{m m})\end{array}$} & $\begin{array}{c}\text { Johnson, } \\
\text { Henderson }\end{array}$ & $\begin{array}{c}\text { Johnson, } \\
\text { LeSueur }\end{array}$ & $\begin{array}{c}\text { Mark, } \\
\text { Underwood }\end{array}$ & $\begin{array}{c}\text { Northern } \\
\text { Con, } \\
\text { Luverne }\end{array}$ & $\begin{array}{c}\text { North Star } \\
\text { Kasota }\end{array}$ & $\begin{array}{c}\text { Osmundson, } \\
\text { Grand } \\
\text { Meadow }\end{array}$ & $\begin{array}{c}\text { Shiely Gray } \\
\text { Cloud } \\
\text { Larson) }\end{array}$ & $\begin{array}{c}\text { SMC, Mankato } \\
\text { Swedberg } \\
\text { Northwood }\end{array}$ \\
\hline 25.0 & 19.15 & 11.66 & 13.93 & 22.52 & 14.46 & 11.78 & 13.40 & 27.15 & 11.22 & 11.46 \\
\hline 19.0 & 12.87 & 24.83 & 20.60 & 10.44 & 21.00 & 18.21 & 20.66 & 9.86 & 22.28 & 20.20 \\
\hline 16.0 & 11.96 & 17.50 & 17.89 & 22.38 & 19.39 & 15.49 & 21.36 & 13.36 & 21.92 & 14.51 \\
\hline 12.5 & 21.67 & 16.57 & 17.35 & 17.48 & 16.75 & 21.45 & 13.20 & 17.18 & 11.82 & 17.10 \\
\hline 9.5 & 18.45 & 10.58 & 14.65 & 9.15 & 9.14 & 19.72 & 16.65 & 18.47 & 13.51 & 13.39 \\
\hline 8.0 & 9.00 & 7.30 & 7.75 & 6.20 & 5.04 & 5.08 & 8.88 & 6.56 & 6.47 & 7.17 \\
\hline 6.35 & 6.04 & 8.33 & 6.22 & 8.58 & 7.24 & 6.88 & 4.71 & 4.83 & 7.12 & 9.28 \\
\hline 4.75 & 0.86 & 3.24 & 1.60 & 3.25 & 6.98 & 1.39 & 1.14 & 2.60 & 5.66 & 6.89 \\
\hline pan & 0.00 & 0.00 & 0.00 & 0.00 & 0.00 & 0.00 & 0.00 & 0.00 & 0.00 & 0.00 \\
\hline Total: & 100 & 100 & 100 & 100 & 100 & 100 & 100 & 100 & 100 & 100 \\
\hline
\end{tabular}




\section{APPENDIX C}

Hydraulic Fracture Test Results - Small Chamber 
Table C.1. HFT results (mass retained) for small chamber samples (4.75 to $12.5 \mathrm{~mm}$ [\#4 to $0.5 \mathrm{in}]$ ).

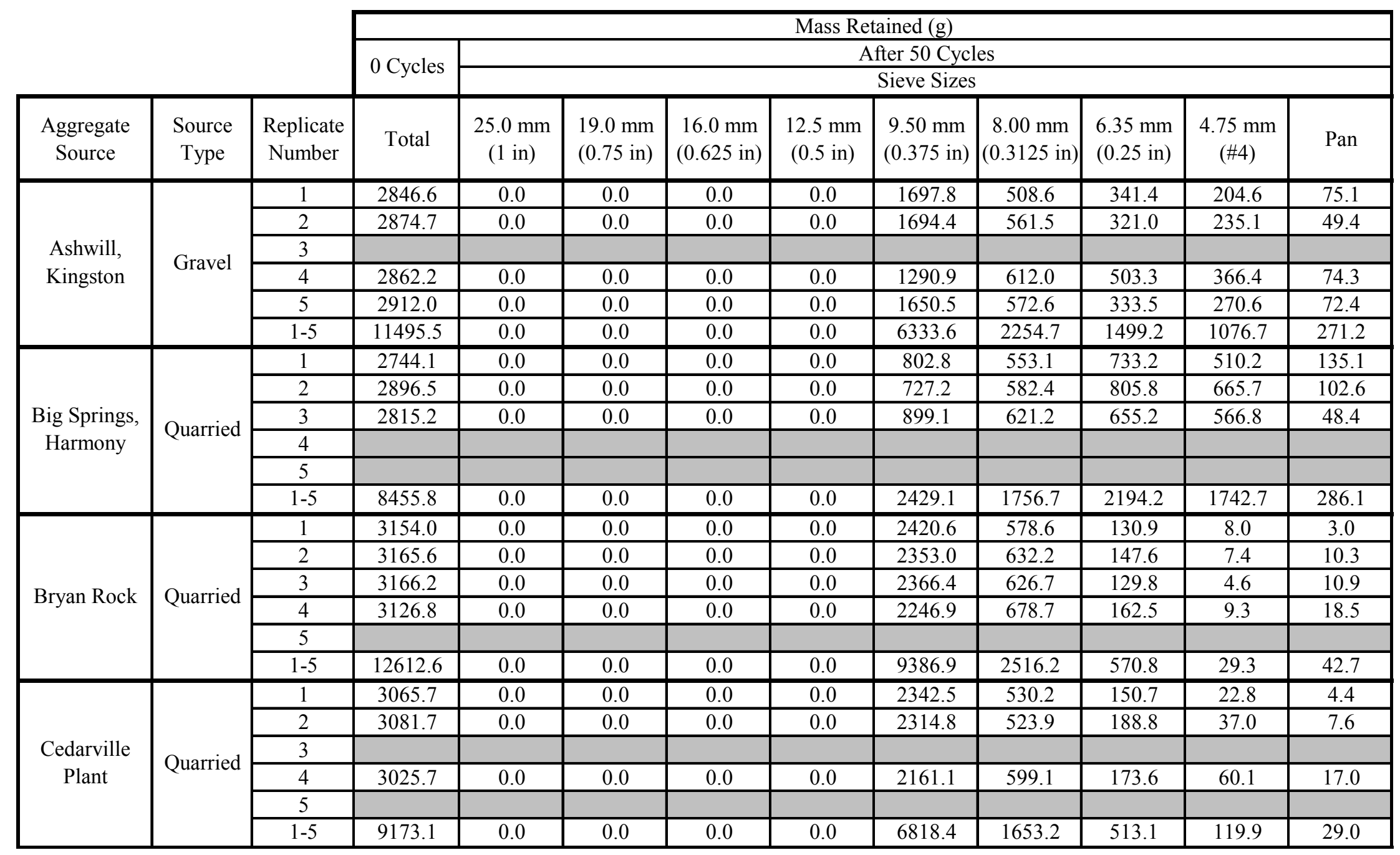


Table C.1. HFT results (mass retained) for small chamber samples (4.75 to $12.5 \mathrm{~mm}$ [\#4 to $0.5 \mathrm{in}]$ ) (continued).

\begin{tabular}{|c|c|c|c|c|c|c|c|c|c|c|c|c|}
\hline & & & \multicolumn{10}{|c|}{ Mass Retained (g) } \\
\hline & & & \multirow{2}{*}{0 Cycles } & \multicolumn{9}{|c|}{ After 50 Cycles } \\
\hline & & & & \multicolumn{9}{|c|}{ Sieve Sizes } \\
\hline $\begin{array}{l}\text { Aggregate } \\
\text { Source }\end{array}$ & $\begin{array}{l}\text { Source } \\
\text { Type }\end{array}$ & $\begin{array}{l}\text { Replicate } \\
\text { Number }\end{array}$ & Total & $\begin{array}{l}25.0 \mathrm{~mm} \\
\quad(1 \mathrm{in})\end{array}$ & $\begin{array}{l}19.0 \mathrm{~mm} \\
(0.75 \mathrm{in})\end{array}$ & $\begin{array}{c}16.0 \mathrm{~mm} \\
(0.625 \mathrm{in})\end{array}$ & $\begin{array}{c}12.5 \mathrm{~mm} \\
(0.5 \mathrm{in})\end{array}$ & $\begin{array}{c}9.50 \mathrm{~mm} \\
(0.375 \mathrm{in})\end{array}$ & $\begin{array}{c}8.00 \mathrm{~mm} \\
(0.3125 \mathrm{in})\end{array}$ & $\begin{array}{l}6.35 \mathrm{~mm} \\
(0.25 \mathrm{in})\end{array}$ & $\begin{array}{c}4.75 \mathrm{~mm} \\
(\# 4)\end{array}$ & Pan \\
\hline \multirow{6}{*}{ Early Chapel } & \multirow{6}{*}{ Quarried } & 1 & 3089.6 & 0.0 & 0.0 & 0.0 & 0.0 & 1718.3 & 793.9 & 433.2 & 120.4 & 12.7 \\
\hline & & 2 & 3050.7 & 0.0 & 0.0 & 0.0 & 0.0 & 1697.7 & 822.2 & 399.8 & 90.5 & 21.4 \\
\hline & & 3 & 3090.8 & 0.0 & 0.0 & 0.0 & 0.0 & 1582.3 & 903.5 & 447.8 & 113.8 & 15.3 \\
\hline & & 4 & 2977.6 & 0.0 & 0.0 & 0.0 & 0.0 & 1735.6 & 756.1 & 353.2 & 90.2 & 19.4 \\
\hline & & 5 & 3050.6 & 0.0 & 0.0 & 0.0 & 0.0 & 1383.4 & 904.2 & 527.0 & 198.4 & 23.4 \\
\hline & & $1-5$ & 15259.3 & 0.0 & 0.0 & 0.0 & 0.0 & 8117.3 & 4179.9 & 2161.0 & 613.3 & 92.2 \\
\hline \multirow{6}{*}{$\begin{array}{c}\text { Edward } \\
\text { Kramer \& } \\
\text { Sons }\end{array}$} & \multirow{6}{*}{ Quarried } & 1 & 2621.4 & 0.0 & 0.0 & 0.0 & 0.0 & 832.6 & 557.6 & 669.0 & 468.1 & 69.7 \\
\hline & & 2 & 2482.7 & 0.0 & 0.0 & 0.0 & 0.0 & 675.7 & 607.3 & 596.2 & 501.7 & 71.2 \\
\hline & & 3 & & & & & & & & & & \\
\hline & & 4 & 2450.0 & 0.0 & 0.0 & 0.0 & 0.0 & 645.6 & 517.0 & 650.5 & 541.6 & 64.2 \\
\hline & & 5 & 2529.5 & 0.0 & 0.0 & 0.0 & 0.0 & 711.4 & 603.0 & 615.1 & 493.2 & 80.8 \\
\hline & & $1-5$ & 10083.6 & 0.0 & 0.0 & 0.0 & 0.0 & 2865.3 & 2284.9 & 2530.8 & 2004.6 & 285.9 \\
\hline \multirow{6}{*}{$\begin{array}{l}\text { Goldberg, } \\
\text { Rochester }\end{array}$} & \multirow{6}{*}{ Quarried } & 1 & 2584.9 & 0.0 & 0.0 & 0.0 & 0.0 & 645.2 & 560.8 & 694.6 & 516.8 & 128.5 \\
\hline & & 2 & 2633.7 & 0.0 & 0.0 & 0.0 & 0.0 & 739.6 & 648.3 & 627.7 & 526.7 & 63.5 \\
\hline & & 3 & 2569.9 & 0.0 & 0.0 & 0.0 & 0.0 & 747.6 & 544.7 & 622.6 & 552.4 & 79.8 \\
\hline & & 4 & 2571.2 & 0.0 & 0.0 & 0.0 & 0.0 & 590.6 & 565.0 & 619.7 & 597.4 & 168.1 \\
\hline & & 5 & & & & & & & & & & \\
\hline & & $1-5$ & 10359.7 & 0.0 & 0.0 & 0.0 & 0.0 & 2723.0 & 2318.8 & 2564.6 & 2193.3 & 439.9 \\
\hline \multirow{6}{*}{$\begin{array}{l}\text { Grand } \\
\text { Meadow }\end{array}$} & \multirow{6}{*}{ Quarried } & 1 & 3190.5 & 0.0 & 0.0 & 0.0 & 0.0 & 1643.6 & 729.8 & 648.2 & 112.6 & 10.9 \\
\hline & & 2 & 3161.9 & 0.0 & 0.0 & 0.0 & 0.0 & 1707.8 & 747.7 & 549.5 & 128.5 & 16.9 \\
\hline & & 3 & 3149.8 & 0.0 & 0.0 & 0.0 & 0.0 & 1547.3 & 780.1 & 580.8 & 190.9 & 16.9 \\
\hline & & 4 & 2809.2 & 0.0 & 0.0 & 0.0 & 0.0 & 1260.8 & 737.2 & 572.2 & 194.1 & 23.3 \\
\hline & & 5 & & & & & & & & & & \\
\hline & & $1-5$ & 12311.4 & 0.0 & 0.0 & 0.0 & 0.0 & 6159.5 & 2994.8 & 2350.7 & 626.1 & 68.0 \\
\hline
\end{tabular}


Table C.1. HFT results (mass retained) for small chamber samples (4.75 to $12.5 \mathrm{~mm}$ [\#4 to $0.5 \mathrm{in}]$ ) (continued).

\begin{tabular}{|c|c|c|c|c|c|c|c|c|c|c|c|c|}
\hline & & & \multicolumn{10}{|c|}{ Mass Retained (g) } \\
\hline & & & \multirow{2}{*}{0 Cycles } & \multicolumn{9}{|c|}{ After 50 Cycles } \\
\hline & & & & \multicolumn{9}{|c|}{ Sieve Sizes } \\
\hline $\begin{array}{l}\text { Aggregate } \\
\text { Source }\end{array}$ & $\begin{array}{l}\text { Source } \\
\text { Type }\end{array}$ & $\begin{array}{l}\text { Replicate } \\
\text { Number }\end{array}$ & Total & $\begin{array}{l}25.0 \mathrm{~mm} \\
\quad(1 \mathrm{in})\end{array}$ & $\begin{array}{l}19.0 \mathrm{~mm} \\
(0.75 \mathrm{in})\end{array}$ & $\begin{array}{c}16.0 \mathrm{~mm} \\
(0.625 \mathrm{in})\end{array}$ & $\begin{array}{c}12.5 \mathrm{~mm} \\
(0.5 \mathrm{in})\end{array}$ & $\begin{array}{c}9.50 \mathrm{~mm} \\
(0.375 \mathrm{in})\end{array}$ & $\begin{array}{c}8.00 \mathrm{~mm} \\
(0.3125 \mathrm{in})\end{array}$ & $\begin{array}{l}6.35 \mathrm{~mm} \\
(0.25 \mathrm{in})\end{array}$ & $\begin{array}{c}4.75 \mathrm{~mm} \\
(\# 4)\end{array}$ & Pan \\
\hline \multirow{6}{*}{ Halma } & \multirow{6}{*}{ Gravel } & 1 & 3147.7 & 0.0 & 0.0 & 0.0 & 0.0 & 1404.7 & 839.6 & 707.5 & 180.8 & 10.9 \\
\hline & & 2 & 3082.5 & 0.0 & 0.0 & 0.0 & 0.0 & 1311.2 & 864.5 & 676.8 & 210.3 & 11.5 \\
\hline & & 3 & 3059.3 & 0.0 & 0.0 & 0.0 & 0.0 & 1389.3 & 764.2 & 667.3 & 212.3 & 17.6 \\
\hline & & 4 & 3056.7 & 0.0 & 0.0 & 0.0 & 0.0 & 1454.0 & 642.9 & 753.9 & 188.4 & 11.3 \\
\hline & & 5 & 3065.0 & 0.0 & 0.0 & 0.0 & 0.0 & 1371.7 & 784.4 & 690.3 & 189.9 & 16.8 \\
\hline & & $1-5$ & 15411.2 & 0.0 & 0.0 & 0.0 & 0.0 & 6930.9 & 3895.6 & 3495.8 & 981.7 & 68.1 \\
\hline \multirow{6}{*}{$\begin{array}{l}\text { Johnson, } \\
\text { Henderson }\end{array}$} & \multirow{6}{*}{ Gravel } & 1 & 3115.1 & 0.0 & 0.0 & 0.0 & 0.0 & 1563.0 & 813.1 & 648.8 & 71.0 & 5.8 \\
\hline & & 2 & 3394.6 & 0.0 & 0.0 & 0.0 & 0.0 & 1526.2 & 1025.7 & 695.5 & 110.9 & 16.9 \\
\hline & & 3 & & & & & & & & & & \\
\hline & & 4 & 3233.7 & 0.0 & 0.0 & 0.0 & 0.0 & 1455.6 & 1012.5 & 637.0 & 103.5 & 11.4 \\
\hline & & 5 & 3263.7 & 0.0 & 0.0 & 0.0 & 0.0 & 1560.2 & 955.8 & 619.7 & 100.6 & 21.5 \\
\hline & & $1-5$ & 13007.1 & 0.0 & 0.0 & 0.0 & 0.0 & 6105.0 & 3807.1 & 2601.0 & 386.0 & 55.6 \\
\hline \multirow{6}{*}{$\begin{array}{c}\text { Johnson, Le } \\
\text { Sueur }\end{array}$} & \multirow{6}{*}{ Gravel } & 1 & 2973.0 & 0.0 & 0.0 & 0.0 & 0.0 & 817.0 & 707.9 & 1011.7 & 381.0 & 45.8 \\
\hline & & 2 & 2925.1 & 0.0 & 0.0 & 0.0 & 0.0 & 894.8 & 777.0 & 848.4 & 345.8 & 40.7 \\
\hline & & 3 & & & & & & & & & & \\
\hline & & 4 & 2949.1 & 0.0 & 0.0 & 0.0 & 0.0 & 884.2 & 802.2 & 825.1 & 373.2 & 42.4 \\
\hline & & 5 & 3039.0 & 0.0 & 0.0 & 0.0 & 0.0 & 928.8 & 860.9 & 909.5 & 297.6 & 35.5 \\
\hline & & $1-5$ & 11886.2 & 0.0 & 0.0 & 0.0 & 0.0 & 3524.8 & 3148.0 & 3594.7 & 1397.6 & 164.4 \\
\hline \multirow{6}{*}{$\begin{array}{c}\text { Mark, } \\
\text { Underwood }\end{array}$} & \multirow{6}{*}{ Gravel } & 1 & 3058.3 & 0.0 & 0.0 & 0.0 & 0.0 & 1284.4 & 805.6 & 737.1 & 200.3 & 26.9 \\
\hline & & 2 & 3034.8 & 0.0 & 0.0 & 0.0 & 0.0 & 1451.6 & 812.0 & 596.2 & 158.3 & 10.0 \\
\hline & & 3 & 3067.3 & 0.0 & 0.0 & 0.0 & 0.0 & 1295.3 & 912.6 & 652.3 & 190.5 & 10.2 \\
\hline & & 4 & 3092.3 & 0.0 & 0.0 & 0.0 & 0.0 & 1287.5 & 856.4 & 722.4 & 204.8 & 15.8 \\
\hline & & 5 & & & & & & & & & & \\
\hline & & $1-5$ & 12252.7 & 0.0 & 0.0 & 0.0 & 0.0 & 5318.8 & 3386.6 & 2708.0 & 753.9 & 62.9 \\
\hline
\end{tabular}


Table C.1. HFT results (mass retained) for small chamber samples (4.75 to $12.5 \mathrm{~mm}$ [\#4 to $0.5 \mathrm{in}]$ ) (continued).

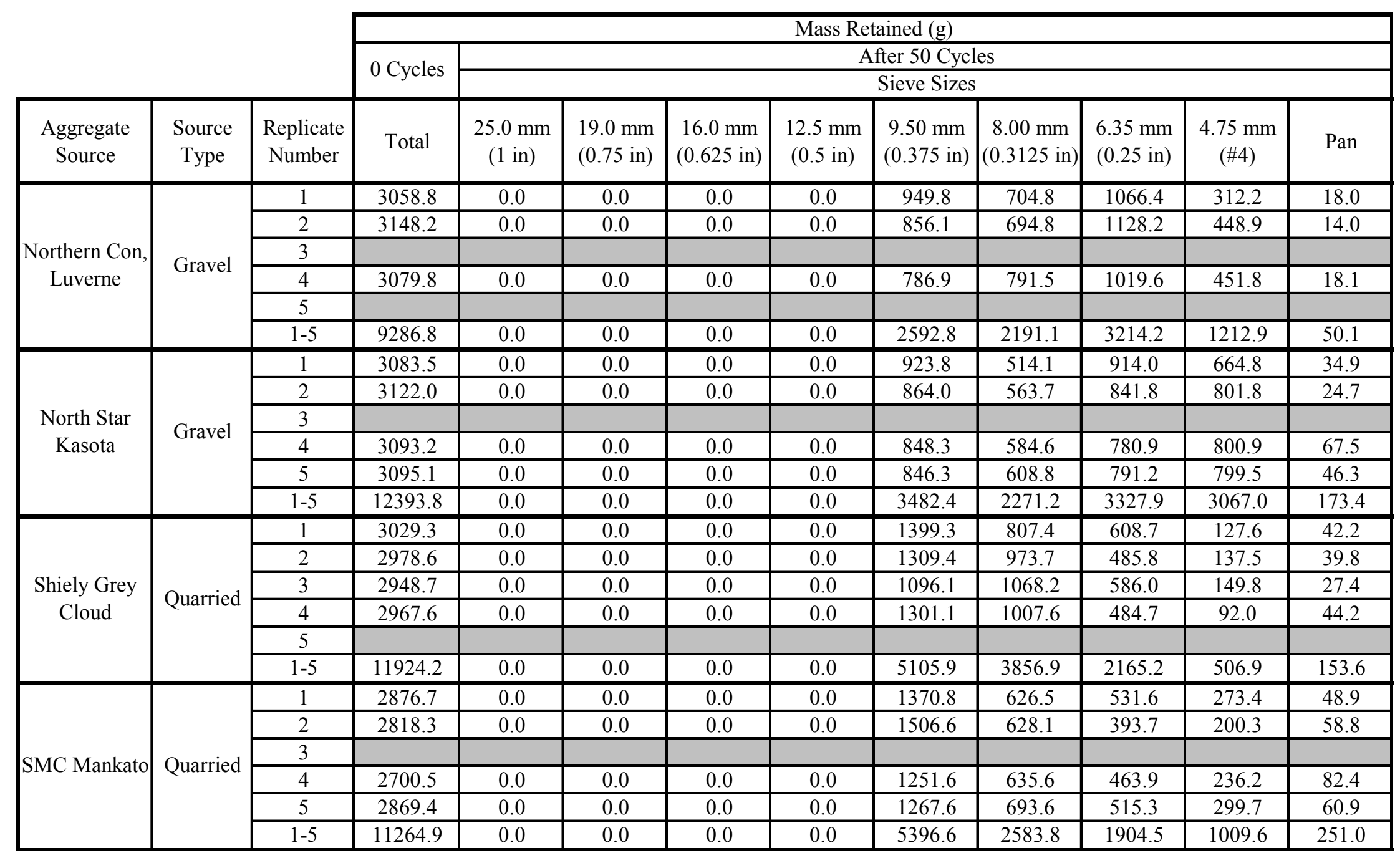


Table C.1. HFT results (mass retained) for small chamber samples (4.75 to $12.5 \mathrm{~mm}$ [\#4 to $0.5 \mathrm{in}]$ ) (continued).

\begin{tabular}{|c|c|c|c|c|c|c|c|c|c|c|c|c|}
\hline & & & \multicolumn{10}{|c|}{ Mass Retained (g) } \\
\hline & & & \multirow{2}{*}{0 Cycles } & \multicolumn{9}{|c|}{ After 50 Cycles } \\
\hline & & & & \multicolumn{9}{|c|}{ Sieve Sizes } \\
\hline $\begin{array}{l}\text { Aggregate } \\
\text { Source }\end{array}$ & $\begin{array}{c}\text { Source } \\
\text { Type }\end{array}$ & $\begin{array}{c}\text { Replicate } \\
\text { Number }\end{array}$ & Total & $\begin{array}{c}25.0 \mathrm{~mm} \\
(1 \mathrm{in})\end{array}$ & $\begin{array}{l}19.0 \mathrm{~mm} \\
(0.75 \mathrm{in})\end{array}$ & $\begin{array}{c}16.0 \mathrm{~mm} \\
(0.625 \mathrm{in})\end{array}$ & $\begin{array}{c}12.5 \mathrm{~mm} \\
(0.5 \mathrm{in})\end{array}$ & $\begin{array}{c}9.50 \mathrm{~mm} \\
(0.375 \mathrm{in})\end{array}$ & $\begin{array}{c}8.00 \mathrm{~mm} \\
(0.3125 \mathrm{in})\end{array}$ & $\begin{array}{l}6.35 \mathrm{~mm} \\
(0.25 \mathrm{in})\end{array}$ & $\begin{array}{l}4.75 \mathrm{~mm} \\
\quad(\# 4)\end{array}$ & Pan \\
\hline \multirow{6}{*}{ Swedberg } & \multirow{6}{*}{ Quarried } & 1 & 2688.9 & 0.0 & 0.0 & 0.0 & 0.0 & 950.7 & 539.1 & 640.6 & 474.3 & 71.2 \\
\hline & & 2 & 2597.3 & 0.0 & 0.0 & 0.0 & 0.0 & 935.2 & 592.2 & 554.6 & 452.1 & 53.4 \\
\hline & & 3 & 2559.8 & 0.0 & 0.0 & 0.0 & 0.0 & 885.6 & 572.7 & 594.8 & 435.1 & 55.6 \\
\hline & & 4 & 2577.3 & 0.0 & 0.0 & 0.0 & 0.0 & 841.3 & 520.5 & 651.1 & 488.0 & 59.9 \\
\hline & & 5 & 2601.3 & 0.0 & 0.0 & 0.0 & 0.0 & 877.1 & 593.1 & 560.0 & 480.7 & 75.5 \\
\hline & & $1-5$ & 13024.6 & 0.0 & 0.0 & 0.0 & 0.0 & 4489.9 & 2817.6 & 3001.1 & 2330.2 & 315.6 \\
\hline \multirow{6}{*}{$\begin{array}{c}\text { Ulland } \\
\text { Northwood }\end{array}$} & \multirow{6}{*}{ Quarried } & 1 & 2944.6 & 0.0 & 0.0 & 0.0 & 0.0 & 832.9 & 627.4 & 848.4 & 533.6 & 92.4 \\
\hline & & 2 & 2844.5 & 0.0 & 0.0 & 0.0 & 0.0 & 637.9 & 648.6 & 803.5 & 692.5 & 44.2 \\
\hline & & 3 & 2953.1 & 0.0 & 0.0 & 0.0 & 0.0 & 769.6 & 765.7 & 792.5 & 579.9 & 30.3 \\
\hline & & 4 & 2855.9 & 0.0 & 0.0 & 0.0 & 0.0 & 593.9 & 583.1 & 936.8 & 673.2 & 56.0 \\
\hline & & 5 & 2964.4 & 0.0 & 0.0 & 0.0 & 0.0 & 866.3 & 715.7 & 754.3 & 576.1 & 40.5 \\
\hline & & $1-5$ & 14562.5 & 0.0 & 0.0 & 0.0 & 0.0 & 3700.6 & 3340.5 & 4135.5 & 3055.3 & 263.4 \\
\hline \multirow{6}{*}{ Waterloo } & \multirow{6}{*}{ Quarried } & 1 & 3091.5 & 0.0 & 0.0 & 0.0 & 0.0 & 827.6 & 541.2 & 821.3 & 801.3 & 91.0 \\
\hline & & 2 & 2935.5 & 0.0 & 0.0 & 0.0 & 0.0 & 807.3 & 658.8 & 712.8 & 685.0 & 44.2 \\
\hline & & 3 & 2945.5 & 0.0 & 0.0 & 0.0 & 0.0 & 884.8 & 663.9 & 709.7 & 621.5 & 42.7 \\
\hline & & 4 & 2970.9 & 0.0 & 0.0 & 0.0 & 0.0 & 1108.7 & 741.6 & 622.2 & 454.4 & 26.7 \\
\hline & & 5 & 2872.0 & 0.0 & 0.0 & 0.0 & 0.0 & 865.1 & 618.8 & 678.0 & 653.3 & 40.1 \\
\hline & & $1-5$ & 14815.4 & 0.0 & 0.0 & 0.0 & 0.0 & 4493.5 & 3224.3 & 3544.0 & 3215.5 & 244.7 \\
\hline \multirow{6}{*}{ Zumbrota } & \multirow{6}{*}{ Quarried } & 1 & 3178.6 & 0.0 & 0.0 & 0.0 & 0.0 & 1742.6 & 658.4 & 564.7 & 158.0 & 33.5 \\
\hline & & 2 & 3182.3 & 0.0 & 0.0 & 0.0 & 0.0 & 1805.0 & 742.6 & 442.9 & 140.7 & 30.9 \\
\hline & & 3 & 3162.6 & 0.0 & 0.0 & 0.0 & 0.0 & 1678.7 & 802.5 & 439.9 & 174.4 & 39.7 \\
\hline & & 4 & 2790.0 & 0.0 & 0.0 & 0.0 & 0.0 & 1237.6 & 790.2 & 458.9 & 197.4 & 73.0 \\
\hline & & 5 & 3050.5 & 0.0 & 0.0 & 0.0 & 0.0 & 1468.8 & 804.6 & 469.1 & 204.2 & 74.4 \\
\hline & & $1-5$ & 15364.0 & 0.0 & 0.0 & 0.0 & 0.0 & 7932.7 & 3798.3 & 2375.5 & 874.7 & 251.5 \\
\hline
\end{tabular}


Table C.2. HFT results (normalized, mass retained) for small chamber samples (4.75 to $12.5 \mathrm{~mm}$ [\#4 to $0.5 \mathrm{in}]$ ).

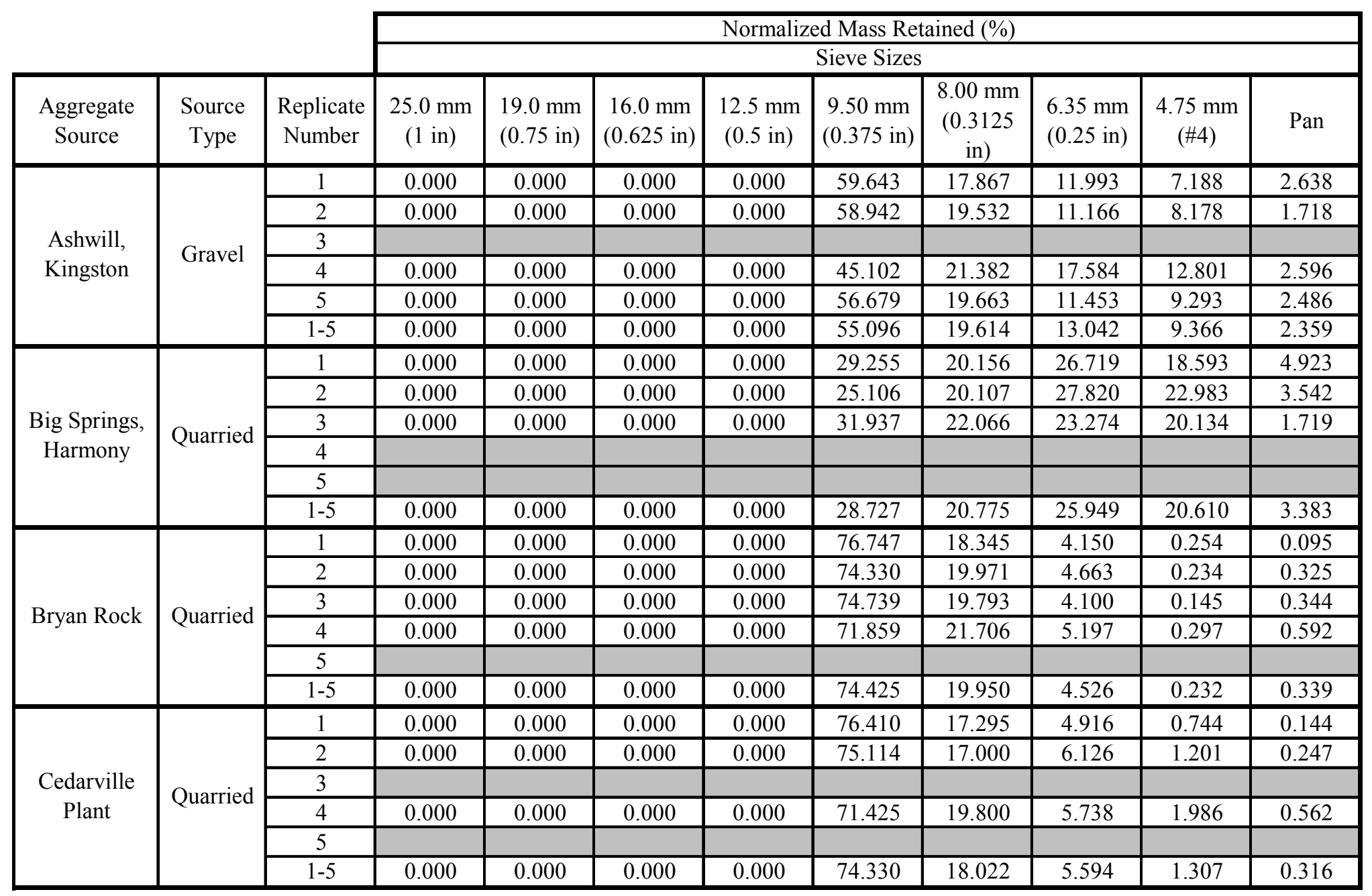


Table C.2. HFT results (normalized, mass retained) for small chamber samples (4.75 to $12.5 \mathrm{~mm}$ [\#4 to 0.5 in]) (cont.).

\begin{tabular}{|c|c|c|c|c|c|c|c|c|c|c|c|}
\hline \multirow{4}{*}{$\begin{array}{c}\text { Aggregate } \\
\text { Source }\end{array}$} & \multirow{4}{*}{$\begin{array}{c} \\
\text { Source } \\
\text { Type }\end{array}$} & \multirow{4}{*}{$\begin{array}{c} \\
\text { Replicate } \\
\text { Number }\end{array}$} & \\
\hline & & & & & & & & & & & \\
\hline & & & \multicolumn{9}{|c|}{$\begin{array}{c}\text { Normalized Mass Retained (\%) } \\
\text { Sieve Sizes } \\
\end{array}$} \\
\hline & & & $\begin{array}{l}25.0 \mathrm{~mm} \\
(1 \mathrm{in})\end{array}$ & $\begin{array}{l}19.0 \mathrm{~mm} \\
(0.75 \mathrm{in})\end{array}$ & $\begin{array}{c}16.0 \mathrm{~mm} \\
(0.625 \mathrm{in})\end{array}$ & $\begin{array}{l}12.5 \mathrm{~mm} \\
(0.5 \mathrm{in})\end{array}$ & $\begin{array}{c}9.50 \mathrm{~mm} \\
(0.375 \mathrm{in})\end{array} \mid$ & $\begin{array}{c}8.00 \mathrm{~mm} \\
(0.3125 \\
\text { in })\end{array}$ & $\begin{array}{l}6.35 \mathrm{~mm} \\
(0.25 \mathrm{in})\end{array}$ & $\begin{array}{l}4.75 \mathrm{~mm} \\
(\# 4)\end{array}$ & Pan \\
\hline \multirow{6}{*}{ Early Chapel } & \multirow{6}{*}{ Quarried } & 1 & 0.000 & 0.000 & 0.000 & 0.000 & 55.616 & 25.696 & 14.021 & 3.897 & 0.411 \\
\hline & & 2 & 0.000 & 0.000 & 0.000 & 0.000 & 55.650 & 26.951 & 13.105 & 2.967 & 0.701 \\
\hline & & 3 & 0.000 & 0.000 & 0.000 & 0.000 & 51.194 & 29.232 & 14.488 & 3.682 & 0.495 \\
\hline & & 4 & 0.000 & 0.000 & 0.000 & 0.000 & 58.289 & 25.393 & 11.862 & 3.029 & 0.652 \\
\hline & & 5 & 0.000 & 0.000 & 0.000 & 0.000 & 45.348 & 29.640 & 17.275 & 6.504 & 0.767 \\
\hline & & $1-5$ & 0.000 & 0.000 & 0.000 & 0.000 & 53.196 & 27.392 & 14.162 & 4.019 & 0.604 \\
\hline \multirow{6}{*}{$\begin{array}{c}\text { Edward } \\
\text { Kramer \& } \\
\text { Sons }\end{array}$} & \multirow{6}{*}{ Quarried } & 1 & 0.000 & 0.000 & 0.000 & 0.000 & 31.762 & 21.271 & 25.521 & 17.857 & 2.659 \\
\hline & & 2 & 0.000 & 0.000 & 0.000 & 0.000 & 27.216 & 24.461 & 24.014 & 20.208 & 2.868 \\
\hline & & 3 & & & & & & & & & \\
\hline & & 4 & 0.000 & 0.000 & 0.000 & 0.000 & 26.351 & 21.102 & 26.551 & 22.106 & 2.620 \\
\hline & & 5 & 0.000 & 0.000 & 0.000 & 0.000 & 28.124 & 23.839 & 24.317 & 19.498 & 3.194 \\
\hline & & $1-5$ & 0.000 & 0.000 & 0.000 & 0.000 & 28.415 & 22.660 & 25.098 & 19.880 & 2.835 \\
\hline \multirow{6}{*}{$\begin{array}{l}\text { Goldberg, } \\
\text { Rochester }\end{array}$} & \multirow{6}{*}{ Quarried } & 1 & 0.000 & 0.000 & 0.000 & 0.000 & 24.960 & 21.695 & 26.871 & 19.993 & 4.971 \\
\hline & & 2 & 0.000 & 0.000 & 0.000 & 0.000 & 28.082 & 24.616 & 23.833 & 19.998 & 2.411 \\
\hline & & 3 & 0.000 & 0.000 & 0.000 & 0.000 & 29.091 & 21.195 & 24.227 & 21.495 & 3.105 \\
\hline & & 4 & 0.000 & 0.000 & 0.000 & 0.000 & 22.970 & 21.974 & 24.102 & 23.234 & 6.538 \\
\hline & & 5 & & & & & & & & & \\
\hline & & $1-5$ & 0.000 & 0.000 & 0.000 & 0.000 & 26.285 & 22.383 & 24.756 & 21.171 & 4.246 \\
\hline \multirow{6}{*}{$\begin{array}{l}\text { Grand } \\
\text { Meadow }\end{array}$} & \multirow{6}{*}{ Quarried } & 1 & 0.000 & 0.000 & 0.000 & 0.000 & 51.515 & 22.874 & 20.317 & 3.529 & 0.342 \\
\hline & & 2 & 0.000 & 0.000 & 0.000 & 0.000 & 54.012 & 23.647 & 17.379 & 4.064 & 0.534 \\
\hline & & 3 & 0.000 & 0.000 & 0.000 & 0.000 & 49.124 & 24.767 & 18.439 & 6.061 & 0.537 \\
\hline & & 4 & 0.000 & 0.000 & 0.000 & 0.000 & 44.881 & 26.242 & 20.369 & 6.909 & 0.829 \\
\hline & & 5 & & & & & & & & & \\
\hline & & $1-5$ & 0.000 & 0.000 & 0.000 & 0.000 & 50.031 & 24.325 & 19.094 & 5.086 & 0.552 \\
\hline
\end{tabular}


Table C.2. HFT results (normalized, mass retained) for small chamber samples (4.75 to $12.5 \mathrm{~mm}$ [\#4 to 0.5 in]) (cont.).

\begin{tabular}{|c|c|c|c|c|c|c|c|c|c|c|c|}
\hline & & & \multirow{2}{*}{\multicolumn{9}{|c|}{ Normalized Mass Retained (\%) }} \\
\hline \multirow{3}{*}{$\begin{array}{l}\text { Aggregate } \\
\text { Source }\end{array}$} & \multirow[b]{3}{*}{$\begin{array}{l}\text { Source } \\
\text { Type }\end{array}$} & \multirow[b]{3}{*}{$\begin{array}{c}\text { Replicate } \\
\text { Number }\end{array}$} & & & & & & & & & \\
\hline & & & \multicolumn{9}{|c|}{ Sieve Sizes } \\
\hline & & & $\begin{array}{c}25.0 \mathrm{~mm} \\
(1 \mathrm{in})\end{array}$ & $\begin{array}{l}19.0 \mathrm{~mm} \\
(0.75 \mathrm{in})\end{array}$ & $\begin{array}{c}16.0 \mathrm{~mm} \\
(0.625 \mathrm{in})\end{array}$ & $\begin{array}{c}12.5 \mathrm{~mm} \\
(0.5 \mathrm{in})\end{array}$ & $\begin{array}{c}9.50 \mathrm{~mm} \\
(0.375 \mathrm{in})\end{array}$ & $\begin{array}{c}8.00 \mathrm{~mm} \\
(0.3125 \\
\text { in })\end{array}$ & $\begin{array}{l}6.35 \mathrm{~mm} \\
(0.25 \mathrm{in})\end{array}$ & $\begin{array}{c}4.75 \mathrm{~mm} \\
(\# 4)\end{array}$ & Pan \\
\hline \multirow{6}{*}{ Halma } & \multirow{6}{*}{ Gravel } & 1 & 0.000 & 0.000 & 0.000 & 0.000 & 44.626 & 26.673 & 22.477 & 5.744 & 0.346 \\
\hline & & 2 & 0.000 & 0.000 & 0.000 & 0.000 & 42.537 & 28.045 & 21.956 & 6.822 & 0.373 \\
\hline & & 3 & 0.000 & 0.000 & 0.000 & 0.000 & 45.412 & 24.980 & 21.812 & 6.939 & 0.575 \\
\hline & & 4 & 0.000 & 0.000 & 0.000 & 0.000 & 47.568 & 21.032 & 24.664 & 6.164 & 0.370 \\
\hline & & 5 & 0.000 & 0.000 & 0.000 & 0.000 & 44.754 & 25.592 & 22.522 & 6.196 & 0.548 \\
\hline & & $1-5$ & 0.000 & 0.000 & 0.000 & 0.000 & 44.973 & 25.278 & 22.684 & 6.370 & 0.442 \\
\hline \multirow{6}{*}{$\begin{array}{l}\text { Johnson, } \\
\text { Henderson }\end{array}$} & \multirow{6}{*}{ Gravel } & 1 & 0.000 & 0.000 & 0.000 & 0.000 & 50.175 & 26.102 & 20.828 & 2.279 & 0.186 \\
\hline & & 2 & 0.000 & 0.000 & 0.000 & 0.000 & 44.960 & 30.216 & 20.488 & 3.267 & 0.498 \\
\hline & & 3 & & & & & & & & & \\
\hline & & 4 & 0.000 & 0.000 & 0.000 & 0.000 & 45.013 & 31.311 & 19.699 & 3.201 & 0.353 \\
\hline & & 5 & 0.000 & 0.000 & 0.000 & 0.000 & 47.805 & 29.286 & 18.988 & 3.082 & 0.659 \\
\hline & & $1-5$ & 0.000 & 0.000 & 0.000 & 0.000 & 46.936 & 29.269 & 19.997 & 2.968 & 0.427 \\
\hline \multirow{6}{*}{$\begin{array}{c}\text { Johnson, Le } \\
\text { Sueur }\end{array}$} & \multirow{6}{*}{ Gravel } & 1 & 0.000 & 0.000 & 0.000 & 0.000 & 27.481 & 23.811 & 34.030 & 12.815 & 1.541 \\
\hline & & 2 & 0.000 & 0.000 & 0.000 & 0.000 & 30.590 & 26.563 & 29.004 & 11.822 & 1.391 \\
\hline & & 3 & & & & & & & & & \\
\hline & & 4 & 0.000 & 0.000 & 0.000 & 0.000 & 29.982 & 27.202 & 27.978 & 12.655 & 1.438 \\
\hline & & 5 & 0.000 & 0.000 & 0.000 & 0.000 & 30.563 & 28.328 & 29.928 & 9.793 & 1.168 \\
\hline & & $1-5$ & 0.000 & 0.000 & 0.000 & 0.000 & 29.655 & 26.484 & 30.243 & 11.758 & 1.383 \\
\hline \multirow{6}{*}{$\begin{array}{c}\text { Mark, } \\
\text { Underwood }\end{array}$} & \multirow{6}{*}{ Gravel } & 1 & 0.000 & 0.000 & 0.000 & 0.000 & 41.997 & 26.341 & 24.102 & 6.549 & 0.880 \\
\hline & & 2 & 0.000 & 0.000 & 0.000 & 0.000 & 47.832 & 26.756 & 19.645 & 5.216 & 0.330 \\
\hline & & 3 & 0.000 & 0.000 & 0.000 & 0.000 & 42.229 & 29.753 & 21.266 & 6.211 & 0.333 \\
\hline & & 4 & 0.000 & 0.000 & 0.000 & 0.000 & 41.636 & 27.695 & 23.361 & 6.623 & 0.511 \\
\hline & & 5 & & & & & & & & & \\
\hline & & $1-5$ & 0.000 & 0.000 & 0.000 & 0.000 & 43.409 & 27.640 & 22.101 & 6.153 & 0.513 \\
\hline
\end{tabular}


Table C.2. HFT results (normalized, mass retained) for small chamber samples (4.75 to $12.5 \mathrm{~mm}$ [\#4 to 0.5 in]) (cont.).

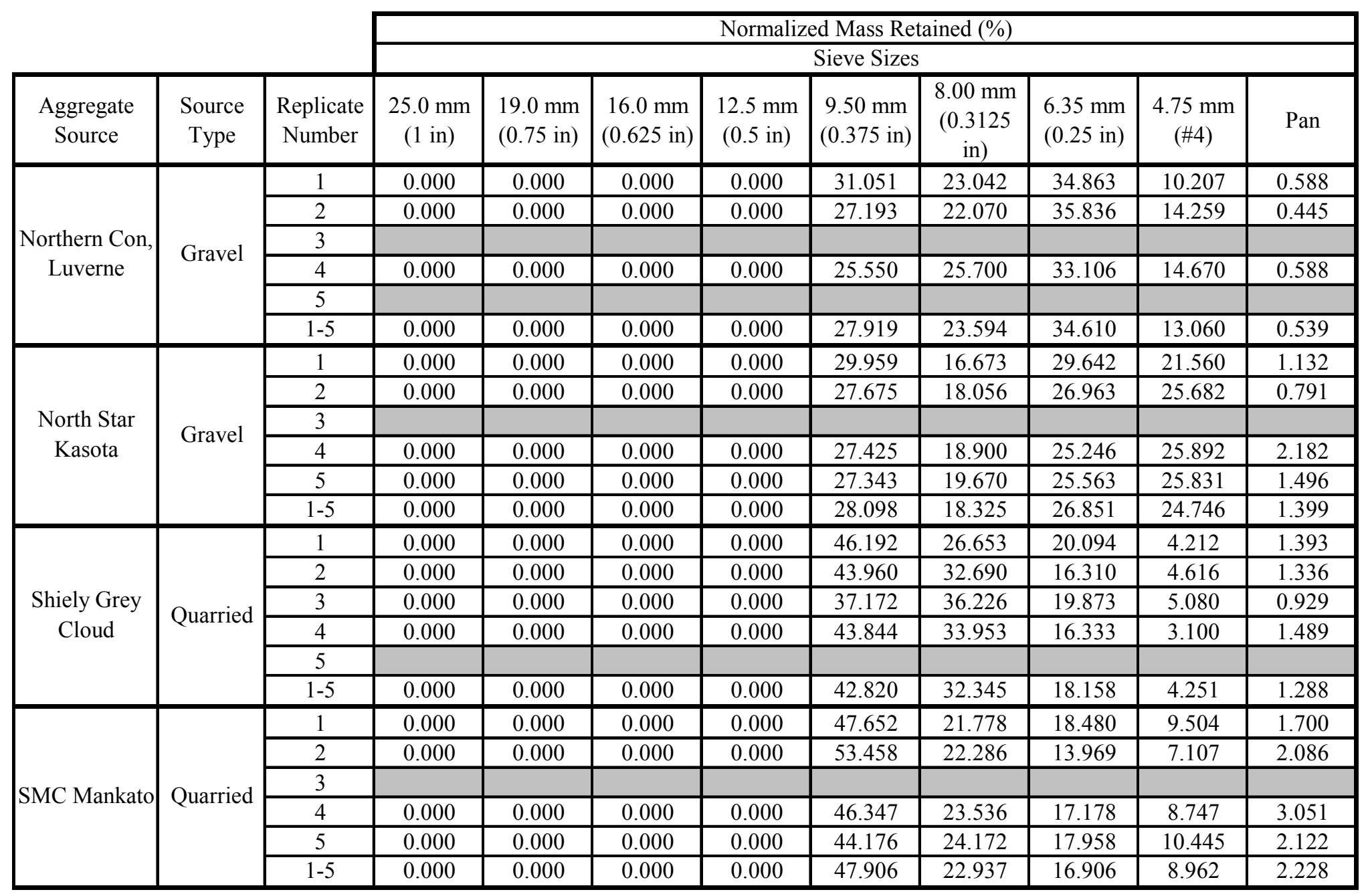


Table C.2. HFT results (normalized, mass retained) for small chamber samples (4.75 to $12.5 \mathrm{~mm}$ [\#4 to 0.5 in]) (cont.).

\begin{tabular}{|c|c|c|c|c|c|c|c|c|c|c|c|}
\hline \multirow{3}{*}{$\begin{array}{l}\text { Aggregate } \\
\text { Source }\end{array}$} & \multirow[b]{3}{*}{$\begin{array}{c}\text { Source } \\
\text { Type }\end{array}$} & \multirow[b]{3}{*}{$\begin{array}{l}\text { Replicate } \\
\text { Number }\end{array}$} & \multicolumn{9}{|c|}{ Normalized Mass Retained (\%) } \\
\hline & & & \multicolumn{9}{|c|}{ Sieve Sizes } \\
\hline & & & $\begin{array}{c}25.0 \mathrm{~mm} \\
\quad(1 \mathrm{in})\end{array}$ & $\begin{array}{l}19.0 \mathrm{~mm} \\
(0.75 \mathrm{in})\end{array}$ & $\begin{array}{c}16.0 \mathrm{~mm} \\
(0.625 \mathrm{in})\end{array}$ & $\begin{array}{c}12.5 \mathrm{~mm} \\
(0.5 \mathrm{in})\end{array}$ & $\begin{array}{c}9.50 \mathrm{~mm} \\
(0.375 \mathrm{in})\end{array}$ & $\begin{array}{c}8.00 \mathrm{~mm} \\
(0.3125 \\
\text { in })\end{array}$ & $\begin{array}{l}6.35 \mathrm{~mm} \\
(0.25 \mathrm{in})\end{array}$ & $\begin{array}{l}4.75 \mathrm{~mm} \\
\quad(\# 4)\end{array}$ & Pan \\
\hline \multirow{6}{*}{ Swedberg } & \multirow{6}{*}{ Quarried } & 1 & 0.000 & 0.000 & 0.000 & 0.000 & 35.356 & 20.049 & 23.824 & 17.639 & 2.648 \\
\hline & & 2 & 0.000 & 0.000 & 0.000 & 0.000 & 36.007 & 22.801 & 21.353 & 17.407 & 2.056 \\
\hline & & 3 & 0.000 & 0.000 & 0.000 & 0.000 & 34.596 & 22.373 & 23.236 & 16.997 & 2.172 \\
\hline & & 4 & 0.000 & 0.000 & 0.000 & 0.000 & 32.643 & 20.196 & 25.263 & 18.935 & 2.324 \\
\hline & & 5 & 0.000 & 0.000 & 0.000 & 0.000 & 33.719 & 22.800 & 21.528 & 18.479 & 2.902 \\
\hline & & $1-5$ & 0.000 & 0.000 & 0.000 & 0.000 & 34.473 & 21.633 & 23.042 & 17.891 & 2.423 \\
\hline \multirow{6}{*}{$\begin{array}{c}\text { Ulland } \\
\text { Northwood }\end{array}$} & \multirow{6}{*}{ Quarried } & 1 & 0.000 & 0.000 & 0.000 & 0.000 & 28.286 & 21.307 & 28.812 & 18.121 & 3.138 \\
\hline & & 2 & 0.000 & 0.000 & 0.000 & 0.000 & 22.426 & 22.802 & 28.247 & 24.345 & 1.554 \\
\hline & & 3 & 0.000 & 0.000 & 0.000 & 0.000 & 26.061 & 25.929 & 26.836 & 19.637 & 1.026 \\
\hline & & 4 & 0.000 & 0.000 & 0.000 & 0.000 & 20.796 & 20.417 & 32.802 & 23.572 & 1.961 \\
\hline & & 5 & 0.000 & 0.000 & 0.000 & 0.000 & 29.223 & 24.143 & 25.445 & 19.434 & 1.366 \\
\hline & & $1-5$ & 0.000 & 0.000 & 0.000 & 0.000 & 25.412 & 22.939 & 28.398 & 20.981 & 1.809 \\
\hline \multirow{6}{*}{ Waterloo } & \multirow{6}{*}{ Quarried } & 1 & 0.000 & 0.000 & 0.000 & 0.000 & 26.770 & 17.506 & 26.566 & 25.919 & 2.944 \\
\hline & & 2 & 0.000 & 0.000 & 0.000 & 0.000 & 27.501 & 22.443 & 24.282 & 23.335 & 1.506 \\
\hline & & 3 & 0.000 & 0.000 & 0.000 & 0.000 & 30.039 & 22.539 & 24.094 & 21.100 & 1.450 \\
\hline & & 4 & 0.000 & 0.000 & 0.000 & 0.000 & 37.319 & 24.962 & 20.943 & 15.295 & 0.899 \\
\hline & & 5 & 0.000 & 0.000 & 0.000 & 0.000 & 30.122 & 21.546 & 23.607 & 22.747 & 1.396 \\
\hline & & $1-5$ & 0.000 & 0.000 & 0.000 & 0.000 & 30.330 & 21.763 & 23.921 & 21.704 & 1.652 \\
\hline \multirow{6}{*}{ Zumbrota } & \multirow{6}{*}{ Quarried } & 1 & 0.000 & 0.000 & 0.000 & 0.000 & 54.823 & 20.714 & 17.766 & 4.971 & 1.054 \\
\hline & & 2 & 0.000 & 0.000 & 0.000 & 0.000 & 56.720 & 23.335 & 13.918 & 4.421 & 0.971 \\
\hline & & 3 & 0.000 & 0.000 & 0.000 & 0.000 & 53.080 & 25.375 & 13.909 & 5.514 & 1.255 \\
\hline & & 4 & 0.000 & 0.000 & 0.000 & 0.000 & 44.358 & 28.323 & 16.448 & 7.075 & 2.616 \\
\hline & & 5 & 0.000 & 0.000 & 0.000 & 0.000 & 48.149 & 26.376 & 15.378 & 6.694 & 2.439 \\
\hline & & $1-5$ & 0.000 & 0.000 & 0.000 & 0.000 & 51.632 & 24.722 & 15.461 & 5.693 & 1.637 \\
\hline
\end{tabular}


Table C.3. HFT results (mass retained) for small chamber samples (12.5 to $19.0 \mathrm{~mm}$ [0.5 to $0.75 \mathrm{in}]$ ).

\begin{tabular}{|c|c|c|c|c|c|c|c|c|c|c|c|c|}
\hline & & \multicolumn{10}{|c|}{ Mass Retained (g) } \\
\hline & & & \multirow{2}{*}{0 Cycles } & \multicolumn{9}{|c|}{ After 50 Cycles } \\
\hline & & & & \multicolumn{9}{|c|}{ Sieve Sizes } \\
\hline $\begin{array}{l}\text { Aggregate } \\
\text { Source }\end{array}$ & $\begin{array}{l}\text { Source } \\
\text { Type }\end{array}$ & $\begin{array}{c}\text { Replicate } \\
\text { Number }\end{array}$ & Total & $\begin{array}{c}25.0 \mathrm{~mm} \\
(1 \mathrm{in})\end{array}$ & $\begin{array}{l}19.0 \mathrm{~mm} \\
(0.75 \mathrm{in})\end{array}$ & $\begin{array}{l}16.0 \mathrm{~mm} \\
(0.625 \mathrm{in})\end{array}$ & $\begin{array}{c}12.5 \mathrm{~mm} \\
(0.5 \mathrm{in})\end{array}$ & $\begin{array}{l}9.50 \mathrm{~mm} \\
(0.375 \mathrm{in})\end{array}$ & $\begin{array}{c}8.00 \mathrm{~mm} \\
(0.3125 \mathrm{in})\end{array}$ & $\begin{array}{l}6.35 \mathrm{~mm} \\
(0.25 \mathrm{in})\end{array}$ & $\begin{array}{l}4.75 \mathrm{~mm} \\
\quad(\# 4)\end{array}$ & Pan \\
\hline \multirow{6}{*}{$\begin{array}{l}\text { Ashwill, } \\
\text { Kingston }\end{array}$} & \multirow{6}{*}{ Gravel } & 1 & 3090.7 & 0.0 & 0.0 & 610.7 & 1889.5 & 564.3 & 7.1 & 2.9 & 0.8 & 7.7 \\
\hline & & 2 & 3076.2 & 0.0 & 0.0 & 700.8 & 1848.1 & 512.3 & 0.5 & 1.1 & 0.0 & 6.8 \\
\hline & & 3 & 3093.6 & 0.0 & 0.0 & 633.7 & 1976.9 & 459.9 & 2.7 & 2.1 & 1.9 & 14.4 \\
\hline & & 4 & 3059.7 & 0.0 & 0.0 & 618.4 & 1964.0 & 435.2 & 6.7 & 1.9 & 2.2 & 15.5 \\
\hline & & 5 & 3000.0 & 0.0 & 0.0 & 569.9 & 1927.0 & 463.6 & 2.4 & 1.1 & 0.0 & 11.5 \\
\hline & & $1-5$ & 15320.2 & 0.0 & 0.0 & 3133.5 & 9605.5 & 2435.3 & 19.4 & 9.1 & 4.9 & 55.9 \\
\hline \multirow{6}{*}{$\begin{array}{c}\text { Big Springs, } \\
\text { Harmony }\end{array}$} & \multirow{6}{*}{ Quarried } & 1 & 3051.1 & 0.0 & 0.0 & 1092.0 & 1542.9 & 381.9 & 1.4 & 2.5 & 0.5 & 3.9 \\
\hline & & 2 & 3122.0 & 0.0 & 0.0 & 1122.7 & 1509.4 & 464.9 & 0.0 & 0.6 & 1.2 & 12.7 \\
\hline & & 3 & 3167.5 & 0.0 & 0.0 & 1003.1 & 1714.6 & 411.7 & 4.8 & 3.3 & 1.4 & 16.5 \\
\hline & & 4 & 3093.5 & 0.0 & 0.0 & 938.9 & 1617.5 & 492.0 & 2.0 & 2.2 & 1.5 & 22.9 \\
\hline & & 5 & 3146.4 & 0.0 & 0.0 & 1311.2 & 1393.9 & 399.5 & 1.2 & 1.8 & 0.9 & 17.8 \\
\hline & & $1-5$ & 15580.5 & 0.0 & 0.0 & 5467.9 & 7778.3 & 2150.0 & 9.4 & 10.4 & 5.5 & 73.8 \\
\hline \multirow{6}{*}{ Bryan Rock } & \multirow{6}{*}{ Quarried } & 1 & 3170.3 & 0.0 & 0.0 & 1345.0 & 1581.2 & 225.7 & 0.0 & 0.0 & 0.0 & 3.1 \\
\hline & & 2 & 3002.0 & 0.0 & 0.0 & 1108.8 & 1599.3 & 269.1 & 0.0 & 0.0 & 0.0 & 11.1 \\
\hline & & 3 & 3101.8 & 0.0 & 0.0 & 948.4 & 1773.7 & 337.4 & 0.0 & 0.0 & 0.0 & 10.4 \\
\hline & & 4 & 3216.6 & 0.0 & 0.0 & 1051.5 & 1739.2 & 403.3 & 0.0 & 0.0 & 0.0 & 9.5 \\
\hline & & 5 & 3015.1 & 0.0 & 0.0 & 894.7 & 1653.4 & 419.3 & 0.0 & 0.3 & 0.2 & 26.6 \\
\hline & & $1-5$ & 15505.8 & 0.0 & 0.0 & 5348.4 & 8346.8 & 1654.8 & 0.0 & 0.3 & 0.2 & 60.7 \\
\hline \multirow{6}{*}{$\begin{array}{l}\text { Cedarville } \\
\text { Plant }\end{array}$} & \multirow{6}{*}{ Quarried } & 1 & 3095.2 & 0.0 & 0.0 & 766.1 & 1559.3 & 747.0 & 4.4 & 0.7 & 0.0 & 6.0 \\
\hline & & 2 & 3039.8 & 0.0 & 0.0 & 978.5 & 1425.9 & 611.9 & 4.0 & 2.1 & 0.0 & 13.4 \\
\hline & & 3 & 3132.2 & 0.0 & 0.0 & 933.7 & 1650.1 & 521.5 & 5.0 & 0.5 & 0.0 & 11.2 \\
\hline & & 4 & 3021.2 & 0.0 & 0.0 & 871.4 & 1641.7 & 486.6 & 0.0 & 1.2 & 0.1 & 6.5 \\
\hline & & 5 & 3065.5 & 0.0 & 0.0 & 848.7 & 1559.5 & 623.4 & 4.0 & 0.3 & 0.3 & 15.8 \\
\hline & & $1-5$ & 15353.9 & 0.0 & 0.0 & 4398.4 & 7836.5 & 2990.4 & 17.4 & 4.8 & 0.4 & 52.9 \\
\hline
\end{tabular}


Table C.3. HFT results (mass retained) for small chamber samples (12.5 to $19.0 \mathrm{~mm}$ [0.5 to 0.75 in]) (continued).

\begin{tabular}{|c|c|c|c|c|c|c|c|c|c|c|c|c|}
\hline & & & \multirow{2}{*}{\multicolumn{10}{|c|}{ Mass Retained (g) }} \\
\hline & & & & & & & & & & & & \\
\hline & & & \multirow{2}{*}{0 Cycles } & \multicolumn{9}{|c|}{ After 50 Cycles } \\
\hline & & & & \multicolumn{9}{|c|}{ Sieve Sizes } \\
\hline $\begin{array}{l}\text { Aggregate } \\
\text { Source }\end{array}$ & $\begin{array}{l}\text { Source } \\
\text { Type }\end{array}$ & $\begin{array}{l}\text { Replicate } \\
\text { Number }\end{array}$ & Total & $\begin{array}{c}25.0 \mathrm{~mm} \\
(1 \mathrm{in})\end{array}$ & $\begin{array}{l}19.0 \mathrm{~mm} \\
(0.75 \mathrm{in})\end{array}$ & $\begin{array}{c}16.0 \mathrm{~mm} \\
(0.625 \mathrm{in})\end{array}$ & $\begin{array}{c}12.5 \mathrm{~mm} \\
(0.5 \mathrm{in})\end{array}$ & $\begin{array}{c}9.50 \mathrm{~mm} \\
(0.375 \mathrm{in})\end{array}$ & $\begin{array}{c}8.00 \mathrm{~mm} \\
(0.3125 \mathrm{in})\end{array}$ & $\begin{array}{l}6.35 \mathrm{~mm} \\
(0.25 \mathrm{in})\end{array}$ & $\begin{array}{c}4.75 \mathrm{~mm} \\
(\# 4)\end{array}$ & Pan \\
\hline \multirow{6}{*}{ Early Chapel } & \multirow{6}{*}{ Quarried } & 1 & 3163.3 & 0.0 & 0.0 & 1558.3 & 1450.6 & 136.7 & 0.0 & 0.4 & 0.4 & 5.6 \\
\hline & & 2 & 3186.9 & 0.0 & 0.0 & 1134.0 & 1699.3 & 321.4 & 1.2 & 3.0 & 0.0 & 17.5 \\
\hline & & 3 & 3451.5 & 0.0 & 0.0 & 1425.7 & 1614.0 & 342.5 & 11.0 & 3.0 & 1.7 & 27.6 \\
\hline & & 4 & 3011.8 & 0.0 & 0.0 & 1407.6 & 1359.0 & 216.9 & 0.0 & 0.0 & 0.0 & 14.8 \\
\hline & & 5 & 3255.2 & 0.0 & 0.0 & 1388.2 & 1528.6 & 260.0 & 10.1 & 6.6 & 3.1 & 35.3 \\
\hline & & $1-5$ & 16068.7 & 0.0 & 0.0 & 6913.8 & 7651.5 & 1277.5 & 22.3 & 13.0 & 5.2 & 100.8 \\
\hline \multirow{6}{*}{$\begin{array}{c}\text { Edward } \\
\text { Kramer \& } \\
\text { Sons }\end{array}$} & \multirow{6}{*}{ Quarried } & 1 & 2813.8 & 0.0 & 0.0 & 1143.0 & 1268.9 & 341.3 & 3.9 & 5.5 & 3.2 & 27.5 \\
\hline & & 2 & 2789.4 & 0.0 & 0.0 & 981.8 & 1338.8 & 409.4 & 4.6 & 0.8 & 1.4 & 28.9 \\
\hline & & $3 *$ & 2897.8 & 0.0 & 0.0 & 1222.3 & 1287.6 & 313.0 & 5.3 & 2.1 & 2.0 & 35.6 \\
\hline & & 4 & 2790.9 & 0.0 & 0.0 & 924.6 & 1295.1 & 485.8 & 3.7 & 4.1 & 1.3 & 46.7 \\
\hline & & 5 & & & & & & & & & & \\
\hline & & $1-5$ & 8394.1 & 0.0 & 0.0 & 3049.4 & 3902.8 & 1236.5 & 12.2 & 10.4 & 5.9 & 103.1 \\
\hline \multirow{6}{*}{$\begin{array}{l}\text { Goldberg, } \\
\text { Rochester }\end{array}$} & \multirow{6}{*}{ Quarried } & 1 & 2782.7 & 0.0 & 0.0 & 1025.5 & 1248.0 & 436.1 & 3.0 & 0.5 & 0.7 & 30.3 \\
\hline & & 2 & & & & & & & & & & \\
\hline & & 3 & 2978.6 & 0.0 & 0.0 & 1063.9 & 1446.7 & 406.5 & 3.7 & 0.8 & 0.4 & 30.7 \\
\hline & & 4 & 2969.2 & 0.0 & 0.0 & 1118.5 & 1273.9 & 508.3 & 2.8 & 1.6 & 0.5 & 41.2 \\
\hline & & 5 & 2870.9 & 0.0 & 0.0 & 1029.3 & 1307.4 & 448.6 & 0.7 & 5.8 & 1.5 & 47.9 \\
\hline & & $1-5$ & 11601.4 & 0.0 & 0.0 & 4237.2 & 5276.0 & 1799.5 & 10.2 & 8.7 & 3.1 & 150.1 \\
\hline \multirow{6}{*}{$\begin{array}{l}\text { Grand } \\
\text { Meadow }\end{array}$} & \multirow{6}{*}{ Quarried } & 1 & 3103 & 0.0 & 0.0 & 989.5 & 1667.5 & 337.5 & 2.1 & 1.1 & 0.8 & 3.2 \\
\hline & & 2 & 3064.6 & 0.0 & 0.0 & 695.0 & 1835.7 & 498.5 & 0.7 & 0.9 & 0.0 & 12.1 \\
\hline & & 3 & 3262.8 & 0.0 & 0.0 & 766.1 & 1837.0 & 615.9 & 3.8 & 1.4 & 0.5 & 21.3 \\
\hline & & 4 & 3147.3 & 0.0 & 0.0 & 716.7 & 1853.1 & 536.5 & 2.2 & 0.0 & 0.7 & 15.2 \\
\hline & & 5 & 3062.2 & 0.0 & 0.0 & 754.7 & 1773.8 & 481.3 & 6.6 & 0.4 & 0.9 & 22.4 \\
\hline & & $1-5$ & 15639.9 & 0.0 & 0.0 & 3922.0 & 8967.1 & 2469.7 & 15.4 & 3.8 & 2.9 & 74.2 \\
\hline
\end{tabular}


Table C.3. HFT results (mass retained) for small chamber samples (12.5 to $19.0 \mathrm{~mm}$ [0.5 to $0.75 \mathrm{in}]$ ) (continued).

\begin{tabular}{|c|c|c|c|c|c|c|c|c|c|c|c|c|}
\hline & & & \multicolumn{10}{|c|}{ Mass Retained (g) } \\
\hline & & & \multirow{2}{*}{0 Cycles } & \multicolumn{9}{|c|}{ After 50 Cycles } \\
\hline & & & & \multicolumn{9}{|c|}{ Sieve Sizes } \\
\hline $\begin{array}{l}\text { Aggregate } \\
\text { Source }\end{array}$ & $\begin{array}{l}\text { Source } \\
\text { Type }\end{array}$ & $\begin{array}{c}\text { Replicate } \\
\text { Number }\end{array}$ & Total & $\begin{array}{l}25.0 \mathrm{~mm} \\
(1 \mathrm{in})\end{array}$ & $\begin{array}{l}19.0 \mathrm{~mm} \\
(0.75 \mathrm{in})\end{array}$ & $\begin{array}{c}16.0 \mathrm{~mm} \\
(0.625 \mathrm{in})\end{array}$ & $\begin{array}{c}12.5 \mathrm{~mm} \\
(0.5 \mathrm{in})\end{array}$ & $\begin{array}{l}9.50 \mathrm{~mm} \\
(0.375 \mathrm{in})\end{array}$ & $\begin{array}{c}8.00 \mathrm{~mm} \\
(0.3125 \mathrm{in})\end{array}$ & $\begin{array}{l}6.35 \mathrm{~mm} \\
(0.25 \mathrm{in})\end{array}$ & $\begin{array}{l}4.75 \mathrm{~mm} \\
(\# 4)\end{array}$ & Pan \\
\hline \multirow{6}{*}{ Halma } & \multirow{6}{*}{ Gravel } & 1 & 3120.5 & 0.0 & 11.2 & 1367.8 & 1512.1 & 206.5 & 0.0 & 0.9 & 0.6 & 8.0 \\
\hline & & 2 & 3023.0 & 0.0 & 0.0 & 1419.8 & 1455.8 & 126.2 & 2.5 & 1.4 & 1.1 & 10.2 \\
\hline & & 3 & 3028.4 & 0.0 & 0.0 & 1418.8 & 1415.0 & 173.6 & 1.2 & 1.7 & 0.3 & 9.1 \\
\hline & & 4 & 3051.4 & 0.0 & 0.0 & 1341.2 & 1469.8 & 221.4 & 2.3 & 0.0 & 0.2 & 6.8 \\
\hline & & 5 & 3126.3 & 0.0 & 0.0 & 1438.3 & 1482.9 & 130.0 & 1.3 & 1.3 & 0.9 & 9.6 \\
\hline & & $1-5$ & 12229.1 & 0.0 & 0.0 & 5618.1 & 5823.5 & 651.2 & 7.3 & 4.4 & 2.5 & 35.7 \\
\hline \multirow{6}{*}{$\begin{array}{l}\text { Johnson, } \\
\text { Henderson }\end{array}$} & \multirow{6}{*}{ Gravel } & 1 & 3011.7 & 0.0 & 0.0 & 1269.7 & 1553.9 & 153.3 & 8.8 & 0.4 & 0.3 & 4.1 \\
\hline & & 2 & 3335.8 & 0.0 & 0.0 & 1073.0 & 1883.4 & 348.9 & 1.3 & 2.4 & 0.7 & 10.3 \\
\hline & & 3 & 3287.7 & 0.0 & 0.0 & 1125.6 & 1758.1 & 378.5 & 3.1 & 0.7 & 0.7 & 8.9 \\
\hline & & 4 & 3337.3 & 0.0 & 0.0 & 1034.6 & 1880.2 & 388.4 & 5.0 & 2.5 & 1.1 & 13.8 \\
\hline & & 5 & 3350.6 & 0.0 & 0.0 & 973.2 & 1859.7 & 466.2 & 4.5 & 0.0 & 0.8 & 8.8 \\
\hline & & $1-5$ & 16323.1 & 0.0 & 0.0 & 5476.1 & 8935.3 & 1735.3 & 22.7 & 6.0 & 3.6 & 45.9 \\
\hline \multirow{6}{*}{$\begin{array}{l}\text { Johnson, Le } \\
\text { Sueur }\end{array}$} & \multirow{6}{*}{ Gravel } & 1 & 3050.3 & 0.0 & 0.0 & 1408.2 & 1363.0 & 256.9 & 0.3 & 3.8 & 0.8 & 6.9 \\
\hline & & 2 & 3018.8 & 0.0 & 0.0 & 1252.2 & 1507.5 & 216.3 & 3.2 & 5.7 & 2.5 & 18.0 \\
\hline & & 3 & 3017.7 & 0.0 & 0.0 & 1304.7 & 1486.2 & 201.4 & 3.9 & 1.2 & 3.4 & 13.7 \\
\hline & & 4 & 3080.1 & 0.0 & 0.0 & 1379.5 & 1473.2 & 197.3 & 1.8 & 1.5 & 1.6 & 12.8 \\
\hline & & 5 & 3094.2 & 0.0 & 0.0 & 1210.8 & 1631.3 & 217.3 & 1.1 & 2.0 & 0.6 & 12.9 \\
\hline & & $1-5$ & 15261.1 & 0.0 & 0.0 & 6555.4 & 7461.2 & 1089.2 & 10.3 & 14.2 & 8.9 & 64.3 \\
\hline \multirow{6}{*}{$\begin{array}{c}\text { Mark, } \\
\text { Underwood }\end{array}$} & \multirow{6}{*}{ Gravel } & 1 & 3081.9 & 0.0 & 0.0 & 1543.7 & 1321.8 & 195.1 & 3.1 & 1.6 & 0.4 & 2.9 \\
\hline & & 2 & 3164.8 & 0.0 & 0.0 & 1606.9 & 1402.5 & 136.9 & 2.4 & 3.7 & 1.0 & 9.4 \\
\hline & & 3 & 3087.6 & 0.0 & 0.0 & 1491.2 & 1414.2 & 159.2 & 0.0 & 2.1 & 1.0 & 11.2 \\
\hline & & 4 & 3013.2 & 0.0 & 0.0 & 1237.5 & 1592.8 & 161.4 & 3.6 & 1.3 & 0.6 & 8.3 \\
\hline & & 5 & 3034.2 & 0.0 & 0.0 & 950.0 & 1789.0 & 277.5 & 0.0 & 0.9 & 0.9 & 6.2 \\
\hline & & $1-5$ & 15381.7 & 0.0 & 0.0 & 6829.3 & 7520.3 & 930.1 & 9.1 & 9.6 & 3.9 & 38.0 \\
\hline
\end{tabular}


Table C.3. HFT results (mass retained) for small chamber samples (12.5 to $19.0 \mathrm{~mm}$ [0.5 to $0.75 \mathrm{in}]$ ) (continued).

\begin{tabular}{|c|c|c|c|c|c|c|c|c|c|c|c|c|}
\hline & & & \multirow{2}{*}{\multicolumn{10}{|c|}{ Mass Retained (g) }} \\
\hline & & & & & & & & & & & & \\
\hline & & & \multirow{2}{*}{0 Cycles } & \multicolumn{9}{|c|}{ After 50 Cycles } \\
\hline & & & & \multicolumn{9}{|c|}{ Sieve Sizes } \\
\hline $\begin{array}{l}\text { Aggregate } \\
\text { Source }\end{array}$ & $\begin{array}{l}\text { Source } \\
\text { Type }\end{array}$ & $\begin{array}{c}\text { Replicate } \\
\text { Number }\end{array}$ & Total & $\begin{array}{l}25.0 \mathrm{~mm} \\
(1 \mathrm{in})\end{array}$ & $\begin{array}{l}19.0 \mathrm{~mm} \\
(0.75 \mathrm{in})\end{array}$ & $\begin{array}{c}16.0 \mathrm{~mm} \\
(0.625 \mathrm{in})\end{array}$ & $\begin{array}{c}12.5 \mathrm{~mm} \\
(0.5 \mathrm{in})\end{array}$ & $\begin{array}{c}9.50 \mathrm{~mm} \\
(0.375 \mathrm{in})\end{array}$ & $\begin{array}{c}8.00 \mathrm{~mm} \\
(0.3125 \mathrm{in})\end{array}$ & $\begin{array}{l}6.35 \mathrm{~mm} \\
(0.25 \mathrm{in})\end{array}$ & $\begin{array}{c}4.75 \mathrm{~mm} \\
(\# 4)\end{array}$ & Pan \\
\hline \multirow{6}{*}{$\begin{array}{c}\text { Northern Con, } \\
\text { Luverne }\end{array}$} & \multirow{6}{*}{ Gravel } & 1 & 2901.0 & 0.0 & 0.0 & 1517.2 & 1170.6 & 178.3 & 2.3 & 0.5 & 0.6 & 15.5 \\
\hline & & 2 & 2919.8 & 0.0 & 0.0 & 1131.3 & 1526.4 & 211.5 & 12.0 & 3.2 & 1.4 & 12.6 \\
\hline & & 3 & 3020.4 & 0.0 & 0.0 & 1548.9 & 1228.3 & 217.5 & 2.5 & 1.2 & 0.2 & 10.9 \\
\hline & & 4 & 3119.8 & 0.0 & 0.0 & 1805.3 & 1107.1 & 152.2 & 6.1 & 3.3 & 1.1 & 16.0 \\
\hline & & 5 & 3119.2 & 0.0 & 0.0 & 1371.3 & 1556.6 & 183.5 & 4.1 & 0.5 & 1.2 & 11.0 \\
\hline & & $1-5$ & 15080.2 & 0.0 & 0.0 & 7374.0 & 6589.0 & 943.0 & 27.0 & 8.7 & 4.5 & 66.0 \\
\hline \multirow{6}{*}{$\begin{array}{l}\text { North Star } \\
\text { Kasota }\end{array}$} & \multirow{6}{*}{ Gravel } & 1 & 3077.3 & 0.0 & 0.0 & 1675.4 & 1300.9 & 42.1 & 5.6 & 2.1 & 2.0 & 2.3 \\
\hline & & 2 & 3314.2 & 0.0 & 0.0 & 1414.4 & 1704.6 & 178.0 & 3.6 & 1.8 & 2.0 & 8.8 \\
\hline & & 3 & 3468.8 & 0.0 & 0.0 & 1695.6 & 1551.0 & 193.3 & 3.9 & 1.3 & 2.8 & 11.4 \\
\hline & & 4 & 3159.0 & 0.0 & 0.0 & 1419.2 & 1548.9 & 161.0 & 2.3 & 0.0 & 0.2 & 10.5 \\
\hline & & 5 & 3538.4 & 0.0 & 0.0 & 1824.1 & 1490.2 & 176.6 & 7.5 & 3.4 & 2.7 & 28.7 \\
\hline & & $1-5$ & 16557.7 & 0.0 & 0.0 & 8028.7 & 7595.6 & 751.0 & 22.9 & 8.6 & 9.7 & 61.7 \\
\hline \multirow{6}{*}{$\begin{array}{l}\text { Shiely Grey } \\
\text { Cloud }\end{array}$} & \multirow{6}{*}{ Quarried } & 1 & 3054.7 & 0.0 & 0.0 & 1484.0 & 1238.6 & 290.5 & 4.7 & 4.8 & 2.0 & 13.2 \\
\hline & & 2 & 3011.1 & 0.0 & 0.0 & 1580.4 & 1143.9 & 239.8 & 0.0 & 0.0 & 0.1 & 26.1 \\
\hline & & 3 & 3051.7 & 0.0 & 0.0 & 1362.6 & 1213.7 & 428.6 & 0.0 & 1.6 & 0.7 & 24.8 \\
\hline & & 4 & 2961.2 & 0.0 & 0.0 & 1524.6 & 993.2 & 374.9 & 0.9 & 0.5 & 0.3 & 42.7 \\
\hline & & 5 & 3051.1 & 0.0 & 0.0 & 1540.5 & 1131.3 & 320.4 & 1.1 & 1.1 & 1.4 & 46.5 \\
\hline & & $1-5$ & 15129.8 & 0.0 & 0.0 & 7492.1 & 5720.7 & 1654.2 & 6.7 & 8.0 & 4.5 & 153.3 \\
\hline \multirow{5}{*}{ SMC Mankato } & \multirow{5}{*}{ Quarried } & 1 & 3028.5 & 0.0 & 0.0 & 920.4 & 1606.6 & 419.2 & 7.1 & 2.9 & 2.2 & 34.9 \\
\hline & & 2 & 3034.7 & 0.0 & 0.0 & 973.2 & 1580.7 & 375.8 & 9.3 & 7.4 & 3.6 & 54.0 \\
\hline & & 3 & 3034.3 & 0.0 & 0.0 & 1044.7 & 1563.1 & 355.8 & 1.6 & 1.4 & 2.6 & 38.5 \\
\hline & & 5 & 3026.7 & 0.0 & 0.0 & 856.9 & 1674.5 & 387.8 & 5.5 & 6.6 & 2.1 & 53.8 \\
\hline & & $1-5$ & 12124.2 & 0.0 & 0.0 & 3795.2 & 6424.9 & 1538.6 & 23.5 & 18.3 & 10.5 & 181.2 \\
\hline
\end{tabular}


Table C.3. HFT results (mass retained) for small chamber samples (12.5 to $19.0 \mathrm{~mm}$ [0.5 to $0.75 \mathrm{in}]$ ) (continued).

\begin{tabular}{|c|c|c|c|c|c|c|c|c|c|c|c|c|}
\hline & & & \multicolumn{10}{|c|}{ Mass Retained (g) } \\
\hline & & & \multirow{2}{*}{0 Cycles } & \multicolumn{9}{|c|}{ After 50 Cycles } \\
\hline & & & & \multicolumn{9}{|c|}{ Sieve Sizes } \\
\hline $\begin{array}{l}\text { Aggregate } \\
\text { Source }\end{array}$ & $\begin{array}{l}\text { Source } \\
\text { Type }\end{array}$ & $\begin{array}{c}\text { Replicate } \\
\text { Number }\end{array}$ & Total & $\begin{array}{c}25.0 \mathrm{~mm} \\
(1 \mathrm{in})\end{array}$ & $\begin{array}{l}19.0 \mathrm{~mm} \\
(0.75 \mathrm{in})\end{array}$ & $\begin{array}{c}16.0 \mathrm{~mm} \\
(0.625 \mathrm{in})\end{array}$ & $\begin{array}{c}12.5 \mathrm{~mm} \\
(0.5 \mathrm{in})\end{array}$ & $\begin{array}{c}9.50 \mathrm{~mm} \\
(0.375 \mathrm{in})\end{array}$ & $\begin{array}{c}8.00 \mathrm{~mm} \\
(0.3125 \mathrm{in})\end{array}$ & $\begin{array}{l}6.35 \mathrm{~mm} \\
(0.25 \mathrm{in})\end{array}$ & $\begin{array}{c}4.75 \mathrm{~mm} \\
(\# 4)\end{array}$ & Pan \\
\hline \multirow{6}{*}{ Swedberg } & \multirow{6}{*}{ Quarried } & 1 & 2812.9 & 0.0 & 0.0 & 1491.0 & 1077.0 & 196.4 & 6.2 & 5.0 & 3.5 & 13.7 \\
\hline & & 2 & 2835.6 & 0.0 & 0.0 & 1592.6 & 950.5 & 255.1 & 4.7 & 3.4 & 3.8 & 15.1 \\
\hline & & 3 & 2798.2 & 0.0 & 0.0 & 1569.9 & 994.9 & 204.6 & 2.0 & 2.0 & 2.9 & 15.3 \\
\hline & & 4 & 2677.5 & 0.0 & 0.0 & 1563.0 & 953.2 & 131.2 & 3.6 & 1.8 & 1.1 & 14.9 \\
\hline & & 5 & 2917.1 & 0.0 & 0.0 & 1460.2 & 1221.0 & 200.7 & 3.6 & 3.4 & 2.8 & 14.9 \\
\hline & & $1-5$ & 14041.3 & 0.0 & 0.0 & 7676.7 & 5196.6 & 988.0 & 20.1 & 15.6 & 14.1 & 73.9 \\
\hline \multirow{6}{*}{$\begin{array}{c}\text { Ulland } \\
\text { Northwood }\end{array}$} & \multirow{6}{*}{ Quarried } & 1 & 3024.0 & 0.0 & 0.0 & 846.9 & 1611.9 & 535.2 & 0.0 & 2.4 & 0.2 & 6.1 \\
\hline & & 2 & 3042.5 & 0.0 & 0.0 & 957.0 & 1537.9 & 507.6 & 6.0 & 5.2 & 1.2 & 15.1 \\
\hline & & 3 & 3050.1 & 0.0 & 0.0 & 1027.5 & 1510.5 & 492.8 & 0.7 & 0.7 & 0.6 & 10.0 \\
\hline & & 4 & 2794.6 & 0.0 & 0.0 & 960.8 & 1396.0 & 405.1 & 3.3 & 0.5 & 1.2 & 14.5 \\
\hline & & 5 & 3025.6 & 0.0 & 0.0 & 1089.9 & 1515.2 & 393.6 & 0.8 & 1.1 & 0.5 & 14.5 \\
\hline & & $1-5$ & 14936.8 & 0.0 & 0.0 & 4882.1 & 7571.5 & 2334.3 & 10.8 & 9.9 & 3.7 & 60.2 \\
\hline \multirow{6}{*}{ Waterloo } & \multirow{6}{*}{ Quarried } & 1 & 2966.2 & 0.0 & 0.0 & 854.2 & 1530.6 & 559.7 & 3.0 & 2.0 & 0.0 & 5.6 \\
\hline & & 2 & 3066.4 & 0.0 & 0.0 & 974.1 & 1651.5 & 414.3 & 2.8 & 0.5 & 0.8 & 12.0 \\
\hline & & 3 & 2929.6 & 0.0 & 0.0 & 936.6 & 1524.1 & 444.7 & 1.0 & 1.1 & 0.0 & 7.9 \\
\hline & & 4 & 2934.3 & 0.0 & 0.0 & 1024.2 & 1498.7 & 391.5 & 0.0 & 0.0 & 0.0 & 6.9 \\
\hline & & 5 & 3008.0 & 0.0 & 0.0 & 782.8 & 1551.7 & 645.1 & 0.0 & 0.2 & 0.2 & 9.4 \\
\hline & & $1-5$ & 14904.5 & 0.0 & 0.0 & 4571.9 & 7756.6 & 2455.3 & 6.8 & 3.8 & 1.0 & 41.8 \\
\hline \multirow{6}{*}{ Zumbrota } & \multirow{6}{*}{ Quarried } & 1 & 3156.2 & 0.0 & 0.0 & 1424.9 & 1319.1 & 353.6 & 5.5 & 1.5 & 2.4 & 27.9 \\
\hline & & 2 & 3146.6 & 0.0 & 0.0 & 1221.6 & 1533.2 & 307.5 & 9.4 & 5.9 & 2.6 & 42.5 \\
\hline & & 3 & 3134.7 & 0.0 & 0.0 & 1376.4 & 1434.3 & 240.4 & 2.4 & 4.0 & 1.5 & 53.8 \\
\hline & & 4 & 3088.2 & 0.0 & 0.0 & 1300.2 & 1354.2 & 362.6 & 5.9 & 3.5 & 1.2 & 34.6 \\
\hline & & 5 & 3197.5 & 0.0 & 0.0 & 1301.1 & 1437.7 & 356.9 & 7.4 & 4.7 & 2.8 & 55.1 \\
\hline & & $1-5$ & 15723.2 & 0.0 & 0.0 & 6624.2 & 7078.5 & 1621.0 & 30.6 & 19.6 & 10.5 & 213.9 \\
\hline
\end{tabular}


Table C.4. HFT results (particle counts) for small chamber samples ( 12.5 to $19.0 \mathrm{~mm}$ [0.5 to $0.75 \mathrm{in}]$ ).

\begin{tabular}{|c|c|c|c|c|c|c|c|c|c|c|c|c|}
\hline & & & \multicolumn{10}{|c|}{ Particle Count Retained } \\
\hline & & & \multirow{2}{*}{0 Cycles } & \multicolumn{9}{|c|}{ After 50 Cycles } \\
\hline & & & & \multicolumn{9}{|c|}{ Sieve Sizes } \\
\hline $\begin{array}{l}\text { Aggregate } \\
\text { Source }\end{array}$ & $\begin{array}{c}\text { Source } \\
\text { Type }\end{array}$ & $\begin{array}{c}\text { Replicate } \\
\text { Number }\end{array}$ & Total & $\begin{array}{c}25.0 \mathrm{~mm} \\
(1 \mathrm{in})\end{array}$ & $\begin{array}{l}19.0 \mathrm{~mm} \\
(0.75 \mathrm{in})\end{array}$ & $\begin{array}{c}16.0 \mathrm{~mm} \\
(0.625 \mathrm{in})\end{array}$ & $\begin{array}{c}12.5 \mathrm{~mm} \\
(0.5 \mathrm{in})\end{array}$ & $\begin{array}{c}9.50 \mathrm{~mm} \\
(0.375 \mathrm{in})\end{array}$ & $\begin{array}{c}8.00 \mathrm{~mm} \\
(0.3125 \mathrm{in})\end{array}$ & $\begin{array}{l}6.35 \mathrm{~mm} \\
(0.25 \mathrm{in})\end{array}$ & $\begin{array}{c}4.75 \mathrm{~mm} \\
(\# 4)\end{array}$ & Pan \\
\hline \multirow{6}{*}{$\begin{array}{l}\text { Ashwill, } \\
\text { Kingston }\end{array}$} & \multirow{6}{*}{ Gravel } & 1 & 623 & 0 & 0 & 77 & 372 & 171 & 4 & 4 & 4 & 11 \\
\hline & & 2 & 627 & 0 & 0 & 92 & 376 & 158 & 1 & 2 & 0 & 57 \\
\hline & & 3 & 620 & 0 & 0 & 80 & 395 & 143 & 3 & 4 & 8 & 37 \\
\hline & & 4 & 616 & 0 & 0 & 79 & 392 & 144 & 8 & 4 & 8 & 138 \\
\hline & & 5 & 616 & 0 & 0 & 75 & 388 & 151 & 2 & 2 & 0 & 33 \\
\hline & & $1-5$ & 3102 & 0 & 0 & 403 & 1923 & 767 & 18 & 16 & 20 & 276 \\
\hline \multirow{6}{*}{$\begin{array}{c}\text { Big Springs, } \\
\text { Harmony }\end{array}$} & \multirow{6}{*}{ Quarried } & 1 & 594 & 0 & 0 & 124 & 346 & 124 & 1 & 5 & 2 & 51 \\
\hline & & 2 & 615 & 0 & 0 & 134 & 327 & 154 & 0 & 1 & 4 & 30 \\
\hline & & 3 & 622 & 0 & 0 & 120 & 370 & 133 & 4 & 6 & 6 & 40 \\
\hline & & 4 & 629 & 0 & 0 & 113 & 353 & 164 & 1 & 4 & 5 & 22 \\
\hline & & 5 & 594 & 0 & 0 & 158 & 296 & 138 & 1 & 3 & 4 & 12 \\
\hline & & $1-5$ & 3054 & 0 & 0 & 649 & 1692 & 713 & 7 & 19 & 21 & 155 \\
\hline \multirow{6}{*}{ Bryan Rock } & \multirow{6}{*}{ Quarried } & 1 & 579 & 0 & 0 & 170 & 334 & 73 & 0 & 0 & 0 & 59 \\
\hline & & 2 & 559 & 0 & 0 & 139 & 341 & 88 & 0 & 0 & 0 & 0 \\
\hline & & 3 & 600 & 0 & 0 & 122 & 359 & 109 & 0 & 0 & 0 & 0 \\
\hline & & 4 & 587 & 0 & 0 & 126 & 342 & 119 & 0 & 0 & 0 & 0 \\
\hline & & 5 & 591 & 0 & 0 & 112 & 344 & 139 & 0 & 1 & 1 & 4 \\
\hline & & $1-5$ & 2916 & 0 & 0 & 669 & 1720 & 528 & 0 & 1 & 1 & 63 \\
\hline \multirow{6}{*}{$\begin{array}{c}\text { Cedarville } \\
\text { Plant }\end{array}$} & \multirow{6}{*}{ Quarried } & 1 & 636 & 0 & 0 & 85 & 324 & 226 & 2 & 1 & 0 & 9 \\
\hline & & 2 & 598 & 0 & 0 & 104 & 288 & 195 & 2 & 3 & 0 & 9 \\
\hline & & 3 & 587 & 0 & 0 & 101 & 326 & 159 & 3 & $\overline{1}$ & 0 & 9 \\
\hline & & 4 & 598 & 0 & 0 & 93 & 341 & 157 & 0 & 2 & 1 & 17 \\
\hline & & 5 & 604 & 0 & 0 & 92 & 319 & 192 & 3 & 1 & 1 & 4 \\
\hline & & $1-5$ & 3023 & 0 & 0 & 475 & 1598 & 929 & 10 & 8 & 2 & 48 \\
\hline
\end{tabular}


Table C.4. HFT results (particle counts) for small chamber samples (12.5 to $19.0 \mathrm{~mm}$ [0.5 to $0.75 \mathrm{in}])$ (continued).

\begin{tabular}{|c|c|c|c|c|c|c|c|c|c|c|c|c|}
\hline & & & & & & & & & & & & \\
\hline & & & \multicolumn{10}{|c|}{ Particle Count Retained } \\
\hline & & & \multirow{2}{*}{0 Cycles } & \multicolumn{9}{|c|}{ After 50 Cycles } \\
\hline & & & & \multicolumn{9}{|c|}{ Sieve Sizes } \\
\hline $\begin{array}{l}\text { Aggregate } \\
\text { Source }\end{array}$ & $\begin{array}{l}\text { Source } \\
\text { Type }\end{array}$ & $\begin{array}{c}\text { Replicate } \\
\text { Number }\end{array}$ & Total & $\begin{array}{c}25.0 \mathrm{~mm} \\
(1 \mathrm{in})\end{array}$ & $\begin{array}{l}19.0 \mathrm{~mm} \\
(0.75 \mathrm{in})\end{array}$ & $\begin{array}{c}16.0 \mathrm{~mm} \\
(0.625 \mathrm{in})\end{array}$ & $\begin{array}{c}12.5 \mathrm{~mm} \\
(0.5 \mathrm{in})\end{array}$ & $\begin{array}{c}9.50 \mathrm{~mm} \\
(0.375 \mathrm{in})\end{array}$ & $\begin{array}{c}8.00 \mathrm{~mm} \\
(0.3125 \mathrm{in})\end{array}$ & $\begin{array}{l}6.35 \mathrm{~mm} \\
(0.25 \mathrm{in})\end{array}$ & $\begin{array}{c}4.75 \mathrm{~mm} \\
(\# 4)\end{array}$ & Pan \\
\hline \multirow{5}{*}{ Early Chapel } & \multirow{5}{*}{ Quarried } & 1 & 563 & 0 & 0 & 192 & 321 & 45 & 0 & 1 & 2 & 38 \\
\hline & & 2 & 569 & 0 & 0 & 135 & 338 & 97 & 1 & 6 & 0 & 16 \\
\hline & & 4 & 497 & 0 & 0 & 163 & 271 & 66 & 0 & 0 & 0 & 21 \\
\hline & & 5 & 541 & 0 & 0 & 161 & 304 & 85 & 9 & 11 & 12 & 46 \\
\hline & & $1-5$ & 2764 & 0 & 0 & 821 & 1552 & 403 & 20 & 23 & 20 & 203 \\
\hline \multirow{5}{*}{$\begin{array}{c}\text { Edward } \\
\text { Kramer \& } \\
\text { Sons }\end{array}$} & \multirow{5}{*}{ Quarried } & 1 & 473 & 0 & 0 & 125 & 249 & 109 & 3 & 8 & 11 & 82 \\
\hline & & 2 & 497 & 0 & 0 & 112 & 258 & 127 & 3 & 2 & 4 & 72 \\
\hline & & $3 *$ & 488 & 0 & 0 & 131 & 248 & 100 & 4 & 4 & 7 & 33 \\
\hline & & 4 & 516 & 0 & 0 & 104 & 260 & 160 & 4 & 7 & 6 & 36 \\
\hline & & $1-5$ & 1486 & 0 & 0 & 341 & 767 & 396 & 10 & 17 & 21 & 190 \\
\hline \multirow{6}{*}{$\begin{array}{l}\text { Goldberg, } \\
\text { Rochester }\end{array}$} & \multirow{6}{*}{ Quarried } & 1 & 507 & 0 & 0 & 113 & 249 & 142 & 2 & 1 & 2 & 33 \\
\hline & & 2 & & & & & & & & & & \\
\hline & & 3 & 541 & 0 & 0 & 117 & 187 & 137 & 4 & 2 & 2 & 23 \\
\hline & & 4 & 567 & 0 & 0 & 124 & 275 & 175 & 3 & 3 & 2 & 69 \\
\hline & & 5 & 519 & 0 & 0 & 114 & 264 & 146 & 1 & 8 & 6 & 42 \\
\hline & & $1-5$ & 2134 & 0 & 0 & 468 & 975 & 600 & 10 & 14 & 12 & 167 \\
\hline \multirow{6}{*}{$\begin{array}{l}\text { Grand } \\
\text { Meadow }\end{array}$} & \multirow{6}{*}{ Quarried } & 1 & 627 & 0 & 0 & 130 & 347 & 114 & 2 & 2 & 3 & 59 \\
\hline & & 2 & 667 & 0 & 0 & 88 & 413 & 166 & 1 & 1 & 0 & 5 \\
\hline & & 3 & 705 & 0 & 0 & 94 & 410 & 216 & 3 & 2 & 2 & 33 \\
\hline & & 4 & 672 & 0 & 0 & 92 & 405 & 173 & 3 & 0 & 2 & 6 \\
\hline & & 5 & 666 & 0 & 0 & 96 & 406 & 163 & 6 & 1 & 3 & 25 \\
\hline & & $1-5$ & 3337 & 0 & 0 & 500 & 1981 & 832 & 15 & 6 & 10 & 128 \\
\hline
\end{tabular}


Table C.4. HFT results (particle counts) for small chamber samples (12.5 to $19.0 \mathrm{~mm}$ [0.5 to $0.75 \mathrm{in}])$ (continued).

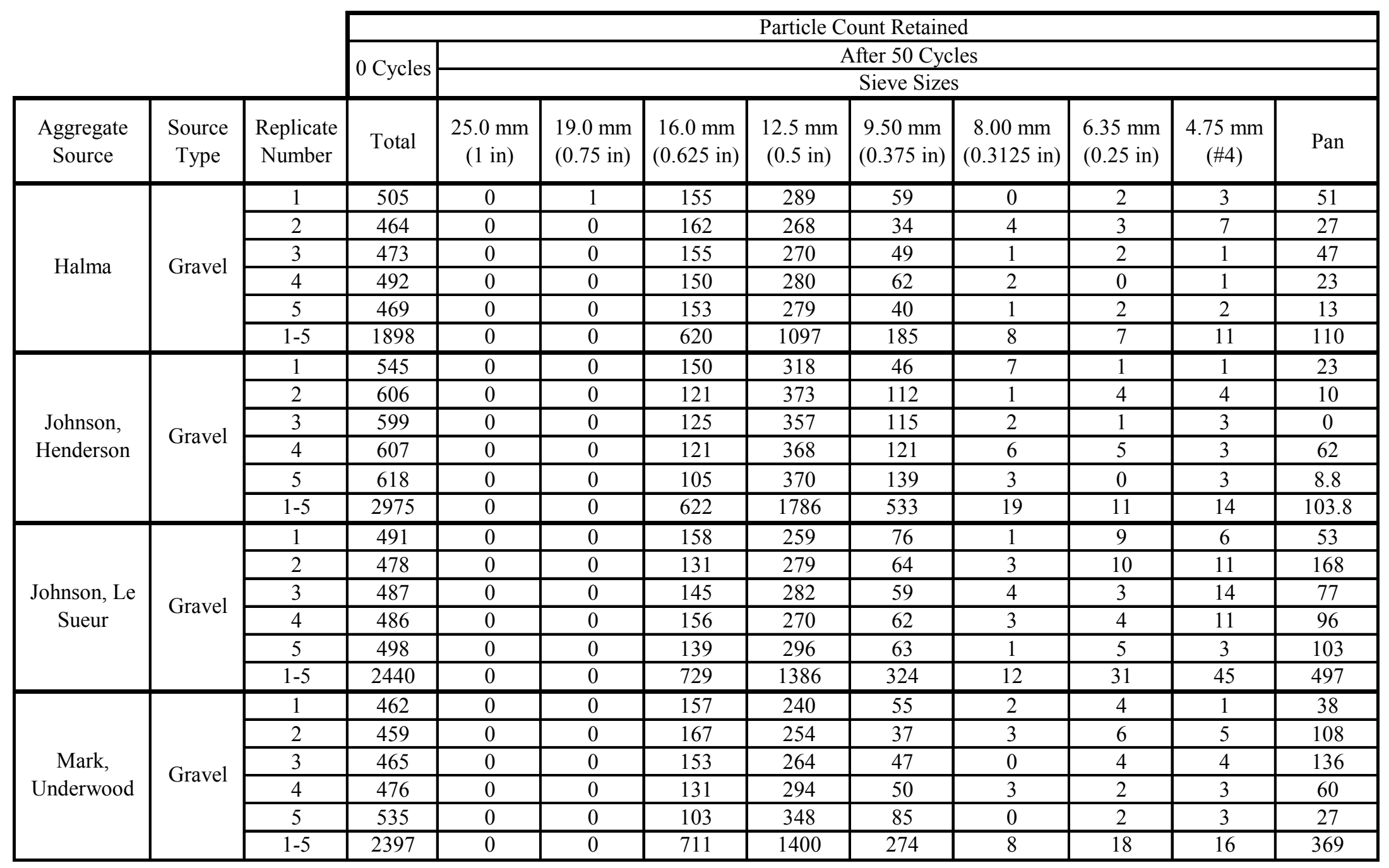


Table C.4. HFT results (particle counts) for small chamber samples (12.5 to $19.0 \mathrm{~mm}$ [0.5 to $0.75 \mathrm{in}]$ ) (continued).

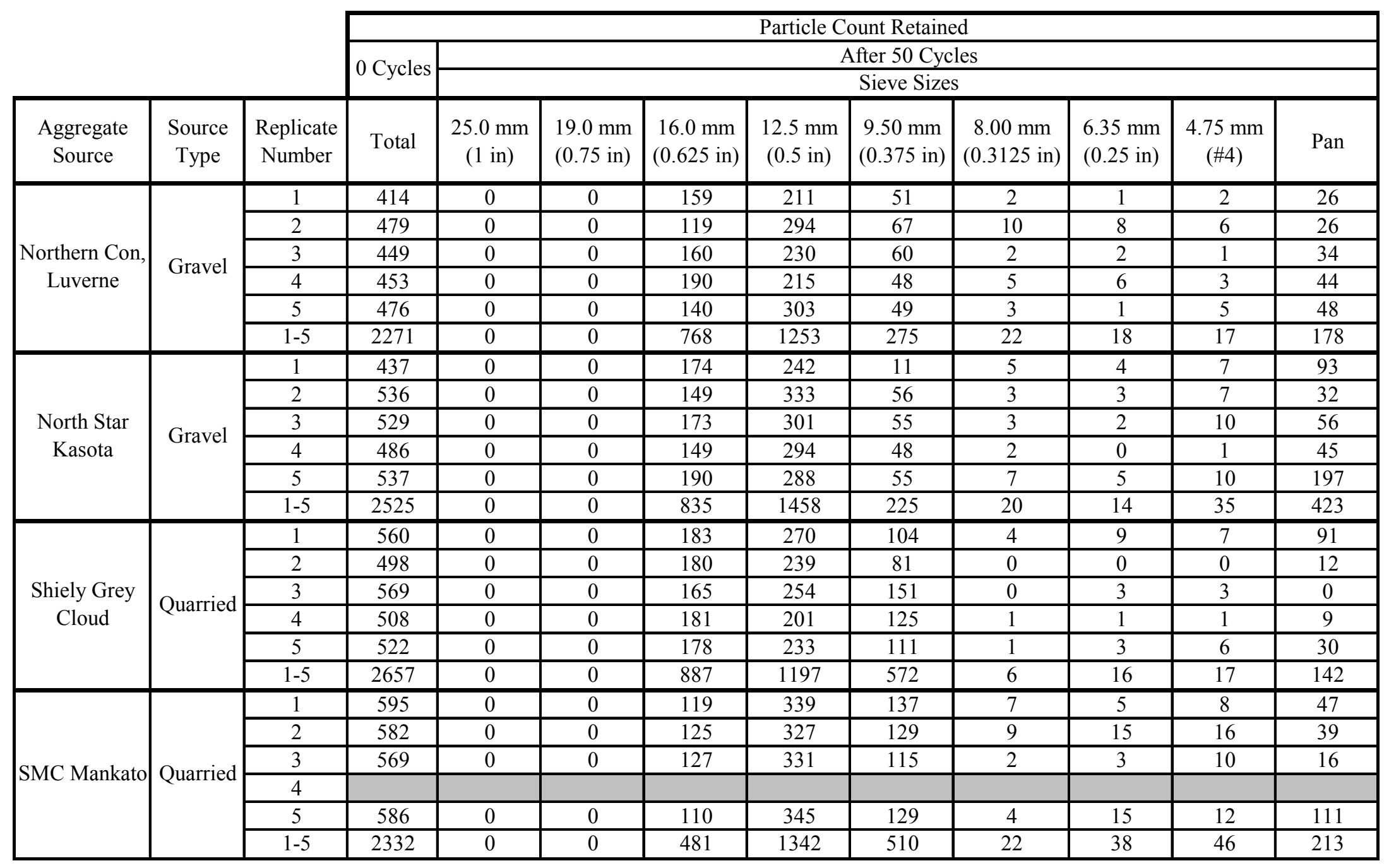


Table C.4. HFT results (particle counts) for small chamber samples (12.5 to $19.0 \mathrm{~mm}$ [0.5 to $0.75 \mathrm{in}]$ ) (continued).

\begin{tabular}{|c|c|c|c|c|c|c|c|c|c|c|c|c|}
\hline & & & \multicolumn{10}{|c|}{ Particle Count Retained } \\
\hline & & & \multirow{2}{*}{0 Cycles } & \multicolumn{9}{|c|}{ After 50 Cycles } \\
\hline & & & & \multicolumn{9}{|c|}{ Sieve Sizes } \\
\hline $\begin{array}{l}\text { Aggregate } \\
\text { Source }\end{array}$ & $\begin{array}{l}\text { Source } \\
\text { Type }\end{array}$ & $\begin{array}{l}\text { Replicate } \\
\text { Number }\end{array}$ & Total & $\begin{array}{l}25.0 \mathrm{~mm} \\
(1 \mathrm{in})\end{array}$ & $\begin{array}{l}19.0 \mathrm{~mm} \\
(0.75 \mathrm{in})\end{array}$ & $\begin{array}{c}16.0 \mathrm{~mm} \\
(0.625 \mathrm{in})\end{array}$ & $\begin{array}{c}12.5 \mathrm{~mm} \\
(0.5 \mathrm{in})\end{array}$ & $\begin{array}{c}9.50 \mathrm{~mm} \\
(0.375 \mathrm{in})\end{array}$ & $\begin{array}{c}8.00 \mathrm{~mm} \\
(0.3125 \mathrm{in})\end{array}$ & $\begin{array}{l}6.35 \mathrm{~mm} \\
(0.25 \mathrm{in})\end{array}$ & $\begin{array}{c}4.75 \mathrm{~mm} \\
(\# 4)\end{array}$ & Pan \\
\hline \multirow{6}{*}{ Swedberg } & \multirow{6}{*}{ Quarried } & 1 & 351 & 0 & 0 & 173 & 214 & 67 & 7 & 8 & 11 & 160 \\
\hline & & 2 & 473 & 0 & 0 & 190 & 197 & 91 & 5 & 7 & 19 & 266 \\
\hline & & 3 & 462 & 0 & 0 & 187 & 208 & 75 & 2 & 4 & 9 & 66 \\
\hline & & 4 & 406 & 0 & 0 & 185 & 180 & 44 & 3 & 4 & 6 & 115 \\
\hline & & 5 & 400 & 0 & 0 & 172 & 250 & 78 & 4 & 8 & 10 & 25 \\
\hline & & $1-5$ & 2092 & 0 & 0 & 907 & 1049 & 355 & 21 & 31 & 55 & 632 \\
\hline \multirow{6}{*}{$\begin{array}{c}\text { Ulland } \\
\text { Northwood }\end{array}$} & \multirow{6}{*}{ Quarried } & 1 & 620 & 0 & 0 & 99 & 339 & 182 & 0 & 3 & 1 & 34 \\
\hline & & 2 & 598 & 0 & 0 & 111 & 317 & 168 & 5 & 10 & 4 & 42 \\
\hline & & 3 & 581 & 0 & 0 & 115 & 309 & 160 & 1 & 1 & 3 & 23 \\
\hline & & 4 & 524 & 0 & 0 & 114 & 277 & 131 & 3 & 1 & 5 & 30 \\
\hline & & 5 & 541 & 0 & 0 & 119 & 303 & 121 & 1 & 2 & 1 & 33 \\
\hline & & $1-5$ & 2864 & 0 & 0 & 558 & 1545 & 762 & 10 & 17 & 14 & 162 \\
\hline \multirow{6}{*}{ Waterloo } & \multirow{6}{*}{ Quarried } & 1 & 620 & 0 & 0 & 110 & 332 & 181 & 3 & 2 & 0 & 13 \\
\hline & & 2 & 614 & 0 & 0 & 120 & 356 & 140 & 3 & 1 & 3 & 46 \\
\hline & & 3 & 596 & 0 & 0 & 115 & 341 & 160 & 1 & 2 & 0 & 1 \\
\hline & & 4 & 575 & 0 & 0 & 124 & 325 & 125 & 0 & 0 & 0 & 16 \\
\hline & & 5 & 628 & 0 & 0 & 98 & 330 & 206 & 0 & 1 & 1 & 27 \\
\hline & & $1-5$ & 3033 & 0 & 0 & 567 & 1684 & 812 & 7 & 6 & 4 & 103 \\
\hline \multirow{6}{*}{ Zumbrota } & \multirow{6}{*}{ Quarried } & 1 & 527 & 0 & 0 & 165 & 261 & 103 & 4 & 3 & 8 & 51 \\
\hline & & 2 & 551 & 0 & 0 & 140 & 314 & 105 & 9 & 10 & 10 & 86 \\
\hline & & 3 & 517 & 0 & 0 & 165 & 286 & 79 & 2 & 7 & 5 & 26 \\
\hline & & 4 & 547 & 0 & 0 & 156 & 273 & 117 & 5 & 5 & 4 & 60 \\
\hline & & 5 & 547 & 0 & 0 & 149 & 292 & 114 & 7 & 7 & 14 & 90 \\
\hline & & $1-5$ & 2689 & 0 & 0 & 775 & 1426 & 518 & 27 & 32 & 41 & 313 \\
\hline
\end{tabular}


Table C.5. HFT results (normalized, mass retained) for small chamber samples (12.5 to $19 \mathrm{~mm}$ [0.5 in to 0.75 in]).

\begin{tabular}{|c|c|c|c|c|c|c|c|c|c|c|c|}
\hline & & & \multicolumn{9}{|c|}{ Normalized Mass Retained (\%) } \\
\hline & & & \multicolumn{9}{|c|}{ Sieve Size } \\
\hline $\begin{array}{l}\text { Aggregate } \\
\text { Source }\end{array}$ & $\begin{array}{l}\text { Source } \\
\text { Type }\end{array}$ & $\begin{array}{l}\text { Replicate } \\
\text { Number }\end{array}$ & $\begin{array}{l}25.0 \mathrm{~mm} \\
(1 \mathrm{in})\end{array}$ & $\begin{array}{l}19.0 \mathrm{~mm} \\
(0.75 \mathrm{in})\end{array}$ & $\begin{array}{c}16.0 \mathrm{~mm} \\
(0.625 \mathrm{in})\end{array}$ & $\begin{array}{c}12.5 \mathrm{~mm} \\
(0.5 \mathrm{in})\end{array}$ & $\begin{array}{c}9.50 \mathrm{~mm} \\
(0.375 \mathrm{in})\end{array}$ & $\begin{array}{c}8.00 \mathrm{~mm} \\
(0.3125 \\
\text { in })\end{array}$ & $\begin{array}{l}6.35 \mathrm{~mm} \\
(0.25 \mathrm{in})\end{array}$ & $\begin{array}{l}4.75 \mathrm{~mm} \\
\quad(\# 4)\end{array}$ & Pan \\
\hline \multirow{6}{*}{$\begin{array}{l}\text { Ashwill, } \\
\text { Kingston }\end{array}$} & \multirow{6}{*}{ Gravel } & 1 & 0.000 & 0.000 & 19.759 & 61.135 & 18.258 & 0.230 & 0.094 & 0.026 & 0.249 \\
\hline & & 2 & 0.000 & 0.000 & 22.781 & 60.077 & 16.654 & 0.016 & 0.036 & 0.000 & 0.221 \\
\hline & & 3 & 0.000 & 0.000 & 20.484 & 63.903 & 14.866 & 0.087 & 0.068 & 0.061 & 0.465 \\
\hline & & 4 & 0.000 & 0.000 & 20.211 & 64.189 & 14.224 & 0.219 & 0.062 & 0.072 & 0.507 \\
\hline & & 5 & 0.000 & 0.000 & 18.997 & 64.233 & 15.453 & 0.080 & 0.037 & 0.000 & 0.383 \\
\hline & & $1-5$ & 0.000 & 0.000 & 20.453 & 62.698 & 15.896 & 0.127 & 0.059 & 0.032 & 0.365 \\
\hline \multirow{6}{*}{$\begin{array}{c}\text { Big Springs, } \\
\text { Harmony }\end{array}$} & \multirow{6}{*}{ Quarried } & 1 & 0.000 & 0.000 & 35.790 & 50.569 & 12.517 & 0.046 & 0.082 & 0.016 & 0.128 \\
\hline & & 2 & 0.000 & 0.000 & 35.961 & 48.347 & 14.891 & 0.000 & 0.019 & 0.038 & 0.407 \\
\hline & & 3 & 0.000 & 0.000 & 31.669 & 54.131 & 12.998 & 0.152 & 0.104 & 0.044 & 0.521 \\
\hline & & 4 & 0.000 & 0.000 & 30.351 & 52.287 & 15.904 & 0.065 & 0.071 & 0.048 & 0.740 \\
\hline & & 5 & 0.000 & 0.000 & 41.673 & 44.301 & 12.697 & 0.038 & 0.057 & 0.029 & 0.566 \\
\hline & & $1-5$ & 0.000 & 0.000 & 35.095 & 49.923 & 13.799 & 0.060 & 0.067 & 0.035 & 0.474 \\
\hline \multirow{6}{*}{ Bryan Rock } & \multirow{6}{*}{ Quarried } & 1 & 0.000 & 0.000 & 42.425 & 49.875 & 7.119 & 0.000 & 0.000 & 0.000 & 0.098 \\
\hline & & 2 & 0.000 & 0.000 & 36.935 & 53.274 & 8.964 & 0.000 & 0.000 & 0.000 & 0.370 \\
\hline & & 3 & 0.000 & 0.000 & 30.576 & 57.183 & 10.878 & 0.000 & 0.000 & 0.000 & 0.335 \\
\hline & & 4 & 0.000 & 0.000 & 32.690 & 54.070 & 12.538 & 0.000 & 0.000 & 0.000 & 0.295 \\
\hline & & 5 & 0.000 & 0.000 & 29.674 & 54.837 & 13.907 & 0.000 & 0.010 & 0.007 & 0.882 \\
\hline & & $1-5$ & 0.000 & 0.000 & 34.493 & 53.830 & 10.672 & 0.000 & 0.002 & 0.001 & 0.391 \\
\hline \multirow{6}{*}{$\begin{array}{l}\text { Cedarville } \\
\text { Plant }\end{array}$} & \multirow{6}{*}{ Quarried } & 1 & 0.000 & 0.000 & 24.751 & 50.378 & 24.134 & 0.142 & 0.023 & 0.000 & 0.194 \\
\hline & & 2 & 0.000 & 0.000 & 32.190 & 46.908 & 20.130 & 0.132 & 0.069 & 0.000 & 0.441 \\
\hline & & 3 & 0.000 & 0.000 & 29.810 & 52.682 & 16.650 & 0.160 & 0.016 & 0.000 & 0.358 \\
\hline & & 4 & 0.000 & 0.000 & 28.843 & 54.339 & 16.106 & 0.000 & 0.040 & 0.003 & 0.215 \\
\hline & & 5 & 0.000 & 0.000 & 27.686 & 50.873 & 20.336 & 0.130 & 0.010 & 0.010 & 0.515 \\
\hline & & $1-5$ & 0.000 & 0.000 & 28.647 & 51.039 & 19.476 & 0.113 & 0.031 & 0.003 & 0.345 \\
\hline
\end{tabular}


Table C.5. HFT results (normalized, mass retained) for small chamber samples (12.5 to $19 \mathrm{~mm}$ [0.5 in to $0.75 \mathrm{in}]$ ) (cont.).

\begin{tabular}{|c|c|c|c|c|c|c|c|c|c|c|c|}
\hline \multirow{3}{*}{$\begin{array}{c}\text { Aggregate } \\
\text { Source }\end{array}$} & \multirow{3}{*}{$\begin{array}{c} \\
\text { Source } \\
\text { Type }\end{array}$} & \multirow{3}{*}{$\begin{array}{c} \\
\text { Replicate } \\
\text { Number }\end{array}$} & \\
\hline & & & \multicolumn{9}{|c|}{$\begin{array}{c}\text { Normalized Mass Retained (\%) } \\
\text { Sieve Size } \\
\end{array}$} \\
\hline & & & $\begin{array}{l}25.0 \mathrm{~mm} \\
(1 \mathrm{in})\end{array}$ & $\begin{array}{l}19.0 \mathrm{~mm} \\
(0.75 \mathrm{in})\end{array}$ & $\begin{array}{c}16.0 \mathrm{~mm} \\
(0.625 \mathrm{in})\end{array}$ & $\begin{array}{l}12.5 \mathrm{~mm} \\
(0.5 \mathrm{in})\end{array}$ & $\begin{array}{c}9.50 \mathrm{~mm} \\
(0.375 \mathrm{in})\end{array}$ & $\begin{array}{c}8.00 \mathrm{~mm} \\
(0.3125 \\
\text { in) }\end{array}$ & $\begin{array}{l}6.35 \mathrm{~mm} \\
(0.25 \mathrm{in})\end{array}$ & $\begin{array}{l}4.75 \mathrm{~mm} \\
(\# 4)\end{array}$ & Pan \\
\hline \multirow{6}{*}{ Early Chapel } & \multirow{6}{*}{ Quarried } & 1 & 0.000 & 0.000 & 49.262 & 45.857 & 4.321 & 0.000 & 0.013 & 0.013 & 0.177 \\
\hline & & 2 & 0.000 & 0.000 & 35.583 & 53.321 & 10.085 & 0.038 & 0.094 & 0.000 & 0.549 \\
\hline & & 3 & 0.000 & 0.000 & 41.307 & 46.762 & 9.923 & 0.319 & 0.087 & 0.049 & 0.800 \\
\hline & & 4 & 0.000 & 0.000 & 46.736 & 45.123 & 7.202 & 0.000 & 0.000 & 0.000 & 0.491 \\
\hline & & 5 & 0.000 & 0.000 & 42.646 & 46.959 & 7.987 & 0.310 & 0.203 & 0.095 & 1.084 \\
\hline & & $1-5$ & 0.000 & 0.000 & 43.027 & 47.617 & 7.950 & 0.139 & 0.081 & 0.032 & 0.627 \\
\hline \multirow{6}{*}{$\begin{array}{c}\text { Edward } \\
\text { Kramer \& } \\
\text { Sons }\end{array}$} & \multirow{6}{*}{ Quarried } & 1 & 0.000 & 0.000 & 40.621 & 45.096 & 12.130 & 0.139 & 0.195 & 0.114 & 0.977 \\
\hline & & 2 & 0.000 & 0.000 & 35.198 & 47.996 & 14.677 & 0.165 & 0.029 & 0.050 & 1.036 \\
\hline & & $3 *$ & 0.000 & 0.000 & 42.180 & 44.434 & 10.801 & 0.183 & 0.072 & 0.069 & 1.229 \\
\hline & & 4 & 0.000 & 0.000 & 33.129 & 46.404 & 17.407 & 0.133 & 0.147 & 0.047 & 1.673 \\
\hline & & 5 & & & & & & & & & \\
\hline & & $1-5$ & 0.000 & 0.000 & 36.328 & 46.495 & 14.731 & 0.145 & 0.124 & 0.070 & 1.228 \\
\hline \multirow{6}{*}{$\begin{array}{l}\text { Goldberg, } \\
\text { Rochester }\end{array}$} & \multirow{6}{*}{ Quarried } & 1 & 0.000 & 0.000 & 36.853 & 44.849 & 15.672 & 0.108 & 0.018 & 0.025 & 1.089 \\
\hline & & 2 & & & & & & & & & \\
\hline & & 3 & 0.000 & 0.000 & 35.718 & 48.570 & 13.647 & 0.124 & 0.027 & 0.013 & 1.031 \\
\hline & & 4 & 0.000 & 0.000 & 37.670 & 42.904 & 17.119 & 0.094 & 0.054 & 0.017 & 1.388 \\
\hline & & 5 & 0.000 & 0.000 & 35.853 & 45.540 & 15.626 & 0.024 & 0.202 & 0.052 & 1.668 \\
\hline & & $1-5$ & 0.000 & 0.000 & 36.523 & 45.477 & 15.511 & 0.088 & 0.075 & 0.027 & 1.294 \\
\hline \multirow{6}{*}{$\begin{array}{c}\text { Grand } \\
\text { Meadow }\end{array}$} & \multirow{6}{*}{ Quarried } & 1 & 0.000 & 0.000 & 31.888 & 53.738 & 10.877 & 0.068 & 0.035 & 0.026 & 0.103 \\
\hline & & 2 & 0.000 & 0.000 & 22.678 & 59.900 & 16.266 & 0.023 & 0.029 & 0.000 & 0.395 \\
\hline & & 3 & 0.000 & 0.000 & 23.480 & 56.301 & 18.876 & 0.116 & 0.043 & 0.015 & 0.653 \\
\hline & & 4 & 0.000 & 0.000 & 22.772 & 58.879 & 17.046 & 0.070 & 0.000 & 0.022 & 0.483 \\
\hline & & 5 & 0.000 & 0.000 & 24.646 & 57.926 & 15.717 & 0.216 & 0.013 & 0.029 & 0.732 \\
\hline & & $1-5$ & 0.000 & 0.000 & 25.077 & 57.335 & 15.791 & 0.098 & 0.024 & 0.019 & 0.474 \\
\hline
\end{tabular}


Table C.5. HFT results (normalized, mass retained) for small chamber samples (12.5 to $19 \mathrm{~mm}$ [0.5 in to $0.75 \mathrm{in}]$ ) (cont.).

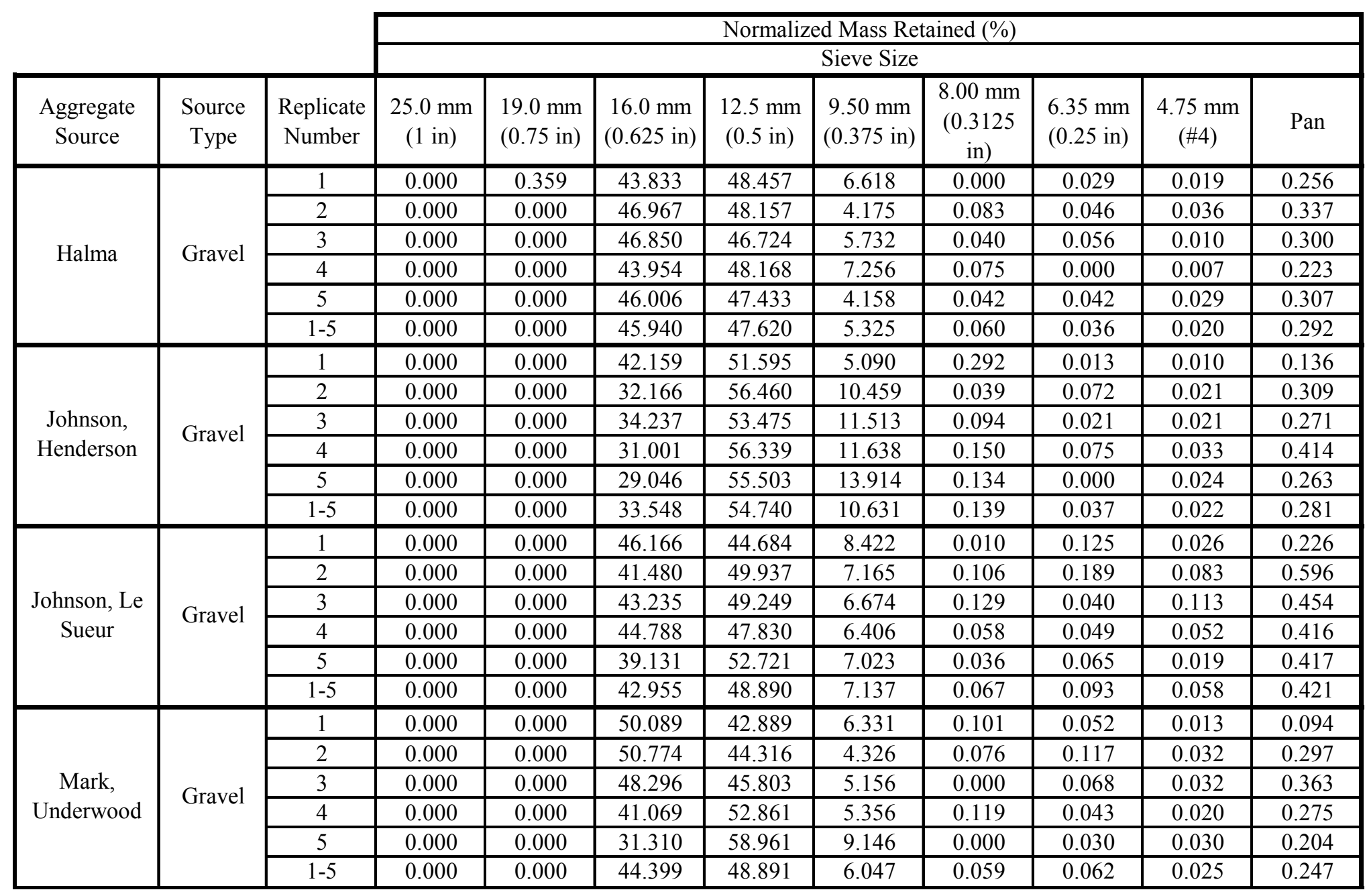


Table C.5. HFT results (normalized, mass retained) for small chamber samples (12.5 to $19 \mathrm{~mm}$ [0.5 in to $0.75 \mathrm{in}]$ ) (cont.).

\begin{tabular}{|c|c|c|c|c|c|c|c|c|c|c|c|}
\hline & & & \multirow{2}{*}{\multicolumn{9}{|c|}{ Normalized Mass Retained (\%) }} \\
\hline & & & & & & & & & & & \\
\hline & & & \multicolumn{9}{|c|}{ Sieve Size } \\
\hline $\begin{array}{l}\text { Aggregate } \\
\text { Source }\end{array}$ & $\begin{array}{l}\text { Source } \\
\text { Type }\end{array}$ & $\begin{array}{l}\text { Replicate } \\
\text { Number }\end{array}$ & $\begin{array}{l}25.0 \mathrm{~mm} \\
(1 \mathrm{in})\end{array}$ & $\begin{array}{l}19.0 \mathrm{~mm} \\
(0.75 \mathrm{in})\end{array}$ & $\begin{array}{c}16.0 \mathrm{~mm} \\
(0.625 \mathrm{in})\end{array}$ & $\begin{array}{l}12.5 \mathrm{~mm} \\
(0.5 \mathrm{in})\end{array}$ & $\begin{array}{c}9.50 \mathrm{~mm} \\
(0.375 \mathrm{in})\end{array}$ & $\begin{array}{c}8.00 \mathrm{~mm} \\
(0.3125 \\
\text { in })\end{array}$ & $\begin{array}{l}6.35 \mathrm{~mm} \\
(0.25 \mathrm{in})\end{array}$ & $\begin{array}{l}4.75 \mathrm{~mm} \\
\quad(\# 4)\end{array}$ & Pan \\
\hline \multirow{6}{*}{$\begin{array}{c}\text { Northern Con, } \\
\text { Luverne }\end{array}$} & \multirow{6}{*}{ Gravel } & 1 & 0.000 & 0.000 & 52.299 & 40.352 & 6.146 & 0.079 & 0.017 & 0.021 & 0.534 \\
\hline & & 2 & 0.000 & 0.000 & 38.746 & 52.278 & 7.244 & 0.411 & 0.110 & 0.048 & 0.432 \\
\hline & & 3 & 0.000 & 0.000 & 51.281 & 40.667 & 7.201 & 0.083 & 0.040 & 0.007 & 0.361 \\
\hline & & 4 & 0.000 & 0.000 & 57.866 & 35.486 & 4.879 & 0.196 & 0.106 & 0.035 & 0.513 \\
\hline & & 5 & 0.000 & 0.000 & 43.963 & 49.904 & 5.883 & 0.131 & 0.016 & 0.038 & 0.353 \\
\hline & & $1-5$ & 0.000 & 0.000 & 48.899 & 43.693 & 6.253 & 0.179 & 0.058 & 0.030 & 0.438 \\
\hline \multirow{6}{*}{$\begin{array}{l}\text { North Star } \\
\text { Kasota }\end{array}$} & \multirow{6}{*}{ Gravel } & 1 & 0.000 & 0.000 & 54.444 & 42.274 & 1.368 & 0.182 & 0.068 & 0.065 & 0.075 \\
\hline & & 2 & 0.000 & 0.000 & 42.677 & 51.433 & 5.371 & 0.109 & 0.054 & 0.060 & 0.266 \\
\hline & & 3 & 0.000 & 0.000 & 48.881 & 44.713 & 5.573 & 0.112 & 0.037 & 0.081 & 0.329 \\
\hline & & 4 & 0.000 & 0.000 & 44.926 & 49.031 & 5.097 & 0.073 & 0.000 & 0.006 & 0.332 \\
\hline & & 5 & 0.000 & 0.000 & 51.552 & 42.115 & 4.991 & 0.212 & 0.096 & 0.076 & 0.811 \\
\hline & & $1-5$ & 0.000 & 0.000 & 48.489 & 45.874 & 4.536 & 0.138 & 0.052 & 0.059 & 0.373 \\
\hline \multirow{6}{*}{$\begin{array}{c}\text { Shiely Grey } \\
\text { Cloud }\end{array}$} & \multirow{6}{*}{ Quarried } & 1 & 0.000 & 0.000 & 48.581 & 40.547 & 9.510 & 0.154 & 0.157 & 0.065 & 0.432 \\
\hline & & 2 & 0.000 & 0.000 & 52.486 & 37.989 & 7.964 & 0.000 & 0.000 & 0.003 & 0.867 \\
\hline & & 3 & 0.000 & 0.000 & 44.651 & 39.771 & 14.045 & 0.000 & 0.052 & 0.023 & 0.813 \\
\hline & & 4 & 0.000 & 0.000 & 51.486 & 33.540 & 12.660 & 0.030 & 0.017 & 0.010 & 1.442 \\
\hline & & 5 & 0.000 & 0.000 & 50.490 & 37.078 & 10.501 & 0.036 & 0.036 & 0.046 & 1.524 \\
\hline & & $1-5$ & 0.000 & 0.000 & 49.519 & 37.811 & 10.933 & 0.044 & 0.053 & 0.030 & 1.013 \\
\hline \multirow{6}{*}{ SMC Mankato } & \multirow{6}{*}{ Quarried } & 1 & 0.000 & 0.000 & 30.391 & 53.049 & 13.842 & 0.234 & 0.096 & 0.073 & 1.152 \\
\hline & & 2 & 0.000 & 0.000 & 32.069 & 52.088 & 12.383 & 0.306 & 0.244 & 0.119 & 1.779 \\
\hline & & 3 & 0.000 & 0.000 & 34.430 & 51.514 & 11.726 & 0.053 & 0.046 & 0.086 & 1.269 \\
\hline & & 4 & & & & & & & & & \\
\hline & & 5 & 0.000 & 0.000 & 28.311 & 55.324 & 12.813 & 0.182 & 0.218 & 0.069 & 1.778 \\
\hline & & $1-5$ & 0.000 & 0.000 & 31.303 & 52.992 & 12.690 & 0.194 & 0.151 & 0.087 & 1.495 \\
\hline
\end{tabular}


Table C.5. HFT results (normalized, mass retained) for small chamber samples (12.5 to $19 \mathrm{~mm}$ [0.5 in to 0.75 in]) (cont.).

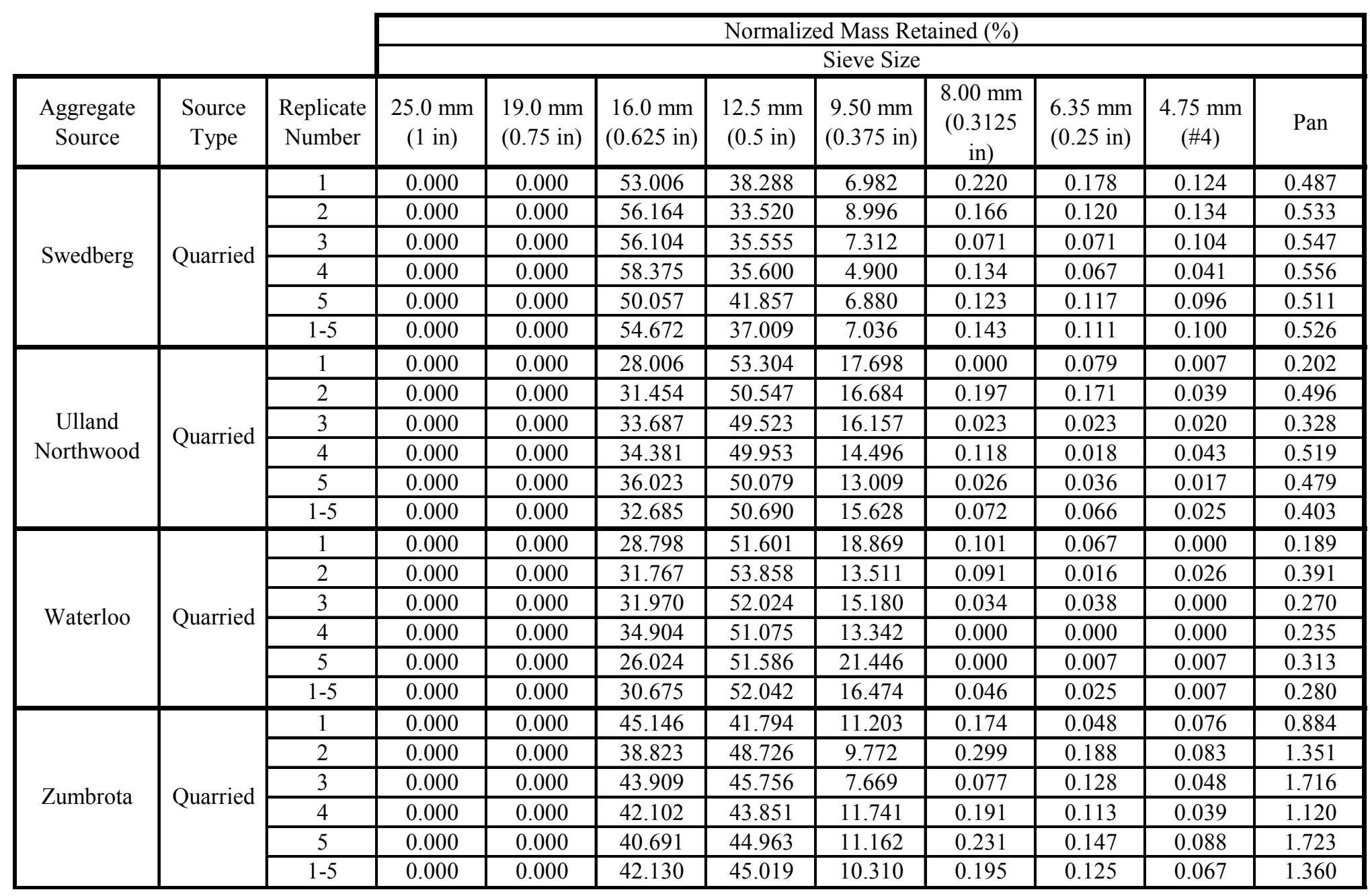


Table C.6. HFT results (normalized, particle counts) for small chamber samples (12.5 to $19 \mathrm{~mm}$ [0.5 in to $0.75 \mathrm{in}]$ ).

\begin{tabular}{|c|c|c|c|c|c|c|c|c|c|c|c|}
\hline & & \multicolumn{9}{|c|}{ Normalized Particle Count Retained (\%) } \\
\hline & & & \multicolumn{9}{|c|}{$\begin{array}{c}\text { Sieve Size } \\
\end{array}$} \\
\hline $\begin{array}{l}\text { Aggregate } \\
\text { Source }\end{array}$ & $\begin{array}{l}\text { Source } \\
\text { Type }\end{array}$ & $\begin{array}{l}\text { Replicate } \\
\text { Number }\end{array}$ & $\begin{array}{l}25.0 \mathrm{~mm} \\
(1 \mathrm{in})\end{array}$ & $\begin{array}{l}19.0 \mathrm{~mm} \\
(0.75 \mathrm{in})\end{array}$ & $\begin{array}{c}16.0 \mathrm{~mm} \\
(0.625 \mathrm{in})\end{array}$ & $\begin{array}{c}12.5 \mathrm{~mm} \\
(0.5 \mathrm{in})\end{array}$ & $\begin{array}{c}9.50 \mathrm{~mm} \\
(0.375 \mathrm{in})\end{array}$ & $\begin{array}{c}8.00 \mathrm{~mm} \\
(0.3125 \\
\text { in })\end{array}$ & $\begin{array}{l}6.35 \mathrm{~mm} \\
(0.25 \mathrm{in})\end{array}$ & $\begin{array}{l}4.75 \mathrm{~mm} \\
\quad(\# 4)\end{array}$ & Pan \\
\hline \multirow{6}{*}{$\begin{array}{l}\text { Ashwill, } \\
\text { Kingston }\end{array}$} & \multirow{6}{*}{ Gravel } & 1 & 0.000 & 0.000 & 12.360 & 59.711 & 27.448 & 0.642 & 0.642 & 0.642 & 1.766 \\
\hline & & 2 & 0.000 & 0.000 & 14.673 & 59.968 & 25.199 & 0.159 & 0.319 & 0.000 & 9.091 \\
\hline & & 3 & 0.000 & 0.000 & 12.903 & 63.710 & 23.065 & 0.484 & 0.645 & 1.290 & 5.968 \\
\hline & & 4 & 0.000 & 0.000 & 12.825 & 63.636 & 23.377 & 1.299 & 0.649 & 1.299 & 22.403 \\
\hline & & 5 & 0.000 & 0.000 & 12.175 & 62.987 & 24.513 & 0.325 & 0.325 & 0.000 & 5.357 \\
\hline & & $1-5$ & 0.000 & 0.000 & 12.992 & 61.992 & 24.726 & 0.580 & 0.516 & 0.645 & 8.897 \\
\hline \multirow{6}{*}{$\begin{array}{c}\text { Big Springs, } \\
\text { Harmony }\end{array}$} & \multirow{6}{*}{ Quarried } & 1 & 0.000 & 0.000 & 20.875 & 58.249 & 20.875 & 0.168 & 0.842 & 0.337 & 8.586 \\
\hline & & 2 & 0.000 & 0.000 & 21.789 & 53.171 & 25.041 & 0.000 & 0.163 & 0.650 & 4.878 \\
\hline & & 3 & 0.000 & 0.000 & 19.293 & 59.486 & 21.383 & 0.643 & 0.965 & 0.965 & 6.431 \\
\hline & & 4 & 0.000 & 0.000 & 17.965 & 56.121 & 26.073 & 0.159 & 0.636 & 0.795 & 3.498 \\
\hline & & 5 & 0.000 & 0.000 & 26.599 & 49.832 & 23.232 & 0.168 & 0.505 & 0.673 & 2.020 \\
\hline & & $1-5$ & 0.000 & 0.000 & 21.251 & 55.403 & 23.346 & 0.229 & 0.622 & 0.688 & 5.075 \\
\hline \multirow{6}{*}{ Bryan Rock } & \multirow{6}{*}{ Quarried } & 1 & 0.000 & 0.000 & 29.361 & 57.686 & 12.608 & 0.000 & 0.000 & 0.000 & 10.190 \\
\hline & & 2 & 0.000 & 0.000 & 24.866 & 61.002 & 15.742 & 0.000 & 0.000 & 0.000 & 0.000 \\
\hline & & 3 & 0.000 & 0.000 & 20.333 & 59.833 & 18.167 & 0.000 & 0.000 & 0.000 & 0.000 \\
\hline & & 4 & 0.000 & 0.000 & 21.465 & 58.262 & 20.273 & 0.000 & 0.000 & 0.000 & 0.000 \\
\hline & & 5 & 0.000 & 0.000 & 18.951 & 58.206 & 23.519 & 0.000 & 0.169 & 0.169 & 0.677 \\
\hline & & $1-5$ & 0.000 & 0.000 & 22.942 & 58.985 & 18.107 & 0.000 & 0.034 & 0.034 & 2.160 \\
\hline \multirow{6}{*}{$\begin{array}{l}\text { Cedarville } \\
\text { Plant }\end{array}$} & \multirow{6}{*}{ Quarried } & 1 & 0.000 & 0.000 & 13.365 & 50.943 & 35.535 & 0.314 & 0.157 & 0.000 & 1.415 \\
\hline & & 2 & 0.000 & 0.000 & 17.391 & 48.161 & 32.609 & 0.334 & 0.502 & 0.000 & 1.505 \\
\hline & & 3 & 0.000 & 0.000 & 17.206 & 55.537 & 27.087 & 0.511 & 0.170 & 0.000 & 1.533 \\
\hline & & 4 & 0.000 & 0.000 & 15.552 & 57.023 & 26.254 & 0.000 & 0.334 & 0.167 & 2.843 \\
\hline & & 5 & 0.000 & 0.000 & 15.232 & 52.815 & 31.788 & 0.497 & 0.166 & 0.166 & 0.662 \\
\hline & & $1-5$ & 0.000 & 0.000 & 15.713 & 52.861 & 30.731 & 0.331 & 0.265 & 0.066 & 1.588 \\
\hline
\end{tabular}


Table C.6. HFT results (normalized, particle counts) for small chamber samples (12.5 to $19 \mathrm{~mm}$ [0.5 in to 0.75 in])(cont.).

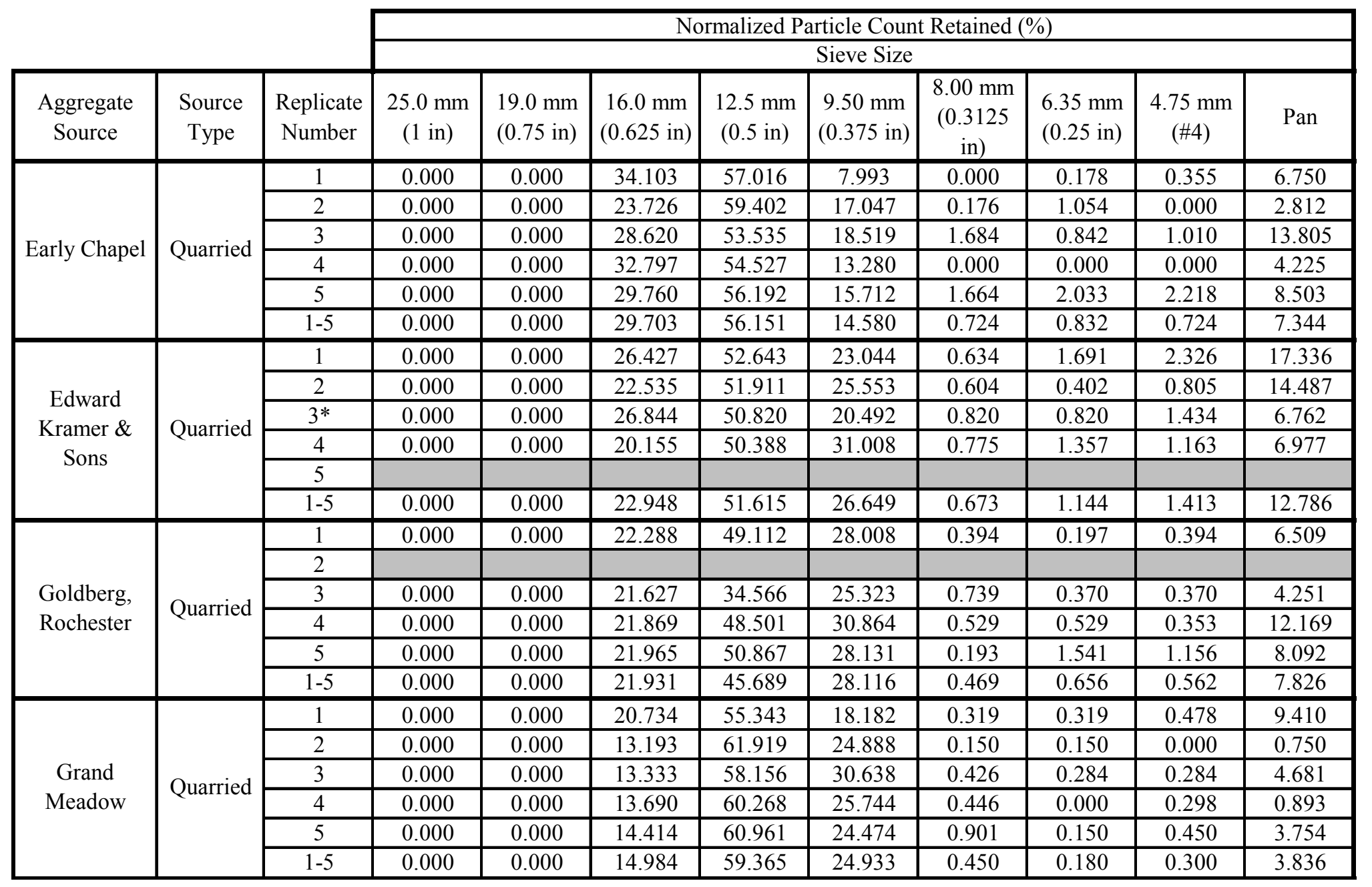


Table C.6. HFT results (normalized, particle counts) for small chamber samples (12.5 to $19 \mathrm{~mm}$ [0.5 in to $0.75 \mathrm{in}]$ )(cont.).

\begin{tabular}{|c|c|c|c|c|c|c|c|c|c|c|c|}
\hline \multirow{3}{*}{$\begin{array}{c}\text { Aggregate } \\
\text { Source }\end{array}$} & \multirow[b]{3}{*}{$\begin{array}{l}\text { Source } \\
\text { Type }\end{array}$} & \multirow[b]{3}{*}{$\begin{array}{l}\text { Replicate } \\
\text { Number }\end{array}$} & \multicolumn{9}{|c|}{ Normalized Particle Count Retained (\%) } \\
\hline & & & \multicolumn{9}{|c|}{ Sieve Size } \\
\hline & & & $\begin{array}{l}25.0 \mathrm{~mm} \\
(1 \mathrm{in})\end{array}$ & $\begin{array}{l}19.0 \mathrm{~mm} \\
(0.75 \mathrm{in})\end{array}$ & $\begin{array}{c}16.0 \mathrm{~mm} \\
(0.625 \mathrm{in})\end{array}$ & $\begin{array}{l}12.5 \mathrm{~mm} \\
(0.5 \mathrm{in})\end{array}$ & $\begin{array}{c}9.50 \mathrm{~mm} \\
(0.375 \mathrm{in})\end{array}$ & $\begin{array}{c}8.00 \mathrm{~mm} \\
(0.3125 \\
\text { in })\end{array}$ & $\begin{array}{l}6.35 \mathrm{~mm} \\
(0.25 \mathrm{in})\end{array}$ & $\begin{array}{l}4.75 \mathrm{~mm} \\
\quad(\# 4)\end{array}$ & Pan \\
\hline \multirow{6}{*}{ Halma } & \multirow{6}{*}{ Gravel } & 1 & 0.000 & 0.198 & 30.693 & 57.228 & 11.683 & 0.000 & 0.396 & 0.594 & 10.099 \\
\hline & & 2 & 0.000 & 0.000 & 34.914 & 57.759 & 7.328 & 0.862 & 0.647 & 1.509 & 5.819 \\
\hline & & 3 & 0.000 & 0.000 & 32.770 & 57.082 & 10.359 & 0.211 & 0.423 & 0.211 & 9.937 \\
\hline & & 4 & 0.000 & 0.000 & 30.488 & 56.911 & 12.602 & 0.407 & 0.000 & 0.203 & 4.675 \\
\hline & & 5 & 0.000 & 0.000 & 32.623 & 59.488 & 8.529 & 0.213 & 0.426 & 0.426 & 2.772 \\
\hline & & $1-5$ & 0.000 & 0.000 & 32.666 & 57.798 & 9.747 & 0.421 & 0.369 & 0.580 & 5.796 \\
\hline \multirow{6}{*}{$\begin{array}{l}\text { Johnson, } \\
\text { Henderson }\end{array}$} & \multirow{6}{*}{ Gravel } & 1 & 0.000 & 0.000 & 27.523 & 58.349 & 8.440 & 1.284 & 0.183 & 0.183 & 4.220 \\
\hline & & 2 & 0.000 & 0.000 & 19.967 & 61.551 & 18.482 & 0.165 & 0.660 & 0.660 & 1.650 \\
\hline & & 3 & 0.000 & 0.000 & 20.868 & 59.599 & 19.199 & 0.334 & 0.167 & 0.501 & 0.000 \\
\hline & & 4 & 0.000 & 0.000 & 19.934 & 60.626 & 19.934 & 0.988 & 0.824 & 0.494 & 10.214 \\
\hline & & 5 & 0.000 & 0.000 & 16.990 & 59.871 & 22.492 & 0.485 & 0.000 & 0.485 & 1.424 \\
\hline & & $1-5$ & 0.000 & 0.000 & 20.908 & 60.034 & 17.916 & 0.639 & 0.370 & 0.471 & 3.489 \\
\hline \multirow{6}{*}{$\begin{array}{c}\text { Johnson, Le } \\
\text { Sueur }\end{array}$} & \multirow{6}{*}{ Gravel } & 1 & 0.000 & 0.000 & 32.179 & 52.749 & 15.479 & 0.204 & 1.833 & 1.222 & 10.794 \\
\hline & & 2 & 0.000 & 0.000 & 27.406 & 58.368 & 13.389 & 0.628 & 2.092 & 2.301 & 35.146 \\
\hline & & 3 & 0.000 & 0.000 & 29.774 & 57.906 & 12.115 & 0.821 & 0.616 & 2.875 & 15.811 \\
\hline & & 4 & 0.000 & 0.000 & 32.099 & 55.556 & 12.757 & 0.617 & 0.823 & 2.263 & 19.753 \\
\hline & & 5 & 0.000 & 0.000 & 27.912 & 59.438 & 12.651 & 0.201 & 1.004 & 0.602 & 20.683 \\
\hline & & $1-5$ & 0.000 & 0.000 & 29.877 & 56.803 & 13.279 & 0.492 & 1.270 & 1.844 & 20.369 \\
\hline \multirow{6}{*}{$\begin{array}{c}\text { Mark, } \\
\text { Underwood }\end{array}$} & \multirow{6}{*}{ Gravel } & 1 & 0.000 & 0.000 & 33.983 & 51.948 & 11.905 & 0.433 & 0.866 & 0.216 & 8.225 \\
\hline & & 2 & 0.000 & 0.000 & 36.383 & 55.338 & 8.061 & 0.654 & 1.307 & 1.089 & 23.529 \\
\hline & & 3 & 0.000 & 0.000 & 32.903 & 56.774 & 10.108 & 0.000 & 0.860 & 0.860 & 29.247 \\
\hline & & 4 & 0.000 & 0.000 & 27.521 & 61.765 & 10.504 & 0.630 & 0.420 & 0.630 & 12.605 \\
\hline & & 5 & 0.000 & 0.000 & 19.252 & 65.047 & 15.888 & 0.000 & 0.374 & 0.561 & 5.047 \\
\hline & & $1-5$ & 0.000 & 0.000 & 29.662 & 58.406 & 11.431 & 0.334 & 0.751 & 0.668 & 15.394 \\
\hline
\end{tabular}


Table C.6. HFT results (normalized, particle counts) for small chamber samples (12.5 to $19 \mathrm{~mm}$ [ 0.5 in to $0.75 \mathrm{in}]$ )(cont.).

\begin{tabular}{|c|c|c|c|c|c|c|c|c|c|c|c|}
\hline & & & \multirow{2}{*}{\multicolumn{9}{|c|}{ Normalized Particle Count Retained (\%) }} \\
\hline & & & & & & & & & & & \\
\hline & & & \multicolumn{9}{|c|}{ Sieve Size } \\
\hline $\begin{array}{l}\text { Aggregate } \\
\text { Source }\end{array}$ & $\begin{array}{l}\text { Source } \\
\text { Type }\end{array}$ & $\begin{array}{l}\text { Replicate } \\
\text { Number }\end{array}$ & $\begin{array}{c}25.0 \mathrm{~mm} \\
(1 \mathrm{in})\end{array}$ & $\begin{array}{l}19.0 \mathrm{~mm} \\
(0.75 \mathrm{in})\end{array}$ & $\begin{array}{c}16.0 \mathrm{~mm} \\
(0.625 \mathrm{in})\end{array}$ & $\begin{array}{c}12.5 \mathrm{~mm} \\
(0.5 \mathrm{in})\end{array}$ & $\begin{array}{c}9.50 \mathrm{~mm} \\
(0.375 \mathrm{in})\end{array}$ & $\begin{array}{c}8.00 \mathrm{~mm} \\
(0.3125 \\
\text { in })\end{array}$ & $\begin{array}{l}6.35 \mathrm{~mm} \\
(0.25 \mathrm{in})\end{array}$ & $\begin{array}{l}4.75 \mathrm{~mm} \\
\quad(\# 4)\end{array}$ & Pan \\
\hline \multirow{6}{*}{$\begin{array}{c}\text { Northern Con, } \\
\text { Luverne }\end{array}$} & \multirow{6}{*}{ Gravel } & 1 & 0.000 & 0.000 & 38.406 & 50.966 & 12.319 & 0.483 & 0.242 & 0.483 & 6.280 \\
\hline & & 2 & 0.000 & 0.000 & 24.843 & 61.378 & 13.987 & 2.088 & 1.670 & 1.253 & 5.428 \\
\hline & & 3 & 0.000 & 0.000 & 35.635 & 51.225 & 13.363 & 0.445 & 0.445 & 0.223 & 7.572 \\
\hline & & 4 & 0.000 & 0.000 & 41.943 & 47.461 & 10.596 & 1.104 & 1.325 & 0.662 & 9.713 \\
\hline & & 5 & 0.000 & 0.000 & 29.412 & 63.655 & 10.294 & 0.630 & 0.210 & 1.050 & 10.084 \\
\hline & & $1-5$ & 0.000 & 0.000 & 33.818 & 55.174 & 12.109 & 0.969 & 0.793 & 0.749 & 7.838 \\
\hline \multirow{6}{*}{$\begin{array}{l}\text { North Star } \\
\text { Kasota }\end{array}$} & \multirow{6}{*}{ Gravel } & 1 & 0.000 & 0.000 & 39.817 & 55.378 & 2.517 & 1.144 & 0.915 & 1.602 & 21.281 \\
\hline & & 2 & 0.000 & 0.000 & 27.799 & 62.127 & 10.448 & 0.560 & 0.560 & 1.306 & 5.970 \\
\hline & & 3 & 0.000 & 0.000 & 32.703 & 56.900 & 10.397 & 0.567 & 0.378 & 1.890 & 10.586 \\
\hline & & 4 & 0.000 & 0.000 & 30.658 & 60.494 & 9.877 & 0.412 & 0.000 & 0.206 & 9.259 \\
\hline & & 5 & 0.000 & 0.000 & 35.382 & 53.631 & 10.242 & 1.304 & 0.931 & 1.862 & 36.685 \\
\hline & & $1-5$ & 0.000 & 0.000 & 33.069 & 57.743 & 8.911 & 0.792 & 0.554 & 1.386 & 16.752 \\
\hline \multirow{6}{*}{$\begin{array}{c}\text { Shiely Grey } \\
\text { Cloud }\end{array}$} & \multirow{6}{*}{ Quarried } & 1 & 0.000 & 0.000 & 32.679 & 48.214 & 18.571 & 0.714 & 1.607 & 1.250 & 16.250 \\
\hline & & 2 & 0.000 & 0.000 & 36.145 & 47.992 & 16.265 & 0.000 & 0.000 & 0.000 & 2.410 \\
\hline & & 3 & 0.000 & 0.000 & 28.998 & 44.640 & 26.538 & 0.000 & 0.527 & 0.527 & 0.000 \\
\hline & & 4 & 0.000 & 0.000 & 35.630 & 39.567 & 24.606 & 0.197 & 0.197 & 0.197 & 1.772 \\
\hline & & 5 & 0.000 & 0.000 & 34.100 & 44.636 & 21.264 & 0.192 & 0.575 & 1.149 & 5.747 \\
\hline & & $1-5$ & 0.000 & 0.000 & 33.384 & 45.051 & 21.528 & 0.226 & 0.602 & 0.640 & 5.344 \\
\hline \multirow{6}{*}{ SMC Mankato } & \multirow{6}{*}{ Quarried } & 1 & 0.000 & 0.000 & 20.000 & 56.975 & 23.025 & 1.176 & 0.840 & 1.345 & 7.899 \\
\hline & & 2 & 0.000 & 0.000 & 21.478 & 56.186 & 22.165 & 1.546 & 2.577 & 2.749 & 6.701 \\
\hline & & 3 & 0.000 & 0.000 & 22.320 & 58.172 & 20.211 & 0.351 & 0.527 & 1.757 & 2.812 \\
\hline & & 4 & & & & & & & & & \\
\hline & & 5 & 0.000 & 0.000 & 18.771 & 58.874 & 22.014 & 0.683 & 2.560 & 2.048 & 18.942 \\
\hline & & $1-5$ & 0.000 & 0.000 & 20.626 & 57.547 & 21.870 & 0.943 & 1.630 & 1.973 & 9.134 \\
\hline
\end{tabular}


Table C.6. HFT results (normalized, particle counts) for small chamber samples (12.5 to $19 \mathrm{~mm}$ [0.5 in to 0.75 in])(cont.).

\begin{tabular}{|c|c|c|c|c|c|c|c|c|c|c|c|}
\hline & & \multicolumn{9}{|c|}{ Normalized Particle Count Retained (\%) } \\
\hline & & & \multicolumn{9}{|c|}{ Sieve Size } \\
\hline $\begin{array}{l}\text { Aggregate } \\
\text { Source }\end{array}$ & $\begin{array}{l}\text { Source } \\
\text { Type }\end{array}$ & $\begin{array}{c}\text { Replicate } \\
\text { Number }\end{array}$ & $\begin{array}{c}25.0 \mathrm{~mm} \\
(1 \mathrm{in})\end{array}$ & $\begin{array}{l}19.0 \mathrm{~mm} \\
(0.75 \mathrm{in})\end{array}$ & $\begin{array}{c}16.0 \mathrm{~mm} \\
(0.625 \mathrm{in})\end{array}$ & $\begin{array}{c}12.5 \mathrm{~mm} \\
(0.5 \mathrm{in})\end{array}$ & $\begin{array}{c}9.50 \mathrm{~mm} \\
(0.375 \mathrm{in})\end{array}$ & $\begin{array}{c}8.00 \mathrm{~mm} \\
(0.3125 \\
\text { in })\end{array}$ & $\begin{array}{l}6.35 \mathrm{~mm} \\
(0.25 \mathrm{in})\end{array}$ & $\begin{array}{l}4.75 \mathrm{~mm} \\
(\# 4)\end{array}$ & Pan \\
\hline \multirow{6}{*}{ Swedberg } & \multirow{6}{*}{ Quarried } & 1 & 0.000 & 0.000 & 49.288 & 60.969 & 19.088 & 1.994 & 2.279 & 3.134 & 45.584 \\
\hline & & 2 & 0.000 & 0.000 & 40.169 & 41.649 & 19.239 & 1.057 & 1.480 & 4.017 & 56.237 \\
\hline & & 3 & 0.000 & 0.000 & 40.476 & 45.022 & 16.234 & 0.433 & 0.866 & 1.948 & 14.286 \\
\hline & & 4 & 0.000 & 0.000 & 45.567 & 44.335 & 10.837 & 0.739 & 0.985 & 1.478 & 28.325 \\
\hline & & 5 & 0.000 & 0.000 & 43.000 & 62.500 & 19.500 & 1.000 & 2.000 & 2.500 & 6.250 \\
\hline & & $1-5$ & 0.000 & 0.000 & 43.356 & 50.143 & 16.969 & 1.004 & 1.482 & 2.629 & 30.210 \\
\hline \multirow{6}{*}{$\begin{array}{c}\text { Ulland } \\
\text { Northwood }\end{array}$} & \multirow{6}{*}{ Quarried } & 1 & 0.000 & 0.000 & 15.968 & 54.677 & 29.355 & 0.000 & 0.484 & 0.161 & 5.484 \\
\hline & & 2 & 0.000 & 0.000 & 18.562 & 53.010 & 28.094 & 0.836 & 1.672 & 0.669 & 7.023 \\
\hline & & 3 & 0.000 & 0.000 & 19.793 & 53.184 & 27.539 & 0.172 & 0.172 & 0.516 & 3.959 \\
\hline & & 4 & 0.000 & 0.000 & 21.756 & 52.863 & 25.000 & 0.573 & 0.191 & 0.954 & 5.725 \\
\hline & & 5 & 0.000 & 0.000 & 21.996 & 56.007 & 22.366 & 0.185 & 0.370 & 0.185 & 6.100 \\
\hline & & $1-5$ & 0.000 & 0.000 & 19.483 & 53.946 & 26.606 & 0.349 & 0.594 & 0.489 & 5.656 \\
\hline \multirow{6}{*}{ Waterloo } & \multirow{6}{*}{ Quarried } & 1 & 0.000 & 0.000 & 17.742 & 53.548 & 29.194 & 0.484 & 0.323 & 0.000 & 2.097 \\
\hline & & 2 & 0.000 & 0.000 & 19.544 & 57.980 & 22.801 & 0.489 & 0.163 & 0.489 & 7.492 \\
\hline & & 3 & 0.000 & 0.000 & 19.295 & 57.215 & 26.846 & 0.168 & 0.336 & 0.000 & 0.168 \\
\hline & & 4 & 0.000 & 0.000 & 21.565 & 56.522 & 21.739 & 0.000 & 0.000 & 0.000 & 2.783 \\
\hline & & 5 & 0.000 & 0.000 & 15.605 & 52.548 & 32.803 & 0.000 & 0.159 & 0.159 & 4.299 \\
\hline & & $1-5$ & 0.000 & 0.000 & 18.694 & 55.523 & 26.772 & 0.231 & 0.198 & 0.132 & 3.396 \\
\hline \multirow{6}{*}{ Zumbrota } & \multirow{6}{*}{ Quarried } & 1 & 0.000 & 0.000 & 31.309 & 49.526 & 19.545 & 0.759 & 0.569 & 1.518 & 9.677 \\
\hline & & 2 & 0.000 & 0.000 & 25.408 & 56.987 & 19.056 & 1.633 & 1.815 & 1.815 & 15.608 \\
\hline & & 3 & 0.000 & 0.000 & 31.915 & 55.319 & 15.280 & 0.387 & 1.354 & 0.967 & 5.029 \\
\hline & & 4 & 0.000 & 0.000 & 28.519 & 49.909 & 21.389 & 0.914 & 0.914 & 0.731 & 10.969 \\
\hline & & 5 & 0.000 & 0.000 & 27.239 & 53.382 & 20.841 & 1.280 & 1.280 & 2.559 & 16.453 \\
\hline & & $1-5$ & 0.000 & 0.000 & 28.821 & 53.031 & 19.264 & 1.004 & 1.190 & 1.525 & 11.640 \\
\hline
\end{tabular}


Table C.7. HFT results (mass retained) for small chamber samples (19.0 to $37.5 \mathrm{~mm}$ [0.75 to $1.5 \mathrm{in}]$ ).

\begin{tabular}{|c|c|c|c|c|c|c|c|c|c|c|c|c|}
\hline & & & \multicolumn{10}{|c|}{ Mass Retained (g) } \\
\hline & & & \multirow{2}{*}{0 Cycles } & \multicolumn{9}{|c|}{ After 50 Cycles } \\
\hline & & & & \multicolumn{9}{|c|}{ Sieve Sizes } \\
\hline $\begin{array}{l}\text { Aggregate } \\
\text { Source }\end{array}$ & $\begin{array}{l}\text { Source } \\
\text { Type }\end{array}$ & $\begin{array}{c}\text { Replicate } \\
\text { Number }\end{array}$ & Total & $\begin{array}{l}25.0 \mathrm{~mm} \\
(1 \mathrm{in})\end{array}$ & $\begin{array}{l}19.0 \mathrm{~mm} \\
(0.75 \mathrm{in})\end{array}$ & $\begin{array}{c}16.0 \mathrm{~mm} \\
(0.625 \mathrm{in})\end{array}$ & $\begin{array}{c}12.5 \mathrm{~mm} \\
(0.5 \mathrm{in})\end{array}$ & $\begin{array}{c}9.50 \mathrm{~mm} \\
(0.375 \mathrm{in})\end{array}$ & $\begin{array}{c}8.00 \mathrm{~mm} \\
(0.3125 \\
\text { in })\end{array}$ & $\begin{array}{l}6.35 \mathrm{~mm} \\
(0.25 \mathrm{in})\end{array}$ & $\begin{array}{c}4.75 \mathrm{~mm} \\
(\# 4)\end{array}$ & Pan \\
\hline \multirow{6}{*}{$\begin{array}{l}\text { Ashwill, } \\
\text { Kingston }\end{array}$} & \multirow{6}{*}{ Gravel } & 1 & & & & & & & & & & \\
\hline & & 2 & & & & & & & & & & \\
\hline & & 3 & & & & & & & & & & \\
\hline & & 4 & & & & & & & & & & \\
\hline & & 5 & & & & & & & & & & \\
\hline & & $1-5$ & & & & & & & & & & \\
\hline \multirow{6}{*}{$\begin{array}{c}\text { Big Springs, } \\
\text { Harmony }\end{array}$} & \multirow{6}{*}{ Quarried } & 1 & 3087.5 & 1911.8 & 1039.6 & 108.0 & 0.0 & 7.2 & 1.3 & 3.1 & 0.7 & 11.1 \\
\hline & & 2 & 3158.9 & 2029.6 & 1068.4 & 33.5 & 3.4 & 1.4 & 0.0 & 1.0 & 0.4 & 9.8 \\
\hline & & 3 & 3047.4 & 2383.4 & 595.6 & 27.4 & 21.6 & 0.0 & 2.3 & 0.0 & 1.2 & 5.4 \\
\hline & & 4 & 3017.9 & 1593.6 & 1305.4 & 100.2 & 0.0 & 0.0 & 0.0 & 0.0 & 0.3 & 7.2 \\
\hline & & 5 & 3041.3 & 1841.6 & 997.7 & 155.1 & 0.0 & 11.8 & 1.4 & 4.5 & 1.1 & 15.0 \\
\hline & & $1-5$ & 15353.0 & 9760.0 & 5006.7 & 424.2 & 25.0 & 20.4 & 5.0 & 8.6 & 3.7 & 48.5 \\
\hline \multirow{6}{*}{ Bryan Rock } & \multirow{6}{*}{ Quarried } & 1 & 3024.9 & 1580.3 & 1214.8 & 200.7 & 3.9 & 5.7 & 1.9 & 2.2 & 1.2 & 9.3 \\
\hline & & 2 & 2992.7 & 1472.2 & 1366.7 & 124.9 & 4.0 & 0.0 & 0.0 & 3.7 & 1.0 & 10.0 \\
\hline & & 3 & 2953.2 & 1335.0 & 1440.5 & 199.4 & 8.0 & 0.0 & 0.0 & 1.1 & 0.0 & 8.1 \\
\hline & & 4 & 2389.8 & 687.4 & 1454.4 & 227.5 & 0.0 & 1.0 & 0.0 & 0.0 & 0.0 & 9.2 \\
\hline & & 5 & 3000.7 & 1353.2 & 1277.4 & 328.2 & 0.0 & 9.7 & 0.0 & 1.4 & 0.6 & 18.9 \\
\hline & & $1-5$ & 14361.3 & 6428.1 & 6753.8 & 1080.7 & 15.9 & 16.4 & 1.9 & 8.4 & 2.8 & 55.5 \\
\hline \multirow{6}{*}{$\begin{array}{c}\text { Cedarville } \\
\text { Plant }\end{array}$} & \multirow{6}{*}{ Quarried } & 1 & 3008.4 & 793.8 & 2112.8 & 81.2 & 5.1 & 0.0 & 0.0 & 1.0 & 0.0 & 7.8 \\
\hline & & 2 & 3079.9 & 902.1 & 2005.9 & 158.5 & 0.0 & 0.0 & 0.0 & 0.0 & 0.0 & 4.5 \\
\hline & & 3 & 3017.5 & 956.9 & 1877.6 & 162.2 & 6.2 & 2.7 & 0.0 & 0.0 & 0.1 & 4.5 \\
\hline & & 4 & & & & & & & & & & \\
\hline & & 5 & 3056.4 & 734.0 & 2043.7 & 245.0 & 2.6 & 4.0 & 1.6 & 1.5 & 0.6 & 10.9 \\
\hline & & $1-5$ & 12162.2 & 3386.8 & 8040.0 & 646.9 & 13.9 & 6.7 & 1.6 & 2.5 & 0.7 & 27.7 \\
\hline
\end{tabular}


Table C.7. HFT results (mass retained) for small chamber samples (19.0 to $37.5 \mathrm{~mm}$ [0.75 to 1.5 in]) (cont.).

\begin{tabular}{|c|c|c|c|c|c|c|c|c|c|c|c|c|}
\hline & & & & & & & \multicolumn{3}{|c|}{ Mass Retained (g) } & & & \\
\hline & & & \multirow{2}{*}{0 Cycles } & \multicolumn{9}{|c|}{ After 50 Cycles } \\
\hline & & & & \multicolumn{9}{|c|}{ Sieve Sizes } \\
\hline $\begin{array}{l}\text { Aggregate } \\
\text { Source }\end{array}$ & $\begin{array}{l}\text { Source } \\
\text { Type }\end{array}$ & $\begin{array}{c}\text { Replicate } \\
\text { Number }\end{array}$ & Total & $\begin{array}{l}25.0 \mathrm{~mm} \\
(1 \mathrm{in})\end{array}$ & $\begin{array}{l}19.0 \mathrm{~mm} \\
(0.75 \mathrm{in})\end{array}$ & $\begin{array}{c}16.0 \mathrm{~mm} \\
(0.625 \mathrm{in})\end{array}$ & $\begin{array}{c}12.5 \mathrm{~mm} \\
(0.5 \mathrm{in})\end{array}$ & $\begin{array}{c}9.50 \mathrm{~mm} \\
(0.375 \mathrm{in})\end{array}$ & $\begin{array}{c}8.00 \mathrm{~mm} \\
(0.3125 \\
\text { in) }\end{array}$ & $\begin{array}{l}6.35 \mathrm{~mm} \\
(0.25 \mathrm{in})\end{array}$ & $\begin{array}{l}4.75 \mathrm{~mm} \\
(\# 4)\end{array}$ & Pan \\
\hline \multirow{6}{*}{ Early Chapel } & \multirow{6}{*}{ Quarried } & 1 & 3027.8 & 206.5 & 2429.6 & 373.6 & 0.0 & 1.8 & 2.1 & 1.6 & 0.2 & 6.4 \\
\hline & & 2 & 3014.0 & 204.0 & 2417.8 & 348.9 & 7.3 & 0.0 & 1.5 & 0.5 & 0.8 & 16.8 \\
\hline & & 3 & 3046.8 & 106.4 & 2414.0 & 478.1 & 7.3 & 0.0 & 1.9 & 0.0 & 0.4 & 24.2 \\
\hline & & 4 & 2911.0 & 0.0 & 2322.6 & 548.6 & 0.0 & 1.6 & 0.0 & 0.6 & 0.0 & 19.3 \\
\hline & & 5 & 3013.0 & 203.7 & 2125.3 & 641.3 & 0.0 & 1.0 & 0.0 & 1.3 & 0.0 & 22.3 \\
\hline & & $1-5$ & 15012.6 & 720.6 & 11709.3 & 2390.5 & 14.6 & 4.4 & 5.5 & 4.0 & 1.4 & 89.0 \\
\hline \multirow{6}{*}{$\begin{array}{c}\text { Edward } \\
\text { Kramer \& } \\
\text { Sons }\end{array}$} & \multirow{6}{*}{ Quarried } & 1 & 2901.1 & 662.7 & 1885.4 & 269.6 & 25.0 & 0.0 & 2.6 & 1.7 & 1.4 & 23.3 \\
\hline & & 2 & 2785.0 & 1040.2 & 1449.8 & 245.6 & 6.9 & 2.3 & 1.3 & 0.9 & 0.6 & 22.5 \\
\hline & & 3 & 2889.2 & 1032.5 & 1659.3 & 147.4 & 3.1 & 0.9 & 0.2 & 0.0 & 0.7 & 25.7 \\
\hline & & 4 & 2888.4 & 1003.6 & 1436.4 & 392.0 & 6.3 & 0.0 & 0.0 & 1.5 & 1.1 & 31.1 \\
\hline & & 5 & 2916.0 & 1080.4 & 1211.7 & 566.4 & 0.0 & 3.4 & 0.0 & 1.4 & 0.3 & 34.1 \\
\hline & & $1-5$ & 14379.7 & 4819.4 & 7642.6 & 1621.0 & 41.3 & 6.6 & 4.1 & 5.5 & 4.1 & 136.7 \\
\hline \multirow{6}{*}{$\begin{array}{l}\text { Goldberg, } \\
\text { Rochester }\end{array}$} & \multirow{6}{*}{ Quarried } & 1 & 3007.6 & 1755.2 & 1071.5 & 119.4 & 28.9 & 4.9 & 1.3 & 2.7 & 0.6 & 13.9 \\
\hline & & 2 & 3005.8 & 1165.4 & 1702.8 & 104.1 & 0.0 & 5.1 & 1.3 & 3.4 & 0.8 & 10.6 \\
\hline & & 3 & 3011.4 & 1149.2 & 1753.5 & 78.2 & 0.0 & 0.0 & 0.0 & 0.6 & 0.2 & 16.8 \\
\hline & & 4 & 2804.1 & 1012.9 & 1353.7 & 394.3 & 0.0 & 3.6 & 0.0 & 0.3 & 0.6 & 26.5 \\
\hline & & 5 & 2992.3 & 788.7 & 1932.9 & 167.1 & 39.8 & 9.8 & 5.8 & 3.5 & 1.9 & 29.2 \\
\hline & & $1-5$ & 14821.2 & 5871.4 & 7814.4 & 863.1 & 68.7 & 23.4 & 8.4 & 10.5 & 4.1 & 97.0 \\
\hline \multirow{6}{*}{$\begin{array}{c}\text { Grand } \\
\text { Meadow }\end{array}$} & \multirow{6}{*}{ Quarried } & 1 & 3057.0 & 1064.4 & 1546.5 & 380.4 & 13.7 & 4.5 & 1.3 & 1.5 & 0.8 & 6.5 \\
\hline & & 2 & 3011.4 & 1268.5 & 1520.1 & 169.0 & 7.8 & 1.4 & 0.0 & 2.4 & 0.0 & 12.2 \\
\hline & & 3 & 2848.8 & 796.8 & 1665.7 & 346.4 & 0.0 & 8.9 & 0.8 & 0.6 & 0.5 & 16.3 \\
\hline & & 4 & 3081.8 & 694.4 & 1411.5 & 886.3 & 24.2 & 3.8 & 2.6 & 1.6 & 1.8 & 32.1 \\
\hline & & 5 & 3071.9 & 785.0 & 1653.0 & 594.5 & 0.0 & 3.3 & 0.0 & 2.3 & 0.0 & 14.5 \\
\hline & & $1-5$ & 15070.9 & 4609.1 & 7796.8 & 2376.6 & 45.7 & 21.9 & 4.7 & 8.4 & 3.1 & 81.6 \\
\hline
\end{tabular}


Table C.7. HFT results (mass retained) for small chamber samples (19.0 to $37.5 \mathrm{~mm}$ [0.75 to $1.5 \mathrm{in}]$ ) (cont.).

\begin{tabular}{|c|c|c|c|c|c|c|c|c|c|c|c|c|}
\hline & & & \multirow{2}{*}{\multicolumn{10}{|c|}{ Mass Retained $(\mathrm{g})$}} \\
\hline & & & & & & & & & & & & \\
\hline & & & \multirow{2}{*}{0 Cycles } & \multicolumn{9}{|c|}{ After 50 Cycles } \\
\hline & & & & \multicolumn{9}{|c|}{ Sieve Sizes } \\
\hline $\begin{array}{l}\text { Aggregate } \\
\text { Source }\end{array}$ & $\begin{array}{c}\text { Source } \\
\text { Type }\end{array}$ & $\begin{array}{c}\text { Replicate } \\
\text { Number }\end{array}$ & Total & $\begin{array}{c}25.0 \mathrm{~mm} \\
(1 \mathrm{in})\end{array}$ & $\begin{array}{l}19.0 \mathrm{~mm} \\
(0.75 \mathrm{in})\end{array}$ & $\begin{array}{c}16.0 \mathrm{~mm} \\
(0.625 \mathrm{in})\end{array}$ & $\begin{array}{c}12.5 \mathrm{~mm} \\
(0.5 \mathrm{in})\end{array}$ & $\begin{array}{c}9.50 \mathrm{~mm} \\
(0.375 \mathrm{in})\end{array}$ & $\begin{array}{c}8.00 \mathrm{~mm} \\
(0.3125 \\
\text { in })\end{array}$ & $\begin{array}{l}6.35 \mathrm{~mm} \\
(0.25 \mathrm{in})\end{array}$ & $\begin{array}{c}4.75 \mathrm{~mm} \\
(\# 4)\end{array}$ & Pan \\
\hline \multirow{6}{*}{ Halma } & \multirow{6}{*}{ Gravel } & 1 & 3080.3 & 0.0 & 2770.3 & 290.2 & 0.0 & 0.0 & 0.0 & 0.0 & 0.0 & 5.3 \\
\hline & & 2 & 3092.5 & 0.0 & 2682.6 & 387.7 & 6.1 & 2.6 & 1.2 & 0.6 & 0.4 & 6.4 \\
\hline & & 3 & 3063.3 & 0.0 & 2708.2 & 338.4 & 0.0 & 1.9 & 0.0 & 0.0 & 0.0 & 7.6 \\
\hline & & 4 & 3050.7 & 0.0 & 2746.9 & 289.3 & 0.0 & 0.0 & 0.0 & 0.0 & 0.0 & 7.0 \\
\hline & & 5 & 3103.6 & 0.0 & 2711.0 & 366.7 & 5.8 & 3.1 & 0.0 & 0.4 & 0.2 & 10.3 \\
\hline & & $1-5$ & 15390.4 & 0.0 & 13619.0 & 1672.3 & 11.9 & 7.6 & 1.2 & 1.0 & 0.6 & 36.6 \\
\hline \multirow{6}{*}{$\begin{array}{l}\text { Johnson, } \\
\text { Henderson }\end{array}$} & \multirow{6}{*}{ Gravel } & 1 & 3116.2 & 1932.5 & 1105.2 & 61.2 & 7.6 & 0.0 & 0.0 & 0.0 & 0.0 & 5.1 \\
\hline & & 2 & 3088.5 & 1784.1 & 1224.6 & 22.8 & 0.0 & 12.7 & 8.3 & 8.5 & 3.3 & 25.4 \\
\hline & & 3 & 3104.2 & 1703.4 & 1304.9 & 69.8 & 8.1 & 2.3 & 0.0 & 0.0 & 0.0 & 6.7 \\
\hline & & 4 & 3118.4 & 1705.4 & 1340.1 & 44.8 & 4.5 & 4.1 & 0.0 & 0.0 & 0.3 & 9.2 \\
\hline & & 5 & 3097.8 & 1989.9 & 933.9 & 153.4 & 0.0 & 0.0 & 0.0 & 0.0 & 0.1 & 8.9 \\
\hline & & $1-5$ & 15525.1 & 9115.3 & 5908.7 & 352.0 & 20.2 & 19.1 & 8.3 & 8.5 & 3.7 & 55.3 \\
\hline \multirow{6}{*}{$\begin{array}{l}\text { Johnson, Le } \\
\text { Sueur }\end{array}$} & \multirow{6}{*}{ Gravel } & 1 & 3246.0 & 1120.2 & 2066.3 & 56.9 & 0.0 & 0.0 & 0.0 & 0.0 & 0.0 & 8.7 \\
\hline & & 2 & 3397.9 & 1125.4 & 2087.9 & 104.3 & 5.8 & 13.1 & 6.7 & 7.4 & 7.1 & 25.5 \\
\hline & & 3 & 3261.5 & 962.1 & 2161.1 & 80.4 & 0.0 & 2.4 & 0.9 & 0.2 & 1.0 & 35.4 \\
\hline & & 4 & 3213.6 & 994.9 & 2014.2 & 172.1 & 0.0 & 0.0 & 3.9 & 0.7 & 1.2 & 15.1 \\
\hline & & 5 & 3375.2 & 1103.8 & 1801.9 & 397.8 & 20.8 & 2.6 & 6.5 & 4.1 & 3.1 & 25.7 \\
\hline & & $1-5$ & 16494.2 & 5306.4 & 10131.4 & 811.5 & 26.6 & 18.1 & 18.0 & 12.4 & 12.4 & 110.4 \\
\hline \multirow{6}{*}{$\begin{array}{c}\text { Mark, } \\
\text { Underwood }\end{array}$} & \multirow{6}{*}{ Gravel } & 1 & 3104.9 & 1322.2 & 1580.2 & 215.9 & 0.0 & 0.0 & 0.0 & 0.0 & 0.0 & 2.1 \\
\hline & & 2 & 3135.7 & 1461.1 & 1609.6 & 53.8 & 0.0 & 2.1 & 0.0 & 0.5 & 0.0 & 3.7 \\
\hline & & 3 & 2991.7 & 700.7 & 2045.5 & 205.9 & 14.6 & 0.0 & 2.4 & 1.3 & 0.9 & 13.0 \\
\hline & & 4 & 3125.5 & 1091.2 & 1961.0 & 65.6 & 0.0 & 0.0 & 0.8 & 1.0 & 1.1 & 3.9 \\
\hline & & 5 & 3092.6 & 1005.2 & 1922.3 & 140.2 & 2.5 & 0.0 & 2.7 & 1.6 & 1.6 & 10.7 \\
\hline & & $1-5$ & 15450.4 & 5580.4 & 9118.6 & 681.4 & 17.1 & 2.1 & 5.9 & 4.4 & 3.6 & 33.4 \\
\hline
\end{tabular}


Table C.7. HFT results (mass retained) for small chamber samples (19.0 to $37.5 \mathrm{~mm}$ [0.75 to $1.5 \mathrm{in}]$ ) (cont.).

\begin{tabular}{|c|c|c|c|c|c|c|c|c|c|c|c|c|}
\hline & & & \multirow{2}{*}{\multicolumn{10}{|c|}{ Mass Retained (g) }} \\
\hline & & & & & & & & & & & & \\
\hline & & & \multirow{2}{*}{0 Cycles } & \multicolumn{9}{|c|}{ After 50 Cycles } \\
\hline & & & & \multicolumn{9}{|c|}{ Sieve Sizes } \\
\hline $\begin{array}{l}\text { Aggregate } \\
\text { Source }\end{array}$ & $\begin{array}{l}\text { Source } \\
\text { Type }\end{array}$ & $\begin{array}{c}\text { Replicate } \\
\text { Number }\end{array}$ & Total & $\begin{array}{c}25.0 \mathrm{~mm} \\
(1 \mathrm{in})\end{array}$ & $\begin{array}{l}19.0 \mathrm{~mm} \\
(0.75 \mathrm{in})\end{array}$ & $\begin{array}{c}16.0 \mathrm{~mm} \\
(0.625 \mathrm{in})\end{array}$ & $\begin{array}{c}12.5 \mathrm{~mm} \\
(0.5 \mathrm{in})\end{array}$ & $\begin{array}{c}9.50 \mathrm{~mm} \\
(0.375 \mathrm{in})\end{array}$ & $\begin{array}{c}8.00 \mathrm{~mm} \\
(0.3125 \\
\text { in) }\end{array}$ & $\begin{array}{l}6.35 \mathrm{~mm} \\
(0.25 \mathrm{in})\end{array}$ & $\begin{array}{l}4.75 \mathrm{~mm} \\
(\# 4)\end{array}$ & Pan \\
\hline \multirow{6}{*}{$\begin{array}{l}\text { Northern Con, } \\
\text { Luverne }\end{array}$} & \multirow{6}{*}{ Gravel } & 1 & 3094.6 & 1902.8 & 1083.0 & 86.8 & 15.7 & 3.7 & 0.0 & 0.0 & 0.0 & 3.2 \\
\hline & & 2 & 3048.0 & 2153.8 & 849.9 & 10.8 & 15.1 & 2.6 & 0.0 & 0.5 & 0.7 & 4.9 \\
\hline & & 3 & 3067.7 & 2152.3 & 858.3 & 9.9 & 5.0 & 2.2 & 0.0 & 0.0 & 0.0 & 5.8 \\
\hline & & 4 & 3114.7 & 2353.6 & 711.3 & 40.7 & 0.0 & 0.0 & 0.0 & 0.0 & 0.0 & 2.3 \\
\hline & & 5 & 3075.8 & 1739.9 & 1123.7 & 193.4 & 0.0 & 0.0 & 0.0 & 0.0 & 0.0 & 7.4 \\
\hline & & $1-5$ & 15400.8 & 10302.4 & 4626.2 & 341.6 & 35.8 & 8.5 & 0.0 & 0.5 & 0.7 & 23.6 \\
\hline \multirow{6}{*}{$\begin{array}{c}\text { North Star } \\
\text { Kasota }\end{array}$} & \multirow{6}{*}{ Gravel } & 1 & 3217.9 & 1825.0 & 1341.7 & 45.7 & 0.0 & 2.1 & 0.0 & 0.0 & 0.0 & 0.9 \\
\hline & & 2 & 3289.5 & 1031.1 & 2105.3 & 118.3 & 0.0 & 0.0 & 7.6 & 7.3 & 1.0 & 10.1 \\
\hline & & 3 & 3270.6 & 1279.1 & 1830.4 & 147.2 & 0.0 & 1.3 & 0.0 & 0.0 & 0.0 & 5.1 \\
\hline & & 4 & 3411.6 & 1008.4 & 2179.7 & 165.8 & 15.5 & 20.3 & 1.1 & 2.3 & 0.8 & 9.6 \\
\hline & & 5 & 3402.9 & 907.8 & 2326.1 & 126.5 & 12.4 & 3.5 & 2.1 & 2.4 & 3.0 & 12.5 \\
\hline & & $1-5$ & 16592.5 & 6051.4 & 9783.2 & 603.5 & 27.9 & 27.2 & 10.8 & 12.0 & 4.8 & 38.2 \\
\hline \multirow{6}{*}{$\begin{array}{l}\text { Shiely Grey } \\
\text { Cloud }\end{array}$} & \multirow{6}{*}{ Quarried } & 1 & 3038.4 & 1237.4 & 1589.7 & 175.3 & 12.3 & 3.4 & 0.0 & 0.6 & 0.2 & 8.2 \\
\hline & & 2 & 3039.3 & 924.6 & 1897.9 & 124.2 & 7.8 & 12.8 & 7.1 & 5.0 & 6.1 & 34.2 \\
\hline & & 3 & 3030.4 & 754.7 & 2054.9 & 166.5 & 7.4 & 4.8 & 1.0 & 1.3 & 0.7 & 31.8 \\
\hline & & 4 & 3067.5 & 1019.2 & 1730.9 & 264.8 & 6.4 & 0.0 & 0.8 & 1.7 & 0.5 & 23.1 \\
\hline & & 5 & 3056.0 & 882.5 & 1492.4 & 633.8 & 0.0 & 5.7 & 0.0 & 0.0 & 1.0 & 23.7 \\
\hline & & $1-5$ & 15231.6 & 4818.4 & 8765.8 & 1364.6 & 33.9 & 26.7 & 8.9 & 8.6 & 8.5 & 121.0 \\
\hline \multirow{6}{*}{ SMC Mankato } & \multirow{6}{*}{ Quarried } & 1 & 3059.2 & 2066.5 & 625.2 & 203.8 & 46.0 & 32.9 & 11.5 & 11.0 & 6.1 & 33.9 \\
\hline & & 2 & 3067.6 & 2157.0 & 678.7 & 89.4 & 43.2 & 34.1 & 5.9 & 8.3 & 6.2 & 29.8 \\
\hline & & 3 & 2668.4 & 1553.3 & 895.1 & 170.2 & 7.6 & 6.9 & 0.0 & 2.1 & 1.3 & 20.1 \\
\hline & & 4 & 2907.2 & 1822.8 & 794.3 & 228.8 & 5.1 & 9.6 & 1.2 & 3.5 & 1.2 & 21.7 \\
\hline & & 5 & 3019.9 & 1885.9 & 668.3 & 416.8 & 0.0 & 3.5 & 0.0 & 0.5 & 0.6 & 23.9 \\
\hline & & $1-5$ & 14722.3 & 9485.5 & 3661.6 & 1109.0 & 101.9 & 87.0 & 18.6 & 25.4 & 15.4 & 129.4 \\
\hline
\end{tabular}


Table C.7. HFT results (mass retained) for small chamber samples (19.0 to $37.5 \mathrm{~mm}$ [0.75 to $1.5 \mathrm{in}])$ (cont.).

\begin{tabular}{|c|c|c|c|c|c|c|c|c|c|c|c|c|}
\hline & & & \multicolumn{10}{|c|}{ Mass Retained $(\mathrm{g})$} \\
\hline & & & \multirow{2}{*}{0 Cycles } & \multicolumn{9}{|c|}{ After 50 Cycles } \\
\hline & & & & \multicolumn{9}{|c|}{ Sieve Sizes } \\
\hline $\begin{array}{l}\text { Aggregate } \\
\text { Source }\end{array}$ & $\begin{array}{l}\text { Source } \\
\text { Type }\end{array}$ & $\begin{array}{c}\text { Replicate } \\
\text { Number }\end{array}$ & Total & $\begin{array}{l}25.0 \mathrm{~mm} \\
(1 \mathrm{in})\end{array}$ & $\begin{array}{l}19.0 \mathrm{~mm} \\
(0.75 \mathrm{in})\end{array}$ & $\begin{array}{c}16.0 \mathrm{~mm} \\
(0.625 \mathrm{in})\end{array}$ & $\begin{array}{c}12.5 \mathrm{~mm} \\
(0.5 \mathrm{in})\end{array}$ & $\begin{array}{l}9.50 \mathrm{~mm} \\
(0.375 \mathrm{in})\end{array}$ & $\begin{array}{c}8.00 \mathrm{~mm} \\
(0.3125 \\
\text { in })\end{array}$ & $\begin{array}{l}6.35 \mathrm{~mm} \\
(0.25 \mathrm{in})\end{array}$ & $\begin{array}{c}4.75 \mathrm{~mm} \\
(\# 4)\end{array}$ & Pan \\
\hline \multirow{6}{*}{ Swedberg } & \multirow{6}{*}{ Quarried } & 1 & 2961.3 & 743.7 & 1981.4 & 185.2 & 5.2 & 9.0 & 2.3 & 2.5 & 0.4 & 12.0 \\
\hline & & 2 & 3023.6 & 1012.3 & 1818.2 & 162.1 & 8.1 & 1.7 & 2.3 & 0.0 & 0.8 & 8.5 \\
\hline & & 3 & 2969.5 & 742.3 & 1967.3 & 187.6 & 13.7 & 4.9 & 7.1 & 4.7 & 1.5 & 12.3 \\
\hline & & 4 & 2962.8 & 899.4 & 1790.0 & 239.3 & 0.0 & 2.8 & 1.4 & 4.0 & 0.8 & 1.3 \\
\hline & & 5 & 3021.8 & 798.8 & 1680.5 & 515.7 & 0.0 & 1.7 & 0.9 & 2.7 & 0.1 & 12.1 \\
\hline & & $1-5$ & 14939.0 & 4196.5 & 9237.4 & 1289.9 & 27.0 & 20.1 & 14.0 & 13.9 & 3.6 & 46.2 \\
\hline \multirow{6}{*}{$\begin{array}{c}\text { Ulland } \\
\text { Northwood }\end{array}$} & \multirow{6}{*}{ Quarried } & 1 & 3047.2 & 1034.8 & 1522.8 & 438.9 & 21.5 & 3.4 & 0.0 & 0.3 & 0.0 & 8.5 \\
\hline & & 2 & 3063.1 & 999.7 & 1875.2 & 174.4 & 0.0 & 0.0 & 0.0 & 0.9 & 0.4 & 5.9 \\
\hline & & 3 & 3035.2 & 785.3 & 1998.0 & 236.1 & 0.0 & 0.0 & 0.0 & 0.5 & 0.0 & 5.6 \\
\hline & & 4 & 3051.8 & 1108.8 & 1804.5 & 116.3 & 6.3 & 0.0 & 0.0 & 0.0 & 0.7 & 7.0 \\
\hline & & 5 & 3075.6 & 793.3 & 1608.3 & 618.6 & 3.1 & 0.0 & 2.5 & 1.5 & 0.2 & 14.4 \\
\hline & & $1-5$ & 15272.9 & 4721.9 & 8808.8 & 1584.3 & 30.9 & 3.4 & 2.5 & 3.2 & 1.3 & 41.4 \\
\hline \multirow{6}{*}{ Waterloo } & \multirow{6}{*}{ Quarried } & 1 & 2915.4 & 0.0 & 2271.5 & 630.7 & 0.0 & 0.0 & 0.0 & 0.0 & 0.0 & 5.7 \\
\hline & & 2 & 2898.4 & 0.0 & 2157.4 & 723.2 & 0.0 & 0.0 & 0.0 & 0.7 & 0.1 & 7.2 \\
\hline & & 3 & & & & & & & & & & \\
\hline & & 4 & 2806.4 & & 1089.0 & 1691.0 & 0.0 & 0.0 & 0.0 & 0.0 & 0.0 & 13.6 \\
\hline & & 5 & & & & & & & & & & \\
\hline & & $1-5$ & 8620.2 & 0.0 & 5517.9 & 3044.9 & 0.0 & 0.0 & 0.0 & 0.7 & 0.1 & 26.5 \\
\hline \multirow{6}{*}{ Zumbrota } & \multirow{6}{*}{ Quarried } & $1^{*}$ & 3023.2 & 1572.9 & 1250.4 & 100.0 & 10.6 & 19.2 & 4.1 & 9.8 & 5.1 & 6.9 \\
\hline & & 2 & 2963.3 & 1694.3 & 1175.5 & 35.2 & 5.2 & 7.5 & 0.0 & 1.2 & 0.3 & 28.7 \\
\hline & & 3 & 3006.4 & 1491.8 & 1295.8 & 34.9 & 20.5 & 17.1 & 5.0 & 5.5 & 3.9 & 38.5 \\
\hline & & 4 & 3007.9 & 1113.6 & 1639.8 & 159.8 & 18.9 & 5.6 & 1.0 & 1.0 & 1.1 & 41.4 \\
\hline & & 5 & 2992.5 & 871.3 & 1779.2 & 217.7 & 29.3 & 14.3 & 5.9 & 4.6 & 2.3 & 51.3 \\
\hline & & $1-5$ & 11970.1 & 5171.0 & 5890.3 & 447.6 & 73.9 & 44.5 & 11.9 & 12.3 & 7.6 & 159.9 \\
\hline
\end{tabular}


Table C.8. HFT results (particle counts) for small chamber samples (19.0 to $37.5 \mathrm{~mm}$ [0.75 to $1.5 \mathrm{in}]$ ).

\begin{tabular}{|c|c|c|c|c|c|c|c|c|c|c|c|c|}
\hline & \multicolumn{10}{|c|}{ Particle Count Retained } \\
\hline & & & \multirow{2}{*}{0 Cycles } & \multicolumn{9}{|c|}{ After 50 Cycles } \\
\hline & & & & \multicolumn{9}{|c|}{ Sieve Sizes } \\
\hline $\begin{array}{l}\text { Aggregate } \\
\text { Source }\end{array}$ & $\begin{array}{l}\text { Source } \\
\text { Type }\end{array}$ & $\begin{array}{c}\text { Replicate } \\
\text { Number }\end{array}$ & Total & $\begin{array}{l}25.0 \mathrm{~mm} \\
(1 \mathrm{in})\end{array}$ & $\begin{array}{l}19.0 \mathrm{~mm} \\
(0.75 \mathrm{in})\end{array}$ & $\begin{array}{c}16.0 \mathrm{~mm} \\
(0.625 \mathrm{in})\end{array}$ & $\begin{array}{c}12.5 \mathrm{~mm} \\
(0.5 \mathrm{in})\end{array}$ & $\begin{array}{c}9.50 \mathrm{~mm} \\
(0.375 \mathrm{in})\end{array}$ & $\begin{array}{c}8.00 \mathrm{~mm} \\
(0.3125 \\
\text { in) }\end{array}$ & $\begin{array}{l}6.35 \mathrm{~mm} \\
(0.25 \mathrm{in})\end{array}$ & $\begin{array}{l}4.75 \mathrm{~mm} \\
(\# 4)\end{array}$ & Pan \\
\hline \multirow{6}{*}{$\begin{array}{l}\text { Ashwill, } \\
\text { Kingston }\end{array}$} & \multirow{6}{*}{ Gravel } & 1 & & & & & & & & & & \\
\hline & & 2 & & & & & & & & & & \\
\hline & & 3 & & & & & & & & & & \\
\hline & & 4 & & & & & & & & & & \\
\hline & & 5 & & & & & & & & & & \\
\hline & & $1-5$ & & & & & & & & & & \\
\hline \multirow{6}{*}{$\begin{array}{c}\text { Big Springs, } \\
\text { Harmony }\end{array}$} & \multirow{6}{*}{ Quarried } & 1 & 109 & 41 & 58 & 11 & 0 & 4 & 2 & 6 & 4 & 125 \\
\hline & & 2 & 116 & 53 & 59 & 4 & 1 & 1 & 0 & 2 & 2 & 164 \\
\hline & & 3 & 82 & 48 & 30 & 3 & 4 & 0 & 2 & 0 & 3 & 36 \\
\hline & & 4 & 130 & 39 & 82 & 9 & 0 & 0 & 0 & 0 & 2 & 32 \\
\hline & & 5 & 99 & 40 & 49 & 14 & 0 & 5 & 1 & 7 & 4 & 60 \\
\hline & & $1-5$ & 536 & 221 & 278 & 41 & 5 & 10 & 5 & 15 & 15 & 417 \\
\hline \multirow{6}{*}{ Bryan Rock } & \multirow{6}{*}{ Quarried } & 1 & 133 & 41 & 75 & 19 & 1 & 3 & 2 & 4 & 2 & 134 \\
\hline & & 2 & 131 & 39 & 81 & 12 & 1 & 0 & 0 & 6 & 3 & 73 \\
\hline & & 3 & 136 & 34 & 86 & 16 & 2 & 0 & 0 & 1 & 0 & 43 \\
\hline & & 4 & 131 & 22 & 89 & 20 & 0 & 1 & 0 & 0 & 0 & 0 \\
\hline & & 5 & 133 & 31 & 71 & 32 & 0 & 5 & 0 & 2 & 3 & 38 \\
\hline & & $1-5$ & 664 & 167 & 402 & 99 & 4 & 9 & 2 & 13 & 8 & 288 \\
\hline \multirow{6}{*}{$\begin{array}{c}\text { Cedarville } \\
\text { Plant }\end{array}$} & \multirow{6}{*}{ Quarried } & 1 & 138 & 24 & 107 & 7 & 1 & 0 & 0 & 1 & 0 & 50 \\
\hline & & 2 & 152 & 27 & 110 & 14 & 0 & 0 & 0 & 0 & 0 & 0 \\
\hline & & 3 & 141 & 31 & 97 & 13 & 1 & 1 & 0 & 0 & 1 & 20 \\
\hline & & 4 & & & & & & & & & & \\
\hline & & 5 & 83 & 23 & 110 & 21 & 1 & 2 & 2 & 3 & 2 & 10.9 \\
\hline & & $1-5$ & 514 & 105 & 424 & 55 & 3 & 3 & 2 & 4 & 3 & 80.9 \\
\hline
\end{tabular}


Table C.8. HFT results (particle counts) for small chamber samples (19.0 to $37.5 \mathrm{~mm}$ [0.75 to $1.5 \mathrm{in}])$ (cont.).

\begin{tabular}{|c|c|c|c|c|c|c|c|c|c|c|c|c|}
\hline & & & \multirow{2}{*}{\multicolumn{10}{|c|}{ Particle Count Retained }} \\
\hline & & & & & & & & & & & & \\
\hline & & & \multirow{2}{*}{0 Cycles } & \multicolumn{9}{|c|}{ After 50 Cycles } \\
\hline & & & & \multicolumn{9}{|c|}{ Sieve Sizes } \\
\hline $\begin{array}{l}\text { Aggregate } \\
\text { Source }\end{array}$ & $\begin{array}{l}\text { Source } \\
\text { Type }\end{array}$ & $\begin{array}{c}\text { Replicate } \\
\text { Number }\end{array}$ & Total & $\begin{array}{c}25.0 \mathrm{~mm} \\
(1 \mathrm{in})\end{array}$ & $\begin{array}{l}19.0 \mathrm{~mm} \\
(0.75 \mathrm{in})\end{array}$ & $\begin{array}{c}16.0 \mathrm{~mm} \\
(0.625 \mathrm{in})\end{array}$ & $\begin{array}{c}12.5 \mathrm{~mm} \\
(0.5 \mathrm{in})\end{array}$ & $\begin{array}{c}9.50 \mathrm{~mm} \\
(0.375 \mathrm{in})\end{array}$ & $\begin{array}{c}8.00 \mathrm{~mm} \\
(0.3125 \\
\text { in) }\end{array}$ & $\begin{array}{l}6.35 \mathrm{~mm} \\
(0.25 \mathrm{in})\end{array}$ & $\begin{array}{c}4.75 \mathrm{~mm} \\
(\# 4)\end{array}$ & Pan \\
\hline \multirow{6}{*}{ Early Chapel } & \multirow{6}{*}{ Quarried } & 1 & 198 & 7 & 155 & 35 & 0 & 1 & 2 & 3 & 1 & 48 \\
\hline & & 2 & 197 & 7 & 156 & 33 & 1 & 0 & 1 & 1 & 2 & 14 \\
\hline & & 3 & 209 & 4 & 157 & 47 & 1 & 0 & 2 & 0 & 2 & 5 \\
\hline & & 4 & 206 & 0 & 152 & 54 & 0 & 1 & 0 & 1 & 0 & 17 \\
\hline & & 5 & 191 & 7 & 127 & 57 & 0 & 1 & 0 & 3 & 0 & 8 \\
\hline & & $1-5$ & 803 & 18 & 592 & 191 & 2 & 2 & 3 & 5 & 4 & 44 \\
\hline \multirow{6}{*}{$\begin{array}{c}\text { Edward } \\
\text { Kramer \& } \\
\text { Sons }\end{array}$} & \multirow{6}{*}{ Quarried } & 1 & 160 & 21 & 114 & 25 & 4 & 0 & 3 & 3 & 6 & 23.3 \\
\hline & & 2 & 136 & 30 & 90 & 23 & 2 & 1 & 2 & 2 & 3 & 63 \\
\hline & & 3 & 132 & 30 & 88 & 13 & 1 & 1 & 1 & 0 & 3 & 57 \\
\hline & & 4 & 144 & 31 & 79 & 35 & 2 & 0 & 0 & 4 & 4 & 40 \\
\hline & & 5 & 151 & 32 & 70 & 49 & 0 & 2 & 0 & 2 & 1 & 34 \\
\hline & & $1-5$ & 723 & 144 & 441 & 145 & 9 & 4 & 6 & 11 & 17 & 217.3 \\
\hline \multirow{6}{*}{$\begin{array}{l}\text { Goldberg, } \\
\text { Rochester }\end{array}$} & \multirow{6}{*}{ Quarried } & 1 & 117 & 48 & 57 & 10 & 4 & 1 & 1 & 4 & 2 & 93 \\
\hline & & 2 & 136 & 34 & 94 & 9 & 0 & 2 & 1 & 4 & 2 & 42 \\
\hline & & 3 & 129 & 32 & 92 & 6 & 0 & 0 & 0 & 1 & 1 & 14 \\
\hline & & 4 & 140 & 29 & 0 & 32 & 0 & 1 & 0 & 1 & 2 & 6 \\
\hline & & 5 & 150 & 21 & 112 & 16 & 7 & 5 & 4 & 6 & 8 & 56 \\
\hline & & $1-5$ & 672 & 164 & 355 & 73 & 11 & 9 & 6 & 16 & 15 & 211 \\
\hline \multirow{6}{*}{$\begin{array}{c}\text { Grand } \\
\text { Meadow }\end{array}$} & \multirow{6}{*}{ Quarried } & 1 & 167 & 30 & 103 & 38 & 3 & 2 & 1 & 3 & 4 & 96 \\
\hline & & 2 & 157 & 36 & 103 & 17 & 2 & 1 & 0 & 3 & 0 & 0 \\
\hline & & 3 & 166 & 22 & 108 & 36 & 0 & 4 & 1 & 1 & 2 & 23 \\
\hline & & 4 & 199 & 22 & 91 & 84 & 5 & 2 & 3 & 3 & 6 & 34 \\
\hline & & 5 & 188 & 23 & 107 & 57 & 0 & 1 & 0 & 3 & 0 & 79 \\
\hline & & $1-5$ & 877 & 133 & 512 & 232 & 10 & 10 & 5 & 13 & 12 & 232 \\
\hline
\end{tabular}


Table C.8. HFT results (particle counts) for small chamber samples (19.0 to $37.5 \mathrm{~mm}$ [0.75 to $1.5 \mathrm{in}]$ ) (cont.).

\begin{tabular}{|c|c|c|c|c|c|c|c|c|c|c|c|c|}
\hline & & & \multicolumn{10}{|c|}{ Particle Count Retained } \\
\hline & & & \multirow{2}{*}{0 Cycles } & \multicolumn{9}{|c|}{ After 50 Cycles } \\
\hline & & & & & & & & Sieve Sizes & & & & \\
\hline $\begin{array}{l}\text { Aggregate } \\
\text { Source }\end{array}$ & $\begin{array}{c}\text { Source } \\
\text { Type }\end{array}$ & $\begin{array}{l}\text { Replicate } \\
\text { Number }\end{array}$ & Total & $\begin{array}{c}25.0 \mathrm{~mm} \\
(1 \mathrm{in})\end{array}$ & $\begin{array}{l}19.0 \mathrm{~mm} \\
(0.75 \mathrm{in})\end{array}$ & $\begin{array}{c}16.0 \mathrm{~mm} \\
(0.625 \mathrm{in})\end{array}$ & $\begin{array}{c}12.5 \mathrm{~mm} \\
(0.5 \mathrm{in})\end{array}$ & $\begin{array}{c}9.50 \mathrm{~mm} \\
(0.375 \mathrm{in})\end{array}$ & $\begin{array}{c}8.00 \mathrm{~mm} \\
(0.3125 \\
\text { in })\end{array}$ & $\begin{array}{l}6.35 \mathrm{~mm} \\
(0.25 \mathrm{in})\end{array}$ & $\begin{array}{l}4.75 \mathrm{~mm} \\
(\# 4)\end{array}$ & Pan \\
\hline \multirow{6}{*}{ Halma } & \multirow{6}{*}{ Gravel } & 1 & 220 & 0 & 192 & 28 & 0 & 0 & 0 & 0 & 0 & 11 \\
\hline & & 2 & 224 & 0 & 188 & 35 & 1 & 1 & 1 & 1 & 1 & 13 \\
\hline & & 3 & 219 & 0 & 186 & 31 & 0 & 1 & 0 & 0 & 0 & 25 \\
\hline & & 4 & 212 & 0 & 187 & 25 & 0 & 0 & 0 & 0 & 0 & 6 \\
\hline & & 5 & 222 & & 189 & 32 & 1 & 1 & 0 & 1 & 1 & 8 \\
\hline & & $1-5$ & 1097 & 0 & 942 & 151 & 2 & 3 & 1 & 2 & 2 & 63 \\
\hline \multirow{6}{*}{$\begin{array}{l}\text { Johnson, } \\
\text { Henderson }\end{array}$} & \multirow{6}{*}{ Gravel } & 1 & 108 & 51 & 53 & 5 & 1 & 0 & 0 & 0 & 0 & 71 \\
\hline & & 2 & 110 & 48 & 61 & 2 & 0 & 4 & 7 & 14 & 10 & 432 \\
\hline & & 3 & 109 & 41 & 60 & 6 & 2 & 1 & 0 & 0 & 0 & 29 \\
\hline & & 4 & 114 & 44 & 66 & 5 & 1 & 2 & 0 & 0 & 1 & 29 \\
\hline & & 5 & 106 & 48 & 46 & 14 & 0 & 0 & 0 & 0 & 1 & 2 \\
\hline & & $1-5$ & 547 & 232 & 286 & 32 & 4 & 7 & 7 & 14 & 12 & 563 \\
\hline \multirow{6}{*}{$\begin{array}{c}\text { Johnson, Le } \\
\text { Sueur }\end{array}$} & \multirow{6}{*}{ Gravel } & 1 & 145 & 30 & 112 & 5 & 0 & 0 & 0 & 0 & 0 & 27 \\
\hline & & 2 & 154 & 31 & 112 & 9 & 2 & 7 & 6 & 17 & 30 & 503 \\
\hline & & 3 & 149 & 24 & 116 & 8 & 0 & 1 & 2 & 1 & 6 & 650 \\
\hline & & 4 & 155 & 26 & 114 & 16 & 0 & 0 & 5 & 1 & 5 & 77 \\
\hline & & 5 & 160 & 30 & 95 & 34 & 4 & 1 & 6 & 7 & 12 & 234 \\
\hline & & $1-5$ & 618 & 111 & 437 & 67 & 6 & 9 & 19 & 26 & 53 & 1464 \\
\hline \multirow{6}{*}{$\begin{array}{c}\text { Mark, } \\
\text { Underwood }\end{array}$} & \multirow{6}{*}{ Gravel } & 1 & 125 & 30 & 79 & 17 & 0 & 0 & 0 & 0 & 0 & 17 \\
\hline & & 2 & 123 & 31 & 87 & 5 & 0 & 1 & 0 & 1 & 0 & 25 \\
\hline & & 3 & 167 & 17 & 126 & 21 & 3 & 0 & 3 & 2 & 3 & 64 \\
\hline & & 4 & 133 & 26 & 101 & 6 & 0 & 0 & 1 & 2 & 4 & 44 \\
\hline & & 5 & 145 & 22 & 111 & 12 & 1 & 0 & 2 & 3 & 6 & 88 \\
\hline & & $1-5$ & 693 & 126 & 504 & 61 & 4 & 1 & 6 & 8 & 13 & 238 \\
\hline
\end{tabular}


Table C.8. HFT results (particle counts) for small chamber samples (19.0 to $37.5 \mathrm{~mm}$ [0.75 to $1.5 \mathrm{in}]$ ) (cont.).

\begin{tabular}{|c|c|c|c|c|c|c|c|c|c|c|c|c|}
\hline & & & \multicolumn{10}{|c|}{ Particle Count Retained } \\
\hline & & & \multirow{2}{*}{0 Cycles } & \multicolumn{9}{|c|}{ After 50 Cycles } \\
\hline & & & & \multicolumn{9}{|c|}{ Sieve Sizes } \\
\hline $\begin{array}{l}\text { Aggregate } \\
\text { Source }\end{array}$ & $\begin{array}{l}\text { Source } \\
\text { Type }\end{array}$ & $\begin{array}{l}\text { Replicate } \\
\text { Number }\end{array}$ & Total & $\begin{array}{l}25.0 \mathrm{~mm} \\
(1 \mathrm{in})\end{array}$ & $\begin{array}{l}19.0 \mathrm{~mm} \\
(0.75 \mathrm{in})\end{array}$ & $\begin{array}{c}16.0 \mathrm{~mm} \\
(0.625 \mathrm{in})\end{array}$ & $\begin{array}{c}12.5 \mathrm{~mm} \\
(0.5 \mathrm{in})\end{array}$ & $\begin{array}{c}9.50 \mathrm{~mm} \\
(0.375 \mathrm{in})\end{array}$ & $\begin{array}{c}8.00 \mathrm{~mm} \\
(0.3125 \\
\text { in })\end{array}$ & $\begin{array}{l}6.35 \mathrm{~mm} \\
(0.25 \mathrm{in})\end{array}$ & $\begin{array}{l}4.75 \mathrm{~mm} \\
\quad(\# 4)\end{array}$ & Pan \\
\hline \multirow{6}{*}{$\begin{array}{c}\text { Northern Con, } \\
\text { Luverne }\end{array}$} & \multirow{6}{*}{ Gravel } & 1 & 109 & 41 & 56 & 8 & 3 & 1 & 0 & 0 & 0 & 81 \\
\hline & & 2 & 97 & 49 & 46 & 1 & 3 & 1 & 0 & 1 & 3 & 7 \\
\hline & & 3 & 91 & 45 & 45 & 1 & 1 & 1 & 0 & 0 & 0 & 55 \\
\hline & & 4 & 78 & 43 & 32 & 3 & 0 & 0 & 0 & 0 & 0 & 95 \\
\hline & & 5 & 108 & 34 & 59 & 15 & 0 & 0 & 0 & 0 & 0 & 35 \\
\hline & & $1-5$ & 483 & 212 & 238 & 28 & 7 & 3 & 0 & 1 & 3 & 273 \\
\hline \multirow{5}{*}{$\begin{array}{l}\text { North Star } \\
\text { Kasota }\end{array}$} & \multirow{5}{*}{ Gravel } & 1 & 116 & 42 & 71 & 4 & 0 & 1 & 0 & 0 & 0 & 25 \\
\hline & & 2 & 153 & 27 & 116 & 9 & 0 & 0 & 8 & 12 & 5 & 166 \\
\hline & & 3 & 148 & 33 & 104 & 11 & 0 & 0 & 0 & 0 & 0 & 9 \\
\hline & & 4 & 170 & 26 & 127 & 15 & 3 & 7 & 1 & 4 & 5 & 65 \\
\hline & & $1-5$ & 758 & 151 & 547 & 51 & 5 & 10 & 11 & 20 & 18 & 407 \\
\hline \multirow{6}{*}{$\begin{array}{c}\text { Shiely Grey } \\
\text { Cloud }\end{array}$} & \multirow{6}{*}{ Quarried } & 1 & 149 & 38 & 94 & 16 & 3 & 2 & 0 & 1 & 1 & 40 \\
\hline & & 2 & 155 & 27 & 115 & 12 & 2 & 6 & 7 & 9 & 25 & 141 \\
\hline & & 3 & 165 & 24 & 127 & 17 & 1 & 2 & 1 & 3 & 2 & 25 \\
\hline & & 4 & 165 & 32 & 109 & 23 & 2 & 0 & 1 & 2 & 2 & 11 \\
\hline & & 5 & 176 & 30 & 89 & 57 & 0 & 2 & 0 & 0 & 4 & 7 \\
\hline & & $1-5$ & 810 & 151 & 534 & 125 & 8 & 12 & 9 & 15 & 34 & 224 \\
\hline \multirow{6}{*}{ SMC Mankato } & \multirow{6}{*}{ Quarried } & 1 & 99 & 41 & 42 & 21 & 9 & 13 & 10 & 20 & 24 & 167 \\
\hline & & 2 & 93 & 43 & 45 & 10 & 8 & 15 & 6 & 15 & 23 & 295 \\
\hline & & 3 & 105 & 35 & 55 & 17 & 1 & 3 & 0 & 4 & 6 & 51 \\
\hline & & 4 & 114 & 38 & 54 & 24 & 1 & 4 & 1 & 6 & 5 & 56 \\
\hline & & 5 & 120 & 42 & 42 & 40 & 0 & 2 & 0 & 1 & 3 & 26 \\
\hline & & $1-5$ & 531 & 199 & 238 & 112 & 19 & 37 & 17 & 46 & 61 & 595 \\
\hline
\end{tabular}


Table C.8. HFT results (particle counts) for small chamber samples (19.0 to $37.5 \mathrm{~mm}$ [0.75 to $1.5 \mathrm{in}]$ ) (cont.).

\begin{tabular}{|c|c|c|c|c|c|c|c|c|c|c|c|c|}
\hline & & & \multicolumn{10}{|c|}{ Particle Count Retained } \\
\hline & & & \multirow{2}{*}{0 Cycles } & \multicolumn{9}{|c|}{ After 50 Cycles } \\
\hline & & & & \multicolumn{9}{|c|}{ Sieve Sizes } \\
\hline $\begin{array}{l}\text { Aggregate } \\
\text { Source }\end{array}$ & $\begin{array}{l}\text { Source } \\
\text { Type }\end{array}$ & $\begin{array}{c}\text { Replicate } \\
\text { Number }\end{array}$ & Total & $\begin{array}{c}25.0 \mathrm{~mm} \\
(1 \mathrm{in})\end{array}$ & $\begin{array}{l}19.0 \mathrm{~mm} \\
(0.75 \mathrm{in})\end{array}$ & $\begin{array}{c}16.0 \mathrm{~mm} \\
(0.625 \mathrm{in})\end{array}$ & $\begin{array}{c}12.5 \mathrm{~mm} \\
(0.5 \mathrm{in})\end{array}$ & $\begin{array}{c}9.50 \mathrm{~mm} \\
(0.375 \mathrm{in})\end{array}$ & $\begin{array}{c}8.00 \mathrm{~mm} \\
(0.3125 \\
\text { in })\end{array}$ & $\begin{array}{l}6.35 \mathrm{~mm} \\
(0.25 \mathrm{in})\end{array}$ & $\begin{array}{c}4.75 \mathrm{~mm} \\
(\# 4)\end{array}$ & Pan \\
\hline \multirow{6}{*}{ Swedberg } & \multirow{6}{*}{ Quarried } & 1 & 169 & 21 & 130 & 17 & 2 & 4 & 3 & 4 & 2 & 244 \\
\hline & & 2 & 159 & 32 & 110 & 17 & 2 & 1 & 2 & 0 & 4 & 66 \\
\hline & & 3 & 175 & 23 & 133 & 19 & 3 & 3 & 6 & 11 & 10 & 87 \\
\hline & & 4 & 166 & 26 & 118 & 24 & 0 & 1 & 2 & 6 & 4 & 47 \\
\hline & & 5 & 178 & 24 & 104 & 50 & 0 & 1 & 1 & 5 & 1 & 81 \\
\hline & & $1-5$ & 847 & 126 & 595 & 127 & 7 & 10 & 14 & 26 & 21 & 525 \\
\hline \multirow{6}{*}{$\begin{array}{c}\text { Ulland } \\
\text { Northwood }\end{array}$} & \multirow{6}{*}{ Quarried } & 1 & 162 & 28 & 92 & 38 & 4 & 1 & 0 & 1 & 0 & 22 \\
\hline & & 2 & 152 & 24 & 112 & 16 & 0 & 0 & 0 & 1 & 1 & 0 \\
\hline & & 3 & 169 & 19 & 129 & 22 & 0 & 0 & 0 & 1 & 0 & 28 \\
\hline & & 4 & 147 & 27 & 109 & 11 & 1 & 0 & 0 & 0 & 3 & 34 \\
\hline & & 5 & 176 & 21 & 102 & 55 & 1 & 0 & 2 & 2 & 2 & 50 \\
\hline & & $1-5$ & 806 & 119 & 544 & 142 & 6 & 1 & 2 & 5 & 6 & 134 \\
\hline \multirow{6}{*}{ Waterloo } & \multirow{6}{*}{ Quarried } & 1 & 253 & 0 & 194 & 59 & 0 & 0 & 0 & 0 & 0 & 92 \\
\hline & & 2 & 252 & 0 & 182 & 67 & 0 & 0 & 0 & 2 & 1 & 16 \\
\hline & & 3 & & & & & & & & & & \\
\hline & & 4 & 243 & 0 & 88 & 155 & 0 & 0 & 0 & 0 & 0 & 4 \\
\hline & & 5 & & & & & & & & & & \\
\hline & & $1-5$ & 748 & 0 & 464 & 281 & 0 & 0 & 0 & 2 & 1 & 112 \\
\hline \multirow{6}{*}{ Zumbrota } & \multirow{6}{*}{ Quarried } & $1^{*}$ & 116 & 40 & 67 & 12 & 3 & 8 & 5 & 20 & 21 & 471 \\
\hline & & 2 & 103 & 41 & 61 & 4 & 1 & 2 & 0 & 2 & 1 & 62 \\
\hline & & 3 & 120 & 37 & 71 & 12 & 4 & 8 & 5 & 10 & 16 & 161 \\
\hline & & 4 & 146 & 31 & 101 & 16 & 4 & 2 & 1 & 1 & 6 & 75 \\
\hline & & 5 & 156 & 23 & 109 & 23 & 6 & 7 & 5 & 9 & 12 & 170 \\
\hline & & $1-5$ & 525 & 132 & 342 & 55 & 15 & 19 & 11 & 22 & 35 & 468 \\
\hline
\end{tabular}


Table C.9. HFT results (normalized, mass retained) for small chamber samples (19.0 to $37.5 \mathrm{~mm}$ [0.75 to 1.5 in])

\begin{tabular}{|c|c|c|c|c|c|c|c|c|c|c|c|}
\hline & & & \multicolumn{9}{|c|}{ Normalized Mass Retained (\%) } \\
\hline & & & \multicolumn{9}{|c|}{ Sieve Sizes } \\
\hline $\begin{array}{l}\text { Aggregate } \\
\text { Source }\end{array}$ & $\begin{array}{l}\text { Source } \\
\text { Type }\end{array}$ & $\begin{array}{l}\text { Replicate } \\
\text { Number }\end{array}$ & $\begin{array}{l}25.0 \mathrm{~mm} \\
(1 \mathrm{in})\end{array}$ & $\begin{array}{l}19.0 \mathrm{~mm} \\
(0.75 \mathrm{in})\end{array}$ & $\begin{array}{c}16.0 \mathrm{~mm} \\
(0.625 \mathrm{in})\end{array}$ & $\begin{array}{c}12.5 \mathrm{~mm} \\
(0.5 \mathrm{in})\end{array}$ & $\begin{array}{c}9.50 \mathrm{~mm} \\
(0.375 \mathrm{in})\end{array}$ & $\begin{array}{c}8.00 \mathrm{~mm} \\
(0.3125 \\
\text { in })\end{array}$ & $\begin{array}{l}6.35 \mathrm{~mm} \\
(0.25 \mathrm{in})\end{array}$ & $\begin{array}{l}4.75 \mathrm{~mm} \\
\quad(\# 4)\end{array}$ & Pan \\
\hline \multirow{6}{*}{$\begin{array}{l}\text { Ashwill, } \\
\text { Kingston }\end{array}$} & \multirow{6}{*}{ Gravel } & 1 & & & & & & & & & \\
\hline & & 2 & & & & & & & & & \\
\hline & & 3 & & & & & & & & & \\
\hline & & 4 & & & & & & & & & \\
\hline & & 5 & & & & & & & & & \\
\hline & & $1-5$ & & & & & & & & & \\
\hline \multirow{6}{*}{$\begin{array}{c}\text { Big Springs, } \\
\text { Harmony }\end{array}$} & \multirow{6}{*}{ Quarried } & 1 & 61.921 & 33.671 & 3.498 & 0.000 & 0.233 & 0.042 & 0.100 & 0.023 & 0.360 \\
\hline & & 2 & 64.250 & 33.822 & 1.060 & 0.108 & 0.044 & 0.000 & 0.032 & 0.013 & 0.310 \\
\hline & & 3 & 78.211 & 19.545 & 0.899 & 0.709 & 0.000 & 0.075 & 0.000 & 0.039 & 0.177 \\
\hline & & 4 & 52.805 & 43.255 & 3.320 & 0.000 & 0.000 & 0.000 & 0.000 & 0.010 & 0.239 \\
\hline & & 5 & 60.553 & 32.805 & 5.100 & 0.000 & 0.388 & 0.046 & 0.148 & 0.036 & 0.493 \\
\hline & & $1-5$ & 63.571 & 32.611 & 2.763 & 0.163 & 0.133 & 0.033 & 0.056 & 0.024 & 0.316 \\
\hline \multirow{6}{*}{ Bryan Rock } & \multirow{6}{*}{ Quarried } & 1 & 52.243 & 40.160 & 6.635 & 0.129 & 0.188 & 0.063 & 0.073 & 0.040 & 0.307 \\
\hline & & 2 & 49.193 & 45.668 & 4.173 & 0.134 & 0.000 & 0.000 & 0.124 & 0.033 & 0.334 \\
\hline & & 3 & 45.205 & 48.778 & 6.752 & 0.271 & 0.000 & 0.000 & 0.037 & 0.000 & 0.274 \\
\hline & & 4 & 28.764 & 60.859 & 9.520 & 0.000 & 0.042 & 0.000 & 0.000 & 0.000 & 0.385 \\
\hline & & 5 & 45.096 & 42.570 & 10.937 & 0.000 & 0.323 & 0.000 & 0.047 & 0.020 & 0.630 \\
\hline & & $1-5$ & 44.760 & 47.028 & 7.525 & 0.111 & 0.114 & 0.013 & 0.058 & 0.019 & 0.386 \\
\hline \multirow{6}{*}{$\begin{array}{l}\text { Cedarville } \\
\text { Plant }\end{array}$} & \multirow{6}{*}{ Quarried } & 1 & 26.386 & 70.230 & 2.699 & 0.170 & 0.000 & 0.000 & 0.033 & 0.000 & 0.259 \\
\hline & & 2 & 29.290 & 65.129 & 5.146 & 0.000 & 0.000 & 0.000 & 0.000 & 0.000 & 0.146 \\
\hline & & 3 & 31.712 & 62.224 & 5.375 & 0.205 & 0.089 & 0.000 & 0.000 & 0.003 & 0.149 \\
\hline & & 4 & & & & & & & & & \\
\hline & & 5 & 24.015 & 66.866 & 8.016 & 0.085 & 0.131 & 0.052 & 0.049 & 0.020 & 0.357 \\
\hline & & $1-5$ & 27.847 & 66.106 & 5.319 & 0.114 & 0.055 & 0.013 & 0.021 & 0.006 & 0.228 \\
\hline
\end{tabular}


Table C.9. HFT results (normalized, mass retained) for small chamber samples (19.0 to $37.5 \mathrm{~mm}$ [0.75 to 1.5 in])(cont.)

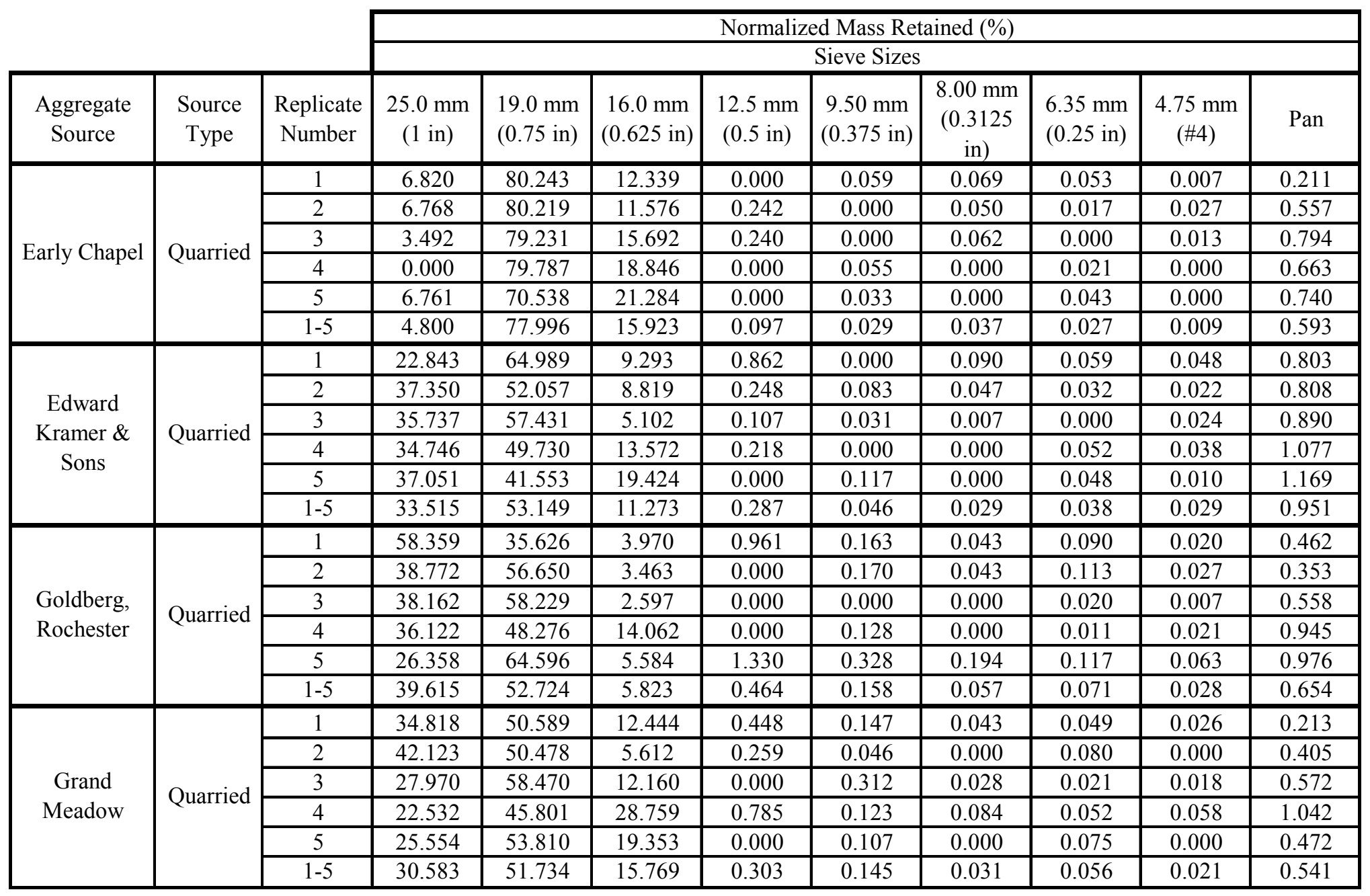


Table C.9. HFT results (normalized, mass retained) for small chamber samples (19.0 to $37.5 \mathrm{~mm}$ [0.75 to $1.5 \mathrm{in}]$ )(cont.)

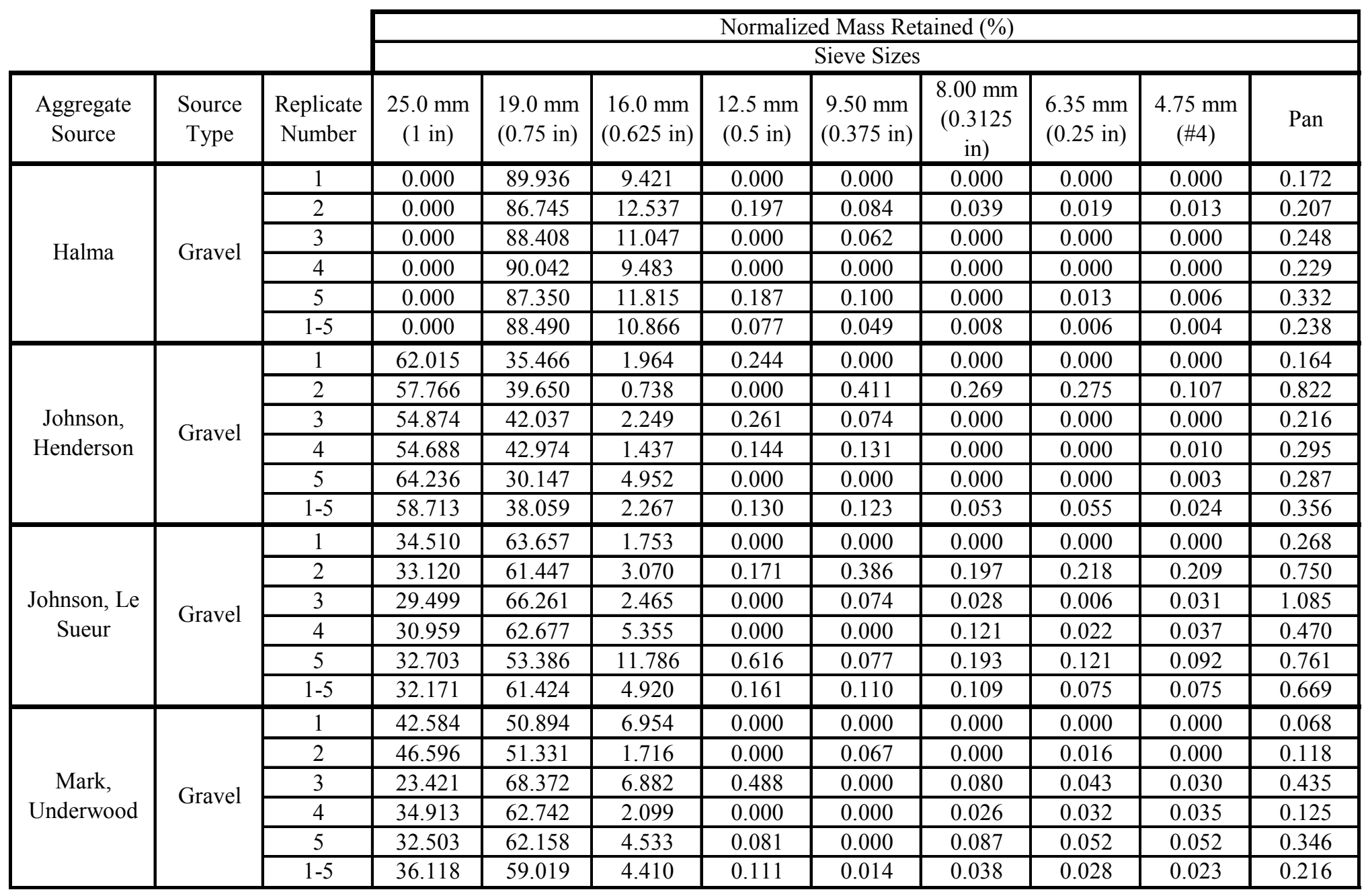


Table C.9. HFT results (normalized, mass retained) for small chamber samples (19.0 to $37.5 \mathrm{~mm}$ [0.75 to $1.5 \mathrm{in}]$ )(cont.)

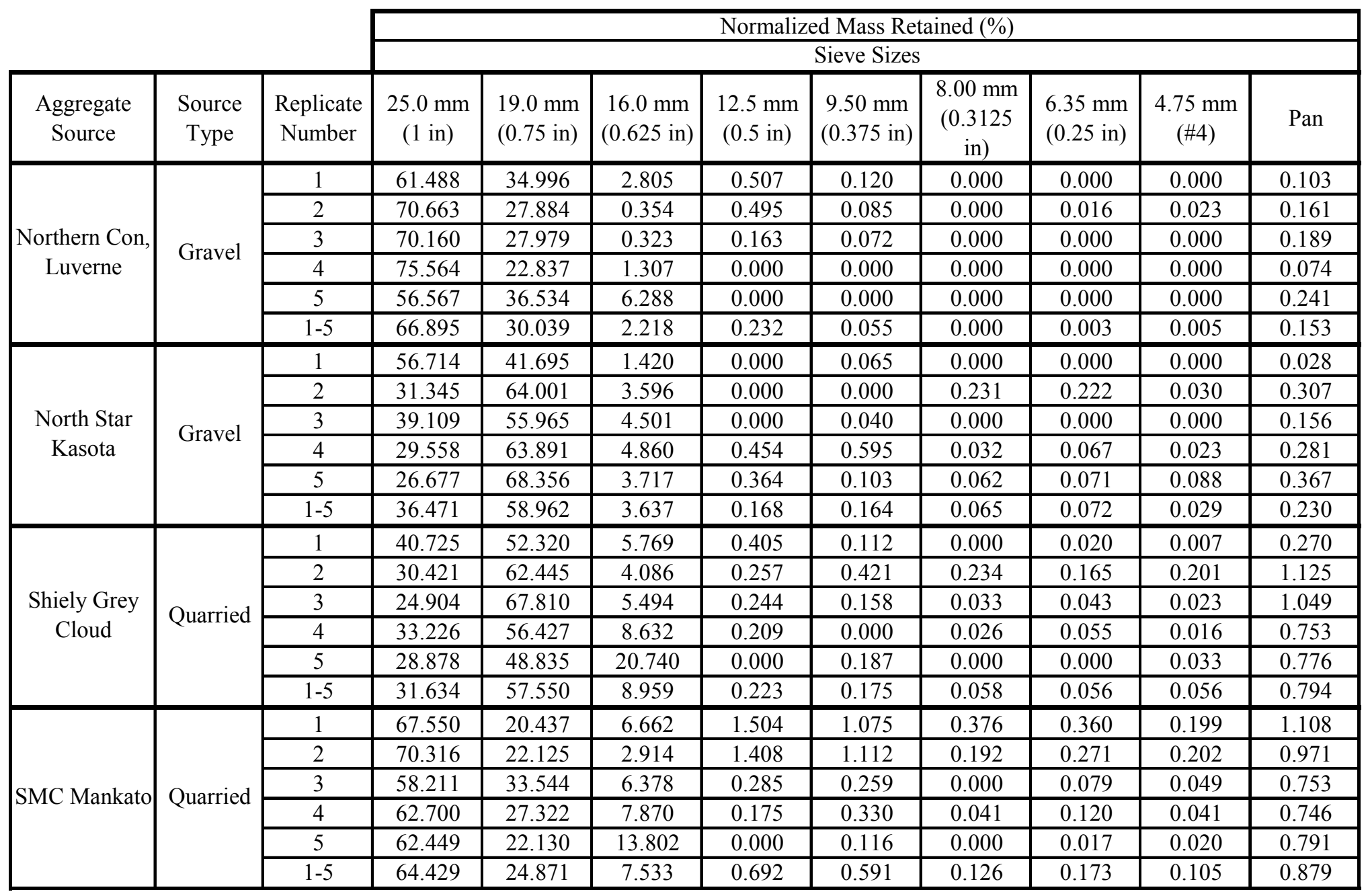


Table C.9. HFT results (normalized, mass retained) for small chamber samples (19.0 to $37.5 \mathrm{~mm}$ [0.75 to 1.5 in])(cont.)

\begin{tabular}{|c|c|c|c|c|c|c|c|c|c|c|c|}
\hline & & & \multicolumn{9}{|c|}{ Normalized Mass Retained (\%) } \\
\hline & & & \multicolumn{9}{|c|}{ Sieve Sizes } \\
\hline $\begin{array}{l}\text { Aggregate } \\
\text { Source }\end{array}$ & $\begin{array}{c}\text { Source } \\
\text { Type }\end{array}$ & $\begin{array}{c}\text { Replicate } \\
\text { Number }\end{array}$ & $\begin{array}{c}25.0 \mathrm{~mm} \\
\quad(1 \mathrm{in})\end{array}$ & $\begin{array}{l}19.0 \mathrm{~mm} \\
(0.75 \mathrm{in})\end{array}$ & $\begin{array}{c}16.0 \mathrm{~mm} \\
(0.625 \mathrm{in})\end{array}$ & $\begin{array}{c}12.5 \mathrm{~mm} \\
(0.5 \mathrm{in})\end{array}$ & $\begin{array}{c}9.50 \mathrm{~mm} \\
(0.375 \mathrm{in})\end{array}$ & $\begin{array}{c}8.00 \mathrm{~mm} \\
(0.3125 \\
\text { in })\end{array}$ & $\begin{array}{l}6.35 \mathrm{~mm} \\
(0.25 \mathrm{in})\end{array}$ & $\begin{array}{l}4.75 \mathrm{~mm} \\
\quad(\# 4)\end{array}$ & Pan \\
\hline \multirow{6}{*}{ Swedberg } & \multirow{6}{*}{ Quarried } & 1 & 25.114 & 66.910 & 6.254 & 0.176 & 0.304 & 0.078 & 0.084 & 0.014 & 0.405 \\
\hline & & 2 & 33.480 & 60.134 & 5.361 & 0.268 & 0.056 & 0.076 & 0.000 & 0.026 & 0.281 \\
\hline & & 3 & 24.997 & 66.250 & 6.318 & 0.461 & 0.165 & 0.239 & 0.158 & 0.051 & 0.414 \\
\hline & & 4 & 30.356 & 60.416 & 8.077 & 0.000 & 0.095 & 0.047 & 0.135 & 0.027 & 0.044 \\
\hline & & 5 & 26.435 & 55.613 & 17.066 & 0.000 & 0.056 & 0.030 & 0.089 & 0.003 & 0.400 \\
\hline & & $1-5$ & 28.091 & 61.834 & 8.634 & 0.181 & 0.135 & 0.094 & 0.093 & 0.024 & 0.309 \\
\hline \multirow{6}{*}{$\begin{array}{c}\text { Ulland } \\
\text { Northwood }\end{array}$} & \multirow{6}{*}{ Quarried } & 1 & 33.959 & 49.974 & 14.403 & 0.706 & 0.112 & 0.000 & 0.010 & 0.000 & 0.279 \\
\hline & & 2 & 32.637 & 61.219 & 5.694 & 0.000 & 0.000 & 0.000 & 0.029 & 0.013 & 0.193 \\
\hline & & 3 & 25.873 & 65.828 & 7.779 & 0.000 & 0.000 & 0.000 & 0.016 & 0.000 & 0.185 \\
\hline & & 4 & 36.333 & 59.129 & 3.811 & 0.206 & 0.000 & 0.000 & 0.000 & 0.023 & 0.229 \\
\hline & & 5 & 25.793 & 52.292 & 20.113 & 0.101 & 0.000 & 0.081 & 0.049 & 0.007 & 0.468 \\
\hline & & $1-5$ & 30.917 & 57.676 & 10.373 & 0.202 & 0.022 & 0.016 & 0.021 & 0.009 & 0.271 \\
\hline \multirow{6}{*}{ Waterloo } & \multirow{6}{*}{ Quarried } & 1 & 0.000 & 77.914 & 21.633 & 0.000 & 0.000 & 0.000 & 0.000 & 0.000 & 0.196 \\
\hline & & 2 & 0.000 & 74.434 & 24.952 & 0.000 & 0.000 & 0.000 & 0.024 & 0.003 & 0.248 \\
\hline & & 3 & & & & & & & & & \\
\hline & & 4 & 0.000 & 38.804 & 60.255 & 0.000 & 0.000 & 0.000 & 0.000 & 0.000 & 0.485 \\
\hline & & 5 & & & & & & & & & \\
\hline & & $1-5$ & 0.000 & 64.011 & 35.323 & 0.000 & 0.000 & 0.000 & 0.008 & 0.001 & 0.307 \\
\hline \multirow{6}{*}{ Zumbrota } & \multirow{6}{*}{ Quarried } & $1 *$ & 52.028 & 41.360 & 3.308 & 0.351 & 0.635 & 0.136 & 0.324 & 0.169 & 0.228 \\
\hline & & 2 & 57.176 & 39.669 & 1.188 & 0.175 & 0.253 & 0.000 & 0.040 & 0.010 & 0.969 \\
\hline & & 3 & 49.621 & 43.101 & 1.161 & 0.682 & 0.569 & 0.166 & 0.183 & 0.130 & 1.281 \\
\hline & & 4 & 37.023 & 54.516 & 5.313 & 0.628 & 0.186 & 0.033 & 0.033 & 0.037 & 1.376 \\
\hline & & 5 & 29.116 & 59.455 & 7.275 & 0.979 & 0.478 & 0.197 & 0.154 & 0.077 & 1.714 \\
\hline & & $1-5$ & 43.199 & 49.208 & 3.739 & 0.617 & 0.372 & 0.099 & 0.103 & 0.063 & 1.336 \\
\hline
\end{tabular}


Table C.10. HFT results (normalized, particle counts) for small chamber samples (19.0 to $37.5 \mathrm{~mm}$ [0.75 to $1.5 \mathrm{in}]$ ).

\begin{tabular}{|c|c|c|c|c|c|c|c|c|c|c|c|}
\hline & \multicolumn{9}{|c|}{ Normalized Particle Count Retained (\%) } \\
\hline & & & \multicolumn{9}{|c|}{$\begin{array}{c}\text { Sieve Sizes } \\
\end{array}$} \\
\hline $\begin{array}{l}\text { Aggregate } \\
\text { Source }\end{array}$ & $\begin{array}{l}\text { Source } \\
\text { Type }\end{array}$ & $\begin{array}{c}\text { Replicate } \\
\text { Number }\end{array}$ & $\begin{array}{c}25.0 \mathrm{~mm}(1 \\
\text { in) }\end{array}$ & $\begin{array}{l}19.0 \mathrm{~mm} \\
(0.75 \mathrm{in})\end{array}$ & $\begin{array}{c}16.0 \mathrm{~mm} \\
(0.625 \mathrm{in})\end{array}$ & $\begin{array}{c}12.5 \mathrm{~mm} \\
(0.5 \mathrm{in})\end{array}$ & $\begin{array}{l}9.50 \mathrm{~mm} \\
(0.375 \mathrm{in})\end{array}$ & $\mid \begin{array}{c}8.00 \mathrm{~mm} \\
(0.3125 \mathrm{in})\end{array}$ & $\begin{array}{l}6.35 \mathrm{~mm} \\
(0.25 \mathrm{in})\end{array}$ & $\begin{array}{l}4.75 \mathrm{~mm} \\
(\# 4)\end{array}$ & Pan \\
\hline \multirow{6}{*}{$\begin{array}{l}\text { Ashwill, } \\
\text { Kingston }\end{array}$} & \multirow{6}{*}{ Gravel } & 1 & & & & & & & & & \\
\hline & & 2 & & & & & & & & & \\
\hline & & 3 & & & & & & & & & \\
\hline & & 4 & & & & & & & & & \\
\hline & & 5 & & & & & & & & & \\
\hline & & $1-5$ & & & & & & & & & \\
\hline \multirow{6}{*}{$\begin{array}{c}\text { Big Springs, } \\
\text { Harmony }\end{array}$} & \multirow{6}{*}{ Quarried } & 1 & 37.615 & 53.211 & 10.092 & 0.000 & 3.670 & 1.835 & 5.505 & 3.670 & 114.679 \\
\hline & & 2 & 45.690 & 50.862 & 3.448 & 0.862 & 0.862 & 0.000 & 1.724 & 1.724 & 141.379 \\
\hline & & 3 & 58.537 & 36.585 & 3.659 & 4.878 & 0.000 & 2.439 & 0.000 & 3.659 & 43.902 \\
\hline & & 4 & 30.000 & 63.077 & 6.923 & 0.000 & 0.000 & 0.000 & 0.000 & 1.538 & 24.615 \\
\hline & & 5 & 40.404 & 49.495 & 14.141 & 0.000 & 5.051 & 1.010 & 7.071 & 4.040 & 60.606 \\
\hline & & $1-5$ & 41.231 & 51.866 & 7.649 & 0.933 & 1.866 & 0.933 & 2.799 & 2.799 & 77.799 \\
\hline \multirow{6}{*}{ Bryan Rock } & \multirow{6}{*}{ Quarried } & 1 & 30.827 & 56.391 & 14.286 & 0.752 & 2.256 & 1.504 & 3.008 & 1.504 & 100.752 \\
\hline & & 2 & 29.771 & 61.832 & 9.160 & 0.763 & 0.000 & 0.000 & 4.580 & 2.290 & 55.725 \\
\hline & & 3 & 25.000 & 63.235 & 11.765 & 1.471 & 0.000 & 0.000 & 0.735 & 0.000 & 31.618 \\
\hline & & 4 & 16.794 & 67.939 & 15.267 & 0.000 & 0.763 & 0.000 & 0.000 & 0.000 & 0.000 \\
\hline & & 5 & 23.308 & 53.383 & 24.060 & 0.000 & 3.759 & 0.000 & 1.504 & 2.256 & 28.571 \\
\hline & & $1-5$ & 25.151 & 60.542 & 14.910 & 0.602 & 1.355 & 0.301 & 1.958 & 1.205 & 43.373 \\
\hline \multirow{6}{*}{$\begin{array}{c}\text { Cedarville } \\
\text { Plant }\end{array}$} & \multirow{6}{*}{ Quarried } & 1 & 17.391 & 77.536 & 5.072 & 0.725 & 0.000 & 0.000 & 0.725 & 0.000 & 36.232 \\
\hline & & 2 & 17.763 & 72.368 & 9.211 & 0.000 & 0.000 & 0.000 & 0.000 & 0.000 & 0.000 \\
\hline & & 3 & 21.986 & 68.794 & 9.220 & 0.709 & 0.709 & 0.000 & 0.000 & 0.709 & 14.184 \\
\hline & & 4 & & & & & & & & & \\
\hline & & 5 & 27.711 & 132.530 & 25.301 & 1.205 & 2.410 & 2.410 & 3.614 & 2.410 & 13.133 \\
\hline & & $1-5$ & 20.428 & 82.490 & 10.700 & 0.584 & 0.584 & 0.389 & 0.778 & 0.584 & 15.739 \\
\hline
\end{tabular}


Table C.10. HFT results (normalized, particle counts) for small chamber samples (19.0 to $37.5 \mathrm{~mm}$ [0.75 to 1.5 in]) (cont.).

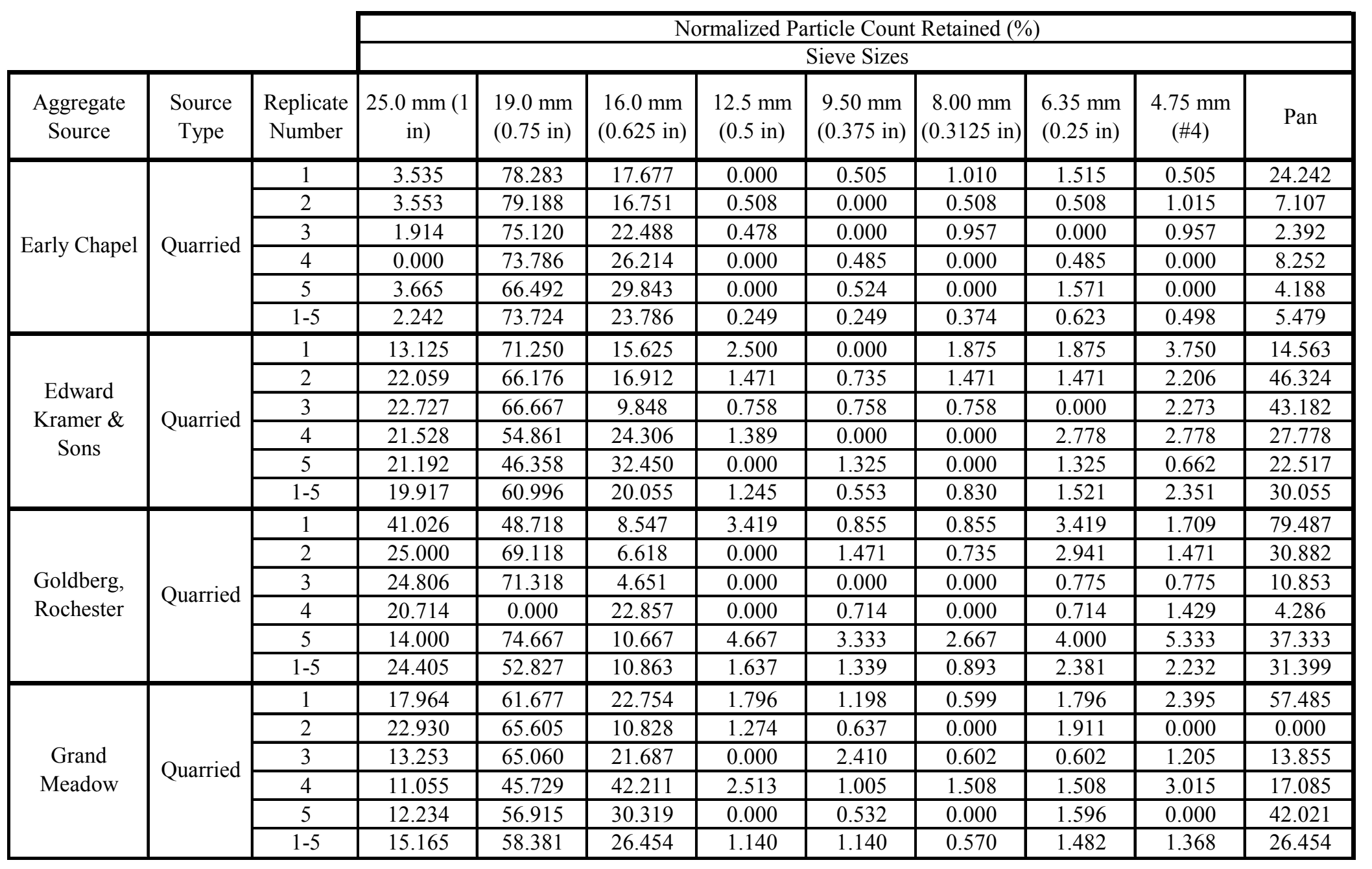


Table C.10. HFT results (normalized, particle counts) for small chamber samples (19.0 to $37.5 \mathrm{~mm}$ [0.75 to 1.5 in]) (cont.).

\begin{tabular}{|c|c|c|c|c|c|c|c|c|c|c|c|}
\hline & & \multicolumn{9}{|c|}{ Normalized Particle Count Retained (\%) } \\
\hline & & & \multicolumn{9}{|c|}{$\begin{array}{c}\text { Sieve Sizes } \\
\end{array}$} \\
\hline $\begin{array}{l}\text { Aggregate } \\
\text { Source }\end{array}$ & $\begin{array}{c}\text { Source } \\
\text { Type }\end{array}$ & $\begin{array}{l}\text { Replicate } \\
\text { Number }\end{array}$ & $\begin{array}{c}25.0 \mathrm{~mm}(1 \\
\text { in) }\end{array}$ & $\begin{array}{l}19.0 \mathrm{~mm} \\
(0.75 \mathrm{in})\end{array}$ & $\begin{array}{c}16.0 \mathrm{~mm} \\
(0.625 \mathrm{in})\end{array}$ & $\begin{array}{c}12.5 \mathrm{~mm} \\
(0.5 \mathrm{in})\end{array}$ & $\begin{array}{l}9.50 \mathrm{~mm} \\
(0.375 \mathrm{in})\end{array}$ & $\begin{array}{c}8.00 \mathrm{~mm} \\
(0.3125 \mathrm{in})\end{array}$ & $\begin{array}{l}6.35 \mathrm{~mm} \\
(0.25 \mathrm{in})\end{array}$ & $\begin{array}{c}4.75 \mathrm{~mm} \\
(\# 4)\end{array}$ & Pan \\
\hline \multirow{6}{*}{ Halma } & \multirow{6}{*}{ Gravel } & 1 & 0.000 & 87.273 & 12.727 & 0.000 & 0.000 & 0.000 & 0.000 & 0.000 & 5.000 \\
\hline & & 2 & 0.000 & 83.929 & 15.625 & 0.446 & 0.446 & 0.446 & 0.446 & 0.446 & 5.804 \\
\hline & & 3 & 0.000 & 84.932 & 14.155 & 0.000 & 0.457 & 0.000 & 0.000 & 0.000 & 11.416 \\
\hline & & 4 & 0.000 & 88.208 & 11.792 & 0.000 & 0.000 & 0.000 & 0.000 & 0.000 & 2.830 \\
\hline & & 5 & 0.000 & 85.135 & 14.414 & 0.450 & 0.450 & 0.000 & 0.450 & 0.450 & 3.604 \\
\hline & & $1-5$ & 0.000 & 85.871 & 13.765 & 0.182 & 0.273 & 0.091 & 0.182 & 0.182 & 5.743 \\
\hline \multirow{6}{*}{$\begin{array}{l}\text { Johnson, } \\
\text { Henderson }\end{array}$} & \multirow{6}{*}{ Gravel } & 1 & 47.222 & 49.074 & 4.630 & 0.926 & 0.000 & 0.000 & 0.000 & 0.000 & 65.741 \\
\hline & & 2 & 43.636 & 55.455 & 1.818 & 0.000 & 3.636 & 6.364 & 12.727 & 9.091 & 392.727 \\
\hline & & 3 & 37.615 & 55.046 & 5.505 & 1.835 & 0.917 & 0.000 & 0.000 & 0.000 & 26.606 \\
\hline & & 4 & 38.596 & 57.895 & 4.386 & 0.877 & 1.754 & 0.000 & 0.000 & 0.877 & 25.439 \\
\hline & & 5 & 45.283 & 43.396 & 13.208 & 0.000 & 0.000 & 0.000 & 0.000 & 0.943 & 1.887 \\
\hline & & $1-5$ & 42.413 & 52.285 & 5.850 & 0.731 & 1.280 & 1.280 & 2.559 & 2.194 & 102.925 \\
\hline \multirow{6}{*}{$\begin{array}{c}\text { Johnson, Le } \\
\text { Sueur }\end{array}$} & \multirow{6}{*}{ Gravel } & 1 & 20.690 & 77.241 & 3.448 & 0.000 & 0.000 & 0.000 & 0.000 & 0.000 & 18.621 \\
\hline & & 2 & 20.130 & 72.727 & 5.844 & 1.299 & 4.545 & 3.896 & 11.039 & 19.481 & 326.623 \\
\hline & & 3 & 16.107 & 77.852 & 5.369 & 0.000 & 0.671 & 1.342 & 0.671 & 4.027 & 436.242 \\
\hline & & 4 & 16.774 & 73.548 & 10.323 & 0.000 & 0.000 & 3.226 & 0.645 & 3.226 & 49.677 \\
\hline & & 5 & 18.750 & 59.375 & 21.250 & 2.500 & 0.625 & 3.750 & 4.375 & 7.500 & 146.250 \\
\hline & & $1-5$ & 17.961 & 70.712 & 10.841 & 0.971 & 1.456 & 3.074 & 4.207 & 8.576 & 236.893 \\
\hline \multirow{6}{*}{$\begin{array}{c}\text { Mark, } \\
\text { Underwood }\end{array}$} & \multirow{6}{*}{ Gravel } & 1 & 24.000 & 63.200 & 13.600 & 0.000 & 0.000 & 0.000 & 0.000 & 0.000 & 13.600 \\
\hline & & 2 & 25.203 & 70.732 & 4.065 & 0.000 & 0.813 & 0.000 & 0.813 & 0.000 & 20.325 \\
\hline & & 3 & 10.180 & 75.449 & 12.575 & 1.796 & 0.000 & 1.796 & 1.198 & 1.796 & 38.323 \\
\hline & & 4 & 19.549 & 75.940 & 4.511 & 0.000 & 0.000 & 0.752 & 1.504 & 3.008 & 33.083 \\
\hline & & 5 & 15.172 & 76.552 & 8.276 & 0.690 & 0.000 & 1.379 & 2.069 & 4.138 & 60.690 \\
\hline & & $1-5$ & 18.182 & 72.727 & 8.802 & 0.577 & 0.144 & 0.866 & 1.154 & 1.876 & 34.343 \\
\hline
\end{tabular}


Table C.10. HFT results (normalized, particle counts) for small chamber samples (19.0 to $37.5 \mathrm{~mm}$ [0.75 to $1.5 \mathrm{in}])$ (cont.).

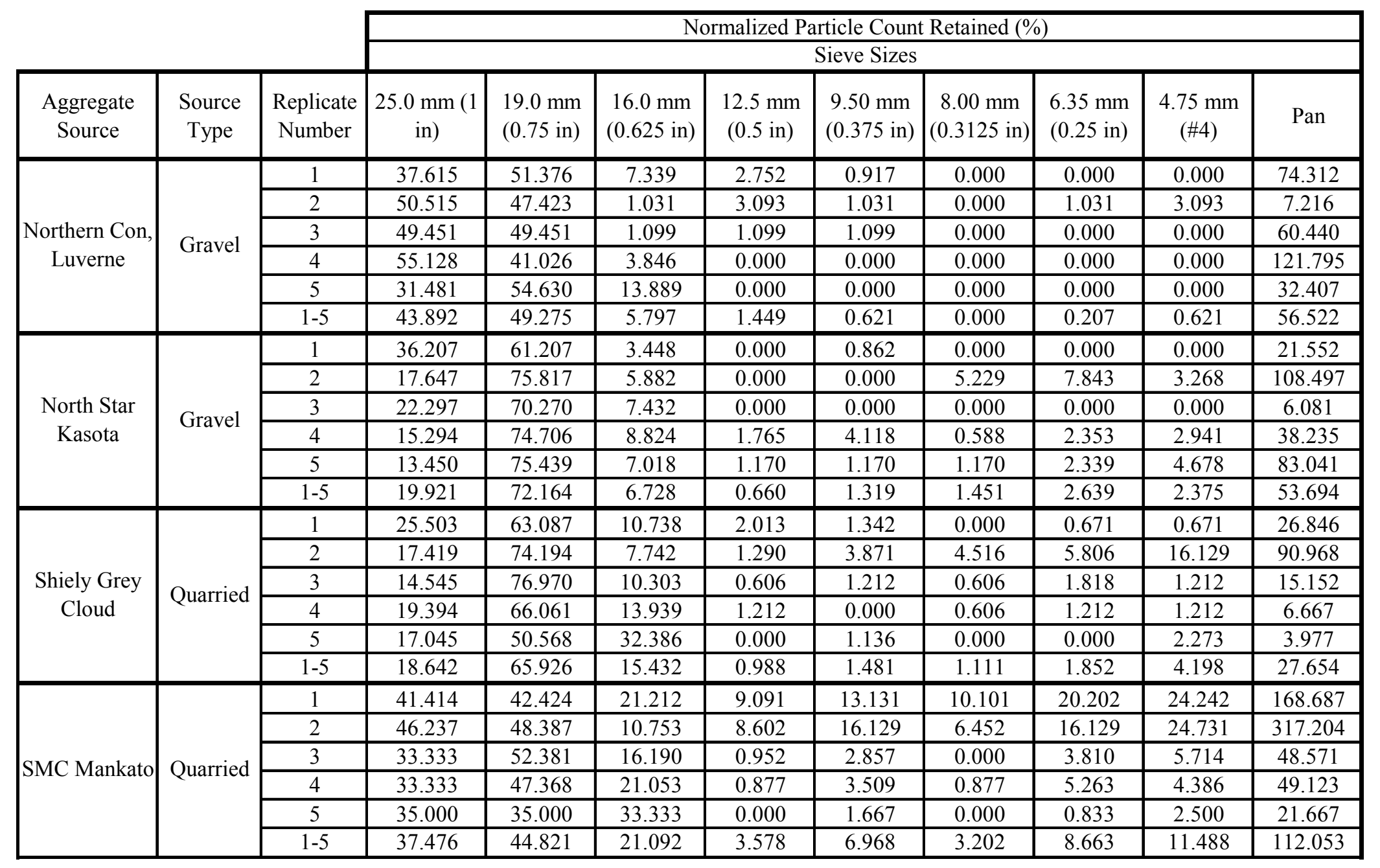


Table C.10. HFT results (normalized, particle counts) for small chamber samples (19.0 to $37.5 \mathrm{~mm}$ [0.75 to 1.5 in]) (cont.).

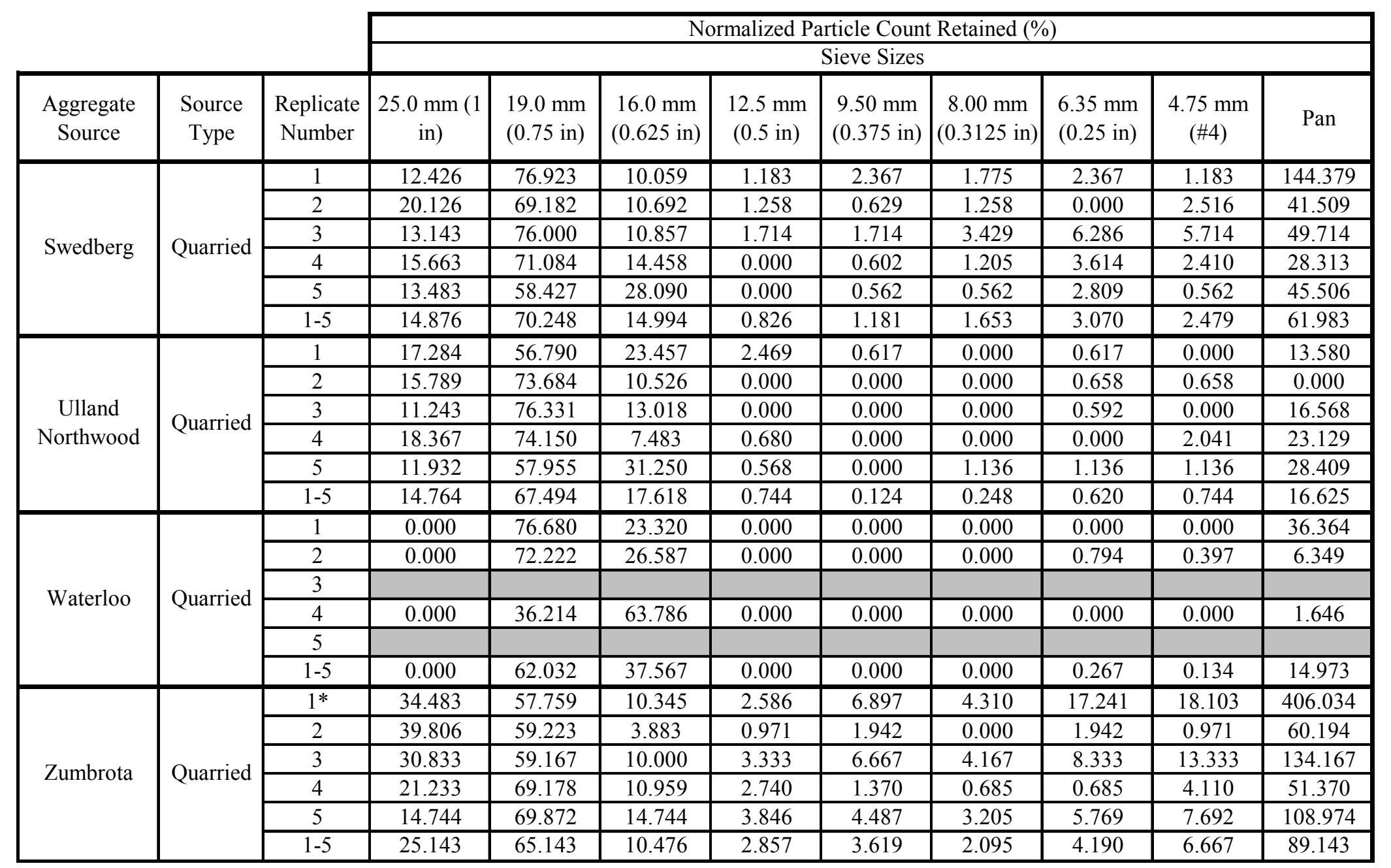




\section{APPENDIX D}

Hydraulic Fracture Test Results - Large Chamber 
Table D.1. HFT results (mass retained) for large chamber samples (19.0 to $37.5 \mathrm{~mm}$ [0.75 to $1.5 \mathrm{in}]$ )

\begin{tabular}{|c|c|c|c|c|c|c|c|c|c|c|c|c|}
\hline & & & \multicolumn{10}{|c|}{ Mass Retained (g) } \\
\hline & & & \multirow{2}{*}{0 Cycles } & \multicolumn{9}{|c|}{ After 50 Cycles } \\
\hline & & & & \multicolumn{9}{|c|}{ Sieve Sizes } \\
\hline $\begin{array}{l}\text { Aggregate } \\
\text { Source }\end{array}$ & $\begin{array}{l}\text { Source } \\
\text { Type }\end{array}$ & $\begin{array}{c}\text { Replicate } \\
\text { Number }\end{array}$ & Total & $\begin{array}{l}25.0 \mathrm{~mm} \\
(1 \mathrm{in})\end{array}$ & $\begin{array}{l}19.0 \mathrm{~mm} \\
(0.75 \mathrm{in})\end{array}$ & $\begin{array}{c}16.0 \mathrm{~mm} \\
(0.625 \mathrm{in})\end{array}$ & $\begin{array}{c}12.5 \mathrm{~mm} \\
(0.5 \mathrm{in})\end{array}$ & $\begin{array}{c}9.50 \mathrm{~mm} \\
(0.375 \mathrm{in})\end{array}$ & $\begin{array}{c}8.00 \mathrm{~mm} \\
(0.3125 \\
\text { in })\end{array}$ & $\begin{array}{l}6.35 \mathrm{~mm} \\
(0.25 \mathrm{in})\end{array}$ & $\begin{array}{l}4.75 \mathrm{~mm} \\
(\# 4)\end{array}$ & Pan \\
\hline \multirow{4}{*}{$\begin{array}{l}\text { Johnson, } \\
\text { Henderson }\end{array}$} & \multirow{4}{*}{ Gravel } & 1 & 15220.2 & 8499.7 & 6287.1 & 253.7 & 12.9 & 0.0 & 0.0 & 0.0 & 1.9 & 101.9 \\
\hline & & 2 & 15007.9 & 8006.6 & 6641.6 & 208.5 & 5.2 & 0.9 & 0.0 & 0.0 & 7.1 & 94.9 \\
\hline & & 3 & 14986.8 & 7131.6 & 7493.2 & 189.2 & 0.0 & 1.7 & 0.0 & 0.0 & 4.6 & 90.3 \\
\hline & & $1-3$ & 45214.9 & 23637.9 & 20421.9 & 651.4 & 18.1 & 2.6 & 0.0 & 0.0 & 13.6 & 287.1 \\
\hline \multirow{4}{*}{$\begin{array}{l}\text { Edward } \\
\text { Kramer and } \\
\text { Sons }\end{array}$} & \multirow{4}{*}{ Quarried } & 1 & 15144.3 & 4165.7 & 9183.8 & 1202.2 & 80.2 & 38.6 & 0.0 & 0.0 & 31.3 & 279.1 \\
\hline & & 2 & 15496.3 & 4005.9 & 9461.9 & 1454.6 & 89.4 & 32.3 & 0.0 & 0.0 & 35.1 & 264.7 \\
\hline & & 3 & 14824.1 & 4689.7 & 8344.7 & 1224.0 & 92.4 & 31.3 & 0.0 & 0.0 & 27.6 & 264.8 \\
\hline & & $1-3$ & 45464.7 & 12861.3 & 26990.4 & 3880.8 & 262.0 & 102.2 & 0.0 & 0.0 & 94.0 & 808.6 \\
\hline \multirow{4}{*}{$\begin{array}{l}\text { North Star } \\
\text { Kasota }\end{array}$} & \multirow{4}{*}{ Gravel } & 1 & 15261.4 & 5150.0 & 9663.7 & 346.6 & 0.0 & 4.4 & 0.0 & 0.0 & 1.4 & 73.6 \\
\hline & & 2 & 15112.9 & 5239.4 & 9199.0 & 526.2 & 27.6 & 0.0 & 0.0 & 0.0 & 6.2 & 59.3 \\
\hline & & 3 & 15173.1 & 5575.2 & 9217.8 & 248.1 & 8.4 & 4.5 & 0.0 & 0.0 & 2.3 & 63.7 \\
\hline & & $1-3$ & 45547.4 & 15964.6 & 28080.5 & 1120.9 & 36.0 & 8.9 & 0.0 & 0.0 & 9.9 & 196.6 \\
\hline \multirow{4}{*}{ Early Chapel } & \multirow{4}{*}{ Quarried } & 1 & 14802.3 & 592.5 & 12309.8 & 1564.7 & 2.3 & 6.5 & 0.0 & 0.0 & 9.2 & 218.0 \\
\hline & & 2 & 14806.9 & 903.7 & 11774.3 & 1774.0 & 12.7 & 10.1 & 0.0 & 0.0 & 13.2 & 238.9 \\
\hline & & 3 & 14874.8 & 708.9 & 11945.7 & 1883.4 & 29.9 & 7.7 & 0.0 & 0.0 & 7.3 & 226.0 \\
\hline & & $1-3$ & 44484.0 & 2205.1 & 36029.8 & 5222.1 & 44.9 & 24.3 & 0.0 & 0.0 & 29.7 & 682.9 \\
\hline
\end{tabular}


Table D.2. HFT results (particle counts) for large chamber samples (19.0 to $37.5 \mathrm{~mm}$ [0.75 to $1.5 \mathrm{in}]$ )

\begin{tabular}{|c|c|c|c|c|c|c|c|c|c|c|c|c|}
\hline & & & \multirow{2}{*}{\multicolumn{10}{|c|}{ Particle Count Retained }} \\
\hline & & & & & & & & & & & & \\
\hline & & & \multirow{2}{*}{0 Cycles } & \multicolumn{9}{|c|}{ After 50 Cycles } \\
\hline & & & & \multicolumn{9}{|c|}{ Sieve Sizes } \\
\hline $\begin{array}{l}\text { Aggregate } \\
\text { Source }\end{array}$ & $\begin{array}{l}\text { Source } \\
\text { Type }\end{array}$ & $\begin{array}{c}\text { Replicate } \\
\text { Number }\end{array}$ & Total & $\begin{array}{c}25.0 \mathrm{~mm} \\
(1 \mathrm{in})\end{array}$ & $\begin{array}{l}19.0 \mathrm{~mm} \\
(0.75 \mathrm{in})\end{array}$ & $\begin{array}{c}16.0 \mathrm{~mm} \\
(0.625 \mathrm{in})\end{array}$ & $\begin{array}{c}12.5 \mathrm{~mm} \\
(0.5 \mathrm{in})\end{array}$ & $\begin{array}{c}9.50 \mathrm{~mm} \\
(0.375 \mathrm{in})\end{array}$ & $\begin{array}{c}8.00 \mathrm{~mm} \\
(0.3125 \\
\text { in) }\end{array}$ & $\begin{array}{l}6.35 \mathrm{~mm} \\
(0.25 \mathrm{in})\end{array}$ & $\begin{array}{l}4.75 \mathrm{~mm} \\
(\# 4)\end{array}$ & Pan \\
\hline \multirow{4}{*}{$\begin{array}{l}\text { Johnson, } \\
\text { Henderson }\end{array}$} & \multirow{4}{*}{ Gravel } & 1 & 570 & 218 & 328 & 25 & 2 & 0 & 0 & 0 & 6 & 34 \\
\hline & & 2 & 577 & 210 & 351 & 20 & 1 & 1 & 0 & 0 & 12 & 0 \\
\hline & & 3 & 597 & 184 & 294 & 18 & 0 & 1 & 0 & 0 & 8 & 0 \\
\hline & & $1-3$ & 1744 & 612 & 973 & 63 & 3 & 2 & 0 & 0 & 26 & 34 \\
\hline \multirow{4}{*}{$\begin{array}{c}\text { Edward } \\
\text { Kramer and } \\
\text { Sons }\end{array}$} & \multirow{4}{*}{ Quarried } & 1 & 794 & 127 & 541 & 117 & 18 & 18 & 0 & 0 & 76 & 0 \\
\hline & & 2 & 806 & 118 & 555 & 135 & 18 & 16 & 0 & 0 & 67 & 0 \\
\hline & & 3 & 777 & 142 & 509 & 122 & 19 & 14 & 0 & 0 & 68 & 57 \\
\hline & & $1-3$ & 2377 & 387 & 1605 & 374 & 55 & 48 & 0 & 0 & 211 & 57 \\
\hline \multirow{4}{*}{$\begin{array}{c}\text { North Star } \\
\text { Kasota }\end{array}$} & \multirow{4}{*}{ Gravel } & 1 & 719 & 134 & 554 & 31 & 0 & 2 & 0 & 0 & 4 & 0 \\
\hline & & 2 & 715 & 132 & 532 & 47 & 6 & 0 & 0 & 0 & 13 & 0 \\
\hline & & 3 & 688 & 145 & 518 & 24 & 1 & 2 & 0 & 0 & 6 & 0 \\
\hline & & $1-3$ & 2122 & 411 & 1604 & 102 & 7 & 4 & 0 & 0 & 23 & 0 \\
\hline \multirow{4}{*}{ Early Chapel } & \multirow{4}{*}{ Quarried } & 1 & 978 & 23 & 814 & 147 & 1 & 3 & 0 & 0 & 17 & 20 \\
\hline & & 2 & 960 & 37 & 765 & 166 & 2 & 5 & 0 & 0 & 30 & 0 \\
\hline & & 3 & 981 & 27 & 777 & 173 & 6 & 4 & 0 & 0 & 13 & 0 \\
\hline & & $1-3$ & 2919 & 87 & 2356 & 486 & 9 & 12 & 0 & 0 & 60 & 20 \\
\hline
\end{tabular}


Table D.3. HFT results (mass retained, normalized) for large chamber samples (19.0 to $37.5 \mathrm{~mm}$ [0.75 to $1.5 \mathrm{in}]$ )

\begin{tabular}{|c|c|c|c|c|c|c|c|c|c|c|c|}
\hline & & \multicolumn{9}{|c|}{ Normalized Mass Retained (\%) } \\
\hline & & & \multicolumn{9}{|c|}{ Sieve Sizes } \\
\hline $\begin{array}{l}\text { Aggregate } \\
\text { Source }\end{array}$ & $\begin{array}{l}\text { Source } \\
\text { Type }\end{array}$ & $\begin{array}{c}\text { Replicate } \\
\text { Number }\end{array}$ & $\begin{array}{l}25.0 \mathrm{~mm} \\
(1 \mathrm{in})\end{array}$ & $\begin{array}{l}19.0 \mathrm{~mm} \\
(0.75 \mathrm{in})\end{array}$ & $\begin{array}{c}16.0 \mathrm{~mm} \\
(0.625 \mathrm{in})\end{array}$ & $\begin{array}{c}12.5 \mathrm{~mm} \\
(0.5 \mathrm{in})\end{array}$ & $\begin{array}{c}9.50 \mathrm{~mm} \\
(0.375 \mathrm{in})\end{array}$ & $\begin{array}{c}8.00 \mathrm{~mm} \\
(0.3125 \\
\text { in) }\end{array}$ & $\begin{array}{l}6.35 \mathrm{~mm} \\
(0.25 \mathrm{in})\end{array}$ & $\begin{array}{c}4.75 \mathrm{~mm} \\
(\# 4)\end{array}$ & Pan \\
\hline \multirow{4}{*}{$\begin{array}{l}\text { Johnson, } \\
\text { Henderson }\end{array}$} & \multirow{4}{*}{ Gravel } & 1 & 55.8449 & 41.3076 & 1.6669 & 0.0848 & 0.0000 & 0.0000 & 0.0000 & 0.0125 & 0.6695 \\
\hline & & 2 & 53.3492 & 44.2540 & 1.3893 & 0.0346 & 0.0060 & 0.0000 & 0.0000 & 0.0473 & 0.6323 \\
\hline & & 3 & 47.5859 & 49.9987 & 1.2624 & 0.0000 & 0.0113 & 0.0000 & 0.0000 & 0.0307 & 0.6025 \\
\hline & & $1-3$ & 52.2790 & 45.1663 & 1.4407 & 0.0400 & 0.0058 & 0.0000 & 0.0000 & 0.0301 & 0.6350 \\
\hline \multirow{4}{*}{$\begin{array}{c}\text { Edward } \\
\text { Kramer and } \\
\text { Sons }\end{array}$} & \multirow{4}{*}{ Quarried } & 1 & 27.5067 & 60.6420 & 7.9383 & 0.5296 & 0.2549 & 0.0000 & 0.0000 & 0.2067 & 1.8429 \\
\hline & & 2 & 25.8507 & 61.0591 & 9.3868 & 0.5769 & 0.2084 & 0.0000 & 0.0000 & 0.2265 & 1.7081 \\
\hline & & 3 & 31.6356 & 56.2914 & 8.2568 & 0.6233 & 0.2111 & 0.0000 & 0.0000 & 0.1862 & 1.7863 \\
\hline & & $1-3$ & 28.2885 & 59.3656 & 8.5359 & 0.5763 & 0.2248 & 0.0000 & 0.0000 & 0.2068 & 1.7785 \\
\hline \multirow{4}{*}{$\begin{array}{c}\text { North Star } \\
\text { Kasota }\end{array}$} & \multirow{4}{*}{ Gravel } & 1 & 33.7453 & 63.3212 & 2.2711 & 0.0000 & 0.0288 & 0.0000 & 0.0000 & 0.0092 & 0.4823 \\
\hline & & 2 & 34.6684 & 60.8685 & 3.4818 & 0.1826 & 0.0000 & 0.0000 & 0.0000 & 0.0410 & 0.3924 \\
\hline & & 3 & 36.7440 & 60.7509 & 1.6351 & 0.0554 & 0.0297 & 0.0000 & 0.0000 & 0.0152 & 0.4198 \\
\hline & & $1-3$ & 35.0505 & 61.6512 & 2.4610 & 0.0790 & 0.0195 & 0.0000 & 0.0000 & 0.0217 & 0.4316 \\
\hline \multirow{4}{*}{ Early Chapel } & \multirow{4}{*}{ Quarried } & 1 & 4.0028 & 83.1614 & 10.5707 & 0.0155 & 0.0439 & 0.0000 & 0.0000 & 0.0622 & 1.4727 \\
\hline & & 2 & 6.1032 & 79.5190 & 11.9809 & 0.0858 & 0.0682 & 0.0000 & 0.0000 & 0.0891 & 1.6134 \\
\hline & & 3 & 4.7658 & 80.3083 & 12.6617 & 0.2010 & 0.0518 & 0.0000 & 0.0000 & 0.0491 & 1.5193 \\
\hline & & $1-3$ & 4.9571 & 80.9950 & 11.7393 & 0.1009 & 0.0546 & 0.0000 & 0.0000 & 0.0668 & 1.5352 \\
\hline
\end{tabular}


Table D.4. HFT results (particle counts, normalized) for large chamber samples (19.0 to $37.5 \mathrm{~mm}$ [0.75 to $1.5 \mathrm{in}]$ )

\begin{tabular}{|c|c|c|c|c|c|c|c|c|c|c|c|}
\hline & & \multicolumn{9}{|c|}{ Normalized Particle Count Retained (\%) } \\
\hline & & & \multicolumn{9}{|c|}{ Sieve Sizes } \\
\hline $\begin{array}{l}\text { Aggregate } \\
\text { Source }\end{array}$ & $\begin{array}{l}\text { Source } \\
\text { Type }\end{array}$ & $\begin{array}{l}\text { Replicate } \\
\text { Number }\end{array}$ & $\begin{array}{c}25.0 \mathrm{~mm} \\
(1 \mathrm{in})\end{array}$ & $\begin{array}{l}19.0 \mathrm{~mm} \\
(0.75 \mathrm{in})\end{array}$ & $\begin{array}{c}16.0 \mathrm{~mm} \\
(0.625 \mathrm{in})\end{array}$ & $\begin{array}{c}12.5 \mathrm{~mm} \\
(0.5 \mathrm{in})\end{array}$ & $\begin{array}{l}9.50 \mathrm{~mm} \\
(0.375 \mathrm{in})\end{array}$ & $\begin{array}{c}8.00 \mathrm{~mm} \\
(0.3125 \mathrm{in})\end{array}$ & $\begin{array}{l}6.35 \mathrm{~mm} \\
(0.25 \mathrm{in})\end{array}$ & $\begin{array}{c}4.75 \mathrm{~mm} \\
(\# 4)\end{array}$ & Pan \\
\hline \multirow{4}{*}{$\begin{array}{l}\text { Johnson, } \\
\text { Henderson }\end{array}$} & \multirow{4}{*}{ Gravel } & 1 & 38.2456 & 57.5439 & 4.3860 & 0.3509 & 0.0000 & 0.0000 & 0.0000 & 1.0526 & 5.9649 \\
\hline & & 2 & 36.3951 & 60.8319 & 3.4662 & 0.1733 & 0.1733 & 0.0000 & 0.0000 & 2.0797 & 0.0000 \\
\hline & & 3 & 30.8208 & 49.2462 & 3.0151 & 0.0000 & 0.1675 & 0.0000 & 0.0000 & 1.3400 & 0.0000 \\
\hline & & $1-3$ & 35.0917 & 55.7913 & 3.6124 & 0.1720 & 0.1147 & 0.0000 & 0.0000 & 1.4908 & 1.9495 \\
\hline \multirow{4}{*}{$\begin{array}{c}\text { Edward } \\
\text { Kramer and } \\
\text { Sons }\end{array}$} & \multirow{4}{*}{ Quarried } & 1 & 15.9950 & 68.1360 & 14.7355 & 2.2670 & 2.2670 & 0.0000 & 0.0000 & 9.5718 & 0.0000 \\
\hline & & 2 & 14.6402 & 68.8586 & 16.7494 & 2.2333 & 1.9851 & 0.0000 & 0.0000 & 8.3127 & 0.0000 \\
\hline & & 3 & 18.2754 & 65.5084 & 15.7014 & 2.4453 & 1.8018 & 0.0000 & 0.0000 & 8.7516 & 7.3359 \\
\hline & & $1-3$ & 16.2810 & 67.5221 & 15.7341 & 2.3138 & 2.0194 & 0.0000 & 0.0000 & 8.8767 & 2.3980 \\
\hline \multirow{4}{*}{$\begin{array}{l}\text { North Star } \\
\text { Kasota }\end{array}$} & \multirow{4}{*}{ Gravel } & 1 & 18.6370 & 77.0515 & 4.3115 & 0.0000 & 0.2782 & 0.0000 & 0.0000 & 0.5563 & 0.0000 \\
\hline & & 2 & 18.4615 & 74.4056 & 6.5734 & 0.8392 & 0.0000 & 0.0000 & 0.0000 & 1.8182 & 0.0000 \\
\hline & & 3 & 21.0756 & 75.2907 & 3.4884 & 0.1453 & 0.2907 & 0.0000 & 0.0000 & 0.8721 & 0.0000 \\
\hline & & $1-3$ & 19.3685 & 75.5891 & 4.8068 & 0.3299 & 0.1885 & 0.0000 & 0.0000 & 1.0839 & 0.0000 \\
\hline \multirow{4}{*}{ Early Chapel } & \multirow{4}{*}{ Quarried } & 1 & 2.3517 & 83.2311 & 15.0307 & 0.1022 & 0.3067 & 0.0000 & 0.0000 & 1.7382 & 2.0450 \\
\hline & & 2 & 3.8542 & 79.6875 & 17.2917 & 0.2083 & 0.5208 & 0.0000 & 0.0000 & 3.1250 & 0.0000 \\
\hline & & 3 & 2.7523 & 79.2049 & 17.6351 & 0.6116 & 0.4077 & 0.0000 & 0.0000 & 1.3252 & 0.0000 \\
\hline & & $1-3$ & 2.9805 & 80.7126 & 16.6495 & 0.3083 & 0.4111 & 0.0000 & 0.0000 & 2.0555 & 0.6852 \\
\hline
\end{tabular}




\section{APPENDIX E}

\section{Development of Regression Models}




\section{APPENDIX E}

\section{DEVELOPMENT OF REGRESSION MODELS}

\section{E.1 Introduction}

The small chamber hydraulic fracture test results were modeled using the computer software package called $A R C$ developed at the University of Minnesota Department of Applied Statistics. Cook and Weisberg discuss the use of this software package in reference (9).

Separate models were developed for each initial size fraction using the cumulative percentage of mass or particles passing each screen as the predictors for the response variables "percent dilation per 100 cycles of freezing and thawing" and "durability factor," which are described in section 4.1 "Concrete Properties." Table E.1 presents a summary of the regression models developed under this study.

Table E.1. Regression analysis matrix.

\begin{tabular}{|c|l|c|}
\hline \hline $\begin{array}{c}\text { Explanatory Variables } \\
\text { (Cumulative } \\
\text { Percentage Passing) }\end{array}$ & \multicolumn{1}{|c|}{ Response Variable } & $\begin{array}{c}\text { Initial Size } \\
\text { Fraction }\end{array}$ \\
\hline \hline \multirow{2}{*}{ Mass } & Percent Dilation per 100 Cycles & \multirow{2}{*}{4.75 to $12.5 \mathrm{~mm}$} \\
\cline { 2 - 2 } & Durability Factor & \multirow{3}{*}{12.5 to $19.0 \mathrm{~mm}$} \\
\hline \multirow{2}{*}{ Particle Counts } & Percent Dilation per 100 Cycles & \\
\cline { 2 - 2 } Mass & Durability Factor & \multirow{3}{*}{19.0 to $37.5 \mathrm{~mm}$} \\
\hline \hline \multirow{2}{*}{ Particle Counts } & Percent Dilation per 100 Cycles & \\
\cline { 2 - 2 } & Durability Factor & \\
\cline { 2 - 2 } & Percent Dilation per 100 Cycles & \\
\hline \multirow{2}{*}{ Mass } & Percent Dilation per 100 Cycles & \\
\cline { 2 - 2 } & Durability Factor & \\
\hline \hline
\end{tabular}

The following subsections describe the development of the models generated for each size fraction and the selection of the final model in each category. 


\section{E.2 Initial Size Fraction: 4.75 to $12.5 \mathrm{~mm}$ (\#4 to 0.5 in)}

Hydraulic fracture testing on the initial size fraction 4.75 to $12.5 \mathrm{~mm}$ (\#4 to $0.5 \mathrm{in}$ ) was performed according to the procedure outlined in appendix A. The percentage of mass retained (POMR) on the specified sieves for each sample (replicate) and the average percentage of original mass retained (APOMR) were computed for each source using the equations presented in section 3.5.3. Table C.1 of appendix C presents the actual masses retained on the specified sieves at 0 and 50 cycles for each replicate test sample of each source. The normalized data (i.e., POMR and APOMR) are presented in table C.2 of appendix C.

\section{E.2.1 Mass Retained Data}

\section{E.2.1.1 Explanatory Variables}

As stated previously, models were developed to predict both percent dilation per 100 cycles of rapid freezing and thawing (dil) and durability factor (DF). The following predictors were initially selected as the independent or explanatory variables for these models:

38M: $\quad$ Percentage of mass passing the $9.50 \mathrm{~mm}(0.375 \mathrm{in})$ screen.

516M: $\quad$ Percentage of mass passing the $8.00 \mathrm{~mm}(0.3125 \mathrm{in})$ screen.

14M: $\quad$ Percentage of mass passing the $6.35 \mathrm{~mm}(0.25 \mathrm{in})$ screen.

4M: $\quad$ Percentage of mass passing the $4.75 \mathrm{~mm}$ (\#4) screen.

C: $\quad$ Carbonate content of the source, percent.

The percentage of mass passing each specified screen was calculated as described below using the APOMR data presented in table C.2.

a Total Percentage of Original Mass Retained [TPOMR]:

$$
\mathrm{TPOMR}=\sum_{i=1}^{n} \mathrm{APOMR}_{i}=100 \% \text { * }
$$

where: $\quad \mathrm{APOMR}_{i}=$ average percentage of original mass retained on screen $i$ and $\mathrm{n}=$ total number of screens.

*Use a TPOMR of 100 percent. Mass losses due to screening operations are accounted for in equations E.6 and E.7. 
口 Percentage of mass passing the $9.50 \mathrm{~mm}(0.375 \mathrm{in})$ screen $[38 \mathrm{M}]$ :

$$
38 \mathrm{M}=\mathrm{TPOMR}-\mathrm{APOMR}_{38}
$$

where: $\quad$ TPOMR $=$ Total percentage of original mass retained and

$\mathrm{APOMR}_{38}=$ average percentage of original mass retained on the $9.50 \mathrm{~mm}(0.375 \mathrm{in})$ screen.

口 Percentage of mass passing the $8.00 \mathrm{~mm}(0.3125 \mathrm{in})$ screen [516M]:

$$
516 \mathrm{M}=38 \mathrm{M}-\mathrm{APOMR}_{516}
$$

where: $\quad 38 \mathrm{M}=$ Percentage of mass passing the $9.50 \mathrm{~mm}(0.375 \mathrm{in})$ screen and

$\mathrm{APOMR}_{516}=$ average percentage of original mass retained on the $8.00 \mathrm{~mm}(0.3125 \mathrm{in})$ screen.

Percentage of mass passing the $6.35 \mathrm{~mm}(0.25 \mathrm{in})$ screen $[14 \mathrm{M}]$ :

$$
14 \mathrm{M}=516 \mathrm{M}-\mathrm{APOMR}_{14}
$$

where: $\quad 516 \mathrm{M}=$ Percentage of mass passing the $8.00 \mathrm{~mm}(0.3125 \mathrm{in})$ screen and

$\mathrm{APOMR}_{14}=$ average percentage of original mass retained on the $6.35 \mathrm{~mm}(0.25 \mathrm{in})$ screen.

a Percentage of mass passing the $4.75 \mathrm{~mm}(\# 4)$ screen [4 $\left.4_{\text {actual }}\right]$ :

$$
4_{\text {actual }}=14 \mathrm{M}-\mathrm{APOMR}_{4}
$$

where: $\quad 14 \mathrm{M}=$ Percentage of mass passing the $6.35 \mathrm{~mm}(0.25 \mathrm{in})$ screen and

$\mathrm{APOMR}_{4}=$ average percentage of original mass retained on the $4.75 \mathrm{~mm}$ (\#4) screen.

a Percentage of mass lost due to testing $\left[\mathrm{M}_{\mathrm{loss}}\right]$ :

$$
\mathrm{M}_{\text {loss }}=4_{\text {actual }}-\mathrm{APOMR}_{\text {pan }}
$$

where: $\quad 4_{\text {actual }}=$ Percentage of mass passing the $4.75 \mathrm{~mm}(\# 4)$ screen and $\mathrm{APOMR}_{\mathrm{pan}}=$ average percentage of original mass retained on the pan.

․ Percentage of mass passing the $4.75 \mathrm{~mm}(\# 4)$ screen (adjusted for mass loss during testing) [4M]:

$$
4 \mathrm{M}=4_{\text {actual }}-\mathrm{M}_{\text {loss }}
$$


- Percentage of mass passing the pan [pan]:

$$
\mathrm{Pan}=4 \mathrm{M}-\mathrm{APOMR}_{\mathrm{pan}}=0
$$

The predictors defined by equations E. 2 - E.4 and E.7 were calculated for each of 20 sources tested and were then transferred as an $l s p$ file into $A R C$. Equation E.8 was used as a check to make sure that there were no computational errors.

It should be noted that as much as one percent of the mass of a given test sample was sometimes lost during testing. As a result, the total percentage of original material mass retained during the final sieve analyses was sometimes reduced to 99 percent or more. Because of the great care taken during testing, it was assumed that the material lost during testing was probably very fine and would have passed the $4.75 \mathrm{~mm}$ (\#4) sieve. Equations E.5 - E.7 were developed to account for this mass loss and attribute it to the proper particle size in the regression analysis.

\section{E.2.1.2 Transformations to Normality}

Two-dimensional scatter plots were developed to show the conditional distribution of the response variables (dilation/100 cycles and durability factor) to changes in each explanatory variable. The scatter plot matrix for the previously defined explanatory and response variables is presented in figure E.1. Normality is achieved when the mean functions are linear and the variance functions are constant (9). Figure E.1 shows that there is little normality between the response and explanatory variables in the inverse fitted value plots (marginal distribution plots).

Normality can sometimes be achieved or improved through transformations of the explanatory variables. In this study, explanatory variable transformations were performed using the Box-Cox method (a numerical procedure) in an attempt to improve the linearity of the relationships. Figure E. 2 presents the scatter plot matrix for the transformed explanatory variables and shows that the Box-Cox transformations were not effective in producing linear relationships between the percentage of particles passing the designated screens and either percent dilation or the durability factor. 
Even though normality was apparently not achieved, nonlinear and multiple linear regression analyses were performed on this data set, as described in subsections E2.1.3 and E2.1.4.

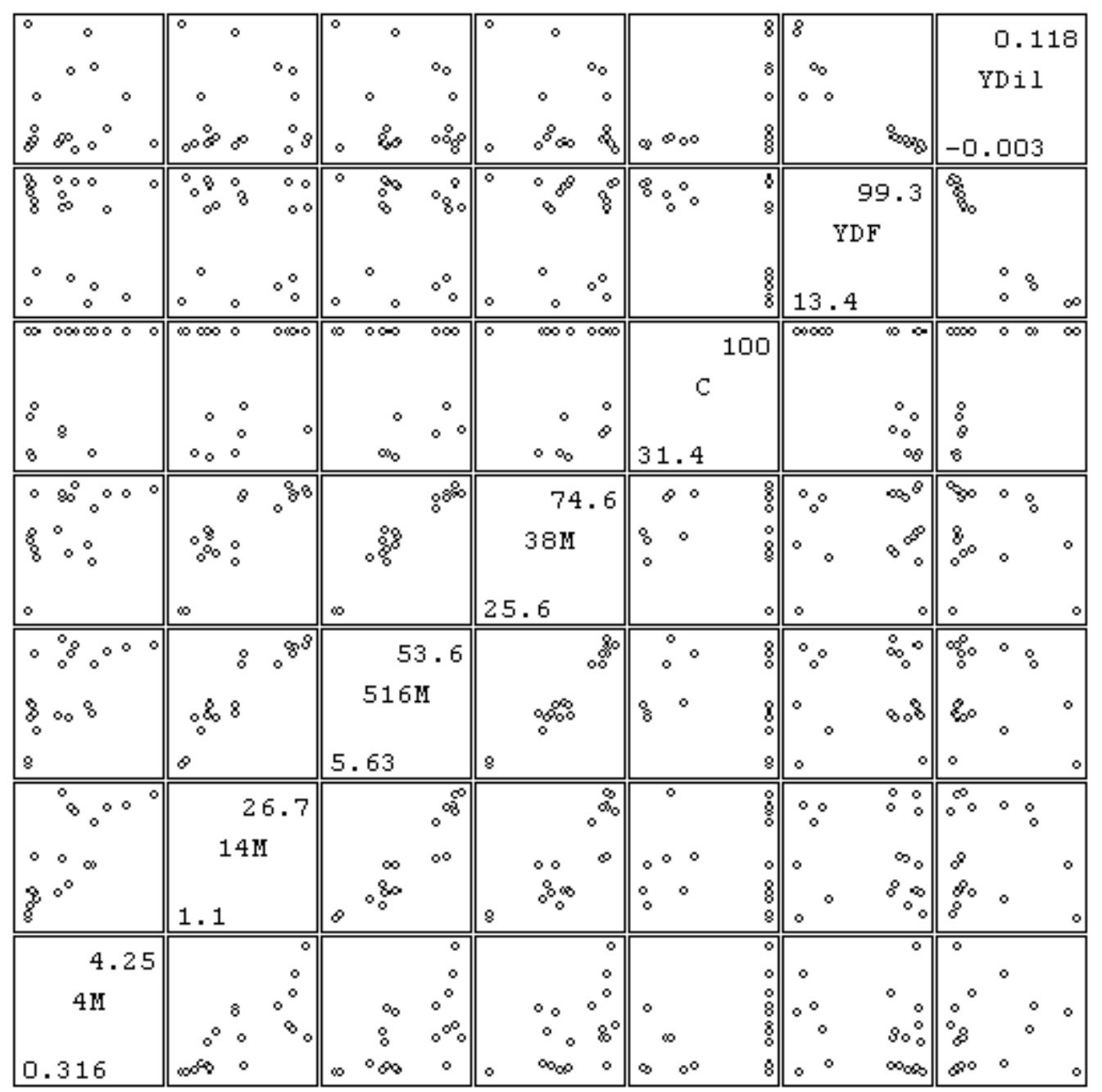

Figure E.1. Scatter plot matrix for responses and explanatory variables (percentage of mass passing, 4.75 to $12.5 \mathrm{~mm}$ [\#4 to $0.5 \mathrm{in}]$ ).

\section{E.2.1.3 Nonlinear Regression}

Previous studies have shown that concrete freeze-thaw durability is often a function of carbonate content. Therefore, the following general form was adopted for both models:

$$
\begin{aligned}
& \mathrm{E}(\mathrm{y} \mid \mathrm{x})=\mathrm{C} *(\text { linear combination of } 38 \mathrm{M}, 516 \mathrm{M}, 14 \mathrm{M} \text { and } 4 \mathrm{M}) \\
& \text { therefore, } \\
& \mathrm{E}(\mathrm{y} \mid \mathrm{x})=\mathrm{C}^{*}\left(\alpha+\beta_{1} * 38 \mathrm{M}+\beta_{2} * 516 \mathrm{M}+\beta_{3} * 14 \mathrm{M}+\beta_{4} * 4 \mathrm{M}\right)
\end{aligned}
$$




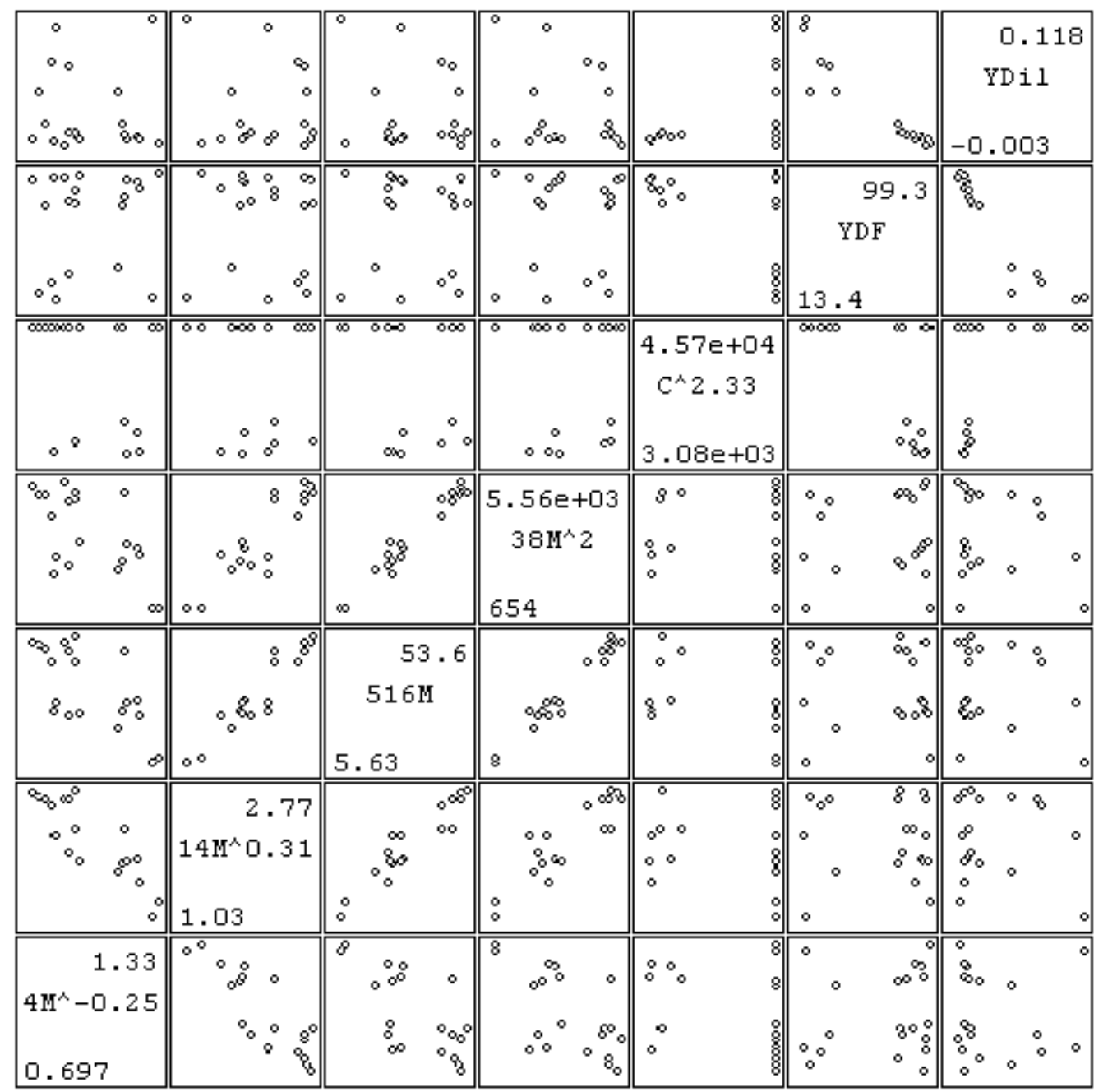

Figure E.2. Scatter plot matrix for responses and transformed explanatory variables (percentage of mass passing, 4.75 to $12.5 \mathrm{~mm}$ [\#4 to $0.5 \mathrm{in}]$ ).

Regression analyses were performed using both the untransformed (identity) and transformed explanatory variables. Tables E. 2 and E.3 present the results of regression analyses for the untransformed and transformed explanatory variables, respectively, including the parameter estimates, Wald statistics, degrees of freedom, number of observations (n), coefficent of multiple determination $\left(\mathrm{R}^{2}\right)$, standard deviation about the least squares line $(\hat{\sigma})$, adjusted $\mathrm{R}^{2}$ and a subsection presenting the model expressions. 
Table E.2. Nonlinear regression models using untransformed data (percentage of mass passing, 4.75 to $12.5 \mathrm{~mm}$ [\#4 to $0.5 \mathrm{in}]$ ).

\begin{tabular}{lcc} 
& \multicolumn{2}{c}{ Estimate (Wald Test) [p-value] } \\
\cline { 2 - 3 } & \multicolumn{2}{c}{ Model Number } \\
\hline Parameter & N1 (\% Dil/100 cycles) & N2 (DF) \\
\hline \hline$\alpha$ & 0.00103401 & 0.550572 \\
& $(1.340)$ & $(0.539)$ \\
& {$[0.1803]$} & {$[0.5897]$} \\
\hline $38 \mathrm{M}$ & -0.0000102810 & -0.0185399 \\
& $(-0.271)$ & $(-0.369)$ \\
& {$[0.7866]$} & {$[0.7120]$} \\
\hline $516 \mathrm{M}$ & -0.0000223007 & 0.0861688 \\
& $(-0.357)$ & $(1.041)$ \\
& {$[0.7215]$} & {$[0.2977]$} \\
\hline $14 \mathrm{M}$ & 0.0000538035 & -0.120840 \\
& $(0.840)$ & $(-1.426)$ \\
& {$[0.4010]$} & {$[0.1538]$} \\
\hline $4 \mathrm{M}$ & -0.0000412558 & 0.0162062 \\
& $(-0.252)$ & $(0.075)$ \\
& {$[0.8008]$} & {$[0.9403]$} \\
\hline $\mathrm{Df}$ & 15 & 15 \\
\hline $\mathrm{N}$ & 20 & 20 \\
\hline $\mathrm{r}^{2}$ & 0.5753 & 0.7224 \\
\hline$\hat{\sigma}$ & 0.0352171 & 0.623 \\
\hline $\mathrm{r}_{\text {adj }}^{2}$ & 0.424 & \\
\hline $\mathrm{N1} 1 \mathrm{N2} \mathrm{Y}=\mathrm{C}^{*}\left(\alpha+\beta_{1} * 38 \mathrm{M}+\beta_{2} * 516 \mathrm{M}+\beta_{3}{ }^{*} 14 \mathrm{M}+\beta_{4}^{*} 4 \mathrm{M}\right)$ \\
\hline
\end{tabular}

The Wald statistic is used to perform a significance test for each parameter (i.e., to test the hypotheses $\mathrm{H}_{0}: \beta=0$ ). This statistic divides a parameter estimate by its standard error and then squares it (10).

The coefficient of multiple determination, interpreted as the proportion of variation in observed $y$ values that is explained by the fitted model, is defined as follows (11): 
Table E.3. Nonlinear regression models using transformed data (percentage of mass passing, 4.75 to $12.5 \mathrm{~mm}$ [\#4 to $0.5 \mathrm{in}$ ]).

\begin{tabular}{|c|c|c|c|c|c|c|}
\hline \multirow{4}{*}{ Parameter } & \multicolumn{6}{|c|}{ Estimate (Wald Test) [p-value] } \\
\hline & \multicolumn{6}{|c|}{ Model Number } \\
\hline & N3 & N4 & N5 & N6 & $\mathrm{N} 7$ & N8 \\
\hline & $(\%$ dil $/ 100$ cycles $)$ & $(\mathrm{DF})$ & ( $\%$ dil $/ 100$ cycles $)$ & $(\mathrm{DF})$ & ( $\%$ dil $/ 100$ cycles $)$ & $(\mathrm{DF})$ \\
\hline \multirow{3}{*}{$\alpha$} & $8.070412 \mathrm{E}-6$ & -0.000825088 & $2.228873 \mathrm{E}-6$ & 0.00160539 & 0.00371456 & -0.471868 \\
\hline & $(1.037)$ & $(-0.058)$ & (1.269) & $(0.541)$ & $(1.069)$ & $(-0.094)$ \\
\hline & [0.2997] & [0.9538] & {$[0.2046]$} & {$[0.5888]$} & {$[0.2850]$} & {$[0.9250]$} \\
\hline \multirow[t]{3}{*}{$\beta_{1}$} & $-2.005917 \mathrm{E}-9$ & $1.296718 \mathrm{E}-6$ & $-1.307060 \mathrm{E}-8$ & -0.0000854055 & $-8.468595 \mathrm{E}-7$ & 0.000492543 \\
\hline & $(-1.962)$ & $(0.693)$ & $(-0.141)$ & $(-0.543)$ & $(-1.811)$ & $(0.730)$ \\
\hline & [0.0498] & {$[0.4884]$} & {$[0.8882]$} & {$[0.5868]$} & {$[0.0702]$} & {$[0.4654]$} \\
\hline \multirow[t]{3}{*}{$\beta_{2}$} & $2.638897 \mathrm{E}-7$ & -0.0000590968 & $-7.864361 \mathrm{E}-8$ & 0.000298937 & 0.000110288 & -0.0243830 \\
\hline & $(1.334)$ & $(-0.163)$ & $(-0.457)$ & $(1.027)$ & $(1.274)$ & $(-0.195)$ \\
\hline & {$[0.1823]$} & {$[0.8704]$} & [0.6479] & [0.3043] & [0.2026] & {$[0.8452]$} \\
\hline \multirow[t]{3}{*}{$\beta_{3}$} & $-2.900323 \mathrm{E}-6$ & -0.00122456 & $1.587959 \mathrm{E}-7$ & -0.000383144 & -0.00126279 & -0.368799 \\
\hline & $(-0.721)$ & $(-0.166)$ & $(0.868)$ & $(-1.240)$ & $(-0.737)$ & $(-0.149)$ \\
\hline & {$[0.4706]$} & [0.8678] & {$[0.3852]$} & {$[0.2151]$} & {$[0.4613]$} & {$[0.8814]$} \\
\hline \multirow[t]{3}{*}{$\beta_{4}$} & $-2.992015 \mathrm{E}-6$ & 0.00246889 & $-1.351930 \mathrm{E}-7$ & 0.0000900020 & -0.00144596 & 1.11655 \\
\hline & $(-0.934)$ & $(0.421)$ & $(-0.361)$ & $(0.142)$ & $(-0.997)$ & $(0.534)$ \\
\hline & {$[0.3503]$} & {$[0.6737]$} & {$[0.7179]$} & {$[0.8868]$} & {$[0.3187]$} & {$[0.5936]$} \\
\hline Df & 15 & 15 & 15 & 15 & 15 & 15 \\
\hline $\mathrm{N}$ & 20 & 20 & 20 & 20 & 20 & 20 \\
\hline$r^{2}$ & 0.5753 & 0.5450 & 0.5848 & 0.5569 & 0.6187 & 0.7035 \\
\hline$\hat{\sigma}$ & 0.0325792 & 59.6342 & 0.0348194 & 58.85 & 0.0333705 & 48.145 \\
\hline $\mathrm{r}_{\mathrm{adi}}^{2}$ & 0.424 & 0.383 & 0.437 & 0.399 & 0.482 & 0.598 \\
\hline $\begin{array}{l}{ }^{\mathrm{N} 3, \mathrm{~N} 4} Y=C^{2} . \\
{ }^{\mathrm{N} 5, \mathrm{~N} 6} Y=C^{2 .} \\
{ }^{\mathrm{N} 7, \mathrm{~N} 8} Y=C^{*}\end{array}$ & $\begin{array}{l}\alpha+\beta_{1} * 38 \mathrm{M}^{2}+\beta_{2} * 510 \\
\left(\alpha+\beta_{1} * 38 \mathrm{M}+\beta_{2} * 516\right. \\
+\beta_{1} * 38 \mathrm{M}^{2}+\beta_{2} * 516 \mathrm{M} \\
\end{array}$ & $\begin{array}{l}\mathrm{M}+\beta_{3} * 14 \mathrm{M}^{0.31}+\beta \\
\mathrm{I}+\beta_{3} * 14 \mathrm{M}+\beta_{4} * 4 \mathrm{I} \\
\beta_{3} * 14 \mathrm{M}^{0.31}+\beta_{4} * 4\end{array}$ & $\begin{array}{l}\left.\mathrm{M}^{-0.25}\right) \\
.25) \\
\end{array}$ & & & \\
\hline
\end{tabular}




$$
\mathrm{R}^{2}=1-\left(\mathrm{SS}_{\text {Resid }} / \mathrm{SS}_{\text {Total }}\right)
$$

where: $\quad \mathrm{SS}_{\text {Resid }}=$ residual (or error) sum of squares, and $\mathrm{SS}_{\text {Total }}=$ total sum of squares.

Additionally, an estimate of the random deviation variance $\left(\hat{\sigma}^{2}\right)$ is expressed by (11):

$$
\hat{\sigma}^{2}=\mathrm{SS}_{\text {Resid }} /(\mathrm{n}-\mathrm{k}+1)
$$

where: $\quad \mathrm{SS}_{\text {Resid }}=$ residual (or error) sum of squares,

$\mathrm{n}=$ number of observations, and

$\mathrm{k}=$ number of predictors.

A desirable model is generally considered to be one with a high $\mathrm{R}^{2}$ and low $\hat{\sigma}^{2}$. These conditions can often be achieved by adding predictors to the model, regardless of whether the additional variables are statistically significant. Thus, it is possible to have models that yield large values of $\mathrm{R}^{2}$, but are poor predictors of new observations or of the mean function.

The parameter $\mathrm{R}^{2}$ can be adjusted to account for the numbers of predictors and observations used

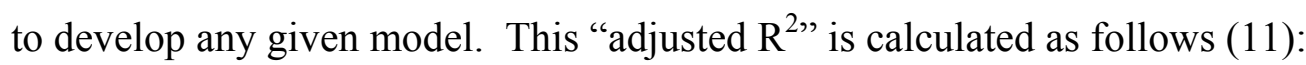

$$
\text { Adjusted } \mathrm{R}^{2}=1-\frac{n-1}{n-(k+1)} \cdot \frac{\mathrm{SS}_{\text {Resid }}}{\mathrm{SS}_{\text {Total }}}
$$

Where: $\quad \mathrm{SS}_{\text {Resid }}=$ residual (or error) sum of squares,

$\mathrm{SS}_{\text {Total }}=$ total sum of squares,

$\mathrm{n}=$ number of observations, and

$\mathrm{k}=$ number of predictors.

A reasonable strategy in model selection is to identify the model with the largest value of adjusted $\mathrm{R}^{2}$ (typically a model using fewer than the total number of predictors available) and 
then to consider only that model and any others whose adjusted $\mathrm{R}^{2}$ values are nearly as large (11).

Figures E.3 through E.6 present 2-dimensional plots of actual versus predicted response variable values for the models produced using the untransformed and transformed data sets, respectively. As illustrated in figures E.3 through E.6, models N1 - N8 do a poor job of accurately modeling the data. Therefore, further regression analyses were performed to determine whether a better model of freeze-thaw test results might be developed as a function of the cumulative percentage of mass passing each designated sieve.

\section{E.2.1.4 Multiple Linear Regression}

Equation E.9 was modified slightly for multiple linear regression using both the transformed and untransformed data. The following general model forms were adopted for use:

$$
\begin{gathered}
E(y \mid x)=\alpha+\beta_{1}{ }^{*} C^{*} 38 \mathrm{M}+\beta_{2} * C^{*} 516 \mathrm{M}+\beta_{3} * C^{*} 14 \mathrm{M}+\beta_{4} * \mathrm{C} * 4 \mathrm{M} \\
\mathrm{E}(\mathrm{y} \mid \mathrm{x})=\alpha+\beta_{1} * 38 \mathrm{M}+\beta_{2} * 516 \mathrm{M}+\beta_{3} * 14 \mathrm{M}+\beta_{4} * 4 \mathrm{M}
\end{gathered}
$$

Numerous linear regression models were formulated based on the above two base equations; however, only the model with the best adjusted $\mathrm{R}^{2}$ was recorded in tables E. 4 and E.5 for the response variables percent dilation (model L1) and durability factor (model L2), respectively. As in the nonlinear regression tables, these tables contain a list of the parameter estimates, degrees of freedom, number of observations (n), coefficient of determination $\left(R^{2}\right)$, standard deviation about the least squares line $(\hat{\sigma})$, adjusted $\mathrm{R}^{2}$, a subsection presenting the model expression, and the t-statistics, which is used in place of the Wald statistic in multiple linear regression.

Tables E.4 and E.5 also contain the modeling information resulting from stepwise regression, addition of main-effects terms, performed on the models. Again, from this subset of models, the model containing the largest adjusted $\mathrm{R}^{2}$ was chosen for further analysis. Therefore, from the set 


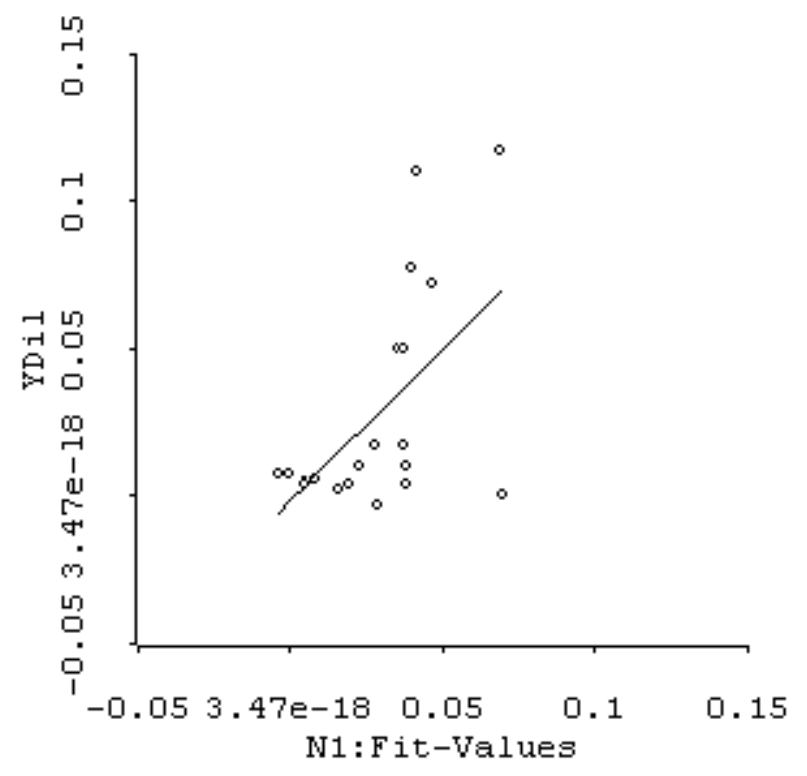

a. Model N1.

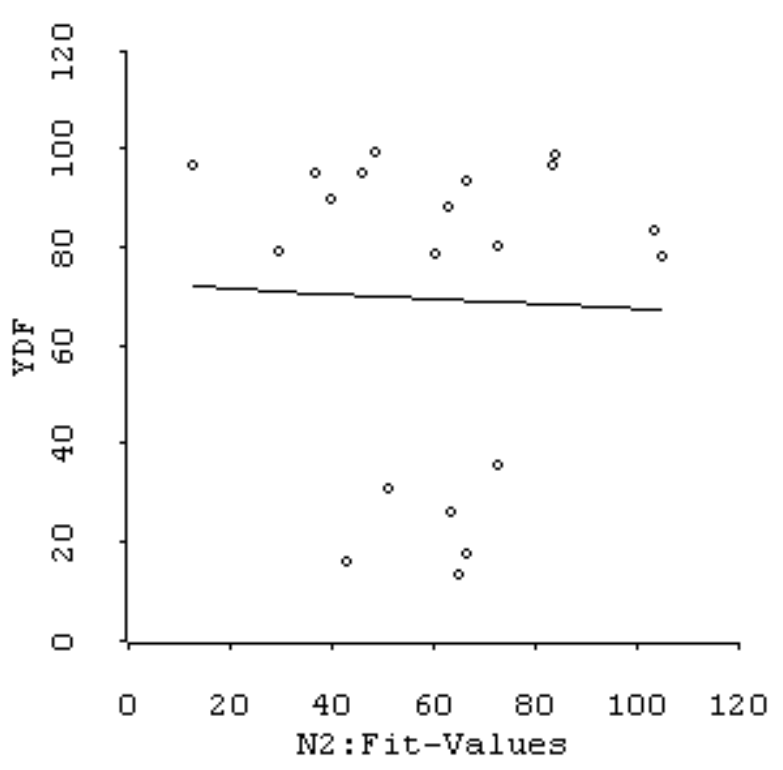

b. Model N2.

Figure E.3. Actual versus predicted rapid freezing and thawing test results for models N1 and $\mathrm{N} 2$ (untransformed data, percentage of mass passing, 4.75 to $12.5 \mathrm{~mm}$ [\#4 to $0.5 \mathrm{in}$ ])

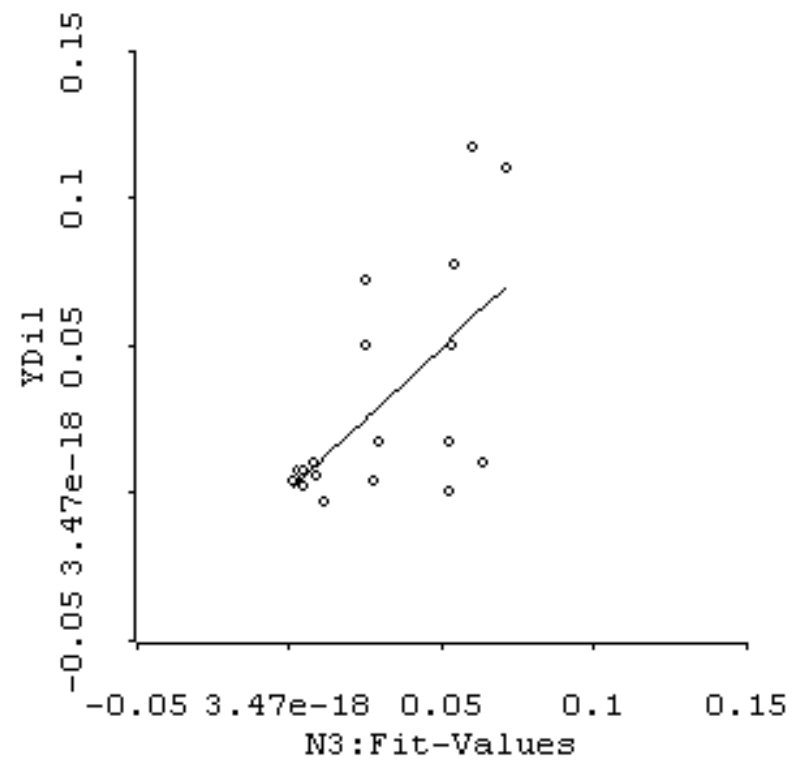

a. Model N3.

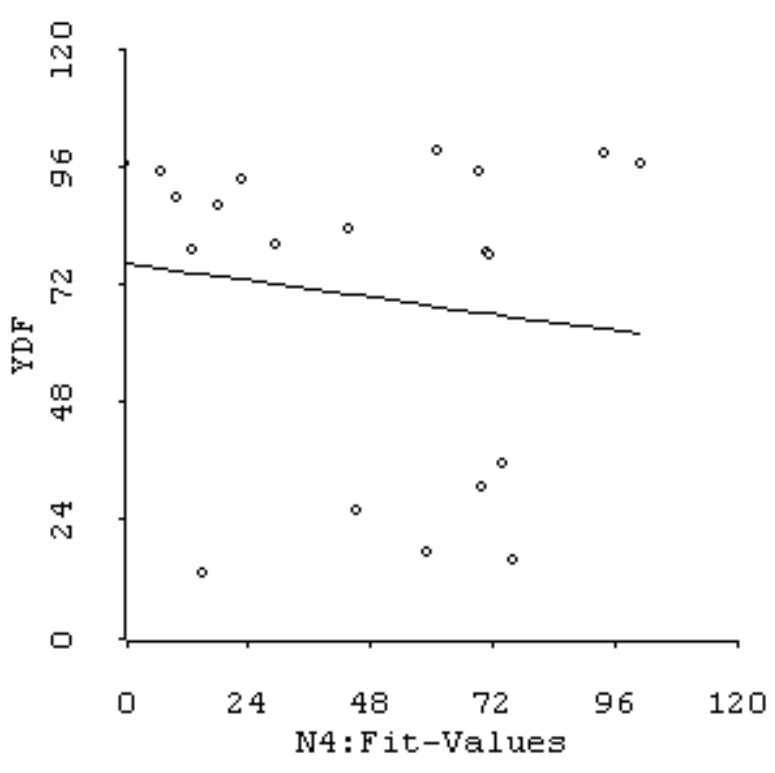

b. Model N4.

Figure E.4. Actual versus predicted rapid freezing and thawing test results for models N3 and N4 (transformed data, percentage of mass passing, 4.75 to $12.5 \mathrm{~mm}$ [\#4 to $0.5 \mathrm{in}$ ]). 


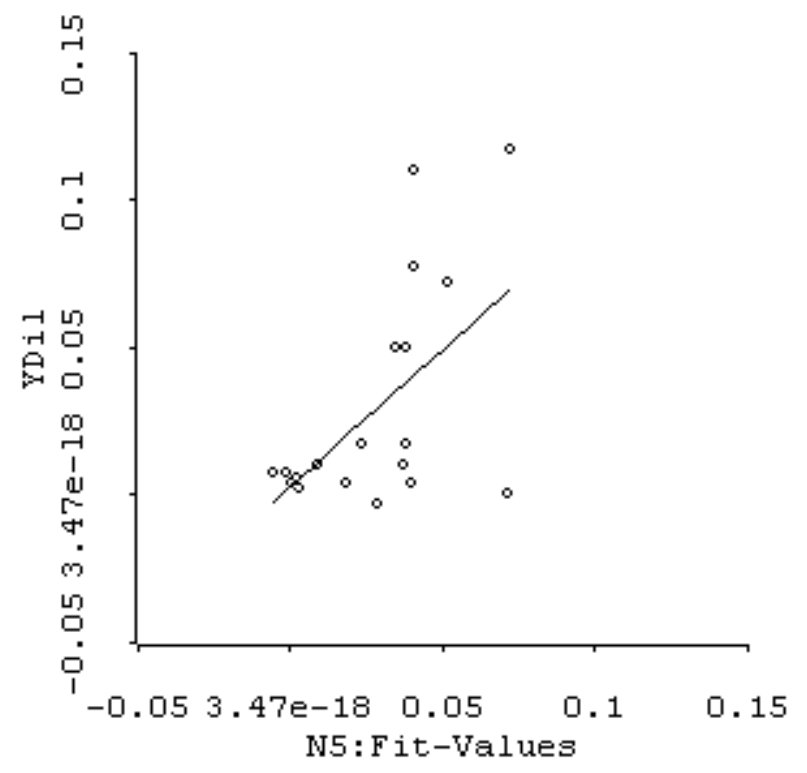

a. Model N5.

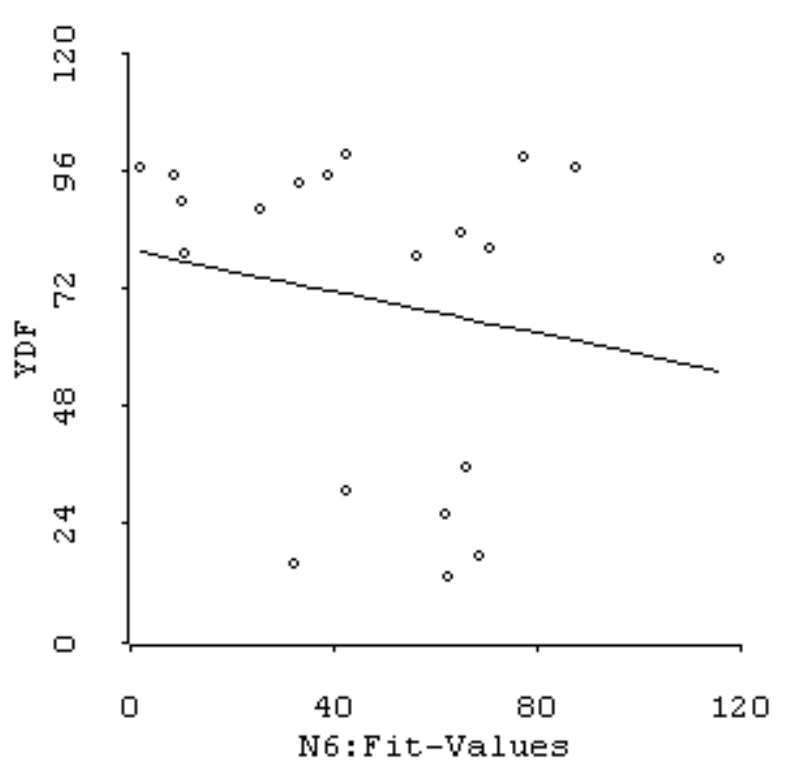

b. Model N6.

Figure E.5. Actual versus predicted rapid freezing and thawing test results for models N5 and N6 (transformed data, percentage of mass passing, 4.75 to $12.5 \mathrm{~mm}$ [\#4 to $0.5 \mathrm{in}$ ]).

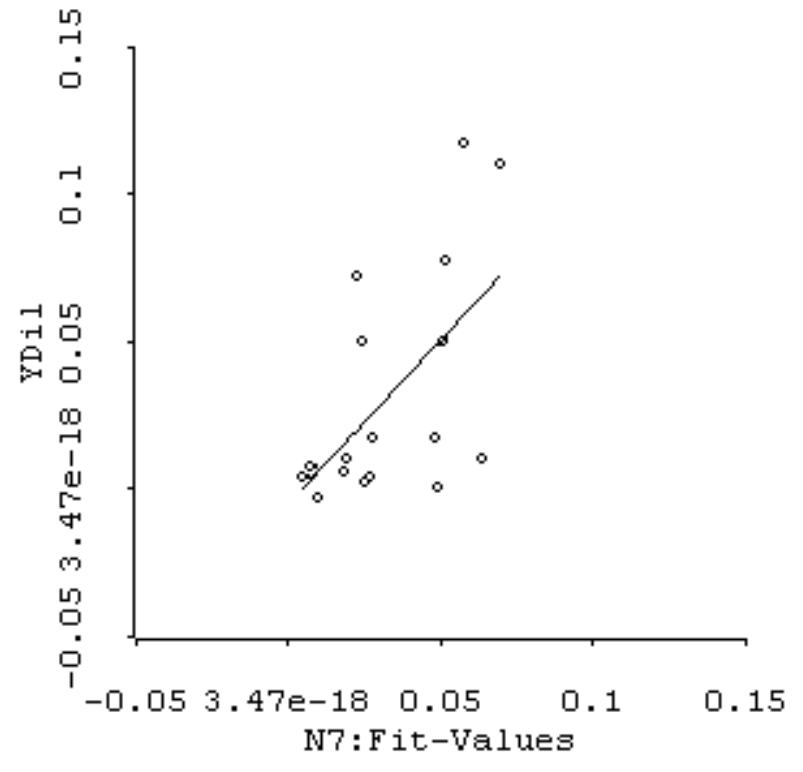

a. Model N7.

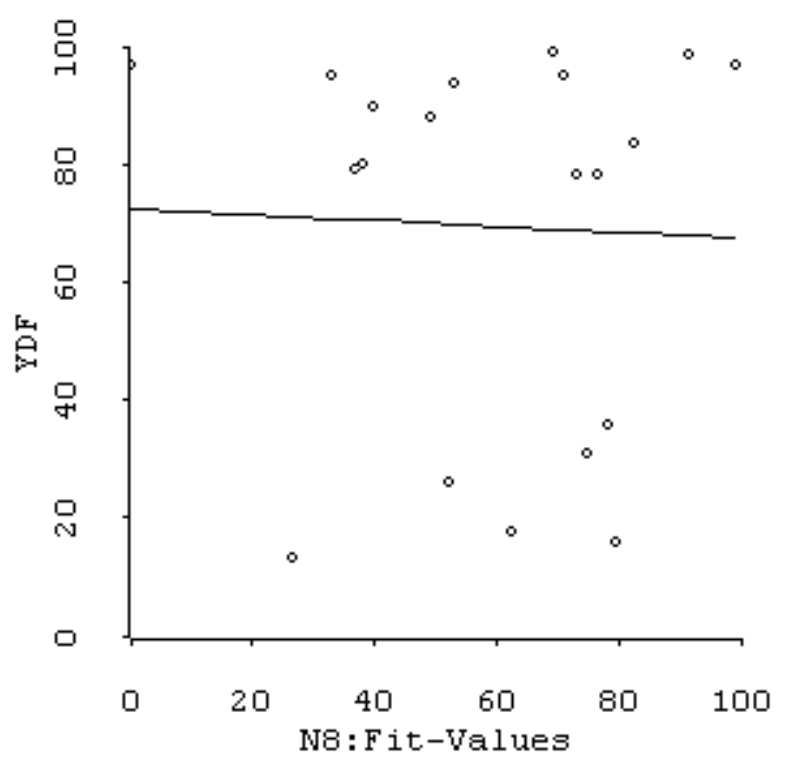

b. Model N8.

Figure E.6. Actual versus predicted rapid freezing and thawing test results for models N7 and N8 (transformed data, percentage of mass passing, 4.75 to $12.5 \mathrm{~mm}$ [\#4 to $0.5 \mathrm{in}$ ]). 
Table E.4. Multiple linear regression models for response variable "percent dilation per 100 cycles" (percentage of mass passing, 4.75 to $12.5 \mathrm{~mm}$ [\#4 to $0.5 \mathrm{in}]$ ).

\begin{tabular}{|c|c|c|c|c|c|}
\hline \multirow{3}{*}{ Variable } & \multicolumn{5}{|c|}{ Estimates (t-value) [p-value] } \\
\hline & \multicolumn{5}{|c|}{ Model Number } \\
\hline & L1 & L1A & L1B & L1C & L1D \\
\hline Constant & $\begin{array}{c}0.00341740 \\
(0.221) \\
{[0.8281]}\end{array}$ & $\begin{array}{c}0.0221772 \\
(0.232) \\
{[0.8201]}\end{array}$ & $\begin{array}{c}0.0951994 \\
(0.443) \\
{[0.6648]}\end{array}$ & $\begin{array}{c}0.217903 \\
(0.752) \\
{[0.4667]}\end{array}$ & $\begin{array}{c}0.312224 \\
(0.806) \\
{[0.4372]} \\
\end{array}$ \\
\hline $\mathrm{C}^{2.33} * 38 \mathrm{M}^{2}$ & $\begin{array}{c}-1.346140 \mathrm{E}-9 \\
(-1.622) \\
{[0.1256]}\end{array}$ & $\begin{array}{c}-1.378032 \mathrm{E}-9 \\
(-1.579) \\
{[0.1366]} \\
\end{array}$ & $\begin{array}{c}-1.534070 \mathrm{E}-9 \\
(-1.552) \\
{[0.1447]} \\
\end{array}$ & $\begin{array}{c}-1.773046 \mathrm{E}-9 \\
(-1.648) \\
{[0.1254]} \\
\end{array}$ & $\begin{array}{c}-9.505134 \mathrm{E}-10 \\
(-0.396) \\
{[0.7000]}\end{array}$ \\
\hline $\mathrm{C}^{2.33} * 516 \mathrm{M}$ & $\begin{array}{c}9.199502 \mathrm{E}-8 \\
(0.793) \\
{[0.4402]}\end{array}$ & $\begin{array}{c}1.021024 \mathrm{E}-7 \\
(0.784) \\
{[0.4462]}\end{array}$ & $\begin{array}{c}1.434840 \mathrm{E}-7 \\
(0.832) \\
{[0.4205]}\end{array}$ & $\begin{array}{c}1.484940 \mathrm{E}-7 \\
(0.841) \\
{[0.4169]}\end{array}$ & $\begin{array}{c}4.011051 \mathrm{E}-8 \\
(0.120) \\
{[0.9068]}\end{array}$ \\
\hline $\mathrm{C}^{2.33} * 14 \mathrm{M}^{0.31}$ & $\begin{array}{c}1.084382 \mathrm{E}-6 \\
(0.811) \\
{[0.4303]}\end{array}$ & $\begin{array}{c}8.446276 \mathrm{E}-7 \\
(0.460) \\
{[0.6523]}\end{array}$ & $\begin{array}{c}3.994725 \mathrm{E}-7 \\
(0.180) \\
{[0.8601]}\end{array}$ & $\begin{array}{c}6.739372 \mathrm{E}-7 \\
(0.292) \\
{[0.7756]}\end{array}$ & $\begin{array}{c}1.365622 \mathrm{E}-6 \\
(0.456) \\
{[0.6570]}\end{array}$ \\
\hline $\mathrm{C}^{2.33 * 4 \mathrm{M}^{-0.25}}$ & $\begin{array}{c}9.663262 \mathrm{E}-8 \\
(0.091) \\
{[0.9284]}\end{array}$ & $\begin{array}{c}3.580062 \mathrm{E}-7 \\
(0.209) \\
{[0.8371]}\end{array}$ & $\begin{array}{c}4.559344 \mathrm{E}-7 \\
(0.256) \\
{[0.8021]}\end{array}$ & $\begin{array}{c}5.769563 \mathrm{E}-7 \\
(0.315) \\
{[0.7583]}\end{array}$ & $\begin{array}{c}2.552498 \mathrm{E}-9 \\
(0.001) \\
{[0.9992]}\end{array}$ \\
\hline $4 \mathrm{M}^{-0.25}$ & & $\begin{array}{c}-0.0179345 \\
(-0.199) \\
{[0.8453]} \\
\end{array}$ & $\begin{array}{c}-0.0475858 \\
(-0.393) \\
{[0.7007]} \\
\end{array}$ & $\begin{array}{c}-0.105374 \\
(-0.691) \\
{[0.5029]}\end{array}$ & $\begin{array}{c}-0.118252 \\
(-0.731) \\
{[0.4800]}\end{array}$ \\
\hline $14 \mathrm{M}^{0.31}$ & & & $\begin{array}{c}-0.0205449 \\
(-0.383) \\
{[0.7080]}\end{array}$ & $\begin{array}{c}-0.0870829 \\
(-0.749) \\
{[0.4684]}\end{array}$ & $\begin{array}{c}-0.162111 \\
(-0.709) \\
{[0.4929]} \\
\end{array}$ \\
\hline $516 \mathrm{M}$ & & & & $\begin{array}{c}0.00216516 \\
(0.649) \\
{[0.5285]}\end{array}$ & $\begin{array}{c}0.00882893 \\
(0.502) \\
{[0.6255]}\end{array}$ \\
\hline $38 \mathrm{M}^{2}$ & & & & & $\begin{array}{c}-0.0000438370 \\
(-0.387) \\
{[0.7064]}\end{array}$ \\
\hline Df & 15 & 14 & 13 & 12 & 11 \\
\hline $\mathrm{N}$ & 20 & 20 & 20 & 20 & 20 \\
\hline $\mathrm{r}^{2}$ & 0.372418 & 0.374185 & 0.381164 & 0.402152 & 0.410165 \\
\hline$\hat{\sigma}$ & 0.0336723 & 0.034805 & 0.0359169 & 0.0367441 & 0.0381199 \\
\hline $\mathrm{r}_{\text {adj }}^{2}$ & 0.205 & 0.151 & 0.096 & 0.053 & -0.019 \\
\hline $\begin{aligned} & \text { L1 } Y=\alpha+C \\
&{ }^{\text {L1A }} Y=\alpha+C \\
& \text { L1B }=\alpha=\alpha+C \\
&{ }^{\text {L1C } Y}=\alpha+C \\
&{ }^{\text {L1D } Y}=\alpha+C\end{aligned}$ & $\begin{array}{l}* 38 \mathbf{M}^{2}+\beta_{2} * 5 \\
* 38 \mathrm{M}^{2}+\beta_{2} * 51 \\
* 38 \mathrm{M}^{2}+\beta_{2} * 51 \\
* 38 \mathrm{M}^{2}+\beta_{2} * 51 \\
* 38 \mathrm{M}^{2}+\beta_{2} * 51\end{array}$ & $\begin{array}{l}\beta_{3}{ }^{*} \mathbf{1 4 M}^{\mathbf{0 . 3 1}}+ \\
-\beta_{3}{ }^{*} 14 \mathrm{M}^{0.31}+ \\
-\beta_{3}{ }^{*} 14 \mathrm{M}^{0.31}+ \\
-\beta_{3}{ }^{*}{ }^{*} 14 \mathrm{M}^{0.31}+ \\
-\beta_{3}{ }^{*} 14 \mathrm{M}^{0.31}+ \\
\end{array}$ & $\begin{array}{l}\left.\mathbf{M}^{-0.25}\right) \\
\left.M^{-0.25}\right)+\beta_{5} * 4 \mathrm{~N} \\
\left.M^{-0.25}\right)+\beta_{5} * 4 \mathrm{~N} \\
\left.M^{-0.25}\right)+\beta_{5} * 4 \mathrm{~N} \\
\left.\mathrm{M}^{-0.25}\right)+\beta_{5} * 4 \mathrm{~N}\end{array}$ & $\begin{array}{l}+\beta_{6} * 14 \mathrm{M}^{0.31} \\
+\beta_{6} * 14 \mathrm{M}^{0.31}+ \\
+\beta_{6} * 14 \mathrm{M}^{0.31}+ \\
\end{array}$ & $516 \mathrm{M}$ \\
\hline
\end{tabular}


Table E.5. Multiple linear regression models for response variable "durability factor" (percentage of mass passing, 4.75 to $12.5 \mathrm{~mm}$ [\#4 to $0.5 \mathrm{in}]$ ).

\begin{tabular}{|c|c|c|c|c|c|}
\hline \multirow{3}{*}{ Variable } & \multicolumn{5}{|c|}{ Estimates (t-value) [p-value] } \\
\hline & \multicolumn{5}{|c|}{ Model Number } \\
\hline & L2 & L2A & L2B & $\mathrm{L} 2 \mathrm{C}$ & L2D \\
\hline Constant & $\begin{array}{c}93.5617 \\
(7.245) \\
{[0.0000]}\end{array}$ & $\begin{array}{c}78.2013 \\
(0.979) \\
{[0.3444]}\end{array}$ & $\begin{array}{c}46.4641 \\
(0.258) \\
{[0.8004]}\end{array}$ & $\begin{array}{c}-74.1006 \\
(-0.307) \\
{[0.7642]}\end{array}$ & $\begin{array}{c}-154.416 \\
(-0.479) \\
{[0.6414]}\end{array}$ \\
\hline $\mathrm{C}^{2.33} * 38 \mathrm{M}^{2}$ & $\begin{array}{c}1.312434 \mathrm{E}-6 \\
(1.894) \\
{[0.0777]}\end{array}$ & $\begin{array}{c}1.338547 \mathrm{E}-6 \\
(1.837) \\
{[0.0876]} \\
\end{array}$ & $\begin{array}{c}1.406365 \mathrm{E}-6 \\
(1.697) \\
{[0.1135]}\end{array}$ & $\begin{array}{c}1.641175 \mathrm{E}-6 \\
(1.831) \\
{[0.0921]}\end{array}$ & $\begin{array}{c}9.407716 \mathrm{E}-7 \\
(0.470) \\
{[0.6474]} \\
\end{array}$ \\
\hline $\mathrm{C}^{2.33} * 516 \mathrm{M}$ & $\begin{array}{c}-0.000111392 \\
(-1.150) \\
{[0.2683]}\end{array}$ & $\begin{array}{c}-0.000119667 \\
(-1.100) \\
{[0.2898]}\end{array}$ & $\begin{array}{c}-0.000137653 \\
(-0.952) \\
{[0.3586]}\end{array}$ & $\begin{array}{c}-0.000142575 \\
(-0.969) \\
{[0.3516]}\end{array}$ & $\begin{array}{c}-0.0000502847 \\
(-0.180) \\
{[0.8602]}\end{array}$ \\
\hline $\mathrm{C}^{2.33} * 14 \mathrm{M}^{0.31}$ & $\begin{array}{c}-0.000693093 \\
(-0.620) \\
{[0.5443]}\end{array}$ & $\begin{array}{c}-0.000496784 \\
(-0.324) \\
{[0.7505]}\end{array}$ & $\begin{array}{c}-0.000303309 \\
(-0.163) \\
{[0.8732]}\end{array}$ & $\begin{array}{c}-0.000572989 \\
(-0.298) \\
{[0.7711]}\end{array}$ & $\begin{array}{c}-0.00116197 \\
(-0.466) \\
{[0.6501]}\end{array}$ \\
\hline $\mathrm{C}^{2.33 * 4 \mathrm{M}^{-0.25}}$ & $\begin{array}{c}-0.000105434 \\
(-0.119) \\
{[0.9065]}\end{array}$ & $\begin{array}{c}-0.000319445 \\
(-0.224) \\
{[0.8261]}\end{array}$ & $\begin{array}{c}-0.000362007 \\
(-0.242) \\
{[0.8124]}\end{array}$ & $\begin{array}{c}-0.000480919 \\
(-0.315) \\
{[0.7582]}\end{array}$ & $\begin{array}{c}8.197391 \mathrm{E}-6 \\
(0.004) \\
{[0.9968]}\end{array}$ \\
\hline $4 \mathrm{M}^{-0.25}$ & & $\begin{array}{c}14.6847 \\
(0.195) \\
{[0.8482]} \\
\end{array}$ & $\begin{array}{c}27.5718 \\
(0.272) \\
{[0.7902]} \\
\end{array}$ & $\begin{array}{c}84.3523 \\
(0.664) \\
{[0.5194]} \\
\end{array}$ & $\begin{array}{c}95.3184 \\
(0.708) \\
{[0.4938]} \\
\end{array}$ \\
\hline $14 \mathrm{M}^{0.31}$ & & & $\begin{array}{l}8.92931 \\
(0.198) \\
{[0.8457]}\end{array}$ & $\begin{array}{c}74.3074 \\
(0.767) \\
{[0.4578]} \\
\end{array}$ & $\begin{array}{l}138.195 \\
(0.726) \\
{[0.4829]} \\
\end{array}$ \\
\hline $516 \mathrm{M}$ & & & & $\begin{array}{c}-2.12742 \\
(-0.766) \\
{[0.4587]} \\
\end{array}$ & $\begin{array}{c}-7.80175 \\
(-0.533) \\
{[0.6047]} \\
\end{array}$ \\
\hline $38 \mathrm{M}^{2}$ & & & & & $\begin{array}{c}0.0373281 \\
(0.395) \\
{[0.7002]} \\
\end{array}$ \\
\hline Df & 15 & 14 & 13 & 12 & 11 \\
\hline $\mathrm{N}$ & 20 & 20 & 20 & 20 & 20 \\
\hline $\mathrm{r}^{2}$ & 0.39742 & 0.399051 & 0.400867 & 0.428768 & 0.436769 \\
\hline$\hat{\sigma}$ & 28.1177 & 29.0652 & 30.1168 & 30.6079 & 31.7443 \\
\hline $\mathrm{r}_{\text {adj }}^{2}$ & 0.237 & 0.184 & 0.124 & 0.096 & 0.027 \\
\hline 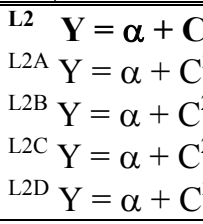 & $\begin{array}{l}1 * 38 \mathbf{M}^{2}+\beta_{2} * 51 \\
* 38 \mathrm{M}^{2}+\beta_{2} * 51 \\
* 38 \mathrm{M}^{2}+\beta_{2} * 51 \\
138 \mathrm{M}^{2}+\beta_{2} * 51 \\
* 38 \mathrm{M}^{2}+\beta_{2} * 51\end{array}$ & $\begin{array}{l}+\beta_{3} * \mathbf{1 4 M}^{\mathbf{0 . 3 1}}+ \\
+\beta_{3} * 14 \mathrm{M}^{0.31}+ \\
+\beta_{3} * 14 \mathrm{M}^{0.31}+ \\
+\beta_{3} * 14 \mathrm{M}^{0.31}+\beta \\
+\beta_{3} * 14 \mathrm{M}^{0.31}+\end{array}$ & $\begin{array}{l}\left.\mathbf{4} \mathbf{M}^{-0.25}\right) \\
\left.M^{-0.25}\right)+\beta_{5} * 4 \mathrm{M} \\
\left.M^{-0.25}\right)+\beta_{5} * 4 \mathrm{M} \\
\left.\mathrm{M}^{-0.25}\right)+\beta_{5} * 4 \mathrm{M} \\
\left.\mathrm{M}^{-0.25}\right)+\beta_{5} * 4 \mathrm{M}\end{array}$ & $\begin{array}{l}+\beta_{6} * 14 \mathrm{M}^{0.31} \\
+\beta_{6} * 14 \mathrm{M}^{0.31}+ \\
+\beta_{6} * 14 \mathrm{M}^{0.31}+ \\
\end{array}$ & $\begin{array}{l}516 \mathrm{M} \\
516 \mathrm{M}+\beta_{8} * 38 \mathrm{M}^{2}\end{array}$ \\
\hline
\end{tabular}


of models presented in table E.4, the model L1 exhibited the largest adjusted $\mathrm{R}^{2}$ value of 0.205 and was selected for further evaluation. Similarly, model L2 was selected from the set of models presented in table E.5 because it exhibited the largest adjusted $\mathrm{R}^{2}$ value (0.237). Figure E.7 presents 2-dimensional plots of the actual versus predicted responses for models L1 and L2.

These models were further reduced (based on t-values) to eliminate explanatory variables that have no significant effect on the predicted response. This procedure involves removing predictors until no $\mathrm{t}$-value satisfies $-\mathrm{t}_{\text {out }}<\mathrm{t}$-value $<\mathrm{t}_{\text {out }}$. It is customary to use a $\mathrm{t}_{\text {out }}$ value of 2 , since many t-critical values for a two-tailed test with a level of significance of 0.05 are close to this value (11). Tables E.6 and E.7 summarize the information concerning these reduced submodels for percent dilation per 100 cycles of freezing and thawing and durability factor, respectively.

From the models presented in tables E.6 and E.7, models L1b and L2a had the largest adjusted $\mathrm{R}^{2}$ values of 0.256 and 0.284 , respectively. Figure E. 8 presents the actual versus predicted rapid freezing and thawing test results for these two models.

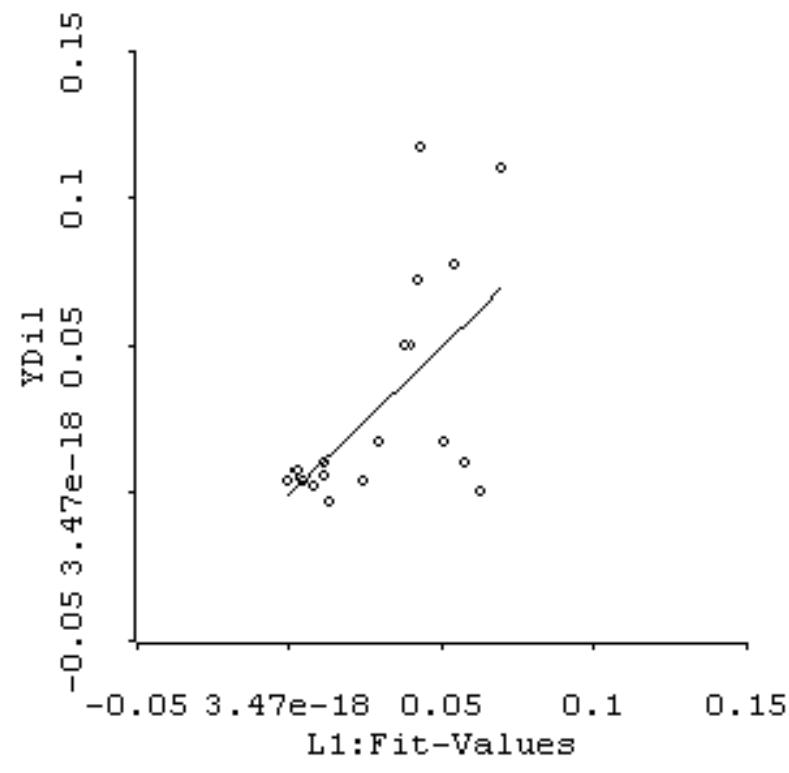

a. Model L1.

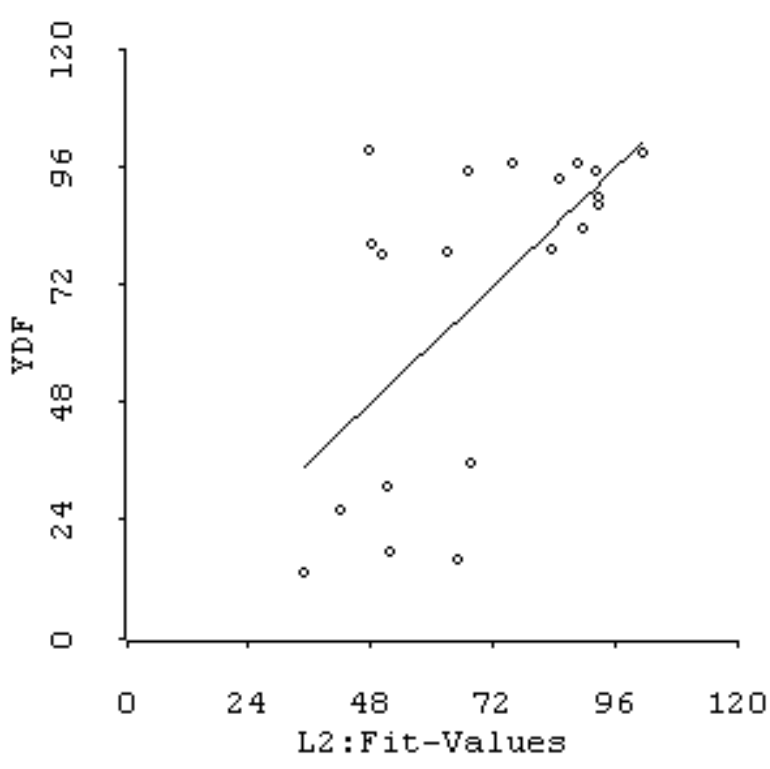

b. Model L2.

Figure E.7. Actual versus predicted rapid freezing and thawing test results for models L1 and L2 (percentage of mass passing, 4.75 to $12.5 \mathrm{~mm}$ [\#4 to $0.5 \mathrm{in}]$ ). 
Table E.6. Reduced multiple linear regression models for response variable "percent dilation per 100 cycles" (percentage of mass passing, 4.75 to $12.5 \mathrm{~mm}$ [\#4 to $0.5 \mathrm{in}]$ ).

\begin{tabular}{|c|c|c|c|}
\hline \multirow{3}{*}{ Variable } & \multicolumn{3}{|c|}{ Estimates (t-value) [p-value] } \\
\hline & \multicolumn{3}{|c|}{ Model Number } \\
\hline & L1 & L1a & L1b \\
\hline Constant & $\begin{array}{c}0.00341740 \\
(0.221) \\
{[0.8281]} \\
\end{array}$ & $\begin{array}{c}0.00463338 \\
(0.305) \\
{[0.7646]} \\
\end{array}$ & $\begin{array}{c}0.00154258 \\
(0.112) \\
{[0.9123]} \\
\end{array}$ \\
\hline $\mathrm{C}^{2.33 * 38 \mathrm{M}^{2}}$ & $\begin{array}{c}-1.346140 \mathrm{E}-9 \\
(-1.622) \\
{[0.1256]}\end{array}$ & $\begin{array}{c}-7.762051 \mathrm{E}-10 \\
(-1.894) \\
{[0.0765]}\end{array}$ & $\begin{array}{c}-6.044320 \mathrm{E}-10 \\
(-2.385) \\
{[0.0290]}\end{array}$ \\
\hline $\mathrm{C}^{2.33} * 516 \mathrm{M}$ & $\begin{array}{c}9.199502 \mathrm{E}-8 \\
(0.793) \\
{[0.4402]} \\
\end{array}$ & & \\
\hline $\mathrm{C}^{2.33 *} 14 \mathrm{M}^{0.31}$ & $\begin{array}{c}1.084382 \mathrm{E}-6 \\
(0.811) \\
{[0.4303]}\end{array}$ & $\begin{array}{c}1.823883 \mathrm{E}-6 \\
(1.924) \\
{[0.0723]} \\
\end{array}$ & $\begin{array}{c}1.390784 \mathrm{E}-6 \\
(2.807) \\
{[0.0121]}\end{array}$ \\
\hline $\mathrm{C}^{2.33} * 4 \mathrm{M}^{-0.25}$ & $\begin{array}{c}9.663262 \mathrm{E}-8 \\
(0.091) \\
{[0.9284]} \\
\end{array}$ & $\begin{array}{c}-4.359265 \mathrm{E}-7 \\
(-0.540) \\
{[0.5963]} \\
\end{array}$ & \\
\hline Df & 15 & 16 & 17 \\
\hline $\mathrm{N}$ & 20 & 20 & 20 \\
\hline $\mathrm{r}^{2}$ & 0.372418 & 0.346116 & 0.334179 \\
\hline$\hat{\sigma}$ & 0.0336723 & 0.0332792 & 0.032579 \\
\hline $\mathrm{r}_{\text {adi }}^{2}$ & 0.205 & 0.224 & 0.256 \\
\hline $\begin{array}{ll}\mathrm{L1} & \mathrm{Y}=\alpha+\mathrm{C}^{2} \\
\text { Lla } & \mathrm{Y}=\alpha+\mathrm{C} \\
\text { L1b } & \mathbf{Y}=\alpha+\mathbf{C}\end{array}$ & $\begin{array}{l}* 38 \mathrm{M}^{2}+\beta_{2} * 51 \\
* 38 \mathrm{M}^{2}+\beta_{2} * 14 \\
{ }_{1}^{*} \mathbf{3 8} \mathbf{M}^{2}+\beta_{2} * \mathbf{1}\end{array}$ & $\begin{array}{l}+\beta_{3} * 14 \mathrm{M}^{0.31}+ \\
\left.+\beta_{3} * 4 \mathrm{M}^{-0.25}\right) \\
\left.{ }^{331}\right)\end{array}$ & $\left(\mathrm{M}^{-0.25}\right)$ \\
\hline
\end{tabular}


Table E.7. Reduced multiple linear regression models for response variable "durability factor" (percentage of mass passing, 4.75 to $12.5 \mathrm{~mm}$ [\#4 to $0.5 \mathrm{in}]$ ).

\begin{tabular}{|c|c|c|c|c|}
\hline \multirow{3}{*}{ Variable } & \multicolumn{4}{|c|}{ Estimates (t-value) [p-value] } \\
\hline & \multicolumn{4}{|c|}{ Model Number } \\
\hline & L2 & L2a & $\mathrm{L} 2 \mathrm{~b}$ & L2c \\
\hline Constant & $\begin{array}{c}93.5617 \\
(7.245) \\
{[0.0000]}\end{array}$ & $\begin{array}{c}93.0188 \\
(7.943) \\
{[0.0000]}\end{array}$ & $\begin{array}{c}95.9138 \\
(8.067) \\
{[0.0000]}\end{array}$ & $\begin{array}{c}90.1184 \\
(7.351) \\
{[0.0000]}\end{array}$ \\
\hline $\mathrm{C}^{2.33 * 38 \mathrm{M}^{2}}$ & $\begin{array}{c}1.312434 \mathrm{E}-6 \\
(1.894) \\
{[0.0777]}\end{array}$ & $\begin{array}{c}1.291634 \mathrm{E}-6 \\
(1.988) \\
{[0.0642]}\end{array}$ & $\begin{array}{c}4.097814 \mathrm{E}-7 \\
(1.877) \\
{[0.0779]}\end{array}$ & \\
\hline $\mathrm{C}^{2.33} * 516 \mathrm{M}$ & $\begin{array}{c}-0.000111392 \\
(-1.150) \\
{[0.2683]}\end{array}$ & $\begin{array}{c}-0.000104036 \\
(-1.436) \\
{[0.1704]}\end{array}$ & & \\
\hline $\mathrm{C}^{2.33 * 14 \mathrm{M}^{0.31}}$ & $\begin{array}{c}-0.000693093 \\
(-0.620) \\
{[0.5443]} \\
\end{array}$ & $\begin{array}{c}-0.000814665 \\
(-1.826) \\
{[0.0866]} \\
\end{array}$ & $\begin{array}{c}-0.00105260 \\
(-2.465) \\
{[0.0247]} \\
\end{array}$ & $\begin{array}{c}-0.000295691 \\
(-1.975) \\
{[0.0638]} \\
\end{array}$ \\
\hline $\mathrm{C}^{2.33} * 4 \mathrm{M}^{-0.25}$ & $\begin{array}{c}-0.000105434 \\
(-0.119) \\
{[0.9065]} \\
\end{array}$ & & & \\
\hline Df & 15 & 16 & 17 & 18 \\
\hline $\mathrm{N}$ & 20 & 20 & 20 & 20 \\
\hline $\mathrm{r}^{2}$ & 0.39742 & 0.396847 & 0.319153 & 0.178119 \\
\hline$\hat{\sigma}$ & 28.1177 & 27.2378 & 28.0749 & 29.9769 \\
\hline $\mathrm{r}_{\text {adj }}^{2}$ & 0.237 & 0.284 & 0.239 & 0.132 \\
\hline $\begin{array}{ll}\text { L2 } & Y=\alpha+C \\
\text { L2a } & Y=\alpha+C \\
\text { L2b } & Y=\alpha+C \\
& Y 2 c \\
& Y=\alpha+C\end{array}$ & $\begin{array}{l}1 * 38 \mathrm{M}^{2}+\beta_{2} * 51 \\
3_{1} * 38 \mathrm{M}^{2}+\beta_{2} * 5 \\
1 * 38 \mathrm{M}^{2}+\beta_{2} * 14 \\
\left.* 14 \mathrm{M}^{0.31}\right)\end{array}$ & $\begin{array}{l}+\beta_{3} * 14 \mathrm{M}^{0.31}+ \\
\left.+\beta_{\mathbf{3}} * \mathbf{1 4} \mathbf{M}^{\mathbf{0 . 3 1}}\right) \\
\left.{ }^{1}\right)\end{array}$ & $\left.\mathrm{M}^{-0.25}\right)$ & \\
\hline
\end{tabular}




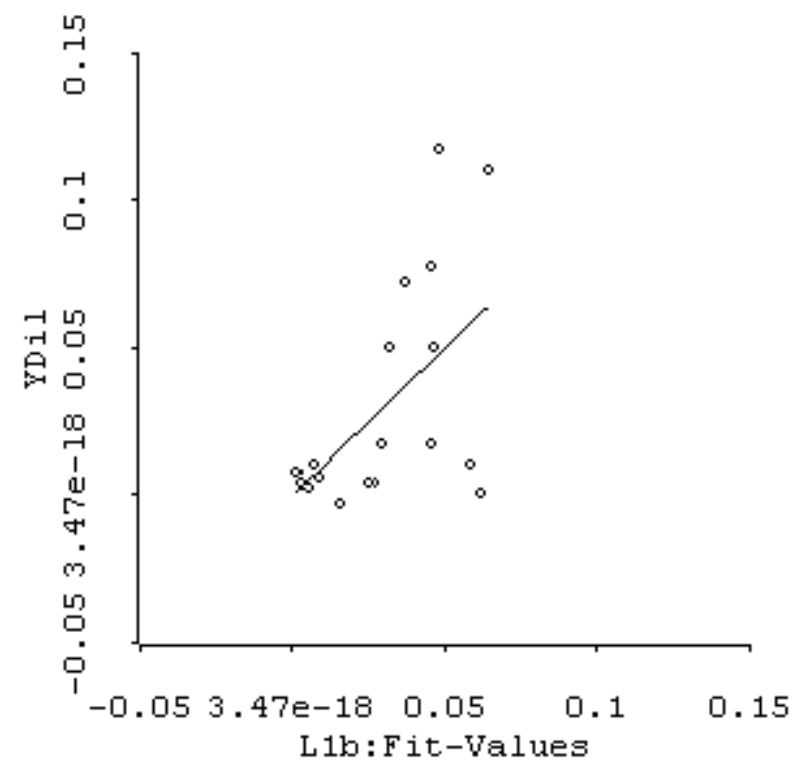

a. Model L1b.

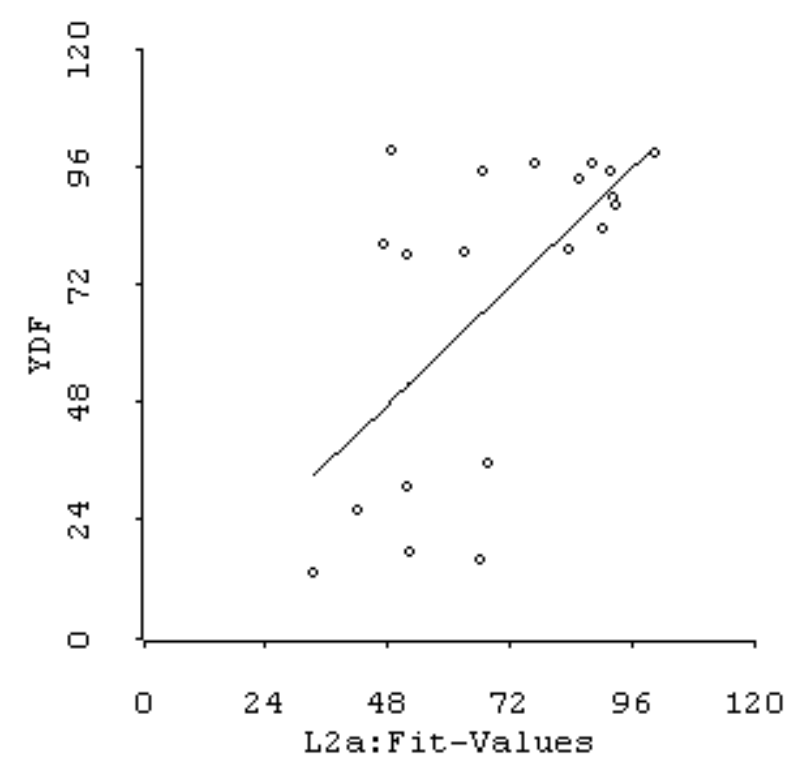

b. Model L2a.

Figure E.8. Actual versus predicted rapid freezing and thawing test results for models L1b and L2a (percentage of mass passing, 4.75 to $12.5 \mathrm{~mm}$ [\#4 to $0.5 \mathrm{in}]$ ).

\section{E.2.2 Model Selection}

At this point in the analysis, the best models would be further evaluated by checking the residual and model checking plots (as discussed in the preceding section 4.5.2.1) to ensure model adequacy. However, as illustrated in figures E.5 through E.8, there is a poor correlation between the hydraulic fracture test results for this size fraction (i.e., 4.75 to $12.5 \mathrm{~mm}$ [\#4 to $0.5 \mathrm{in}$ ]) and rapid freezing and thawing test results (dilation and durability factor), so none of the models identified for this size fraction were evaluated further. The general lack of correlation also suggests that this particle size range has little, if any, effect on concrete freeze-thaw durability, as previously suggested by Schwartz (4) and others.

\section{E.3 Initial Size Fraction: 12.5 to $19.0 \mathrm{~mm}(0.5$ to $0.75 \mathrm{in})$}

Hydraulic fracture testing was performed on the initial size fraction 12.5 to $19.0 \mathrm{~mm}$ [0.5 to 0.75 in] using the procedures outlined in appendix A. The POMR and POPR on specified sieves were calculated for each replicate sample, along with the APOMR and APOPR for each source, using the equations presented in section 3.5.3. Tables D.3 and D.4 (see appendix D) present the mass and particle counts retained, respectively, on the specified sieves at 0 and 50 cycles for the 
replicate samples for each source. The normalized mass and particle count retained data (i.e., POMR, APOMR, POPR and APOPR) are presented in tables D.5 and D.6 (see appendix D), respectively.

\section{E.3.1 Mass Retained Data}

\section{E.3.1.1 Explanatory Variables}

As stated previously, models were developed to predict percent dilation per 100 cycles of rapid freezing and thawing (dil) and durability factor (DF) as a function of the following explanatory variables:

58M: $\quad$ Percentage of mass passing the $16.0-\mathrm{mm}(0.625$-in $)$ screen.

12M: $\quad$ Percentage of mass passing the $12.50-\mathrm{mm}(0.5$-in) screen.

38M: $\quad$ Percentage of mass passing the $9.50-\mathrm{mm}(0.375$-in) screen.

516M: $\quad$ Percentage of mass passing the $8.00-\mathrm{mm}(0.3125$-in) screen.

14M: $\quad$ Percentage of mass passing the $6.35-\mathrm{mm}(0.25$-in $)$ screen.

4M: $\quad$ Percentage of mass passing the 4.75-mm (\#4) screen.

C: $\quad$ Percentage of carbonates present in source.

The percentage of mass passing each specified screen was calculated using the APOMR data presented in table D.5 and as defined below:

- Total Percentage of Original Mass Retained [TPOMR] - see equation E.1

a Percentage of mass passing the $16.0-\mathrm{mm}(0.625$-in) screen $[58 \mathrm{M}]$ :

$$
58 \mathrm{M}=\mathrm{TPOMR}-\mathrm{APOMR}_{58}
$$

where: $\quad$ TPOMR $=$ Total percentage of original mass retained and

$\mathrm{APOMR}_{58}=$ average percentage of original mass retained on the $16.0-\mathrm{mm}(0.625$-in $)$ screen .

Percentage of mass passing the $12.5-\mathrm{mm}(0.5$-in) screen [12M]:

$$
12 \mathrm{M}=58 \mathrm{M}-\mathrm{APOMR}_{12}
$$

where: $\quad 58 \mathrm{M}=$ Percentage of mass passing the $16.0-\mathrm{mm}(0.625-\mathrm{in})$ screen and 
$\mathrm{APOMR}_{12}=$ average percentage of original mass retained on the $12.5-\mathrm{mm}(0.5-\mathrm{in})$ screen.

a Percentage of mass passing the $9.50-\mathrm{mm}(0.375$-in) screen $[38 \mathrm{M}]$ :

$$
38 \mathrm{M}=12 \mathrm{M}-\mathrm{APOMR}_{38}
$$

where: $\quad 12 \mathrm{M}=$ Percentage of mass passing the $12.5-\mathrm{mm}(0.5-\mathrm{in})$ screen and

$\mathrm{APOMR}_{38}=$ average percentage of original mass retained on the $9.50-\mathrm{mm}(0.375$-in $)$ screen.

a Percentage of mass passing the $8.00-\mathrm{mm}(0.3125$-in) screen [516M] - see equation E.3

․ Percentage of mass passing the $6.35-\mathrm{mm}(0.25$-in) screen $[14 \mathrm{M}]$ - see equation E. 4

․ Percentage of mass passing the 4.75-mm (\#4) screen [ $\left.4_{\text {actual }}\right]$ - see equation E.5

- Percentage of mass lost due to testing $\left[\mathrm{M}_{\mathrm{loss}}\right]-$ see equation E.6

․ Percentage of mass passing the 4.75-mm (\#4) screen (adjusted for mass loss during testing) [4M] - see equation E.7

- Percentage of mass passing the pan [pan] - see equation E.8

The predictors defined by equations E.3 to E.4, E.7 and E.15 to E.17 were calculated for each of 20 sources and then transferred as an $l_{s p}$ file into $A R C$. Equation E.8 was used as a check to make sure that there were no computational errors.

It should be noted that as much as one percent of the mass of a given test sample was sometimes lost during testing. As a result, the total percentage of original material mass retained during the final sieve analyses was sometimes reduced to 99 percent or more. Because of the great care taken during testing, it was assumed that the material lost during testing was probably very fine 
and would have passed the 4.75-mm (\#4 sieve). Equations E.5 to E.7 were developed to account for this mass loss and attribute it to the proper particle size in the regression analysis.

\section{E.3.1.2 Transformations to Normality}

Two-dimensional scatter plots were developed to show the conditional distribution of the response variables (dilation/100 cycles and durability factor) given changes in each explanatory variable. Normality is achieved when the mean functions are linear and the variance functions are constant (9). The scatter plot matrix for the previously defined explanatory and response variables is presented in figure E.9, which shows that there is little normality between the response and explanatory variables in the inverse fitted value plots (marginal distribution plots).

\begin{tabular}{|c|c|c|c|c|c|c|c|c|c|c|}
\hline $\begin{array}{cc} & \\
00 & \\
00 & \\
\% & 0 \%\end{array}$ & $\begin{array}{ccccc}\circ & & & 0 \\
0 & & & \\
\infty & & \\
\% & 8 & 8\end{array}$ & $\begin{array}{|ccc|}\circ & & \\
0 & & \\
\infty & & \\
\infty & 8 & 8\end{array}$ & $\begin{array}{|ccc|}0 & & 0 \\
0 & & \\
\infty & \\
0 & 8 & 8\end{array}$ & 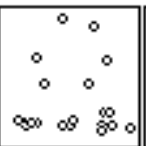 & $\begin{array}{cc} & \% \\
\circ & \circ \\
0 & \circ \\
600 \% 0 & \circ\end{array}$ & $\infty \infty$ & \begin{tabular}{l||}
8 \\
8 \\
8
\end{tabular} & $\begin{array}{l}8 \\
\therefore \\
\therefore 0\end{array}$ & 3008 & $\begin{array}{c}\text { O. } 118 \\
\text { YDil } \\
-0.003\end{array}$ \\
\hline 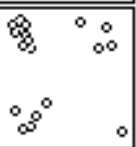 & \begin{tabular}{lll|} 
& $\circ$ & $\circ$ \\
$\circ$ & $\circ$ & \\
$\circ$ & & 0
\end{tabular} & 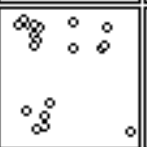 & 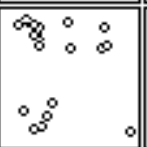 & 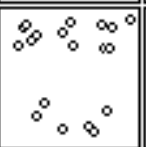 & $\begin{array}{c}809^{\circ} \circ \\
88 \\
\circ 0^{\circ} \\
\infty^{\circ}\end{array}$ & $\infty 80$ & 8 & $\begin{array}{r}99 \\
Y D F \\
13.4\end{array}$ & & $\begin{array}{l}\text { है, } \\
: 0 \\
0\end{array}$ \\
\hline $\begin{array}{ll}000 & 0000 \\
8 & \\
8 & \\
8\end{array}$ & \begin{tabular}{|l|l|}
000000 & 0 \\
8 & \\
8
\end{tabular} & 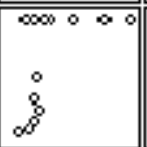 & 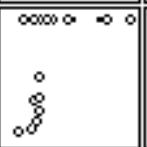 & 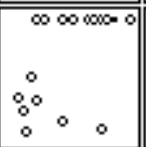 & $\begin{array}{|ccc|}00000000 \\
0 \\
\vdots & & \\
0 & 0 & 0 \\
0 & 0 & 0\end{array}$ & $c^{10}$ & & $\overline{c o s \infty}$ & $\begin{array}{l}\circ \\
\infty_{8} \\
8\end{array}$ & $\begin{array}{llll}\infty & 000 & 0 \\
0 & & \\
8 & & & \end{array}$ \\
\hline $\begin{array}{ll} & \\
8 & \\
8_{0}^{\circ} & 0 \\
0 & 0\end{array}$ & \begin{tabular}{ccc|} 
& 0 & \\
$8_{8}$ & & 0 \\
$\circ 0^{\circ}$ & 0 \\
0 & 0 & \\
0
\end{tabular} & \begin{tabular}{ll||} 
& 0 \\
$8_{2}$ & 0 \\
$8_{0}^{\circ}$ & 0 \\
0
\end{tabular} & $\begin{array}{l}8_{8}^{\circ} \circ \\
\circ 8_{\circ}^{\circ} \circ \\
0\end{array}$ & 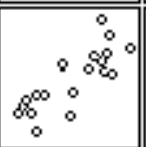 & $\begin{array}{r}79.5 \\
58 \mathrm{M} \\
45.3\end{array}$ & $\begin{array}{l}0 \\
\circ \\
\circ 0\end{array}$ & 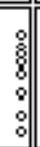 & $8^{\circ}$ & \begin{tabular}{l|}
0 \\
0 \\
08 \\
$\infty$ \\
$\infty$
\end{tabular} & $\begin{array}{lll}\circ & \\
80 & \circ \\
8 & \circ \\
8 & \circ\end{array}$ \\
\hline \begin{tabular}{lll|} 
& & \\
$\infty$ & & 0 \\
$\infty$ & 0 & 0 \\
$\infty^{\circ}$ & \\
$\infty$
\end{tabular} & \begin{tabular}{llll|} 
& 0 & & \\
$\infty_{\circ}$ & 0 & 0 \\
$\infty$ & 0 & 0 \\
0 & & & \\
0 & &
\end{tabular} & 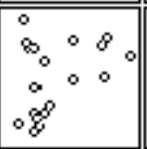 & 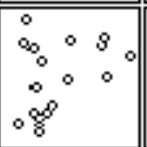 & $\begin{array}{c}20.3 \\
12 \mathrm{M} \\
5.64\end{array}$ & $\begin{array}{r}\circ \\
\circ 8 \\
\circ 8\end{array}$ & $\begin{array}{l}\circ \\
0 \\
0 \%\end{array}$ & 告 & $8^{\circ}$ & $\begin{array}{l}88^{\circ} \\
\% \\
\%\end{array}$ & $\begin{array}{lll}88 & 0 & \\
8 & 0 & \\
8 & \circ & \circ \\
8 & & \circ\end{array}$ \\
\hline $\mathscr{\beta}^{\circ} 0^{\circ}$ & $\mathscr{b}^{\circ}$ & $\theta^{\circ}$ & $\begin{array}{c}3.02 \\
38 \mathrm{M} \\
0.663\end{array}$ & 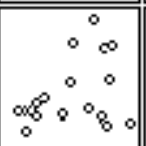 & $\begin{array}{c}0_{0}^{\circ} \\
\circ \infty_{0}^{\circ} \infty_{0}\end{array}$ & & 8 & $\delta_{\circ}^{\circ}$ & \begin{tabular}{ll|}
$\theta$ & 0 \\
0 & 0 \\
0 & 8
\end{tabular} & $\begin{array}{lll} & & \\
\circ & & \\
\circ & 8 \circ \\
\%^{\circ} & 8 & \circ\end{array}$ \\
\hline $\mathscr{\%}^{\circ} 0^{\circ}$ & $\mathscr{\beta}^{\circ}$ & $\begin{array}{l}5.82 \\
516 \mathrm{M} \\
0.604\end{array}$ & $\theta^{\circ}$ & 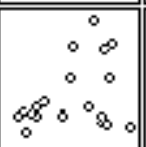 & 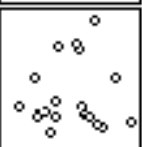 & $8^{\circ} 0^{\circ}$ & 8 & $8_{0}^{\circ}$ & \begin{tabular}{ll|}
0 & 0 \\
0 & 0 \\
0 & 0
\end{tabular} & $\begin{array}{ll}\infty & \\
\infty & \\
\infty & \\
8 & 0\end{array}$ \\
\hline$\oiint^{\circ} 0^{\circ}$ & $\begin{array}{c}2.67 \\
14 \mathrm{M} \\
0.542\end{array}$ & $s^{\circ}$ & $\not^{\circ}$ & $\begin{array}{r}0^{\circ} 8 \\
0^{\circ} \\
0_{0}^{\circ} 8^{\circ} 8\end{array}$ & 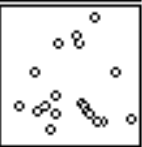 & $8^{\circ \circ}$ & 8 & $\infty 0^{\circ}$ & \begin{tabular}{ll|}
$\circ$ & 0 \\
0 & 0 \\
0 & $\beta$
\end{tabular} & $\begin{array}{lll}8 & & \\
8^{\circ} & & \\
\gamma^{8} & 8\end{array}$ \\
\hline $\begin{array}{l}\frac{1}{M} \cdot 5 \\
.247\end{array}$ & $\circ^{\circ} 8^{\circ}$ & $0^{8}{ }^{8}$ & $\beta^{\circ} \beta^{\circ}$ & \begin{tabular}{c|}
$0^{\circ} \circ$ \\
$8^{\circ} 8^{\circ} 8 \circ$
\end{tabular} & \begin{tabular}{|c|}
${ }^{\circ}{ }^{\circ}$ \\
${ }^{\circ} 8 \circ$ \\
8
\end{tabular} & $20^{\circ}$ & 8 & $\delta_{\circ}^{\circ}$ & $\begin{array}{c}80 \\
\circ \\
\%\end{array}$ & $\begin{array}{lll}\varphi_{0} & & \\
\circ & & \\
\% & : & 0\end{array}$ \\
\hline
\end{tabular}

Figure E.9. Scatter plot matrix for responses and explanatory variables (percentage of mass passing, 12.5 to $19.0 \mathrm{~mm}$ [0.5 to $0.75 \mathrm{in}])$. 
Normality can sometimes be achieved or improved through transformations of the explanatory variables. In this study, explanatory variable transformations were performed using the Box-Cox method (a numerical procedure) in an attempt to improve the linearity of the relationships.

Figure E.10 presents the scatter plot matrix for the transformed explanatory variables and shows that the Box-Cox transformations were not effective in producing linear relationships between the percentage of mass passing the designated screens and either percent dilation or the durability factor.

\begin{tabular}{|c|c|c|c|c|c|c|c|c|c|}
\hline $\begin{array}{ll}\therefore & 0 \\
\therefore & \therefore \\
\infty & 8\end{array}$ & $\begin{array}{ll}\circ & 0 \\
\infty & \\
\infty & 88\end{array}$ & $\begin{array}{lll}\therefore & & \\
\infty & & \\
\infty & 8 & 3\end{array}$ & 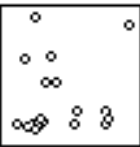 & $\begin{array}{ccc} & 0 & 0 \\
\circ & \circ \\
\circ & \circ \\
000 & 0 & 8\end{array}$ & $\begin{array}{c}0.0 \\
00000\end{array}$ & $\infty \infty$ & : & $\begin{array}{l}s \\
\therefore\end{array}$ & $\begin{array}{c}0.118 \\
\text { YDil } \\
-0.003\end{array}$ \\
\hline 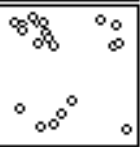 & $\begin{array}{l}8 \%: 8 \\
\circ 8:\end{array}$ & 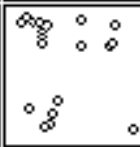 & $\begin{array}{l}0 \%: 0 \\
\therefore 8\end{array}$ & $\begin{array}{c}\therefore 0^{\circ} \\
\therefore \%\end{array}$ & 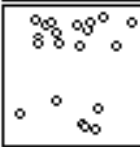 & \%。 & 8 & $\begin{array}{r}\frac{99.3}{\mathrm{YDF}} \\
13.4\end{array}$ & $\begin{array}{l}\overline{8}_{5} \\
\\
: 8\end{array}$ \\
\hline $\begin{array}{l}000000000 \\
3_{0}^{\circ}\end{array}$ & $0000 \infty 0$ & $100000 \infty 0$ & 10000000 & $\begin{array}{l}\infty 000000 \\
80 \\
80\end{array}$ & $\%$ & $\begin{array}{l}{ }_{C^{\wedge}} e^{+0} \\
403\end{array}$ & & 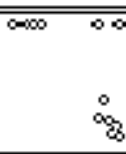 & $\infty \infty 0^{\circ}$ \\
\hline $\begin{array}{l} \\
8^{\circ}: \\
\therefore \circ \\
\infty_{0}^{\circ}:\end{array}$ & & $\begin{array}{l}8 \\
.80 \\
0\end{array}$ & 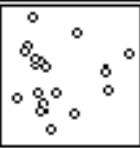 & 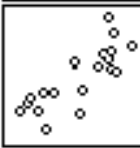 & 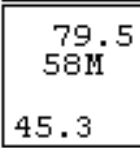 & : & 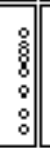 & $\begin{array}{ll}8^{\circ} & 0 \\
0 & 8 \\
0 & \infty \\
\circ \quad & 8 \\
\end{array}$ & $\begin{array}{ll} & \\
8 & \\
80 & 0 \\
8 & 0 \\
3 & 0\end{array}$ \\
\hline $\begin{array}{ll} & \theta_{0} \\
\therefore & 0 \\
0 & 0 \\
\infty_{0}^{\circ}\end{array}$ & $\begin{array}{l}\infty \\
\infty \\
\infty \\
8\end{array}$ & 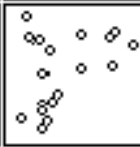 & $\begin{array}{l}\circ \\
\infty \\
\infty \\
08\end{array}$ & $\begin{array}{r}4.51 \\
12 \mathrm{M}^{\circ} 0.5 \\
2.37\end{array}$ & $\begin{array}{r}\circ \\
\therefore 8\end{array}$ & $\begin{array}{l}\circ \\
: \\
\infty\end{array}$ & & $\begin{array}{l}8^{\circ} \\
\therefore\end{array}$ & $\begin{array}{ll}8 & \\
80 & 0 \\
8 & 0 \\
8 & 0 \\
8 & 0 \\
\end{array}$ \\
\hline $\mathscr{8}^{\circ}$ & & & 0.756 & 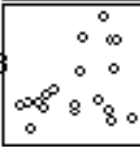 & & & 8 & $8_{\circ}^{\circ}$ & $\begin{array}{l}\infty \\
\infty \\
8\end{array}$ \\
\hline $8^{\circ} 8^{\circ}$ & & 0.699 & & $\begin{array}{r}\therefore \therefore \\
\therefore \therefore \\
\therefore 8 \\
\therefore \quad 80\end{array}$ & $\begin{array}{c}\circ 8^{\circ} \\
\therefore 8^{\circ}\end{array}$ & & 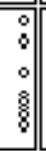 & $\begin{array}{ll}\circ & \therefore \\
\sigma^{\circ} & 0 \\
\circ & 0\end{array}$ & $\begin{array}{l}\infty \\
\infty \\
\infty \\
8 \\
8\end{array}$ \\
\hline $0^{\circ} 0^{\circ}$ & $\begin{array}{r}2.19 \\
14 \mathrm{M}^{\circ} \cdot 0\end{array}$ & & & $\begin{array}{r}\therefore \% \\
\therefore \therefore \\
\therefore 8 \\
0\end{array}$ & $\begin{array}{c}\circ \\
\therefore \circ \\
\therefore \circ\end{array}$ & & \begin{tabular}{l|||c||}
8 \\
8 \\
8 \\
8
\end{tabular} & $\infty^{\circ}$ & $\begin{array}{l}\infty \\
\infty \\
8^{8} \\
8\end{array}$ \\
\hline $\begin{array}{l}0.402 \\
\operatorname{og}[4 \mathrm{M}] \\
1.4\end{array}$ & $0^{\circ}$ & $\beta^{\circ} \circ$ & $8^{\circ}$ & 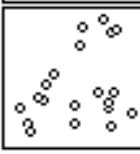 & $\begin{array}{l}\therefore 0^{\circ} \\
\therefore 8 \% \\
800 \\
80\end{array}$ & & & $\begin{array}{ll}\circ & 8 \% \\
\AA^{\circ} & 8 \% \\
\circ & 8 \\
\end{array}$ & 8 \\
\hline
\end{tabular}

Figure E.10. Scatter plot matrix for responses and transformed explanatory variables (percentage of mass passing, 12.5 to $19.0 \mathrm{~mm}$ [0.5 to $0.75 \mathrm{in}]$ ).

Even though normality was apparently not achieved, nonlinear and multiple linear regression analyses were performed on this data set, as described below in subsection F3.1.3. 


\section{E.3.1.3 Nonlinear and Multiple Linear Regression}

As stated previously, past studies have shown that concrete freeze-thaw durability is often a function of carbonate content. Therefore, the following general nonlinear model form was adopted:

$\mathrm{E}(\mathrm{y} \mid \mathrm{x})=\mathrm{C}^{*}($ linear combination of $58 \mathrm{M}, 12 \mathrm{M}, 38 \mathrm{M}, 516 \mathrm{M}, 14 \mathrm{M}$ and $4 \mathrm{M})$ therefore,

$\mathrm{E}(\mathrm{y} \mid \mathrm{x})=\mathrm{C} *\left(\alpha+\beta_{1} * 58 \mathrm{M}+\beta_{2} * 12 \mathrm{M}+\beta_{3} * 38 \mathrm{M}+\beta_{4} * 516 \mathrm{M}+\beta_{5} * 14 \mathrm{M}+\beta_{6} * 4 \mathrm{M}\right)$

Equation E.18 was modified slightly for multiple linear regression to produce basic forms for modeling dilation and durability factor as a function of percentages of mass passing the specified sieves either with or without an interaction term for carbonate content:

$$
\begin{gathered}
\mathrm{E}(\mathrm{y} \mid \mathrm{x})=\alpha+\beta_{1} * \mathrm{C} * 38 \mathrm{M}+\beta_{2} * \mathrm{C} * 516 \mathrm{M}+\beta_{3} * \mathrm{C} * 14 \mathrm{M}+\beta_{4} * \mathrm{C} * 4 \mathrm{M} \\
\mathrm{E}(\mathrm{y} \mid \mathrm{x})=\alpha+\beta_{1} * 38 \mathrm{M}+\beta_{2} * 516 \mathrm{M}+\beta_{3} * 14 \mathrm{M}+\beta_{4} * 4 \mathrm{M}
\end{gathered}
$$

Regression analyses were performed using the model forms presented in equations E.18 through E. 20 with both the transformed and untransformed (identity) explanatory variables. Numerous nonlinear and multiple linear regression models were formulated in the manner described previously in section E.2.1.3; however, only the models with the best adjusted $\mathrm{R}^{2}$ for the response variables percentage of dilation per 100 cycles (model N1) and durability factor (model L2) were recorded in tables E.8 and E.9, respectively. As described previously, these models were reduced to eliminate predictors that have no significant effect on the mean function. The reduced models are designated with lowercase letters behind the model number (e.g., N1a, N1b, etc.).

\section{E.3.1.4 Model Selection}

The F-statistic was used to determine the most compact model that adequately represents the data. The F-statistic is expressed as follows (9): 
Table E.8. Nonlinear regression models for response variable "percent dilation per 100 cycles" (percentage of mass passing, 12.5 to $19.0 \mathrm{~mm}$ [0.5 to $0.75 \mathrm{in}]$ ).

\begin{tabular}{|c|c|c|c|c|c|}
\hline \multirow{3}{*}{ Variable } & \multicolumn{5}{|c|}{ Estimates (Wald Test) } \\
\hline & \multicolumn{5}{|c|}{ Model Number } \\
\hline & N1 & N1a & N1b & N1c & N1d \\
\hline$\alpha$ & $\begin{array}{c}-0.0000106798 \\
(-1.209)\end{array}$ & $\begin{array}{c}-0.0000101023 \\
(-1.318)\end{array}$ & $\begin{array}{c}-4.883484 \mathrm{E}-6 \\
(-0.672)\end{array}$ & $\begin{array}{c}-5.680484 \mathrm{E}-6 \\
(-0.811)\end{array}$ & $\begin{array}{c}-4.421358 \mathrm{E}-6 \\
(-0.695)\end{array}$ \\
\hline $58 \mathrm{M}$ & $\begin{array}{c}5.610871 \mathrm{E}-7 \\
(2.597)\end{array}$ & $\begin{array}{c}5.421653 \mathrm{E}-7 \\
(3.206)\end{array}$ & $\begin{array}{c}4.369152 \mathrm{E}-7 \\
(2.678)\end{array}$ & $\begin{array}{c}4.397408 \mathrm{E}-7 \\
(2.752)\end{array}$ & $\begin{array}{c}4.242641 \mathrm{E}-7 \\
(2.771)\end{array}$ \\
\hline $12 \mathrm{M}$ & $\begin{array}{c}-1.390522 \mathrm{E}-6 \\
(-3.297)\end{array}$ & $\begin{array}{c}-1.361274 \mathrm{E}-6 \\
(-3.776)\end{array}$ & $\begin{array}{c}-1.300747 \mathrm{E}-6 \\
(-3.458)\end{array}$ & $\begin{array}{c}-1.277577 \mathrm{E}-6 \\
(-3.484)\end{array}$ & $\begin{array}{c}-1.237859 \mathrm{E}-6 \\
(-3.543)\end{array}$ \\
\hline $38 \mathrm{M}$ & $\begin{array}{c}-0.0000381508 \\
(-1.506)\end{array}$ & $\begin{array}{c}-0.0000386800 \\
(-1.598)\end{array}$ & $\begin{array}{c}-0.0000103731 \\
(-0.606)\end{array}$ & & \\
\hline $516 \mathrm{M}$ & $\begin{array}{c}0.0000988808 \\
(1.528)\end{array}$ & $\begin{array}{c}0.000101786 \\
(1.709)\end{array}$ & $\begin{array}{c}0.0000114510 \\
(0.636)\end{array}$ & $\begin{array}{c}5.626926 \mathrm{E}-7 \\
(0.488)\end{array}$ & \\
\hline $14 \mathrm{M}$ & $\begin{array}{c}-0.0000617554 \\
(-1.438) \\
\end{array}$ & $\begin{array}{c}-0.0000634044 \\
(-1.584) \\
\end{array}$ & & & \\
\hline $4 \mathrm{M}$ & $\begin{array}{c}1.326474 \mathrm{E}-6 \\
(0.150) \\
\end{array}$ & & & & \\
\hline Df & 13 & 14 & 15 & 16 & 17 \\
\hline $\mathrm{N}$ & 20 & 20 & 20 & 20 & 20 \\
\hline $\mathrm{r}^{2}$ & 0.7682 & 0.7678 & 0.7262 & 0.7195 & 0.7154 \\
\hline$\hat{\sigma}$ & 0.0279457 & 0.0269524 & 0.0282751 & 0.0277104 & 0.0270823 \\
\hline $\mathrm{r}_{\text {adj }}^{2}$ & 0.633 & 0.661 & 0.628 & 0.645 & 0.662 \\
\hline $\begin{array}{l}\text { Models } \\
\text { Compared }\end{array}$ & & (N1) - (N1a) & $(\mathrm{N} 1 \mathrm{~b})-(\mathrm{N} 1 \mathrm{a})$ & $(\mathrm{N} 1 \mathrm{c})-(\mathrm{N} 1 \mathrm{~b})$ & $(\mathrm{N} 1 \mathrm{~d})-(\mathrm{N} 1 \mathrm{c})$ \\
\hline P-value & & 0.883 & 0.136 & 0.554 & 0.632 \\
\hline $\begin{array}{l}{ }^{{ }^{\mathrm{N} 1} \mathrm{Y}} \mathrm{Y}=\mathrm{C}^{2 *} \\
{ }^{\mathrm{N} 1 \mathrm{a}} \mathrm{Y}=\mathbf{C}^{2} \\
{ }^{\mathrm{N} 1 \mathrm{~b}} \mathrm{Y}=\mathrm{C}^{2} \\
{ }^{\mathrm{N} 1 \mathrm{c}} \mathrm{Y}=\mathrm{C}^{2} \\
{ }^{\mathrm{N} 1 \mathrm{~d}} \mathrm{Y}=\mathrm{C}^{2}\end{array}$ & $\begin{array}{l}58 \mathrm{M}+\beta_{2} * 12 \mathrm{M}+ \\
\mathbf{5 8 M}+\beta_{2} * \mathbf{1 2 M} \\
58 \mathrm{M}+\beta_{2} * 12 \mathrm{M}+ \\
58 \mathrm{M}+\beta_{2} * 12 \mathrm{M}+ \\
\left.58 \mathrm{M}+\beta_{2} * 12 \mathrm{M}\right)\end{array}$ & $\begin{array}{l}* 38 \mathrm{M}+\beta_{4} * 516 \mathrm{M} \\
{ }_{3}^{* 38 M}+\beta_{4} * 516 \\
* 38 \mathrm{M}+\beta_{4} * 516 \mathrm{P} \\
* 516 \mathrm{M})\end{array}$ & $\begin{array}{l}\beta_{5} * 14 \mathrm{M}+\beta_{6} * 4 \mathrm{I} \\
+\beta_{5}^{*} \text { 14M) }\end{array}$ & & \\
\hline
\end{tabular}


Table E.9. Multiple linear regression models for response variable "durability factor" (percentage of mass passing, 12.5 to $19.0 \mathrm{~mm}$ [0.5 to $0.75 \mathrm{in}]$ ).

\begin{tabular}{|c|c|c|c|c|c|}
\hline \multirow{3}{*}{ Variable } & \multicolumn{5}{|c|}{ Estimates (t-value) } \\
\hline & \multicolumn{5}{|c|}{ Model Number } \\
\hline & L2 & L2a & $\mathrm{L} 2 \mathrm{~b}$ & L2c & L2d \\
\hline$\alpha$ & $\begin{array}{l}131.213 \\
(8.780) \\
\end{array}$ & $\begin{array}{l}132.440 \\
(9.218) \\
\end{array}$ & $\begin{array}{l}133.817 \\
(9.029) \\
\end{array}$ & $\begin{array}{c}131.110 \\
(8.728) \\
\end{array}$ & $\begin{array}{c}131.136 \\
(8.995) \\
\end{array}$ \\
\hline $58 \mathrm{M} * \mathrm{C}$ & $\begin{array}{c}-0.0351875 \\
(-3.746)\end{array}$ & $\begin{array}{c}-0.0375415 \\
(-4.684) \\
\end{array}$ & $\begin{array}{c}-0.0357316 \\
(-4.367) \\
\end{array}$ & $\begin{array}{c}-0.0360867 \\
(-4.312) \\
\end{array}$ & $\begin{array}{c}-0.0362704 \\
(-4.543) \\
\end{array}$ \\
\hline $12 \mathrm{M} * \mathrm{C}$ & $\begin{array}{c}0.100410 \\
(3.403)\end{array}$ & $\begin{array}{c}0.105734 \\
(3.924)\end{array}$ & $\begin{array}{c}0.101912 \\
(3.676)\end{array}$ & $\begin{array}{c}0.106834 \\
(3.800)\end{array}$ & $\begin{array}{c}0.106529 \\
(3.921)\end{array}$ \\
\hline $38 \mathrm{M} * \mathrm{C}$ & $\begin{array}{c}2.60891 \\
(1.461) \\
\end{array}$ & $\begin{array}{c}2.43465 \\
(1.426) \\
\end{array}$ & & & \\
\hline $516 M^{*} \mathrm{C}$ & $\begin{array}{c}-8.62253 \\
(-1.896) \\
\end{array}$ & $\begin{array}{c}-7.61122 \\
(-1.901)\end{array}$ & $\begin{array}{c}-2.55638 \\
(-1.328)\end{array}$ & $\begin{array}{c}-0.0105120 \\
(-0.119)\end{array}$ & \\
\hline $14 \mathrm{M} * \mathrm{C}$ & $\begin{array}{c}5.96333 \\
(1.964) \\
\end{array}$ & $\begin{array}{l}5.30450 \\
(1.974) \\
\end{array}$ & $\begin{array}{c}2.68182 \\
(1.324) \\
\end{array}$ & & \\
\hline $4 \mathrm{M} * \mathrm{C}$ & $\begin{array}{c}0.328906 \\
(0.520)\end{array}$ & & & & \\
\hline Df & 13 & 14 & 15 & 16 & 17 \\
\hline $\mathrm{N}$ & 20 & 20 & 20 & 20 & 20 \\
\hline $\mathrm{R}^{2}$ & 0.672914 & 0.6661 & 0.617604 & 0.572896 & 0.572515 \\
\hline$\hat{\sigma}$ & 22.2524 & 21.6652 & 22.399 & 22.9206 & 22.2461 \\
\hline $\mathrm{R}_{\text {adj }}^{2}$ & 0.522 & 0.547 & 0.516 & 0.493 & 0.522 \\
\hline $\begin{array}{l}\text { Models } \\
\text { Compared }\end{array}$ & & (N1) - (N1a) & $(\mathrm{N} 1 b)-(\mathrm{N} 1 \mathrm{a})$ & $(\mathrm{N} 1 \mathrm{c})-(\mathrm{N} 1 \mathrm{~b})$ & $(\mathrm{N} 1 \mathrm{~d})-(\mathrm{N} 1 \mathrm{c})$ \\
\hline P-value & & 0.6115 & 0.1758 & 0.2052 & 0.9064 \\
\hline $\begin{array}{l}{ }^{\text {L2 }} \mathrm{Y}=\alpha+ \\
{ }^{\text {L2a }} Y=\alpha \\
{ }^{\text {L2b }} Y=\alpha \\
{ }^{\text {L2c }} Y=\alpha \\
{ }^{\text {L2d }} Y=\alpha\end{array}$ & $\begin{array}{l}\mathrm{M}+\beta_{2} * 12 \mathrm{M} \\
\mathbf{M}+\beta_{2} * 12 \mathrm{M} \\
\mathrm{M}+\beta_{2}{ }^{*} 12 \mathrm{M} \\
\mathrm{M}+\beta_{2} * 12 \mathrm{M} \\
\mathrm{M}+\beta_{2}{ }^{*} 12 \mathrm{M}\end{array}$ & $\begin{array}{l}8 \mathrm{M}+\beta_{4} * 516 \mathrm{~N} \\
38 \mathrm{M}+\beta_{4} * 516 \\
516 \mathrm{M}+\beta_{4} * 14 \\
16 \mathrm{M})\end{array}$ & $\begin{array}{l}5^{*} 14 \mathrm{M}+\beta_{6} * 4 \mathrm{M} \\
\left.\beta_{5} * 14 \mathrm{M}\right)\end{array}$ & & \\
\hline
\end{tabular}


Null Hypothesis $(\mathrm{NH})$ : data is adequately represented by nested (smaller) model Alternative Hypothesis (AH): data is adequately represented by larger model

$$
\mathrm{F}=\frac{(\mathrm{RSS}}{\underline{\mathrm{N}}_{\mathrm{NH}}} \frac{\left.-\mathrm{RSS}_{\mathrm{AH}}\right) /\left(\mathrm{df}_{\mathrm{NH}}-\mathrm{df}_{\mathrm{AH}}\right)}{\hat{\sigma}_{A H}^{2}}
$$

where: $\quad \mathrm{RSS}_{\mathrm{AH}}=$ residual sum of squares for $\mathrm{AH}$ model, with $\mathrm{df}_{\mathrm{AH}}$ degrees of freedom; $\mathrm{RSS}_{\mathrm{NH}}=$ residual sum of squares for $\mathrm{NH}$ model, with $\mathrm{df}_{\mathrm{NH}}$ degrees of freedom; and $\hat{\sigma}_{A H}^{2}=\mathrm{RSS}_{\mathrm{AH}} / \mathrm{df}_{\mathrm{AH}}=$ residual mean square for $\mathrm{AH}$ model.

The p-value to determine whether to reject or accept the $\mathrm{NH}$ is obtained by comparing $\mathrm{F}$ to the $\mathrm{F}$ distribution with $\left(\mathrm{df}_{\mathrm{NH}}-\mathrm{df}_{\mathrm{AH}}, \mathrm{df}_{\mathrm{AH}}\right)$ degrees of freedom.

The F-statistic was calculated for each comparison (e.g., NH: N1a versus AH: N1, etc.) to identify the most compact model that adequately captures the data. As illustrated in tables E.8 and E.9, where all p-values are greater than 0.05 , each nested model will adequately represent the data. Therefore, graphs of actual versus predicted rapid freezing and thawing test results (summary plot) and model checking plots were produced to determine the model that most adequately represents the data. The following model checking plots were constructed to check the mean function (9):

- Marginal Plots: Marginal plots are multipanel plots of the response variable versus the fitted values (eta'u) and versus selected predictors (e.g., 58M, 12M, etc.).

- GREG (Graphical Regression) Plots: The first GREG plot selects a linear combination of the selected terms that is most likely to show curvature in the plot of residuals versus that linear combination (i.e., the first GREG plot is an approximation of the worst case). The remaining GREG linear combinations are uncorrelated with the first GREG linear combination, and each is less likely than the one before to show curvature. These plots are multi-panel plots of the response variable versus GREG linear combinations. 
- $\quad$ Random Plots: Random plots are multi-panel plots of the response variable versus a random linear combination of the selection.

A visual assessment of a model's capability of reproducing the information provided by the available data is performed by comparing the smooths (i.e., the response versus fitted values [mean function]). The model has the correct mean function if and only if the model checking plots agree (i.e., the two smooths are equal) for all of the model checking plots (9). In addition to the above plots, a nonconstant variance plot and residual plots (residuals versus predictors and versus fitted values) were constructed to determine the adequacy of the models.

The models shaded in gray in tables E.8 and E.9 (i.e., N1a and L2a) are the final models chosen based on the model checking plots. Figure E.11 presents the summary plots for models N1a and L2a.

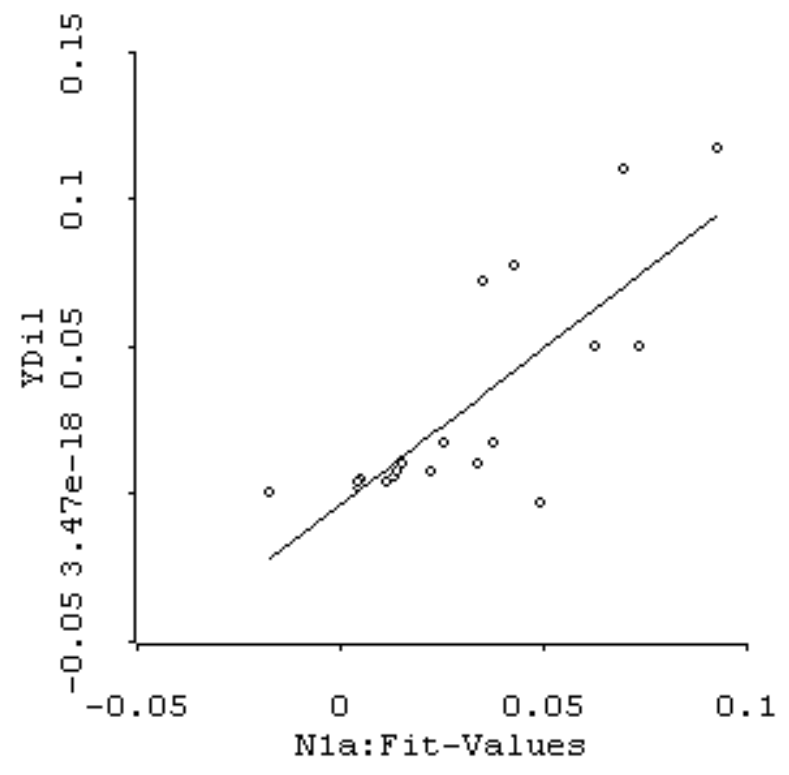

a. Model N1a.

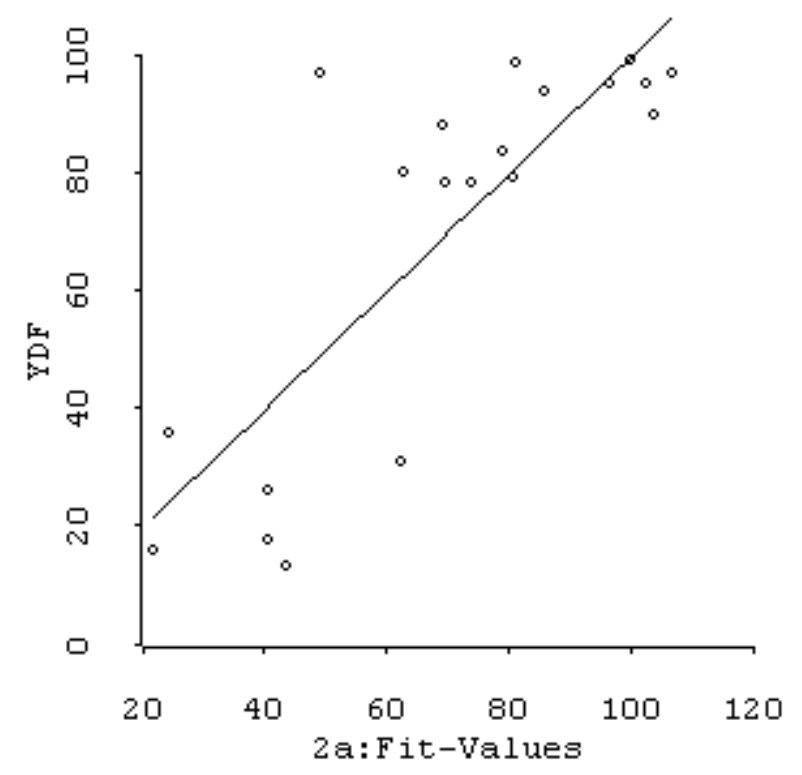

b. Model L2a.

Figure E.11. Actual versus predicted rapid freezing and thawing test results for models N1a and L2a (percentage of mass passing, 12.5 to $19.0 \mathrm{~mm}$ [0.5 to $0.75 \mathrm{in}]$ ).

As illustrated in these plots, the correlation between the hydraulic fracture and freezing and thawing data is increased over that obtained for the 4.75-to 12.5-mm (\#4 to 0.5 in) initial size 
fraction. However, the correlation achieved by these mean functions is still not sufficiently strong.

\section{E.3.2 Particle Count Data}

\section{E.3.2.1 Explanatory Variables}

As stated previously, models were developed to predict percent dilation per 100 cycles of rapid freezing and thawing (dil) and durability factor (DF) as a function of the following explanatory variables:

58P: $\quad$ Percentage of particles passing the $16.0-\mathrm{mm}(0.625$-in) screen.

12P: $\quad$ Percentage of particles passing the $12.50-\mathrm{mm}(0.5$-in) screen.

38P: $\quad$ Percentage of particles passing the $9.50-\mathrm{mm}(0.375$-in) screen.

516P: $\quad$ Percentage of particles passing the $8.00-\mathrm{mm}(0.3125$-in $)$ screen.

14P: $\quad$ Percentage of particles passing the $6.35-\mathrm{mm}(0.25$-in) screen.

4P: $\quad$ Percentage of particles passing the 4.75-mm (\#4) screen.

C: $\quad$ Percentage of carbonates present in source.

The percentage of particles passing each specified screen was calculated using the APOPR data presented in table D.6 and defined below:

- Total Percentage of Original Particles Retained [TPOPR]:

$$
\mathrm{TPOPR}=\sum_{i=1}^{n} \mathrm{APOPR}_{i}
$$

where: $\quad \mathrm{APOPR}_{i}=$ average percentage of original particles retained on screen $i$ and $\mathrm{n}=$ total number of screens.

a Percentage of particles passing the $16.0-\mathrm{mm}(0.625$-in) screen [58P]:

$$
58 \mathrm{P}=\mathrm{TPOPR}-\mathrm{APOPR}_{58}
$$

where: $\quad$ TPOPR $=$ Total percentage of original particles retained and $\mathrm{APOPR}_{58}=$ average percentage of original particles retained on the $16.0-\mathrm{mm}(0.625-\mathrm{in})$ screen. 
Percentage of particles passing the $12.5-\mathrm{mm}(0.5$-in $)$ screen $[12 \mathrm{P}]$ :

$$
12 \mathrm{P}=58 \mathrm{P}-\mathrm{APOPR}_{12}
$$

where: $\quad 58 \mathrm{P}=$ Percentage of particles passing the $16.0-\mathrm{mm}(0.625$-in $)$ screen and

$\mathrm{APOPR}_{12}=$ average percentage of original particles retained on the $12.5-\mathrm{mm}(0.5-\mathrm{in})$ screen.

Percentage of particles passing the $9.50-\mathrm{mm}(0.375$-in) screen [38P]:

$$
38 \mathrm{P}=12 \mathrm{P}-\mathrm{APOPR}_{38}
$$

where: $\quad 12 \mathrm{P}=$ Percentage of particles passing the $12.5-\mathrm{mm}(0.5-\mathrm{in})$ screen and

$\mathrm{APOPR}_{38}=$ average percentage of original particles retained on the $9.50-\mathrm{mm}(0.375$-in $)$ screen.

Percentage of particles passing the $8.00-\mathrm{mm}(0.3125$-in) screen [516P]:

$$
516 \mathrm{P}=38 \mathrm{P}-\mathrm{APOPR}_{516}
$$

where: $\quad 38 \mathrm{P}=$ Percentage of particles passing the $9.50-\mathrm{mm}(0.375$-in $)$ screen and $\mathrm{APOPR}_{516}=$ average percentage of original particles retained on the $8.00-\mathrm{mm}(0.3125-$ in) screen.

Percentage of particles passing the $6.35-\mathrm{mm}(0.25-\mathrm{in})$ screen [14P]:

$$
14 \mathrm{P}=516 \mathrm{P}-\mathrm{APOPR}_{14}
$$

where: $\quad 516 \mathrm{P}=$ Percentage of particles passing the $8.00-\mathrm{mm}(0.3125-\mathrm{in})$ screen and

$\mathrm{APOPR}_{14}=$ average percentage of original particles retained on the $6.35-\mathrm{mm}(0.25$-in $)$ screen.

口 Percentage of particles passing the $4.75-\mathrm{mm}(\# 4)$ screen [4P]:

$$
4 \mathrm{P}=14 \mathrm{P}-\mathrm{APOPR}_{4}
$$

where: $\quad 14 \mathrm{P}=$ Percentage of particles passing the $6.35-\mathrm{mm}(0.25-\mathrm{in})$ screen and

$\mathrm{APOPR}_{4}=$ average percentage of original particles retained on the $4.75-\mathrm{mm}(\# 4)$ screen. 
- Percentage of particles passing the pan [pan]:

$$
\mathrm{Pan}=4 \mathrm{P}-\mathrm{APOPR}_{\mathrm{pan}}=0
$$

where: $\quad 4 \mathrm{P}=$ Cumulative percentage of particles passing the $4.75-\mathrm{mm}(\# 4)$ screen and $\mathrm{APOPR}_{\mathrm{pan}}=$ average percentage of original particles retained on the pan.

The predictors defined by equations E. 23 to E. 28 were calculated for each of 20 sources and then transferred as an $l s p$ file into $A R C$. Equation E.29 was used as a check to make sure that there were no computational errors.

It should be noted, the TPOPR may be greater than 100 percent due to the fracturing of particles during testing, which may increase the number of particles retained to a number greater than the original number of particles.

\section{E.3.2.2 Transformations to Normality}

Two-dimensional scatter plots were developed to show the conditional distributions of the response variables (dilation/100 cycles and durability factor) given changes in each explanatory variable. The scatter plot matrix for the above explanatory and response variables is presented in figure E.12. Normality is achieved when the mean functions are linear and the variance functions are constant (9). As illustrated in figure E.12, there is a lack of normality between the response and explanatory variables in the inverse fitted value plots (marginal distribution plots).

Normality can sometimes be achieved or improved through transformations of the explanatory variables. In this study, explanatory variable transformations were performed using the Box-Cox method (a numerical procedure) in an attempt to improve the linearity of the relationships. Figure E.13 presents the scatter plot matrix for the transformed explanatory variables.

\section{E.3.2.3 Nonlinear and Multiple Linear Regression}

As stated previously, past studies have shown that concrete freeze-thaw durability is often a function of carbonate content. Therefore, the following general nonlinear model form was adopted: 


$$
\begin{array}{r}
\mathrm{E}(\mathrm{y} \mid \mathrm{x})=\mathrm{C} *(\text { linear combination of } 58 \mathrm{P}, 12 \mathrm{P}, 38 \mathrm{P}, 516 \mathrm{P}, 14 \mathrm{P} \text { and } 4 \mathrm{P}) \\
\text { therefore, } \\
\mathrm{E}(\mathrm{y} \mid \mathrm{x})=\mathrm{C} *\left(\alpha+\beta_{1} * 58 \mathrm{P}+\beta_{2} * 12 \mathrm{P}+\beta_{3} * 38 \mathrm{P}+\beta_{4} * 516 \mathrm{P}+\beta_{5} * 14 \mathrm{P}+\beta_{6} * 4 \mathrm{P}\right)
\end{array}
$$

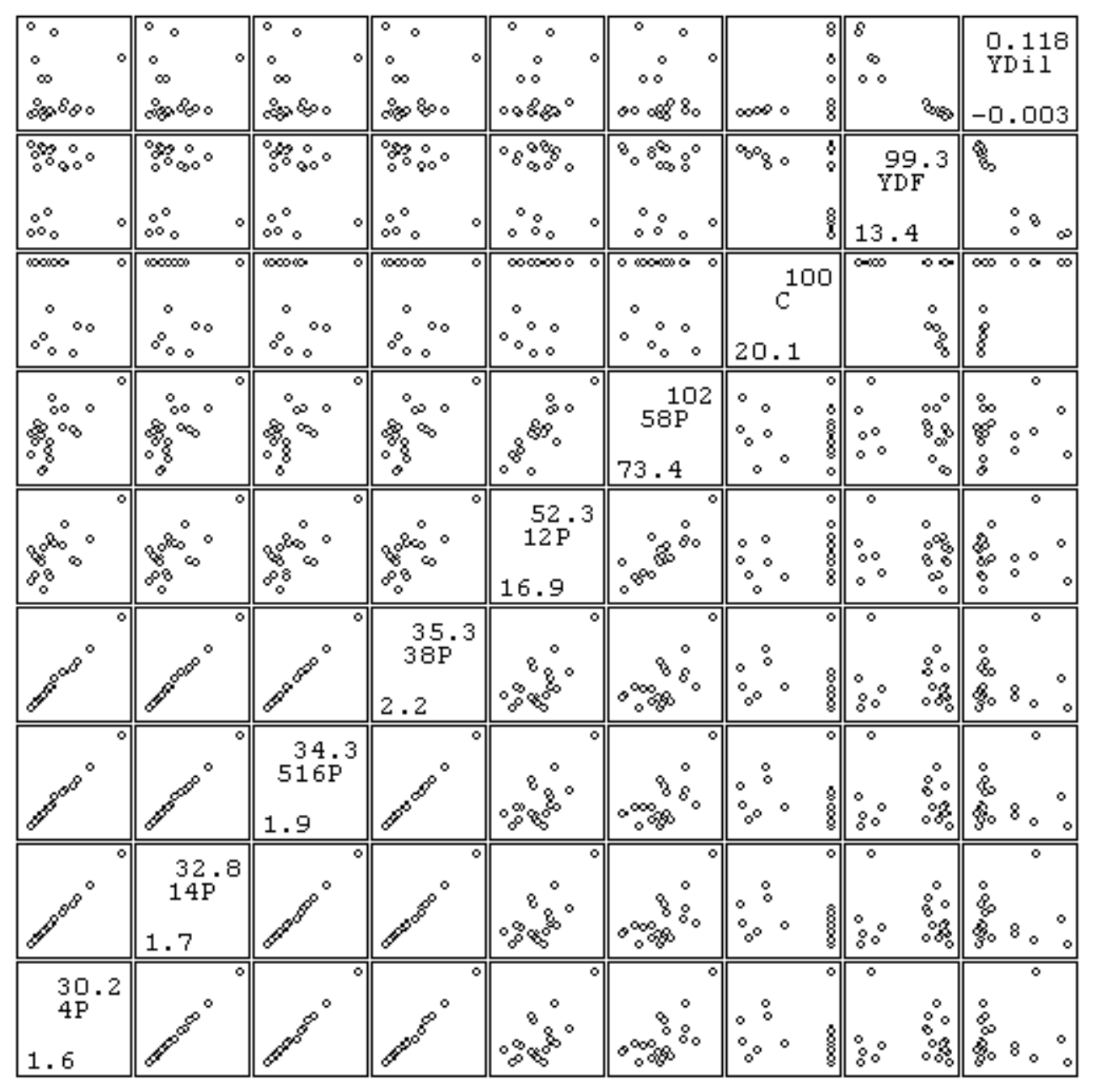

Figure E.12. Scatter plot matrix for responses and explanatory variables (percentage of particles passing, 12.5 to $19.0 \mathrm{~mm}$ [0.5 to $0.75 \mathrm{in}]$ ). 


\begin{tabular}{|c|c|c|c|c|c|c|c|c|}
\hline 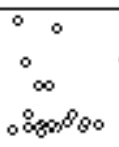 & 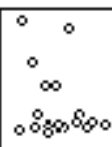 & $\begin{array}{l}0 \\
\circ{ }^{\circ} \\
{ }_{\infty}^{\infty} \\
\therefore 8 \infty\end{array}$ & 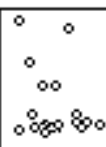 & 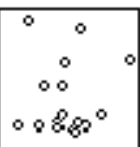 & 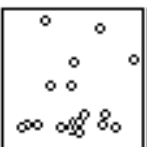 & $\begin{array}{l}8 \\
8 \\
8 \\
8\end{array}$ & 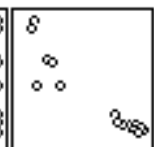 & $\begin{array}{c}0.118 \\
\text { YDil } \\
-0.003\end{array}$ \\
\hline $\begin{array}{l}\therefore \% 0 \\
\therefore\end{array}$ & $\begin{array}{l}\because \% \therefore \\
\therefore 0 \\
\therefore \circ\end{array}$ & $\begin{array}{l}\because \% 0^{\circ} \\
\therefore\end{array}$ & $\begin{array}{l}\therefore \% \circ \\
\therefore \\
\therefore \circ\end{array}$ & $\begin{array}{c}{ }^{8} 80_{0}^{\circ} \\
0_{0}^{\circ} \circ\end{array}$ & $\begin{array}{c}\theta_{0}^{\circ} \theta_{\infty}^{\circ} \\
\therefore: 0 \\
0\end{array}$ & 80 & $\begin{array}{c}99.3 \\
\text { YDF } \\
13.4\end{array}$ & $\begin{array}{ccc}\text { हैं } & & \\
& 0 & \\
& 0 & \end{array}$ \\
\hline $\begin{array}{c}0000000 \\
\therefore \circ: \\
0\end{array}$ & $\therefore \circ$ & $\begin{array}{c}\infty \infty \infty \infty \\
\therefore \circ \\
00\end{array}$ & $\begin{array}{c}\infty-\infty \times \infty \\
0 \\
\infty \circ\end{array}$ & $\begin{array}{c}0000000 \\
\circ: 0 \\
000 \\
\end{array}$ & $\begin{array}{c}0000000 \\
0 \\
0 \\
0\end{array}$ & $\begin{array}{l}31 \mathrm{e}+03 \\
\mathrm{C}^{\wedge} 1.9 \\
299 \\
\end{array}$ & 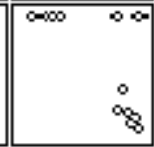 & \begin{tabular}{|llll}
$\infty$ & 0 & 0 & $\infty$ \\
0 & & & \\
8 & & & \\
\end{tabular} \\
\hline $\begin{array}{l}\because 00 \\
\therefore 8^{\circ} \\
8^{\circ} \\
8^{\circ}\end{array}$ & $\begin{array}{r}: \\
\because \% \\
8: \\
8\end{array}$ & $\begin{array}{r}{ }^{\circ} \\
88^{\circ} \\
8^{\circ}\end{array}$ & : $88^{\circ}$ & $\therefore$ & \begin{tabular}{|l|}
2.52 \\
$58 \mathrm{P}^{\wedge} 0.2$ \\
2.36 \\
\end{tabular} & $\begin{array}{l}\therefore \\
\therefore \\
\therefore\end{array}$ & $\mid \begin{array}{cc}0 & 0 \\
0 & 0 \\
0 & 8 \\
0 & \circ\end{array}$ & \begin{tabular}{||ccc} 
& 0 & \\
$\infty$ & & 0 \\
8 & 0 & 0 \\
8 & &
\end{tabular} \\
\hline $\begin{array}{l}{ }_{8}^{8} \\
\therefore 8 \\
08\end{array}$ & & & & $\begin{array}{l}2 \mathrm{P}^{14.2}{ }^{\circ} .6 \\
6.65\end{array}$ & & $\begin{array}{l}\because \\
\therefore \circ \\
\therefore\end{array}$ & $\begin{array}{cc}\therefore & 0 \% \\
\therefore & 8 \% \\
0 & 0 \\
0 & 0 \\
\end{array}$ & $8_{0}^{0}:{ }^{\circ}$ \\
\hline & & & $\begin{array}{l}8 \mathrm{P}^{8} \dot{0} \\
1.62\end{array}$ & & $\begin{array}{l}{ }^{8} \\
0_{\circ}^{\circ} \% \\
0 \%\end{array}$ & $\therefore$ & $\begin{array}{ll}\therefore & 8 \% \\
\therefore & \circ\end{array}$ & \begin{tabular}{|lll}
8 & & \\
8 & & \\
8 & 8 & 0 \\
8 & 8 & 0
\end{tabular} \\
\hline & & 1.45 & & & 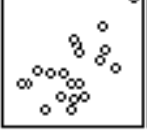 & $\therefore$ & $\begin{array}{ll}\therefore & 8 \\
\therefore & \therefore 8 \\
\therefore & \circ\end{array}$ & 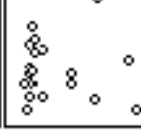 \\
\hline & 1.3 & & & $\begin{array}{l}08^{\circ} \\
\circ 0^{\circ} \\
\circ:\end{array}$ & $\begin{array}{l}8^{\circ} \\
\infty_{\circ}^{\circ 00 \%} \\
0 \%\end{array}$ & $\therefore$ & $\begin{array}{ll} & \therefore \\
\therefore & \therefore 8 \\
\therefore & \therefore \\
0 & 0\end{array}$ & 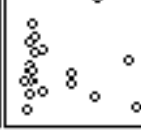 \\
\hline $4 \mathrm{P}^{\circ} 0.5$ & & & & $\because 0^{\circ}$ & $\begin{array}{l}\therefore: \\
0^{\circ 0}: \therefore \\
0 \%\end{array}$ & $\because$ & $\begin{aligned} & \therefore \\
\therefore & : 8 \\
\therefore & \therefore \%\end{aligned}$ & $\stackrel{8}{8} 8 \%$ \\
\hline
\end{tabular}

Figure E.13. Scatter plot matrix for responses and transformed explanatory variables (percentage of particles passing, 12.5 to $19.0 \mathrm{~mm}$ [0.5 to $0.75 \mathrm{in}]$ ). 
Equation E.30 was modified slightly for multiple linear regression to produce basic forms for modeling dilation and durability factor as a function of percentages of particle counts passing the specified sieves either with or without an interaction term for carbonate content:

$$
\begin{gathered}
\mathrm{E}(\mathrm{y} \mid \mathrm{x})=\alpha+\beta_{1}{ }^{*} \mathrm{C} * 38 \mathrm{P}+\beta_{2}{ }^{*} \mathrm{C} * 516 \mathrm{P}+\beta_{3}{ }^{*} \mathrm{C} * 14 \mathrm{P}+\beta_{4}{ }^{*} \mathrm{C} * 4 \mathrm{P} \\
\mathrm{E}(\mathrm{y} \mid \mathrm{x})=\alpha+\beta_{1} * 38 \mathrm{P}+\beta_{2} * 516 \mathrm{P}+\beta_{3}{ }^{*} 14 \mathrm{P}+\beta_{4} * 4 \mathrm{P}
\end{gathered}
$$

Regression analyses were performed using the model forms presented in equations E.30 through E.32 with both the transformed and untransformed (identity) explanatory variables. Numerous nonlinear and multiple linear regression models were formulated (as discussed previously in section E.2.1.3); however, only the models with the best adjusted $\mathrm{R}^{2}$ for the response variables, percentage of dilation per 100 cycles (model N1) and durability factor (model N2), were recorded in tables E.10 and E.11, respectively. As described previously, these models were reduced to eliminate predictors that have no significant effect on the mean function. The reduced models are designated with lowercase letters behind the model number (e.g., N1a, N1b, etc.).

Table E.10. Nonlinear regression models for response variable "percent dilation per 100 cycles"

\begin{tabular}{|c|c|c|c|c|}
\hline \multirow{3}{*}{ Parameter } & \multicolumn{4}{|c|}{ Estimate (Wald Test) } \\
\hline & \multicolumn{4}{|c|}{ Model Number } \\
\hline & \multicolumn{2}{|l|}{$\mathrm{N} 1$} & \multicolumn{2}{|l|}{$\mathrm{N} 1 \mathrm{a}$} \\
\hline$\alpha$ & -0.000341181 & $(-2.650)$ & -0.000354118 & $(-2.867)$ \\
\hline $58 \mathrm{P}^{0.2}$ & 0.000174131 & $(3.163)$ & 0.000177586 & $(3.329)$ \\
\hline$\frac{11}{12 \mathrm{P}^{0.67}}$ & $-5.871615 \mathrm{E}-6$ & $(-4.000)$ & $-5.712814 \mathrm{E}-6$ & $(-4.067)$ \\
\hline $38 \mathrm{P}^{0.61}$ & -0.0000550154 & $(-2.068)$ & -0.0000565347 & $(-2.190)$ \\
\hline $516 \mathrm{P}^{0.58}$ & 0.000123224 & $(2.656)$ & 0.000118035 & $(2.663)$ \\
\hline $14 \mathrm{P}^{0.5}$ & -0.0000958431 & $(-1.814)$ & -0.0000739097 & $(-2.140)$ \\
\hline $4 \mathrm{P}^{0.5}$ & 0.0000129321 & $(0.560)$ & & \\
\hline Df & \multicolumn{2}{|l|}{13} & \multicolumn{2}{|l|}{14} \\
\hline $\mathrm{N}$ & \multicolumn{2}{|l|}{20} & \multicolumn{2}{|l|}{20} \\
\hline$r^{2}$ & \multicolumn{2}{|c|}{0.8107} & \multicolumn{2}{|c|}{0.8061} \\
\hline$\hat{\sigma}$ & \multicolumn{2}{|c|}{0.025257} & \multicolumn{2}{|c|}{0.0246296} \\
\hline $\mathrm{r}_{\mathrm{adj}}^{2}$ & \multicolumn{2}{|l|}{0.700} & \multicolumn{2}{|c|}{0.717} \\
\hline $\begin{array}{l}\text { Models } \\
\text { Compared }\end{array}$ & & & \multicolumn{2}{|c|}{$(\mathrm{N} 1)-(\mathrm{N} 1 \mathrm{a})$} \\
\hline P-value & & & \multicolumn{2}{|l|}{0.5853} \\
\hline $\begin{array}{l}{ }^{\mathrm{N} 1} \mathrm{Y}=\mathrm{C}^{1.9 *} *( \\
{ }^{\mathrm{N} 1 \mathrm{a}} \mathbf{Y}=\mathbf{C}^{1.9 *}\end{array}$ & $\begin{array}{l}\mathrm{P}^{0.2}+\beta_{2} * 12 \mathrm{P}^{0.67}+ \\
\mathbf{8} \mathbf{P}^{0.2}+\beta_{2} * 12 \mathbf{P}^{0.67}\end{array}$ & $\begin{array}{l}+\beta_{3} * 38 \mathrm{P}^{0} \\
7+\beta_{3} * 38 \mathrm{P}\end{array}$ & $\begin{array}{l}\mathrm{P}^{0.58}+\beta_{5}{ }^{*} 14 \mathrm{P}^{0.5} \\
16 \mathrm{P}^{0.58}+\beta_{5} * 14 \mathrm{P}^{0}\end{array}$ & $\begin{array}{l}\left.+\beta_{6} * 4 \mathrm{P}^{0.5}\right) \\
.5)\end{array}$ \\
\hline
\end{tabular}
(percentage of particles passing, 12.5 to $19.0 \mathrm{~mm}$ [0.5 to $0.75 \mathrm{in}]$ ). 
Table E.11. Multiple linear regression models for "durability factor" (percentage of particles passing, 12.5 to $19.0 \mathrm{~mm}$ [0.5 to $0.75 \mathrm{in}]$ ).

\begin{tabular}{|c|c|c|c|c|c|c|c|c|c|}
\hline \multirow{3}{*}{\begin{tabular}{|l|} 
Variable \\
\end{tabular}} & \multicolumn{9}{|c|}{ Estimates (t-value) } \\
\hline & \multicolumn{9}{|c|}{ Model Number } \\
\hline & L2 & L2a & $\mathrm{L} 2 \mathrm{~b}$ & L2c & L2d & L2e & L2f & L2g & $\mathrm{L} 2 \mathrm{~h}$ \\
\hline$\alpha$ & $\begin{array}{c}2165.66 \\
(2.733)\end{array}$ & $\begin{array}{c}2194.42 \\
(3.310)\end{array}$ & $\begin{array}{c}2178.82 \\
(3.493)\end{array}$ & $\begin{array}{c}2156.42 \\
(3.637)\end{array}$ & $\begin{array}{c}2216.63 \\
(3.751)\end{array}$ & $\begin{array}{c}2247.27 \\
(3.943)\end{array}$ & $\begin{array}{c}2264.92 \\
(4.118)\end{array}$ & $\begin{array}{c}2345.11 \\
(4.095)\end{array}$ & $\begin{array}{c}2217.49 \\
(3.782)\end{array}$ \\
\hline $58 \mathrm{P}^{0.2} * \mathrm{C}$ & $\begin{array}{c}-0.453014 \\
(-0.194)\end{array}$ & $\begin{array}{c}-0.302439 \\
(-0.229)\end{array}$ & & & & & & & \\
\hline $12 \mathrm{P}^{0.67} * \mathrm{C}$ & $\begin{array}{c}0.0213513 \\
(0.081)\end{array}$ & & & & & & & & \\
\hline $38 \mathrm{P}^{0.61} * \mathrm{C}$ & $\begin{array}{c}6.84710 \\
(1.059)\end{array}$ & $\begin{array}{c}6.92971 \\
(1.160)\end{array}$ & $\begin{array}{c}6.77741 \\
(1.207)\end{array}$ & $\begin{array}{c}4.90117 \\
(2.734)\end{array}$ & $\begin{array}{c}4.73988 \\
(2.649)\end{array}$ & $\begin{array}{c}4.63603 \\
(2.690)\end{array}$ & $\begin{array}{c}4.52632 \\
(2.748)\end{array}$ & $\begin{array}{c}2.52554 \\
(2.427)\end{array}$ & $\begin{array}{c}3.01206 \\
(2.951)\end{array}$ \\
\hline $516 \mathrm{P}^{0.58 * \mathrm{C}}$ & $\begin{array}{c}-9.78372 \\
(-0.947)\end{array}$ & $\begin{array}{c}-9.52611 \\
(-1.036)\end{array}$ & $\begin{array}{c}-8.22333 \\
(-1.203)\end{array}$ & $\begin{array}{c}-5.96756 \\
(-2.503)\end{array}$ & $\begin{array}{l}6.10594 \\
(-2.561)\end{array}$ & $\begin{array}{c}-5.40820 \\
(-2.826)\end{array}$ & $\begin{array}{c}-5.28112 \\
(-2.889)\end{array}$ & $\begin{array}{c}-3.08762 \\
(-2.621)\end{array}$ & $\begin{array}{c}-3.61041 \\
(-3.106)\end{array}$ \\
\hline $14 \mathrm{P}^{0.5 * \mathrm{C}}$ & $\begin{array}{r}-2.42177 \\
(-0.141)\end{array}$ & $\begin{array}{r}-3.22717 \\
(-0.247)\end{array}$ & $\begin{array}{c}-5.77964 \\
(-0.898)\end{array}$ & $\begin{array}{c}-4.03206 \\
(-1.021)\end{array}$ & & & & & \\
\hline $4 \mathrm{P}^{0.5 * \mathrm{C}}$ & $\begin{array}{c}5.31704 \\
(0.533) \\
\end{array}$ & $\begin{array}{c}5.64498 \\
(0.661)\end{array}$ & $\begin{array}{c}6.57690 \\
(0.927)\end{array}$ & $\begin{array}{c}4.53999 \\
(1.142) \\
\end{array}$ & $\begin{array}{c}0.770985 \\
(0.522) \\
\end{array}$ & & & & \\
\hline $4 \mathrm{P}^{0.5}$ & $\begin{array}{c}-567.483 \\
(-0.578)\end{array}$ & $\begin{array}{c}-597.903 \\
(-0.704)\end{array}$ & $\begin{array}{c}-690.919 \\
(-0.980)\end{array}$ & $\begin{array}{c}-490.973 \\
(-1.213)\end{array}$ & $\begin{array}{c}-134.711 \\
(-0.657)\end{array}$ & $\begin{array}{c}-46.8428 \\
(-0.413)\end{array}$ & & & \\
\hline $14 \mathrm{P}^{0.5}$ & $\begin{array}{c}628.056 \\
(0.384)\end{array}$ & $\begin{array}{l}702.054 \\
(0.552)\end{array}$ & $\begin{array}{c}939.617 \\
(1.354)\end{array}$ & $\begin{array}{l}772.495 \\
(1.589)\end{array}$ & $\begin{array}{c}356.153 \\
(1.343)\end{array}$ & $\begin{array}{c}291.795 \\
(1.282)\end{array}$ & $\begin{array}{c}218.344 \\
(1.590)\end{array}$ & $\begin{array}{c}9.26094 \\
(1.451)\end{array}$ & \\
\hline $516 \mathrm{P}^{0.58}$ & $\begin{array}{c}354.196 \\
(0.383)\end{array}$ & $\begin{array}{c}327.660 \\
(0.405)\end{array}$ & $\begin{array}{c}215.650 \\
(0.355)\end{array}$ & & & & & & \\
\hline $38 \mathrm{P}^{0.61}$ & $\begin{array}{c}-365.277 \\
(-0.625)\end{array}$ & $\begin{array}{c}-370.033 \\
(-0.681)\end{array}$ & $\begin{array}{c}-360.626 \\
(-0.703)\end{array}$ & $\begin{array}{c}-184.238 \\
(-1.544)\end{array}$ & $\begin{array}{c}-136.145 \\
(-1.240)\end{array}$ & $\begin{array}{c}-153.261 \\
(-1.509)\end{array}$ & $\begin{array}{c}-135.301 \\
(-1.524)\end{array}$ & & \\
\hline $12 \mathrm{P}^{0.67}$ & $\begin{array}{l}31.9455 \\
(1.212)\end{array}$ & $\begin{array}{c}33.9394 \\
(3.875)\end{array}$ & $\begin{array}{c}34.3164 \\
(4.217)\end{array}$ & $\begin{array}{l}34.4101 \\
(4.429)\end{array}$ & $\begin{array}{c}33.2394 \\
(4.318)\end{array}$ & $\begin{array}{c}33.1330 \\
(4.442)\end{array}$ & $\begin{array}{c}32.5069 \\
(4.600)\end{array}$ & $\begin{array}{l}31.3148 \\
(4.262)\end{array}$ & $\begin{array}{c}31.5134 \\
(4.140)\end{array}$ \\
\hline $58 \mathrm{P}^{0.2}$ & $\begin{array}{c}-980.100 \\
(-2.144)\end{array}$ & $\begin{array}{c}-1005.89 \\
(-3.278)\end{array}$ & $\begin{array}{c}-1028.20 \\
(-3.736)\end{array}$ & $\begin{array}{c}-1020.47 \\
(-3.894)\end{array}$ & $\begin{array}{c}-1033.27 \\
(-3.940)\end{array}$ & $\begin{array}{c}-1039.64 \\
(-4.094)\end{array}$ & $\begin{array}{c}-1040.46 \\
(-4.235)\end{array}$ & $\begin{array}{c}-1040.08 \\
(-4.047)\end{array}$ & $\begin{array}{r}-979.265 \\
(-3.727)\end{array}$ \\
\hline Df & 7 & 8 & 9 & 10 & 11 & 12 & 13 & 14 & 15 \\
\hline $\mathrm{N}$ & 20 & 20 & 20 & 20 & 20 & 20 & 20 & 20 & \\
\hline$r^{2}$ & 0.773148 & 0.772935 & 0.77145 & 0.768256 & 0.744111 & 0.73777 & 0.734047 & 0.686552 & 0.639432 \\
\hline$\hat{\sigma}$ & 25.2546 & 23.6346 & 22.3557 & 21.3561 & 21.3967 & 20.7381 & 20.0654 & 20.9912 & 21.7504 \\
\hline $\mathrm{r}_{\mathrm{adj}}^{2}$ & 0.384 & 0.461 & 0.518 & 0.560 & 0.558 & 0.585 & 0.611 & 0.575 & 0.543 \\
\hline $\begin{array}{l}\text { Models } \\
\text { Compared }\end{array}$ & & $\begin{array}{l}\text { (N1)- } \\
\text { (N1a) }\end{array}$ & $\begin{array}{c}\text { (N1b) - } \\
(\mathrm{N} 1 \mathrm{a})\end{array}$ & $\begin{array}{c}(\mathrm{N} 1 \mathrm{c})- \\
(\mathrm{N} 1 \mathrm{~b})\end{array}$ & $\begin{array}{c}(\mathrm{N} 1 \mathrm{~d})- \\
(\mathrm{N} 1 \mathrm{c})\end{array}$ & $\begin{array}{c}(\mathrm{N} 1 \mathrm{e})- \\
(\mathrm{N} 1 \mathrm{~d})\end{array}$ & $\begin{array}{c}(\mathrm{N} 1 \mathrm{f})- \\
(\mathrm{N} 1 \mathrm{e})\end{array}$ & $\begin{array}{c}(\mathrm{N} 1 \mathrm{~g})- \\
(\mathrm{N} 1 \mathrm{f})\end{array}$ & $\begin{array}{c}(\mathrm{N} 1 \mathrm{~h})- \\
(\mathrm{N} 1 \mathrm{~g})\end{array}$ \\
\hline
\end{tabular}


Table E.11. Multiple linear regression models for "durability factor" (percentage of particles passing, 12.5 to $19.0 \mathrm{~mm}$ [0.5 to $0.75 \mathrm{in}]$ ) (continued).

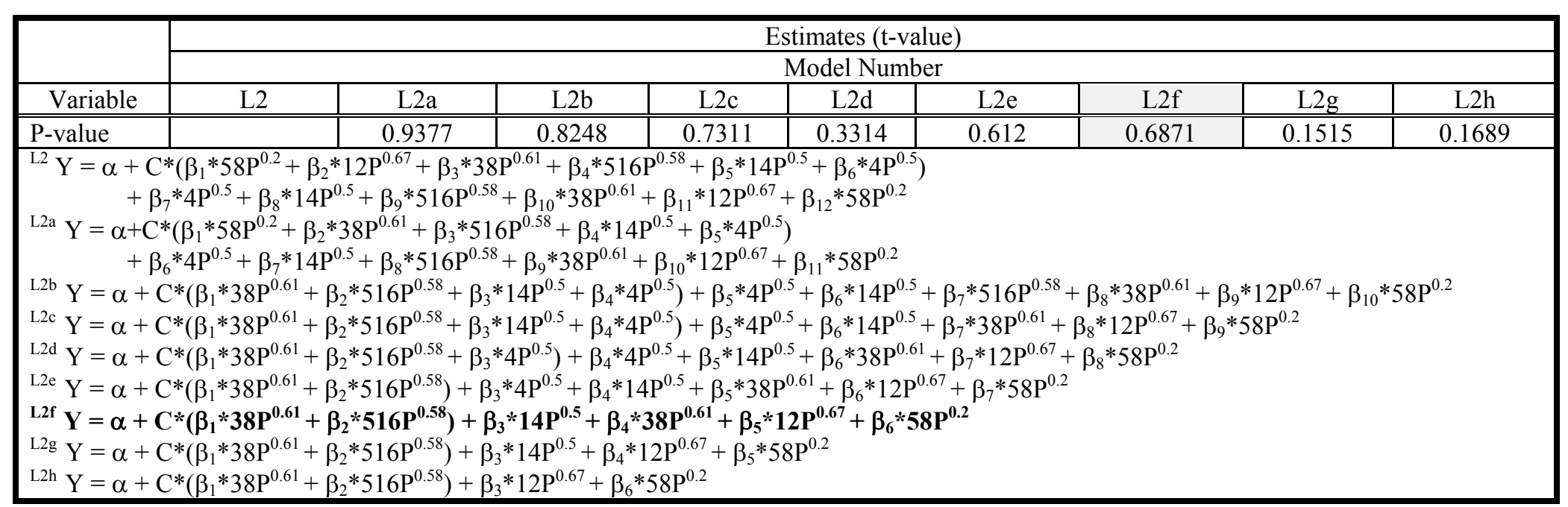




\section{E.3.2.4 Model Selection}

As described previously, the F-statistic was calculated for each comparison to determine the smallest model that adequately describes the data. As illustrated in tables E.10 and E.11, where all $\mathrm{p}$-values are greater than 0.05 , each nested model adequately represents the data. Therefore, the summary, residual, nonconstant variance and model checking plots were produced to determine which model most adequately represents the data.

The models shaded in gray in tables E.10 and E.11 (N1 and L2f) were the final models chosen, based on the plots described above. Figure E.14 presents the summary plots for models N1a and L2f. As illustrated in these plots, the correlation between the hydraulic fracture test data and the freezing and thawing test data was stronger for the particle count data than for the mass data for this size fraction. The mean function for the models illustrated in figure E.14 appears to do a fair job of representing the data.

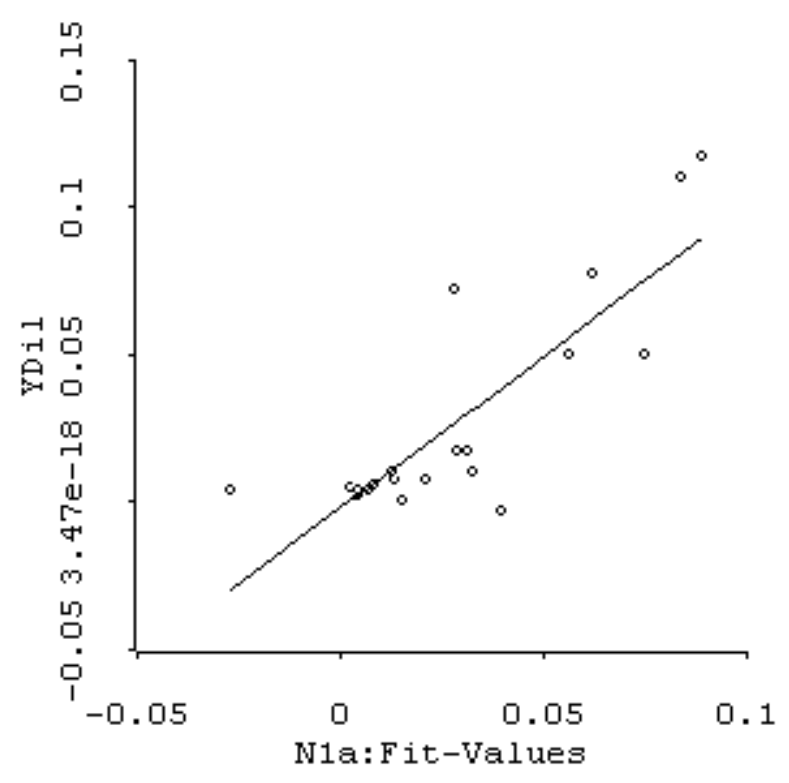

a. Model N1a.

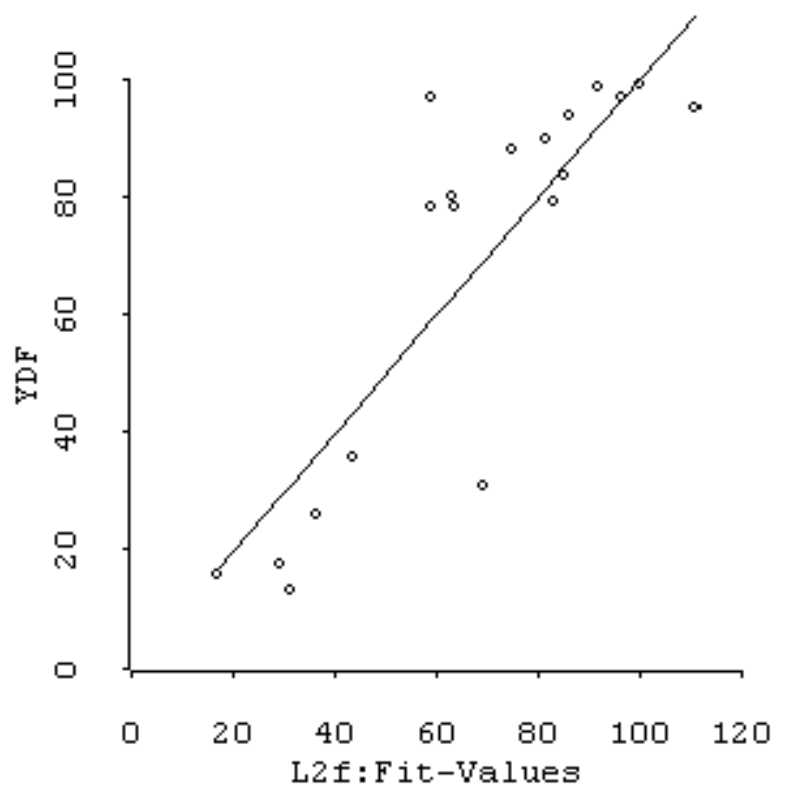

b. Model L2f.

Figure E.14. Actual versus predicted rapid freezing and thawing test results for models N1a and L2f (percentage of particles passing, 12.5 to $19.0 \mathrm{~mm}$ [0.5 to $0.75 \mathrm{in}]$ ). 


\section{E.4 Initial Size Fraction: 19.0 to $37.5 \mathrm{~mm}(0.75$ to $1.5 \mathrm{in})$}

Hydraulic fracture testing was performed on the initial size fraction 19.0 to $37.5 \mathrm{~mm}$ [0.75 to 1.5 in] using the procedures outlined in Appendix A. The POMR and POPR on specified sieves were calculated for each replicate sample, along with the APOMR and APOPR for each source, using the equations presented in section 3.5.3. Tables D.7 and D.8 (see appendix D) present the mass and particle counts retained, respectively, on the specified sieves at 0 and 50 cycles for the replicate samples for each source. The normalized mass and particle count retained data (i.e., POMR, APOMR, POPR and APOPR) are presented in tables D.9 and D.10 (see appendix D), respectively.

\section{E.4.1 Mass Retained Data}

\section{E.4.1.1 Explanatory Variables}

As stated previously, models were developed to predict percent dilation per 100 cycles of rapid freezing and thawing (dil) and durability factor (DF) as a function of the following explanatory variables:

1M: $\quad$ Percentage of mass passing the 25.0-mm (1-in) screen.

34M: $\quad$ Percentage of mass passing the $19.0-\mathrm{mm}(0.75$-in) screen.

58M: $\quad$ Percentage of mass passing the $16.0-\mathrm{mm}(0.625-\mathrm{in})$ screen.

12M: Percentage of mass passing the $12.50-\mathrm{mm}(0.5-\mathrm{in})$ screen.

38M: $\quad$ Percentage of mass passing the $9.50-\mathrm{mm}(0.375$-in) screen.

516M: $\quad$ Percentage of mass passing the $8.00-\mathrm{mm}(0.3125$-in) screen.

14M: $\quad$ Percentage of mass passing the $6.35-\mathrm{mm}(0.25$-in) screen.

4M: $\quad$ Percentage of mass passing the 4.75-mm (\#4) screen.

C: $\quad$ Percentage of carbonates present in source.

The percentage of mass passing each specified screen was calculated using the APOMR data presented in table D.9 as defined below:

a Total Percentage of Original Mass Retained [TPOMR] - see equation E.1

口 Percentage of mass passing the 25.0-mm (1-in) screen [1M]:

$$
1 \mathrm{M}=\mathrm{TPOMR}-\mathrm{APOMR}_{1}
$$


where: $\quad$ TPOMR $=$ Total percentage of original mass retained and $\mathrm{APOMR}_{1}=$ average percentage of original mass retained on the $25.0-\mathrm{mm}$ (1-in) screen.

a Percentage of mass passing the $19.0-\mathrm{mm}(0.75$-in) screen [34M]:

$$
34 \mathrm{M}=1 \mathrm{M}-\mathrm{APOMR}_{34}
$$

where: $\quad 1 \mathrm{M}=$ Percentage of mass passing the $25.0-\mathrm{mm}$ (1-in) screen and $\mathrm{APOMR}_{34}=$ average percentage of original mass retained on the $19.0-\mathrm{mm}(0.75$-in $)$ screen.

a Percentage of mass passing the $16.0-\mathrm{mm}(0.625$-in) screen [58M]:

$$
58 \mathrm{M}=34 \mathrm{M}-\mathrm{APOMR}_{58}
$$

where: $\quad 34 \mathrm{M}=$ Percentage of mass passing the 19.0 -mm $(0.75$-in) screen and $\mathrm{APOMR}_{58}=$ average percentage of original mass retained on the $16.0-\mathrm{mm}(0.625$-in) screen.

a Percentage of mass passing the 12.5 -mm (0.5-in) screen [12M] - see equation E. 16

a Percentage of mass passing the 9.50 -mm (0.375-in) screen [38M] - see equation E.17

a Percentage of mass passing the $8.00-\mathrm{mm}(0.3125$-in) screen [516M] - see equation E.3

a Percentage of mass passing the 6.35 -mm $(0.25$-in) screen $[14 \mathrm{M}]$ - see equation E.4

a Percentage of mass passing the 4.75-mm (\#4) screen [4 actual] - see equation E.5

- Percentage of mass lost due to testing $\left[\mathrm{M}_{\text {loss }}\right]-$ see equation E.6

- Percentage of mass passing the 4.75-mm (\#4) screen (adjusted for mass loss during testing) $[4 \mathrm{M}]$ - see equation E.7

a Percentage of mass passing the pan [pan]- see equation E.8 
The predictors defined by equations E.3 to E.5, E.7, E.16, E.17 and E. 33 to E. 35 were calculated for each of 19 sources and then transferred as an $l s p$ file into $A R C$. Equation E.8 was used as a check to make sure that there were no computational errors.

It should be noted that as much as one percent of the mass of a given test sample was sometimes lost during testing. As a result, the total percentage of original material mass retained during the final sieve analyses was sometimes reduced to 99 percent or more. Because of the great care taken during testing, it was assumed that the material lost during testing was probably very fine and would have passed the $4.75-\mathrm{mm}$ (\#4 sieve). Equations E.5 to E.7 were developed to account for this mass loss and attribute it to the proper particle size in the regression analysis.

\section{E.4.1.2 Transformations to Normality}

Two-dimensional scatter plots were developed to show the conditional distribution of the response variables (dilation/100 cycles and durability factor) given changes in each explanatory variable. The scatter plot matrix for the previously described explanatory and response variables is presented in figure E.15.

Normality is achieved when the mean functions are linear and the variance functions are constant (9). As illustrated in figure E.15, there is a lack of normality between the response and explanatory variables in the inverse fitted value plots (marginal distribution plots).

Normality can sometimes be achieved or improved through transformations of the explanatory variables. In this study, explanatory variable transformations were performed using the Box-Cox method (a numerical procedure) in an attempt to improve the linearity of the relationships. Figure E.16 presents the scatter plot matrix for the transformed explanatory variables.

\section{E.4.1.3 Nonlinear and Multiple Linear Regression}

As stated previously, past studies have shown that concrete freeze-thaw durability is often a function of carbonate content. Therefore, the following general nonlinear model form was 


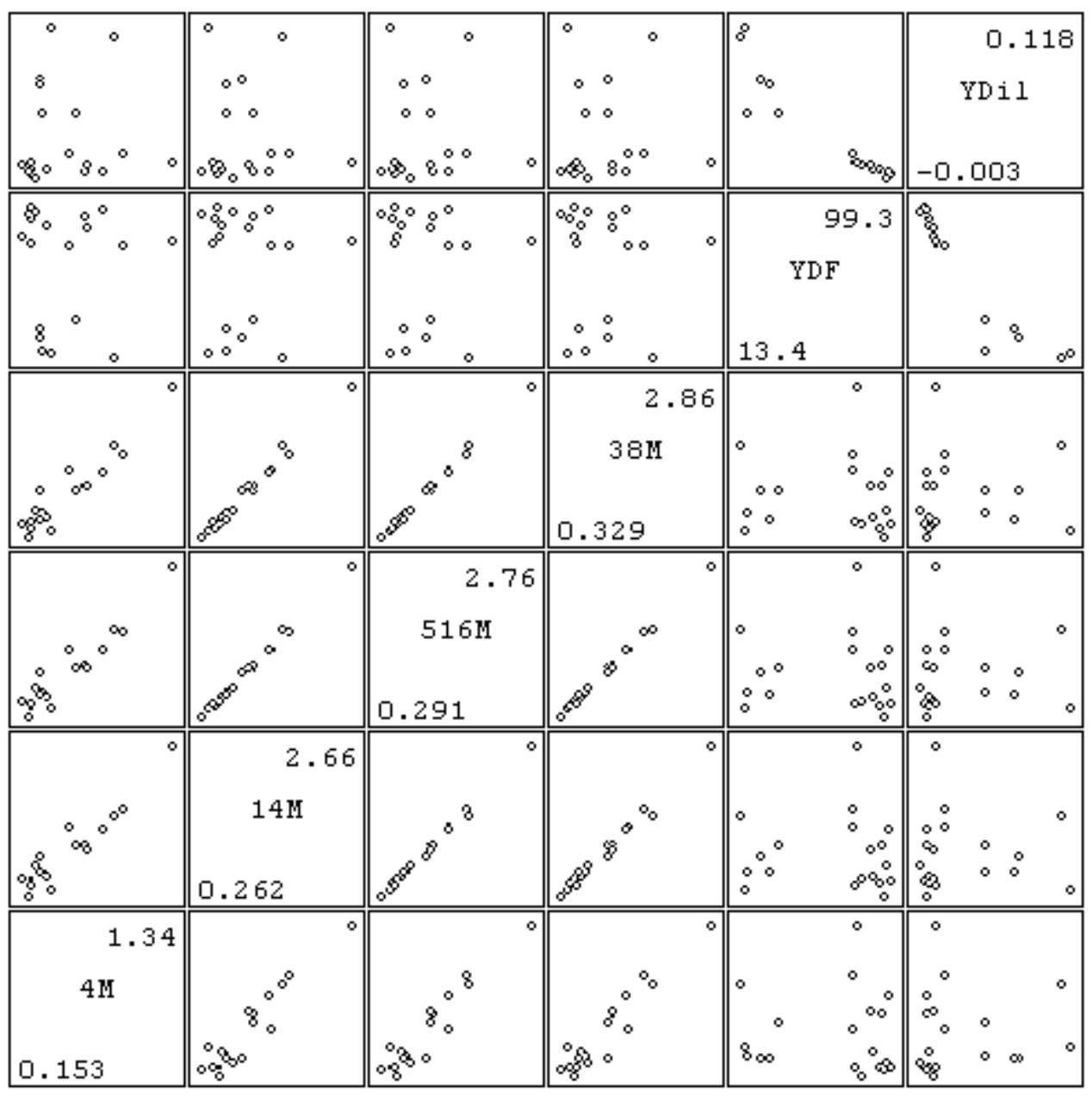

Figure E.15. Scatter plot matrix for responses and explanatory variables (percentage of mass passing, 19.0 to $37.5 \mathrm{~mm}$ [0.75 to $1.5 \mathrm{in}]$ ). 


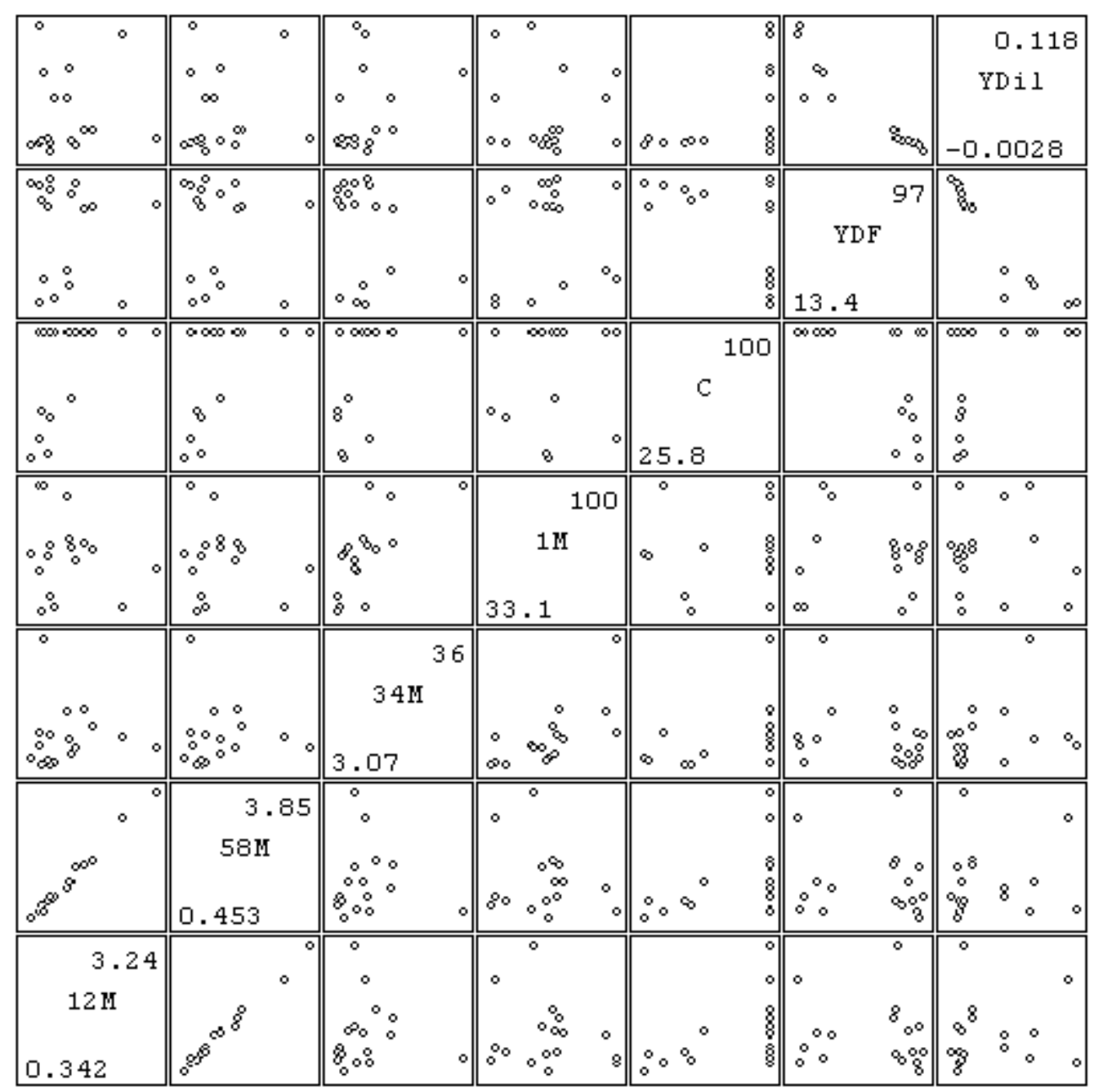

Figure E.15. Scatter plot matrix for responses and explanatory variables (percentage of mass passing, 19.0 to $37.5 \mathrm{~mm}$ [0.75 to $1.5 \mathrm{in}]$ ) (continued). 


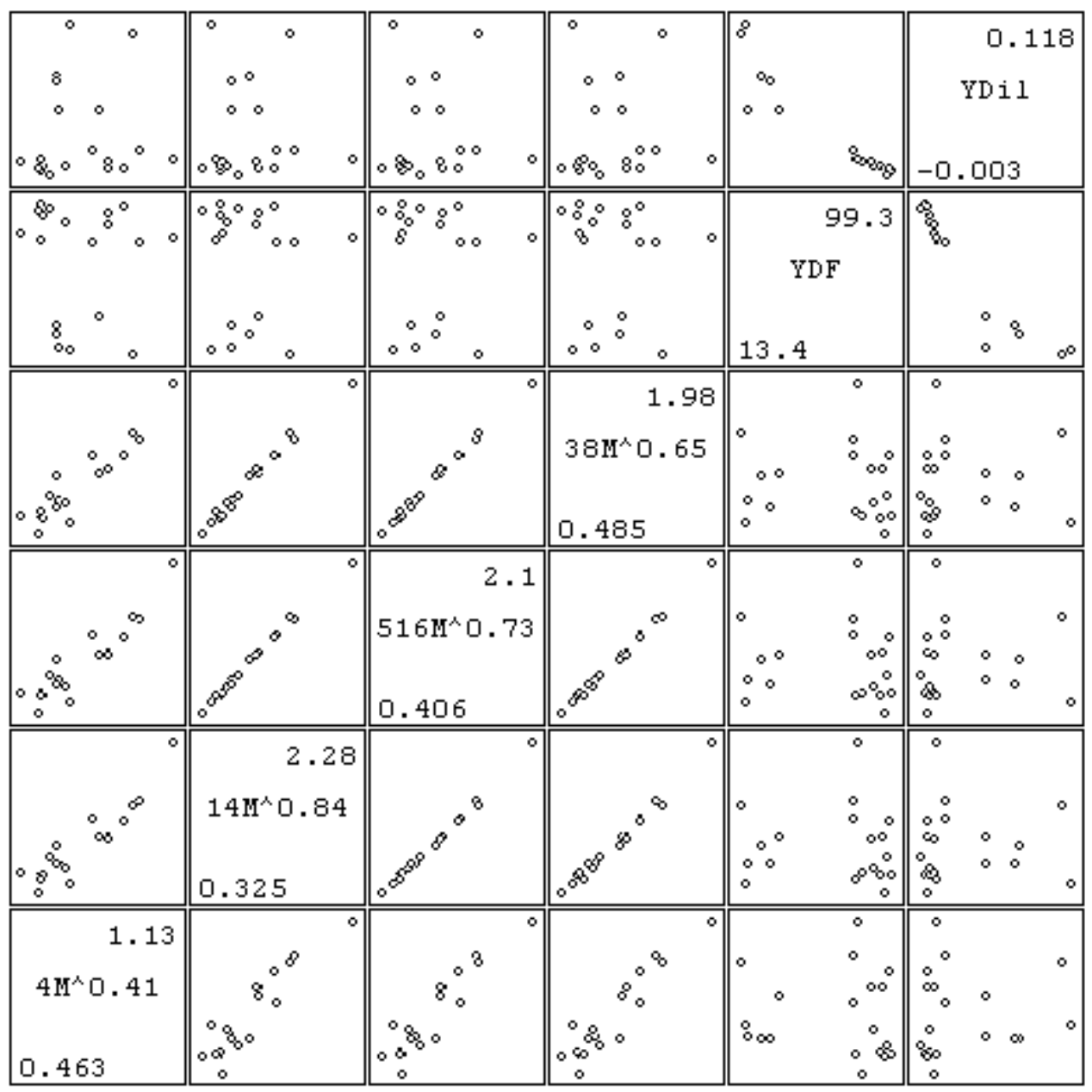

Figure E.16. Scatter plot matrix for responses and transformed explanatory variables (percentage of mass passing, 19.0 to $37.5 \mathrm{~mm}$ [0.75 to $1.5 \mathrm{in}]$ ). 


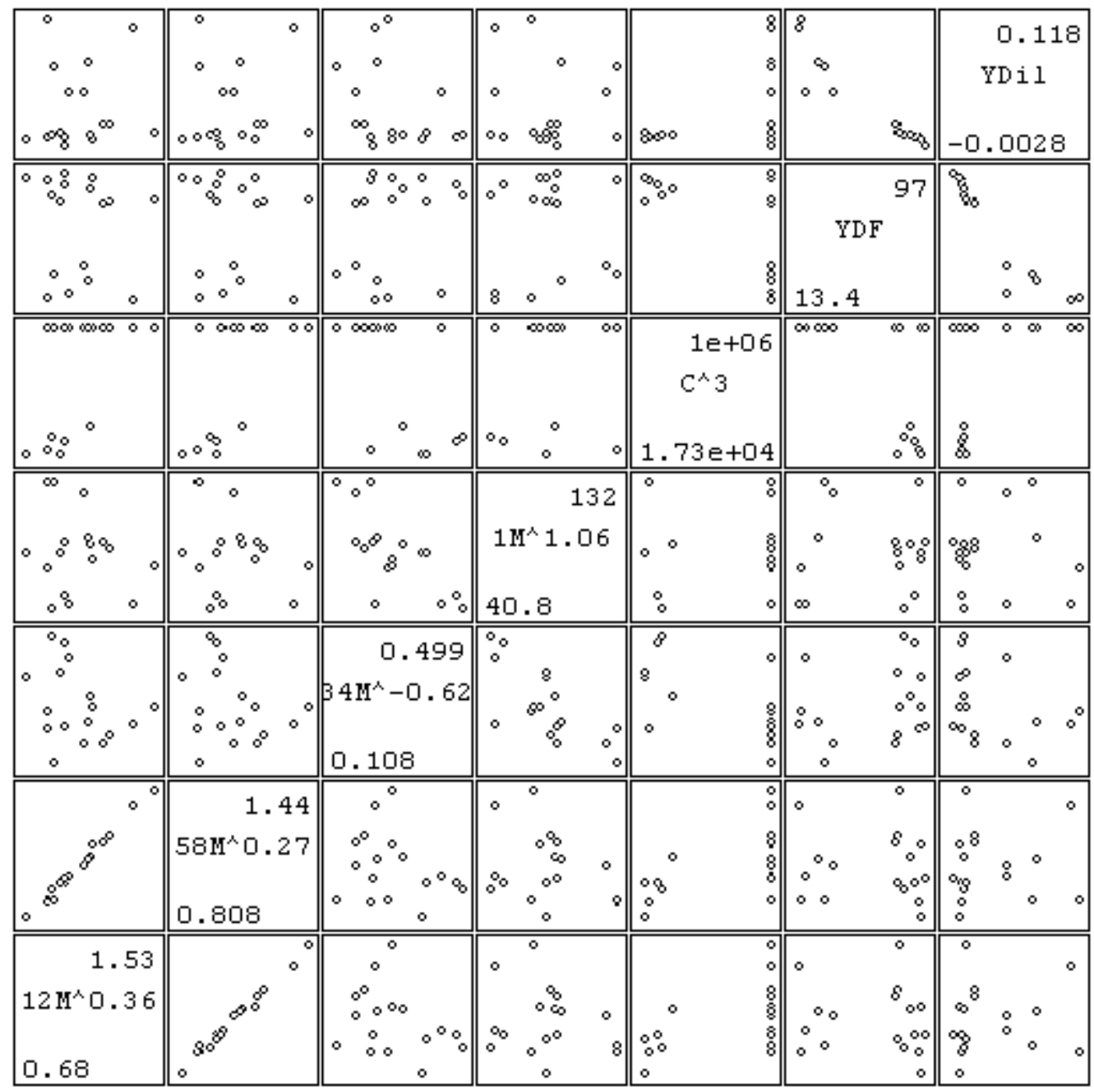

Figure E.16. Scatter plot matrix for responses and transformed explanatory variables (percentage of mass passing, 19.0 to $37.5 \mathrm{~mm}$ [0.75 to $1.5 \mathrm{in}]$ ) (continued). 
adopted:

$\mathrm{E}(\mathrm{y} \mid \mathrm{x})=\mathrm{C}^{*}($ linear combination of $1 \mathrm{M}, 34 \mathrm{M}, 58 \mathrm{M}, 12 \mathrm{M}, 38 \mathrm{M}, 516 \mathrm{M}, 14 \mathrm{M}$ and $4 \mathrm{M})$ therefore,

$$
\begin{gathered}
\mathrm{E}(\mathrm{y} \mid \mathrm{x})=\mathrm{C} *\left(\alpha+\beta_{1} * 1 \mathrm{M}+\beta_{2} * 34 \mathrm{M}+\beta_{3} * 58 \mathrm{M}+\beta_{4} * 12 \mathrm{M}+\beta_{5} * 38 \mathrm{M}+\beta_{6} * 516 \mathrm{M}+\right. \\
\left.\beta_{7} * 14 \mathrm{M}+\beta_{8} * 4 \mathrm{M}\right)
\end{gathered}
$$

Equation E.36 was modified slightly for multiple linear regression to produce basic forms for modeling dilation and durability factor as a function of percentages of mass passing the specified sieves either with or without an interaction term for carbonate content:

$$
\begin{gathered}
\mathrm{E}(\mathrm{y} \mid \mathrm{x})=\alpha+\beta_{1} * \mathrm{C} * 1 \mathrm{M}+\beta_{2}{ }^{*} \mathrm{C} * 34 \mathrm{M}+\beta_{3}{ }^{*} \mathrm{C} * 58 \mathrm{M}+\beta_{4} * \mathrm{C} * 12 \mathrm{M}+\beta_{5} * \mathrm{C} * 38 \mathrm{M}+\beta_{6} * \mathrm{C} * 516 \mathrm{M}+ \\
\beta_{7} * \mathrm{C} * 14 \mathrm{M}+\beta_{8}{ }^{*} \mathrm{C} * 4 \mathrm{M} \\
\mathrm{E}(\mathrm{y} \mid \mathrm{x})=\alpha+\beta_{1} * 1 \mathrm{M}+\beta_{2} * 34 \mathrm{M}+\beta_{3} * 58 \mathrm{M}+\beta_{4} * 12 \mathrm{M}+\beta_{5} * 38 \mathrm{M}+\beta_{6} * 516 \mathrm{M}+ \\
\beta_{7} * 14 \mathrm{M}+\beta_{8} * 4 \mathrm{M}
\end{gathered}
$$

Regression analyses were performed using the model forms presented in equations E.36 through E.38 with both the transformed and untransformed (identity) explanatory variables. Numerous nonlinear and multiple linear regression models were formulated in the manner described previously in section E.2.1.3; however, only the models with the best adjusted $\mathrm{R}^{2}$ for the response variables (percentage of dilation per 100 cycles [model L1] and durability factor [model N2]), were recorded in tables E.12 and E.13, respectively.

As described previously, these models were reduced to eliminate predictors that have no significant effect on the mean function. The reduced models are designated with lowercase letters behind the model number (e.g., N1a, N1b, etc.).

\section{E.4.1.4 Model Selection}

The F-statistic was calculated for each comparison to identify the most compact model that adequately represents the data. As illustrated in tables E.12 and E.13, where all p-values are greater than 0.05 , each nested model adequately represents the data. Therefore, as described in 
previous subsections, the summary, residual, nonconstant variance and model checking plots were produced to identify the model that best represents the data.

Table E.12. Nonlinear regression models for response variable "percent dilation per 100 cycles" (percentage of mass passing, 19.0 to $37.5 \mathrm{~mm}$ [0.75 to $1.5 \mathrm{in}]$ ).

\begin{tabular}{|c|c|c|c|c|c|c|}
\hline \multirow{3}{*}{ Variable } & \multicolumn{6}{|c|}{ Estimates (Wald Statistic) [p-value] } \\
\hline & \multicolumn{6}{|c|}{ Model Number } \\
\hline & N1 & N1a & N1b & $\mathrm{N} 1 \mathrm{c}$ & N1a* & N1a** \\
\hline$\alpha$ & $\begin{array}{c}-3.333247 \mathrm{E}-8 \\
(-0.680) \\
{[0.4967]}\end{array}$ & $\begin{array}{c}-1.029989 \mathrm{E}-8 \\
(-0.587) \\
{[0.5573]}\end{array}$ & $\begin{array}{c}-2.049791 \mathrm{E}-8 \\
(-1.247) \\
{[0.2125]}\end{array}$ & $\begin{array}{c}-2.063279 \mathrm{E}-8 \\
(-1.174) \\
{[0.2406]}\end{array}$ & $\begin{array}{c}6.714711 \mathrm{E}-9 \\
(0.568) \\
{[0.5703]}\end{array}$ & $\begin{array}{c}2.724195 \mathrm{E}-8 \\
(1.864) \\
{[0.0624]} \\
\end{array}$ \\
\hline $1 \mathrm{M}$ & $\begin{array}{c}3.718536 \mathrm{E}-10 \\
(0.506) \\
{[0.6131]}\end{array}$ & & & & & \\
\hline $34 \mathrm{M}$ & $\begin{array}{c}1.253540 \mathrm{E}-9 \\
(1.053) \\
{[0.2923]}\end{array}$ & $\begin{array}{c}1.750269 \mathrm{E}-9 \\
(2.696) \\
{[0.0070]}\end{array}$ & $\begin{array}{c}2.007145 \mathrm{E}-9 \\
(3.120) \\
{[0.0018]}\end{array}$ & $\begin{array}{c}1.860166 \mathrm{E}-9 \\
(2.729) \\
{[0.0063]}\end{array}$ & $\begin{array}{c}1.493469 \mathrm{E}-9 \\
(3.595) \\
{[0.0003]}\end{array}$ & $\begin{array}{c}1.112264 \mathrm{E}-9 \\
(2.702) \\
{[0.0069]}\end{array}$ \\
\hline $58 \mathrm{M}$ & $\begin{array}{c}-2.231705 \mathrm{E}-7 \\
(-3.344) \\
{[0.0008]}\end{array}$ & $\begin{array}{c}-2.235224 \mathrm{E}-7 \\
(-3.469) \\
{[0.0005]}\end{array}$ & $\begin{array}{c}-1.611324 \mathrm{E}-7 \\
(-3.428) \\
{[0.0006]}\end{array}$ & $\begin{array}{c}-1.581656 \mathrm{E}-7 \\
(-3.149) \\
{[0.0016]}\end{array}$ & $\begin{array}{c}-2.824751 \mathrm{E}-7 \\
(-6.546) \\
{[0.0000]}\end{array}$ & $\begin{array}{c}-2.888512 \mathrm{E}-7 \\
(-7.600) \\
{[0.0000]}\end{array}$ \\
\hline $12 \mathrm{M}$ & $\begin{array}{c}2.047589 \mathrm{E}-7 \\
(1.385) \\
{[0.1662]} \\
\end{array}$ & $\begin{array}{c}1.920152 \mathrm{E}-7 \\
(1.365) \\
{[0.1724]}\end{array}$ & & & $\begin{array}{c}3.648412 \mathrm{E}-7 \\
(3.716) \\
{[0.0002]}\end{array}$ & $\begin{array}{c}4.509314 \mathrm{E}-7 \\
(4.679) \\
{[0.0000]}\end{array}$ \\
\hline $38 \mathrm{M}$ & $\begin{array}{c}-1.088391 \mathrm{E}-6 \\
(-1.914) \\
{[0.0556]}\end{array}$ & $\begin{array}{c}-8.837291 \mathrm{E}-7 \\
(-2.291) \\
{[0.0220]}\end{array}$ & $\begin{array}{c}-7.628513 \mathrm{E}-7 \\
(-1.962) \\
{[0.0497]}\end{array}$ & $\begin{array}{c}-9.375310 \mathrm{E}-7 \\
(-2.339) \\
{[0.0193]}\end{array}$ & $\begin{array}{c}-5.631620 \mathrm{E}-7 \\
(-2.200) \\
{[0.0278]}\end{array}$ & $\begin{array}{c}-4.996830 \mathrm{E}-7 \\
(-2.202) \\
{[0.0276]}\end{array}$ \\
\hline $516 \mathrm{M}$ & $\begin{array}{c}3.492742 \mathrm{E}-6 \\
(3.073) \\
{[0.0021]}\end{array}$ & $\begin{array}{c}3.125364 \mathrm{E}-6 \\
(3.704) \\
{[0.0002]}\end{array}$ & $\begin{array}{c}3.403923 \mathrm{E}-6 \\
(4.016) \\
{[0.0001]}\end{array}$ & $\begin{array}{c}3.696021 \mathrm{E}-6 \\
(4.165) \\
{[0.0000]}\end{array}$ & $\begin{array}{c}2.102003 \mathrm{E}-6 \\
(3.578) \\
{[0.0003]}\end{array}$ & $\begin{array}{c}1.557812 \mathrm{E}-6 \\
(2.670) \\
{[0.0076]}\end{array}$ \\
\hline $14 \mathrm{M}$ & $\begin{array}{c}-2.415139 \mathrm{E}-6 \\
(-3.895) \\
{[0.0001]}\end{array}$ & $\begin{array}{c}-2.241926 \mathrm{E}-6 \\
(-4.493) \\
{[0.0000]}\end{array}$ & $\begin{array}{c}-2.520110 \mathrm{E}-6 \\
(-5.345) \\
{[0.0000]}\end{array}$ & $\begin{array}{c}-2.600291 \mathrm{E}-6 \\
(-5.183) \\
{[0.0000]}\end{array}$ & $\begin{array}{c}-1.675012 \mathrm{E}-6 \\
(-4.873) \\
{[0.0000]}\end{array}$ & $\begin{array}{c}-1.277203 \mathrm{E}-6 \\
(-3.532) \\
{[0.0004]} \\
\end{array}$ \\
\hline $4 \mathrm{M}$ & $\begin{array}{c}6.577298 \mathrm{E}-8 \\
(1.444) \\
{[0.1489]} \\
\end{array}$ & $\begin{array}{c}6.912045 \mathrm{E}-8 \\
(1.588) \\
{[0.1123]} \\
\end{array}$ & $\begin{array}{c}7.579290 \mathrm{E}-8 \\
(1.693) \\
{[0.0905]} \\
\end{array}$ & & $\begin{array}{c}1.183342 \mathrm{E}-7 \\
(3.950) \\
{[0.0001]} \\
\end{array}$ & $\begin{array}{c}1.134147 \mathrm{E}-7 \\
(4.294) \\
{[0.0000]} \\
\end{array}$ \\
\hline$\overline{\mathrm{Df}}$ & 10 & 11 & 12 & 13 & 10 & 9 \\
\hline $\mathrm{N}$ & 19 & 19 & 19 & 19 & 18 & 17 \\
\hline $\mathrm{r}^{2}$ & 0.9397 & 0.9381 & 0.9276 & 0.9104 & 0.9775 & 0.9844 \\
\hline$\hat{\sigma}$ & 0.0162562 & 0.0156966 & 0.0162508 & 0.0173773 & 0.00993408 & 0.00871924 \\
\hline $\mathrm{r}_{\mathrm{adj}}^{2}$ & 0.879 & 0.883 & 0.877 & 0.861 & 0.957 & 0.970 \\
\hline Models C & mpared: & $(\mathrm{N} 1 \mathrm{a})-(\mathrm{N} 1)$ & $\begin{array}{c}\text { (N1b) - } \\
\text { (N1a) }\end{array}$ & $(\mathrm{N} 1 \mathrm{c})-(\mathrm{N} 1 \mathrm{~b})$ & & \\
\hline P-value & & 0.6240 & 0.1996 & 0.1163 & & \\
\hline $\begin{array}{l}{ }^{\mathrm{N} 1} \mathrm{Y}=\mathrm{C}^{3} \\
{ }^{\mathrm{N} 1 \mathrm{a}} \mathrm{Y}=\mathrm{C} \\
{ }^{\mathrm{N} 1 \mathrm{~b}} \mathrm{Y}=\mathrm{C} \\
{ }^{\mathrm{N} 1 \mathrm{c}} \mathrm{Y}=\mathrm{C}\end{array}$ & $\begin{array}{l}\left(\alpha+\beta_{1} * 1 M+\beta\right. \\
*\left(\alpha+\beta_{1} * 34 M+\right. \\
*\left(\alpha+\beta_{1} * 34 M+\right. \\
*\left(\alpha+\beta_{1} * 34 M+\right.\end{array}$ & $\begin{array}{l}34 \mathrm{M}+\beta_{3} * 58 \mathrm{M} \\
2 * 58 \mathrm{M}+\beta_{3} * 12 \\
2 * 58 \mathrm{M}+\beta_{3} * 38 \\
* 58 \mathrm{M}+\beta_{3} * 38\end{array}$ & $\begin{array}{l}\beta_{4} * 12 \mathrm{M}+\beta_{5} * 3 \\
\mathbf{I}+\beta_{4} * 38 \mathrm{M}+\beta \\
+\beta_{4} * 516 \mathrm{M}+\beta \\
+\beta_{4} * 516 \mathrm{M}+\beta\end{array}$ & $\begin{array}{l}+\beta_{6} * 516 M+ \\
516 M+\beta_{6} * 141 \\
\left.14 M+\beta_{6} * 4 M\right) \\
14 M)\end{array}$ & $\begin{array}{l}\left.* 14 \mathrm{M}+\beta_{8} * 4 \mathrm{M}\right) \\
\left.\beta_{7}^{*} 4 \mathrm{M}\right)\end{array}$ & \\
\hline
\end{tabular}

* Model N1a with case deletion (Shiely Grey Cloud [Larson]).

** Model N1a with case deletions (Shiely Grey Cloud [Larson] and Cedarville Plant). 
Table E.13. Multiple linear regression models for response variable "durability factor" (percentage of mass passing, 19.0 to $37.5 \mathrm{~mm}$ [0.75 to $1.5 \mathrm{in}]$ ).

\begin{tabular}{|c|c|c|c|}
\hline \multirow{3}{*}{ Variable } & \multicolumn{3}{|c|}{ Estimates (t-value) [p-value] } \\
\hline & \multicolumn{3}{|c|}{ Model Number } \\
\hline & L2 & $\mathrm{L} 2 \mathrm{a}$ & L2b \\
\hline$\alpha$ & $\begin{array}{c}87.4491 \\
(9.570) \\
{[0.0000]}\end{array}$ & $\begin{array}{l}87.5813 \\
(10.034) \\
{[0.0000]}\end{array}$ & $\begin{array}{l}86.9953 \\
(10.203) \\
{[0.0000]}\end{array}$ \\
\hline $1 \mathrm{M}^{1.06} * \mathrm{C}^{3}$ & $\begin{array}{c}-1.810613 \mathrm{E}-6 \\
(-2.281) \\
{[0.0457]}\end{array}$ & $\begin{array}{c}-1.794687 \mathrm{E}-6 \\
(-2.370) \\
0.0371]\end{array}$ & $\begin{array}{c}-2.185788 \mathrm{E}-6 \\
(-4.108) \\
{[0.0015]}\end{array}$ \\
\hline $34 \mathrm{M}^{-0.62 * \mathrm{C}^{3}}$ & $\begin{array}{c}-0.000485517 \\
(-2.364) \\
{[0.0397]}\end{array}$ & $\begin{array}{c}-0.000484275 \\
(-2.466) \\
{[0.0314]}\end{array}$ & $\begin{array}{c}-0.000572332 \\
(-3.733) \\
{[0.0029]}\end{array}$ \\
\hline $58 \mathrm{M}^{0.27} * \mathrm{C}^{3}$ & $\begin{array}{c}0.00119977 \\
(3.399) \\
{[0.0068]}\end{array}$ & $\begin{array}{c}0.00119671 \\
(3.545) \\
{[0.0046]}\end{array}$ & $\begin{array}{c}0.00101968 \\
(4.364) \\
{[0.0009]}\end{array}$ \\
\hline $12 \mathrm{M}^{0.36} * \mathrm{C}^{3}$ & $\begin{array}{c}-0.000518059 \\
(-0.735) \\
{[0.4791]}\end{array}$ & $\begin{array}{c}-0.000494911 \\
(-0.740) \\
{[0.4747]}\end{array}$ & \\
\hline $38 \mathrm{M}^{0.65} * \mathrm{C}^{3}$ & $\begin{array}{c}0.00362540 \\
(2.986) \\
{[0.0137]}\end{array}$ & $\begin{array}{c}0.00354124 \\
(3.164) \\
{[0.0090]}\end{array}$ & $\begin{array}{c}0.00393516 \\
(4.074) \\
{[0.0015]}\end{array}$ \\
\hline $516 \mathrm{M}^{0.73 * \mathrm{C}^{3}}$ & $\begin{array}{c}-0.00797341 \\
(-2.778) \\
{[0.0195]}\end{array}$ & $\begin{array}{c}-0.00786667 \\
(-2.895) \\
{[0.0146]}\end{array}$ & $\begin{array}{c}-0.00922628 \\
(-4.697) \\
{[0.0005]}\end{array}$ \\
\hline $14 \mathrm{M}^{0.84} * \mathrm{C}^{3}$ & $\begin{array}{c}0.00389911 \\
(2.771) \\
{[0.0197]}\end{array}$ & $\begin{array}{c}0.00387102 \\
(2.884) \\
{[0.0149]}\end{array}$ & $\begin{array}{c}0.00458659 \\
(5.023) \\
{[0.0003]}\end{array}$ \\
\hline $4 \mathrm{M}^{0.41} * \mathrm{C}^{3}$ & $\begin{array}{c}0.0000225599 \\
(0.260) \\
{[0.8004]}\end{array}$ & & \\
\hline$\overline{\mathrm{Df}}$ & 10 & 11 & 12 \\
\hline $\mathrm{N}$ & 19 & 19 & 19 \\
\hline $\mathrm{r}^{2}$ & 0.795667 & 0.79429 & 0.784045 \\
\hline$\hat{\sigma}$ & 19.6509 & 18.7995 & 18.4419 \\
\hline $\mathrm{r}_{\mathrm{adj}}^{2}$ & 0.632 & 0.663 & 0.676 \\
\hline $\begin{array}{l}\text { Models } \\
\text { Compared }\end{array}$ & & $(\mathrm{L} 1)-(\mathrm{L} 1 \mathrm{a})$ & $(\mathrm{L} 1 \mathrm{~b})-(\mathrm{L} 1 \mathrm{a})$ \\
\hline P-value & & 0.8005 & 0.4747 \\
\hline $\begin{array}{r}{ }^{\mathrm{L} 2 \mathrm{Y}}=\alpha+\mathrm{C}^{3} \\
\beta_{5} * 38 \mathrm{M} \\
{ }^{\mathrm{L} 2 \mathrm{a}} \mathrm{Y}=\alpha+\mathrm{C} \\
\beta_{5} * 38 \mathrm{M} \\
{ }^{\mathbf{L} b \mathbf{b}} \mathbf{Y}=\alpha+\mathbf{C} \\
\beta_{5} * \mathbf{5 1 6}\end{array}$ & $\begin{array}{l}\mathrm{M}^{1.06}+\beta_{2} * 34 \mathrm{M} \\
3_{6} * 516 \mathrm{M}^{0.73}+\beta_{7} \\
1 \mathrm{M}^{1.06}+\beta_{2} * 34 \mathrm{M} \\
3_{6} * 516 \mathrm{M}^{0.73}+\beta_{7} \\
\mathbf{1 M}^{\mathbf{1 . 0 6}}+\beta_{2} * \mathbf{3 4 I} \\
\left.\beta_{6} \mathbf{6}^{* 14} \mathbf{M}^{\mathbf{0 . 8 4}}\right)\end{array}$ & $\begin{array}{l}+\beta_{3} * 58 \mathrm{M}^{0.27}+ \\
\mathrm{M}^{0.84}+\beta_{8} * 4 \mathrm{M}^{0.2} \\
+\beta_{3} * 58 \mathrm{M}^{0.27}+ \\
\left.\mathbf{M}^{0.84}\right) \\
+\beta_{3} * \mathbf{5 8 M}^{\mathbf{0 . 2 7}}+\end{array}$ & $\begin{array}{l}\mathrm{M}^{0.36}+ \\
\mathrm{M}^{0.36}+ \\
\mathbf{8 M}^{\mathbf{0 . 6 5}+}\end{array}$ \\
\hline
\end{tabular}


The models shaded in gray in tables E.12 and E.13 (N1a and L2b) are the final models chosen based on these model checking plots. Figure E.17 illustrates the summary plots for models N1a* and L2b. As illustrated in these figures, there is a strong correlation between the cumulative percentage of mass passing from hydraulic fracture testing and the rapid freezing and thawing test results.

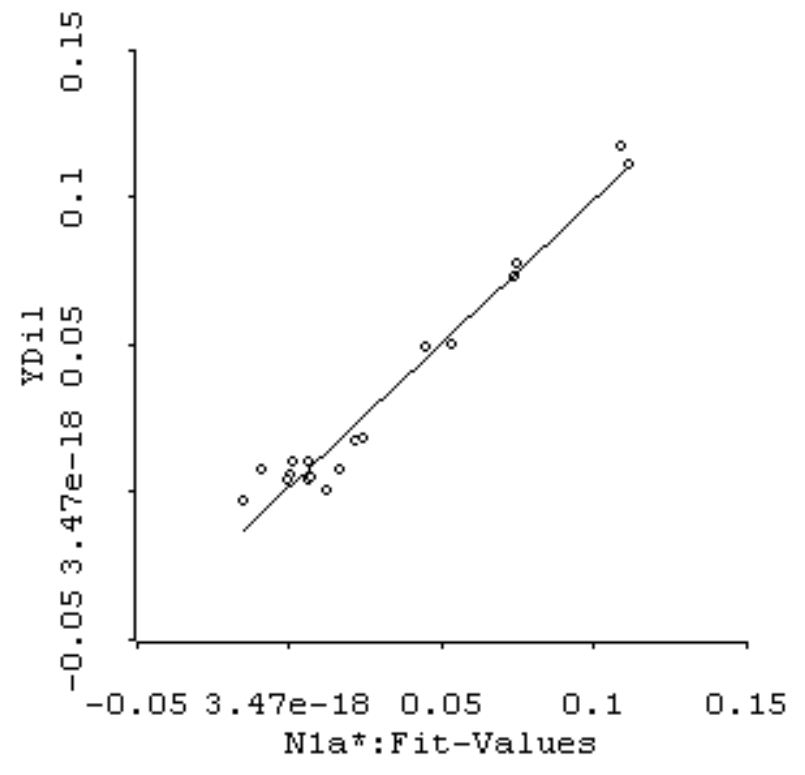

a. Model N1a*.

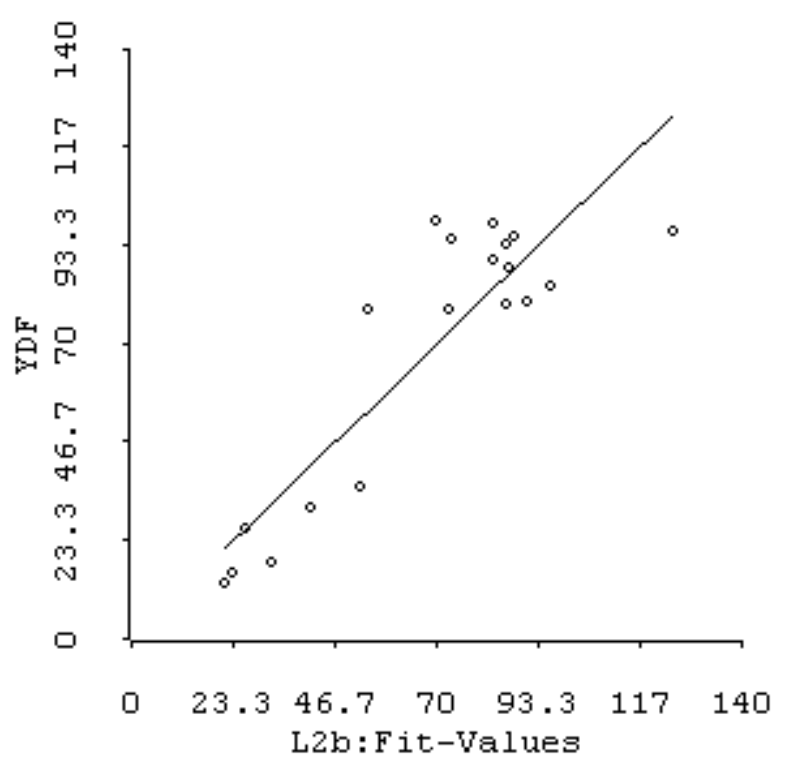

b. Model L2b.

Figure E.17. Actual versus predicted rapid freezing and thawing test results for models N1a* and L $2 \mathrm{~b}$ (percentage of mass passing, 19.0 to $37.5 \mathrm{~mm}$ [0.75 to $1.5 \mathrm{in}]$ ).

\section{E.4.2 Particle Count Data}

\section{E.4.2.1 Explanatory Variables}

As stated previously, models were developed to predict percent dilation per 100 cycles of rapid freezing and thawing (dil) and durability factor (DF) as a function of the following explanatory variables:

1P: $\quad$ Percentage of particles passing the 25.0-mm (1-in) screen.

34P: $\quad$ Percentage of particles passing the $19.0-\mathrm{mm}(0.75$-in) screen.

58P: $\quad$ Percentage of particles passing the 16.0 -mm $(0.625$-in) screen. 
12P: $\quad$ Percentage of particles passing the $12.50-\mathrm{mm}(0.5$-in $)$ screen.

38P: $\quad$ Percentage of particles passing the $9.50-\mathrm{mm}(0.375-\mathrm{in})$ screen.

516P: Percentage of particles passing the $8.00-\mathrm{mm}(0.3125$-in) screen.

14P: $\quad$ Percentage of particles passing the $6.35-\mathrm{mm}(0.25$-in) screen.

4P: $\quad$ Percentage of particles passing the 4.75-mm (\#4) screen.

C: $\quad$ Percentage of carbonates present in source.

The cumulative percentage of particles passing each specified screen was calculated using the APOPR data presented in table D.10 and defined below:

a Total Percentage of Original Particles Retained [TPOPR] - see equation 4.22

a Percentage of particles passing the 25.0-mm (1-in) screen [1P]:

$$
1 \mathrm{P}=\mathrm{TPOPR}-\mathrm{APOPR}_{1}
$$

where: $\quad$ TPOPR $=$ Total percentage of original particles retained and

$\mathrm{APOPR}_{1}=$ average percentage of original particles retained on the $25.0-\mathrm{mm}$ (1-in) screen.

a Percentage of particles passing the 19.0-mm (0.75-in) screen [34P]:

$$
34 \mathrm{P}=1 \mathrm{P}-\mathrm{APOPR}_{34}
$$

where: $\quad 1 \mathrm{P}=$ Percentage of particles passing the $25.0-\mathrm{mm}$ (1-in) screen and

$\mathrm{APOPR}_{34}=$ average percentage of original particles retained on the $19.0-\mathrm{mm}(0.75$-in $)$ screen.

a Percentage of particles passing the $16.0-\mathrm{mm}(0.625$-in) screen [58P]:

$$
58 \mathrm{P}=34 \mathrm{P}-\mathrm{APOPR}_{58}
$$

where: $\quad 34 \mathrm{P}=$ Percentage of particles passing the $19.0-\mathrm{mm}(0.75$-in) screen and

$\mathrm{APOPR}_{58}=$ average percentage of original particles retained on the $16.0-\mathrm{mm}(0.625$-in $)$ screen.

- Percentage of particles passing the 12.5 -mm ( 0.5 -in) screen [12P] - see equation E. 24

- Cumulative percentage of particles passing the 9.50 -mm (0.375-in) screen [38P] - see equation E. 25

- Percentage of particles passing the 8.00-mm (0.3125-in) screen [516P] - see equation E.26

- Percentage of particles passing the 6.35 -mm (0.25-in) screen [14P] - see equation E.27 
a Percentage of particles passing the 4.75-mm (\#4) screen [4P] - see equation E.28

口 Percentage of particles passing the pan [pan] - see equation E.29

The predictors defined by equations E.24 through E.28 and E.39 through E.41 were calculated for each of 19 sources and then transferred as an lsp file into $A R C$. Equation E.29 was used as a check to make sure that there were no computational errors.

It should be noted, the TPOPR may be greater than 100 percent due to the fracturing of particles during testing, which may increase the number of particles retained to a number greater than the original number of particles.

\section{E.4.2.2 Transformations to Normality}

Two-dimensional scatter plots were developed to show the conditional distributions of the response variables (dilation/100 cycles and durability factor) given changes in each explanatory variable. The scatter plot matrix for the above explanatory and response variables is presented in figure E.18. Normality is achieved when the mean functions are linear and the variance functions are constant (9). As illustrated in figure E.18, there is a lack of normality between the response and explanatory variables in the inverse fitted value plots (marginal distribution plots).

Normality can sometimes be achieved or improved through transformations of the explanatory variables. In this study, explanatory variable transformations were performed using the Box-Cox method (a numerical procedure) in an attempt to improve the linearity of the relationships.

Figure E.19 presents the scatter plot matrix for the transformed explanatory variables.

\section{E.4.2.3 Nonlinear and Multiple Linear Regression}

As stated previously, past studies have shown that carbonates are typically deleterious in nature. Therefore, the following general nonlinear model form was adopted:

$$
\begin{array}{r}
\mathrm{E}(\mathrm{y} \mid \mathrm{x})=\mathrm{C} *(\text { linear combination of 58P, 12P, 38P, 516P, 14P and 4P) } \\
\text { therefore, } \\
\mathrm{E}(\mathrm{y} \mid \mathrm{x})=\mathrm{C}^{*}\left(\alpha+\beta_{1} * 58 \mathrm{P}+\beta_{2} * 12 \mathrm{P}+\beta_{3} * 38 \mathrm{P}+\beta_{4} * 516 \mathrm{P}+\beta_{5} * 14 \mathrm{P}+\beta_{6} * 4 \mathrm{P}\right)
\end{array}
$$




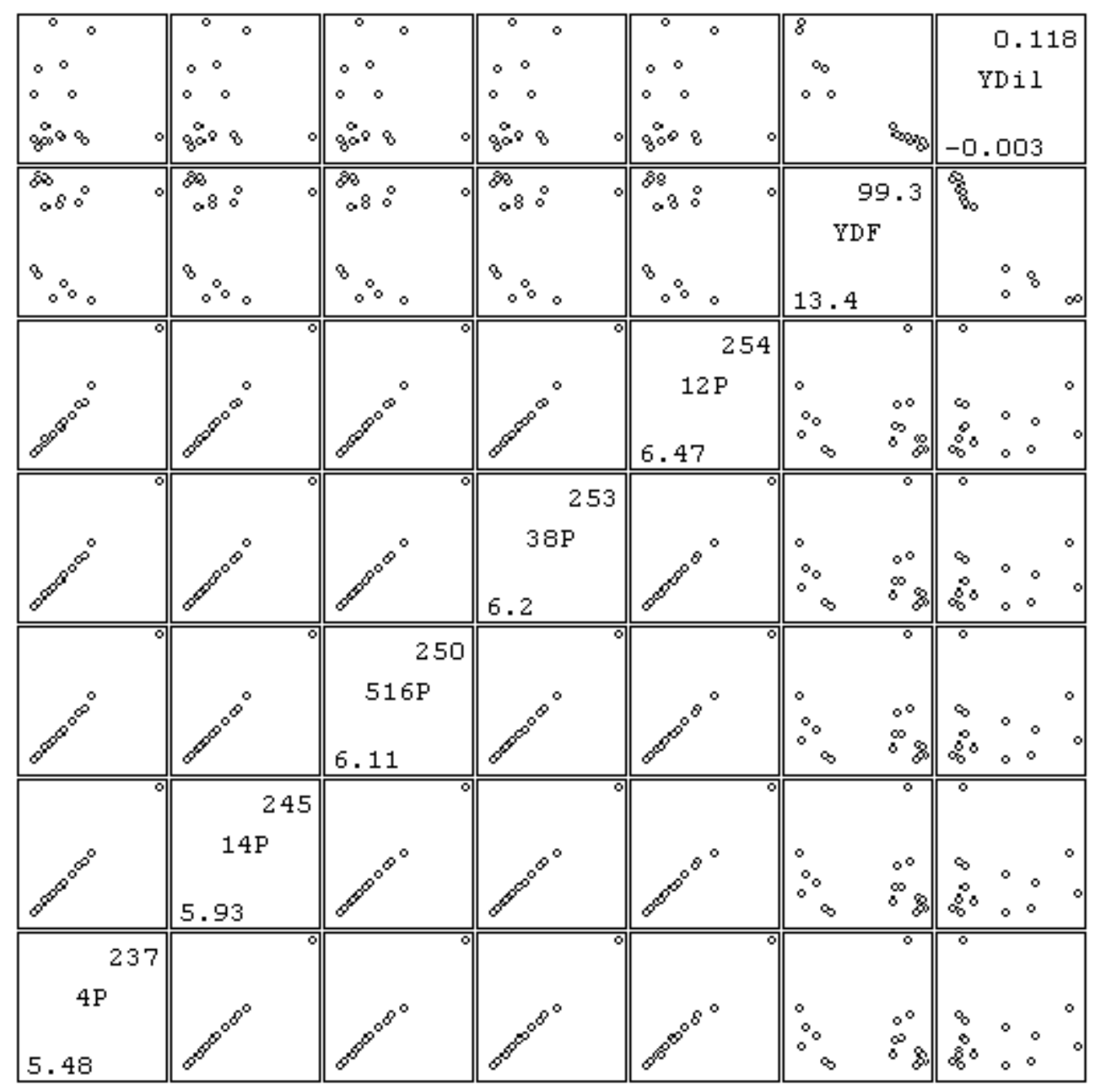

Figure E.18. Scatter plot matrix for responses and explanatory variables (percentage of particles passing, 19.0 to $37.5 \mathrm{~mm}$ [0.75 to $1.5 \mathrm{in}]$ ). 


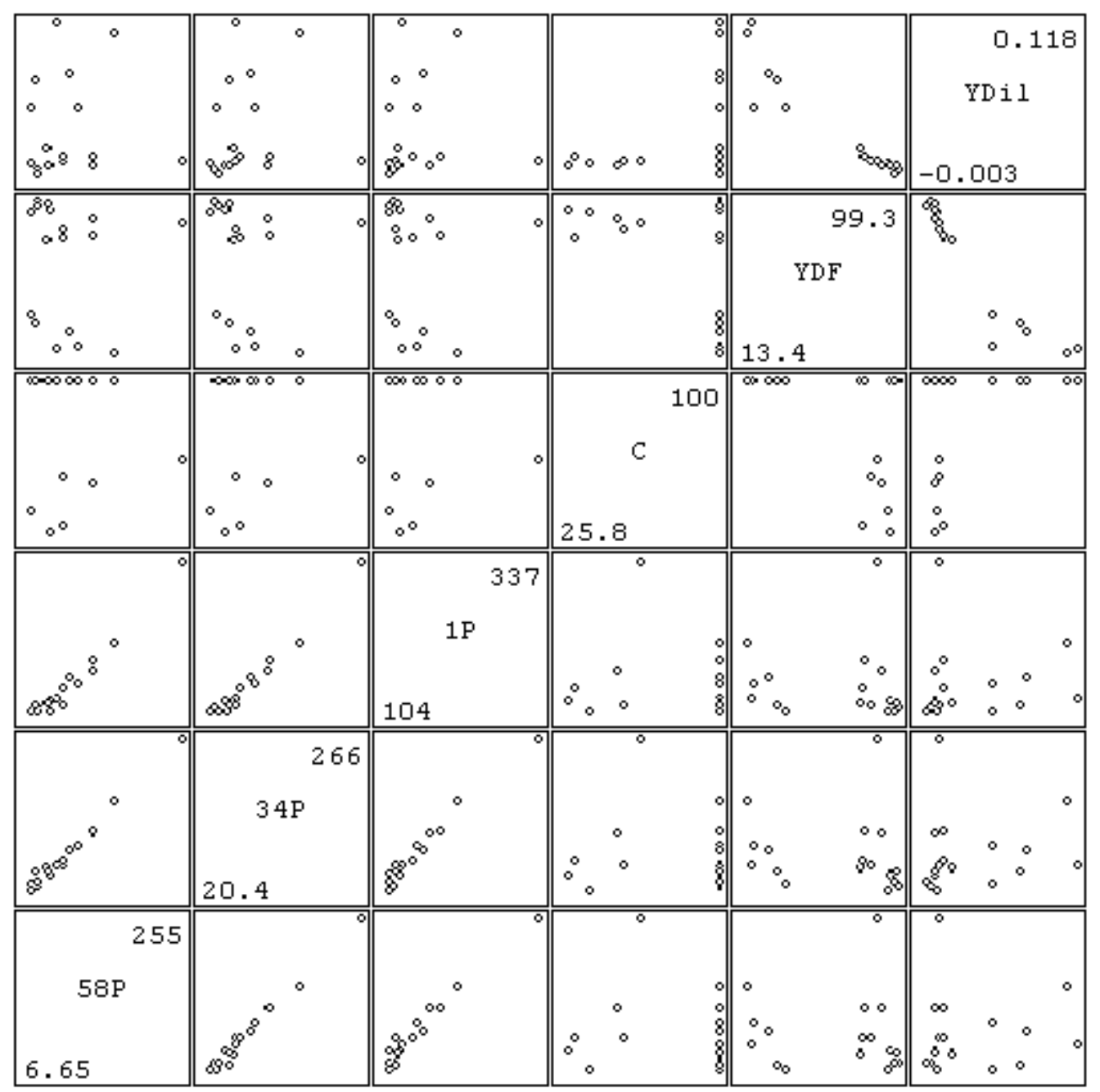

Figure E.18. Scatter plot matrix for responses and explanatory variables (percentage of particles passing, 19.0 to $37.5 \mathrm{~mm}$ [0.75 to $1.5 \mathrm{in}]$ ) (continued). 


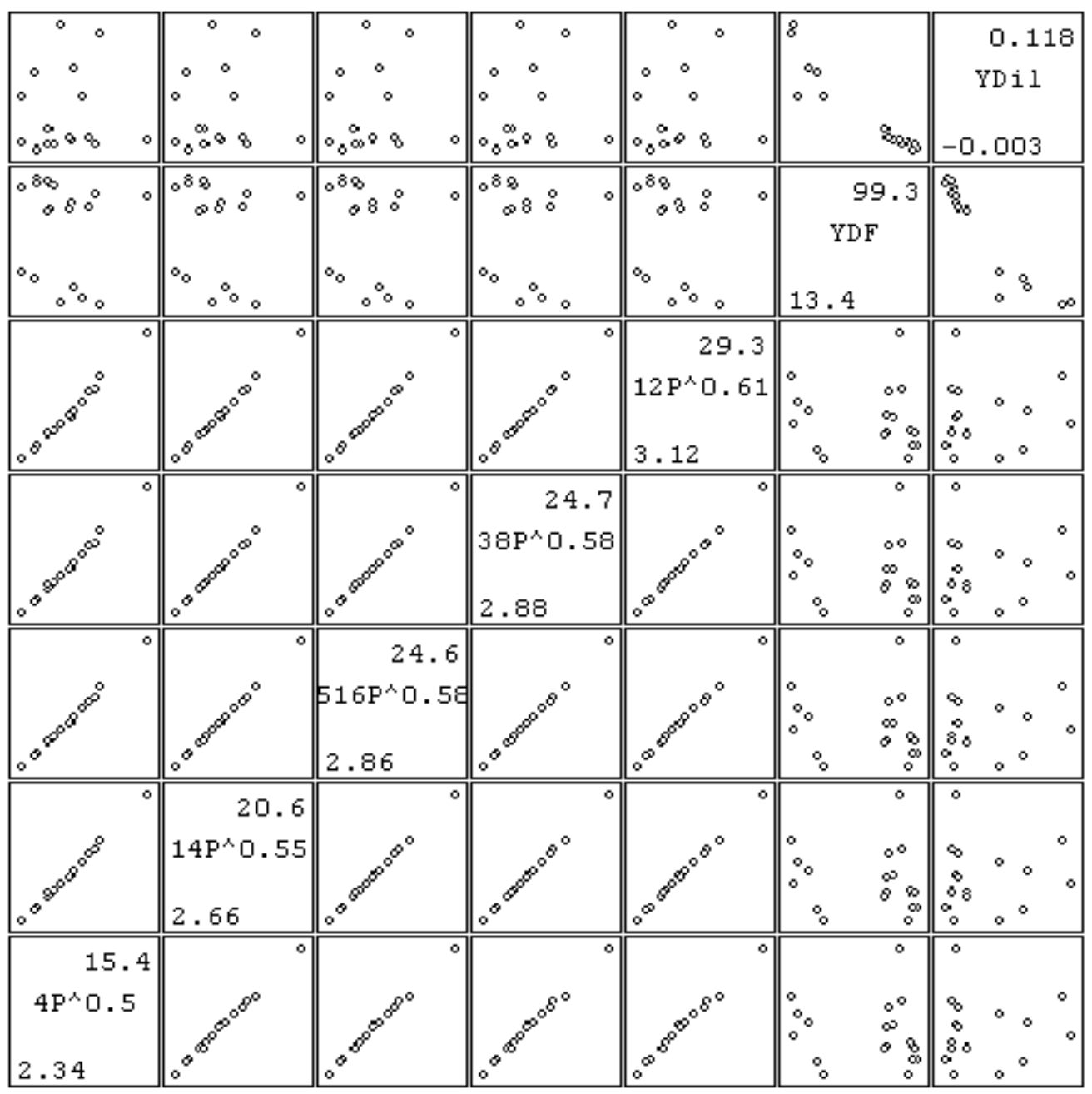

Figure E.19. Scatter plot matrix for responses and transformed explanatory variables (percentage of particles passing, 19.0 to $37.5 \mathrm{~mm}$ [0.75 to $1.5 \mathrm{in}]$ ). 


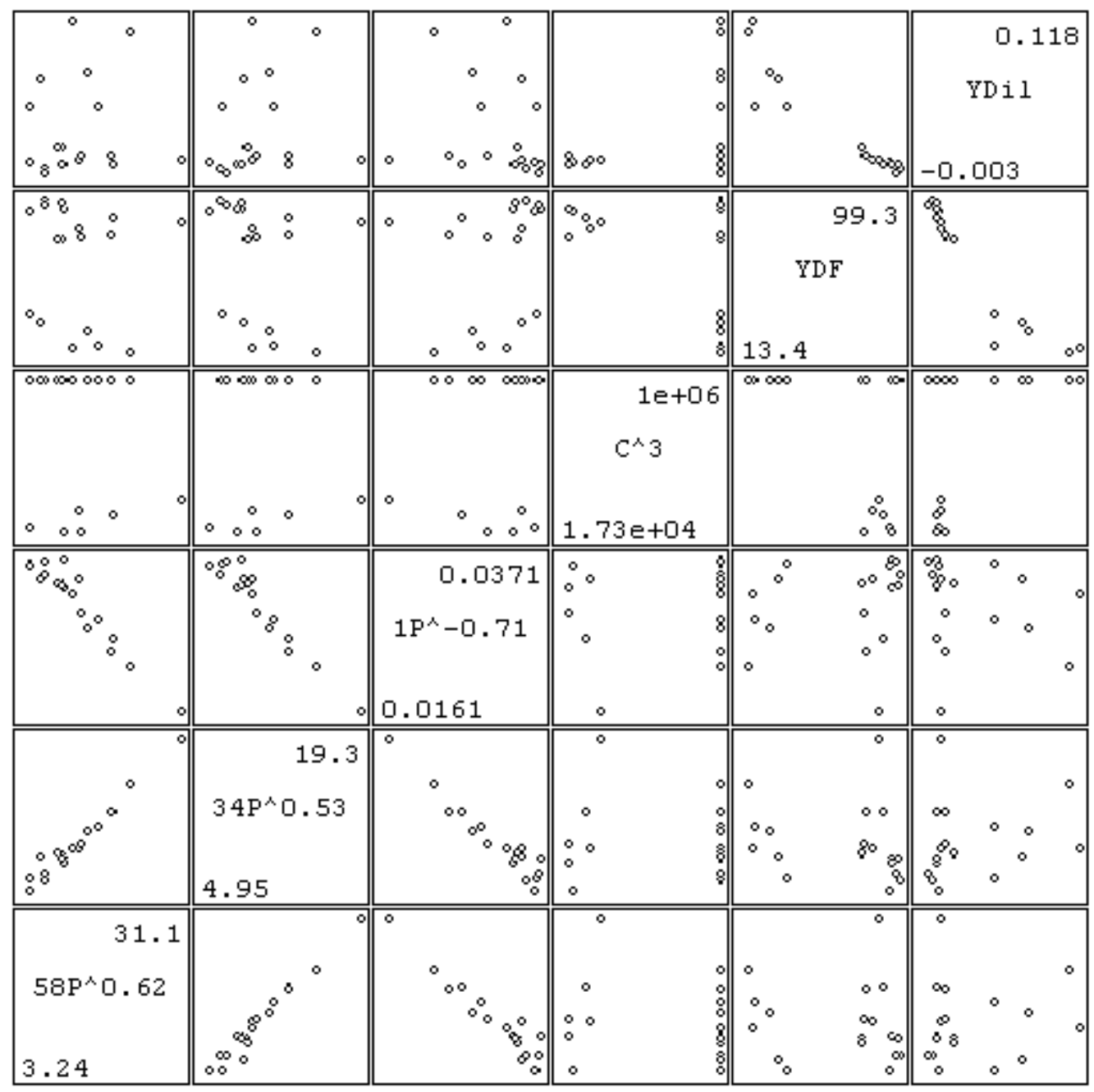

Figure E.19. Scatter plot matrix for responses and transformed explanatory variables (percentage of particles, 19.0 to $37.5 \mathrm{~mm}$ [0.75 to $1.5 \mathrm{in}]$ ) (continued). 
Equation E.42 was slightly modified for multiple linear regression to produce basic forms for modeling dilation and durability factor as a function of percentages of mass passing the specified sieves either with or without an interaction term for carbonate content:

$$
\begin{gathered}
\mathrm{E}(\mathrm{y} \mid \mathrm{x})=\alpha+\beta_{1} * \mathrm{C} * 38 \mathrm{P}+\beta_{2} * \mathrm{C} * 516 \mathrm{P}+\beta_{3} * \mathrm{C} * 14 \mathrm{P}+\beta_{4} * \mathrm{C} * 4 \mathrm{P} \\
\mathrm{E}(\mathrm{y} \mid \mathrm{x})=\alpha+\beta_{1} * 38 \mathrm{P}+\beta_{2} * 516 \mathrm{P}+\beta_{3} * 14 \mathrm{P}+\beta_{4} * 4 \mathrm{P}
\end{gathered}
$$

Regression analyses were performed using the model forms presented in equations E.42 through E.44 with both the transformed and untransformed (identity) explanatory variables. Numerous nonlinear and multiple linear regression models were formulated, as discussed previously in section E.2.1.3; however, only the models with the best adjusted $\mathrm{R}^{2}$ for the response variables, percent dilation per 100 cycles (model N1c) and durability factor (model L2b), were recorded in tables E.14 and E.15, respectively. As described previously, these models were reduced to eliminate predictors that have no significant effect on the mean function. The reduced models are designated with lowercase letters behind the model number (e.g., N1a, N1b, etc.).

\section{E.4.2.4 Model Selection}

As described previously, the F-statistic was calculated for each comparison to identify the most compact model that adequately represents the data. As illustrated in tables E.14 and E.15, where all $\mathrm{p}$-values are greater than 0.05 , each nested model will adequately represent the data. Therefore, as described previously, the summary, residual, nonconstant variance and model checking plots were produced to identify the model that most adequately represents the data.

The models shaded in gray in tables E.14 and E.15 are the final models chosen based on these plots. Figure E. 20 presents the summary plots for models N1c and L2b. As illustrated in the plots, there is a strong correlation between the hydraulic fracture and freezing and thawing data. 
Table E.14. Nonlinear regression models for response variable "percent dilation per 100 cycles" (percentage of particles passing, 19.0 to $37.5 \mathrm{~mm}$ [0.75 to $1.5 \mathrm{in}]$ ).

\begin{tabular}{|c|c|c|c|c|c|}
\hline \multirow[b]{3}{*}{ Variable } & \multicolumn{5}{|c|}{ Estimates (Wald-statistic) [p-value] } \\
\hline & \multicolumn{5}{|c|}{ Model Number } \\
\hline & N1 & N1a & $\mathrm{N} 1 \mathrm{~b}$ & N1c & N1c* \\
\hline$\alpha$ & $\begin{array}{c}-7.845492 \mathrm{E}-8 \\
(-0.855) \\
{[0.3928]} \\
\end{array}$ & $\begin{array}{c}-9.463525 \mathrm{E}-8 \\
(-1.151) \\
{[0.2499]}\end{array}$ & $\begin{array}{c}-1.187643 \mathrm{E}-7 \\
(-1.713) \\
(0.0867) \\
\end{array}$ & $\begin{array}{c}-1.434766 \mathrm{E}-7 \\
(-2.741) \\
{[0.0061]} \\
\end{array}$ & $\begin{array}{c}-1.399018 \mathrm{E}-7 \\
(-3.294) \\
{[0.0010]}\end{array}$ \\
\hline $1 \mathrm{P}$ & $\begin{array}{c}9.933281 \mathrm{E}-10 \\
(0.874) \\
{[0.3822]}\end{array}$ & $\begin{array}{c}1.226417 \mathrm{E}-9 \\
(1.240) \\
{[0.2151]}\end{array}$ & $\begin{array}{c}1.619587 \mathrm{E}-9 \\
(2.283) \\
(0.0224)\end{array}$ & $\begin{array}{c}1.840666 \mathrm{E}-9 \\
(3.196) \\
{[0.0014]}\end{array}$ & $\begin{array}{c}1.747835 \mathrm{E}-9 \\
(3.733) \\
{[0.0002]}\end{array}$ \\
\hline $34 \mathrm{P}$ & $\begin{array}{c}8.393640 \mathrm{E}-10 \\
(0.725) \\
{[0.4687]} \\
\end{array}$ & $\begin{array}{c}5.799580 \mathrm{E}-10 \\
(0.588) \\
{[0.5564]}\end{array}$ & & & \\
\hline $58 \mathrm{P}$ & $\begin{array}{c}-3.991039 \mathrm{E}-8 \\
(-2.179) \\
{[0.0293]}\end{array}$ & $\begin{array}{c}-3.870108 \mathrm{E}-8 \\
(-2.213) \\
{[0.0269]}\end{array}$ & $\begin{array}{c}-3.651148 \mathrm{E}-8 \\
(-2.198) \\
{[0.0280]}\end{array}$ & $\begin{array}{c}-2.804111 \mathrm{E}-8 \\
(-4.025) \\
{[0.0001]}\end{array}$ & $\begin{array}{c}-2.661853 \mathrm{E}-8 \\
(-4.692) \\
{[0.0000]}\end{array}$ \\
\hline $12 \mathrm{P}$ & $\begin{array}{c}3.282497 \mathrm{E}-8 \\
(0.796) \\
{[0.4262]}\end{array}$ & $\begin{array}{c}2.181416 \mathrm{E}-8 \\
(0.662) \\
{[0.5080]}\end{array}$ & $\begin{array}{c}1.768510 \mathrm{E}-8 \\
(0.565) \\
{[0.5722]}\end{array}$ & & \\
\hline $38 \mathrm{P}$ & $\begin{array}{c}-5.521042 \mathrm{E}-8 \\
(-1.752) \\
{[0.0798]} \\
\end{array}$ & $\begin{array}{c}-6.300024 \mathrm{E}-8 \\
(-2.425) \\
{[0.0153]} \\
\end{array}$ & $\begin{array}{c}-6.947822 \mathrm{E}-8 \\
(-3.037) \\
{[0.0024]}\end{array}$ & $\begin{array}{c}-7.072665 \mathrm{E}-8 \\
(-3.190) \\
{[0.0014]}\end{array}$ & $\begin{array}{c}-3.945137 \mathrm{E}-8 \\
(-1.861) \\
{[0.0627]}\end{array}$ \\
\hline $516 \mathrm{P}$ & $\begin{array}{c}1.166125 \mathrm{E}-7 \\
(1.587) \\
{[0.1124]}\end{array}$ & $\begin{array}{c}1.416649 \mathrm{E}-7 \\
(2.864) \\
{[0.0042]}\end{array}$ & $\begin{array}{c}1.553858 \mathrm{E}-7 \\
(3.663) \\
{[0.0002]}\end{array}$ & $\begin{array}{c}1.733689 \mathrm{E}-7 \\
(6.353) \\
{[0.0000]}\end{array}$ & $\begin{array}{c}1.297791 \mathrm{E}-7 \\
(4.789) \\
{[0.0000]}\end{array}$ \\
\hline $14 \mathrm{P}$ & $\begin{array}{c}-6.120006 \mathrm{E}-8 \\
(-2.812) \\
{[0.0049]}\end{array}$ & $\begin{array}{c}-6.310561 \mathrm{E}-8 \\
(-3.059) \\
{[0.0022]}\end{array}$ & $\begin{array}{c}-6.821767 \mathrm{E}-8 \\
(-3.750) \\
{[0.0002]}\end{array}$ & $\begin{array}{c}-7.589939 \mathrm{E}-8 \\
(-6.454) \\
{[0.0000]}\end{array}$ & $\begin{array}{c}-6.512966 \mathrm{E}-8 \\
(-6.329) \\
{[0.0000]}\end{array}$ \\
\hline $4 \mathrm{P}$ & $\begin{array}{c}5.524279 \mathrm{E}-9 \\
(0.477) \\
{[0.6337]} \\
\end{array}$ & & & & \\
\hline Df & 10 & 11 & 12 & 13 & 12 \\
\hline $\mathrm{N}$ & 19 & 19 & 19 & 19 & 18 \\
\hline $\mathrm{r}^{2}$ & 0.9194 & 0.9176 & 0.9150 & 0.9127 & 0.9223 \\
\hline$\hat{\sigma}$ & 0.0187867 & 0.0181147 & 0.0176142 & 0.0171467 & 0.0139059 \\
\hline $\mathrm{r}_{\text {adj }}^{2}$ & 0.839 & 0.852 & 0.861 & 0.869 & 0.880 \\
\hline $\begin{array}{l}\text { Models } \\
\text { Compared }\end{array}$ & & (N1) - (N1a) & $(\mathrm{N} 1 \mathrm{~b})-(\mathrm{N} 1 \mathrm{a})$ & $(\mathrm{N} 1 \mathrm{c})-(\mathrm{N} 1 \mathrm{~b})$ & $(\mathrm{N} 1 \mathrm{~d})-(\mathrm{N} 1 \mathrm{c})$ \\
\hline P-value & & 0.2270 & 0.3460 & 0.3191 & 0.3573 \\
\hline $\begin{array}{l}{ }^{\mathrm{N} 1} \mathrm{Y}=\mathrm{C}^{3 *} \\
{ }^{\mathrm{N} 1 \mathrm{a}} \mathrm{Y}=\mathrm{C}^{3 *} \\
{ }^{\mathrm{N} 1 \mathrm{~b}} \mathrm{Y}=\mathrm{C}^{3 *} \\
{ }^{\mathrm{N} 1 \mathrm{c}} \mathrm{Y}=\mathbf{C}^{3 *}\end{array}$ & $\begin{array}{l}\mathrm{P}+\beta_{2} * 34 \mathrm{P}+\beta \\
1 \mathrm{P}+\beta_{2} * 34 \mathrm{P}+ \\
1 \mathrm{P}+\beta_{2} * 58 \mathrm{P}+ \\
\mathbf{1 P}+\beta_{2} * \mathbf{5 8 P}+\end{array}$ & $\begin{array}{l}\mathrm{P}+\beta_{4} * 12 \mathrm{P}+\beta \\
8 \mathrm{P}+\beta_{4} * 12 \mathrm{P}+ \\
2 \mathrm{P}+\beta_{4} * 38 \mathrm{P}+ \\
\mathbf{8 P}+\beta_{4} * \mathbf{5 1 6 P}\end{array}$ & $\begin{array}{l}\mathrm{P}+\beta_{6} * 516 \mathrm{P}+ \\
8 \mathrm{P}+\beta_{6} * 516 \mathrm{P}+ \\
\left.16 \mathrm{P}+\beta_{6} * 14 \mathrm{P}\right) \\
14 \mathrm{P})\end{array}$ & $\begin{array}{l}\left.4 \mathrm{P}+\beta_{8} * 4 \mathrm{P}\right) \\
14 \mathrm{P})\end{array}$ & \\
\hline
\end{tabular}

*Model N1c with outlier deleted (Bryan Rock). 
Table E.15. Multiple linear regression models for response variable "durability factor" (percentage of particles passing, 19.0 to $37.5 \mathrm{~mm}$ [0.75 to $1.5 \mathrm{in}]$ ).

\begin{tabular}{|c|c|c|c|c|}
\hline \multirow{3}{*}{ Variable } & \multicolumn{4}{|c|}{ Estimates (t-value) [p-value] } \\
\hline & \multicolumn{4}{|c|}{ Model Number } \\
\hline & $\mathrm{L} 2$ & L2a & $\mathrm{L} 2 \mathrm{~b}$ & L2c \\
\hline$\alpha$ & $\begin{array}{c}121.065 \\
(4.850) \\
{[0.0013]}\end{array}$ & $\begin{array}{c}114.796 \\
(5.320) \\
{[0.0005]} \\
\end{array}$ & $\begin{array}{l}111.783 \\
(5.764) \\
{[0.0002]}\end{array}$ & $\begin{array}{c}122.720 \\
(6.422) \\
{[0.0001]} \\
\end{array}$ \\
\hline $1 \mathrm{P}^{-0.71} * \mathrm{C}^{3}$ & $\begin{array}{c}-0.000665517 \\
(-0.656) \\
{[0.5299]}\end{array}$ & $\begin{array}{c}-0.000314796 \\
(-0.405) \\
{[0.6949]}\end{array}$ & & \\
\hline $34 \mathrm{P}^{0.53 * \mathrm{C}^{3}}$ & $\begin{array}{c}-0.0000151755 \\
(-3.380) \\
{[0.0096]}\end{array}$ & $\begin{array}{c}-0.0000150618 \\
(-3.490) \\
{[0.0068]}\end{array}$ & $\begin{array}{c}-0.0000161437 \\
(-4.976) \\
(0.0006) \\
\end{array}$ & $\begin{array}{c}-0.0000156374 \\
(-4.573) \\
{[0.0008]}\end{array}$ \\
\hline $58 \mathrm{P}^{0.62 * \mathrm{C}^{3}}$ & $\begin{array}{c}0.000351834 \\
(5.669) \\
{[0.0005]} \\
\end{array}$ & $\begin{array}{c}0.000344959 \\
(5.889) \\
{[0.0002]} \\
\end{array}$ & $\begin{array}{c}0.000336788 \\
(6.398) \\
{[0.0001]} \\
\end{array}$ & $\begin{array}{c}0.000353735 \\
(6.486) \\
{[0.0001]} \\
\end{array}$ \\
\hline $12 \mathrm{P}^{0.61 * \mathrm{C}^{3}}$ & $\begin{array}{c}-0.000260422 \\
(-2.119) \\
{[0.0669]}\end{array}$ & $\begin{array}{c}-0.000278519 \\
(-2.438) \\
{[0.0375]}\end{array}$ & $\begin{array}{c}-0.000258172 \\
(-2.629) \\
{[0.0252]}\end{array}$ & $\begin{array}{c}-0.000258629 \\
(-2.485) \\
{[0.0303]}\end{array}$ \\
\hline $38 \mathrm{P}^{0.58} * \mathrm{C}^{3}$ & $\begin{array}{c}0.000167750 \\
(1.539) \\
{[0.1623]}\end{array}$ & $\begin{array}{c}0.000153817 \\
(1.505) \\
{[0.1665]}\end{array}$ & $\begin{array}{c}0.000136889 \\
(1.533) \\
{[0.1562]}\end{array}$ & \\
\hline $516 \mathrm{P}^{0.58 *} \mathrm{C}^{3}$ & $\begin{array}{c}-0.000688214 \\
(-3.347) \\
{[0.0101]} \\
\end{array}$ & $\begin{array}{c}-0.000631358 \\
(-3.645) \\
{[0.0054]} \\
\end{array}$ & $\begin{array}{c}-0.000625218 \\
(-3.785) \\
{[0.0036]} \\
\end{array}$ & $\begin{array}{c}-0.000523303 \\
(-3.266) \\
{[0.0075]} \\
\end{array}$ \\
\hline $14 \mathrm{P}^{0.55} * \mathrm{C}^{3}$ & $\begin{array}{c}0.000430044 \\
(4.002) \\
{[0.0039]}\end{array}$ & $\begin{array}{c}0.000449355 \\
(4.578) \\
{[0.0013]}\end{array}$ & $\begin{array}{c}0.000446406 \\
(4.764) \\
{[0.0008]}\end{array}$ & $\begin{array}{c}0.000464517 \\
(4.716) \\
{[0.0006]}\end{array}$ \\
\hline $4 P^{0.5 *} C^{3}$ & $\begin{array}{c}0.0000452896 \\
(0.573) \\
{[0.5825]}\end{array}$ & & & \\
\hline $4 \mathrm{P}^{0.5}$ & $\begin{array}{c}-75.1793 \\
(-2.042) \\
{[0.0755]} \\
\end{array}$ & $\begin{array}{c}-62.8019 \\
(-2.189) \\
{[0.0563]} \\
\end{array}$ & $\begin{array}{c}-60.0509 \\
(-2.251) \\
{[0.0481]} \\
\end{array}$ & $\begin{array}{c}-72.6492 \\
(-2.701) \\
{[0.0206]}\end{array}$ \\
\hline $14 \mathrm{P}^{0.55}$ & $\begin{array}{c}56.8302 \\
(2.118) \\
{[0.0670]} \\
\end{array}$ & $\begin{array}{c}47.6435 \\
(2.303) \\
{[0.0468]} \\
\end{array}$ & $\begin{array}{c}45.7609 \\
(2.371) \\
{[0.0392]} \\
\end{array}$ & $\begin{array}{c}54.5577 \\
(2.794) \\
{[0.0175]} \\
\end{array}$ \\
\hline $\mathrm{df}$ & 8 & 9 & 10 & 11 \\
\hline $\mathrm{N}$ & 19 & 19 & 19 & 19 \\
\hline $\mathrm{r}^{2}$ & 0.951469 & 0.949478 & 0.948558 & 0.936462 \\
\hline$\hat{\sigma}$ & 10.7072 & 10.2999 & 9.85995 & 10.448 \\
\hline $\mathrm{r}_{\mathrm{adj}}^{2}$ & 0.891 & 0.899 & 0.907 & 0.896 \\
\hline $\begin{array}{l}\text { Models } \\
\text { Compared }\end{array}$ & & $(\mathrm{L} 1)-(\mathrm{L} 1 \mathrm{a})$ & $(\mathrm{L} 1 \mathrm{~b})-(\mathrm{L} 1 \mathrm{a})$ & $(\mathrm{L} 1 \mathrm{c})-(\mathrm{L} 1 \mathrm{~b})$ \\
\hline P-value & & 0.5825 & 0.9490 & 0.1562 \\
\hline $\begin{array}{r}{ }^{\mathrm{L} 2} \mathrm{Y}=\alpha+\mathrm{C} \\
\beta_{9} * 4 \mathrm{P}^{0} \\
{ }^{\mathrm{L} 2 \mathrm{a}} \mathrm{Y}=\alpha+\mathrm{C} \\
\beta_{9} * 14 \mathrm{P} \\
{ }^{\mathrm{L} 2 \mathrm{~b}} \mathbf{Y}=\alpha+\mathbf{C} \\
{ }^{\mathrm{L} 2 \mathrm{C}} \mathrm{Y}=\alpha+\mathrm{C} \\
\end{array}$ & 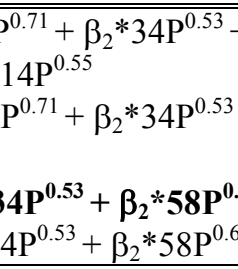 & $\begin{array}{l}\mathrm{P}^{0.62}+\beta_{4} * 12 \mathrm{P}^{0.61} \\
8 \mathrm{P}^{0.62}+\beta_{4} * 12 \mathrm{P}^{0.6} \\
\mathbf{1 2 P}^{\mathbf{0 . 6 1}}+\beta_{4} * \mathbf{3 8 P} \\
12 \mathrm{P}^{0.61}+\beta_{4} * 516 \mathrm{P} \\
\end{array}$ & $\begin{array}{l}* 38 \mathrm{P}^{0.58}+\beta_{6} * 516 \\
* 38 \mathrm{P}^{0.58}+\beta_{6} * 51 \\
\beta_{5} * \mathbf{5 1 6} \mathbf{P}^{\mathbf{0 . 5 8}}+\beta_{6} \\
\left.\beta_{5} * 14 \mathrm{P}^{0.55}\right)+\beta_{6}\end{array}$ & $\begin{array}{l}\left.14 \mathrm{P}^{0.55}+\beta_{8} * 4 \mathrm{P}^{0.5}\right)+ \\
\left.* 14 \mathrm{P}^{0.55}\right)+\beta_{8} * 4 \mathrm{P}^{0.5}+ \\
-\beta_{7} * 4 \mathrm{P}^{\mathbf{0 . 5}}+\beta_{8} * 14 \mathrm{P}^{0.55} \\
* 14 \mathrm{P}^{0.55}\end{array}$ \\
\hline
\end{tabular}


However, the correlation is not as strong as that achieved with the mass data obtained for this size fraction.

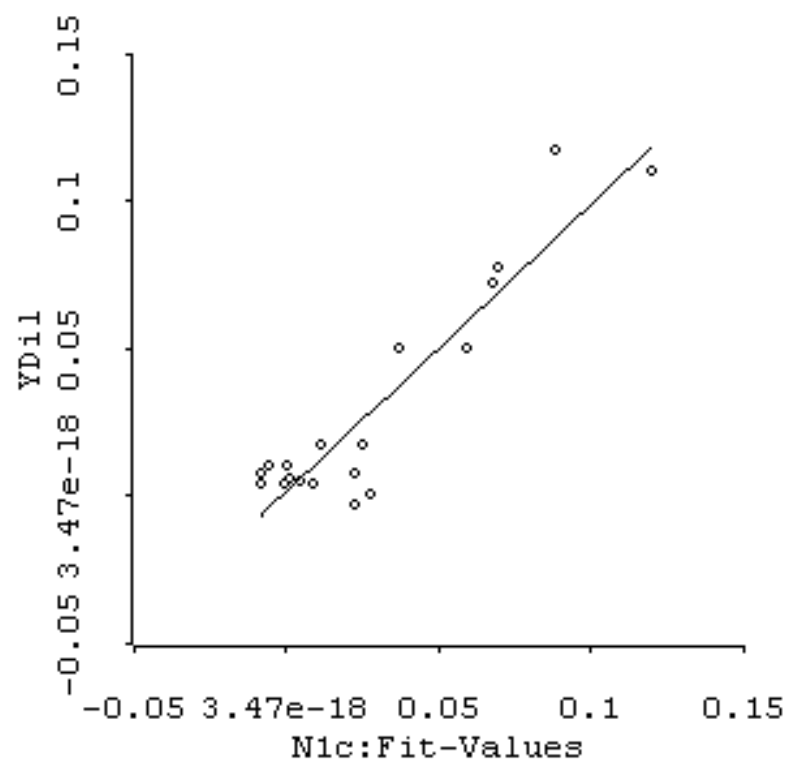

a. Model N1c.

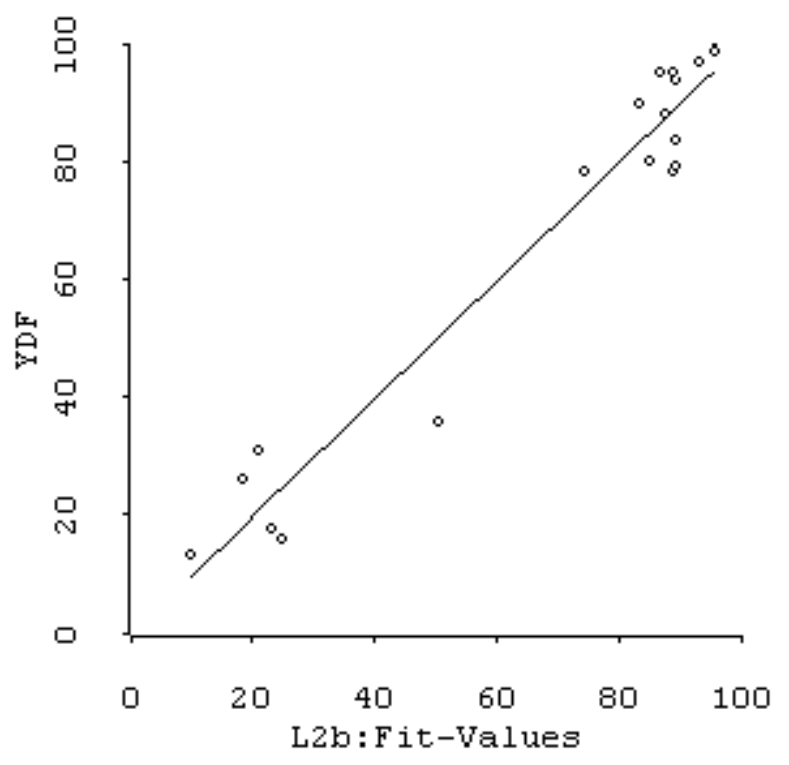

b. Model L2b.

Figure E.20. Actual versus predicted rapid freezing and thawing results for models N1c and L2b (percentage of particles passing, 19.0 to $37.5 \mathrm{~mm}$ [0.75 to $1.5 \mathrm{in}]$ ).

\section{E.5 Final Model Selection}

\section{E.5.1 Summary of Models}

Table E.16 lists the regression models selected for each initial size fraction. In general, the correlation between the hydraulic fracture test results (i.e., percentage of mass or particles passing selected sieves) and rapid freezing and thawing test results (i.e., percent dilation per 100 cycles or durability factor) increases with increased particle sizes incorporated in the initial size fraction. These results support the findings of previous research, where it was found that the greatest amount of freeze-thaw damage occurred with larger size particles due to the greater hydraulic pressures generated due to the greater escape distances (12). 
Table E.16. Summary of regression analysis models.

\begin{tabular}{|c|c|c|c|c|c|}
\hline $\begin{array}{c}\text { Initial Size } \\
\text { Fraction }(\mathrm{mm})\end{array}$ & $\begin{array}{l}\text { Explanatory } \\
\text { Variable } \\
\text { (cumulative } \\
\text { percentage } \\
\text { passing) }\end{array}$ & $\mathrm{R}^{2}$ & Adj. & General Equation & $\begin{array}{l}\text { Table } \\
\text { No.* }\end{array}$ \\
\hline \multicolumn{6}{|c|}{ Percentage of Dilation per 100 Cycles of Rapid Freezing and Thawing } \\
\hline 4.75 to 12.5 & Mass & 0.334 & 0.256 & $\mathrm{Llb} Y=\alpha+\mathrm{C}^{2.33} *\left(\beta_{1} * 38 \mathrm{M}^{2}+\beta_{2} * 14 \mathrm{M}^{0.31}\right)$ & E.6 \\
\hline \multirow{2}{*}{12.5 to 19.0} & Mass & 0.768 & 0.661 & $\begin{array}{l}\text { Nla } Y=C^{2} *\left(\alpha+\beta_{1}^{*} * 58 \mathrm{M}+\beta_{2} * 12 \mathrm{M}+\beta_{3} * 38 \mathrm{M}+\right. \\
\left.\beta_{4} * 516 \mathrm{M}+\beta_{5} * 14 \mathrm{M}\right)\end{array}$ & E. 8 \\
\hline & Particles & 0.806 & 0.717 & $\begin{array}{l}{ }^{N 1 a} \mathrm{Y}=\mathrm{C}^{1.9} *\left(\alpha+\beta_{1} * 58 \mathrm{P}^{0.2}+\beta_{2} * 12 \mathrm{P}^{0.67}+\right. \\
\left.\beta_{3} * 38 \mathrm{P}^{0.61}+\beta_{4} * 516 \mathrm{P}^{0.58}+\beta_{5} * 14 \mathrm{P}^{0.5}\right)\end{array}$ & E. 10 \\
\hline \multirow{2}{*}{19.0 to 37.5} & Mass & 0.978 & 0.957 & $\begin{array}{l}\mathrm{Nla}^{*} \mathrm{Y}=\mathrm{C}^{3 *}\left(\alpha+\beta_{1} * 34 \mathrm{M}+\beta_{2} * 58 \mathrm{M}+\beta_{3}^{*} 12 \mathrm{M}+\right. \\
\left.\beta_{4} * 38 \mathrm{M}+\beta_{5} * 516 \mathrm{M}+\beta_{6} * 14 \mathrm{M}+\beta_{7} * 4 \mathrm{M}\right)\end{array}$ & E.12 \\
\hline & Particles & 0.913 & 0.869 & $\begin{array}{l}{ }^{\mathrm{N} 1 \mathrm{c}} \mathrm{Y}=\mathrm{C}^{3} *\left(\alpha+\beta_{1} * 1 \mathrm{P}+\beta_{2} * 58 \mathrm{P}+\beta_{3} * 38 \mathrm{P}+\right. \\
\left.\beta_{4} * 516 \mathrm{P}+\beta_{5} * 14 \mathrm{P}\right)\end{array}$ & E.14 \\
\hline \multicolumn{6}{|c|}{ Durability Factor } \\
\hline 4.75 to 12.5 & Mass & 0.395 & 0.284 & $\begin{array}{l}{ }^{\mathrm{L} a} \mathrm{Y}=\alpha+\mathrm{C}^{2.33} *\left(\beta_{1} * 38 \mathrm{M}^{2}+\beta_{2} * 516 \mathrm{M}+\right. \\
\left.\beta_{3}^{*} 14 \mathrm{M}^{0.31}\right)\end{array}$ & E.7 \\
\hline \multirow{2}{*}{12.5 to 19.0} & Mass & 0.666 & 0.547 & $\begin{array}{l}\text { L2a } Y=\alpha+C *\left(\beta_{1} * 58 \mathrm{M}+\beta_{2} * 12 \mathrm{M}+\beta_{3} * 38 \mathrm{M}+\right. \\
\left.\beta_{4} * 516 \mathrm{M}+\beta_{5} * 14 \mathrm{M}\right)\end{array}$ & E.9 \\
\hline & Particles & 0.734 & 0.611 & $\begin{array}{l}\mathrm{L}^{\mathrm{Lf}} \mathrm{Y}=\alpha+\mathrm{C}^{*}\left(\beta_{1} * 38 \mathrm{P}^{0.61}+\beta_{2} * 516 \mathrm{P}^{0.58}\right)+ \\
\beta_{3} * 14 \mathrm{P}^{0.5}+\beta_{4} * 38 \mathrm{P}^{0.61}+\beta_{5} * 12 \mathrm{P}^{0.67}+\beta_{6} * 58 \mathrm{P}^{0.2}\end{array}$ & E.11 \\
\hline \multirow{2}{*}{19.0 to 37.5} & Mass & 0.784 & 0.676 & $\begin{array}{l}\mathrm{L} 2 \mathrm{~b} Y=\alpha+\mathrm{C}^{3} *\left(\beta_{1} * 1 \mathrm{M}^{1.06}+\beta_{2} * 34 \mathrm{M}^{-0.62}+\right. \\
\beta_{3} * 58 \mathrm{M}^{0.27}+\beta_{4} * 38 \mathrm{M}^{0.65}+\beta_{5} * 516 \mathrm{M}^{0.73}+ \\
\left.\beta_{6} * 14 \mathrm{M}^{0.84}\right)\end{array}$ & E.13 \\
\hline & Particles & 0.949 & 0.907 & $\begin{array}{l}{ }^{2 b} \mathrm{Y}=\alpha+\mathrm{C}^{3 *}\left(\beta_{1} * 34 \mathrm{P}^{0.53}+\beta_{2} * 58 \mathrm{P}^{0.62}+\right. \\
\left.\beta_{3} * 12 \mathrm{P}^{0.61}+\beta_{4} * 38 \mathrm{P}^{0.58}+\beta_{5} * 516 \mathrm{P}^{0.58}+\beta_{6} * 14 \mathrm{P}^{0.55}\right) \\
+\beta_{7} * 4 \mathrm{P}^{0.5}+\beta_{8} * 14 \mathrm{P}^{0.55}\end{array}$ & E.15 \\
\hline
\end{tabular}

*Coefficient estimates are listed in designated table.

\section{E.5.2 Final Model}

Model N1a* representing percent dilation per 100 cycles of rapid freezing and thawing as a function of the percentages of mass passing the designated sieves when testing the initial size fraction of 19.0 to $37.5 \mathrm{~mm}$ ( 0.75 to $1.5 \mathrm{in})$ was the model identified as best representing the project test data. This model is defined as follows: 
Model N1a*:

$\%$ Dil $/ 100=\mathrm{C}^{3 *}(6.714711 \mathrm{E}-9+1.493469 \mathrm{E}-9 * 34 \mathrm{M}-2.824751 \mathrm{E}-7 * 58 \mathrm{M}+3.648412 \mathrm{E}-7 * 12 \mathrm{M}-$

$5.631620 \mathrm{E}-7 * 38 \mathrm{M}+2.102003 \mathrm{E}-6 * 516 \mathrm{M}-1.675012 \mathrm{E}-6 * 14 \mathrm{M}+1.183342 \mathrm{E}-7 * 4 \mathrm{M})$

(Eqn. E.45)

$$
\mathrm{R}^{2}=0.978, \text { Adjusted } \mathrm{R}^{2}=0.957, \hat{\sigma}=0.009934, \mathrm{n}=18
$$

As illustrated in table E.12, the explanatory variables used in model N1a* are the same as those used in model N1a; however, the outlier Shiely Grey Cloud [Larson] (Case 13) was omitted from the regression analysis for model N1a*.

Figure E.21 presents the summary, nonconstant variance and residual plots for model N1a, where case 13 was not deleted. Case 13 is highlighted in each plot to illustrate the location of this outlier with respect to the other data points. Figure E. 22 presents the final summary, nonconstant variance and residual plots for model N1a* with the outlier (case 13) deleted. As illustrated in these plots, the removal of the outlier greatly improves the correlation of the hydraulic fracture data with the response (i.e., percentage of dilation per 100 cycles). 


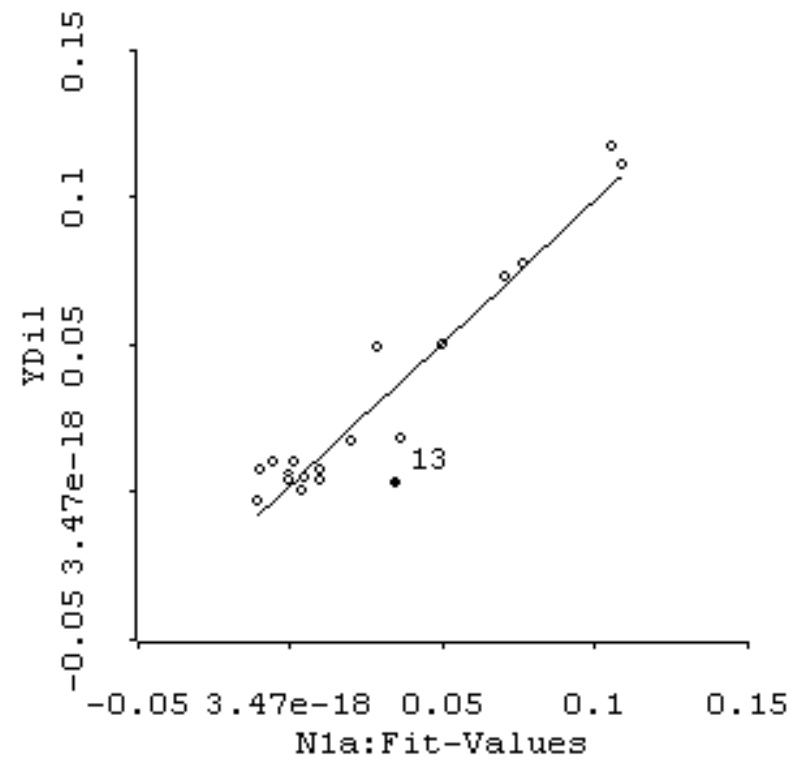

a. Response versus fit-values.

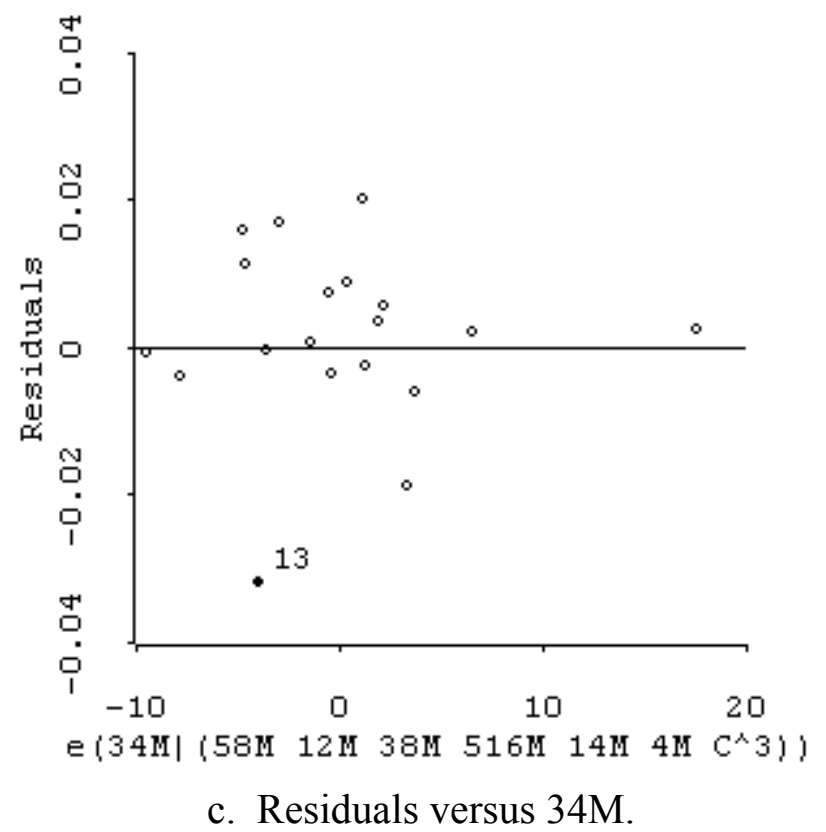

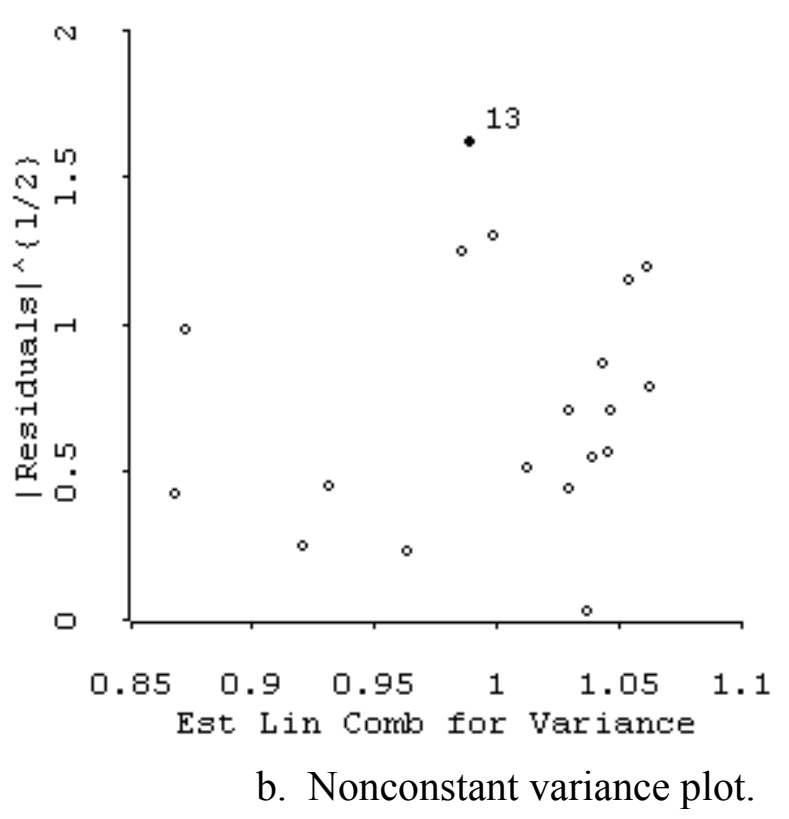

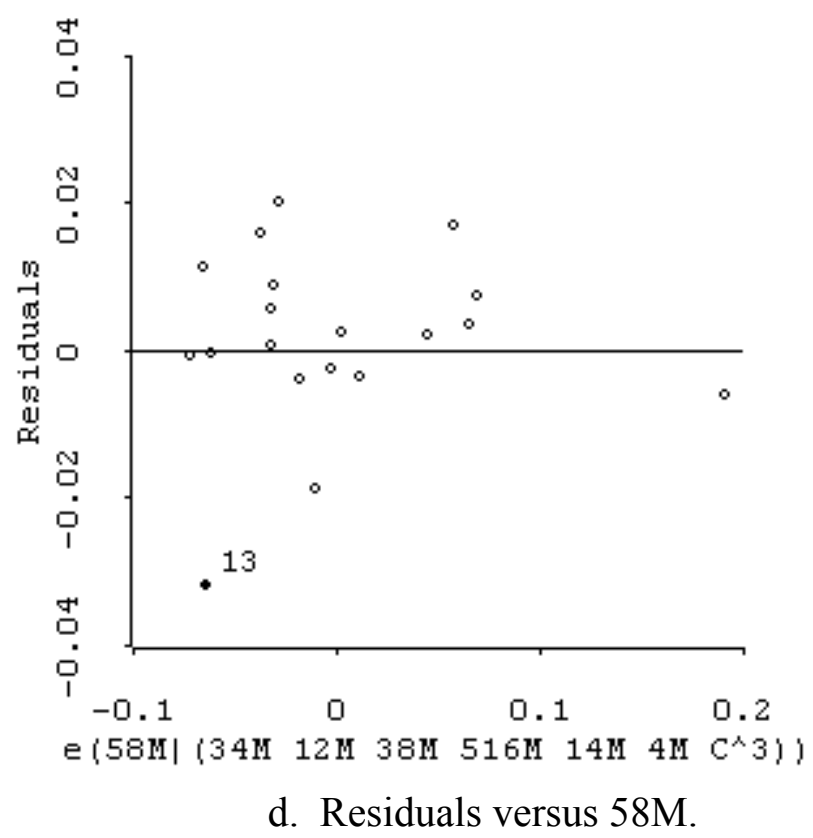

Figure E.21. Graphs $(\mathrm{a}-\mathrm{j})$ illustrating outlier (case 13, Shiely Grey Cloud [Larson]) in model N1a (percentage of mass passing, 19.0 to $37.5 \mathrm{~mm}$ [0.75 to $1.5 \mathrm{in}]$ ). 


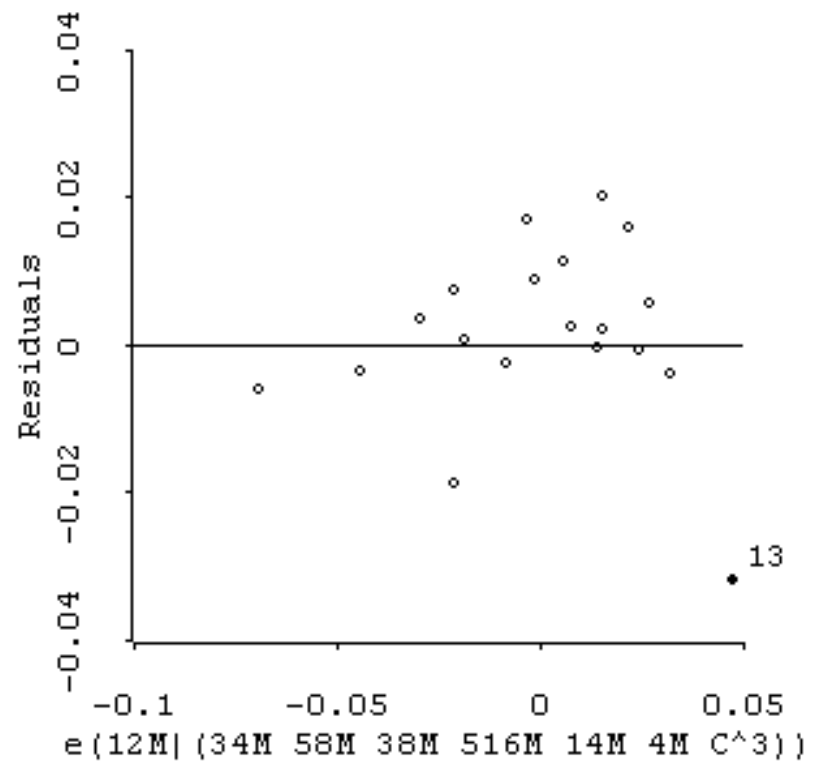

e. Residuals versus $12 \mathrm{M}$.

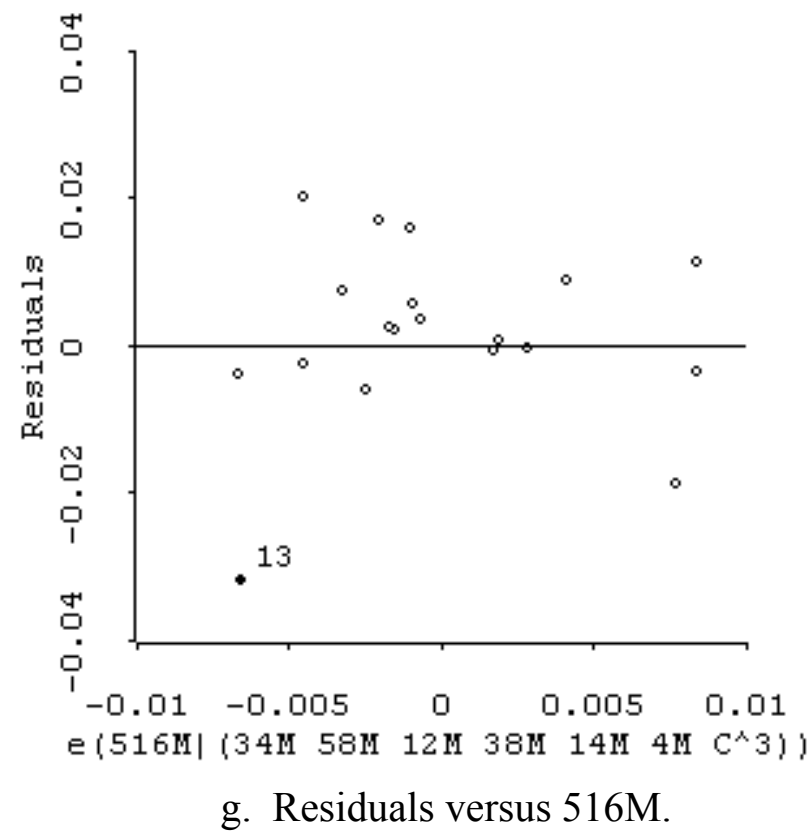

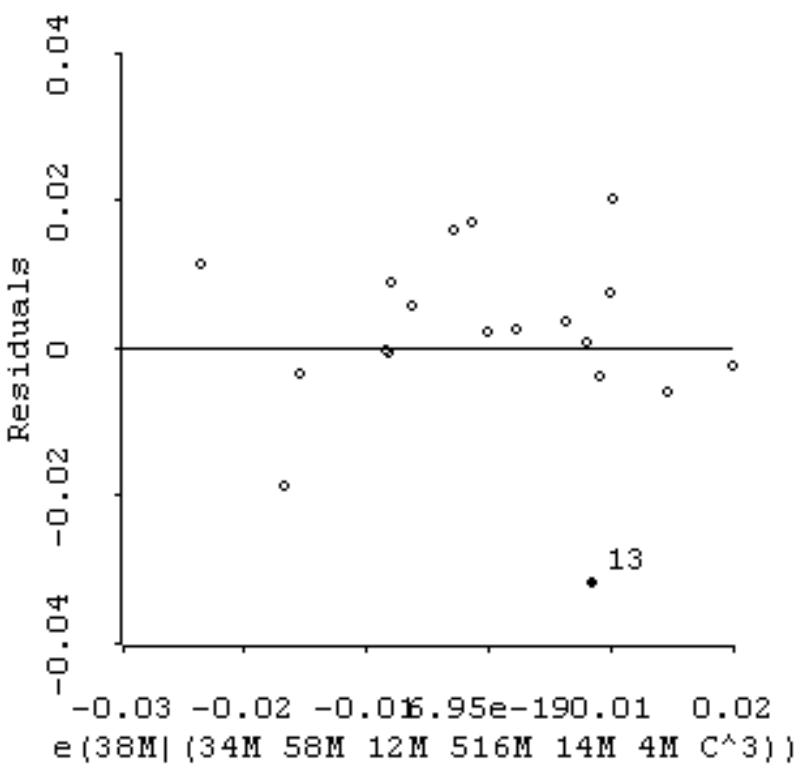

f. Residuals versus $38 \mathrm{M}$.

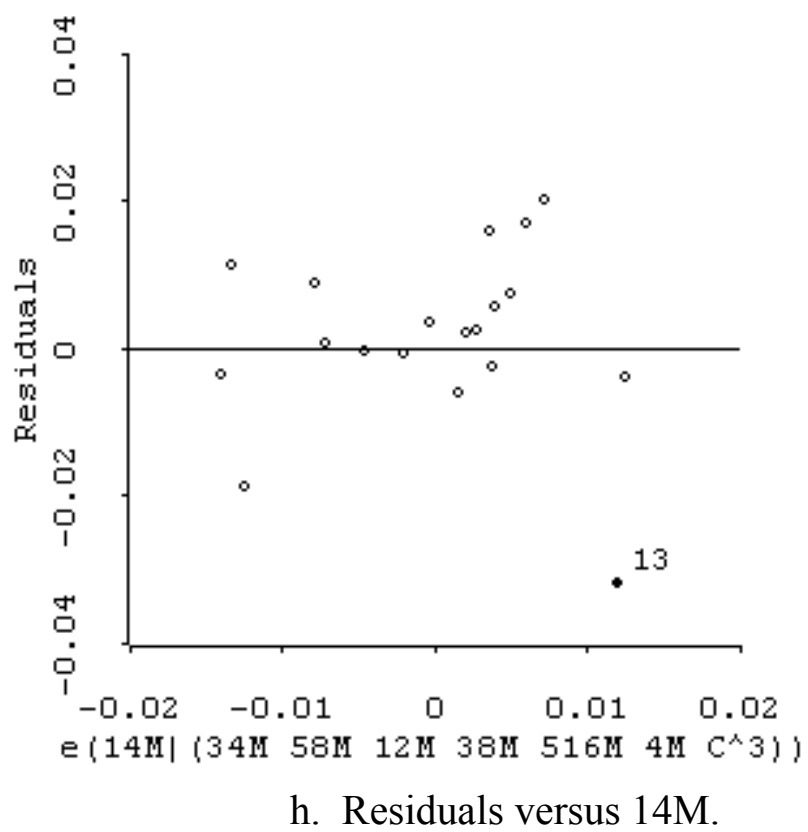

Figure E.21. Graphs $(a-j)$ illustrating outlier (case 13, Shiely Grey Cloud [Larson]) in model N1a (percentage of mass passing, 19.0 to $37.5 \mathrm{~mm}$ [0.75 to $1.5 \mathrm{in}]$ ) (continued). 


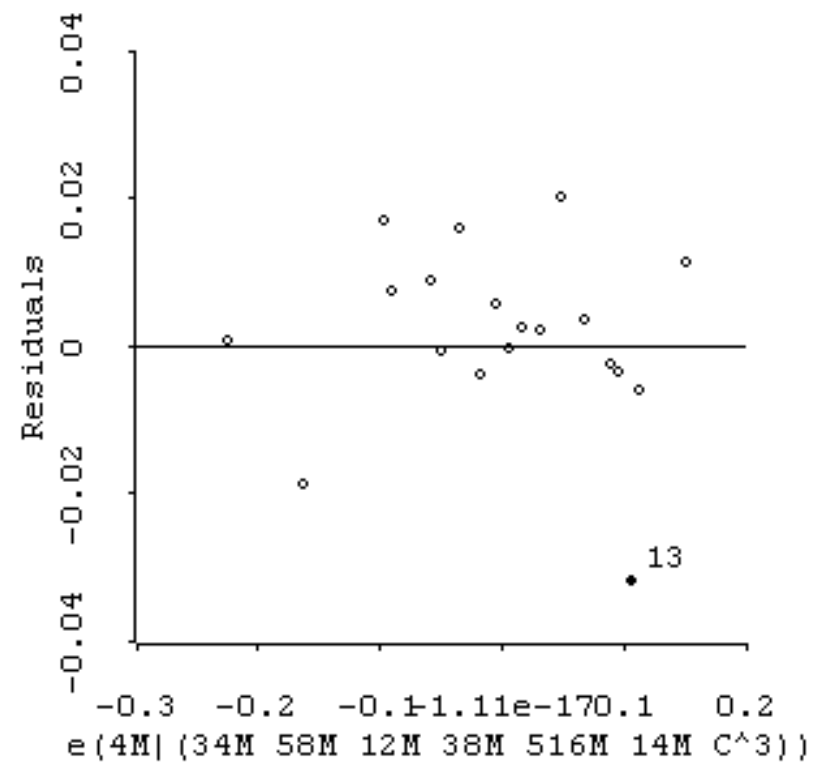

i. Residuals versus $4 \mathrm{M}$.

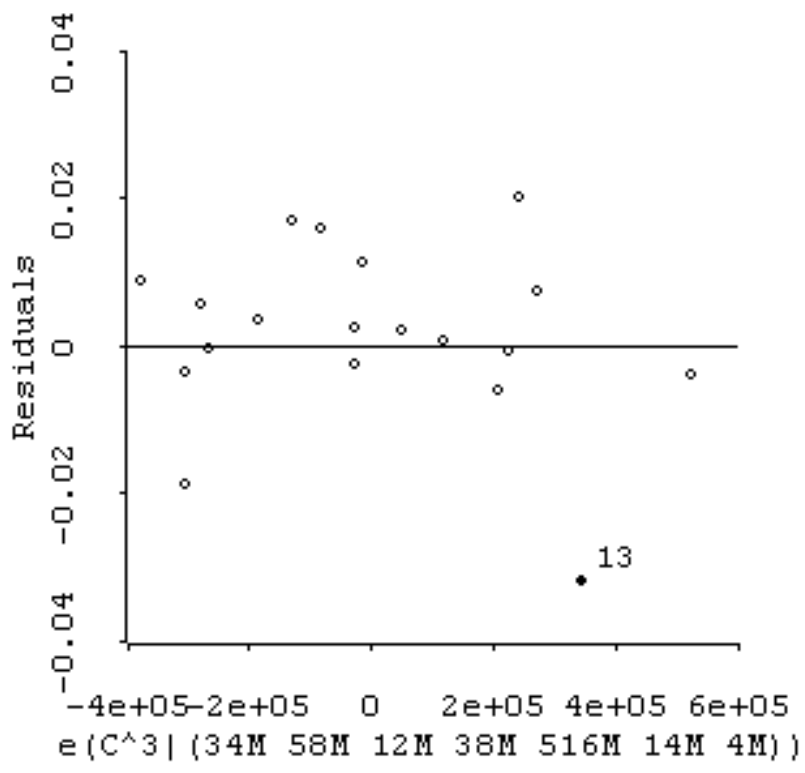

j. Residuals versus $C^{3}$.

Figure E.21. Graphs $(a-j)$ illustrating outlier (case 13, Shiely Grey Cloud [Larson]) in model N1a (percentage of mass passing, 19.0 to $37.5 \mathrm{~mm}$ [0.75 to $1.5 \mathrm{in}]$ ) (continued).

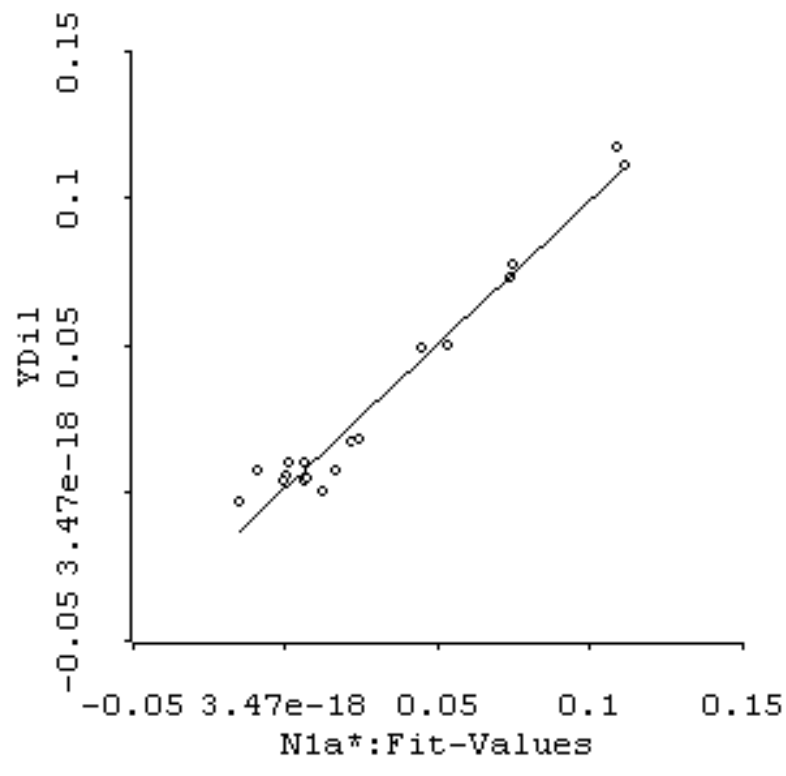

a. Response versus fit-values.

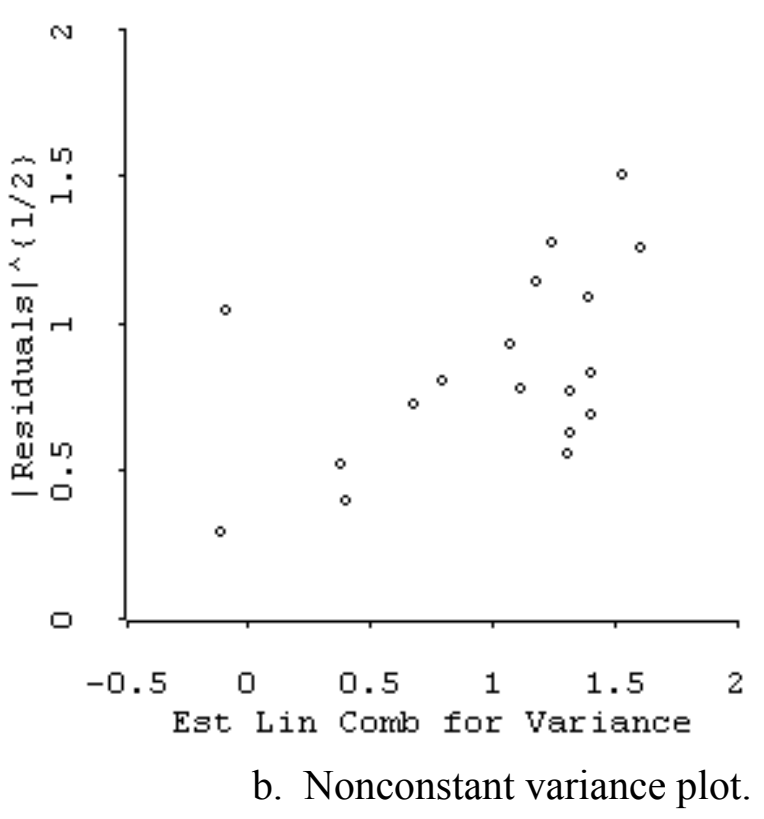

Figure E.22. Graphs $(\mathrm{a}-\mathrm{j})$ illustrating model N1a* with deleted outlier (case 13, Shiely Grey Cloud [Larson]) (percentage of mass passing, 19.0 to $37.5 \mathrm{~mm}$ [0.75 to $1.5 \mathrm{in}]$ ). 


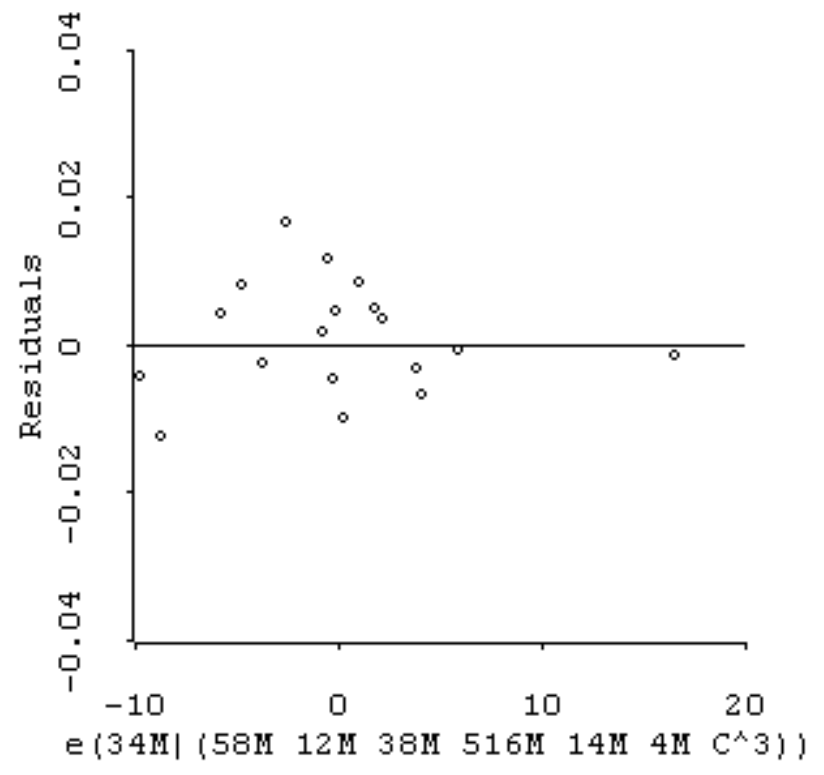

c. Residuals versus $34 \mathrm{M}$.

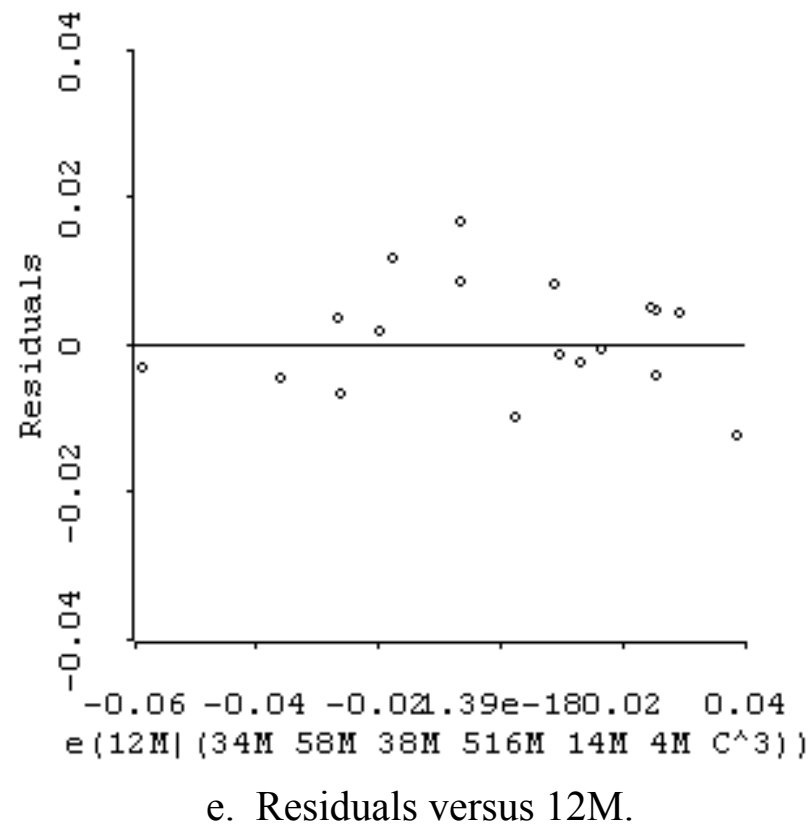

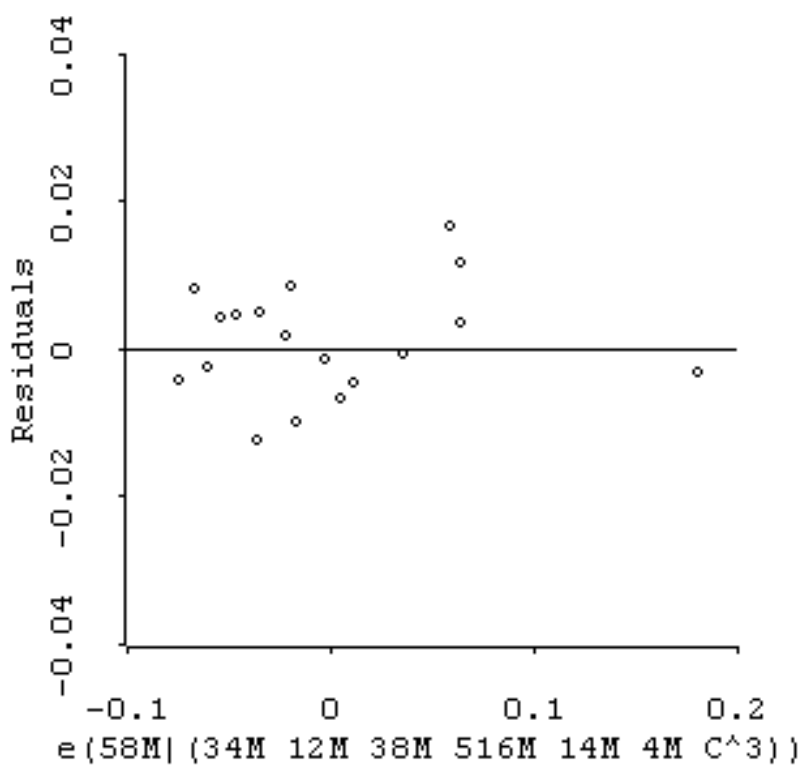

d. Residuals versus $58 \mathrm{M}$.

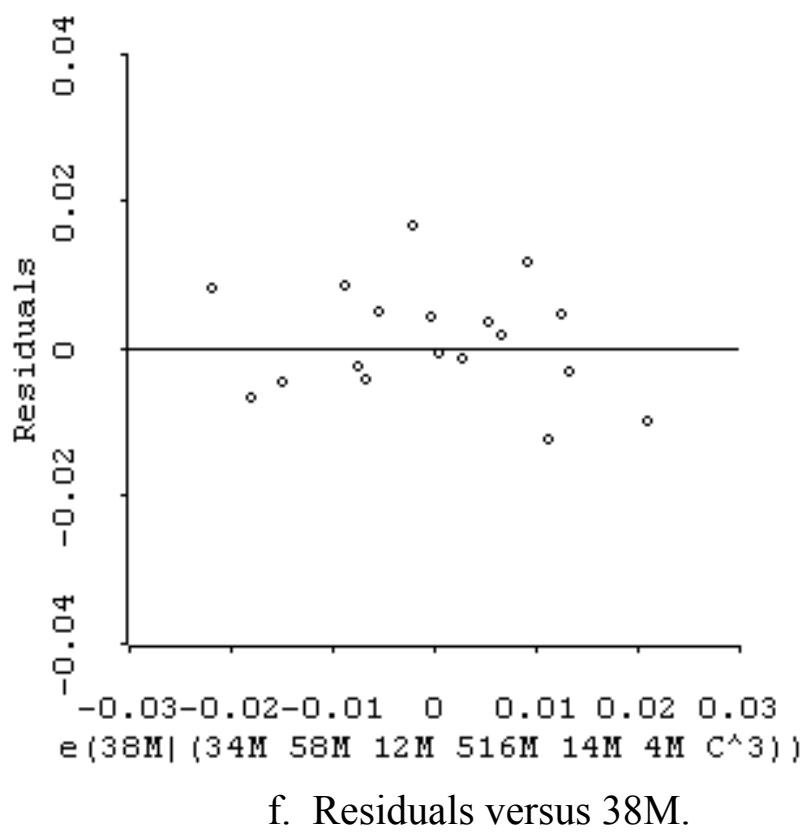

Figure E.22. Graphs $(a-j)$ illustrating model N1a* with deleted outlier (case 13, Shiely Grey Cloud [Larson]) (percentage of mass passing, 19.0 to $37.5 \mathrm{~mm}$ [0.75 to $1.5 \mathrm{in}]$ ) (continued). 


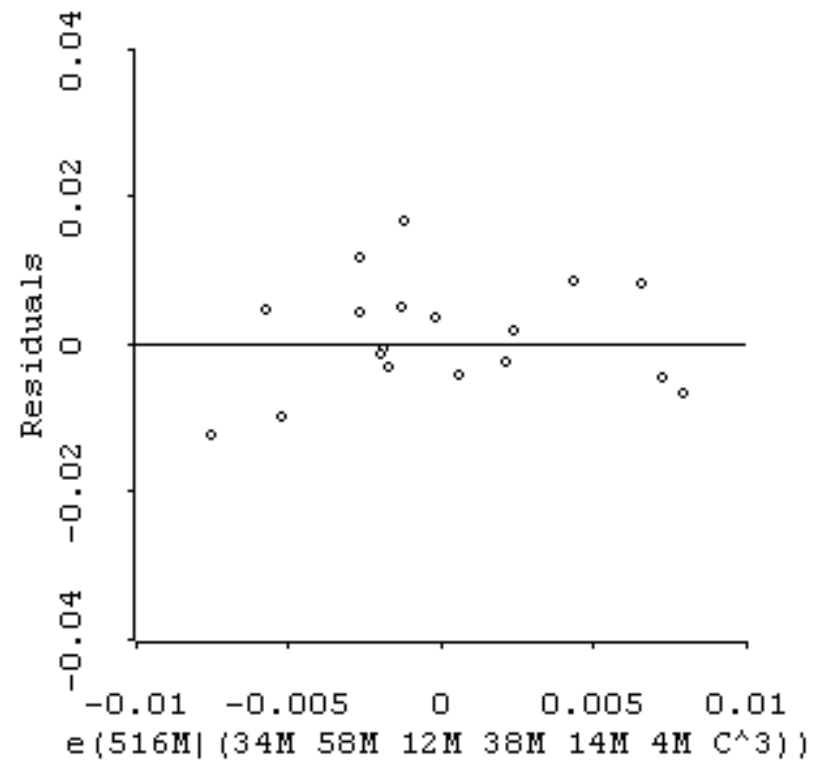

g. Residuals versus 516M.

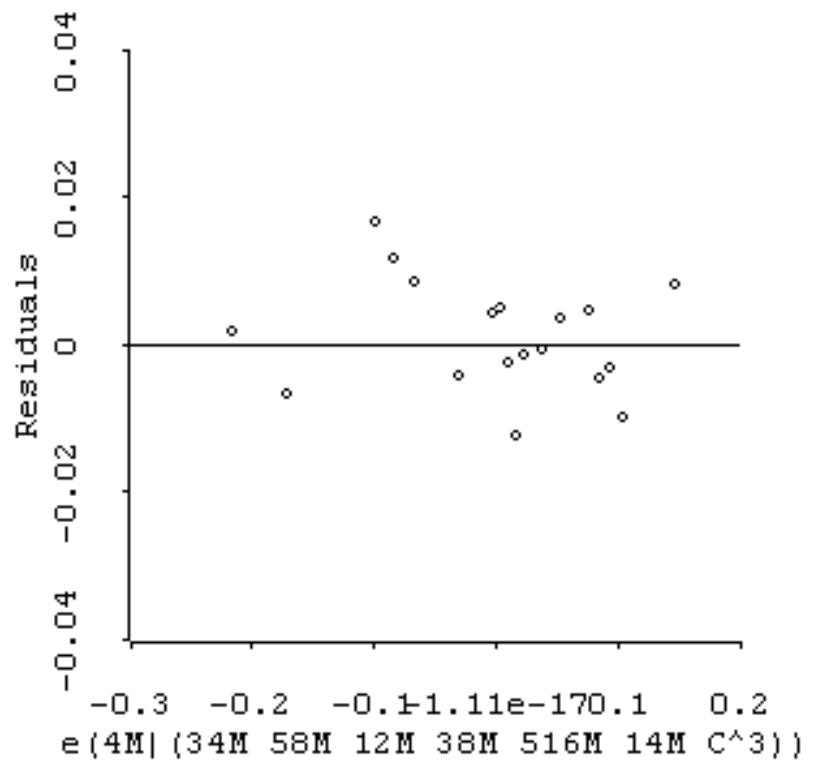

i. Residuals versus $4 \mathrm{M}$.

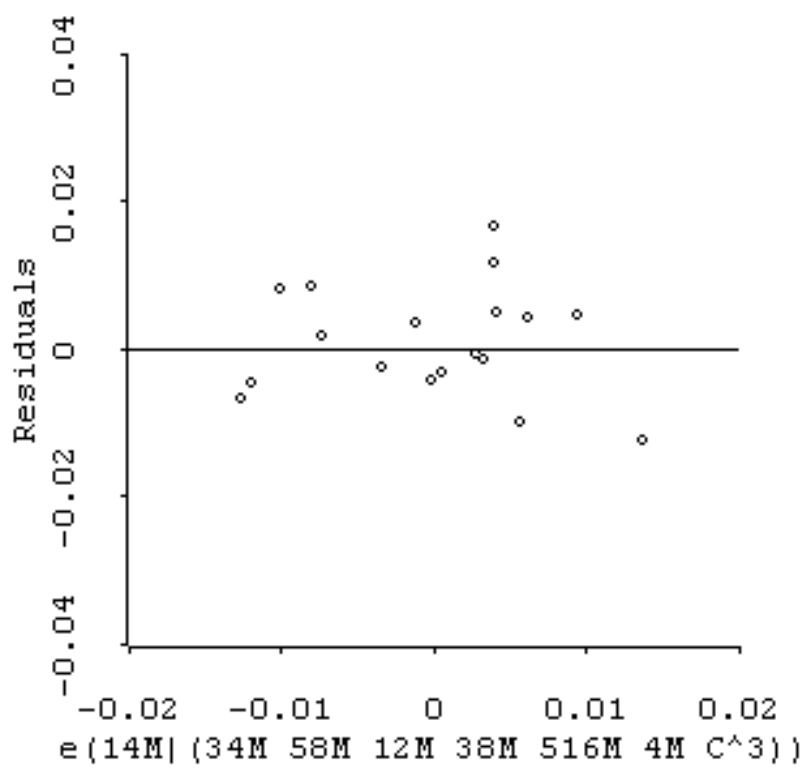

h. Residuals versus $14 \mathrm{M}$.

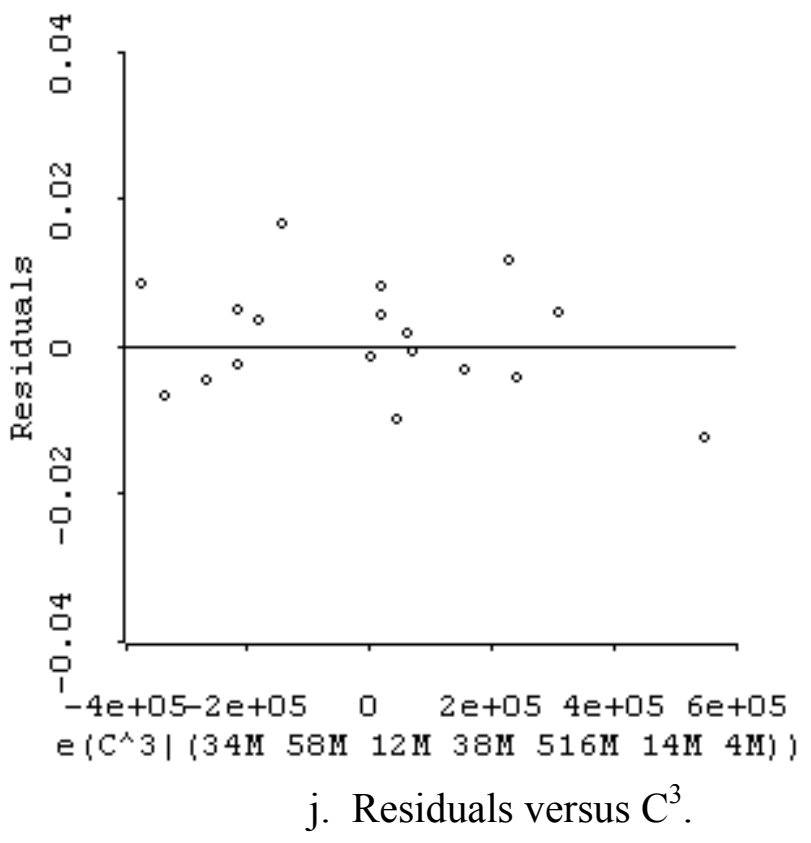

Figure E.22. Graphs $(a-j)$ illustrating model N1a* with deleted outlier (case 13, Shiely Grey Cloud [Larson]) (percentage of mass passing, 19.0 to $37.5 \mathrm{~mm}$ [0.75 to $1.5 \mathrm{in}]$ ) (continued). 